\title{
The Way of the Beer
}

\section{RITUAL RE-ENACTMENT OF HISTORY AMONG THE MAFA}

Terrace farmers of the Mandara Mountains

(North Cameroon)

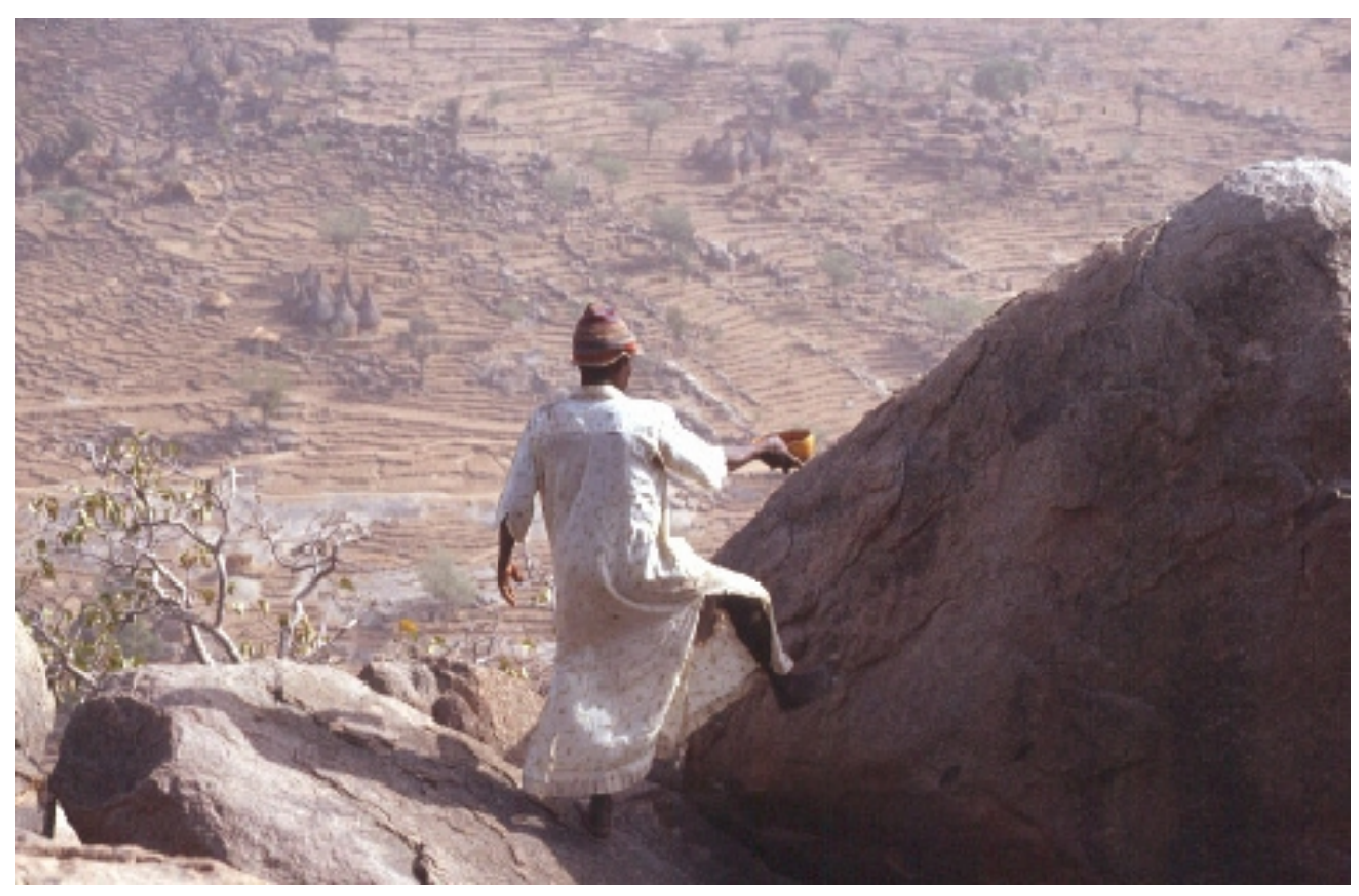

Gerhard Müller-Kosack 


\title{
The Way of the Beer RITUAL RE-ENACTMENT OF HISTORY AMONG THE MAFA Terrace farmers of the Mandara Mountains (North Cameroon)
}

\author{
Inauguraldissertation \\ zur Erlangung des Grades eines Doktors der Philosophie \\ im Fachbereich Geschichtswissenschaften \\ der Johann-Wolfgang-Goethe-Universität \\ zu Franfurt am Main
}

\author{
vorgelegt von \\ Gerhard Müller-Kosack \\ aus 35756 Mittenaar-Ballersbach
}

Einreichungsjahr 1996

Erscheinungsjahr 2001 


\section{TABLE OF CONTENTS}

Orthography

CD-ROM

List of figures

List of tables

List of plates

General introduction $\quad 11$

1 Presenting the regional context 15

$\begin{array}{lll}1.1 & \text { The Mafa and their neighbours } & 15\end{array}$

1.1.1 Physical features of the Northern Mandaras 15

$\begin{array}{ll}\text { 1.1.2 Linking ethnic groups and languages } & 17\end{array}$

1.1.3 The Mafa, an ethnic melting pot 25

1.1.4 Introducing the local study area 26

$\begin{array}{lll}1.2 & \text { A shared historical background } & 27\end{array}$

1.2.1 The era of slavery: an involvement 27

1.2.2 Colonial rule and post-colonial develoments 31

1.3 The compatibility of organisational structures 34

1.3.1 Terrace farming: worldview and social structure 34

1.3.2 Chieftaincy and ceremonies: similarities and differences $\quad 38$

1.4 Introduction to Mafa ethnography 42

1.4.1 The use of Mafa and Matakam 42

1.4.2 Representation of social structure in the literature 44

1.4.3 The increasing diversity of literature on the Mafa 45

1.4.4 The study of Mafa cosmology 46

\section{Constructing the religious worldview}

Introduction $\quad 49$

$\begin{array}{llr}2.1 & \text { God } & 50\end{array}$

2.1.1 Almighty God and his wife $\quad 50$

2.1.2 Personal gods and other divinities 51

2.1.3 God and the issue of gender $\quad 52$

$\begin{array}{lll}2.2 & \text { Parallel worlds } & 54\end{array}$

2.2.1 The architecture of the universe $\quad 54$

2.2.2 The inhabitants of the celestial world 55

2.2.3 The heavenly high court 56

2.2.4 Relationships between the different worlds 57

2.2.5 The world beyond as mirror image of this world 58

2.2.6 The transformation of a deceased person into an ancestor $\quad 59$ 
$\begin{array}{lll}2.3 & \text { The self } & 60\end{array}$

2.3.1 The traditional make-up of the self 60

2.3.2 The concept of the person as an agent of this world 62

2.3.3 The mysterious forces and the nature of things 64

2.4 Mythology 65

2.4.1 Mythological discourse and the nature of the universe 65

2.4.2 The invention of agriculture and the theft of sorghum 67

2.4.3 The cultural construction of rain as a good 68

$\begin{array}{lll}2.5 & \text { Spirits } & 69\end{array}$

2.5.1 The water spirit 70

2.5.2 The spirits of trees and rocks $\quad 71$

$\begin{array}{lll}\text { 2.5.3 The spirit of the house } & 73\end{array}$

3 Conceptualising ritual action 74

$\begin{array}{ll}\text { Introduction } & 74\end{array}$

$\begin{array}{lll}3.1 & \text { Divination } & 74\end{array}$

3.1.1 Pebble and crab divination $\quad 74$

3.1.2 The mythological origin of crab divination $\quad 74$

3.1.3 Symbolic contents of the divination bowl 75

$\begin{array}{lll}3.2 & \text { Home } & 79\end{array}$

3.2.1 The concept of shinek and mposokw $\quad 79$

3.2.2 Ancestral links and ritual ties of the wider family 79

$\begin{array}{lll}\text { 3.2.3 The architectural features of a house } & 81\end{array}$

3.2.4 Relationship terminology 83

$\begin{array}{lll}3.2 .5 & \text { Getting married } & 85\end{array}$

3.2.6 Founding a family home 91

$\begin{array}{lll}3.2 .7 & \text { Inheritance of land } & 92\end{array}$

$\begin{array}{lll}3.2 .8 & \text { The birth of a first child } & 93\end{array}$

3.2.9 Transforming through death 97

3.2.10 Ritual handling of ancestor pots 101

$\begin{array}{lll}3.3 & \text { Community } & 107\end{array}$

3.3.1 The calendar of the Mafa 107

3.3.2 The beer father ceremony 112

$\begin{array}{ll}\text { 3.3.3 The harvest festival } & 114\end{array}$

$\begin{array}{ll}\text { 3.3.4 The bull festival } & 121\end{array}$

3.3.5 Aspects of ritual and social structure 134

3.3.6 The "way of the beer" 139

$4 \quad$ Reconstructing local history 141

$\begin{array}{ll}\text { Introduction } & 141\end{array}$

$\begin{array}{lll}4.1 & \text { The local history of kinship groups } & 144\end{array}$

4.1.1 The Goyé 146

4.1.2 The Wula-Sakon 149 
4.1.3 The Ruwa 154

4.1.4 The Zhwé 155

4.1.5 The Hizhé 158

4.1.6 The Gozla 160

4.1.7 The Zhélé $\quad 161$

4.1.8 The Vuzay 166

4.1.9 The Zlagam 168

4.2 The historical relevance of the "way of the beer" 169

$\begin{array}{ll}\text { Summary and conclusion } & 171\end{array}$

$\begin{array}{ll}\text { Mafa glossary } & 174\end{array}$

$\begin{array}{ll}\text { Bibliography } & 181\end{array}$

General references $\quad 181$

References exclusively on the Mafa 186

Figures 193

$\begin{array}{ll}\text { Tables } & 212\end{array}$

$\begin{array}{ll}\text { Plates } & 224\end{array}$

$\begin{array}{ll}\text { CD-ROM } & 252\end{array}$ 


\section{Orthography}

Mafa words are spelt in general accordance with the conventions used in the Lexique Mafa of Barreteau \& Le Bléis (1990), which is based on the central dialect of Mafa (central mafa). This is the same dialect spoken in the area of Gouzda, where this research was conducted. I have simplified the spelling by dropping the tone marks and have reduced the writing of linguistic fonts to implosive $b$ and $d$, soundless $\partial$, and the lateral fricatives $s l$ and $z l$. Like Barreteau \& Le Bléis (op.cit.: 25) I use 'n and $m^{\prime}$ as nominilising prefixes. The pronunciation of Mafa words is $u$ like in "Cameroun" or "Cameroon", $\infty$ like the German poet "Goethe", $c$ like in the English word "church", $j$ like in the English word "adjustment", and $t s$ like in the German word "Zucker". However, place names found on commonly used maps are spelt in the French way (e.g. 'Gouzda' or 'Maroua'). All Mafa words are written in lower case and in italic, except names of individuals (e.g. Jikdayé) and ethnic names or kin groups (e.g. Mafa or Vuzay). Names of languages or language groups are also written in lower case and italic. 


\section{CD-ROM}

The CD-ROM attached at the end of this publication not only contains everything found in the printed version of this work, but also two digital maps (figure 8 and 9) which are to large to be printed (see Introduction to the digital map (pages 142-144) for detailed information). The CDROM also contains version 1.03 of the Northern Mandaras Homepage. While the text, maps and images can be viewed with Acrobat Reader (version 4.0 has been copied on to CD-ROM) the Northern Mandaras Homepage must be viewed with Microsoft Explorer. The CD-ROM is organised in five main folders which are labelled Text, Figures, Tables, Plates and Homepage. For further guidance insert the CD-ROM and double click the 'Read-me' file. 
List of figures (all figures are also stored on the CD-ROM)

Figure 1: The northern Mandara Mountains of NE Nigeria and N Cameroon 193

Figure 2: Distribution of ethnic groups in the northern Mandara Mountains 194

Figure 3: Geographical location of the study area 195

Figure 4: Pairs of calabash pieces used in Mafa crab divination 196

Figure 5: Plan of a Mafa house 197

Figure 6: Traditional villages and wards of the local study area 198

Figure 7: Clan sections and main pattern of local beer exchange 199

Figure 8: Traditional Mafa Settlements CD-ROM

Figure 9: Key of figure 8 (Traditional Mafa Settlements) 200 
List of tables (all tables are also stored on the CD-ROM)

Table 1: Ethnic groups, their language affiliation and estimated numbers 212

Table 2a: Mafa bibliography (sorted by year) 214

Table 2b: Mafa bibliography (sorted by topic) 217

Table 3: The gad bulom Fibay of Gouzda-Gura 113

Table 4: Settlement names and their meaning $\quad 220$

Table 5: Local lineage tree of the Wéslém of the Wula-Sakon 151

Table 6: Local lineage tree of the Dakowal of Wula-Sakon 152

Table 7: Local lineage tree of the Zhwé 158

Table 8: Local lineage tree of the Hizhé 159

Table 9: Local lineage tree of the Zhélé of Mazay 162

Table 10: Local lineage tree of the Zhélé of Woulad 164

Table 11: Local lineage tree of the Vuzay 167

Table 12: Mafa informants interviewed from 1985 to 1989 
List of plates All photographic images are taken by the author (also stored on CD-ROM).

Plate 1a: Father with the pot of his god. The pot has male sex characteristics and a right arm stretching upwards. 224

Plate 1b: Goddess pot (left hand broken off and placed separately at foot of pot). $\quad 224$

Plate 1c: House god consisting of round (female) and longish (male) stones. 224

Plate 2a: Diviner in front of divination bowl. 225

Plate 2b: Contents of divination bowl, before they are positioned. 225

Plate 3a: Family head libates sorghum beer to the baba pot. 226

Plate 3b: Family head balances the calabash on the baba pot. 226

Plate 3c: Calabash with baba beer for bay is given with the left hand. 227

Plate 3d: $B a b a$ beer is consumed in pairs. $\quad 227$

Plate 3e: Women entering the house to attend baba ceremony. 228

Plate 3f: Women sharing baba beer. 228

Plate 3g: Communal meal during baba ceremony. 229

Plate 3h: Beer libation to var ma gay (front courtyard). 229

Plate 4a: Biy dza and his helpers on their way to perform a community sacrifice. $\quad 230$

Plate 4b Biy dza arrives with his helpers in front of diy mbulom. 230

Plate 4c: Biy dza takes diy wof (lineage ancestor pot) out of diy mbulom. 231

Plate 4d: The lineage of biy $d z a$ is in the position of bay, therefore he offers natron

to his lineage ancestor (represented by diy wof) by using his left hand. 231

Plate 4e: The lineage of biy $d z a$ is in position of bay, therefore he offers $z o m$ to

his lineage ancestor (represented by diy wof) by using his left hand. 232

Plate 4f: Biy dza balances the calabash on the back of his lineage ancestor pot (diy wof). 232

Plate 4g: Biy dza with calabash of zom on his way to the sacred rock of Zlama. 233

Plate 4h: Biy dza performs a beer libation at the main sacred rock of the community of

Zlama (overlooking Gouzda). He now uses his right hand since his clan group, in this ritual context, only represents the former chiefly clan of Zlama.

Plate 5a: New village chief (biy wudam) takes some fibre from a piece of sacred rope $\begin{array}{ll}\text { of the previous village chief. } & 234\end{array}$

Plate 5b: Strings of fibre are being intertwined to make a new ta6a (sacred rope). $\quad 234$

Plate 5c: New sacred rope being curled up for the first time. 235

Plate 5d: New chiefly biy gwala carries new rope for the first time. 235

Plate 5e: New rope is placed in front of the new chief's cattle shed for its consecration. 236

Plate 5f: As part of the consecration ceremony, the new biy gwala cuts euphorbia into a calabash. 236

Plate 5g: New biy gwala consumes sorghum beer with euphorbia pieces inside. $\quad 237$

Plate 5h: First gad bay (deputy) of new village chief leaves the chief's house after he has been dressed inside for the first time. 237

Plate 5i: Group of bay and biy gwala leave the chief's compound to attend the $\begin{array}{ll}\text { bull festival of Zlama. } & 238\end{array}$

Plate 5j: New village chief (biy wudam) of Zlama has to stay behind. His friend (in white robe) keeps him company. 238

Plate 6a: Biy gwala arrive to liberate the first bull of the bull festival of Zlama. 239

Plate 6b: Crowd awaiting the first bull to be released. 239

Plate 6c: Matsam, flute players and dancers await the release of the first bull. $\quad 240$ 
Plate 6d: Wives of the bull's owner leave the house shortly before the bull is released. $\quad 240$

Plate 6e: Man with bean flour waits for the bull to come out. 241

Plate 6f: Bean flour is thrown over the back of the purified bull. 241

Plate 6g: Second gad bay leaves the house after his bull has been released. He is a

Representative of the former chiefly clan of Zlama. This is the reason

why his bull is the first to be purified in Zlama.

Plate 6h: Group of bay praise the release of the first bull. The drummer beats the chiefly drum and the bay sing: "A biy ga, a biy ga...", meaning "oh my great one..." 242

Plate 7a: A ram has been sacrificed and its intestinal contents will be used by the biy gwala to smear over their bodies before they purify the next village ward. 243

Plate 7b: Son of the second gad bay brings the head of the ram to the bay of the next village ward of Zlama, where bulls are going to be released. 243

Plate 7c: Biy gwala apply intestinal contents from a sacrificial ram over their bodies. $\quad 244$

Plate 7d: Biy gwala hand over their sacred ropes to be piled up in front of the cattle shed. 244

Plate 7e: Sacred ropes piled up in front of the cattle shed. The topmost represents the youngest and the bottom one the oldest village ward of Zlama.

Plate 7f: Biy gwala perform "a turn around the head" away from the house followed by a $\begin{array}{ll}\text { sharp turn around towards the house (snakelike walk). } & 245\end{array}$

Plate 7g: Biy gwala liberates the sacred bull. 246

Plate 7h: Biy gwala too leave with bean flour over their backs. 246

Plate 8a: Matsam entertain the crowd. "Matsam man" (in the middle) shows his wooden penis while "matsam wife" stands next to him (on his right). 247

Plate 8b: Crowd awaits the release of the next bull. 247

$\begin{array}{ll}\text { Plate 8c: Flute players. } & 248\end{array}$

Plate 8d: Two gad bay enjoy themselves with the other bay. Only the first gad bay (chief's deputy) carries a red felt hat. The second gad bay is a $\begin{array}{ll}\text { representative of the ancient chiefly clan. } & 248\end{array}$

Plate 9a: Biy gwala demand the chief's drum at the end of the bull festival. 249

Plate 9b: Biy gwala leave with the chief's drum. 249

Plate 9c: Biy gwala and flute players dance with the chief's drum. 250

Plate 9d: Bay join the biy gwala dancing with the chief's drum. Later they receive back the drum, which marks the end of the bull festival of Zlama. 250

Plate 10a: The purified bull is tied with a long rope as a prelude to ritual slaughter. $\quad 251$

Plate 10b: The bull is brought down and his front legs are strung together. 251

Plate 10c: The head of the bull is placed inside the sacrifice room where his throat is cut by the slaughterers.

Plate 10d: Now the owner of the bull enters and taps the body of the bull with the handle of a traditional hoe and he repeatedly calls out: "Who killed my bull?..." 252

Plate 10e: Owner sprinkles water over the bull and slaughterers, requesting "freshness". 253

Plate 10f: Owner places the leaves he used for sprinkling water into the bull's mouth. 253

Plate 10g: Owner of the bull puts sorghum flour on the bull's chest. 254

Plate 10h: Owner finally decorates the sacrificed bull with the water bowl and the $\quad 254$ slaughtering knife. 


\section{General introduction}

This is a revised version of my Ph.D. thesis 'Cived Zom: Studie zur Historizität der Mafa Nordkameruns,' which I completed in April 1997 at the J.W.Goethe-Universität zu Frankfurt am Main in Germany. 'Cived Zom' is the Mafa expression for The Way of the Beer, which I have chosen as the title of this publication in English. It is a metaphor for the social and political relationships which emerge from passing on ceremonial beer between agnatic kin and other members of local Mafa communities. It was originally created as "chemin du vin" by myself and my research assistant, Paul Jikdayé, as the main connecting theme during my second and longest field session in 1985/86. I later discovered that turning germinated sorghum and water into zom is a brewing process and concluded, therefore, that zom is beer and not wine. However, the translation "vin" for zom survives in Mafa land, which may be due to the French cultural connection. Due to the ceremonial aspect of zom being used for libations the word "wine" might even be the better word, but the technical process of brewing clearly contradicts such a translation.

Although the expression cived zom does not exist in Mafa as such, the word cived carries a meaning which makes it suitable for the construction of a metaphor in conjunction with zom in its function as ceremonial beer. The word cived, does not mean only "road", "way" or "path", but also "direction" or "authorisation".The Mafa also have a sacred pot which they call zhigilé cived, meaning "god of the road" and this is often found on the road leading to someone's house to serve as the spiritual guardian of a nuclear family. The ethnographic metaphor cived zom is therefore soundly constructed and served us well, when asking local elders and dignitaries from whom and on which occasions they receive ceremonial beer and when and to whom they pass it on. This does not mean that it is literally the same beer which travels down the road of existing ceremonial links, but simply the beer which has been brewed by the wife of the family head who then passes it on to his elder.

The fact that it is always the social or political elder who receives ceremonial beer leads us straight to the sub-title of this book. The "way of the beer" is a metaphor for the ritual reenactment of history among the Mafa. Ceremonial beer is the "Eucharist" of Mafa religion. It represents the link between God, the ancestors and the living within a patrilocal community. The "way of the beer" begins with those who have a deceased father and who are therefore responsible for the ceremony of the sacred pot called baba, and ends with the mountain priest (biy $d z a$ ) who libates beer at the sacred site of his local kin. Since a Mafa settlement mostly consists of more than one clan group the "way of the beer" is not only determined by agnatic descent but also by group status and size as well as the time a group arrived, in relation to the other kinship groups, of a village community.

Ideally, the "way of the beer" always tries to maintain the principle of seniority either in genealogical or territorial terms, but there are exceptions to the rule. Some relationships turn out not to fit the principle of seniority and we find other criteria come into play, a very important one being purity. We often find that a local mountain priest is, in terms of descent, a relatively young member of his local kin group. The explanation for such an exception is generally that the older representative is not pure due to a certain historical event in the past which has led to his branch being impure. Other exceptions have to do with the changes in political power within a traditional community setting. A representative of a chiefly lineage might be excluded from the political rota of providing the local chief (biy wudam) because his kinship group has become insignificant in

\footnotetext{
${ }^{1}$ René Jaouen (1995), a Catholic priest who worked for many years among the Giziga makes this comparison by pointing out that sorghum beer is much closer to the hearts of montagnards than Christian wine.
} 
terms of number. A kinship group constantly shrinking in size is not a suitable symbol of community prosperity. There are other exceptions too numerous to mention in the context of this introduction. The important thing is that any derivation from the rule of seniority within the "way of the beer" is always accompanied by an explanatory historical account.

With about 150,000 people, the Mafa are by far the largest ethnic group of terrace farmers in the Mandara Mountains. They live in the centre of the northern Mandara Mountains, about 250 kilometres south of Lake Chad, in the Sudan Savannah (about $11^{\circ} \mathrm{N}$ and $14^{\circ} \mathrm{E}$ ). They are surrounded by over 50 smaller ethnic groups, which share similar cultural features. All terrace farming groups of the northern Mandara Mountains speak languages of Central Chadic. Their traditional calendars are guided by the alternation of a rainy season lasting from May/June to September/October and a longer dry season between October and June. Most of them practice annual crop rotation; one year sorghum is planted and the next year millet and beans. The population density is very high, between 100 and 250 people per square kilometre. In the past the keeping of livestock was essential to produce sufficient manure for the fertility of the terrace fields.

English speaking ethnographers of today like to refer to the people of the Mandara Mountains as montagnards. They are also known as Kirdi, which is Kanuri (derived from the Arabic word qird) and means non-Muslim or pagan. The Mafa are also known as Matakam or sometimes WulaMatakam. The word Matakam is probably derived from Fulfulde, while Wula might be a Wandala word. The Wandala are the ethnic population of the Sultanate Mandara or Wandala, who conducted slave raids against the Mafa and their neighbours from the $15^{\text {th }}$ Century onwards or even earlier. In the $19^{\text {th }}$ Century, the Fulbe embarked on a jihad against the montagnards, which led to widespread enslavement. The time of slavery ended in the Mandara Mountains with the arrest, by the British, in 1927, of Hamman Yaji, a local Muslim ruler from Madagali. Between 1902 and 1914 the Mandara Mountains were under German colonial rule. The Treaty of Versailles, in 1919, created mandated areas in the Mandara Mountains with the lion's share for the French and a smaller one for the British. Since 1960/61, the northern Mandara Mountains have been divided between the independent nation states of Cameroon and Nigeria. The Mafa live mainly on the Cameroonian side of the Mandara Mountains.

The aim of this publication is not only to make a contribution to African ethnography but also to present my field data in accordance with certain contextualising trends. In general terms, my underlying theoretical orientation is possibly best described as a conceptual approach. This is where I find myself very much indebted to the works of Mary Douglas and Fredrik Barth; Mary Douglas (1966) for her comparative analysis of ideas of pollution and purity and Fredrik Barth (1987) for his reminder not to treat cultures as closed systems. My historical approach has some affinity with that of The New Cultural History and I adhere to Aletta Biersack's statement: "'local history" refers to significant worlds and the indigenous outlook that give them life' (1989:74). Other theoretical concerns arise from definitions of landholding where I see myself in line with Parker Shipton $^{2}$ (1994.:347f), who suggests we strive for a better understanding of meanings revolving 'around links between human and terrestrial fertility.' Although this monograph of Mafa religious life is a rather idiosyncratic piece of work and far from being theoretical, the following 4 chapters could not have been written without bearing such ideas in mind.

Chapter One aims to present the Mafa in the context of their montagnard neighbours and outline features which they have in common, and those which distinguish them from each other. We discuss the issue of a shared historical background with an emphasis on the eras of slavery and

\footnotetext{
${ }^{2}$ Shipton is particularly concerned with the social and political organisation of classless societies in the context of increasing population density and land shortage an issue of great importance also in the northern Mandara Mountains.
} 
colonial change. Issues of regional comparison will be addressed by concentrating on the ritual complex and the way its varying intensity reflects horizontal and vertical processes of political integration. I will introduce the model of lineage segmentation as a suitable tool to describe the social structure typical for the terrace farming societies of the Northern Mandaras. At the end of this chapter I will highlight some problem areas of Mafa ethnography in relation to the purpose of this work and point to the study of their religious life as one of the most neglected areas.

Chapter Two sets out to construct the religious worldview of the Mafa. The concept of parallel worlds emerges out of the description of the mysterious transformational forces the Mafa attribute not only to the human spirit, but also to plants, animals, rocks and other natural phenomena. The reason why a detailed description of the worldview rather than one of the social structure, is placed at the beginning, has to do with the conceptual approach applied in this study. I believe that the description of the religious worldview of the Mafa will reveal the guiding principles for the understanding of their ritual activities as a strategy to enhance their social and natural resources. To start this book with a description of the social structure would put the main emphasis on persisting features of social and political organisation rather than on the conceptual framework of actors engaged in social processes.

Chapter Three attempts to define key concepts guiding social and political action in relation to the principles essential for the construction of local history. Again we want to avoid a theoretical discussion about institutions and rather concentrate on social and political practice. It is here where we will see the religious worldview coming into play as a guide to help our understanding of the conceptual principles of ritual activities. We will begin with a description of the divination process linking the people of this world with divinity and the ancestors of the parallel metaphysical worlds. Next I will discuss the concept of the family home, including its architectural features and what these stand for in social and religious terms. The relationship between home and community will be examined and criteria will be developed in order to compare the two concepts. This will bring us to the discussion of the seasonal calendar which, in turn, will allow us to distinguish between particular family, lineage and clan representatives and their mutual ritual responsibilities. At the end of this very long chapter I will outline the conceptual design of traditional Mafa communities as it emerges from my ethnographic data.

Chapter Four deals with the reconstruction of the local history of the most important clan groups in six Mafa local communities. I decode the "way of the beer" by linking representatives of local groups to narratives and places. I describe the local history of kinship groups and settlements as described to me by traditional Mafa. I show how communities link themselves together and examine ritual sequences in order to reconstruct the ways in which the historical relatedness of local groups is maintained. The results will be presented together with a digital map of kinship groups and settlement pattern to visually illustrate not only the social and political but also the spatial context in which local history is ritually re-enacted among the Mafa. The analysis shows that the local power structure of the Mafa was historically governed by the principle of number rather than seniority. Although some groups had lived there longer, they often became outnumbered by others who eventually acquired a chiefly status. One of the explanations for this development lies presumably in the historical background of the regional slave economy leading to population increase and shortage of land.

Historically speaking, the "way of the beer" is on its way out and traditional concepts of prosperity and status changing accordingly. Farming methods and the economy of subsistence are in a process of adapting to the requirements of a market economy. The fertility of the land not only has to provide enough to eat, but also income for clothing and modern education for many children. All these factors lead to a moral transformation of the traditional society and changes in 
value orientations. This study shall not only serve African ethnography but also future generations of Mafa when reflecting upon their cultural past.

I could not have conducted this study without the help of my friend and assistant, Paul Jikdayé. During the period of over two years of fieldwork I carried out in the area of Gouzda, between 1985 and the year 2000, he was always available to me. My gratitude also goes to his older brother the Honourable Gonondo Jean, who always welcomes me into his house in Gouzda or Yaoundé. He became a Member of Parliament in 1988 and is now the most influential politician in the northern Mandara Mountains of Cameroon. He has given the Mafa a national voice and access to modern development. My thoughts also go to all the Mafa I got to know during my many years of ethnographic work in Mafa land. Their openness and trust alone allowed me to conduct this study. I also want to thank the Cameroonian authorities who provided me with the necessary permits to visit and successfully carry out my research. My special thanks go to Eldridge Mohammadou who was at the time director of the Garoua office of the Institut de Sciences Humaines. I enjoyed his professional support during my field research and the many discussions on the intricacies of the ethnic histories of the Mandara Mountains and the surrounding plains. In the 1990s I met Eldridge again at the Centre for Trans-Saharan Studies at the University of Maiduguri while I carried out my research in the Gwoza Hills. He is one of the few with a long-standing interest in the region as a whole, which includes not only the Cameroonian but also the Nigerian parts.

Writing this work in English was not an easy task. It would hardly have been possible had I not been assisted by my wife, Stella Cattini-Müller, who patiently waded through my Germanisms and helped to redesign the many drafts. I am also grateful to my friend Adrian Walker who kindly read through the manuscript. Wilhelm Steingrube from the University of Greifswald introduced me into digital cartography which enabled me to process my spatial data. My thanks also go to my friends and colleagues in the field, Nic David and Judy Sterner. Thanks to Nic for inspiring the title of this publication and reading and commenting on the final draft and also to Judy for the many debates on the regional ethnography. For his wealth of information and willingness to indulge in lengthy discussions on trends in ethnographic writing, my warm thanks go to Roger Blench. The German version as well as the revised English version of the thesis have both been written unsupervised, but I would like to thank Ulrich Braukämper from the Univerity of Göttingen and Carola Lentz from the University of Frankfurt for acting as official expert readers. I am also grateful to Ulrich for his assistance in obtaining a grant from the Deutsche Forschungsgemeinschaft which enabled me to extend my research into the Gwoza Hills. 


\section{Presenting the regional context}

\subsection{The Mafa and their neighbours}

\subsubsection{Physical features of the Northern Mandaras}

The densely populated terrace farming societies of the northern Mandara Mountains need to be understood in a twofold way. The first is in the context of the climatic conditions of the Sudan Savannah where a bad harvest presents much more of a threat than in the Guinea Savannah further south, but also where higher rainfalls could provide an advantage over adjacent plains. ${ }^{3}$ The second is in the context of its vicinity to the slave economy of the old Borno empire and the Wandala state from the $15^{\text {th }}$ Century onwards, and the jihad of the Fulbe since the $19^{\text {th }}$ Century, which made the Northern Mandaras a zone of refuge. Both factors, the environmental and the historical, and also the improved modern life conditions, contribute to the particularly high population density we find there today.

\section{Relief}

The northern Mandara Mountains (figure 1) have their origin in the folding and vulcanism associated with tectonic activity and are made up mostly of granite and gneiss. ${ }^{4} \mathrm{We}$ can distinguish between three types of relief consisting of massif, plateau and foothill areas. The most prominent massif areas are found in the west while the east and south of the Northern Mandaras are dominated by extensive plateau areas. The foothill areas are particularly frequent in the east, while the western massif rises steeply against the plain.

The high western massif stretches from the Kapsiki plateau northwards, extending, via the heights of Tourou, as far as the Zelidva massif, the most northern extension of the Northern Mandaras. East of the heights of Tourou, the western massif is separated from that of the Ziver-Oupay by the deep valley of the river Moskota which runs in a northeasterly direction and eventually joins the river Ngassawe in the plain of Mozogo. The river Kerawa comes down from the heights of Tourou and runs through the intra-mountainous plain between the Gwoza and the Moskota hills to form the frontier between Nigeria and Cameroon.

The intra-mountainous plain of Koza, which gives the Northern Mandaras its specific U-shaped form, cuts southwards into the central massif with Mount Ziver rising to the west and the ZoulvaMeri plateau to the east. The central massif and plateau join again at the heights south of Koza town, with the Houva massif in its west and the Ziver plateau stretching east as far as the Soulédé hills and Mount Guegadal. The Ziver plateau connects with the plateau of Mokolo to its south and the Zoulva-Meri plateau to its northeast. The latter divides the eastern chain of the Northern Mandaras into the Mora hills in the north and the Meri hills in the south. The Zoulva-Meri plateau ends in a mountain cliff facing the eastern plains with a range of peripheral foothills stretching parallel to it.

The highest peak of the Northern Mandaras is Mount Oupay $(1,494 \mathrm{~m})$ followed by Mount Ziver $(1,404 \mathrm{~m})$ and then, Mount Cucume $(1,343 \mathrm{~m})$ of the Zelidva massif followed by Mount Zlama $(1,328 \mathrm{~m})$ of the Houva massif and Mount Wa'a $(1,249 \mathrm{~m})$ of the Gwoza Hills. Compared to those

\footnotetext{
${ }^{3}$ The Northern Mandaras are situated in the Sudano-Sahelian zone with average annual rainfalls of 958mm in Mokolo and 786mm in Maroua, slightly further south (Hallaire 1991:17). The southern Mandara Mountains reach as far as the river Benué where they then belong to the Guinea Savannah, with much higher rainfalls. The average annual rainfall in the Southern Mandaras is $1,100 \mathrm{~mm}$ while the annual average in the Northern Mandaras is only $800 \mathrm{~mm}$ (op.cit.).

${ }^{4}$ MacEachern (1990:11) gives a good description of the natural environment. See also Boutrais (1984).
} 
of the western massif, the mountains of the eastern massif are between 200 and $300 \mathrm{~m}$ lower. Its highest mountains are Mount Gouaza $(1,171 \mathrm{~m})$ to the southwest of the Mora hills and Mount Soulédé $(1,110 \mathrm{~m})$ east of the Ziver plateau. There are hardly any mountains in the eastern massif areas of the Northern Mandaras which rise above $1,000 \mathrm{~m}$. To my knowledge, there is only Mount Guegadal $(1,094 \mathrm{~m})$ to the north of Soulédé and Mount Goma $(1056 \mathrm{~m})$ to the west of Meri town.

Mokolo town is found at a height of about $1,000 \mathrm{~m}$ to the south of the Douvar $(1,256 \mathrm{~m})$ and Houva $(1,310 \mathrm{~m})$ mountain, which is the southern extension of the Ziver-Oupay massif. To the west of Mokolo, we find the plateau formation of Wanday at about $900 \mathrm{~m}$, the watershed between the Atlantic Ocean and Lake Chad with the river Louti running south and the river Moskota running north. The river Tsanaga begins its course down to the plain of Diamare from a valley separating Mount Douvar and Mount Houva at about $800 \mathrm{~m}$ east of the Wanday plateau. To its west the plateau of Wanday is bordered by a mountainous cliff about $1,000 \mathrm{~m}$ high with the river Waga descending towards Madagali town into the western plains, from where it eventually joins the river Yedseram. Of these four rivers, the Louti is the only river of the Northern Mandaras which carries its waters, via the rivers Kebi, Benué and Niger, into the Atlantic Ocean. ${ }^{5}$

\section{Population density}

According to Hallaire (1991, fig 5), the most densely populated areas of the northern Mandara Mountains of Cameroon are the eastern slopes of the Ziver-Oupay massif, which include the foothills to the east of Koza and the hill areas south and west of Mora. In these areas the average population density is more than 140 inhabitants per square $/ \mathrm{km}$. In all other mountainous parts of the Northern Mandaras of Cameroon the population density is never less than 100 inhabitants per square $/ \mathrm{km}$. Relatively, the plateau areas of the Northern Mandaras, with under 40 inhabitants per square $/ \mathrm{km}$, display the lowest average population density. This is because the more fertile soils being found on the slopes, as Boutrais (1984:23-62) has pointed out.

The population density of the Southern Mandaras of Cameroon is, for the most part, not more than 40 inhabitants per square $/ \mathrm{km}$ (Hallaire, op.cit.). This is comparable with the low population density we find on the central plateau of the Northern Mandaras. There are no figures available for the Nigerian part, but I estimate from my own field research in the southern parts of the Gwoza Hills (Guduf, Chikide, Dughwede and Gvoko) that the population density seems to be almost as high as in the mountain area west of Koza. The situation is different in the northern parts, especially the Zelidva massif, which is now almost completely abandoned, as are all western slopes and foothills of the Gwoza Hills. Boutrais (1973) describes the process of downhill migration for the Cameroonian part of the Northern Mandaras in great detail.

Downhill migration is a continuing process in the Northern Mandaras, but there are also signs of people returning due to lack of employment in the urban centres of the plains (Gubry 1996). While the adjacent plains remained uninhabited by montagnards during times of slavery they are now almost completely occupied by new settlements. Some of them are designated resettlement areas and legal battling over land is an ongoing problem. This is a particularly difficult issue in the international boundary area between the Gwoza and Moskota hills, along the narrow intramountainous plain on the Nigerian side of the river Kerawa and poses a problem for the ethnic

\footnotetext{
${ }^{5}$ It was Heinrich Barth who, in the mid $19^{\text {th }}$ Century, discovered the Kebi-Benué system. If Barth had known how close he was to the watershed separating the Atlantic from the Chad system when he passed down the western chain, he would almost certainly have climbed up to see it with his own eyes. This presumably would have led to Barth crossing the central plateau rather than doing a second journey to Musgum, and would also have prevented him from mistaking the volcanic remains of Roumsiki for the peaks of Mindif (Barth 1857,II:395f).
} 
groups of the Gwoza Hills who do not have natural access to the western plain. This applies to the Dughwede, the Chikide-Chinene, the Amuda-Ganjara and the Glavda.

\subsubsection{Linking ethnic groups and languages}

The ethnic groups of the Northern Mandaras are often referred to generally as "Kirdi". Kirdi is a word of Kanuri origin and is translated by Cyffer (1994:130) as pagan (kerdi/krdi = pagan). ${ }^{6}$ Historically, the ethnonym Kirdi has a derogatory connotation, but it is also used by montagnards of today to refer to their ethnic pride. Ela (1994:8-14), for example, speaks of 'Kirditude' meaning the attitude of someone who is proud to have a Kirdi background. The historical meaning of the word is possibly best translated as 'all those who were non-Muslims and who could therefore be subjected to enslavement' (Müller-Kosack 1999a:6). This was in accordance with the Qur'anic law against the enslavement of free persons, which stated that Muslims could only be enslaved in clearly defined circumstances (Rihll 1996:106). The word Kirdi can therefore be interpreted as a social ideology of resistance against Islamisation and, historically, the holding on to a localised value system often referred to by anthropologists as "acephalous" or "animist".

The first mentioning of Kirdi is by Denham 1826 (1985:145), who translates the word 'Kerdies' as 'Negroes who have never embraced the Mohammedan faith.' Denham used the word Kirdi not only for montagnards, but also for the pagan groups of the plains. The fact that the ethnonym Kirdi was only applied later in history to montagnards must be seen in the context of the integration of the ethnic groups of the plains into the Muslim community from the late nineteenth century onwards (Müller-Kosack, op.cit.).

The geographical model of group distribution used below is the first of its kind which attempts to present the Northern Mandaras in its ethnographic completeness (see also figure 2 and compare with table 1). ${ }^{7}$ Most data on ethnic groups, population figures, language affiliation and migratory links listed below are drawn from the CD-ROM version of the Northern Mandaras Homepage attached to this publication. ${ }^{8}$

\section{The Mafa and their tribal factions: Mafahay, Kwokwarhay, Mafa-Vara}

According to Barreteau's, Breton's \& Dieu's (1984:167ff) geographical model, the Mafa speak mafa which comprises the dialects ${ }^{9}$ of mafa-west, mafa-centre and mafa-east and is a language of mafa-south. ${ }^{10}$ They live in the centre of the Northern Mandaras and, numbering about 150,000,

\footnotetext{
${ }^{6}$ Tourneux (Seignobos \& Tourneux (in print:151-153) derives the etymology of the word Kirdi from the Arabic word qird for ape or monkey.

${ }^{7}$ Seignobos \& Iyébi-Mandjek (2000:44-51) in their newly published Atlas, are the most recent examples in a long tradition of geographers failing to represent the Northern Mandaras across the international boundaries.

${ }^{8}$ For more details, please refer to the page of the ethnic group on the CD-ROM (version 1.03). With regard to the language affiliation, I will rely on Barreteau's model (1984:167ff) and neglect views of other researchers. The population figures I give for each group are rough estimates from various and often contradicting sources. References to migratory links of each group will mainly concentrate on intra-mountainous traditions.

${ }^{9}$ The generally accepted distinction between a dialect and a language is that dialects of the same language are intelligible, while languages are not intelligible to each other. Since new research (especially by SIL) constantly changes the picture of the linguistic landscape I am not in a position to always make this distinction accurately. What was once a dialect one day might become a language the next. My use of the concept is therefore not analytic but only descriptive, especially when linking it with linguistic groups. Where I have any doubts I will use the word language. 10 According to Barreteau et al (op.cit.) the three Mafa dialects (mafa-west, mafa-centre and mafa-east) belong, together with wuzlam (Uldeme), muyang, mada, melokwo, zulgwa, dugwor (Dugur), merey (Meri), giziga (north and south), mofu (north and south), cuvok and mefele (Bulahay), to the sub-group mafa-south. The other two sub-groups of mafa are all found to the northeast of the Mafa, meaning among ethnic groups of the eastern and not of the western chain of the Northern Mandaras. They consist of mafa-northwest with matal (Muktele) and mafa-northeast with
} 
form by far the largest ethnic group. They consist of two tribal factions, the Mafahay (who speak mainly dialects of mafa-centre and mafa-east) and the Kwokwarhay (who speak predominantly mafa-west). The majority of Mafa belong to the Mafahay faction who occupy the lower slopes and foothills to the east. The Kwokwarhay inhabit the higher massif areas to the west. The term Kwokwarhay is also used by Mafa to refer to montagnards of the higher massif areas outside Mafa territory, particularly to those of the western ranges (including the Gwoza Hills).

A third tribal faction, often mentioned in the context of the Mafa, are the Bulahay, who do not really belong to the Mafa. Lavergne (1944:22f) refers to the Mafahay (or 'Mafa proper') and the Bulahay as the two main factions of the Matakam. He points to the river Tsanaga as the most important geographical landmark dividing two historical streams of migration moving west and northwest from the plain of Diamare into the heart of northern Mandara Mountains.

Lavergne (op.cit.) sees the Bulahay groups, which I classify as southern neighbours of the Mafa, as being inclusive to the Matakam. He also distinguishes between 'Kokwarza (Kokwar = village; za = montagne)' and 'Mafa-Vara'. Another word for 'Kokwarza' is Kwokwarhay ( $k$ wokwar = village; hay = people), which is the word I use. Both Mafa expressions refer to "true montagnard" as opposed to Mafahay and Mafa-Vara (vara = plain). The latter already live on foothills and in adjacent plains and, says Lavergne, often mix with other ethnic groups. Lavergne's 'Kokwarza' mainly occupy the Ziver-Oupay massif, but some of them are also found in Gouzda, where they mix with Mafahay.

The Mafa of Gouzda (figure 3) equate the term Bulahay and Kwokwarhay with those who live in the higher mountain regions and point towards the Ziver-Oupay massif. We do not really know whether some Bulahay actually merged with Kwokwarhay. However, the Matakam were not a very exclusive ethnic group, and Matakam is a derogatory term referring to those montagnards who occupied the centre of the Northern Mandaras. It seems to be a matter of fact that because the Mafahay developed such a strong influence within the so-called Matakam area that the name Mafa eventually evolved as an autonym.

\section{The Mafa and their "Mofu" links: Mofu proper, Mofu-Meri, Mofu-Gudur}

The Duvangar, Wazang and Durum can be referred to as the Mofu proper sub-group of the Mofu-Diamaré. Linguists like to refer to them as northern Mofu. The Wazang in the south and the Duvangar in the north live on the foothills facing the plain of Diamaré, while the Durum live in the mountains to the east. The river Tsanaga in the south of Durum represents the boundary with the Mofu-Gudur or southern Mofu and the river Fogwom to their west separates them from the Mafa of Roua and Soulédé (Vincent 1991:62). The Mofu proper number about 20,000 and the Mofu-Gudur about 25,000 people. Both Mofu groups speak dialects of mafa-south, which is mofu-north for the Mofu proper (Duvangar, Wazang and Durum) and mofu-south for the MofuGudur.

The northern neighbours of the Durum and Duvangar are the Mofu-Meri, classified by Vincent (1991:60ff), together with the Mboko, Gemjek and Zulgo as 'Tsklam' or northern Mofu-Diamaré. The ethnic point of reference for this construction are the Mofu proper, who allegedly say that the Mofu groups north of the river Tsanaga are "true" montagnards. However, the further north this ethnic classification stretches the more inconsistent it seems to become. This is why I tend to refer only to the immediate neighbours of the Mofu proper as Mofu-Diamaré, which includes the Meri, Mboku and Dugur-Mikiri. The Mofu-Meri number about 5,000 people and speak merey, which is a language of mafa-south. The western neighbours of the Durum and Meri are the Mafa

ndreme (Vame-Mbreme). The Muktele and Vame-Mbreme are therefore the only ethnic groups which do not speak mafa-south. This makes mafa-south the most frequently spoken group of languages in the northern Mandara Mountains. 
of Soulédé and Roua (west of the river Fogwom). They speak mafa-east, which is a sub-group of mafa-south (Barreteau et al, op.cit.).

The Mofu-Gudur number about 26,000 people. The Mofu proper do not consider them to be "true" montagnards (Vincent, op.cit.). Lembezat (1961:12f) tells us that their ancestor, Ngueleo, was brought up by the Giziga-Marva, but Jouaux (1989:263f) says that his name was Biya and that he came from Wandala. Ngueleo or Biya was given a bull (by Giziga or Wandala) to take with him when he travelled to the Mandara Mountains. When he arrived in Gudur the bull disappeared into the ground and only his horns remained visible. Gudur is also the name of an influential chiefdom and it is in this context that ethnographers like to refer to Gudur as a regional tradition of chiefly descent. We find the Gudur tradition not only among the Mafa, but also among the Bulahay groups, the Kapsiki, the Wula and Sukur as well as among the Dughwede and Guduf of the Gwoza Hills. It seems unlikely that Lavergne's Bulahay were the historical carriers of the Gudur tradition and I tend to separate the two.

The Gudur tradition is not necessarily a migratory tradition but rather a regional centre of sacred chieftaincy and pilgrimage, comparable in its function with Mecca (Sterner 1998:40ff). Gudur is found in the area of the Mofu-Gudur and until the recent past Mafa chiefs (bay) derived their local entitlement to speak the law from an annual pilgrimage of the biy vardeké to Gudur, where the chief of Gudur (biy Gudur), would renew his kulé (mysterious remedy). After his return the biy vardeké distributed some of his kulé to the traditional chiefs in his Mafa "constituency". The kulé was not only a means to speak the law, but also represented regional power over epidemics, which could be sent or removed by the biy vardeké. The biy vardeké resides in the northern Moskota hills and he was recognized among most Mafa communities as first representative (biy mafa = great Mafa) of the sacred power of Gudur. I will come back to the Gudur tradition later on in this chapter. At this point I only want to point out that the migration of the Bulahay and the Gudur tradition are two different ethnographic issues.

\section{The southern neighbours of the Mafa: Bulahay groups, Gadala, Gavar, Kapsiki}

The southern neighbours of the Mafa are the so-called Bulahay consisting, from northwest to southeast, of the Shugule, Mefele, Sirak, Muhur and Cuvok, numbering altogether about 10,000 people. They seem to speak dialects rather close to those of mafa, but do not consider themselves as Mafa (Sterner 1998:44f), although Martin (1970:14, fig 2) includes them as Matakam. The defining line between Mafa-Kwokwarhay and the Bulahay can be established by using cultural as well as linguistic criteria. Unlike the Mafa, the Bulahay practice male initiation and the roofs of their houses are not in the Mafa style, but similar to those of the Wula proper who also practice male initiation. On the other hand, the Bulahay have endogamous blacksmiths and refer to them as ngwazla, like the Mafa do and some of their pottery is also very similar to that of the Mafa. Most Mafa-Kwokwarhay speak mafa-west, but the Bulahay groups speak mefele, shugule and cuvok, sub-groups of mafa-south. Further linguistic research is needed to establish whether shugule and mefele are dialects of mafa or independent languages.

Martin (op.cit.) also includes the Gadala (Gadala/Buwal) in his Matakam, but it is doubtful whether they ever were. The Gadala number about 3,000 people and speak a language of dabanorth. To the west of the Gadala and to the south of the Bulahay groups we find the HigiKapsiki. We refer only to the Kapsiki, who number about 30,000 people and speak psikye, which is a language of kamwe (Higi). Some ethnic groups of the Gwoza Hills refer to the volcanic remains of Rumsiki as their oldest ancestral home by linking themselves to it via the Hide of the heights of Tourou (Tur tradition). Under good weather conditions the volcanic remains of Roumsiki can be seen from the Gwoza Hills. 
The Kapsiki and Gadala are the northern neighbours of the Hina and Bana, groups belonging to the less densely populated Southern Mandaras. The Gavar are closely associated with the Gadala/Buwal. Like them, they speak a language of daba-north but, with about 5,000 people, are much more numerous than the Gadala/Buwal. Their oral traditions say that they originate from the Mubi area to the southwest of the Northern Mandaras and that they settled after having crossed Kapsiki land, at the mountain Kortchi to the northeast of Gawar town. The Gavar are also referred to as "Kortchi", viewed by Beek (1987, fig 1) as part of Kapsiki land.

The name Gavar also serves as a name for the Fulbe lamidat Gawar, founded by Fulbe Yllaga before the jihad, which was launched at the very beginning of the $19^{\text {th }}$ Century. The second Fulbe lamidat was that of Zamay, which was founded after the beginning of the jihad. The Yllaga and Fereoobe are the most important Fulbe clans of the Northern Mandaras. The Yllaga migrated from Borno up the Yedseram valley leaving the Northern Mandaras to their left and eventually founding Madagali. The Fereoobe migrated in a southeasterly direction and eventually arrived in the plain of Diamaré. Within the Northern Mandaras the highest number of Fulbe are found in the plateau areas (Meri, Mokolo, Mogode and Zamay). They number about 20,000 altogether, with the plateau area south of Mokolo, especially along the Louti river, having the highest number. The Fulbe speak fulfulde, which is a west-atlantic language (Niger-Kordofan).

\section{Sukur massif and Tourou heights: Sukur, Wula, Vizik-Mabas-Vemgo, Waga, Hide}

The Sukur massif stretches south of Madagali westwards into the Nigerian plain connecting, in the east, with the Wanday plateau from where we reach the Tourou heights. The Wula live on the eastern slopes of the Sukur massif and connect at the Wanday plateau with the Mabas, and eventually Vizik, at which point we are already on our way to the heights of Tourou. The Sukur ${ }^{11}$ number about 5,000 people (including those in the Madagali plain) and they speak sakun. It can be disputed whether sakun is an independent language of 'Biu-Mandara' or a language of kamwe (Higi). According to Sterner, (op.cit.) the Sukur have three closely related satellite groups, which are the Damay (who speak sakun) and the Kurang (who speak psikye) as well as the Ndalmi (who speak a language of the margi group). The Muduvu (Sterner 1998:89) are neighbours of the Sukur. Although they speak sakun (op.cit.), they claim to be closer to the Wula than to the Sukur.

The Wula consist of two factions, which are the Wula Mango and Wula Hanko. They are a group of no more than two hundred people and, according to Meek (1931,I:280), speak a language of kamwe. The Wula claim to be close to the Sukur, with whom they share cultural features, like male initiation and the Gudur tradition. We find among the Mafa a clan called Wula-Sakon which claims to have originated from Wula. The Wula-Sakon are found in our study area in Mtskar (figure 3). They have a chiefly tradition and claim to be the first settlers in the area of Gouzda. A Mafa clan of the name Sakon is found on the top of the Ziver massif and Martin (op.cit:33) mentions 'Sakone (Soukour)' in Magoumaz, which is to the southwest of the Ziver massif. The Wula/Sakon tradition of origin seems to be fairly strong among the Mafa-Kwokwarhay and it is of great interest that they have been settled longer in our local study area than the dominant Mafahay.

There is great uncertainty as to how the name Wula can be historically explained. Martin (op. cit.:16) is of the opinion that the expression 'Oulla' is of Wandala origin. We find on Moisel's map (1912-13) 'Ula-Maskate' designating the area east of the Ziver-Oupay massif (which also refers to the local study area). Mathews (1934:40) explains that they are known as 'Wula' in

\footnotetext{
${ }^{11}$ I would just like to mention here the stone architecture (Smith \& David 1995) of the chiefly residence of Sukur, which was declared a World Heritage Site in 1999.
} 
wandala, Matakam in fulfulde and Mafa in mafa. If it is true that Wula is the Wandala version of Matakam, we must conclude that it is historically older and that the Wandala used to refer to the Mafa to the east of the Ziver-Oupay massif as Wula. Such a hypothesis is supported by the fact that the Wula-Sakon have a long chiefly tradition in our local study area. This would also mean that the Wula of the Wandala had migratory links to the Wula proper (Mango and Hanko) and the Sakon/Sukur.

North of the Wula live the Vizik and Mabas. While the Mabas are in Cameroon, the Vizik are found on the Nigerian side. The Vizik say that they are Mabas and that Vizik is only an ethnic place used after the international boundary was established. Martin (1970:fig 2) includes the Mabas with his Matakam, which does not seem to be justified at all. The Vizik and Mabas total about 1,000 to 1,500 people. They speak mabas, which is a language of wandala-west. The small Vemgo group (not more than 500 people) also claims to be close to the Mabas and Vizik, but they have already descended to the Madagali plain.

North of the Mabas, Vizik and Vemgo we find another very small group known to us as the Waga. The Waga number no more than 500 people and they speak a dialect of lamang. They also claim to be closely related to the Lamang. The Waga live in the northern plains of Madagali. In the past they lived uphill towards the heights of Tourou, but descended as soon as the threat of slavery was over. Hide and Vizik claim that the Waga only lived in the hill during the time of Hamman Yaji of Madagali, between 1902 and 1927.

Up on the heights of Tourou (about 1,200 m), along the international boundary, but mainly on the Cameroonian side, live the Hide (also known as Tur). The heights of Tourou descend to the east where the Moskota river separates the Hide from the Mafa-Kwokwarhay of the Ziver-Oupay massif. The Hide are about 10,000 people in number and speak xadi, which is either a language of wandala-west (Barreteau et al, op.cit.) or a dialect of lamang (Wolff 1974:9). The Hide or Tur are a key group for the ethnic groups of the Gwoza Hills who see Tur or "Fitire" as their place of origin. They refer to them as Hide-Mbra or Gra and add Mbra/Gra to their own tribal name to express the idea of ethnic descent. The Hide also have an oral tradition which links them with the Margi Gulak.

\section{Groups of the Gwoza Hills: Gvoko, Dughwede, Guduf, Chikide-Chinene, Glavda, Lamang}

The heights of Tourou connect at their most northern extension with the Gwoza Hills where we find the Gvoko or Gvoko-Mbra. They are also known as Ngoshe. The Gvoko also overlap the international boundary with their majority living in Nigeria. They number (including those in the plain of Gwoza) about 15,000 people. The Gvoko speak a language of wandala-west, which is very close to xadi and mabas. The Gvoko lead us over to the ethnic groups of the Gwoza Hills with the Dughwede as their northern neighbours. The Dughwede live at the southern end of the Gwoza Hills, which are divided by a lower mountain saddle, where we find the Guduf, and then rise again towards the Zelidva massif in its most northerly point. The Dughwede or Dughwede-Mbra are a key group of the Gwoza Hills. The Chikide-Chinene and Guduf, their northern neighbours, derive their founding ancestors through Dughwede-Mbra.. The Zelidva also claim even closer links to the Dughwede. The Dughwede number (including those living in the adjacent plains) about 20,000 people and speak a language of wandala (Wolff 1971:11). We do not know whether they should be grouped under Barreteau's, Breton's \& Dieu's wandala-west or wandala-east.

The uncertainty of the linguistic position of dughwede throws light on a gap in Barreteau's, Breton's \& Dieu's classification system for the Northern Mandaras. Barreteau et al (1984:167ff) do not refer to dughwede, lamang or afakbiya (Guduf). They begin with mabas, xadi (Hide) and gvoko as languages of wandala-west in the southwest of the Northern Mandaras and ends with gelvaxdaxa 
(glavda), malgwe (Gamergu), wandala, parəkwa (Podokwa) and mura (Mora) as languages of wandala-east to the northeast. The Podokwa and Mora already live in the Mora Hills. It remains unclear where the linguistic boundary between Barreteau's, Breton's \& Dieu's wandala-west and wandala-east should be drawn. Are dughwede and guduf languages of wandala-west or wandalaeast and how does lamang fit into this scheme? Wolff (1971:9, 1974:64,69) classifies lamang together with mabas and xadi as an independent lamang group, but refers to dugwhede and glavda as members of a general wandala group. Further linguistic research seems to be necessary.

The Guduf, including those of Gwoza town as well as those of Gava and Kusarha, number, in all, about 30,000 people. According to Wolff (1971:69f), they speak a language of 'Biu-Mandara' (Central Chadic), but it remains open whether they should be classified with his wandala group. The Chikide number about 3,000 but the Chinene only about 350 people. Although the Chikide-Chinene are closely related, their languages differ. While the Chikide speak afakbiya, which is Guduf, the Chinene speak nakacha (Müller-Kosack 1994:114, 117) or cena which seems to be a dialect of glavda (Wolff 1974:23). We find a traditional belief among the Dughwede, Chikide and Guduf that the Podokwa once lived on the eastern slopes of the Gwoza Hills but then decided to leave for the Mora Hills (Müller-Kosack 1999a:25). Renate Lukas (1973:25) has already informed us about this tradition with regard to the Guduf.

The Chikide-Chinene live on the western slopes and adjacent plains of the Gwoza Hills (Nigeria). Their eastern neighbours (already in Cameroon) are the Mafa of the Moskota hills while their northern neighbours (still in Nigeria) are the Amuda-Ganjara. The Amuda are regional specialists in blessing sorghum (which includes the use of euphorbia) and the Ganjara are famous rainmakers. They number less than a hundred people and speak glavda, which, according to Barreteau et al (op.cit.), is a language of wandala-east. The majority of Glavda live in the intra-mountainous plain between the Gwoza Hills and the Kerawa river, but some of them live in Cameroon. They originate from Gvoko, which links them to the Tur tradition. They number about 30,000 people. A minority of about 2,500 Glavda live on the Cameroonian side, to the north of the Moskota hills.

To the west and southwest of the Gwoza Hills live the Lamang, who number (without the Zelidva) about 15,000 people. The ethnic term Lamang, which means "our people" (lamay), goes back to Wolff (1971:63n) who also introduced the lamang group (op.cit.:64) as an independent linguistic group of Biu-Mandara. Wolff's definition of lamang seems to be to inclusive and it remains doubtful whether the Hide, for example, speak a dialect of lamang. I tend to believe that lamang is possibly a language of wandala-west, which would explain the great similarities with hide and mabas. Wolff also includes the Zelidva with the Lamang as an ethnic group, which I myself dispute. My opinion is that the Lamang consist in ethnic terms of the Waga, Uvagha, Hədkala (Vile, Hambagda and Hudugum) and Luvua, and I refer to the Hədkala as Lamang proper.

\section{Mafa neighbours to the north: Zelidva, Wandala, Podokwa, Mora, Vame-Mbreme, Hurza}

The Zelidva trace their ethnic origin via Dughwede-Mbra, but gave up the Dughwede language when they mixed with the lamang, wandala and glavda speaking groups in the north of the Gwoza Hills. This was most likely through intermarriage between a minority of Zelidva and a majority of Juba, ${ }^{12}$ the latter being the wife givers. The Zelidva eventually established ethnic domination over the Juba, presumably after they had adopted lamang from them. A similar scenario applies to the Kiva and Wize, ${ }^{13}$ from whom they took over wandala (wandala-east), and the Glavda of Bokko, through whom they adopted glavda (also wandala-east). The Zelidva are settled today in the adjacent plains encircling the extreme north of the Gwoza Hills and are about 30,000 in number.

\footnotetext{
12 The Juba are a sub-group of the lamang speaking section of the Zelidva.

${ }^{13}$ The Kiva and Wize are both sub-groups of the wandala speaking section of the Zelidva.
} 
The Vale are a very small group of maybe less than a hundred people, living near the mountain of Kerawa. It remains unclear whether they occupied the Kerawa mountain in the past. They speak either wandala or glavda, which are both languages of wandala-east. Duisburg (1927:194) is of the opinion that they were once Wandala. Mathews (1934:7) tells us that the Vale once lived in the Chikide mountains, but that they left, together with the Chinene, as a result of a conflict over land. Mouchet (1947a:113f) identifies a Vale clan among the Hurza which originated from a Vale mountain near Kerawa.

The Wandala number about 40,000 people with their majority in Cameroon. Their main urban settlements are Kerawa and Mora, with the latter being the capital since the beginning of the $18^{\text {th }}$ Century. Barreteau et al (op.cit.) classify their language under wandala-east. The foundation of the Wandala state presumably took place during the $13^{\text {th }}$ Century under King Agamakiya (Fork1 1995:38). In 1723 or 1724 Islam became the state religion in Wandala under King Bukar Aaji (op.cit.). During the $17^{\text {th }}$ Century the Wandala state extended its sphere of influence towards the south and moved its capital to the former Maya capital, Doulo, $8 \mathrm{~km}$ north of Mora town. The Wandala claim an early dynastic link with the Malgwe (Gamergu), and also with the Maya (op.cit:179-184), which they assimilated after Doulo was conquered around 1675. The Wandala are often referred to as Maya-Wandala (MacEachern 1991). The montagnards of the Gwoza Hills claim that Wandala-Mbra was a son of the eponymous ancestor Mbra/Gra and link them to the Tur tradition. The Wandala state historically represents the most important link between the slave economy of the Borno empire and the peoples of the Northern Mandaras.

The Wadela are a very small group who once lived or still live on the inselberg (isolated hill) next to Doulo. They number less than one hundred people and it is very likely that they speak wandala. Forkl $(1983: 456,463)$ mentions them and Boutrais (1973:45) points out that the Wandala refer to them as 'Wandala païen'. It seems to be uncertain whether they form an independent ethnic group or whether they should be classified as Wandala.

The Podokwa live on the most northwestern hills of the eastern chain of the Northern Mandaras. They consist of several clans with different traditions of origin, all arriving in the Mora hills at different times. Some of them are known to have come from the Gwoza Hills a long time ago, but whether this took place before or after the Wandala moved their capital to Doulo, or even Mora, we do not know. The Podokwa, a group of about 15,000 people, speak parzkwa, which is a language of wandala-east. The Mora are their eastern neighbours. Many of them originate, like some Podokwa clans as well, from the inselberg Waza, about $60 \mathrm{~km}$ north of Mora town. The Mora number about 2,500 people and speak mura, which is like wandala and parəkwa, a language of wandala-east.

The next door neighbours of the Mora to the south are the Vame-Mbreme. They number about 3,500 people and speak ndreme, which is a language of mafa-northeast. The Hurza also speak ndreme. They are about 3,000 people in number but have abandoned their inselberg in the eastern plain of Mora. Some authors claim strong customary links between the Mora, Vame-Mbreme and the Mora. They all share traditions of origin from the Zelidva massif which links them, like the Podokwa, to the Gwoza Hills. I assume that they left Zelidva after the Zelidva themselves had left Dughwede, since they claim to have come from a place of this name in the Gwoza Hills. We know from Dughwede traditions that the Zelidva separated from them after the Dughwede had established themselves in Ghwa'a (often referred to as Wa'a).

These traditions close a circle of geographical provenance which points to a migratory route, beginning at the heights of Tourou and reaching the Zelidva massif at the northern end of the Gwoza Hills. It then turns east by crossing the plain of Kerawa and Mozogo to reach the Mora hills. It was Mouchet (1947a:115) who pointed first to 'Zalidevé' (Zelidva tradition), which is also known as 'ngoulele' (Nyssen 1990:229) or 'ngolele' (MacEachern 1990:159). 'Ngololo' 
(Müller-Kosack 1994:45ff) is the highest valley of the Zelidva massif and similarities in oral traditions can be reconstructed on both sides. An oral account I collected among the Zelidva of Ngololo in 1996 matches an account of the Mora recorded by Mouchet (1947a:128), who reports that the reason for the departure of those who left 'Zalidevé' for the Mora hills was that the sorghum refused to ripen. We can assume that migration between areas within the Northern Mandaras was quite often initiated by the threat of a bad harvest.

\section{Eastern neighbours of the Mafa: Muktele, Uldeme, Mada, Muyeng, Mineo, Zulgo, Gemjek}

South of the Podokwa and Vame-Mbreme live the Muktele and the Uldeme. The Muktele are the most northeastern neighbours of the Mafa living in the plain of Koza. They number about 15,000 people and speak matal which is a language of mafa-northwest. They, too, have migratory links across the plain of Koza. The Mafa clan Gozla, who are frequently found north and east of the ZiverOupay massif, claim their origin from a Muktele settlement of the same name. The Uldeme, of whom there are 7,000, are the eastern neighbours of the Muktele. They face the eastern plain of Mora and speak wuzlam which is a language of mafa-south. The Polasla are a sub-group of the Uldeme, but they speak palasla, which is a dialect of ndreme (mafa-northeast). They are only about two hundred strong and function as blacksmiths for the Uldeme (Wente-Lukas 1970:117).

South of the Uldeme live the Mada and east of the Mada, on an inselberg already situated in the plain of Tokombere, live the Muyeng. The Mada is a group of about 10,000 people who speak mada, a language of mafa-south. The Mada have a tradition of Mafa origin which points to Roua (northeast of Soulédé) and which is the same area many Mafa clans claim to have come from. The Muyeng $(8,000$ people) speak muyang, which is a language of mafa-south. The Muyeng are closely related to the Uldeme and claim that their founding ancestor had come from Doulo, the former capital of the Maya and later Wandala. A similar tradition is found among the Hurza and Mboku and is linked by Forkl (1983:181) to the "Sao", according to which the 'Maya ("Sao")' got either killed or fled after the Wandala conquered Doulo around 1675.

South of the Muktele and Mada live the Mineo and Zulgo. The Mineo are the next door neighbours of the Mafa, to the east of Koza town. They too have a Mafa tradition originating from Roua (near Soulédé), but also a Zelidva tradition. This group has about 6,000 people who speak minew, which is a language of mafa-south and very close to zulgwa (Zulgo). The Zulgo number about 8,000 and live on the Zuelva-Meri plateau between the Mora and the Meri hills. The majority of Zulgo claim to have come from Wazang in the area of the Mofu proper (Durum, Duvangar and Wazang). The Gemjek 4,000 people) live to the southeast of the Zulgo bordering the neighbouring plains of Mora and Diamaré. They speak gemzek, which is also a language of mafa-south. The majority of Gemjek claim to originate from an intermarriage with Mada, but are said to be, in customary terms, very close to the Zulgo.

\section{Eastern Mofu Diamaré and Giziga: Mboku, Mokyo-Molkwo, Tsere, Dugur-Mikiri, Giziga}

East of the Gemjek we find a chain of foothills and inselbergs which belong to the Mboku and the Mokyo-Molkwo. There are about 4,000 Mboku and they speak mboku, which is a language of mafanortheast (similar to ndreme of the Hurza inselberg to the north). The Mboku have mixed traditions of origin from all geographical directions. Vincent (1991:60) groups them together with the Meri, Zulgo and Gemjek as the northern Mofu-Diamaré. The Mokyo-Molkwo on the inselberg to the east of Mboku number about 8,000 people and speak malokwo, which is a language of mafa-south (like the Muyang, Mada and Uldeme). They have strong Mada and Giziga traditions. Vincent (op.cit.) classifies them with the Dugur, Mikiri and Tsere as eastern Mofu Diamaré. 
The Tsere, Mikiri and Dugur live on three small inselbergs south of Mokyo-Molkwo and east of Duvangar (Mofu proper). As a whole, they are often referred to as Dugur-Mikiri (Vincent 1991:57). They speak dugwor, which is a language of mafa-south, and total no more than a few hundred. South of Tsere we find the Giziga-Marva (Marva is the old Giziga name for Maroua town) occupying two small foothills forming the montagnard outpost of the Giziga of the Diamaré plain. They are interrelated with the Tsere and share the same sub-group, which is giziga-north. The Giziga are divided into the northern and the southern Giziga, whereas the northern Giziga of the plain of Maroua are the neighbours of the Mofu-Diamaré. Altogether there are about 80,000 Giziga. The jihad forced some Giziga-Marva to withdraw to the southeastern foothills of the Northern Mandaras where they mixed with Mofu-Diamaré.

\subsubsection{The Mafa: an ethnic melting pot}

Most neighbours of the Mafa have somehow contributed to the emergence of the Mafa have become the largest ethnic group of the Northern Mandaras. It seems that the Mafa have closer migratory links with their southeastern (Mofu proper), eastern (Muktele, Mineo, Mada) and southwestern (Wula proper) neighbours, than with those of the Gwoza Hills and their northern neighbours. However, such a view oversimplifies the situation, since it considers only the Mafahay but not the MafaKwokwarhay. If we include the Kwokwarhay as well, then the western neighbours of the Mafa also need to be considered as ethnic groups which contributed to the formation of the Mafa. This applies especially to the Hide, Gvoko and Dughwede, since they are also Kwokwarhay. The Hide were also considered as Matakam in the past (e.g. Hinderling 1955:405). By separating the Bulahay from the Mafa and dropping the concept of Matakam, we have reached a much more exclusive definition of the Mafa as an ethnic group. The Mafahay have become the only prominent group in terms of migratory links with the Mofu groups, in particular with their two dominant clans, the Vuzay and the Zhélé. The Kwokwarhay of the Ziver-Oupay massif became Mafa as well, but it needs to be acknowledged that they only mixed with Mafahay clans when they actually descended east towards the plain of Koza.

At one point the Mafa, especially the Vuzay and Zhélé, by far their largest clans, managed to extend their territory as far north as the Moskota Hills. As we can see from Lavergne's (op.cit.) account, this must have happened before colonial times. The creation of a large Mafa territory, in particular through a system of localised chiefly clans (kar bay), leads to an ethnographic picture in which not only Mafahay but also non-Mafahay clans migrated internally from settlement to settlement and so contributed to the formation of the Mafa. Many of these local groups of non-Mafahay descent can be linked with neighbours of the Mafa, who in turn often claim extra-mountainous origins.

Many clans of the eastern ranges and foothills say that they originally came from Waza to the northeast (about $60 \mathrm{~km}$ away from Mora town) or even Musgum in the southeast (towards the Logone). In contrast to this, most groups of the western range claim intra-mountainous migratory links pointing south along the heights of Tourou. The so-called Tur tradition can even be extended as far as the volcanic remains of Kapsiki land, referred to by the Gvoko as "Uva'i" and by the Dughwede as "Kwir Uvawa" as their first place of origin. Another relevant link is one with the Margi-Gula, which is reported for the Sukur massif (Ndalmi) and the Tourou heights (Hide). There are also migratory links between the two northern extremities of the mountains. As we have seen above, some Podokwa clans claim to have come from the Guduf, Chikide and Dughwede area of the Gwoza Hills and some clans among the Mora, Vame-Mbreme and Hurza claim to originate from the Zelidva massif.

The Mafa, being the largest group of the centre, are surrounded by many small and middle sized groups bridging the mountains with the plains at their periphery. I believe that this is one of the main 
reasons why the neighbours of the Mafa remained much more fragmented in ethnic terms since they were naturally much more exposed to the slave raiding societies of the plains. The greater accessibility of the eastern Northern Mandaras, in particular from the plain of Diamaré, is presumably the geographical reason for a major stream of montagnard migrants entering the centre of the Northern Mandaras from the east. This might explain why the majority of Mafa clans claim to originate from the east and not the western fringes of the northern Mandaras Mountains.

This hypothesis is supported by the distribution of languages and dialects within the Northern Mandaras. Most languages spoken in the mountains belong to two clusters of the central branch of Chadic, which is represented by the mafa-wandala combined group (Barreteau et al 1984:167). While the eastern neighbours of the Mafa and the Mafa themselves belong to the mafa cluster, most western groups belong to the wandala cluster including some languages of the Mora hills. It is therefore reasonable to link the formation of the Mafa predominantly with their southeastern neighbours with whom they share the same language cluster.

\subsubsection{Introducing the local study area}

Figure 3 shows the geographical location of the area of Gouzda (Canton de Koza) where I conducted most of my field studies within Mafa land. The local study area consists of the following six village communities: Gouzda, Mafmay, Mtskar, Mouzoua, Mazay and Woulad. The map also shows the neighbouring settlements of which Vouzod, Ziver, Oupay and Bigidé are already Kwokwarhay settlements. The rest are mainly Mafahay settlements, often dominated by the Vuzay clan whereas Houva and Zlama form a political alliance with Vouzod. This shows that the study area represents a link between Kwokwarhay and Mafahay.

The latter will become more obvious in Chapter Four where I attempt to reconstruct the settlement history of the research area. One of the results will be a relative chronology in which the Wula-Sakon appear as the chiefly clan who settled first in the area, followed by the Zhwé and Hizhé who eventually lost the chieftaincy to the Vuzay and Zhélé. The Wula-Sakon as well as the Zhwé and Hizhé are non-Mafahay clans. The Zhwé are of so-called Bulahay origin and the Hizhé are presumably of Kwokwarhay origin. However, Wula-Sakon, Zhwé as well as Hizhé did not move directly into the area of Gouzda but moved from one local community to the next often leaving alliances of associated villages behind them. Most of these alliances were later overturned by Mafahay clans moving into the area which brought about larger village communities and new chiefly alliances.

The composition of village alliances within the local study area is as follows. The confederation of Mtskar, Mouzoua, Mazay and Woulad are under the ceremonial control of the Wula-Sakon, while the federation of Gouzda and Mafmay is under the ceremonial control of the Vuzay. Although the Zhélé are the chiefly clans of Mazay and Woulad, they are under the ceremonial control of the Wula-Sakon. In the past, the Wula-Sakon settled in Wula of Gouzda, but moved later on to Mazay, Mouzoua and eventually Mtskar. The geographical order of the migratory movement from Gouzda-Wula to Mtskar before the arrival of the Zhélé is reflected in their ceremonial superiority over the Zhélé of Mazay and Woulad.

Altogether I spent about two years in Mafa land. My first period of fieldwork among the Mafa was from October 1981 till January 1982, in Soulédé, where I studied, over four months, the relationship between ngwazla (endogamous blacksmith group) and vavay (non-blacksmith majority of farmers). From May 1985 till February 1986 I spent ten months in Gouzda to advance my study of the social structure and political organisation of the Mafa. The area of Gouzda became my main research location in Mafa land and I spent another seven months there from September 1988 till March 1989 documenting the religious life of the Mafa, hitherto neglected by ethnographers. In 1994 I began my 
survey of ethnic groups of the Gwoza Hills, but often visited Gouzda in order to extend my studies. Last time I went there was in February 2000 for the bull festival of Zlama.

\subsection{A shared historical background}

\subsubsection{The era of slavery: an involvement}

The historical development of the Wandala state lies at the root of our understanding of the times of slavery in the Northern Mandaras. According to the chronicles of Ibn Furtu (Lange 1987), Grand Imam of Borno, Sultan Idris Alauma sent his troops to the 'large' town of Kerawa in 1576 in order to depose the usurper and then 'pagan' ruler of Wandala (op.cit.:76f). This ruler was an uncle of the prince of Wandala who had taken refuge at the Sultan's court. The uncle, who had robbed the prince of his kingdom, took refuge at the 'large rocky mountain' to the west of Kerawa but was defeated and gave himself up to the Sultan who reinstated the prince and son of the 'pagan' ruler of Wandala (op.cit.). We can be sure that the 'large rocky mountain' was the inselberg immediately west of Kerawa town and not the Zelidva massif nearby, otherwise the siege by Idris Alauma would not have been so successful. Unlike the Kerawa mountain, the Zelidva massif has a swampy lake on top which provides water all year round.

This account is interesting for two reasons. The first is that it clearly describes the Wandala state at the time as a 'pagan' kingdom. The second is the function of the mountains as a refuge, a facility Wandala rulers would make use of several times during their history, especially with regard to their relationship to Borno, and not only while they resided in Kerawa. Also Anania (Lange \& Bertoud 1972) mentions the earliest known capital of Wandala in 1582 and refers to the importance of slave trading in which the Wandala were obviously involved. Another important trade good already mentioned at the time was iron (MacEachern 1993). Similar information can already be found in Leo Africanus's work of 1526 (Pory 1896). We can therefore assume with good reason that, from the $16^{\text {th }}$ Century onwards or even earlier, the northern Mandara Mountains served as a source of slaves for a market under the regional control of an evolving Wandala state.

The foundation of the Wandala state presumably took place in the $13^{\text {th }}$ Century under King Agamakiya (Forkl 1995:38). According to the Kirgam-a-Wandala (Mohammadou 1982:7), the Wandala dynasty emerged from a link with the Malgwe (Gamergu) between 900 and 1000 AD. The Kirgam says that Gaya, a foreign hunter from the east, married Soukda of Malgwe and subsequently made Kerawa his capital. This was allegedly the time when the succession rule switched from matrilinearity to patrilinearity which makes Gaya also the founder of the Wandala dynasty. However, it was his wife, Soukda, who had already attached the town of Kerawa to her kingdom by forming an alliance with Agakouma Jato, the chief of Kerawa. However, we have no information as to Agakouma Jato's ethnic affiliation (op.cit.:7ff).

The montagnard groups of the Gwoza Hills claim that the ethnic origin of the Wandala remains in the tradition of Wandala-Mbra of Tur. Dughwede also claim that Wandala once settled in the Chikide mountains of today, to the southeast of the Gwoza Hills. The Dughwede also have a tradition of integrating a certain "Katala-Wandala" into their lineage genealogies and see in her the wife of "Tasa", who was a son of Dughwede. A 'Katalé' also appears in the Kirgam-aWandala as the daughter of Vaya, who allegedly had a son called Wandala. 'Katalé' still appears in the times of Malgwe matrilineal descent of the dynasty (op.cit.). It is rather doubtful whether there is any meaningful connection between Katala and 'Katalé', but what seems to be clear is that the montagnards of the Gwoza Hills are convinced that they share a common ethnic link with the Wandala. 
This is surprising since the Wandala emerged as the gravest threat to the montagnards in the era of slavery. The Kiva and Wize (see figure 2), two montagnard clans in the immediate vicinity of the Wandala of Kerawa, adapted to a dialect of wandala proper because they allegedly believed that this would protect them from slave raids. Oral tradition reports that when they later became incorporated by the Zelidva they too adopted the Wandala language. It remains unclear whether the Kiva and Wize got involved as guides and soldiers in the context of the slave trade during the development of Wandala domination in the Gwoza Hills. Collaboration with slave raiders is often reported for those groups occupying the adjacent plains and foothills, of which the Lamang and Giziga are examples. However, local memories of such involvement mostly refer to a much later time in history.

During the $17^{\text {th }}$ Century, the Wandala state extended its sphere of influence towards the south and moved its capital to Doulo, where it had defeated the small kingdom of Maya in about 1675 (Forkl 1983:300). Over the next hundred years the so-called Maya-Wandala state developed extensive control over many montagnard groups. Forkl's literature study (op.cit.:286-300) identifies the Glavda, 'Hill Margi' (Margi Duhu and Gulak), Guduf, Matakam, Muktele, Podokwa, Mora, Hurza, 'Vame-Urza' (Vame-Mbreme), Mokyo-Molkwa, Uldeme, Mada, Zulgo, Gemjek, Mboku, and 'Mofu' (Mofu proper and Mofu-Gudur) as having been obliged to pay tribute to the Wandala. He points out that the more remote a group the less control the Wandala could establish. The Wandala established particularly close relationships with those groups living along the margins of the Northern Mandaras and Forkl (op.cit.) could not find any evidence of the Wandala reaching the central plateau. At the beginning of the $19^{\text {th }}$ Century the Wandala moved their capital from Doulo to Mora.

From the early $19^{\text {th }}$ Century onwards, with the beginning of Usmanu of Sokoto's jihad, the southern zone of Wandala influence was dramatically reduced. Strümpell (1912:87f) informs us that the Fulbe Yllaga ended the Wandala domination over the 'Hill Margi' of Madagali (presumably the Margi Gulak). The Fulbe Fereoobe conquered Maroua in 1809 and Wandala were forced to withdraw from the plain of Diamaré. The Fulbe Yllaga came from the western plains and founded Gawar. In 1810 Modibbo Adama encouraged the regional Fulbe chiefs to launch the jihad against all pagan populations (Mohammadou 1988:257-264), but it took till about 1830 before the Fulbe Yllaga took serious action against the montagnards.

Fulani pastoralists had lived in peace with montagnards since the $16^{\text {th }}$ Century. Gawar was founded by Fulbe Yllaga who had arrived in the Mandara Mountains, presumably some time before the beginning of the jihad, coming from Borno and ascending the central plateau from the western plains (op.cit.). Zamay was founded by the initiative of Modibbo Adama who, around 1830, invited the Giziga hunter, and possible ex-slave Ardo Gaw, to settle permanently in Zamay (Mohammdou 1988:277-286). Modibbo Adama was searching for allies to convert the montagnards to Islam. The Fulbe Yllaga fought the montagnards, especially the Matakam, for over 50 years, and were finally defeated by the Cuvok (the most southeastern of the Bulahay groups) in 1895 (Mohammadou 1981:238ff). However, we do not know how far, during that time, the Fulbe actually penetrated into the western massif areas in the very centre of the Northern Mandaras.

We have no reliable figures as to how many montagnards ended up as slaves, but we do have some idea what actually happened to them. Barth (1857,I:249f) reports to us his frequent sighting of slave caravans while crossing the Libyan desert and particularly remarks on the high number of women walking on foot (op.cit.). This throws light on what possibly happened to many female slaves from the northern Mandara Mountains. This is also confirmed by Lovejoy (1983, 1995:30ff), who is of the opinion that more women than men were exported. Adult men were used as agricultural slaves, whereas young boys also were exported because of the high prices 
being paid for eunuchs (op.cit.). Many of the captured men ended up in the so-called slave villages of Borno, which are often referred to today as Wula villages. Wula is a synonym for montagnards, particularly for Matakam (Mafa), presumably derived from Wandala. MacEachern (1993:39) refers to the trade with children and quotes estimates (Cost 1923, in Hallaire 1965:58) which suggest that half of the Wandala farming population was made up of captives.

In 1823, Denham visited Mora, which had by then become the capital of the Wandala under Sultan Muhammad Bukar only about 10 years earlier (Bovill 1965). During the second half of the $19^{\text {th }}$ Century, Wandala had become an integrated part of a regional and trans-Saharan slave economy, with the northern Mandara Mountains as its main resource (Forkl 1995:42). It is Denham who gives us the earliest and most vivid description of how the slave economy operated in Mora, when he observed how slaves arrived at the Wandala capital:

By the assistance of a good telescope, I could discover those who, from the terms on which they were with Mandara, had the greatest dread, stealing off into the very heart of the mountains; while others came towards Mora, bearing leopard skins, honey, and slaves, plundered from a neighbouring town, as peace-offerings; also asses and goats, with which their mountains abound: these were not, however, on this occasion destined to suffer. The people of Musgow, whose country it was at first reported (although without foundation) that the Arabs were to plunder, sent two hundred head of their fellow-creatures, besides other presents, to the sultan, with more than fifty horses. Between twenty and thirty horsemen, mounted on small, fiery, and very well formed steeds of about fourteen hands high, with a numerous train, were the bearers of these gifts - and a most extraordinary appearance they made. I saw them on their leaving the sultan's palace; and both then, and on their entrance, they threw themselves on the ground, pouring sand on their heads, and uttering the most piteous cries. The horsemen, who were chiefs, were covered only by the skin of a goat or leopard, so contrived as to hang over the left shoulder, with the head of the animal on the breast; and being confined round the middle, was made to reach nearly half way down the thigh, the skin of the tail and legs being also preserved. On their heads, which were covered with long woolly, or rather bristly, hair, coming quite over their eyes, they wore a cap of the skin of the goat, or some fox-like animal; round their arms, and in their ears, were rings of what to me appeared to be bone; and round the necks of each were from one to six strings of what I was assured were the teeth of the enemies they had slain in battle: teeth and pieces of bone were also pendant from the clotted locks of their hair, and with the red patches with which their body was marked in different places, and of which colour also their own teeth were stained, they really had a most strikingly wild, and truly savage appearance.

Denham's geographical orientation is not always accurate and we can assume, with good reason, that his 'Musgow' is not Musgum in the plains along the Logone river, but Mozogo ('Musgo' on Moisel's map from 1912/13) and therefore the people he describes are presumably Mafa from the Moskota hills. The same view has already been put forward by Vincent (1978:583f) arguing that the Musgum territory is too far away to have collected slaves and brought them to Mora in a day or two. It is quite possible that the peace offer Denham observed was sent by the most regional chief of the Mafa, the biy vardeké (chief of plagues) or biy Moskota, who had his residence at the most northern edge of the Moskota hills (bordering the Glavda). This Mafa chief had been very influential in the past and, according to Mafa and Dughwede oral tradition, was involved in the internal control of the slave trade among the Mafa and their neighbours to the west (Gwoza Hills). The biy vardeké was, to my knowledge, also the only Mafa chief in possession of horses. ${ }^{14}$

\footnotetext{
${ }^{14}$ Nic David (electronic communication) rightly points out that a great deal of doubts remain as to whether Denham's 'Musgow' was in reality Mozogo, especially with reference to the horses, but also in relation to the hair and dress styles. However, it is well possible that Denham confused not only locations, but also events he attached to them.
} 
The second most important Mafa chief was the biy yam (chief of rain) of Moudoukwa or biy Moudoukwa. We know for sure that he was involved in the internal control of the slave trade as the following oral account by Gazawa, a Vagsa lineage elder from lower Gouzda, demonstrates:

Hamman Yaji (Fulbe district head of Madagali from 1902-1927) had raided the area of Gouzda without involving the local dignitaries (bay), who then went to see the biy Moudoukwa complaining about Hamman Yaji's actions. The biy Moudoukwa now went to Madagali where he asked Hamman Yaji to return the captured slaves to Gouzda, since they had been taken without local agreement. Hamman Yaji refused, but the biy Moudoukwa made it rain so heavily that Hamman Yaji's house came under water. Next, Hamman Yaji threw his lance in the air in order to show his power, but the biy Moudoukwa did the same whereby his lance rested above the lance of Hamman Yaji. Hamman Yaji was so impressed by the power of the Mafa rain maker that he gave him back the slaves he had captured and the biy Moudoukwa brought them back to Gouzda.

This account shows that traditional Mafa chiefs were perceived to possess great supernatural powers. These powers allowed them to play the role of mediators in peace negotiations with the Wandala and Fulbe. It also shows that slave raids were not a straightforward matter of the Wandala or Fulbe (the latter from mid $19^{\text {th }}$ century onwards) raiding the mountains, but that the local population had developed some internal control over the output of slaves. Oral accounts from the area of Gouzda tell us that members of kin groups which were small in size and low in status were often the ones who became victimised in this sense. Another group were prisoners of tribal warfare or people who had broken the traditional law (see also Kosack 1992). Mafa have a developed system of chiefly clans, known as kar bay (son of the chief) which became the most numerous over time. I would tend to historically link the development of large chiefly clans among the Mafa (the kar bay) with the attempt of the evolving Mafa tribe (Mafahay) to gain control over the output of slaves in the centre of the northern Mandara Mountains.

Dughwede oral accounts of elders on the local history of slavery inform us about a system of tributes to the Wandala of Kerawa in order to prevent slave raids. This meant that they provided a certain number of slaves, iron and agricultural products. When the Wandala had their capital in Mora, the Dughwede brought their tributes to "Mazagwa", which is Mozogo to the east of the Moskota hills (this too confirms the likelihood that Denham saw Mafa in 1823 and not Musgum). This tribute system collapsed from time to time and when this happened they were punished with slave raids. During these periods of reccurring raids they established an early warning system. This was particularly important because they also used to cultivate in the adjacent plains. When their lookouts saw the Wandala arriving on their horses, they quickly fled up into the mountains.

The Dughwede also saw the Wandala battling with the Mafa at the western side of the Moskota hills. They saw the Mafa fighting with bows and arrows and the Wandala attacking them using spears. The Dughwede accounts tell us that it was not only Wandala who raided the Gwoza Hills, but also the Glavda and the Mafa. They report that many people of the Gwoza Hills who were captured by the Mafa later became Mafa themselves. One way of buying back captured slaves was by paying with cattle and iron, or by exchanging a captured man for one of their women. MacEachern (1990:38f) describes a similar pattern in the context of the slave raids by the Wandala of Mora town to the Uldeme and Vame-Mbreme of the Mora hills.

Extensive slave raids of the Fulbe against the Mofu-Diamare are reported by Vincent (1991:94f). The walls of stone constructed for defence against the Fulbe cavalry can still be seen today. Similar systems can be reported from Wize, south of Kerawa, this time against the Wandala. The thorny hedges around the houses of the Glavda and the Kapsiki had a similar function. Most defence systems had a passive purpose. This applies in particular to the early alarm system of lookouts on tops of mountain hills, who used iron trumpets to warn their people of a possible attack. The people then gathered food supplies and took their cattle with them in order to quickly 
hide in mountain caves. Most of these caves are still remembered and they often have a source which meant that there was water available during a longer hiding period.

The era of slavery ended with the arrest of Hamman Yaji by the British in 1927. When I visited the Gwoza Hills in 1994, elders often wanted to thank me because my "brothers"15 had arrested Hamman Yaji. This shows how vivid the experience of slavery still is. At the time the Wandala had already given up slave raiding, but Hamman Yaji continued to raid. The diary of Hamman Yaji (Vaughan \& Kirk-Greene 1995) documents the process. From 1912, when the diary begins, until 1919, he records the number of female and male slaves as well as the number of cattle he took during his excursions into the northern Mandara Mountains. After 1919, the year of the Treaty of Versailles, he suddenly stops reporting on slave raids and never mentions them again until his arrest in 1927, when the diary ends. However, oral accounts I collected among the Dughwede of the Gwoza Hills strongly suggest that slave raiding only stopped after his arrest.

\subsubsection{Colonial rule and post-colonial develoments}

The era of slavery ended in the northern Mandara Mountains with the establishment of colonial rule. ${ }^{16}$ The Germans established themselves in Mora in 1902. German colonial reports ${ }^{17}$ suggest that they relied on existing Wandala and Fulbe power structures to establish control over the Northern Mandaras. However, there are hints regarding the motives for their first excursions into the centre of the Mandara Mountains. It is suggested that the purpose of these excursions was to explore the possibility of establishing direct contact with the montagnards themselves. Hauptmann Zimmermann's report (1906:458) states that the Germans had developed doubts as to whether the negative image the Wandala and Fulbe had presented about the montagnards was really true and he wanted to go and see for himself. ${ }^{18}$ Moisel's map of $1912-13^{19}$ shows that Zimmermann's excursion, which took place in 1905, was not the first journey of a colonial officer into the Northern Mandaras. There is no indication that his attempt was successful and it seems that the Germans continued to rely on Wandala and Fulbe.

After the defeat of the Germans in North Cameroon in August $1914,{ }^{20}$ British and French troops started to take control in key towns of the surrounding plains. These were in particular Maroua, Mora, ${ }^{21}$ Madagali and Dikwa, although Dikwa was not really at the foot of the Northern Mandaras but quite some distance to its north. The early zones of influence of the British and French were later replaced by mandated areas allocated to them in 1919 by the Treaty of Versailles in which the Germans officially had to renounce all rights over their former colonies.

\footnotetext{
${ }^{15}$ I am not so sure whether an Englishman would likewise have recognised me, being a German, as a "brother", especially in this particular historical context! After all, it was the Germans who had made Hamman Yaji district head of Madagali. However, it should be noted that it took the British until 1927 (more than ten years after the defeat of the Germans) to actually remove Hamman Yaji and it remains an interesting historical question as to why they did not arrest him much earlier.

${ }^{16}$ See Rudin (1938:85-96) for a description of "what The Times of London called a 'race for the Tschad', in which the participants were France, England, and Germany" (op.cit.:85).

${ }_{17}$ Dominik (1903), Puttkammer (1904), Zimmermann (1906), Wolff (1914).

18 Also Martin (1970:41) refers to Zimmermann's critical remarks, especially with regard to the role of the Germans as protectors of the Fulbe against montagnard aggression.

19 The first excursion was by von Bühlow in August 1902 from Madagali to Zamay and he went again in May 1903. from Mora via Moskota and Bao (Ziver plateau) to Zamay. Glauning travelled in October 1903 from Madagali via Libam and Tourou (along the Tourou heights) and Moskota to Mora.

${ }^{20}$ Ferrandi 1928:63 describes the battle of Mora in August 1914 and presents a sketch of the German positions in the Mora Hills as well as his and von Raben's letter in which he refused to surrender.

${ }^{21}$ Nonetheless Hauptmann (Captain) von Raben continued fighting the French in the Mora Hills until 1916, even though Yaoundé itself fell in that year.
} 
The French and British did the same as the Germans. In their attempt to gain control over the populations of the Northern Mandaras they relied mainly on Wandala and Fulbe. Old prejudices were maintained about the montagnards being a particularly uncivilised and backward kind of people with primitive customs. It seems that the colonial powers in charge at the time, in particular the British, had not made much effort to check this for themselves. However, they must have felt that they needed to offically find out more about the montagnards. The colonial office reports ${ }^{22}$ provided by the British to the League of Nations frequently refer to a request, made by colonial officers, to conduct an ethnographic survey in the Gwoza hills. This request was never met.

The reports continued to refer to the population of the Gwoza Hills as 'hill pagans' and did not use ethnic names, although they must have been known since as early as the 1930s. DO Mathews (1934) had produced an ethnographic survey in which he listed all ethnic groups according to their names and languages as well as some of their migratory links. The French, who had received the lion's share of the former German Cameroons, referred to the mountain populations as montagnards and hence, the word montagnard was later adopted by English speaking ethnographers. The French also had to provide annual reports ${ }^{23}$ to the League of Nations and later the United Nations, but unlike the British reports, they did not seem to be produced annually. However, it seems that the French made greater efforts than the British and developed a more productive relationship with the montagnards. One reason might be that the French Cameroon had the potential of becoming a future nation in its own right, while the northern part of the British Cameroon remained an appendix to British Nigeria.

The colonial times of the Northern Mandaras can be roughly divided into four periods: An initial post First World War period, which lasted from 1914 till about 1920/21, followed by a period of pacification and establishment of colonial administration under civil rule. After pacification was achieved, between the late 1920s and the early 1930s, a process was initiated which led to a first period of modern development involving missionary activities, and so on. This period lasted till the end of World War II which then led to a second period of modern development. Colonial rule ended with the achievement of national independence. A referendum was carried out in 1960/1961 and the results made the Gwoza Hills a part of Nigeria, but the greater part of the Northern Mandaras was incorporated into the Republic of Cameroon.

Already during the initial post First World War period the French seemed to have shown a much greater interest in the mountain populations than the British did, which was possibly due to the fact that the Cameroonian part of the mountains was larger and easier to access. During this initial period the French even administered parts of the British zone of influence (Tomlinson 1916:13), but we do not know whether they actually visited the mountains. There must have been a serious lack of colonial presence during this time, although the Wandala and Fulbe continued to act as their representatives. It seems that Hamman Yaji took advantage of this since we know for a fact that he raided the Northern Mandaras for slaves and cattle throughout this initial period (Vaughan \& Kirk-Greene 1995:51-71).

In retrospect, it does not seem to be at all surprising that the montagnards were not very welcoming towards their new colonial masters, since their old oppressors remained their local representatives. Colonial reports (op.cit.) often speak of difficulties in raising taxes and of situations where there was physical conflict between colonial powers and montagnards. ${ }^{24}$ While the British did not seem to have great success in their development attempts, the French

${ }^{22}$ Reports by His/Her British Majesty's Government appeared annually between 1927 and 1961.

${ }^{23}$ Rapport Annuel du Gouvernement Français, année 1950.

${ }^{24}$ See also Beauvilain (1989:320-39) for the French and Kirk-Greene (1969:180-91[1958]) for the British Cameroon. 
eventually achieved pacification on their side around 1929/1930. Capitain Vallin ${ }^{25}$ is still remembered by older Cameroonian montagnards for his frequent visits in the mountains during the years of pacification. In early 1930s the British founded Gwoza, following the killing of a village head by Dughwede. ${ }^{26}$ This event is well remembered by montagnards who often see this as the beginning of their pacification. It was presumably only at this time that the British had come to realise that Dikwa was too far away if they wanted to exercise their control successfully.

The differences between the "direct" French and the indirect British system of colonial rule does not seem to have made much difference to the situation the montagnards must have found themselves in during the intitial post First World War period. Both powers held on to the Wandala and Fulbe as their representatives, whereas the British, due to their system of indirect rule, possibly held on much longer to Hamman Yaji than the French would have done. The British relied much more on existing power structures than the French and their colonial officers might therefore have been more hesitant to remove some individuals from positions of power.

Since the montagnards had a decentralised political structure the colonial powers continued to rely on the Muslims. Their relationship with the montagnards reached back to the era of slavery. However, the French established a system in which local village heads were recruited much more from traditional non-Muslim backgrounds than was the case with the British. This led, over time, to a situation in which ethnic groups of the Cameroonian side made a conscious attempt not to mix traditional and administrative offices. On the Nigerian side they did not. The fact that today all village heads (lawan) of the Gwoza LGA are Muslims, is also a result of 40 years of British indirect rule. ${ }^{27}$ It was helpful to become a Muslim in order to become a village head which was not so much the case on the Cameroonian side.

It appears to me that the ethnic groups of the Cameroonian Northern Mandaras received some kind of historical advantage from the fact that the French did not practice indirect rule. It seems that they enjoyed greater political freedom and therefore maintained a more complex community life. The bull festival, for example, has been abandoned in the Gwoza Hills since the 1970s and a certain form of male initiation had already disappeared in the 1950s. This is different on the Cameroonian side. The traditional seasonal calendar is still much more intact and the bull festival still takes place among the Mafa, although they never did practice male initiation. The situation seems to be different when we go further south, where we find that male initiation is still practised among the Sukur and Wula proper.

Since independence, the lack of interest by the British in the Gwoza Hills continues to manifest itself as neglect by the Nigerian government. This has led to the Gwoza Hills becoming one of the most underdeveloped regions in the whole of Nigeria. Things were different on the Cameroonian side, where the French colonial powers had already developed a scientific interest in the Northern Mandaras. The literature reflects this. French colonial officers published articles and books dealing with the ethnography of the Northern Mandaras. ${ }^{28}$ After independence, French scientific institutions (CNRS and ORSTOM) developed strong links and still dominate academic life in Cameroon. $^{29}$

\footnotetext{
${ }^{25}$ Martin 1970:42n; Sterner 1998:53.

${ }^{26}$ The reason given for the killing of Lawan Buba by Dughwede of Ghwa'a is that he had used physical force to achieve resettlement in the plain of Gwoza in order to establish better administrative control.

27 The Report by Her Majesty's Government for the year 1954 (1955:73) remarks that 'The hill pagans have enjoyed no such unifying element as Islam...'

${ }^{28}$ In 1935 the Société d'Etudes Camerounaises was founded. Its Bulletin (BSEC) started to appear the same year and was later renamed in Etudes Camerounaises (EC). Mouchet published there between 1938 and 1957.

${ }^{29}$ This trend has continued till today and is reflected in the distribution of ethnographic representation per ethnic group. Substantial monographs have been written so far about the: Giziga (Pontie 1973), Kapsiki (Beek 1978), Mafa (Lavergne
} 
Although we seem to be much better informed ethnographically about the groups on the Cameroonian side, the question arises whether the Cameroonian montagnards have also profited more in terms of modern development. More academic literature on modern developmental issues has been produced for the Cameroonian than for the Nigerian sector of the Northern Mandaras. Of particular interest here are the most densely populated areas of the Northern Mandaras. Most of these studies ${ }^{30}$ are conducted along the foothill areas or on densely populated slopes not higher than about $800 \mathrm{~m}$. In terms of practical development there does not seem to be any difference in massif areas above the $800 \mathrm{~m}$ level. Very little infrastructure is in place and there is a genuine lack of fertile land. Another issue is the disproportionately high number of children, women and older men because many male adults are away finding work elsewhere.

However, the political situation is very dissimilar on the Cameroonian side. From 1988 onwards the Wandala completely lost power over the montagnards. This is particularly obvious in Koza, where the chef de canton is now a Mafa. This would have been unthinkable in the early 1980s, a time when the Mafa were still fighting to get schools into their villages, in particular in the areas on the plain to which they had descended during the 1970s. The situation in Nigeria is different. The experience of many years of military rule put a stop to any democratic development. Those schools already in existence, which had developed in the context of an earlier and stronger downhill migration, began to deteriorate during the 1990s and led to political resignation, a situation which has hardly changed until the recent successful democratic elections in 1999.

The fact that the montagnards of the Cameroonian side of the Northern Mandaras are much better represented politically is also apparent when we look at the food shortages which occurred during 1998/99. While the Nigerian side received no international aid, the Cameroonian one was able to access European funds in order to buy maize for public distribution. A similar situation exists in terms of infrastructural development. The Cameroonian side profits from the Mandara Mountain Development Project funded by the European Union, while the Nigerian sector of the mountains has no stake in this at all. We can conclude from this that modern development and the ensuing changes have turned out to be more advantageous for the Cameroonian montagnards. The Nigerian sector of the Northern Mandaras seems to have been forgotten by national as well as by international developers, a familiar trend for the Gwoza Hills.

\subsection{The compatibility of organisational structures}

\subsubsection{Terrace farming: worldview and social structure}

Terrace farming ${ }^{31}$ is the main economic activity of the montagnard societies. We are not certain exactly when the terraces were built in the Northern Mandaras, but we can be fairly sure that terrace farming, as the main economic activity, is historically rooted in the function of the mountains as a refuge during the times of slavery. However, we should not underestimate the environmental advantages of higher rainfalls in the mountains, which must also have contributed to the mountains becoming so attractive within the Sudan Savannah.

1949 and Martin 1970), Mofu proper (Vincent 1991), Gemjek and Zulgo (Graffenried 1984), Muktele (Juillerat 1971), Mada and Muyeng (Richard 1977), Podokwa (Lembezat 1952) and Sukur (Sterner 1998). We can see that these monographs deal almost exclusively with groups of the Cameroonian part of the Northern Mandaras.

${ }^{30}$ See e.g. Fontaine (1995) and Andel (1998) on the area of Tokombere or Zuiderwijk (1998) on the area of Koza.

${ }^{31}$ Hallaire's Hodogway (1971) on the terrace farming system of the Uldeme and her regional account on the Mandara Mountains (1991) are classics. See also Ridell \& Campbell (1986) and Zuiderwijk (1998). 
Terrace farming could have not been historically successful without the production of manure ${ }^{32}$ by montagnards. Until recently the keeping of livestock was essential for maintaining the fertility of the terrace fields for the annual crop rotation of sorghum and millet we frequently find in the northern Mandara Mountains. This is, however, now changing with the increasing application of chemical fertiliser. Cattle are becoming more and more valued as an object to be measured in money rather than in status. In the past it was essential for a man to own cattle otherwise he would have had no sorghum.

Among the crops $^{33}$ cultivated in the Northern Mandaras, sorghum is traditionally the most important plant in the region and therefore has much higher social and religious prestige than millet. Sorghum has a high religious significance and is libated on the ground in the form of beer. It is firmly incorporated in the worldviews of montagnards by its function as a spiritual agent, connecting human and terrestrial fertility. Sorghum seems to have a personality of its own and all aspects of its production and consumption are carefully handled during the obligatory family and communal rituals.

Millet and beans have a much more profane nature, although bean flour is also quite often used in ritual contexts. Most mountain farmers also cultivated mountain yams, which are used among the Mafa as a metaphor for a smaller agnatic kin group within a local community. The metaphor is derived from the fact that the old head of the yams rots away after a group of new tubers have developed underneath. The next one nearest to the top develops into a new head. Mafa use the word gad bulom (gad $=$ head, 6ulom $=$ yams) to name this process. Similar social metaphors drawn from important domestic plants might exist among other groups as well.

\section{The minimal lineage}

The Mafa metaphor throws light on the importance of the small agnatic kinship groups and the socio-economic bonds they represent. I will refer to this type of small kinship group as minimal lineage, generally consisting of hamlets of co-residing family groups comprising up to about four generations. The minimal lineage seems to be the most important unit in a segmentary system of patrilineal descent and patrilocal residence. However, if we compare the regional ethnographic literature available, we cannot always identify a word for minimal lineage. ${ }^{34}$ Many groups of the Gwoza Hills refer to it as kudiga, meaning "kitchen", which signifies the same unit as a metaphor taken from the female sphere of a house. This metaphor for minimal lineage does not only refer to the same type of small agnatic kinship group as the gad bulom (head of yams) of the Mafa, but also points towards the structural importance of the reproductive capacity of women. It is the polygamous family which underpins this reference and forces us to learn that such kin groups often split along the structure of half-brothers. Half-brothers eventually get married themselves and start their own nuclear families not far away from their father's house. After about four or five generations one of those half-brothers is going to become "head of yams" or ancestor of a "kitchen" himself.

\footnotetext{
32 The colonial Report by Her Majesty's Gevernment (1955:60) explicitly speaks of 'the pagans [of the Gwoza Hills who] cultivate their land most intensively, and make great use of manure.'

${ }^{33}$ Nicholas David (1976:244ff) provides us with an archaeologically based account on the crop history in relation to the Northern Mandaras. See also Hallaire (1984:407-427).

${ }^{34}$ Hinderling (1984:34-44) compares the Mafa word 'gole' (gwaliy) for clan or maximal lineage, with expressions of a similar structural meaning among the Uldeme, Mada, Muktele, Podokwa, Muyeng and Giziga, by relying on the ethnographic literature available to him. My own comparison shows that e.g. the Muktele use the word 'tshay' or 'tsaydza' (Juillerat 1971:78) to designate a maximal lineage or a segment of it. Richard (1976:78f) identifies among the Mada the word 'jubé' for clan or patrilineage and the word 'diné' for minimal lineage. No literal meaning is given.
} 
Although there is not really sufficient ethnographic data, I assume that we find a similar social structure among most ethnic groups of the Northern Mandaras. The basic domestic unit is the nuclear family. Its representative is the family head who is interlinked with other families in a network of kinship-based relationships within his local neighbourhood. Political power segments along the lines of agnatic descent in almost equal shares which in turn form minimal lineages, representing the smallest political unit in most ethnic groups.

I believe that the segmentary lineage system is an appropriate model to formulate the social structure of the ethnic groups of the Northern Mandaras. However, I tend to neglect the theory of segmentary oppositions since this would lead us to a reappraisal of the old Lineage or Descent Theory, an approach I want to avoid. ${ }^{35}$ I use the term segmentary lineage system not to prove a particular theory but as a practical tool to describe the social structure of montagnard groups in the Northern Mandaras and what might be typical for them as terrace farming societies.

\section{Population density}

This brings us directly back to the issue of population density in connection with terrace farming. High population density has an effect on lineage segmentation, which in turn influences the formation of local groups and settlement density. Terrace farming is a labour intensive agricultural activity which encourages a high population density. Historically, we cannot derive the high population density in the Northern Mandaras solely from its function as a refuge. We also have to acknowledge that higher rainfalls in the mountains bring about environmental advantages as well. However, the fact is that terrace farming and a high population density are a productive combination, so long as the population pressure does not rise too much.

One of the solutions provided by montagnard societies to regulate these contributing factors is the potential mobility of their small agnatic kinship groups (minimal lineages), which can function as reproductive socio-political cells in a highly independent way. They develop fairly quickly over four or five generations and soon gain a certain level of political independence as a hamlet or a ward. Local communities are usually made up of these minimal segments, which integrate to higher levels of segmentation, thereby maintaining the stability of the system by the very fact that it is made up of units of a fairly similar structure. ${ }^{36} \mathrm{I}$ believe this is how mobility and stability was maintained in the past.

This leads us to examine the internal structure of minimal lineages in the Northern Mandaras. The residential unit is the nuclear family, which is at the same time the domestic and householding group. This group, the family or household, is normally composed of the father and his wife or wives and his children. It is the father who owns the farmland, which he inherited from his father or eldest brother. The farmland is normally divided into the inner and outer fields, with the family house situated within the inner. The inner field is the most fertile piece of land a family normally possesses, since the manure is mostly brought out at this level.

The nuclear family being the basic unit of production and consumption does not necessarily mean that it is completely exclusive. With regard to the ritual bonds of his extended family the father of a nuclear family would not be in a suitable position to cultivate his land without the blessing of his elders. Although the family unit farms and consumes the fruits of its labours it is the wider family context which provides the framework for successful farming to take place. Farming is not just a technical task which automatically yields a good harvest if done correctly. Good farming

\footnotetext{
${ }^{35}$ I prefer not to be caught up in a general discussion as to whether kinship ties between groups are constructed on the basis of descent (lineage theory) or marriage (alliance theory).

${ }^{36}$ MacEachern, (1990:27-34), with regard to the structure of social organisation among montagnards of the Northern Mandaras, came to a similar conclusion.
} 
also demands respect for the moral context within which farming techniques need to be applied. Without the blessing of his elders a man cannot farm successfully. He would seriously risk challenging the spirit of sorghum as a result of inappropriate and careless ritual handling throughout the cycle of production and consumption.

Due to the high population density, especially on the fertile slopes of massif areas, the ritual context for the spiritual handling of farming techniques can be very complex and it is often a matter of developing quite sophisticated calendars to actually achieve the correct timing. Due to the climatic conditions of the Sudano-Sahelian zone the mountains are situated in, the correct timing of the agricultural cycle was often, and still is, very important for the montagnards of the Northern Mandaras. ${ }^{37}$ In comparison to the Southern Mandaras, the lower rainfalls of the Northern Mandaras brought about a calendar which reflects the need for good seasonal timing. In particular, the timing for the beginning of the sowing season includes a high risk of failure and rainmakers, corn blessers and ritual controllers of epidemics can become politically very influential. Local lineages or clans within an ethnic group often hold different ritual positions, which can result in a rigid ritual order in the context of the agricultural calendar.

\section{Ritual density}

The social distribution of religious responsibilities for the successful political management of the agricultural cycle often leads to a very dense process of ritual sequencing, which in turn, mirrors an historical process of ethnic merging. It seems to me that the ritual density is higher among those montagnard groups who have developed higher levels of ethnic inclusiveness. On the other hand, those ethnic groups remaining fairly small and exclusive often have a lower ritual density. ${ }^{38}$ It is noteable that the Mafa, described as an ethnic melting pot in the centre of the montagnard region, perform particularly complex seasonal rituals.

The Mafa have three interrelated calendars in which each is one month advanced or delayed depending on altitude. Those who live and farm between about 900 and $1,300 \mathrm{~m}$ are at the highest level and have the most chronologically advanced calendar. They are followed by a middle range calendar, for those living between about 700 and $900 \mathrm{~m}$, which is delayed for one month. The lowest level is for those communities which settle on foothills and adjacent plains, between 500 and $700 \mathrm{~m}$ height. However, this is not set in stone but only a orientational framework Mafa tend to operate within. We do not know how the Mafa calendar relates to those of their neighbours, but assume that earlier rainfalls in higher mountain regions are the technical reason behind this topographical order.

The ethnographic study of calendars ${ }^{39}$ is not very advanced in the Northern Mandaras but we know that annual rotation of sorghum and millet is practised by many montagnard groups. ${ }^{40} \mathrm{It}$ seems to be that among those groups who practice this system, the sorghum year holds the most ritual importance. During the sorghum year more ritual activities relating to farming are carried

\footnotetext{
${ }^{37}$ Roger Blench made me aware of this aspect.

38 This phenomenon is also apparent among the Mafa. Many Kwokwarhay claim that the Mafahay communities have to perform very complicated rituals. The reason behind this lies presumably in the fact that they often consist of complex sets of local groups, varying in origin and time of settlement, all needing to be politically integrated.

39 Explicit ethnographic studies of montagnard calendars are Vincent (1982) on the Mofu-Diamaré and Müller-Kosack (1996b) on the Dughwede.

${ }^{40}$ The Podokwa cultivate sorghum every year. Nic David (electronic communication) points out that the Sukur annually plant their millet and sorghum in the same field, but rotate other crops.
} 
out than during a millet and beans year. In the Gwoza Hills finger millet ${ }^{41}$ is planted together with sorghum. The planting of sorghum normally requires a longer seasonal year than millet and beans, which is reflected in traditional calendars. For example, the Mafa have one month around October/November called hedek, which is doubled during the sorghum year. While the Mafa have alternating 12 or 13 months per lunar year, amounting to two solar years, the Dughwede of the Gwoza Hills only count the active part of their year, which brings them to alternating 6 and 7 months per lunar year.

We also find an extensive culture of ritual beer consumption in all terrace farming societies of the Northern Mandaras. This sometimes rises out of proportion due to more and more beer being produced for sale. In the past, sorghum beer was mostly consumed in the ritual context of the traditional calendar. This meant that religious family or community events mainly took place during the passive dry season. The calendar year of agricultural activities is divided according to the main annual seasons. These maybe designated as the active and the passive seasons. The active season is when everything is growing and everybody is busy farming and the passive season is the dry season when terraces and houses are repaired. The agriculturally passive season is also the time when most rituals are carried out. I like to refer to this time of year as the slaughtering season when goats and sometimes bulls are sacrificed and ritually consumed during this time of the year.

All this is now changing and the traditional calendars of the terrace farming societies of the Northern Mandaras seem to adjust themselves to annual ritual cycles. Certain ancestral feasts which, in the past, only took place during a sorghum year, are now carried out yearly. Other festivals, which once took place in triennial or even quadrennial cycles, have completely disappeared. I mentioned earlier the bull festival of the Gwoza Hills, which once took place in a biennial cycle, but is no longer performed. All of this has to do with changes in value orientations, a socio-economic process which not only affects the individual's worldview but also their everyday working lives. Cash crops replace subsistence economy on an increasingly larger scale, a development which not only brings blessings on the one hand but can also lead to famine on the other.

The dilemma behind this seems to be that it was, in the past, an achievement for a man to be able to fill up to three granaries ${ }^{42}$ so that his family could survive one or even two bad years. This has changed due to the need for money. Nowadays, a man tends to keep only the equivalent of one granary so he can feed his family for one year and sells the rest. A bad harvest in the following year can then lead to severe hardship. This is exactly what happened in the Northern Mandaras in 1998/99, when severe famine hit the populations of the Northern Mandaras.

\subsubsection{Chieftaincy and ceremonies: similarities and differences}

The above section aims to demonstrate that there is a high level of organisational similarity among the terrace farming societies of the Northern Mandaras but that there are also differences. The most important similarity is to be found in the environmental and historical circumstances in which they evolved. However, the first difference occurs when we examine the general pattern of ethnic distribution within that homogenous region, from which the Mafa emerge as the largest group in the centre surrounded by much smaller neighbours on the periphery. Due to the fact that

\footnotetext{
${ }^{41}$ Kodzo Gavua (1990:69) reports for the Mafa of Soulédé the existence of 'two different underworlds, an underworld where only sorghum is grown (veved-daw) and one in which Eleusine (하retak) is the only source of nourishment (veved-mbretak).'

42 In the past the Dughwede practised a system of male initiation called dzum zugune in which a man had to fill three granaries of sorghum for the last stage of initiation (Müller-Kosack 1996c, unpublished fieldnotes).
} 
the Mafa became the ethnic melting pot of the Northern Mandaras, they seem to have developed a more complex political structure. This, in turn, has brought about a hierarchical system of institutions and offices in order to manage not only a horizontal, but also a vertical segmentary process of ethnic integration.

\section{Horizontal and vertical processes of political organisation}

This brings us to another similarity, the so-called acephalous structure of the political organisation of the terrace farming societies of the Northern Mandaras. The functional importance of the minimal lineage as the most basic reproductive unit enhancing the structural potential for mobility in terms of lineage segmentation in and between ethnic groups has already been pointed out above. In the Northern Mandaras we regularly come across the minimal lineage as the basic unit of social and political reproduction. Sterner (1998:82) also mentions this kind of similarity when she points to "the movements of individuals and small groups interacting with similar others to form communities, some of which grow in size and complexity, while others break off and restart the same process somewhere else.' However, Sterner puts this phrase as a variation in scale 'between kingdoms or chiefdoms on the one hand and acephalous or egalitarian societies on the other,' which covers a more general field, not really allowing for regional comparison. I am applying this on a small scale to the Northern Mandaras by only looking at the organisational links between horizontal and vertical processes and the possible historical explanations as to why they might have occurred.

One of the main reasons for the development of a more vertical process among the Mafa might be their numbers. This might have created a need for some hierarchical political structure, especially if we consider the high population density. Some kind of political centralisation was presumably necessary in order to exercise control. Most smaller neighbours of the Mafa have not developed a vertical dimension as part of their process of lineage segmentation and therefore have not developed chiefly clans ( $k a r$ bay $=$ son of the great one) like the Mafa. There are some exceptions and we find, in particular among their neighbours to the south, features of centralised power. However, wherever we examine vertical political developments, we seem to find that the horizontal level of political power never loses control. It is very rarely that a chief is, or rather was, more than a representative of the prosperity and social development of the group which selected him, although some traditional chiefs were the owners of very large and wealthy compounds. ${ }^{43}$ I conclude from this that the image of a chief in segmentary societies like those of the Northern Mandaras is not one of an autocratic or aristocratic but rather one of a democratic or egalitarian nature. This is also reflected in the fact that chieftaincy is never defined in dynastic, but in lineage terms. Succession is mostly regulated by a selection process among members of a chiefly lineage whose turn it is to provide the chief on the basis of lineage rotation. The guiding principle for selecting a new chief from within a lineage is not so much his genealogical position or relative age but rather the personality a possible candidate is supposed to have. An ideal chief should be honest and straightforward, possess purity of heart, in short, his moral integrity is more important than his internal lineage position.

\section{The example of Gudur}

Gudur $^{44}$ was certainly the most powerful image of chieftaincy in the Northern Mandara Mountains, but not all montagnards with a Gudur tradition necessarily have centralised political

\footnotetext{
43 Lavergne (1944:26) e.g. mentions the Mafa chiefs of 'Moudougo' (Moudoukwa), 'Soulédé' and 'Mbezaou' as having very large compounds because they had so many wives and children.

${ }^{44}$ Gudur is the name normally used in literature. However, there are other names used by different ethnic groups, for example: "Gudul" by the Dughwede or "Mpesakali" or "Cakali" by the Sukur (Sterner 1998:40).
} 
institutions. The Dughwede and Guduf of the Gwoza Hills claim to have had relationships with Gudur but did not develop a vertical process of political organisation, whereas the Sukur and the Mafa did, to some extent. Gudur itself is a place in the area of Mofu-Gudur, where the chief of Gudur resided until $1980 .{ }^{45}$ It seems to be more the location of Gudur rather than the chief of Gudur which symbolised the mysterious forces Gudur once represented. These forces had to be recommemorated by annual pilgrimages and the chief of Gudur was the custodian of them. The chief of Gudur also had the responsibility to legitimise the appointment of other chiefs, which explains the reason why literature often refers to Gudur as a confederation (Forkl 1983:357).

I have great doubts whether Gudur ever was a confederation, but tend to believe that it was politically constructed as a mysterious power centre to which other groups of the Northern Mandaras had access and therefore forged representational links with it. Some of them brought about the rise of regional chiefs who in turn made their own annual pilgrimages to Gudur to renew these links. The main strength of Gudur in relation to the Mafa was the power of the biy vardeke of Moskota over plagues, in particular, locusts, smallpox and diarrhoea. The biy vardeke also had influence over the Gwoza Hills (Dughwede, Chikide-Chinene, Guduf and LamangHodkala), although he resided in Mafa land. However, his clan was not of Mafahay, but of Gudur descent meaning that he derived his mysterious force to control plagues from Gudur.

A similar situation exists among the Mofu groups. The chief of Durum (Mofu proper) was once instated by the chief of Gudur (Marchesseau 1945:16) and so were the chiefs of Kapsiki (Strümpell 1923:56, Lembezat 1961:39) as well as the chief of Sukur (Sterner 1998:40ff). Fork1 is of the opinion that the power of Gudur can be historically derived from the Giziga of Rum in the plain of Diamaré, which he in turn connects back to a Mbana princess of Kotoko/Sao origin (op.cit: 467). Whatever the case, the Gudur tradition was very influential in the Northern Mandaras, its sphere of influence developing particularly strongly in the south, centre and northwestern regions. To my knowledge there are no Gudur traditions in the northeastern parts of the Northern Mandaras.

\section{Purification and initiation ceremonies}

Sterner (1998:101f;156f) makes a distinction between purification and initiation ceremonies. While purification has more to do with purifying the territory and the community, initiation is more about individuals or age groups enhancing their integration into the local or regional community. In the context of male initiation, I distinguish between youth and adult initiation, since both often occur quite separately in the Northern Mandaras. With regard to purification rituals, we can identify a regional pattern of intercommunity and even interethnic links represented by the chasing of the evil spirits into the direction where the next purification ceremony is supposed to take place. Purification, as well as initiation ceremonies, are linked with the seasonal calendar. Where purification seems to have a more spatial or territorial significance, male initiation is more about the ritual transition (rite of passage) from one status to another.

If we compare the ceremonial complex of the ethnic groups of the Northern Mandaras we find the absence of male initiation rites among the Mafa. This is true of most of their northeastern neighbours but their southern neighbours do carry out such rites. Sterner (op.cit.) lists a belt of male initiations beginning with the Mofu proper (Durum, Duvangar, Wazang), the Bulahay groups (Sirak), the Gavar, the Wula proper (Wula-Mango), the Sukur, Muduvu, Vemgo and the Mabas. She also mentions the Kapsiki as well as the Margi Gulak and Duhu. Sterner (op.cit.) says, by also consulting Vincent (1991:301-332), that only the Mofu proper practice male initiation associated with age-classes through which young men pass. Apart from initiation into

\footnotetext{
45 Jouaux (1989:265n). Jouaux has written the most comprehensive account so far on the regional role of Gudur.
} 
the status of an elder, which Sterner (op.cit..:169f) observed in Sirak, all initiation rites of the southern neighbours of the Mafa are concerned with the initiation of male youth into adulthood.

Such is not the case in the Gwoza Hills. The northwestern neighbours of the Mafa practice male initiation as part of a series of rites which guide a man through stages of his personal development in order to realise an ideal of true manhood. While male initiation among the southern neighbours (e.g. in Sukur) enables a man to get married, the entry condition for groups of the Gwoza Hills is that they are married before they can perform adult initiation. We find this kind of initiation after marriage among the Gvoko, Dughwede, Chikide-Chinene, Guduf and Glavda, ${ }^{46}$ but it is no longer practised. I have reconstructed the Dughwede adult initiation cycle and found seven stages, distributed over a similar number of years, through which an adult had to pass in order to reach the status of somebody who has completed dzum zugune. The aim of the rituals are not only to demonstrate physical fitness, but also to demonstrate the man's capacity to fill three granaries with sorghum. The final stage of the initiation consisted of a feast at which much of the sorghum was redistributed in the form of meals (with meat prepared from lots of slaughtered goats and even bulls) and beer for everybody. Only men whose father and senior brothers had performed dzum zugune were allowed to enter this cycle of adult initiation. ${ }^{47}$

There is no evidence whether male initiation took place or still takes place among the northeastern neighbours of the Mafa. This view might change in the future and it might well be that similar initiation rites once took place there as well. We can be sure that the Mafa have no initiation rites at all, ${ }^{48}$ although it could be claimed that the complex marriage ceremonies Mafa perform are also a kind of initiation. ${ }^{49}$ Sterner (op.cit.:158) mentions a marginal form of a girl's initiation among the Sukur, which takes place on the evening she leaves her father's house for that of her husband. Already Lembezat (1961:36f) points to the absence of circumcision, but denies the existence of special rites such as 'isolation, retreat, rebirth, or the like'. ${ }^{50}$ Lembezat's view is corrected by Sterner (op.cit.:173) who shows that elements of isolation, retreat, and even rebirth can be found among the southern neighbours of the Mafa.

Unlike male initiation, purification ceremonies exist everywhere in the Northern Mandaras. Depending on the calendar of the ethnic community concerned, purification ceremonies can take place in an annual, biennial, triennial or quadrennial cycle. Sterner (op.cit:100) believes that purification ceremonies which take place beyond the annual cycle are automatically bull ceremonies. This may be true for many societies in the Northern Mandaras, but certainly not for all. An example comes from the Dughwede who had their most important purification ceremony on the level of the extended family, involving the slaughtering of a he-goat only every sorghum year. This was only recently changed from a biennial to an annual cycle and the reason given for this is that the Traditionalists wanted to adapt their biennial calendar to the annual religious calendar of the Muslims and Christians. The reason for the original biennial calendar was the religious significance of sorghum, which was only planted every second year. It had to do with the purification of the sorghum-cultivating community and we might find similar structures of purification ceremonies which only take place during the sorghum year, since most societies of the Northern Mandaras practice crop rotation. However, I have no knowledge of purification

\footnotetext{
${ }^{46}$ Elisabeth Gula (1996) reconstructs the utiva/tsufga ritual complex among the Glavda.

${ }^{47}$ Müller-Kosack 1996c, unpublished fieldnotes.

48 Dumas-Champion (1995) is incorrect when she includes the Mafa among those groups who practice male initiation.

${ }^{49}$ Boisseau \& Soula (1974:400-06) suggest a similar idea.

50 'Il n'y a pas, nulle part, d'initiation, individuelle ou collective, faisant intervenir des rites spéciaux d'isolement, de retraite, de renaissance, etc.' (Lembezat 1961:36).
} 
ceremonies which take place beyond the triennial cycle and which cannot be described as bull ceremonies. ${ }^{51}$

The biennial cycle of the bull festival is also always connected with the sorghum year. Most ethnic groups of the Gwoza Hills followed the biennial cycle (the Gvoko, Dughwede, ChikideChinene, Guduf, Lamang-Hədkala, and Glavda), but it is now about 20 years since the bull festival took place. The Mafa recognise a triennial and a quadrennial cycle. In the triennial cycle every second bull festival falls into a sorghum year, while in the quadrennial cycle every bull festival falls into a sorghum year. It is noteable that the bull festival which takes place during a millet year has much less religious significance than the one which takes place in a sorghum year. I believe that the calendrial link between sorghum and the bull festival has a religious significance which should not be underestimated.

This brings us to the type of concept of fertility underlying community ceremonies in the Northern Mandaras. I mentioned above that the environmental conditions of the Sahelo-Sudanic zone requires a tight regime of timing with regard to the main cycles of agricultural activities. The concept of fertility of the peoples of the Northern Mandaras reflects this in a specific way. Animal manure is essential for maintaining the fertility of the ground and the concern of the bull festival is therefore terrestrial fertility rather than chieftaincy. In this respect it is of political significance that smaller neighbours of the Mafa perform their bull festival much more on the horizontal level of family heads and lineage elders, while the Mafa incorporate it in a local system of chiefly representatives (bay) and their following (biy gwala). The Dughwede (MüllerKosack 1996b: 163ff) and the Zulgo and Gemjek (Graffenried 1984:109-14), for example, perform their bull festivals although they possess no political hierarchy of office holders representing a chiefly tradition.

If we compare both levels in Mafa society, we find that the concept of land and that of human fertility is symbolically connected with the religious sphere in which God the "father" controls the reproductive capacity of his "wife". In all montagnard societies the personal ownership and communal custodianship over land cannot be held by women, only by men. The concept of fertility is not only concerned with land but also with the reproductive relationship between a man and his wives. In the seasonal calendar men construct moral ownership over the reproductive capacity of women by claiming ownership not only over their land but also over their children. This is why fertility is under the ritual control of men and why almost all societies of the Northern Mandaras sacrifice bulls but never cows. Cows mostly function as bridewealth and are never considered as sacred, whereas bulls are fattened in a shed in order to be ritually released and later slaughtered and the meat shared to friends, in-laws and neighbours by their male owners. The sacred village chief of the Mafa represents the same male-driven concept of fertility as the family elder among the Dughwede or the mountain priest of the Zulgo and Gemjek. The main difference is not so much in concept as in scale. While the sacred bull of the chief represents the community he stands for, the bull of the family elder only represents his extended family.

\subsection{Introduction to Mafa ethnography}

\subsubsection{The use of Mafa and Matakam}

Mafa ethnography begins with Lavergne, a French colonial administrator, who, in 1944, published the first monograph on the Mafa entitled Le pays et la population Matakam. ${ }^{52}$ Lavergne

\footnotetext{
${ }^{51}$ See Renate Lukas $(1973: 416-447)$ for a regional review of the bull festival in the Northern Mandaras. See also Graffenried (1987), Müller-Kosack (1999b), Vincent (1991:74) and Sterner (1998:268;285).
} 
is the first to identify the Mafahay, Kwokwarhay, Mafa-Vara and Bulahay as the main tribal factions of the Matakam, which we have redefined above as Mafa by excluding the so-called Bulahay groups.

Lavergne is the second authority to offer an etymological explanation for the word Matakam and tells us that it was originally used to designate a region rather than a tribe. The German colonial officer Strümpell (1923:60f) made the first attempt to explain the meaning of the word, Matakam, by explicitly referring to the fact that the population of the Northern Mandaras did not wear cotton clothes. Both Strümpell and Lavergne agree that the ethnonym, Matakam, is a word of Fulbe origin, but it is Lavergne (1944:20f) who quotes an historical event in which the Giziga hunter 'Ardo Gaou' organised a meeting between the lieutenants of 'Laoual' (lamido Lawal of Adamawa was the successor of Modibbo Adama) and a group of montagnards. It was during this meeting that the Fulbe lieutenants allegedly called out '"mettayamen"' (pl. of 'mettayamjo'). Lavergne (op.cit.) translates this as an expression which refers negatively to 'the nakedness of these primitive people.' He says that for the Fulbe not wearing clothes was a sign of 'poverty, lack of dignity, and inferiority' and claims that this later changed into 'mettkam' and eventually "Matakam". ${ }^{53}$

It is Mohammadou (1988:277ff) who informs us of a Giziga hunter 'Ardo Gaw', who founded Zamay in 1834, with the backing of Modibbo Adama. Ado Gaw died around 1870 and Mohammodou (op.cit.:278) comments that he 'venait de fonder un lamidat boulahay-matakam, faisant partie du système confédéral peul de l'Adamawa.' Mohammadou (op.cit.) sees Ardo Gaw as the representative of a group of liberated slaves of non-montagnard ethnic origin. According to him they were only superficially Islamised and had married montagnard women. They lived in alliance with the Matakam of 'Soulédé' and 'Roua' to the north, and 'Tchouvouk' (Cuvok) and 'Mouhour' to the south. Between 1834 and 1870 they fought against 'the other Mafa of Baw [Bao]' (Ziver plateau) to the north of Mokolo and of 'Mokola, Mavoumay, Mendézé, Ldamsay, etc.' in the region of Mokolo (op.cit.).

Mohammadou (op.cit.) obviously uses the terms Mafa and Matakam without distinction and includes the Bulahay groups in both. The same applies to Yves Martin, who, in 1970, published Les Matakam du Cameroun, as well as to Paul Hinderling, although the title of his two volume monograph from 1984 is Die Mafa, Ethnographie eines Kirdi-Stammes in Nordkamerun. This means that the issue at stake is not just that the ethnonym Matakam should be dropped because it has a pejorative meaning, but also because Mafa and Matakam are not applied to the same ethnic group. It is David \& Sterner (1988:366f)) who first distinguish between 'Mafa' and 'Bulahay' by pointing out that although the Bulahay groups share similar cultural features they do not share the same ethnic identity. Sterner $(1998: 86,157)$ adds male initiation as another indicator which helps to distinguish between the Bulahay and the Mafa.

The first writer who explicitly points out that Mafa is an autonym, while Matakam is a Fulbe word, is Podlewski (1966:9n) in Les Forgerons Mafa and it is somehow surprising that Martin still uses the ethnonym Matakam in his work of 1970. It is only since Boisseau \& Soula (1974)

\footnotetext{
52 The same account was published in 1949 under the title Une peuplade Haut-Cameroun, les Matakam, which then reappeared in a slightly longer and revised form in 1991 as Folklore africain, une peuplade du Haut-Cameroun, les Matakam.

53 'Quelques païens l'accompagnaient et la légende veut qu'un des lieutenants de Laoual, impressionné par la nudité de ces primitifs, se soit écrié en les voyant: "Sont-ce là nos si redoutables adversaires?" et les ait traités de "metayamen" (pluriel de "mettayamjo"), terme méprisant réservé aux êtres que la nature n'a pas favorisés, l'absence de vêtements étant pour les peuls un signe évident de pauvreté, de manque de dignité... Telle serait l'origine du mot "mettayam" qui, devenu "mettakam" ou "matayam", désigna tout d'abord la montagne, puis, la extension, la tribu elle-même.' (Lavergne 1944:20f).
} 
La femme dans sa communauté territoriale: clef du cosmos mafa (an unpublished work of three volumes), Boulet (1975) Magoumaz: Pays Mafa, and Genest (1976) la transmission des connaissances chez les forgerons mafa, that Matakam is no longer in use.

\subsubsection{Representation of social structure in the literature}

Hinderling $(1955,1984)$ and Martin (1970) are the first to attempt to analyse the social structure of the Mafa. ${ }^{54}$ Of these two authors, it is Martin's work which has become the most influential. Since Hinderling did his fieldwork in 1953 and 1964, before Martin conducted his in 1966, I will begin with his work although his monograph actually appears after Martin's.

Hinderling's Versuch einer Analyse der sozialen Struktur der Matakam (1955) was the first attempt by a trained social anthropologist to analyse the social structure of the Matakam. He discusses the concept of the 'goale' or 'gole' as that of an exogamous patrilineage (op.cit: 410f). Hinderling published his two volume ${ }^{55}$ monograph of 1984 in retrospective but already relies there mainly on Martin (1970). However, Hinderling is the first to compare the social structure of the Mafa with the some of their eastern neighbours (Uldeme, Mada, Muktele, Podokwa, Mouyeng and Giziga), by relying on existing monographs. He comes to the conclusion that all these groups, like the Mafa, have 'unilinear descent groups' (sic) at the root of their social structure. Hinderling uses in his monograph the Mafa term 'gole' for clan as the main unit of reference for his comparison since his field work of 1964 has neither yielded the concept of gwadar (major lineage) nor that of the gad bulom (minimal lineage).

Martin (1970) also applies sociological principals and describes the social structure of the Matakam in lineage terms. He distinguishes between three basic units of social organisation: the 'gwali' or 'clan', the 'godar' or 'lignage majeur', and 'gidbulom'. With regard to the latter he believes that it is neither a lineage nor an age group, but rather a generational one. The unity of the 'gid bulom' is defined by the members of one and the same major lineage (godar) who differentiate between their lineage brothers by classifying them together in one 'gid bulom' according to their generational belonging (op.cit.:72). I reject this definition of a gad bulom and have come to the conclusion that it is a minimal lineage rather than a generational group.

The reproductive cycle of any gad bulom (generational or lineage group) is governed by the fact that Mafa families only worship two generations of male ascendants - their deceased fathers and grandfathers. A deceased great-grandfather is already a potential ancestral candidate for a future gad bulom, which will develop two generations on. Martin (op.cit.) is of the opinion that each generation of living descendants actually moves on with their common 'gid bulom' ancestor whom they refer to as their 'head of yams'. This is the reason why Martin concludes that every generation has his own 'gid bulom' ancestor and why a generation of fathers belong to a different 'gid bulom' than a generation of sons.

My research shows that this is not the case and that the 'head of the yams' is genealogically the oldest father or brother of a group of agnatic descendants and not the ancestor of the gad bulom as Martin believed. According to my field materials, father and son are always members of the same gad bulom. This is why I came to the conclusion that a gad bulom is a minimal lineage rather than a generational group. I have already highlighted this out in my two articles Sakrale Töpfe der Mafa (1988) and Zur Siedlungsstruktur der Mafa (1991). Up to the present, most monographs or articles dealing with the ethnography of the Mafa rely on Martin (1970) as their main source in

\footnotetext{
${ }^{54}$ The spelling of kinship group terms often varies in the literature. I consider the correct spelling to be found in the Lexique Mafa (1990) which is gwaliy (not goale, gole or gwali), gwadar (not godar), and gad bulom (not gidbulom).

${ }^{55}$ Volume Three (Volume Two never appeared) contains all his field materials.
} 
relation to the description of social structure. This means that Martin's 'gid bulom' has survived as a generational group in Mafa ethnography.

\subsubsection{The increasing diversity of literature on the Mafa}

Today we can list over fifty authors who have written on the Mafa covering the following main subject areas: anthropology, archaeology, linguistics, geography and development. Tables $2 \mathrm{a}$ and $2 \mathrm{~b}$ show, with about 100 publications, the wide range of Mafa literature published so far. The tables also include some unpublished sources and a few references to materials found in local or national archives. Table 2a, beginning with 1913 and ending with 1999, shows a continuing flow of academic publishing marked by a constant increase in every following decade. The first noticable increase happened in the 1950s, mainly through the works of Hinderling and Gardi. The main topics in the 1950s are architecture, material culture, social structure and writings on Mafa blacksmiths. From the 1960s onwards we see French authors dominating the scene, which includes the beginning of professional demographic research and the first, but unpublished, MafaFrench dictionary by Boisseau and Laurendeau (1965). During the late 1960s we see Martin (1968) starting his research in Magoumaz and Hinderling (1969) writing an unpublished monograph on the Mafa. In 1970 Martin's monograph appears, and Hinderling's published version appears 14 years later (in 1984).

While the 1960s and 1970s both show equal numbers (15 publications in each decade), the 1980s are more prolific with 24 publications. In the 1970s research on the land tenure system of the Mafa begins with Boulet $(1970,1975)$ and we can see that the local focus is on the community of Magoumaz (see figure 3). There is a clear increase in geographical studies in the 1970s, represented not only by Boulet, but also by Boutrais' work from 1973 on downhill migration. Genest (1976), a social anthropologist, completes his doctoral study on the transmission of traditional knowledge among Mafa blacksmiths. In the 1980s Seignobos, another geographer, begins his work among the Mafa and their neighbours. One of the ethnographic highlights is his publication of architectural styles in the whole of the Mandara Mountains, in 1982. The Mandara Archaeological Project begins its ethnoarchaeological work on style in Mafa material culture, also in the 1980s (see David, Sterner and Gavua). In 1985, I carry out my first research in the area of Gouzda. In 1986, van Santen begins her research on women and conversion to Islam, mainly in the area of Mokolo. The late 1980s and early 1990s also bring an increase in linguistic studies, and Barreteau's and Le Blèis' Lexique Mafa appears.

The 1990s see the publication of about 40 works on the Mafa, almost twice as many as in the 1980s. We see feminist and gender orientated studies (van Santen and Kosack) gaining influence but also development studies increasing dramatically. Throughout the 1990s a group of students from Leiden University establish themselves in Gouzda and carry out local research on land tenure and agricultural change (see Zuiderwijk, Schaafsma and Roymans). ${ }^{56}$

Not all entries of my Mafa bibliography are important for this study. In order to choose from relevant topics, I have compiled table $2 \mathrm{~b}$. Most prominent is the topic on blacksmiths which contains ten publications, beginning with Hinderling (1954) and ending with David \& Sterner (1991). This shows that the study of Mafa blacksmiths has always received great attention by researchers. Other topics relevant for this study contain publications which refer to traditional festivals. For example, we can see that the heading which refers to the bull festival (includes bull fattening) shows six entries in all. However, a closer look shows that four of them are

\footnotetext{
56 The latter heralds an upsurge in competitiveness in Mafa studies. A rather negative example comes from my own experience; the Leiden group from the Centre of Environmental Science (under Aad Zuiderwijk) moved into the research station I had built in Gouzda without ever consulting me or referring to my work there.
} 
unpublished works. The most important among them is presumably Boisseau \& Soula (1975) N'kudi maray: fête du taureau ou la célébration et la convivialité mafa, a manuscript of 108 pages, but, as is often the case with unpublished works, I have not yet been able to trace a copy of it. Other areas of interest for this study on Mafa ritual and social structure are the topics cosmology, ethnography, field notes, funeral, land tenure, marriage and monograph.

Most works mentioned under these headings are short articles and not all of them seem to be relevant. The works under the heading of ethnography are early ethnographic sources, like Strümpell (1923) and Grall (1936) as well as Hurault (1956). Strümpell is the most important among them and I have already referred to him in the context of my introduction into the regional context and the first use of the ethnonym Matakam. Hinderling's (1984) published field notes inform us about various themes relevant to this study and I will refer to them in the chapters to come. Another important source for this study is Boisseau's \& Soula's (1974) unpublished three volume work on Mafa cosmology. It is the first monograph which deals explicitly with Mafa cosmology. Although one might not always agree with the interpretations they put forward (both are French Catholic missionaries), the wealth of ethnographic information (including countless drawings of objects of material culture) contained in this monograph is remarkable. Boisseau and Soula worked in Djinglia, which is a settlement neighbouring Gouzda and Woulad (which are part of my local research area) to its east (see figure 3).

\subsubsection{The study of Mafa cosmology}

Mafa cosmology is an area of study which has often been touched on, but only seldom been made the main focus. This also applies to Martin's work. Although he analyses most aspects of social organisation, from kinship terminology to matrimonial relationships and the spatial organisation of the community to the organisation of subsistence, his viewpoint somehow remains external. This becomes obvious when we examine his coverage of Mafa religion, to which he devotes only eight pages at the end of his study. His discussion on the vertical elements of political organisation of the Mafa is similarly brief. The latter is of particular importance with regard to linking religious life and political culture, especially in the context of the system of bay (great one or chief) and biy gwala (great follower or disciple) as practised by Mafa. These designations not only serve political but also religious ends and, as such, are not simply functional representations of social structure.

The only published study, so far, which has attempted to put a higher explanatory emphasis on religion is José van Santen's doctoral thesis (1991) where she describes Mafa ritual life being driven by an engendered worldview of male and female principles. She correctly describes the cosmology of the Mafa as an example of the two-tier system Horton (1971) has defined in his famous article on African conversion. In analysing the conversion of practitioners of traditional religions to the 'prayer' or Aladura churches, Horton (op.cit.:88) speaks of the continuation of 'the coexistence of God and a host of lesser spirits.' Horton (op.cit.) then adds: 'Unlike pagans, however, they [Aladura members] believe that God has strong moral concerns, punishing sinners with disease and misfortune, and rewarding the virtuous with health and success. Also unlike the pagans, they believe that the lesser spirits are uniformly evil, and that they are in retreat.'

My description of the religious worldview of the Mafa does not aim to understand conversion, although some aspects, like the "heavenly high court" (see Chapter 2.2.3) much traditional Mafa seem to believe in, reminds us of Horton's description of the Aladura God as a moral category. Van Santen does not refer to such a belief, but this does not mean that it does not exist, but only demonstrates how incomplete our knowledge of the Mafa cosmology still is. Another point to make is that there are regional differences and there is always a high possibility that elements of 
their belief system exist in some places and not in others, or in a different form. This also seems to apply to structural elements of their symbolic order. Van Santen, for example, reports that the Mafa symbolically classify the right hand as female and the left hand as male but odd as male and even as female. Vincent (1978) reports the same phenomenon for the Mofu proper, but points out that they are well aware that this is somehow at odds with the general principle of righthandedness. ${ }^{57}$ Although the latter is symbolically reversed in certain social and ritual contexts, the universal principle of considering odd numbers as male and even numbers as female is generally maintained.

The Mafa of the area of Gouzda not only reverse right and left but also odd and even. They insist that even is male and that odd is female. The second reversal might not be recognised at first, since Mafa count "two" for a first born girl and "three" for a first born boy. However, they add an invisible "one" to each in order to make male even again. The explanation given to me was that they count "three" for a boy because men are considered as being superior to women and therefore should have a higher number. Since "two" is the first but lowest even number available, it has to be allocated to a first born girl and cannot be used for a first born boy. This means that they do not apply "three" to a first born boy because "three" is considered to represent male, but because female must be symbolically subordinate to male. This puts the principle of female subordination or, conversely, male domination firmly into the world of action, rather than into the purely structural realm of symbolic dualism. The reversal of both principles of symbolic classification, the left and right as well as odd and even, can now be much better explained. Both actions serve the accomplishment of male superiority not only over women, but also over other men. We do not know yet whether the reversal of odd and even also applies to other Mafa areas, but what we can be sure about is that male dominance is an issue there as well.

I believe that the achievement of symbolic dominance, by adding an invisible one in order to allow for the possibility of hierarchy, also has a cosmological dimension. This becomes apparent if we examine Mafa religious pottery where we find that male gods always have a right arm and female gods, a left arm. Boisseau \& Soula (1974,III:629) also point out that Mafa men are buried lying on their right and Mafa women on their left side. ${ }^{58}$ This indicates that the two symbolic sides are only reversed in the physical, but not in the metaphysical world. This new reversal demonstrates that the Mafa after all do embrace the universal model of right for man and left for woman. It also establishes a cosmological principle of relativity with regard to the way they symbolically construct social and political relationships. In Mafa society the principle of female subordination is thus a metaphor used by autonomous patrilineal groups to refer to certain associated groups as their ngwaz biy = "woman chief". In the context of the "way of the beer" such a relationship might be ritually expressed by the right of the ngwaz biy group to scoop the religious beer for the local kar bay (chiefly clan). Boisseau \& Soula (1974:720) are the first to mention the ritual role '...de l'homme-femme' who they believe represents '...la vraie femme du prêtre. Il apporte les offrandes. C'est "elle” qui les passe au célébrant. Ne dit rien. Frappera des mains durant l'action sacrificielle.' They also refer to a particular clan from which the male who performs the role of ngwaz biy (great woman) is chosen.

I interpret the Mafa use of the male-female metaphor of dominance and subordination as an attempt to ritually control all reproductive capacities available, which includes human (male and female) and terrestial fertility (including land rights) as well as livestock. It is therefore crucial to

\footnotetext{
${ }^{57}$ Hertz (1909) pointed first to the universal 'prééminence de la main droit' or the right side of the human body as symbolically associated with good and the left hand or left side with evil. Right may also symbolise male, and left, female, etc. The anthropological classic on this subject is Right and Left: Essays on Dual Symbolic Classification. It was edited by Needham and appeared first in 1973. The last reprint was in 1998, which is now already out of print. ${ }^{58}$ This only applies when the father of a deceased is still alive, otherwise Mafa are buried in a sitting postion (op.cit.).
} 
give the study of Mafa cosmology a much higher profile since it can provide us with a better understanding of the conceptual principles guiding their ritual activities. I first became aware of this when Mafa translated the word biy gwala for me as "disciple". I also realised that the word bay is derived from the adjective biya' $a$ for great or big and I began to understand that greatness is also a representation of auspiciousness in relation to future growth and reproduction. Claims for wealth and prosperity are aspirations which begin at the religious rather than the material end of life and therefore need to be understood from the perspective of worldview rather than social structure.

Mafa ritual needs to be interpreted in the context of such an all-embracing concept of reproduction if we want to understand the epistemological grounds on which Mafa re-enact their history. We will see in later chapters that the ritual complex of the Mafa is highly structured which entails a complicated system of social and political dignitaries managing communities of chiefly and non-chiefly clans in which greatness and following are intrinsically linked with the problem of a growing population competing over limited resources of land. Understanding the conceptual intricacies involved in the ritual maintenance and making of a worldview and political culture, which can be referred to as being specifically Mafa, is one of the main aims of this study. 


\section{Constructing the religious worldview}

\section{Introduction}

My understanding of the religious worldview of the Mafa is based on an extensive number of interviews I conducted, between 1985 and 1989 (see table 12 ${ }^{59}$ ), in the area of Gouzda, with Mafa men who still practice their traditional religion. I begin my description with God almighty and his supreme wife as first principles of Mafa metaphysics and in the context of this we soon become aware of an ontological gender issue. God the father is seen as the creator of all things and is therefore perceived to be of a higher ontological order than his supreme wife and "mother" of his children, who are his first disciples. Each person is born with a personal god who functions as a spiritual guardian, but who becomes superfluous after the death of that person. Ancestors do not need personal gods since they are believed to have direct contact with God the father. The Mafa wish to be on good terms with their ancestors, regarding them as spiritual agents who not only do good but can also cause severe damage.

Traditional Mafa share a metaphysical image of the world which sees God and his children as inhabiting a celestial realm, and the ancestors and the dead in a hereafter to which I also like to refer as the world beyond or the world below. ${ }^{60}$ The metaphysical world is like a universal building of the highest transcendental order whereas the physical world is the actual outer world and contains all tangible, olfactory, visual and auditory things. The Mafa have a specific understanding of the architecture of the metaphysical universe and elements of its symbolic building refer to existing styles in this world.

Traditional Mafa do not see the metaphysical world separately from the world of matter but see these as parallel worlds linked by the mysterious force nya' $a$ (being born differently). ${ }^{61}$ One way of linking in with the causes of events unfolding in the metaphysical sections of the universe is through divination. Identifying hidden causes for misfortune or sickness is the purpose of most divinatory sessions. The belief in the omnipresence of God (zhigilé) is the truth condition not only for divination but for everything that exists. The Western concept of metaphysics is generally the philosophical study of categories and things which are beyond experience and which cannot therefore be explained by science. The Mafa view of parallel worlds contradicts such a concept of metaphysics, believing that certain people can access the metaphysical world because of their special gift of having been born differently (nya'a). This shows that the Mafa tend to see the metaphysical and the physical world as being non-dualistic. The unity of the physical and metaphysical world is governed by a belief in the ubiquity of God, which is the reason why I interpret their worldview to be primarily religious.

\footnotetext{
${ }^{59}$ The interviews were originally conducted in Mafa and French and then translated into German. The numbering of the interviews on table 12 is the same as in Cived Zom: Studie zur Historizität der Mafa Nordkameruns (the unpublished German version of my Ph.D. thesis), Müller-Kosack 1997b, Band II (Archivband).

${ }^{60}$ Although in English the world beyond might refer to either the celestial or the ancestor's world and the world below might refer to a kind of underworld or hell, I want to repeat that the world beyond and the world below in this text means the ancestor's world only.

${ }^{61}$ The expression ńya' $a$ as reference to a mysterious force considered as inherent or natural must be derived from the word nye or ńye meaning "to be born" or ńya' a meaning "he is born" or "he is born differently". One can also say nyi na which means "he is born like this".
} 


\subsection{God}

\subsubsection{Almighty God and his wife}

Mafa refer to a supreme God, seen as the master of all things, as zhigilé mbiya'a, meaning God, the greatest of all. God resides in a celestial world above everything that exists. Mafa also refer to the universe as zhigilé, which includes the idea of a spatial-temporal existence. The concept of zhigilé comprises not only all that is, but also zhigilé as a person. As such, he is perceived as the first universal cause and Mafa like to refer to this by saying that God is behind everything and is like a father. It is in this context that we find the social reality of the Mafa metaphysically reflected.

To interpret the conceptual link Mafa make between God and father it is essential to understand the moral capacity they attribute to him. They say that God is watching over people like a father protecting his children. The idea of God as the almighty father puts women (in metaphysical terms) into an ontologically secondary position. Mafa express this view by saying, for example, that a woman cannot conceive unless God has slept with her. This does not mean that God himself physically makes love to her, but that God exercises his divine powers through her husband in order to create new life. The moral context is set by the universal view of traditional Mafa that God's power to initiate the making of human life is a male capacity.

God is not only like a father, but he is a father himself. He is seen as being married with children. God is the head of a divine family and makes love to his supreme wife. However, she is seen as a separate unity, indicated by the belief that she does not live in his house. God's wife is referred to as ngwaz biy zhigilé, which means the wife of the great God, while his children are known as wudahiy gay zhigiléhay, meaning the children of the house of God. God, the divine father, never sleeps. He resides in the upper part of the universe because he has to supervise what is going on in heaven and on earth. Mafa do not distinguish between heaven and the sky, but only refer to it as the place of zhigilé. They like to imagine that God, his supreme wife and his children live up there, while the earth is the place where humans and animals and the rest of all things exist.

The concept that God is mirrored in the social life of the Mafa becomes obvious if we examine the relationship between God and his wife. Although it is God's wife who makes the children, it is he who tells her to do so. It is he who decides whether she should produce a male or a female child. In this context, Mafa like to use the word rémé, which means to make or to build. Regarding God's potency as the divine creator, they say a zlats a na a deba, meaning "he guides her" when he produces a child in the womb of a woman. God the divine father has the commanding power over everything including the making of new life.

The procreative capacity of God lies in his divine power to "command" his own children to be born to him by his wife. The great God, who hardly leaves his celestial home, sends his children to appear in this world as male and female deities. Nobody can see God, except those who are dead and become ancestors or, occasionally, very powerful sorcerers. This does not stop Mafa from having an idea of what God might look like. They envisage that he has only one leg, one arm, one ear, one eye and even one nostril. Mafa like to refer to God's one-dimensional appearance in the context of the possible event of death. They say that someone who sees God in his dream is likely to die soon after. The original singularity or oneness of God the father is of great importance for Mafa, who consider the number one as being reserved for God, whereas humans are only represented by the numbers greater than one. ${ }^{62}$

\footnotetext{
${ }^{62}$ Schoffeleers (1991:347) also describes spirits with 'one leg, one arm, one ear, one eye,' in other parts of Africa. He refers to unilateral figures as images of symmetry and order and to twins as images of asymmetry and potential
} 
God is the ultimate moral category. Everything goes in accordance with his will. It is thanks to his constant supervision of heaven and earth that everything remains in place. He is like a father in this world who takes care of his family and his children keep him informed about what is going on in this world. If God should neglect his moral duty for one split second the world would immediately fall into a catastrophic state. People would die and many terrible things would occur in this world. Due to God's singularity, he also has only one wife. This view somehow contradicts the polygyny practised by Mafa men. God and his wife are both seen as universal images of a male and female principle representing a metaphysical concept of divinity, which is not reflected as such in their social reality. However, God and his wife have children and, as we see next, they can be spiritual representations of humans as well as of their environment.

\subsubsection{Personal gods and other deities}

To keep in touch with God's will, Mafa practice divination. There are particular objects and places Mafa identify as divine and they sacrifice to them according to the outcome of divination. They say that God communicates with the people of this world through these objects and places. God also communicates messages on earthly matters via his children, his envoys, who report back to him. God's children can be both personal gods for the living and at the same time representatives of God almighty and his supreme wife, as the divine guardians of humans. They are referred to by the general name zhigile ndo, meaning god of a human. Unlike God and his supreme wife, who are ontological entities, their offspring are spirits of divine origin attached to every human being born into this world.

A god of a human is represented in the form of a sacred pot, which also carries the general name zhigilé ndo. These pots, made of clay are found in every compound, and are either male or female, being equipped with sexual characteristics, a head with a wide open mouth. If they are male, they are referred to as zhigilé nngura' $a$ and have a outstretched right arm pointing upwards (see plate 1a). Female zhigilé pots have a left arm, which is shorter and normally not pointing upwards $^{63}$ (see plate $1 b^{64}$ ). This is significant since the arm of a male personal god symbolizes the commanding power a man has as the head of a family. It is equally significant that the arms of the zhigilé pots are right for male and left for female. This is reversed in the ritual context where a man, in his role as bay (great one), may use his the left hand to serve God through an offering (see plates $4 \mathrm{~d}, 4 \mathrm{e}, 7 \mathrm{c}$ ). However, in a non-ritual context a wife serves food to her husband with her left hand supported by the right and he receives it with his right. The analogy can be made that for Mafa, God is to men what men are to women.

A personal god is always born at the same time as an individual and is believed to take care of that particular person throughout their whole life. If a personal god is good, the person will be good. If a personal god is poor or rich the person will be poor or rich. If a personal god has no children, the person too will have no children. A personal god occupies himself with nothing else but looking after the person he or she is born with. However, there are some limitations regarding the ownership of the pottery which represents personal gods. Children only have a collective zhigilé pot, called zhigilé wudahay, meaning personal god of the children, and this is looked after

disorder. The latter destroy the order of the invisible one (which means death when it becomes visible) through their very nature of being replicas of each other, an aspect of the person which should normally remain invisible.

${ }^{63}$ See Müller-Kosack (1987b) for details about Mafa religious pottery (including drawings of nearly all the surviving sacred pots).

${ }^{64}$ Boisseau \& Soula (1974,III:711) report that zhigilé pots of the father of a house, which are normally placed on a stone in front of the house, can be both male or female. It depends upon divination which sex such a zhigilé pot should have. This explains why the female zhigile pot I have documented in plate $2 b$ is placed on a stone in front of a house. Women are only allowed to keep theirs in the kitchen (near the grindstone), which is inside and not outside the house. 
by their father. The zhigilé pot of a woman (zhigilé riy vava = god of the grindstone) is usually only owned by a woman who has passed her menopause. However, most sacred pots are under the control of the father of the house who acts as family priest.

There are other representations of God, in the form of pots, occupied with different tasks of spiritual guardianship. They are all ritually looked after by a bab gay, meaning father of the house. They represent God, not so much in his capacity as a spiritual guardian of individual selves, but more as the guardian of the particular spaces occupied by them. The most significant ones are the zhigile gay, referring to the personal god of the inside of a house (see plate 1c), and the zhigilé wuda, being the spiritual guardian of the outdoor space surrounding a house. A further one is zhigile cived which is responsible for the road or pathway leading to a house. Again, it is the father of the house who is the custodian of all these sacred pots.

Mafa like to refer to the spiritual responsibility held by a father of a house for his children as similar to that of a personal god. The protective analogy between him and his personal god incorporates not only his own future, but the potential future of his children as well. In performing his priestly role for the prosperity of his family, his personal god is looking after him by carrying him in his "divine bag". The Mafa notion of the "divine bag" or "bag of God" (gezhem zhigilé) refers to the fact that a person is constantly being looked after by his or her personal god or goddess. All personal gods are at the same time God's children and, therefore, envoys of God who look after the well being of humans. As God's children and envoys of God, the gods of humans are representatives of the supreme God, thereby helping him to keep the world in order.

The similarity between a personal god of a man and a father of a house is also pointed out with regard to him being the begetter of his children. The same applies to a mother who is perceived to be even more like a personal goddess since she has carried the child in her womb. This view is coupled with the idea Mafa often express that God's wife is looking after the children of God, thus presenting her in the role of a divine mother. It is said, in this context, that it is the great goddess who passes on the name of a new born child through divination performed by the father.

\subsubsection{God and the issue of gender}

We have already seen that God is conceptualised as a family head according to the social reality of the Mafa and that he is, as divine father, the creator of life and all things. However, he does not bring this into form himself. This is the task of his wife who, as a divine mother, is responsible for the actual making of new life which takes place after a woman has conceived. Mafa derive the reason for this from the fact that the development of new life happens in a woman's womb, although God, in his role as divine father, would always stand behind his wife since it is his role to oversee all things. It is he who holds the ultimate power over any decision to be made and, in particular, whether new life is going to be procreated or not.

The belief that God's wife is unique like him can be interpreted as the metaphysical reason why God is seen as having only one wife. The supreme power of the female principle is expressed in the traditional view that God's wife is responsible for the fact that women exist. Similarly, we see this in the statement of traditional Mafa that God's wife does not live in his house, but has her own residence. This all points to a philosophical idea of God and goddess as universal entities, although he is at the same time perceived as being the first mover and therefore holding the power over everything existing in heaven and on earth.

The divine division of labour between God and his wife brings us to the idea of him being the initiator of new life and his wife actually giving it form. It helps our understanding if we 
metaphysically ascribe gender to God by seeing him as substance because he is male. Substance, being one of the oldest metaphysical concepts is something which can exist alone, without the need for anything from outside. ${ }^{65}$ It is in accordance with the metaphysical worldview of the Mafa to ascribe gender to the ability of God to be the first cause of new life and to his wife, the ability to bring newly created life into its physical form. New life is born through women, but the ultimate potency to create it is male. Such a view legitimises the power of men over women as a natural condition of a divine order.

The claim of an active male principle being of a higher metaphysical order than that of a passive female principle has moral consequences. This becomes clear if we examine how the Mafa define their relationship to the male and female images of God. Mafa men say that they fear the goddess of a woman more than the god of a man they feel she may be more dangerous for them than their own male gods. They explain that the reason for this is that a woman carries the child in her womb, and, additionally, in this context, cares more for the development of a child than a man. They point out that God's wife has given this power to women because women face more difficulties in life than men. God only has to look after the potency of men which is much more straightforward and far less complicated. Mafa men say that God is in accordance with his wife and he therefore supports her in holding this protective power over women against men.

The protective powers of God's wife are seen by Mafa as the reason behind a divorced woman having the right to visit her children in the house of her ex-husband. If a man stops his divorced wife from visiting her children in his house, without good reason, her personal goddess could intervene. This could result in the father meeting with an accident or falling seriously ill. The goddess of a woman might also arrest a man (meaning the spirit of a man) who has taken the property of his wife without good reason. To reconcile this, a man would then be obliged to quickly declare to his wife which items he has taken from her room. When the personal goddess of the woman reports to God (her father) what this man has done, God might give orders for such a man to be killed.

While the metaphysical issue of gender appears to be problematic in the case of a man in relation to his wife, it seems to be less complicated regarding his daughter. Mafa point out that the personal goddess of a daughter of a man could not cause an accident for her father, since the father had suffered in order to love her. The day a man marries he gives nine goats or whatever the father of his bride asks him as bridewealth. Even in case of poverty, a man would be obliged to pay this to his future father-in-law. Mafa like to add here that God would then see how a man has suffered in order to win the heart of his future mother-in-law.

Whichever way we look at it, the idea of God remains male in the first place. This is also reflected in the linguistic fact that the singular zhigile refers primarily to God as the male universal divinity while there is no such singular term available to address his supreme wife. Although she is his only wife and therefore clearly represents the idea of a female universal divinity she remains ontologically secondary. While the fact that God has only one wife is not in accordance with the social reality of the Mafa, her subordinate position and the limited decisionmaking powers ascribed to it actually is. We can therefore conclude, with good reason, that the word zhigile refers in the first instance to a male God as the ruling principle in the philosophical thinking of traditional Mafa.

${ }^{65}$ See Simons (1995:480f). 


\subsection{Parallel worlds}

\subsubsection{The architecture of the universe}

The concept of a supreme God being a divine father in charge of creation itself also appears in the cosmological view of the world. Traditional Mafa link the image of the universe with that of God as an individual with sections of his body being seen as parts of a cosmological building. In this context it is the image of the human body, as well as architectural images, which are used to metaphorically describe the structure of the universe. This is why Mafa perceive the celestial world above this one as a kind of upper part of a cosmological structure, carried by the "legs of God" (sak zhigilé). Another expression for the same cosmological view of the world is to speak of the "bone of the universe" (tasl or vatasl zhigilé), this time referring to God as a kind of a hard material. The word tasl means bone while $v a$ refers to the body as a whole. Together with zhigilé, it means a hard structure in the form of a skeleton. The "bone" or "skeleton of the universe" is similarly referred to as "hard sky" which is also seen as a metaphorical shelter for this world.

According to the worldview of traditional Mafa, the "legs of God" transcend this world as well as the one beyond and thought to be underneath ours. They finally reach up to support the roof of this world, where the "legs of God" end and the celestial world begins. The "hard sky" or tasl zhigile is thought to divide the two, being the ceiling between this earthly world and the heavenly one. Mafa perceive the beginning of an upper world as a kind of a celestial platform which they refer to as balak zhigilé meaning the "shelf of God", or we could say the "shelf of the universe". The word balak is the general word for a raised clay mantel found in traditional houses. The world beyond is geographically located as a huge hollow space inside the earth. Mafa refer to it as veved which is the general word for a hole or a cave. All three are parallel in time and vertical in terms of space so that the invisible worlds above and underneath the physical one are explained as social mirror images of this world.

Mafa call this world wuda, meaning "outside", and this refers to total of all visible and tangible objects in this world. It is the outside world of physical things as they appear in the reality of this world. This is located on the surface of the earth and includes the physical environment filled with rivers, rocks, plants, animals, humans, as well as the air, the clouds, the rain above the earth and the soils covering the earth. The general word for earth is hakeda, describing the earth in general as a horizontal mass of land carrying this world. Mafa are of the opinion that the earth is round like a coin along its outer limits and surrounded by a wild, untended space they refer to as hesheked. It is difficult to say whether this uncultivated space surrounding the earth as a whole is still seen as part of the earth or not. The word hesheked is also the word for uncultivated bushland, but as a part of the cosmological structure of the world it is used to distinguish the civilised world of wuda from its metaphysical counterpart, being the universal wilderness surrounding this world on the surface of the earth.

It is difficult to say how deep or thick the Mafa imagine the earth to be, since it is a horizontal mass and not a globe. The deepest possible place inside the earth is thought to consist of deep water and is pictured as being located underneath the world below. It is said that this is where the "legs of God" are rooted and where the great water spirit has his home. In contrast to the multiplicity of the hereafter ${ }^{66}$ the celestial one is seen as being of a less repetitive nature. God's home is located in the upper part of the celestial world and the space above him is thought to be limitless. Mafa generally say that the celestial world exists only on two levels. The first level is the lower with the shelf of God forming its ground. The second level is high up above this where the great God himself can be found.

\footnotetext{
${ }^{66}$ Mafa often express the idea that there are several ancestral worlds replicating themselves in the hereafter.
} 
Mafa do not hold fixed views on the architecture of the world when it comes to debates over its structural details. Discussions are very much centred around the question of how many "legs" the world actually rests upon, where they are supposed to be found and whether they are rather like pillars made out of wood or iron. According to some there is only one pillar, located in the centre of this world, while others are of the opinion that there are two, one on each side. All agree, nevertheless, about the function of these "pillars" which is to support the shield of the sky sheltering this world. However, the argument continues as to whether the limits of this world are found where the "hard sky" or "bone of the universe" reaches the surface of the earth or whether the "hard sky" is more like a sun or drying roof supported by four pillars. Another notion is that the roof of this world consists of a huge flat rock which demarcates the limits of this world. Another view is to imagine the "legs of God" being like the trunk of a tree with its crown reaching into heaven.

Whatever image we utilise it seems clear that this world is perceived as a shelter which is separated from the celestial by a firm sky resting on one or more pillars to form the heavenly platform above. The "legs" or "pillars" of God are rooted in the earth, providing on its surface the physical ground for all things to exist in this world. Wuda can therefore be described as a cylindrical space containing the environment of the visible world, which is metaphysically bound by others of an invisible nature.

\subsubsection{The inhabitants of the celestial world}

Mafa are aware that they have no certain way of knowing how the celestial world and the one beyond are organised, but they rely on their experience of this world as a conceptual resource to metaphorically describe them. They imagine the other worlds above and beyond this world as social realms filled with people who live in a similar way to themselves. In relation to the people of this world, to whom they refer as ndohiy nta wuda, they speak of the people of the one beyond as ndohiy nta veved. The inhabitants of the celestial are not human beings but superhuman beings of a divine nature.

We have seen earlier that the inhabitants of the celestial world consist of the great God (zhigile ḿbiya'a) and his wife (ngwaz biy zhigilé) joined by the gods of humans and the envoys of God. All the different gods are the children of God. Like him and his wife they have a sexual identity, are also married and have children. Since personal gods are the divine mirror image of living humans and look after them in their "heavenly bag", we can certainly assume that male personal gods have several wives. Being the divine counterparts of humans also exposes them to good or bad actions, although they do not seem to suffer the same physical death like the human beings they are born with.

In order to distinguish God and his supreme wife from the children of God we address the latter as gods or deities (zhigiléhiy). Altogether they form the inhabitants of the celestial world. Although all deities are seen as children of God, not every deity is a god of a human or a personal god (zhigilé ndo). There are two main categories of God's children (wudahiy zhigilé). The first are the zhigilé ndo and the second are the biy gwalahiy zhigilé. The second category can be literally translated as "great followers of God". Mafa also refer to them as envoys or disciples (biy gwala $^{67}$ of God. All gods are mediators of a divine order situated between the supreme God as the ultimate moral category and the people of this world.

\footnotetext{
${ }^{67}$ We will see in Chapters Three and Four the social and political roles and functions of biy gwala (great followers) and bay (great) unfolding in the context of the various ritual activities Mafa perform throughout the seasonal year.
} 
Mafa like to imagine the celestial world not only as the space where the children and envoys of God live, but also as a place a sorcerer (mide) from this world can access. In this context the difference between the upper heaven where God himself lives and a lower heaven referred to as the "shelf of God" is of significance. It is the "shelf of God" which sorcerers can normally reach although Mafa believe that very powerful sorcerers can even get as far as God himself. Sorcerers are frequent visitors to the celestial because they have the gift of being able to mysteriously transform themselves into other states of being for psychic travel. Mafa have no way to describe this mysterious force except by referring to it as nya' $a$, meaning that somebody is "born differently".

Somebody who is born like this is either mide (sorcerer) or méslégéd (diviner), meaning that the same talent can be used morally to good or bad ends. Sorcerers who are capable of regularly travelling to heaven can take sorcerers who do not have this ability. They also take people who are not sorcerers. Someone discovering that his spirit has been taken to the "shelf of God" can receive help from a diviner who is capable of travelling to heaven as well. It is sometimes found among Mafa that a person only discovers later in life that he has a special talent for helping people who are diagnosed as being spiritually imprisoned at the "shelf of God". These people, (mostly former blacksmiths) can become griots, although this is not very common. They often play the traditional guitar (gandzavar) of the Mafa and compose songs to help free these imprisoned souls.

The person whose spirit (mezhe6) is held against his will at the "shelf of God" does not possess the special talent to transform himself of his own accord to visit the celestial world. We can assume that most Mafa would describe themselves as not being capable of achieving this. This is why every traditional Mafa has a personal spirit pot ( $g a d$ pats) which is supposed to protect him from something like that happening. At the same time there is the personal god as well as his ancestor who can function as divine mediators to protect a person's spirit from imprisonment on the shelf of God. Ancestors are yet another category of visitors to the heavenly world we need to mention here.

These ideas show that the celestial world is very much occupied with matters of the mind referring at the same time to a concept of experience which considers the temporary detachment of the spirit from the body of a person as part of a wider reality. However, it seems to be obvious that traditional Mafa consider it to be detrimental to a person's health when this is the case. The unity of mind and body are seen as the normal state for a human to have in this world and there is general agreement that people who are imprisoned on the "shelf of God" need help to fully regain their health.

\subsubsection{The heavenly high court}

The gods and the ancestors communicate with each other. If an ancestor or an ordinary person of the world beyond has done something wrong, he or she is criticised by the "children of god" or, vice-versa, the ancestors criticise a god. In the event of a person from the world below calling a living person to join him there, the personal god of that particular person could intervene. It would depend on the personal god to intervene or not to intervene as to whether a person of this world should actually die. However, neither an ancestor nor a god could kill a healthy person from this world without the great God knowing about it, and only he would know whether this person had truly done wrong.

Everybody who is brought before the heavenly high court is assembled at one particular place. One can find people there from all local communities gathered at this place where the court is actually held. Mafa explain that God asks a person brought before him for judgement as to what 
his failings have actually been. God listens to the plaintiff and if he believes that person has seriously failed, God recommends that his envoys either kill that individual or keep him locked up in heaven for a while. If the person turns out to be innocent, the great God would give the order for him to be released and taken back to the earthly world. Traditional Mafa conclude that the supreme God is the only master who is able to judge. He is the one who knows the forgivable and the unforgivable failures, and he is infallible.

They all appear at the heavenly high court where God pronounces his judgements about a living person's destiny. The sorcerers, along with the divine healers from this world as well as ancestors from the one beyond, all visit the celestial world to safeguard or to destroy the life of a human being. It is important to note, in this context, that this does not compare with a last judgement which determines whether someone should go to hell or to heaven as is the case in the Moslem and Christian religions. The situation is quite different because the victim is still alive in this world, possibly suffering an illness. The judgement therefore concerns the question whether the moral conduct of a person should lead to his recovery or death.

Traditional Mafa say that, in the past, sorcerers used to kill their fellow humans without reporting to the great God. As a reaction to this, God punished these people and explained that man was not capable of deciding who should or should not be killed for their moral failings. So, from that day on everybody was to be brought to the heavenly high court to be judged by God himself. This statement sounds as if it has a Moslem or Christian influence, but traditional Mafa claim that this is their view about how God should be seen, in a moral capacity, as the only one who can finally judge whether a person should die or stay alive.

\subsubsection{Relationships between the different worlds}

Although the inhabitants of the celestial world and the people of the one beyond are related, both groups belonging to an invisible world, they are distinct in nature. One of the differences is that the inhabitants of the heavenly world do not die. Mafa express this view by referring to death as an invention, whilst God's children are thought to have always been there. However, they make no clear statements about what happens to a personal god after a person has died, but are of the opinion that somebody who has entered the world beyond no longer has the need for a personal god. Mafa say that someone in this world could make sacrifices to the personal god of his ancestor to find help. This indirectly confirms that a personal god goes back to heaven after the death of a person.

Only the living people of the material world need divine protection from the world above, and in relation to this, Mafa like to point out that the people from the world below can enter the celestial world fairly easy. They are thought to communicate with God directly and are perceived to be spiritually equal to the children of God. The difference is thought to be that the children of God are to be found regularly at God's place, while ancestors are only able to see him regarding urgent and problematic cases they might encounter. Such a situation might arise where an descendant in this world has not performed an important cult for a particular ancestor.

Due to the metaphysical nature of the world below and similarities between ancestors and the children of God, Mafa sometimes locate the hereafter between the world above and this world. This is somehow confusing, since they also claim that the world beyond is supposed to be found inside the earth. The use of the word veved (meaning also hole or cave) as the name for the beyond is presumably drawn from the image of the grave. To locate the world beyond inside the earth is in keeping with the cosmological view of the Mafa. The earth in its totality as a horizontal mass of land is supposed to carry this world on its outside and to contain the world 
beyond inside. Mafa say that a dead person is connected with his grave, but that one would need to imagine that the world beyond goes far deeper than the actual grave.

The world beyond is imagined as part of the physical mass of the earth as well as the metaphysical structure of the universe. As such the earth contains not only the mortal, but also the immortal remains of the people of this world. It is a most essential part of the religious worldview of the Mafa that the past of this world is linked with the past of the world beyond. Since Mafa like to explain the world beyond as a geographical mirror image of this world, they say that the world beyond of a particular local community of this world is to be found underneath that community. Unlike in this world, there is no new life born in the world beyond, but since the total population of the world beyond is much higher than this world, Mafa express the idea that there are several ancestral worlds replicating themselves underneath this one.

Since the total population of the world beyond consists of all people who once lived here, the time a dead person holds the status of an ancestor varies. Whether someone in the world beyond becomes an important ancestor in this world depends on the number of sons his living ascendants are going to have. This is not a matter of the past but one of the future which is why the changes in the demographic structure of the world beyond is guided by new life being born in this world. The latter again is a matter of how many children the personal god or goddess of a living individual carries in its "divine bag" which takes us back to the celestial world and the idea of a supreme God as first mover. Mafa believe that the day a personal god lets a person out of his bag is the day the personal god knows with certainty that this person is going to die.

\subsubsection{The world beyond as mirror image of this world}

If we ask traditional Mafa how the people of world beyond live, they say that they live in a universe like a mirror image of this world. They explain that if we were to fill a clay bowl with water we would see somebody inside the bowl making the same movements as ourselves. They claim that a person's physical body dissolves after death but that his mirror image (mezheb) survives. Such a mirror image might appear in someone's dream as the dead person from the world beyond. They conclude that the mirror image one can see in the water has a similar nature to a person surviving in the world beyond.

Such "mirror images" can make this world available through dreams in order to make somebody ill or to cause someone's death. As well as being able to see the people of this world, the people of the world beyond can see God in his physical appearance. If God is angry with somebody from the world beyond and this person does not improve, God transforms that person into ochre. The physical appearance of the people of the world beyond is the same as that of the people of this one.

The people of the world beyond build houses for the people of this world and finish the roof at the very same moment someone dies. The world beyond as a mirror image is not maintained when it comes to modernisation and change. They do not wear modern clothes, only their traditional goat skin. Although they build houses for newcomers from this world, the houses are made in an old fashioned style. Nothing changes in the world beyond and there are, of course, no Christians and Moslems there.

Mafa believe that someone can also die in the world beyond. The dying person from the world beyond would need to find the skin of a person here so he could organise his funeral in the world beyond. This need is supposed to be the reason why people from the world beyond come here and kill. If a child were to die in the world beyond the father would have to kill a child from this world for the funeral. If an old person were to die in the world beyond similarly it would need to 
be an old person who had to die in this one. Some Mafa are of the opinion that a person only dies once in the world beyond and after that it is finished for ever (aa medep), while others claim that the people there die several times.

Mafa distinguish between ancestors and the rest of the people of the world beyond. The difference between both is that only ancestors are directly connected with the genealogy of their relatives in this world. Mafa refer to their close ancestors as bab babhiy nga, meaning "my father's father's people" and to their remote ancestors as ndohiy halalay, meaning "the people of the sacred grove". The latter are the common ancestors of a local kin group and the sacred grove is their place of spiritual communication. Close ancestors are family ancestors going back no more than three or four generations above the eldest living male of an extended family. All others beyond that are generally referred to as ndohiy nta veved, meaning literally the "people of the hole" and translated by us as the "people of the world beyond" or the thereafter.

To get in touch with this world the people of the world beyond can call upon their ancestors there to represent them here. Since every deceased person who has children is represented by an ancestor pot called $b a b a$, for a father, $b a b$ ' $b a b a$, for a father of a father, mama, for a mother, and mam'baba, for the mother of a father, they are always indirectly connected with this world. However, somebody in here who finds out by divination that he should make a sacrifice to his deceased father will not know that this demand was actually made to settle another demand in the world beyond. People of the world beyond who are not ancestors for this world have to rely on their children in the world beyond to pass good or bad fortune on to this one. This is why Mafa like to imagine that the people of the world beyond have ancestor pots as well and conclude that they also die and have funerals as people do here.

Whenever a son celebrates a sacrifice to his father who is in the world beyond, Mafa imagine that the father is spiritually present next to his son. The deceased father who is the closest genealogical link to this world is accompanied by his ancestors from the world beyond. They are imagined standing invisibly behind him when his oldest living son serves the cult of his deceased father. In turn, it is the eldest son who is the link in this world, representing, as the eldest male and family head, his younger brothers' families.

While it is the eldest son of a deceased person who represents the living group of family relations here, a family ancestor himself represents the youngest generation of the deceased population and is therefore the son of his deceased father in the world beyond. After a few generations, family ancestors are naturally forgotten, or, because they did not have many sons they become unimportant for a local kin group. This is the reason why Mafa differentiate between close, or family ancestors, and remote ancestors of the local group.

\subsubsection{The transformation of a deceased person into an ancestor}

The transformation of the spirit of a dead person into ancestor is part of the traditional funeral. I will give a description of its main ritual features in the next chapter and concentrate here only on a brief outline of the last part of a funeral which is concerned with the ritual installation of an ancestor pot. The complete ceremony of transforming a deceased person into an ancestor is called ndé ndo veved, which can be translated as "accompanying a deceased person into the world beyond". The installation of a new ancestor pot can be split into two phases. The first is the "mysterious meal for the ancestor to be" (ncék daf sagam) and the second is the "introduction into the handling of an ancestor pot" (mpiy baba a ray).

About a month after the deceased has been interred, his family prepare a meal and sorghum beer for the ancestor to be (ncék daf sagam). After a while the future ancestor arrives disguised as a 
mouse (kwam sagam) and eats. After the ceremony is successfully completed, it is the blacksmith who collects the leftovers together with the pot or calabash in which the "mysterious meal" (ncék $=$ mysterious, $d a f=$ meal) for the "ancestor to be" (sagam) was served and carries it home for his personal consumption.

A few days after ncék daf sagam a new ceremonial beer is brewed and a new ancestor pot, baba, made by the blacksmith's wife, is brought into the house. A family elder who is already responsible for a $b a b a$ is invited to introduce the oldest son into the ceremonial handling of the pot. The beer is poured into the baba pot and the elder slaughters a cock and drips some of the blood over the new ancestor pot. Later on, the he-goat is killed and some of its intestinal contents is smeared for the first time over the back of the baba pot. The family elder now introduces the son to the ritual handling by teaching him a prayer which can be translated as follows: "My father, give us your blessing, make it so that freshness is with us and that the heat of illness disappears." After the brother of the deceased has instructed the son in what to say, he passes him a calabash filled with sorghum beer The son is now supposed to celebrate his first sacrifice over his deceased father's ancestor pot.

There is a third element which takes place before the "mysterious meal for the ancestor to be" and to which Mafa refer to as mmbel ndo meaning "chasing the deceased". The ritual "chasing of the deceased' is the precondition for a family head to become a family ancestor. It is an act of separation driven by the fear of being haunted by a deceased person, which is why it is so important for the bereaved to get him to accept his "mysterious meal" as the first step of his spiritual transformation. In some cases this might go on for quite a while and divination after divination might be necessary to find out what this ancestor really wants. The deceased, who lost his physical existence in this world, needs to enter the world beyond as an ancestor, otherwise his ascendants in this world cannot rest in peace. To whom should one pray and sacrifice if no successful link between this world and the world beyond has been established?

\subsection{The self}

\subsubsection{The traditional make-up of the self}

If we summarise what we have described so far as the worldview of the Mafa, we can say that a person seems to consists of five main components, four of them are invisible and only one is visible. The visible part is the physical body which characterises the person as a member of this world, while the four other parts signify the invisible aspects of a person which are as such much more difficult to categorise. Two of the four spiritual or invisible aspects seem to represent the idea of an everlasting existence, while the other two can be seen to have a rather temporary existence. At the same time all invisible components of the person seem to overlap in terms of them being more or less transcendental or transformational. For descriptive purposes I will address the aspects which appear to be everlasting as being divine and therefore pointing to the belief in the existence of a soul. Those with a temporary or transformational rather than transcendental existence I will classify as being mainly relevant for the handling of spiritual rather than divine matters.

The first invisible aspect of a person is what I would describe as the dimension of divinity represented by a personal god who keeps the self in his or her "heavenly bag". This is the part of a self which does not die, but which continues to live in the celestial world as a kind of ancestral guardian angel. The second aspect of the person is its soul, being the idea of a non-physical self which lives on forever. This is the aspect Mafa like to imagine as the free travelling shadow or mirror image of a person appearing in somebody's dream as an ancestor. The third invisible 
aspect is the actual spirit of a person possibly best described as the vital self of a living human. This is the personal spirit which will be transformed into an ancestor spirit after death, living on in this world for as long as the ceremony with an ancestor pot is carried out.

The fourth invisible aspect of a person is the mysterious force used by sorcerers and diviners known as ńya'a, meaning "born differently". This too, is a transformational agent of the mind, but not one everybody can command. Being nya'a is more of a force rather than a spirit, which means it is more about using the spirit as a force to temporarily detach from the physical body. Being born differently is not only a quality of certain humans, but can also be ascribed to other living as well as non-living things, also described as having the same transformational qualities as some humans. The fact that the possibility of being born differently does not exist for humans alone gives the concept of the person a meaning beyond the human.

Last, but not least, there is the physical body of a person ( $v a$ ) which only exists in this world, and it seems that it is the physical reality of the body which is capable of delivering a suitable image for the invisible aspects of the mind. The Mafa word for soul and for spirit is mezheb. The word mezheb is not only referred to as soul, but also as somebody's spirit although it is a common belief that the spirit dissolves after death while the soul lives on. The idea of spirit and soul seems to carry conceptual similarities both being developed from the image of a shadow thrown by a person's body in this world. The idea is that of a shadow image of the spirit or soul of a person being fixed to a person's body $(v a)$, which is the physical cause for the shadow to exist. We can therefore assume that the concept of the person is derived from the unity of mind and body. Since the unity of mind and body only exists as long as a person is alive, we can conclude that the concept of a person in the world beyond must be purely spiritual.

We have learnt that Mafa only use the word mezheb if they are asked to describe the spiritual aspects of the self. They have various ways to express this, and as we have seen, one way is by speaking of the mirror image of a person as if it could be seen in a clay bowl filled with water. This is emphasised by the fact that the word mezheb refers not only to the image of a shadow, but also to that of a mirror. The metaphor of the mirror for the spirit or the soul of an individual is also expressed by saying that somebody has several shadows which are all part of him. To explain this, Mafa say that someone has not only one, but four shadows in all, and one can be aware of these shadows in those parts of the house where there is indirect sunlight. In these places one can see these shadows; two to the right of a person and two to his left. In full sunlight all these shadows are all blended into one.

This view of the spirit as a blend of shadows or the mirror image of the body of a living person is typical for the Mafa. When they are ill they tend to check the number of their shadows. If they think one shadow is missing they consult a diviner to find out what needs to be done. It could have been a sorcerer kidnapping the personal spirit, or an ancestor demanding an obligatory sacrifice which has been delayed for various reasons. To do something about it involves initially consulting the diviner to find out the possible causes for the problem. Solving the problem could lead to a sacrifice being performed with someone's personal spirit pot or with one of the pots representing the personal gods of the house. It could also mean carrying out a sacrifice using one of the ancestor pots or making a sacrifice on one of the public sacred sites of the community.

All actions taken seem to be concerned primarily with the spirit rather than with the soul of a person, although we can assume that a sacrifice to one of the zhigile pots is a matter of requesting help from divinity. Even in this case it still has more to do with the spiritual well being of the person, for example, asking for assistance from divinity to join forces against the attack of a sorcerer or an unhappy ancestor. This explains why the gad pats (personal spirit pot) is very much at the centre of traditional Mafa belief. 
After being named, every new born child receives a personal spirit pot. The personal spirit is believed to be most exposed during the night and this is why the pot is kept near the top end of the traditional bed. The word gad means head or top and pats refers to the traditional bed (a mahogany plank). Boisseau \& Soula (1974:662) link the personal spirit pot with the personal god each person is believed to be born with by referring to this aspect of the self as the "double" every human being is born with. I do not share this interpretation and like to differentiate between gad pats and zhigilé ndo, a view which is supported by what Mafa call the "heavenly bag", gezhem zhigilé, when referring to the container where their divine "double" is kept. This means that there are two "doubles", one divine and one human. It is the latter which is represented by the personal spirit pot. However, Mafa might not always make this distinction explicit.

After death the personal spirit pot is often smashed on the road to the grave and the deceased person will receive an ancestral pot called baba, if it is the father who died, or mama, in case of the death of the mother. The transformation of a newly deceased person of this world into a person of the world beyond is a process which takes place as part of a traditional funeral. It is the body which disintegrates in the grave after death while the spirit dissolves with the wind. The personal god has taken the dead individual out of her or his "divine bag", and it now becomes clear at this point that only a living person with a physical body is in need of individual protection for its divine component. The ancestor soul is believed to be capable of travelling freely in all worlds and can gain access to the celestial world of its own accord.

The transformation of a living into a dead individual divides the spirit of a person in two. One is the spirit of the living person which dissolves in the wind, while the other is the spirit of the ancestor which lives on as long as the ceremony for the deceased is carried out. While the spirit which dissolves in the wind is the one which was attached to the physical body, it is the ancestor soul which survives (like a ghost) as mirror image of the body, but without its physical existence. At this point in time a new personal spirit is introduced by traditional Mafa to represent the temporary existence of an ancestor, being the genealogical link between the people of this world and the people of the one beyond. What seems to happen is the mysterious transformation of the vitality of a person represented by the unity of body and mind in this world into a metaphor of that unity, which enables that person to live on as its own mirror image in the world beyond.

\subsubsection{The concept of the person as an agent of this world}

If we examine these insights into the religious worldview of a traditional individual we can assume that the first cause for them to come into existence must be seen as being of a divine order. This puts (in metaphysical terms) the divine components of the invisible aspects of the self ontologically at the beginning where it seems to be a matter of taking two steps to achieve that. The first is the principle of a male zhigile initiating the birth of a new person as divine substance subsequently formed by a female zhigilé in order to be born in this world.

The word for life in Mafa is ńshefe, meaning breath. It is therefore the concept of breathing from which the word for life is derived. A dead person does not breathe. The word for health is also ńshefe. This semantic link reflects a significant reality. The concept of ńshefe has a strong mental dimension, and it is the mezheb (spirit or soul) which receives the most attention if a person's health is seen to be at risk. This is possibly the reason why the spiritual components of a living person appear to be much more complex than that of a dead person. This might have to do with the living person being seen as extremely vulnerable to the mysterious forces of the universe which are thought to be genuinely under the control of various metaphysical agents.

There is, on the one hand, the zhigile ndo (personal god) of a living person, who "holds" that person in his "divine bag", and on the other, there is the gad pats (spirit pot), protecting an 
individual's mezheb. A personal god is perceived as a person, but by its very nature, belongs to a different world. We can ask to what extent such a god should be described as a genuine part of the personality of a living individual. Two points are important in this context. The first is that only living humans seem to have the need to be kept in the "divine bag" of their personal god, and the second is that a personal god reflects in his or her divinity the future of a newborn individual. We can therefore interpret the idea of a personal god as representing a genuine part of the personality of a living person.

The interpretation of the conceptual position of ancestors as persons seems to be much easier in this context. A living human has several ancestors but only one personal god. Ancestors are, by definition, not part of the personality of a living human. The aim of the person's ancestor is to establish him or her as a separate individual in the world beyond. The declared aim is to "chase the deceased" (mmbel ndo), an essential part of the spiritual transformation of a deceased person. The new ancestor is established as a particular individual in the world beyond, acting as a spiritual link to this world.

The latter leads us to the assumption that an ancestor, as spiritual agent, is potentially much more threatening than a personal god. This is confirmed by traditional Mafa who often express the view that the deceased father of an individual is considered to be more dangerous than his deceased grandfather. The deceased mother or father's mother, who are also represented by ancestor pots are seen as even less dangerous. Interestingly, in this context, the situation has reversed. We remember that the personal goddess of a man's wife is seen to be more dangerous than the personal god of the man himself. What seems to be at stake is the personal independence of a man, which is most at risk in this life from his father's side. He has to replace him as the traditional family head, but is still watched over by his father from the world beyond. To achieve or maintain his personal freedom as family head he can ask assistance from his personal god or even from the personal god of his deceased father.

The idea of independence leads us back to the idea of God being the ultimate moral arbiter in his capacity to supervise the universe like a father in charge of his family. The freedom of the father in his supremacy of being, like a personal god for his children and wives, is embodied in his capacity to create life, somehow on behalf of God, who remains, as male substance, its universal cause. The responsibility of being family head bears heavily on a man, but he has his forefathers who have shown him the way and given him the practical knowledge as to how he should rightly act. Doing wrong would undermine his moral capacity and finally destroy not only him but also the future of his family. Many threats occurring are of an invisible or spiritual dimension and are therefore a matter of great social and political delicacy.

The concept of the person among traditional Mafa must be interpreted in the context of life as a spiritual matter. The freshness of sprinkled water conceptualised in the prayer of a son to his deceased father, "my father, give us your blessing, make it so that freshness is with us and that the heat of illness disappears," gives us an indication of this. Mafa express the view that the people of the world beyond can perform cures among themselves just by sprinkling water over a sick person. They are similar in this capacity to the inhabitants of the celestial world. Like them, they do not have a physical body but only a spiritual "body", although unlike the children of God they once had a physical body. They have gone through the experience of a physical existence and maybe this is why they are seen as spiritual lifeguards, beyond reproach, for their living relatives. However, this also makes them in some way competitive, and they might even take life away from this world because they are pressurised by their ancestors in the world beyond. This can be seen as one reason why traditional Mafa make an appeal to their ancestors and ask them to give them their blessings and assistance to cope with life in this world. 
Life is not an abstract thing for Mafa, although it is seen as having an invisible side to it. The concept of nya'a expresses this. Being born with the special talent of applying spiritual powers seems to have at its very roots a concept of the person which includes an idea of experience alien to Western philosophy. The ability to spiritually transform into another form of life is not an irrational concept among Mafa, but a matter of fact. Someone who transforms himself into a bird might be caught by a sorcerer, who then cages the bird and keeps it imprisoned somewhere in his home. This bird is not only metaphorically but literally the spirit of that person and if the sorcerer were to kill the bird, the person would certainly die.

This brings us back to the idea of the spirit of a person being contained in his physical body. Somebody can temporarily leave his physical body, but doing so proves dangerous because it puts the unity of body and mind at serious risk. The idea of the spirit as a shadow and its connection with the personal spirit pot protecting the spirit from injury also facilitates treatment in case the spirit gets lost. To re-establish the unity of body and mind the person is supposed to take his personal spirit pot and to catch the shadow of a bird soaring over the surface of the earth and then to close his spirit pot firmly and take it home. He is then supposed to keep his personal spirit pot closed until he has regained his full physical and mental strength.

This example shows that the idea of the unity of spirit and body is at the very root of the concept of the person among traditional Mafa. It also shows that the concept of the person is not just an abstract idea, but an actual matter of life and death and that the maintenance of the well being of the person is attached to that unity. The spirit appears in this concept not as a philosophical idea but as a spiritual force. The mastery of this force is the mastery of life, wherein the transformational aspects of the spirit are the most difficult to handle.

\subsubsection{The mysterious forces and the nature of things}

Traditional Mafa distinguish between physical force or willpower and psychic or mysterious forces. The name for a physically applied force is wuday va, explained as someone's physical or bodily strength, as when throwing someone to the ground in traditional combat. The word wuday on its own refers to willpower as a sign of personal strength. Physical strength and willpower are primarily a matter of this world while nya'a is transcending the universe as such and has mysterious spiritual properties. We have already heard above that the invisible forces of the universe are considered to be much more dangerous than the visible ones of this world.

In this context, speaking of nya'a as the psychic talent to transform is not enough, since this talent is not only ascribed to human beings, but also to living and non-living things of the natural environment. To speak of it, therefore, as a mysterious force seems an appropriate way to conceptualise it. This is how Mafa themselves explain it when they say that someone or something is born or equipped with this talent and someone or something else is not. It is somehow a force beyond experience, but at the same time it is there, although only available to or applied by those born or equipped with it. Such people or things are perceived to be very close to sorcery.

It appears to be the transformational property of the spirit which is at stake and the fact that entities can transform themselves by mysteriously changing their nature from being a non-living to a living thing and the other way around. This leads us to ask about the nature of things and how they are metaphysically constructed. The main difference from the Western approach of defining living and non-living things is found to be in the definition of the nature of the spirit as an agent of the human mind. 
On the one hand Mafa construct the self more from a practical rather than a theoretical aspect. The concept of willpower (wuda), for example, is not applied to reasoning about the nature of things as such, but is always related to achievements in the context of farming and physical survival. On the other hand, some people are capable of temporarily leaving their physical bodies to travel the universe, due to their mysterious talent of being born differently. Whereas the ideas of physical strength and will power fits well with Western rationale, the notion of nya'a does not. Western thought cannot bridge the two aspects of the self except to refer to cultural relativism or to label them as irrational. The latter is the more common reaction, hence such phenomena are not considered as producing any empirical evidence, especially when it comes to describing mental states. As long as it is not possible to bring about empirical proof for their existence they are classified as irrational, which is tantamount to claiming they do not exist.

This is different for traditional Mafa. The outside world of experience (wuda) is accepted as the world of physical things. One can touch, smell, see and hear these and move them by applied physical force or one can achieve things in this world by personal strengths or will power. The concept of wuda is also part of the concept of the mind, but, as noted earlier, it is rather related to the willpower to work hard physically and achieve a good harvest. It might also manifest as someone's courage to perform dangerous but obligatory ritual tasks on behalf of the community. Such a person has to be pure and courageous at the same time, but he does not necessarily need to be born differently. It is a different matter, however, when someone can increase his harvest through his spiritual talent for accessing those mysterious forces also inherent in sorghum. Different again is someone who has the special talents of divining and is able to predict a potentially dangerous situation. In the past this would often have been in the context of a war to come, giving strategic advice to help avoid such conflicts. These people are either blacksmith (ngwazla), diviners (méslégéd') or sorcerers (mide).

The concept of the existence of mysterious forces, meaning those which are claimed to be invisible, involves a belief in the spirit being able to transcend the world in all sorts of mysterious ways. Material things can transform themselves in the darkness of the night into spiritual agents, giving the living as well as the non-living things of this world a quality which bridges the inner and the outer world not only as idea but as reality. This means that water, rocks, rain, animals and plants as well as humans are all things which have not only a visible or physical, but also an invisible reality. It is in this unseen reality of the mysterious forces that the transformational agencies affecting the actual or physical nature of things are located.

It is mostly human beings who hold a kind of a spiritual ownership over such processes, and they are seen as especially talented if they hold these powers because they are born or made differently. Such a spiritual ownership is most naturally endowed by birth to a certain clan or lineage and can be used effectively in social and political practice. However, this would not work if natural phenomena, (like the rain) or living things (like certain animals and plants) and nonliving things (like particular rocks and stones) were not endowed with the same transformational capacity. All these things are nya'a, meaning born differently. They are not like other animals or

plants, or other rocks and stones. The concept of nya'a also extents into the world of mythological thought of the Mafa where natural phenomena and cultural goods merge into one.

\subsection{Mythology}

\subsubsection{Mythological discourse and the nature of the universe}

The mysterious forces of nature and their transformational properties become apparent if we examine the mythological imagination of traditional Mafa. The cosmological structure of the 
universe and the mythological discourse about its genesis, its maintenance and cyclical or seasonal transformation overlap each other. It is quite difficult to separate the discussion about the nature of the universe from the mythological discourse about it. Nevertheless, there is a difference since the mythological imagination is more concerned with transformational issues and matters of maintenance and change than cosmological structures.

The mythological account of the sun ram gives an example of this. When the sun is sinking behind the horizon it transforms itself into a ram. The sun ram walks and walks through the night and finally changes back into the sun again when he rises in the morning. This happens every day, but nobody can see how the transformation actually takes place. Some Mafa are of the opinion that the ram of the sun does not walk on earth, but that he only walks through the night like that. Others think that he follows a river and others again believe that he treks through the bush (hesheked). Agreement seems to exist that the sun ram journeys through a kind of noncivilised space surrounding the earth which traditional Mafa also refer to as hesheked.

The sun ram is born to transform himself in mysterious ways and his talent is attributed to him being nya'a. He walks through the metaphysical wilderness flanking the earth, which Mafa refer to as cived zlazlad, meaning "the way on the side". Mythological discourse lets him walk near the point at which the "legs of God" reach the surface of the earth, where we find an old woman constantly sweeping termites. The myth is told that the "pillars of the universe" would break down and bury this world if the old woman stopped guarding the pillars. The woman herself is sometimes referred to as the one who erected the pillars. She is also sometimes referred to as being a chameleon and, as such, is believed to have brought about the first human being. She is invisible but nonetheless there, and so too, is the sun ram who passes by in the night on its invisible path in the wilderness flanking the civilised world, only to appear again in this world the next morning, as the sun.

The old woman who guards the "pillars of the world" and the sun ram are both related to the cosmological structure of the universe. While these "pillars" and the old woman are invisible per se, it is the sun ram who transforms himself and is at one point in time part of the visible world and at another point in time part of the invisible world. The same applies to the wilderness surrounding the horizontal earth as a whole. There is, on the one hand, the idea of a non-civilised world being part of the invisible structure of the world, but, on the other hand, the idea seems to be drawn from this world since hesheked is also the word for uncultivated bushland. The earth as a whole also exists as part of the visible and tangible world of wuda, but at the same time she contains the world beyond inside and the metaphysical wilderness outside, surrounding the earth. It seems obvious that these cosmological images are taken from the experience of this world. A deceased person comes from the civilized world and is buried in the ground under which the invisible world beyond also exists as a mirror image of this civilized world. The metaphysical wilderness is an image of hesheked or uncultivated bushland which exists beyond the space of cultivated terrace fields and the human settlements.

The concept of wuda, as this world, can also be understood as a concept of the civilised or inhabitable world. The old woman who guards the "pillars of the universe" or "legs of God" is therefore not only preventing the physical world from breaking down, but also maintaining the civilization and order of this world. Although the civilized order of this world is induced by divinity and historically endowed by the ancestors, the possibility of disorder or collapse of civilization exists and has already happened in the far distant past. The mythological discourse about how disorder once came about and the ways in which order was re-established is very much about cultural inventions. However, the mysterious forces which were once at work are still operating and are part of the actual nature of things, and will remain so as long as the metaphysical worldview of traditional Mafa remains intact. 


\subsubsection{The invention of agriculture and the theft of sorghum}

If we inquire into the beginning of the civilised world we find the belief that stones had once been soft and that they had been served as food. The soft stones were the daf, meaning porridge, and the soil was the traditional sauce, known as lak. Life at this point in time was comfortable and there were no worries. The world was in a state of purity, and we also hear that people did not die during this time. The end of this rather paradisiacal or heavenly age is again marked by an old woman, this time in a negative sense. The mythological record tells that one day an old woman urinated over the stones which used to be food and, as a result, they had become hard and dry. The old woman had spoiled the earth and invented impurity (sak).

If we ask Mafa what the difference between the two old women was, they often answer that they are related and say that the one who swept away the termites is good (pure), while the other one was bad or dangerous (impure). They frequently add that the action of the bad woman was intentional and that her plan had been to deprive the people of the world of the pleasures of living in such an easy place. What happened next was that people began to bury the stones and to build terraces for sowing and planting. This eventually leads us on to hear the myth of a man called Goyé who went to heaven where he "stole" the first sorghum, which Mafa accordingly refer to as daw Goyé. In the myth it was told that this first sorghum was much bigger in size than the sorghum of today, and is said to have formed the base for all other varieties of sorghum, referred to generally by Mafa as $d a w-d a w-a-g \partial d$. This was a development which came about after Goyé had reduced the enormous size of its grains.

Goyé is perceived to be the first settler the area of Gouzda. People believe that he originally lived in a cave and only learnt how to build a house later, from others arriving in the area, especially the first settlers of the clan Zhwé. Goyé later became the ancestor of a clan of the same name and his task of bringing sorghum from heaven to earth is still remembered in the area. A local custom has survived in which the first calabash of any ceremonial beer is drunk in honour of Goyé, referred to as zom Goyé.

The story of Goyé is as follows. He went to heaven and while God's wife was feeding the chickens with sorghum he managed to hide two grains of this underneath his foreskin. He was arrested and searched by God's children who checked in his ears, his anus, his mouth and his armpits, but they could not find the grains. They had to release him and Goyé went back to earth and planted the first sorghum. The corn grew to a high tree and people had to climb up the tree with sticks in their hands to hit the branches and make the ripe grains to fall down to the ground. They collected, ground and ate the corn.

A woman, newly married into Goyé's clan, asked for the sorghum. She ground it and ground it only to keep asking for more and more. She continued doing so until the sorghum asked her why she was constantly asking for more. What happened next was that the grains she had in the kitchen developed into a huge tree which subsequently fell on the woman and killed her. People outside the kitchen heard the noise and then wondered why the woman had stopped grinding. When they went to check up on her they found her dead. Goyé, on seeing the dead woman in the kitchen, was very upset and he called out loudly "Oh, oh, all this happened only because I brought the sorghum from heaven to earth. I now want you, sorghum, to become small." This was how sorghum is said to have became reduced to the size it is today.

Before Goyé brought the sorghum from heaven to earth people ate the fruits of trees and stones. After Goyé had diminished the size of the grains, shocked by the sudden death of the woman, dog went to heaven to get millet (metemas). Soon after, dog went again to heaven and collected fire by carrying it on his tail. This is why people throw some of their food to a passing dog while they eat their daily meal, and they say to the dog "Go and get me my millet!" 
Mafa explain that dog went to heaven like sorcerers do in order to steal millet and fire from God, meaning that this particular dog was also born differently. They add that nobody saw dog doing that since he went like a sorcerer in the night. Later on, man produced fire himself by using a millet stalk or a U-shaped iron. The same applies to Goyé who went to heaven with his mysterious talent of ńya'a intending to "steal" sorghum from God's wife. If we ask Mafa whether Goyé really went to heaven, some of them say that he did not and that people only used that notion to express the idea that it was Goyé who invented the cultivation of sorghum. They add that the actual invention was such a long time ago that people had forgotten how it really happened. This view does not necessarily contradict the mythological discourse of Goyé going like a sorcerer with his special talent. It only confirms that it was not only about an idea but a real thing, and marks one of the most important events in the history of agriculture of the Mafa.

\subsubsection{The cultural construction of rain as a good}

Mafa often say that there was no rain before the appearance of man. According to many traditional Mafa, man came to earth through his invisible talent ńya' $a$ and then produced rain with this same mysterious force which had led to his birth in the first place. This talent he was born with become incorporated in the office of the biy yam, meaning "great one of the rain", who is not just metaphorically, but literally, born to make rain. Without him there would be no rain, only wilderness. This means that the biy yam as a cultural task master and the natural phenomena of rain are intrinsically linked, which blurs the boundaries between natural and cultural phenomena. Again, it is the transformational force of nya'a which provides us with the key concept for understanding that not only natural and cultural phenomena but also things and persons share the same mysterious quality.

Rain is a part of wuda, the world of visible and tangible things, and it is the biy yam who guarantees that rain remains available and accessible as the most essential cultural good of traditional Mafa. If we examine the mythological context we find that the cultural construction of rain is linked to the beginning of terrace farming. The beginning of terrace farming was not a freely man-made decision but became a necessity after the old woman had urinated over the stones and thrown the world into a temporary state of impurity. The urine of the old woman which had spoilt the earth transformed itself, thanks to its inherent talent of nya' $a$ into the rainbow. Mafa refer to the rainbow as kwa kuray, meaning loosely "stones of the rainbow" as well as "stones of urine", since kuray is not only the word for rainbow but also for urine.

Traditional Mafa tend to believe that it is the rainmaker who produces the rainbow, due to his nya' $a$, and that rain does not simply fall. They claim that the rainmaker uses the kwa kuray to produce rain. This entails him removing the rainbow by applying the special talent he was born with. Rain stones are only accessible to somebody who is born into the rainmaker's family. They are always found in pairs, for example, between the roots of the plant vandzal (Cympogon giganteus), in a gap between rocks or in an anthill.

Rainbow stones have been found ever since the old woman spoilt the food stones with her urine. These food stones transformed themselves first into components of the water spirit (nihed), and after that into rainbow stones. If Mafa see a rainbow they say that the urine of the old woman is in the sky. They think that the rainmaker produced the rainbow and people who see him passing by ask him to remove the rainbow which he then promises to do. It can also happen that when there is no rain for several weeks during the rainy season that people think that the rainmaker is holding on to the rainbow.

The old woman who urinated over the food stones seems to be the negative counterpart of the old woman who sweeps away the termites from the "pillars of the universe". Both old women are 
there because of their mysterious talents and of course they are both invisible. They were both born like this and while the one is good, the other is bad. Both have an effect on the natural environment. The first one guarantees its structural maintenance and so it is important to notice the moral aspect of her task and the second incorporates the constant possibility of interruption and disorder. Both are old and have passed the menopause which characterises them as having past their fertile cycle.

Mafa are of the opinion that a woman who is not fertile anymore has easier access to the mysterious forces for spiritual transformation. Women who have passed their menopause have an increased potential to channel their talents either to serve and maintain as well as to try to disrupt and destroy the order of this world. They are seen to have a much higher potential for being morally constructive or morally destructive for the world than a woman of child bearing age. This might be due to the fact that they are naturally withdrawn or distant from the male powers of holding control and moral ownership over the reproductive capacity of women.

The cultural construction of rain as a good and its mythological context of the old woman who urinated over the food stones can be interpreted as a gender-driven discourse about infertility versus fertility as part of the seasonal cycle. The equation of the infertile (postmenopausal) woman's urine with the rainbow as a sign of the rain being held back by the rainmaker brings this power back to a male sphere of influence. He is the one who has found the rain stones which once transformed themselves from the urine of the old woman. This view is supported by the fact that rain stones are always found in pairs. Mafa consider even numbers as male and odd numbers as female. Religious rituals are preferably performed in months of even numbers. By applying the mysterious talents the rainmaker is born with he can overcome the threat of drought by removing the rainbow. He can also hold the rain back by producing the rainbow/urine of the old woman. This power has a moral dimension and rain has become a cultural good which can serve as an instrument of political power to control good or bad behaviour. Mafa often tell stories in which the rainmaker withholds rain because of someone's conduct in the community. Only after the inappropriate behaviour has been reversed or readjusted will the rainbow be removed.

\subsection{Spirits}

We learnt that wuda means the outside world. The notion of an outside world refers to things which are tangible and visible, things we can smell, taste and hear, in short, the empirical world of particulars. We have translated wuda as the word for this world, but if we take a closer look, we find that things are not just things in Mafa land. Water is not just water, rocks are not always just rocks and a tree is not always just a tree. They all have a spirit dimension to them, like many other things in the natural environment. The same applies to a house, which is not just a material structure, but needs to have a good spirit in order to become a home.

All spirits are by their very nature invisible. Traditional Mafa tend to distinguish between four different spirits of the natural environment: a water spirit, tree spirit, rock spirit, and a house spirit. Living, as well as non-living, things can be nya'a and are perceived to possess transformational forces of a spirit quality which is seen as being similar to that of sorcerers. The concept of nya'a allows Mafa to metaphysically transcend the material existence of things and to ascribe a spirit to them. Certain natural things are therefore believed to have a mind of their own, and it is the water spirit which is considered as the most powerful among them. The house spirit has a separate position since he belongs to the domestic sphere.

The word for a spirit in general is nihéd which also means water spirit since this is the most powerful one. However, if someone wants to specifically refer to a water spirit he might speak of 
a particular nihéd yam, because yam refers to water. It remains unclear whether there is only one or many water spirits. On the one hand people speak of the water spirit if someone is affected by its presence, and on the other hand, there may be several, depending on the location where it appears. We can assume from this that it is the actual nature of the spirit that traditional Mafa refer to when they speak of the water spirit. This not only qualifies the water spirit, but also other spirits which are referred to by the word nihéd.

\subsubsection{The water spirit}

A water spirit lives in water courses, lakes and pools, inland seas (like Lake Chad), swampy areas, wells, sources and any other places which show signs of humidity. If a water spirit leaves a humid place this place falls dry and, in reverse, a place which was dry before can become wet if a water spirit arrives. Water spirits seem to be related to each other and are believed to kidnap and exchange human beings among themselves. The most powerful water spirit is the one who lives deep in the earth underneath the world beyond, but other important ones are found in major water courses, lakes and pools. It seems that the water spirit transcends the earth as a whole, which characterises it as one of the most important spirits in the metaphysical world view of the Mafa.

We do not know how the water spirit came into existence, but in the context of the mythological discourse, he is referred to as a transformational stage between the food stones, the urine of the old woman and the rain stones. After the old woman urinated over the food stones, they became hard. The now hardened stones which covered the mountain slopes had to be buried by the humans so they could build the first terraces for agriculture. Some of the urine transformed into water spirits which then transformed into the first rain stones. This account makes the water spirit a being of this world, and traditional Mafa, for example, add, in this context, that we can verify their existence by observing that certain water courses dry out faster than others during the dry season.

As one would expect, a water spirit lives in water. However, its actual home, although it is perceived as being in water, contains none. This is where the water spirit hides people it has kidnapped from the river bank. People might find a person's body lying as if dead next to the water course, which indicates that the water spirit has stolen his spirit. A water spirit can kidnap the body of a person, as well as his spirit. This not only happens to humans, but also to animals. If a water spirit has taken the whole person or somebody's cow, his relatives or the owner of the cow have to go to consult the custodian of this particular water course. Divination is carried out and a sacrifice with tobacco and coarse ground sorghum (njeme) is performed accordingly. After a while, the dead body of the person or animal can be recovered, although Mafa often refer to people who have "disappeared" and who have never been recovered.

In the case of a water spirit returning the body of a person or an animal, the guardian of this particular water course and the relatives of the disappeared person return again to express their gratitude by performing another sacrifice. The same thing happens if the water spirit has not taken the whole person, but just the spirit and thus the person has recovered. Mafa say that a water spirit does not really kill the person and would normally return the body. However, they also stress the point that a water spirit could well kill a vicious sorcerer. Water spirits are not referred to as wicked, only as cunning. They like the company of people for a while, especially a twin for whom they seem to have a preference. Mafa say they like to kidnap twins in order to live with them.

Although water spirits in general are not perceived as being evil, there can be good and bad water spirits. A vicious water spirit never returns a kidnapped person and the number of people or animals disappearing increases. If repetitive sacrifices, including the use of the water bracelet 
(dasay yam) tapped on a stone in the river bed and devoted to the water spirit, remain constantly unsuccessful, then the water spirit is evil. It is possible to expel a vicious water spirit by throwing a hot silex (flint) into the water. After a while there will be less water at the place, but one knows that the water spirit has left. It is believed that once a water spirit has left it is very difficult for it to return.

A bad-tempered water spirit constantly asks for offerings. Water snakes are found more frequently if there is a bad spirit about and the water of a pool or lake can change its colour. Sometimes it is possible to predict that a water spirit is searching for a person and one knows that a sacrifice is necessary. The water spirit is normally surrounded by fishes and can transform itself into a water snake, but normally a water spirit remains invisible. Only diviners and sorcerers are believed to be capable of seeing a water spirit and they tend to describe it as a being white with long hair.

Water spirits can bring good or bad luck. A man with lots of animals who lives nearby the river might become very wealthy or stay extremely poor, depending on the will of the water spirit. A vicious sorcerer would not go to the river with a powerful water spirit, since the burning energy of the sorcerer is the enemy of the water spirit. Newly created water points require a sacrifice and an appointed guardian to be responsible for them. The water spirit has great significance for twins and a woman who has given birth to twins repetitively is believed to have been in contact with the water spirit before her pregnancy. A twin can be kidnapped by a water spirit if the father of the twins does not perform a special ceremony known as halalay in order to protect them. The water spirit is believed to have special divinatory powers. The water crab used by Mafa for divination is believed to be inspired by the water spirit.

The other spiritual beings of the natural environment are not as powerful as the water spirit. This could be due to the climatic conditions of the Sudano-Sahelian zone and the importance of water for the subsistence economy. Water is essential and is used for blessing and healing by sprinkling it during religious cermonies. Mythology records that the first sacred bull ever used in a bull festival (maray) was born to a cow previously owned by the water spirit. A man had sprinkled earth over three cows he had discovered by a river. This meant that the water spirit had lost its cows to man. Today people still sprinkle earth over the backs of their cows to prevent the water spirit from taking them into its possession.

\subsubsection{The spirits of trees and rocks}

The spirits of trees and rocks are the other two manifestations of the natural environment and Mafa call them nihéd without necessarily identifying them as tree or rock spirits. Trees are very important for the subsistence economy. Their leaves are used to cook sauces, they provide firewood and the branches are important for building materials. Trees have a cosmological dimension and serve as metaphors for the structure of the universe, connecting this world with the world above (crown) and the world beyond (roots). They are a very important symbol in linking the people of this world with the people of world beyond. Every local community has particular trees which form part of their ancestor shrines. They are often found on summits in the vicinity of rocks. These shrines are called diy mbulom (diy $=$ eye; mbulom $^{68}=$ a magical wild cat) and possess as such the mysterious talent of nya'a.

\footnotetext{
${ }^{68}$ The Mafa also use the word mbulom to refer to a powerful spirit who can kill sorcerers. The pot representing this spirit is similar to a male zhigilé (deity) pot. Only men who have heard the magic wild cat cry in the night are allowed to have such a pot, installed on top of a large stone, in front of their houses. The word mbulom appears as the term for God among the Zulgo (Graffenried 1984:97). Vincent (1995:343) refers, in the context of the territorial cult of the Mofu proper, to 'mbolom' as the name for the spirit nature of sacred sites. R. Lukas (1973:342) sees in the prefix 'mbu'
} 
The tree spirit is not only connected with shrines within local communities, but also outside a village in the uncultivated bush land. A tree with a spirit is not necessarily a shrine and one can identify such a tree by large snakes which would particularly enjoy resting nearby. During the night such trees can move themselves from one community to another. This can even happen with the tree from a local shrine. The tree spirit is normally invisible, but it is said that a tree spirit can be seen, like a water spirit, in the form of a snake which lives near the tree. Wild animals like to live near a tree with a spirit and Mafa tend to believe that it is the tree spirit which has attracted them.

The tree spirit is perceived as a good mediator in communicating the wishes of the ancestors to their relatives in this world. This is why traditional Mafa like to assume that a tree with a spirit makes a good shrine. Tree spirits of different local shrines are believed to communicate with each other, which is how they are always up to date about what is going on in the world. They transmit ideas to each other and by doing so they can affect the moral behaviour of local people in a good as well as a bad way.

A tree of a local shrine might fall over or die, and the custodian of that shrine would then have to ask the diviner what the reason was for this and which sacrifice was required. Another scenario where a tree communicates the needs of ancestors to the people might be if a rock fell against this tree. Traditional Mafa are of the opinion that such incidents on local shrines are caused by the combined mysterious forces of the tree spirit and the ancestors. Such a tree loses its vitality if the tree spirit departs to settle at another place. If this happens a whole series of sacrifices need to be performed to bring the tree spirit back. Mafa believe that the tree spirit is strong enough to kill, or to cause madness and physical illness. It can also bring good or bad fortune, fertility or sterility, wealth or poverty and so on.

The rock spirit can reside in rocks within a village as well as in the bush land, but also inside a mountain or in a rock found in a river bed. A rock spirit who lives in a rock inside a village can have several custodians, who are responsible for performing a sacrifice if needed. A rock spirit found alongside a public path who intends to do something vicious might transform itself in the night and become as huge as a mountain, so that the road will be blocked for those who want to pass by. An individual can lose his orientation completely if he has to go somewhere in the darkness of the night when the rock spirit decides to multiply itself, along the way, into several smaller rocks. Another possible scenario is that big snakes might come out from beneath these rocks. While a rock might be seen during daylight still in its usual place, during the night the spirit of the rock might leave this spot and travel around for a while.

The rock spirit can kill, bring sickness, make a woman sterile and cause a stranger to lose his way during the dark hours. The bite of a snake sent by the rock spirit could kill, although traditional Mafa believe that the rock spirit is not necessarily vicious by nature. It does not want to harm everyone, only sorcerers and thieves and to punish those who do not respect the traditional way of life. Everyone who passes by a rock which is believed to be inhabited by the rock spirit tends to put some tobacco or natron (sodium bicarbonate) on the rock. If these are not to hand, the person passing by takes a small stone always left on the rock and after rubbing it on the rock the person presses it to the chest and the left shoulder. Nobody, and especially women, are supposed to make a full circle around such a rock.

or 'mbo' the word 'bay' for 'Herr' (great one or chief) and in the syllable 'lom' or 'lam' a reference to the word 'Erlam', meaning God among the Mofu of 'Wazang'. 


\subsubsection{The spirit of the house}

Last comes the spirit of the house. We have already heard, at the beginning of this chapter, that the traditional house accommodates a whole range of divine pots representing the gods of the house and its surroundings as well as ancestor and personal spirit pots of the family members. Unlike the water, tree or rock spirit, the spirit of the house is only supposed to be a good spirit. A good house spirit is gathered by assembling a postmenopausal woman from the neighbourhood and some children in a newly built house to spend the night there. Food is cooked and eaten at particular times during a vigil performed by them. The little group of girls and boys sit listening to the old woman telling stories, and they sing songs and play the traditional guitar. This performance transforms the house into a home which is believed to be represented by the spirit of the house.

Traditional Mafa say that after an influential man has died one can feel a few days later that the vitality of the house has gone, not only because of the loss of the head of the family but also because the house has lost its spirit. The spirit they mean in this instance is not the spirit of the deceased but that of the family home.

To have a good house spirit is particularly important for someone freshly married and who therefore needs to build a new house. We will hear in the next chapter more about all the preparations for building and consecrating a new family home. The good spirit of a house seems to be a kind of a domesticated relative of the spirits of the natural environment. As soon as two people marry they move into the newly built house, the husband carrying his personal spirit pot in his hand to establish himself as head of a new house.

A week or two after moving in, the new father of a house asks his wife to prepare a ceremonial beer called zom ńngwece ma gay, which means "making a trace". On this occasion the eldest of his extended family, his tsava, comes and makes a libation by pouring beer on the floor of each of the rooms and gives some of the beer to the shrine of the god of the house and to all other existing shrines in and outside the new house. For this purpose, the elder uses some of the beer from the first day of preparation, which is known as manda besl or ziy wézhém. The beer has been kept especially for this first sacrifice and is hardly fermented so it still has a sweet taste.

One main difference between a house spirit and the spirits of the natural environment seems to be that the latter are much less predictable and have a higher potential to be vicious. However, all these spirits are seen as having a soul (mezheb), and one could say that their physical body is the rock, the water, the tree or the house they belong to. They all have the mysterious talent (nya'a) to transform themselves in the night to travel around. They seem to possess vitality and have a temper and we can plausibly conclude that they have all the features of a person. At the same time they do not really have a physical appearance, since they can leave their 'bodies' (rock, water, tree or house) to find a new "body" somewhere else.

This characterises them as beings, and not only can they communicate among themselves, but also with other spiritual and divine agents of the universe. Such communications can be natural phenomena, like a fallen tree or rock, the weather, a bad harvest or the death of a person. Since they belong to the invisible world the contents of their communications can only be discovered indirectly. The main tool for reading the "language" of the invisible world is divination. The practice of divination is the interface between the visible and invisible part of the universe of traditional Mafa and provides us with an understanding of how their religious worldview determines and guides many of their daily activities. 


\section{Conceptualising ritual action}

\section{Introduction}

Divination is at the heart of Mafa ritual activities and a major tool not only for public but also for private decision making. This is why I begin this chapter with a description of crab divination as the most socially complex divination method used by the Mafa. This will then lead us to a description of the design of a traditional family as the nucleus of their social cosmos, which will help us to understand how ritual activities are constructed from within the perspective of the home. Our understanding of the concept of a home leads us to an understanding of the key elements in the workings of the traditional Mafa community. I will concentrate mainly on those ritual activities which have a historical component. This is not always possible so we therefore need to take a wider view as well. However, I try not put the central focus on the description of social structure, but prefer to maintain the momentum of a conceptual approach and the meaning it can provide for the reconstruction of Mafa local history.

\subsection{Divination}

\subsubsection{Pebble and crab divination}

Mafa distinguish between two main forms of divination, pebble divination and crab divination. The first one is referred to as mpiy kwa and the second one as ntsiy zlara. The word kwa means stone and mpiy means handling or manipulating, hence pebble divination is about manipulating a set of pebbles. Although stone divination is the most ancient and original way of divination in Mafa land, I am only going to give a brief summary here, and will come back to it at a later point since it is the official oracle of the Mafa. Pebble divination is part of every funeral as well as all public feasts, like the bull and the harvest festival. However, it is fairly simple and is conducted by dividing a pile of small pebbles into odd and even numbers resulting in a yes or no to the question being asked. ${ }^{69}$ Crab divination is only used in an unofficial context, but has become increasingly popular since it is not the diviner himself who manipulates the divinatory objects, but the crab. This is why Mafa tend to ascribe greater objectivity to crab divination. Pebble and crab divination are often applied as consecutive alternatives when exploring one and the same question, but the crab divination is much more complex. This is the reason why I have chosen it as a suitable way to illustrate how traditional Mafa put their worldview into practice.

\subsubsection{The mythological origin of crab divination}

The name ńtsiy zlora means literally "tapping the crab" (zlora is the word for crab), and refers to the divinatory usefulness of the crab. This expression ties in with the mythological discourse traditional Mafa use to explain why the crab is particularly talented (nya'a) at reading the hidden meaning of human intentions. First of all the crab originates from the water. She lives in rivers and her capacity to "know" what sorcerers are about to do to their fellow humans is seen to have been received from the water spirit. Mafa express this by saying that the water spirit gives the crab the intelligence to speak only the truth and nothing but the truth.

\footnotetext{
${ }^{69}$ Vincent (1971) describes the pebble divination among the Mofu proper and Graffenried (1984:126-130) among the Zulgo and Gemjek. Both descriptions show great similarities with the way Mafa perform theirs. We can assume with good reason that we find more similarities among the montagnards of the western parts of the Northern Mandaras while among the eastern neighbours of the Mafa pebble divination does not seem to be very common.
} 
In the past the people went to the riverside or swampy areas and the crab spoke directly to them. Nobody ever touched the crab. In the case of illness people consulted her at the riverbank and the crab informed them about the causes of their illnesses. Totally open and without ulterior motives, she disclosed everything that led to a particular illness and gave advice on which sacrifice was to be performed to ensure a complete recovery. Both those who suffered the illness as well as the sorcerers could hear the crab's words. On one occasion a man who was held responsible for the illness of his brother gathered together with his fellow sorcerers and then they all went and tried to kill the crab with a stone.

One day the crab spoke to another man who had come to ask advice from her. She said that she could not disclose information about the harmful behaviour of his brother unless he took her home. The man then asked the crab what he could do at home to understand what she was telling him. The crab advised him to go and see the blacksmith's wife (ngwaz ngwazla) and to ask her to make a clay bowl which could serve as a divination bowl (kezlid). Next he should go and get branches of the plant wasl (Saccharum spontaneum). He was then told to cut one stick for someone whose father ad already died and which should represent his $b a b a$ ancestor pot. For the mama ancestor pot, he should cut another stick and also another for someone's personal spirit pot (gad pats). He should also cut a stick to represent a madzagay, a pot which represents the spirit of a person someone has killed during a fight or by accident. The crab advised the man to fill the divination bowl half with sand and water and to arrange the sticks inside. She also told him that he should feed her with millet, insects and grasshoppers (nhel-héléw).

To learn crab divination is a process which can take several years. The point was stressed to me that it is particularly important to speak to the crab before placing her in the divination bowl. The crab is told what to do and asked to concentrate on her work and not to be distracted by what is going on outside the bowl. She is advised to climb over the sticks and small calabash pieces representing the social environment of the client. By doing so the flow of speech should not be interrupted and at the end of this communication the diviner says "kulef", meaning: "I am without any ulterior motives" and covers the bowl. After about twenty minutes the bowl is uncovered and the diviner checks whether the crab has moved any objects and, if she has, where she has placed them. Depending on the circumstances, he then re-arranges the bowl and places the crab inside again to find out what action should be taken. This normally results in the diviner advising his client to carry out a certain sacrifice. In comparison to "manipulating" or "playing the stones", crab divination has the advantage in that the diviner does not move the objects himself. It is the crab which is doing it and Mafa say that, unlike a human being, a crab is in a state of purity, which brings more objective results.

\subsubsection{Symbolic contents of the divination bowl}

A complex divination bowl contains not only lots of sticks, but also a set of twelve shaped and decorated pieces of a broken calabash, a tiny rope of fibre, a pot shard and a couple of small ceramic balls (see plates $2 \mathrm{a}$ and $2 \mathrm{~b}$ ). A typical arrangement begins with the rope (teba) being placed in the centre of the bowl, representing a goat tied up outside the house ready for a sacrifice. The rope can represent a she or he-goat as a potential offering. The goat should not originate from the herd of the father of the house and needs to be kept outside his house until the sacrifice takes place. In front of the rope a shard of a broken pot is placed representing a large oval wooden bowl (wuram), in which the goat is slaughtered and the meat arranged. Next, the calabash pieces are put down to cover the rope and the pot shard by being placed on top of each other forming a little mountain. Now the two ceramic balls are buried in the sand next to the calabash pieces, symbolising the heads of husband and wife. What follows next are the sticks. A stick representing a woman is smooth and without knots. A man without children has a knot at the 
upper end of the stick while a man with children has a knot in the middle. A household is normally signified by three sticks, one for the head of the family, one for his wife or wives, and one for his children.

\section{Placing calabash pieces}

Some diviners use only six, others use eight, ten or even twelve calabash pieces. They are always used in pairs. The twelve calabash pieces can signify the following (see figure 4): a quiver (gwadama), triumph or laughter (ńngwashè), a well established young man (mishél ndo), a woman (ngwaz), sorghum (daw), road or direction (cived), a young girl (dama'a), a young man (ńngura'a), the blacksmith (ngwazla), a calabash used for beer libations (ndelek zom), disease caused by incest (ńngwéslè) and misfortune caused by sorcery (mide). We can see from these examples that each calabash piece represents a category of moral, social or political significance.

They are placed together in pairs, the established man and the woman, the young man and the girl, the ceremonial calabash and the sorghum, the quiver and joy or laughter, misfortune and disease caused by incest, with the blacksmith and the road or direction together as the final pair. Most pairs explain themselves more or less naturally, like man and woman, or boy and girl, misfortune and disease, while others are more difficult to understand, like the blacksmith and road or direction, or calabash and sorghum. The first presumably refers to the special talents the blacksmith is born with (nya' $a$ ) which enable him to identify misfortune and disease and provide guidance and healing. The road might also refer to him being quite mobile, a free agent who relies on these special gifts to make a living. The calabash and the sorghum belong together because the sorghum is the plant providing the cereal for beer making and the beer (zom) in turn is the "Eucharist" of Mafa religion. Finally, we come to a pair of symbols, that of the quiver and triumph, for which it has been difficult to identify the meaning. A hint towards the correct link might be that the quiver is interlaced with the fibre of the wuma tree (Bauhinia reticulata), which is used to produce the quiver. The wuma tree is a symbol of good fortune and also features as symbol of ritual vengeance in funeral rites. The quiver and triumphant laughter might therefore be interpreted as symbolising the victory over sorcery which has caused the death of a man.

Depending on how the crab rearranges the pieces, one session can lead to a multitude of different outcomes open to interpretation by the diviner, who then tries to translate them into solutions to the problem presented by the client. The situation can become very complex especially when we consider the variations of single sticks and sets of two or three sticks numbering altogether over one hundred sticks. The diviner plants the mass of the sticks around the inner walls of the bowl by first moving clockwise from above the mountain of calabash pieces in the centre and then anticlockwise depending on the circumstances the client finds himself in.

\section{Placing the sticks}

Before the diviner moves to the outer circle he plants some sets of sticks around the calabash pieces. He might set some sticks to the left of the mountain of decorated calabash pieces to represent the diviner's view of the east. These sticks could be for the sacred pots, which are traditionally placed under the main granary where the sorghum of the family is stored. Mafa refer to the area under the granary as shœekwétév and a variety of sacred pots are found there. One pot is called shokwétév and represents the spirit of sorghum. Another pot, also referring to the sorghum as a person, is called zhigilé daw shokwétév, meaning literally "god of the sorghum under the granary". What we might also find there are the twin pots of a man who is the father of twins. The granary of the father of the house is the most sacred place in a traditional homestead, especially the area beneath his granary. Mafa cannot bear to imagine that this granary could ever be empty. 
Next, a single stick might be planted to the left in front of the calabash mountain. Another single stick might be planted representing the front court yard of a house, which is normally facing east. The name of the stick is mamal var ma gay which refers to a wild onion and is linked to a ritual to demonstrate forgiveness. Somebody might bite into the onion and spit some of it over his chest by saying "God forgive me, but I was angry with this person, but now it shall be over." This action might be related to a neighbour coming to visit and the father of the house doing this to reconcile with him after a conflict. Sticks might be planted above the calabash pieces to indicate the grave of a man and the grave of a woman.

When the sticks around the centre have been arranged, the diviner might begin at the top of the inner circle of the bowl by first planting sticks for all the spirit pots of the client's matrilateral ancestors. They are the ones of his mother's brother, referred to as kükga, and of his father's mother's brother, referred to as kük'baba. Following on clockwise the sticks represent a man's maternal ancestors. Another set of three sticks might be planted to represent three blacksmiths. The crab is given the power to choose the specialist to whom the client might eventually go to resolve his problem. During the placing of the sticks the diviner names them according to the information the client gives him.

Next are pairs of sticks being planted to represent the two main water courses travelling through the community to which the client belongs. Sticks are planted for two neighbouring settlements his community is traditionally associated with and which are seen as their traditional enemies. These places are chosen depending on whether the client is a frequent visitor to these villages. It is very likely that sticks are planted for the departmental capital, Mokolo, and the capital of the canton, Koza. When all these sticks have been planted the upper half circle will have reached completion. The diviner might now start to plant single sticks in an anti-clockwise manner in order to complete the lower circle beginning alongside the inner rim of the divination bowl.

The lower circle might be started with single sticks being planted to represent the house and the inner fields of the client. There would be a stick for his shrine in front of his house, often consisting of a stone with a sacred pot on top. This shrine might be referred to as zhigilé var ma gay, meaning "god in front of my house". One stick would represent his goat house and another his cattle shed. He continues with a stick each for his personal spirit pot (gad pats), for the ancestor pot for his deceased mother (mama), and for the god of the inside of his house (zhigilé gay). He also plants sticks for the personal spirit pot of his son, the personal spirit pots of his first and his second wife and those of his daughters. A stick is planted for the ancestor pots of his deceased father and his father's father, although the client might not himself be the owner of those pots. In order to perform a sacrifice he has to go to his eldest brother's house, but the sticks would be still planted together with his own family components. If the client is an office holder, which could be religious (e.g. mountain priest) or administrative (e.g. ward head), this will be marked by a stick.

The lower part of the circle of sticks also contains representations of most neighbours of the clients, especially those belonging to his own lineage. The sacred centre of his group is illustrated by a stick representing the most important local shrine which Mafa generally refer to as diy halalay, meaning "eye of the great ancestor". There might be other less important shrines owned by kin groups. These shrines might belong to his own paternal kinfolk, but it is also possible that they are shrines of his maternal kin or of his wife's kin. Normally all these shrines are found in his own or in neighbouring communities, since Mafa traditionally marry within their local region. Local shrines represented by sticks are not only shrines of the client's kin, but also of neighbouring communities where he might not have any relations, since the cause of his problem could well be connected with anything or anybody in the wider locality. 
However, what seems to be the case is that a distant relationship is represented by fewer sticks than a close one. Neighbours and relations nearby are normally represented in great detail. Sticks are planted for the number of wives and the number and sex of their children, while houses of people from outside the community, to which the client belongs, only seem to be mentioned if they have a particular significance as part of the problem presented. Such cases generally refer to an individual who represents official functions, like the regional rainmaker or even a government officer. This illustrates the fact that most problems Mafa explore through crab divination are considered to be caused within their own neighbourhood.

\section{A potential problem and its possible solution}

From our description of symbols placed in the divination bowl to be moved around by the crab, we can conclude that the basic residential unit of the Mafa is the nuclear family consisting of the father of the house, his wife or wives and his children. This is the social structure of a house wherein the father of the house is the head of the family. The power of a family head seems to engender social conflicts many of which have to do with the complications of being a married man.

The arrangement of the divination bowl makes this perfectly clear. If the crab, for example, moves the head of the wife away from the ceramic ball representing the head of her husband, it may well be interpreted as her intention to leave him. This might coincide with an ongoing conflict between a husband and one of his wives, so if the husband was the one who went to present his problem to the diviner, he would immediately know which of his wives the crab is referring to. What happens next is to see where the crab actually took the head of his wife, and he might find out that it has landed next to the stick representing his father's mother's brother.

The diviner might now conduct a second session and propose a solution to the problem, by asking the crab whether it would be helpful to make a sacrifice to the ancestor pot representing his father's patrilateral uncle. The head of the wife would have to be put back into place next to her husband's head and the crab would be left alone to move around once more. If the crab were to sit next to his father's mother's brother's stick, this would indicate that the crab has confirmed the proposed solution. In cases of marriage problems it is a choice among Mafa to ensure the spiritual assistance of the father's maternal uncle via a sacrifice to his baba. It is believed that a deceased matrilateral uncle can mediate in the world beyond between a man and his wife's patrilateral kin.

We can see from this example that divinatory decision making involves all social and metaphysical agencies described so far, in particular those of this world and their representatives in the world beyond. The crab is moving around in the divination bowl. What is remarkable is that the sacrifice proposed by the diviner is actually accepted by the crab who in the second session is standing next to the stick to which it had moved the head of a particular husband's wife in a first session. For traditional Mafa there is no explanation for this other than that of divinity and here we are back to God as first philosophical principle guiding their ritual actions. However, when we ask traditional Mafa why this works, they tend not to refer to God but to the ancestors which is to say that the ancestors have been there before and did the same thing. They are also seen as mediators between God and their living descendants. 


\subsection{Home}

\subsubsection{The concept of shinek and mposokw}

A Mafa man might say Ye shinek ga, meaning "I am descended from my forefathers who existed in this community for a long time," whereas the same man might use the word mposokw instead when explaining that he is not a stranger in a particular locality. While the term mposokw refers to the family home ${ }^{70}$ where the placenta (bay) of an individual is buried, the term shinek refers to a particular kin group within the local community where the family home exists and refers to its lineage connections. A person can therefore refer to his natal village as mposokw but not as shinek. This is why Mafa explain that shinek is the more important concept since the placenta can be placed in a village without having a lineage connection to it. This means that the place of mposokw and shinek a man refers to as his home can consist of two different local communities, which would be the case if someone's father has settled in a neighbouring village. His children would now refer to their natal village as mposokw but to the natal village of their father as shinek. We can conclude that the concept of shinek refers to the home of a person in terms of patrilineal descent while that of mposokw has solely to do with the home as the place of residence. ${ }^{71}$

The difference between shinek and mposokw addresses an important issue with regard to the underlying concept of home applied by Mafa since it genuinely overlaps with that of community. To get away from the danger of examining the underlying concept of home and community in a far too general and group-related way, I will focus on types of social actions individuals have to perform in order to make these concepts work. In this context it seems to me that the concept of mposokw, although not as politically powerful as that of shinek is somehow more basic. It is difficult to imagine that a person could ever become a social actor in the context of shinek (for example as a father or lineage elder) without an individual home where his placenta is buried. This is the reason why I begin this section with a description of the individual home.

\subsubsection{Ancestral links and ritual ties of the wider family}

The Mafa word for house and nuclear family is gay. The family head is the bab gay (father of the house) while his first wife is referred to as ngwaz gay (woman of the house). The first wife has certain privileges not shared by her co-wives. One of them, which is particularly relevant in this work, is the brewing of sorghum beer for religious consumption. When a man is the oldest among a group of collateral brothers and his father and father's father are deceased he will be the elder (tsava) of a joint family. ${ }^{72}$ Each of his collateral brothers and their married sons possess their own family homes but are at the same time interlinked by ties of patrilocality and patrilineal descent.

\section{Primary links}

The elder of a joint family is at the same time the head of an extended family. ${ }^{73}$ While the joint family he ritually heads includes the wives of the married males but excludes the married females, his extended family also includes the latter. Due to the virilocal rule of postmarital residence those females who are already married no longer reside in his neighbourhood and are therefore members of their husband's joint family. However, in the case of a marriage breakdown, the daughter of a man might temporarily return home to her father's neighbourhood or she might live at her brother's place when she is old and has no son to take care of her. Joint and

\footnotetext{
${ }^{70}$ The word also refers to the pot in which the placenta is buried.

${ }^{71}$ Martin (1970:87) explains the concept of 'sinek' (shinek) and 'posok' (mposokw) in a similar way.

${ }^{72}$ A joint family consists of several nuclear families settled in one neighbourhood and linked by ties of siblingship.

${ }^{73}$ An extended family includes all married daughters of a family ancestor while a joint family excludes them.
} 
extended family ties are more or less identical but there is a difference which might come into play in the context of succession in family ancestor worship. In the rare case that there is no male descendant left to conduct the ancestor ceremony for a deceased father then the married daughter might become a token elder. However, patrilocality is always maintained, which means that the ancestor pot remains in someone's house in the late father's neighbourhood.

The Mafa do not have a specific word for joint or extended family but use the word gwaliy to refer to their patrilineal kin. The expression gwaliy not only refers to direct relatives but is also the word for clan. ${ }^{74}$ The word gwaliy is most inclusive and not a territorial term at all but simply a term to designate that one is related through a common agnate independent of how close or removed he is in genealogical terms. However, there is a difference between male and married female members of a local gwaliy which becomes apparent on the ceremonial level. A married daughter has certain rights to benefit from religious blessings in her father's house, but is not allowed inside the house while the ceremony for her late grandfather or great-grandfather takes place. The reason is that she has become a member of the gwaliy of her husband where she attends the same ceremony in his family home. The same applies to her children, especially her sons, who often bond closely with their mother's brother (kükwa). Such a relationship often leads to a situation where the son of a man's sister settles in the neighbourhood of his matrilateral uncle even before he gets married. He might eventually marry a girl from the gwaliy of his mother, so long as she is at least three generations removed from her mother's brother's lineage ${ }^{75}$. He might then settle permanently in his kükwa's neighbourhood. Such a situation would bring about a relationship in which the children of a new bab gay would have their mposokw (place of individual birth) and shinek (place of patrilineal descent) separated.

A man who has settled in his mother's brother's neighbourhood can profit from the ancestral ceremonies of his uncle's family but, like his mother, he is not allowed inside the house while the actual ceremony of his mother's deceased father takes place. To establish spiritual protection for his nuclear family (gay) he has to go to his father's neighbourhood since this is where his father's placenta is buried. The same applies to his children, but once their father has died an ancestor pot $(b a b a)$ will be placed to spiritually represent him and his oldest son will celebrate the ceremony in his house. However, since the ancestor pot for his son's father's father ( $b a b$ 'baba) is still in the neighbourhood of his grandfather's place of birth (mposokw) he and the other members of his joint family will go and celebrate their $b a b$ 'baba ceremony there. The situation will remain unchanged until his late father has become an ancestral grandfather himself. However, whether his co-lineal descendants refer to their new neighbourhood as mposokw as well as shinek, depends on additional factors. One of these factors is whether or not they have long lasting lineage ties in their former neighbourhood. These questions will be examined in the section where we discuss the community.

At this point I only want to explore the ritual activities within the family home and the wider family ties as a social consequence of patrilineal descent and virilocal residence. We can see from the above that those who participate in ancestor worship by being allowed inside the house during a $b a b a$ or $b a b$ 'baba ceremony are all co-lineal men and their respective nuclear families. This means that only the male descendants of a deceased father or grandfather, their wives and children (but not their married daughters and their children), can be present inside the house while

\footnotetext{
${ }^{74}$ Vincent (1995:343) refers among the Mofu proper to lineage segments as 'gwalay'.

${ }^{75}$ Van Santen (1993:236,253) speaks of 'kuyuk' as mother's patri-clan. Barreteau \& Le Bléis (1990:208) translate the word 'kuyokw' as 'oncle maternel, lignage maternel'. I stick with the spelling kükwa since there might well be a difference in pronounciation. The word is in the first instance a relationship term referring to the matrilateral uncle and as a derivation from this perhaps also to mother's patri-clan, but I doubt whether the translation 'lignage maternel' is correct.
} 
such a ceremony takes place. All those who have a right to directly participate go to the house of their respective family elder while all those relatives and neighbours who are excluded wait outside until the ceremony is over. The objects, which represent the spirit of a late father or grandfather, consist of clay pots with anthropomorphic features indicating their sex. The spirit pot of a family ancestor only leaves the house to be disposed of after the last collateral brother responsible for the ceremony has died.

\section{Secondary links}

Apart from the $b a b a$ and $b a b$ 'baba pots there are also ancestor pots for female members of a family. These are the pots for the deceased mother and father's mother. These pots also never leave the house before the last person responsible for a mama or mam 'baba ceremony has died. Both pots are kept in the house of the eldest son or grandson, but in the context of the mama pot it is the youngest son who carries out the ceremony in his eldest full-brother's house. The members of a nuclear family are split during the actual ritual along the lines of half-siblingship. The ceremony for the late mother of a deceased father (mam'baba) is carried out by her eldest grandson. All descendants of their father's mother may attend the ceremony inside the house.

A patrilateral and matrilateral grandmother (father's or mother's mother) is referred to as jejé by her grandchildren, which are not only the children of her sons, but also those of her daughters. The latter are usually married in one of the neighbouring villages but, as mentioned above, they are all allowed to participate in the ceremony of her ancestor pot (mam'baba) inside the house. The same applies to the married daughter of a late mother and we can conclude from this that cognatic links are, in terms of participatory rights, more inclusive than agnatic links. The latter are more exclusive because of their spiritual function for the social construction of the family home. It shows that the male descendants are in control of the house as a place of religious worship, a view which is also reflected in the architecture of a house and in the way ancestor ceremonies are carried out in the context of the individual home. The ritual handling of ancestral spirits will be discussed at the end of this section.

\subsubsection{The architectural features of a house}

Every house (figure 5) has a front court referred to as var ma gay (court in front of my house). From the front court yard one enters the nngala or foyer and from there we reach the dzadzaw, the room where the father of the house sleeps and keeps his belongings. Some men have a second dzadzaw immediately attached to the first. From the $d z a d z a w$ we come to the hudokw which can function as a granary or sacrifice room. Next comes the huzhéb, which is the main granary of the father and then finally, the hucéd (kitchen). All these rooms are interconnected and one can walk right through from the foyer to the kitchen. Other rooms are built onto the main string of rooms over time. They consist of interconnected or freestanding granary or store rooms as well as accommodation for domestic animals.

\section{The core rooms of a house}

The ńngala (foyer or entry room) often has a large built in bench made of stones and plastered with clay. It is here that the libation to the deceased father or father's father is carried out. The dzadzaw of the father of the house usually contains a long mahogany plank which functions as his bed and many of his personal belongings are kept in this room. Essential items are his bow and quiver with some arrows, a large shield and of course his personal spirit pot. If a house has two hudokw (often granaries) the first one is for the father of the house while the second is for his first wife. The hudokw ńngura (father's sacrifice room) is where a man keeps his ancestor pots most 
of the year and also, a large wooden bowl, an item used in the sacrifice of goats. The hudokw ngwaz (house of the first wife) is where the females of the house (wives and daughters) stay when a sacrifice or libation takes place. One of the hudokw normally contains a granary.

The huzhéb is the main granary of the father of a house. Most of the time it contains two granaries and always has a ceiling and a clay dome. The huzhéb is where a man stores his sorghum and it is where we find the pot of the spirit of the sorghum (shokwétév) and the spirit pots of any twins born into the family, all placed underneath the granary. To enter the granary one has to climb through a hole in the ceiling in order to reach the dome. During one month of the year, usually malama (September/October), the family ancestor pots have to be kept up there. After the main granary of the father of the house comes the hucéd (kitchen). The kitchen serves all the wives of a family head and therefore contains several grinding stones sunken into a clay shelf of about $1 \mathrm{~m}$ height. The first wife keeps her zhigilé riy vava (female deity pot) in the kitchen, serving not only her, but also her co-wives, as spiritual protection.

The interconnected string of rooms I have described so far are the core rooms of a house. They often form a slight curve on the hillside from where they appear to be inaccessible. The roofs are traditionally made out of millet stalks, but sometimes sorghum stalks are used. They are carefully linked with strings and rolled out and fixed over an apex of wooden sticks similarly bound together by fibre string. The form of the roof is conical, curving to a high point and often decorated with rings of broken clay pots round the top. Unlike many of their smaller eastern and western neighbours Mafa do not use stone as the main building material but only partly build with stone which they cement and plaster with a mixture of sand and earth. The granaries are always found within a room and are made out of sandy clay. They stand on a platform supported by several stones with a space of about $25 \mathrm{~cm}$ underneath. A granary invariably has a ceiling and a dome, which is then covered by a thatched roof. The platform and ceiling are made of wood and flat stones, which are cemented with a sandy clay mixture. The rooms have no windows, except the kitchen at the end which has a small hole to look out and to allow ventilation. If we look through the kitchen window hole we see the galiy taba (tobacco garden) behind the house which is surrounded by a thorn fence.

\section{Side rooms and cattle sheds}

In addition to the main string of rooms Mafa have connected cattle sheds and free standing small rooms. These are grouped in such a way that a Mafa house is accessible through the ńngala or through a side entrance leading to an inner court. The inner court is referred to as dalala providing an open air space inside the compound where many household tasks are carried out. The inner court is often covered with a canopy of sorghum or millet stalks.

The two types of side rooms are the granaries and the sleeping rooms, which are frequently used by the women of the house. They are often granaries with ceilings and a clay domes. One type is referred to as zlangay and the other one as zlanglokw. While the first is connected, the latter is a free standing side room contributing to the physical enclosure of the inner court. A wealthy family might have several side rooms. The free standing side rooms are always accessible from the inner court but the connected ones can only be reached by entering the string of core rooms via the foyer or entrance room. The first connected side room built is usually linked to the father's main granary and often contains the female ancestor pots held in a family.

Every traditional Mafa house has a kudam bokw (goat house), which is a small freestanding building facing the inner yard. The name kudam bokw only applies to the lower section of the building, while the upper section is called gurdede, which also serves as a name for the building as a whole. The gurdede is a good example of the sophistication of Mafa architecture. It is 
lowered about $50 \mathrm{~cm}$ deep into the ground and the actual walls, made out of a mixture of sand and earth, are not much higher than another $50 \mathrm{~cm}$ above ground level. The ceiling separating the kudam bokw and the gurdede section is made out of spliced wood and flat stones cemented in with a sandy clay mixture. The upper section is formed into a dome using only this mixture of sandy clay. While the lower section, the kudam bokw, has a round opening functioning as an entry for the goats, the upper section, the actual gurdede, has a semi-circular hole as an entry. The whole building is covered with a thatched roof made out of millet stalks. The gurdede section serves to dry the germinated sorghum corn for beer making.

While every traditional house has a gurdede (which includes the goat house) it depends on the economic success of the father of the house whether he has a kudam zlé (cattle shed). A cattle shed is always attached to the chain of main buildings facing the outside of the house. It is connected to the dzadzaw of the father and often only accessible from there. The cattle shed is sunk about $50 \mathrm{~cm}$ into the ground and is built out of large stones and boulders about $1 \mathrm{~m}$ above the ground with a thatched roof. If a man can afford it he encloses a bull for some length of time in this shed in order to fatten it for the next bull festival to come. During times when a man does not have the means to fatten a bull he often keeps a cow in his kudam zlé.

Lastly, there are the small rooms or sheds Mafa refer to as kalak. A kalak is a multipurpose building, which can be free standing or connected to the core buildings of the house. They are made out of earth and never have a ceiling. The thatched roof of a kalak is not very sophisticated. A kalak often serves as storeroom or as sleeping/living room for children. The father of a house might have a kalak connected to his dzadzaw facing the inner courtyard. A kalak might also be found some distance away from the house or even far away in the outer fields for protection from bad weather while working in the fields.

In summary (see figure 5), the main architectural features of a traditional house consist of the var ma gay (front court), dalala (inner court) and a group of interconnected and freestanding rooms. The interconnected rooms are the nngala (foyer), dzadzaw (father's living/sleeping room), kalak (son's room), kudam zlé (cattle shed), hudokw ńngura (father's sacrifice room), hudokw ngwaz (first wife's granary and sleeping room), huzhéb (father's main granary), zlanglokw (granary and female sleeping area), and hucéd (kitchen). The free standing rooms consist of the gurdede with kudam bokw (store room and goat house), zlanggay (granary and female sleeping area) and kalak (shed), some distance from the house.

\subsubsection{Relationship terminology}

Mafa distinguish between descriptive, metaphorical and classificatory relationship terms. The descriptive terms are the most important while the classificatory terms are only used to refer to matrilateral kin. Metaphorical terms used frequently are always derived from descriptive relationship terms.

\section{Descriptive terms}

Mafa have a descriptive relationship terminology. I have already pointed out that the words $b a b a$ (deceased father), $b a b$ 'baba (deceased father's father), mama (deceased mother), and mam 'baba (deceased mother's father), refer to ancestral relationships within the social cosmos of the Mafa. In the case of baba and mama the same words are used to refer to the father or the mother by adding the possessive pronoun ga by simply saying babga (my father) or mamga (my mother). The same system applies to the grandparents to whom one would refer as bab'babga (father of my father), mam'babga (mother of my father), bab'mamga (father of my mother) and mam 'mamga (mother of my mother). 
Since the Mafa practice polygyny most people have full and half-siblings and here too the relationship terms remain strictly descriptive. Brothers of the same mother refer to each other as kar'mamga (son of my mother) while brothers of different mothers refer to each other as kar'babga (son of my father). Full-sisters refer to each other as dom'mamga (daughter of my mother) while half-sisters would call each other dom'babga (daughter of my father). The same terms would apply when a brother refers to his full or half-sister or the other way around.

Husband and wife refer to each other as ngwazga (my wife) and bakiyga (my husband) but cowives refer to each other as ngwaz-bakiyga (wife of my husband) ${ }^{76}$ Father or mother call their son karga (my son) and their daughter damga (my daughter).

The system consists altogether of a combination of the words for father ( $b a b a)$, mother (mama), son $(k \partial r)$ and daughter $(\mathrm{d} \partial \mathrm{m})$. A description involving a co-reference via a father is inclusive while a co-reference via a mother is exclusive. We have already seen that this pattern repeats itself if someone refers to his grandparents, whereby the family member he or she refers to is always mentioned before the intermediate reference the person uses to make herself explicit, as, for example, in mam 'babga (mother of my father) or bab 'mamga (father of my mother).

The same system applies if someone wants to refer to a cousin or nephew. The description begins with the actual person he or she wants to refer to and then goes on to this person's father or mother followed by the possessive pronoun $g a$ (my or mine). If, for example, someone wants to refer to the father's full-brother's son this person would say kar'kar'mam 'babga (son of the son of the mother of my father) or kar'ker'mam 'mamga (son of the son of the mother of my mother). When someone wants to refer to the same line of relationship but with reference to an uncle, one would call father's full brother kar'mam 'babga (son of the mother of my father) and mother's full brother kar'mam 'mamga (son of the mother of my mother).

The situation is similar if a person wants to refer to the children of his or her full-siblings. One would refer to the brother's son as kar'kar'mamga (son of the son of my mother) and to the sister's son as kar'dom 'mamga (son of the daughter of my mother). If someone wants to refer to the children of his or her half-siblings someone would use the father as intermediate reference and say kar'kar'babga (son of the son my father) or kar'dam'babga (son of the daughter my father).

\section{Metaphorical and classificatory terms}

Although Mafa have a descriptive relationship terminology, they also use metaphorical and classificatory relationship terms. The metaphorical use of descriptive terms is always derived from real patrilateral and matrilateral relationships like babga (my father), mamga (my mother), karga (my son) or damga (my daughter). Classificatory relationship terms are centred around references to a matrilateral uncles (kükwa) and bilateral grandmothers (jéjé).

Metaphorical relationship terms are used on two levels, inside but also beyond the extended family. Inside the family there are some exceptions where the descriptive version is maintained. This is particularly the case if the reference is made to matrilateral kin of the same or a younger generation, but also on the patrilateral side if it is a reference to a child of father's or father's brother's sister. For example, a man would refer to his father's brother's son's son not as kar'kar'kar'mam 'babga but as karga (my son) while he would refer to his father's brother's son's daughter's son as kar'dam'kar'mam'babga and not as karga. However, the metaphorical relationship term karga (my son) or damga (my daughter) is all inclusive if an older man or

\footnotetext{
${ }^{76}$ A general word for co-wife is ńndarday.
} 
woman refers to a younger person who is not a member of his or her family. A similar pattern applies to the metaphorical use of babga (my father) and mamga (my mother).

With regard to the classificatory relationship terms jéjé (grandmother) and kükwa (matrilateral uncle) there are also exceptions on the maternal side. The word jéjé is most commonly used when someone refers to his or her mother's mother or father's mother ${ }^{77}$ as jéjéga (my grandmother). Someone can refer to father's older brother's son as kar'jéjéga (son of my grandmother) but not to mother's brother's son. The latter is considered as an insult due to the virilocal rule of postmarital residence Mafa hold good. It is only because of kükwa (mother's brother) that jéjé (a matrilateral grandmother) has gained significance. To call mother's brother's son kar'jéjéga would be regarded as an insult. ${ }^{78}$

The word kükwa is the general word for matrilateral uncle and includes mother's brother (kər'mam 'mamga) as well as father's mother's brother (kər'mam 'babga). The first is referred to as kükga (my maternal uncle), while the second is referred to as kük'babga (my father's maternal uncle). In some ways father's kükwa is more important when it comes to spritual matters because it was a person's father who originally fostered that relationship. This is why this kükwa is often picked as mediator between a man's bilateral ancestors, as we have seen above in the section on divination. However, in terms of relationships in this world the mother's brother (kükga) is much more relevant than the father's mother's brother (kük'babga), especially for a young man. The mother brother is a consanguineal relative of enormous social importance, which also implies that a young man can settle in his kükwa's neighbourhood. ${ }^{79}$

\subsubsection{Getting married}

This description of celebrations relating to a primary marriage is a reconstruction from oral accounts of male and female informants from Gouzda. They represent a view of older members of the community describing that this was how a wedding was celebrated in the past. Today, wedding celebrations might miss out some of the stages, but the performance of ńngerma (sexual intercourse) remains essential and the most important part of a primary marriage. Celebrations for secondary marriages are only affected by changes if one of the partners has not been married before. This is particularly an issue with regard to the bride.

Before I go on to describe the various stages in the traditional wedding celebrations I will briefly comment on marriage payments made by the family of the groom to the family of the bride. In the past, the bridewealth for a primary marriage consisted of at least nine goats. Today money is becoming more and more important as a means for marriage payments. Negotiating marriage payments was and still is a matter between the father of the bride and the bridegroom. A bride will only find out what exactly was given when she wants to marry someone else and her new husband is then obliged to compensate her former husband. ${ }^{80}$ The obligatory nine goats had not always been paid and often more than nine goats had been given, depending on how favourable the possible marriage was considered to be. Often other goods, preferably made of iron, were also added. Iron has now been replaced by money payments but goats are still considered as the main

\footnotetext{
${ }^{77}$ Martin (1970:70ff) is of the opinion that the term jéjé is also applied to the father's father and to the mother's father, which cannot be confirmed by me.

${ }^{78}$ Martin (op.cit) sees the term kar'jéjéga being only applied to someone's mother's father's brother's son's son. It seems to me that this is a misconstruction. Only father's mother's older brother's son's son can be referred to as jéjéga and someone applying the same term to his mother's line would be inappropriate since this would be a reference via mother's father and not via father's mother.

${ }^{79}$ Martin (op.cit.) does not refer at all to kükwa, but only to jéjé.

${ }^{80}$ Kosack (1997:172ff) gives a detailed description of marriage payments from the perspective of the bride.
} 
preference in marriage payment, although, even here, money is increasingly becoming an alternative.

\section{Wedding celebrations for a primary marriage}

A young man and a young woman who get married for the first time in their life might have already been promised to each other in childhood by their fathers. Since Mafa practice clan exogamy it is likely that the girl comes from a neighbouring clan settlement. In order to establish such a promise it is necessary that the girl's gwada (female best friend) and the boy's maslay (male best friend) guide the girl from the house of her father to the house of the father of the boy. The boy and girl are taken inside the house, and will be expected to stay during the day in two separate rooms. Towards the evening the girl is guided back to her father's house and after this the promise is established and it is said that a boy has a medemay (fiancée).

As soon as the girl reaches puberty, the arrangements for the marriage can be made. At this point in time boy and girl have to find a maslay and a gwada, who are already married, to function as best man and best woman. As soon as the marriage is announced the actual marriage ceremony has to be completed within six days. These best friends play a very important role in the preparations as well as being ceremonial assistants at the first consummation of their marriage.

A traditional wedding has two main parts. The first part is called ńkilébe and serves as preparation for the first consummation of the marriage, which Mafa refer to as nngerma. The aim of the wedding seems to be a rite of passage of the girl and the boy from childhood to adulthood. The description I give here is one of how a traditional wedding was conducted in the past, and is therefore a reconstruction. My informants were mainly men over sixty years old and they reported mostly from the experiences of their own first marriages.

\section{Before the wedding night (ńkilébe)}

On the first day of ńkilébe, the bride receives sorghum to grind in the kitchen. She is accompanied by her best woman who will give her a new vava (grinding stone). Her best woman will hold her hand with the grinding stone and guide it over the main grindstone. After the sorghum is ground, gwada will ask the bride to call out: "Who is calling me now?" and the bride is going to call this out. This takes place in the house of her future father in-law, since her future husband's house is not ready yet. Like her husband to be, who is waiting in another room with a bukway (goat hide) over his head, she too has spent all day inside the building. The bride will now prepare a sauce from the wild vegetable bazlava (Cassia obtusifolia) which her best woman has brought with her as well. After the sauce is prepared the bride and her best woman will put the backs of their hands against each other and pour the sauce where their hands meet.

Meanwhile, the bridegroom and his best man have prepared a large ceremonial sickle made of iron called béré-béré. The best man also attaches the leaves of a particular tree around the ankles of the bridegroom and smears lines of ochre along his shoulders and down his spine. Next, the best man starts to beat his drum, signalling that he is ready to leave the house together with the bridegroom. The bridegroom holds the béré-béré in his hand and they start to stroll through the local community. They stop at neighbourhood boundaries where they sit down for a rest. On their journey they visit the houses of some elders where they are given tobacco and a chicken. This goes on until the evening. During the following six days the bridegroom and bride remain physically separated. After the six days ńkilébe is completed and ńngerma can be celebrated. 


\section{First sexual intercourse (ńngerma)}

The actual wedding, which entails the first consummation of the marriage (ńngerma), begins on the evening of the first waxing moon if the first child of the father of the bridegroom was a son. If the first born child was a girl nngerma would begin at full moon. ${ }^{81}$ Bride and bridegroom will sexually unite on the first night of ńngerma in order to mark what is considered among traditional Mafa as the most important part of a first marriage.

On the day of ńngerma, the best woman arrives with tiger nut paste and, for a whole week, will prepare an evening meal for the freshly married couple. The evening before the husband and wife to be are going to have sexual intercourse for the first time, the bride's best friend arrives together with other women of the neighbourhood. She enters the father-in-law's huzhéb (main granary) and helps the bride to take off the mozokw (cache sex made of fibre) and replaces it with a vazak (cache sex made of a leather strip). The change of cache sex will "baptise" her as an adult and mark the transition from medemay (girl) to ngwaz (woman). During this evening the bridegroom and his best man will go and visit the bridegroom's kükwa (maternal uncle) and continue on afterwards to visit his married sisters, his father's and his mother's sisters as well as his childhood friends. Wherever they call on this night, chicken and sesame are given to them as gifts.

Late in the night the bridegroom and his best man return home to see the bride. The best man will now take the goat hide the bridegroom was wearing over his head during ńkilébe and use it to cover the private parts of the bride. Bridegroom and bride will now be guided by the best man and best woman to the main granary and put to rest. With the sound of the first cockerel just before dawn the best woman arrives with a meal and takes both their right hands and sticks them into the gandaf (eating bowl made of clay). Next she will ask the bridegroom whether his oldest sibling is male or female by saying: "How many hands has your father?" If the groom answers two she would know it is a female, whereas three hands would mean that it is a man. Depending on whether the first born child of his father was a boy or a girl the best woman would dip both left or right hands of bride and bridegroom two or three times into the gandaf. ${ }^{82}$

After this ritual they eat. After they have finished the best man says to the bridegroom: "Look, my he-goat, now you are allowed to make love to her," and the best woman says to the bride: "Look, now you are there for this, your man, as he will be there for you." The groom will now take the goat hide off the private parts of the bride and the best woman helps both to lie down comfortably. She will turn them in such a way that they first come to lie back to back and then face to face and says before she leaves: "Now you should be there for each other." The best woman and best man then leave the granary.

Later that morning the best woman returns and throws a piece of charcoal into the father's granary. If the couple has consummated their marriage they will keep the piece, but if they have not they will return the charcoal by throwing it back out. After a successful wedding night the newly married couple are washed with warm water, which is repeated for the next few days. They also receive, every morning and evening, a dish of water mixed with sorghum and tiger nut flour. The mixture is filtered and the residue kept. The last day of nngerma a goat and some chickens are slaughtered. The best man receives the ma zhigile (the part of the animal stomach which contains partly digested herbs) of the goat and the best woman the hind thighs. In return, the best

\footnotetext{
${ }^{81}$ Mafa consider the full moon as female (dem kiya = female moon) but the first waxing moon as male (kiya nngura'a $=$ moon man). Mafa avoid starting important festivals during full moon.

${ }^{82}$ During Mafa ritual counting "one" remains invisible. This is why a girl appears as even, meaning riy cew (two hands) plus the invisible one adds up to three (odd). In the case of a boy Mafa say riy makar (three hands) plus the invisible "one" adds up to four (even).
} 
woman will bring an eating bowl filled with a particular vegetable and the best man will bring a wuram (wooden bowl) filled with sorghum.

The newly married woman (ngwaz gay) now prepares a meal from the rest of the meat of the sacrificed goat and also cooks the chicken. She takes a part of the intestine of the goat and after she has cleaned it she will stuff it alternately with cooked meat and stomach mixed with blood. The couple will now each put one end of the filled intestine in their mouths and pull until it tears apart. They will then each eat their share. Next the residue of the filtered sorghum and tiger nut flour is formed into small balls and together with small pieces of the cooked meat is distributed among the neighbours who wait outside the house to cheer the successful first consummation of the marriage. In return, the couple will receive bowls filled with sorghum and it is the task of the best woman to help the freshly married woman to grind the sorghum and to mix it with some sesame and tiger nut flour. This will be kept to be served to the "warriors" of the var medemay, "war of the bride", which takes place later in the early hours of the evening of the last day of nngerma.

\section{"War of the bride" (var medemay)}

During the late afternoon of the sixth and last day the young unmarried men start to gather some distance away from the house, where the wedding took place, while the young married men meet up nearby the house. Both groups are equipped with small but hard pieces of soil and pieces of wood from the poisonous bush mbav (Adenium obesum) as well as with some dry cattle dung. They carry shields made out of branches from the tree hawan (Diospyros mespiliformis). While the unmarried "warriors" wait in their position, the best man helps the newly married husband to deck himself out in a special way. Again, he will smear lines of ochre over his shoulders, but this time not down the spine but down the middle of his chest to his navel. Around his body he attaches the goat hide which was first on his head and then over the private parts of the bride. Next the new husband takes the large ceremonial sickle, béré-béré, and smears ochre over one side of the blade. The best man takes his walking stick and tobacco horn and both leave the house to go for a stroll. Chatting to each other they aim for the meeting place of their neighbourhood where they sit down to sniff some tobacco. After a short while they go back and enter the house but only to come out again and walk in a different direction, talking to each other and enjoying their freedom. Depending on whether the first born child of the father of the new husband was a boy or a girl, they would repeat their little outing two or three times.

It is towards the end of the last walk that the "war of the bride" will suddenly break out. The group of unmarried young men, observing their friends enjoying themselves as married men, will "attack" them with their "weapons" but the group of young married men will "defend" them. At the same time the best woman and the new spouse will block the entrance to prevent the best man and the new husband from withdrawing too quickly. Their intention is to see the "battle" going on. Only after some time of "fighting" are they allowed to feel sorry for the new husband and his best man and let them back in to take refuge while the group of young married men "cover their retreat". Both "warrior" groups will now enjoy a rest whereby the young unmarried men gather further away from the house than the group of their married friends. The new spouse and her best woman now serve the "exhausted" participants of the "war of the bride" with calabashes of sorghum flour in water mixed with some sesame or tiger nut flour. The "warriors" go home soon after. From this day on the new husband can go out on his own, while the new spouse is still housebound. 


\section{Ritual fetching of water}

One day after the "war of the bride" the best woman shaves the head of her newly married friend, leaving the hair along the middle part unshaved. Next she takes the goat hide worn by the husband during the "war of the bride" and attaches it over the back of the new spouse. She will then dress her with a motsod yam (cache sex made of fine forged lamellated iron). The best woman grinds some sorghum and prepares two portions of sesame and sorghum paste. She also mixes some sorghum flour with water and pours it into a calabash. Next she places a dasay yam (iron armlet related to the water spirit) on the head of the new spouse who will carry a water jug on top. The best woman carries the calabash and both walk to the next source where the best woman pours some of the sorghum flour water over a prominent stone in the river, in order to please the water spirit. They then both sit down and eat from their portion of sesame and sorghum paste. After this they fill the jug with water and find their way home. When the wedding takes place towards the end of the dry season and no more water is found in the river, they are then allowed to go home without.

There are serious consequences if the new spouse breaks the water jug on the way home, since this indicates a divorce and the wedding would be considered as having failed. In a case where the bonds between the newly married couple are very passionate, the bride would be asked to first marry a man from an enemy village and to then return later for a secondary marriage. However it is much more likely that the water jug will not break and the new spouse would now also be free to go out whenever she wants. She can also leave the main granary of her father in-law to go and live with her husband.

\section{"Meal of the mother of a kitchen"}

The next day the new spouse enters the kitchen where she prepares the "meal of the mother of a kitchen". This is a meal for the family, and it is also prepared on other occasions. As the name "mother" implies, the meal needs to be cooked by a woman who is married. A few days after the new spouse has prepared this meal the best woman returns in order to shave off the rest of her hair. We will see below that the "meal of the mother of a kitchen" often becomes the most important ritual in secondary marriages.

\section{"Beer under the bed"}

About a month later, the new spouse prepares a beer which is known as "beer under the bed". For the consumption of this beer she invites her new neighbours, who are mostly the close relatives of her husband. On this occasion she prepares sesame and tiger nut paste for her best woman and the best man of her husband. When everybody is present to enjoy this, she is asked: "Which boy do you want to be your friend?" and she calls out: "I want the son of this man as my friend!" The boy chosen is called and the new spouse and her new friend drink the sorghum water mouth to mouth from one calabash. The friendship will be mutual, but since it is a boy the new spouse can call him to help her with little tasks around the farm. This event of choosing a boy as friend and helper in the neigbourhood of her husband marks the end of a wedding ceremony for a primary marriage. The wedding took place in the husband's father's house, but the new couple will soon be established in their own house. Before I describe how a new home is founded, I will outline how wedding celebrations for secondary marriages are performed.

\section{Wedding celebrations for secondary marriages}

If a man is or was already married and his future wife was not, the bride would have to go through the whole cycle of a first marriage. Her future husband would be allowed to be present 
while the various rituals took place, but not to actively participate. However, since the bride was obliged to perform the whole wedding it would be advisable for him to choose a best man. The "war of the bride" would not take place, but he would have to perform ńngerma, meaning that sexual intercourse with his new wife would be an obligatory part of the wedding ritual. The "war of the bride" would not take place simply because this part of the wedding ritual is solely for young men who are marrying for the first time. This "war" is a dramatisation of a competition in relation to primary marriages only and indicates a competition over women between young unmarried men and those who have just got married. A man who gets married for the second time would not be part of this competition.

In a case where a woman was already married but a man was not, then the man has to perform all parts of a first marriage together with his wife to be, but she would be the one free to go out. She would have to perform the first part, ńkilébe, and, with the help of her best friend, grind the first sorghum of her new marriage in the kitchen of her new home. During ńngerma her friend would assist her in exchanging the cache sex of a married woman she has from her former marriage for a new one, given to her by her new husband. She would only stay in the house during the actual wedding night and would again be free to go out the next morning. Her new husband would then perform the "war of the bride", and after that he too would be free to go out. Finally, a woman performing a secondary marriage would have to go with her best woman to ritually fetch water from the river, since she will have changed home. Again, if she were to break the water jug, the marriage would be ended with a divorce.

The wedding rules for widows show some variations to those of a secondary marriage of a woman who simply left her husband for another man or who was divorced by her former husband. A widow often formally re-marries a brother of her deceased husband. ${ }^{83}$ In order to do so, she enters the kitchen of the house of her new husband very early in the morning and prepares the "meal of the mother of a kitchen". If she had children with her late husband, she continues to live in her deceased husband's house, but everybody knows that she has married again. When a widow marries outside her deceased husband's neighbourhood, she would prepare the "meal of the mother of a kitchen" after the first consummation of the marriage. From then on she would be considered to have remarried and be expected to live in the house of her new husband. If she had children with her deceased husband, the unmarried children could not move in with her but would have to live in the house of one of her late husband's brothers. This example shows that the children of a woman belong to the kin group of her husband and that she has no right to take them away from their land.

The secondary marriage of a pregnant woman is only possible if her future husband is already married. A woman who already has children from a former marriage but is not pregnant at the time can get married to a man who was not married before. A man who was already married can, in both cases, consume the marriage without having to celebrate nngerma. However, if a woman is pregnant from her previous marriage he will be asked to celebrate ńngerma for his new wife at a later time in order to give her the status of a married woman in his neighbourhood.

Not to perform ńngerma as part of a secondary marriage can have serious consequences for a woman in the case of her death, since she can be refused full mortuary honors. She could not be buried in the cemetery for the married women of her husband's neighbourhood, but would have an isolated grave somewhere on his farmland. The dead body of a girl who dies before the wedding night while she is in the process of performing her first marriage would be carried back

\footnotetext{
${ }^{83}$ Levirate, or the "inheritance" of a woman as a wife of her late husband's brother was assumed to happen among Mafa in the past but not so much today. It indicated that a woman has become a member of her husband's kingroup.
} 
to the house of her father. She would not yet be recognised as being married and would therefore have her funeral in the local community of her father.

\subsubsection{Founding a family home}

A young man who gets married for the first time builds his own house. He might choose a place near a tree, which can later serve as his family shrine. It is his family elder (tsova) who will come and lay the foundation stone. When the nngala (foyer) is completed, his family elder will return and place a suitable stone into its walls, which will serve as base for his zhigilé gay (god of the house). The new bab gay will later add smaller stones in order to develop his zhigilé gay. Such stones are very often long thin pieces of gneiss (metamorphic rocks), which can be found in dry riverbeds. Small round pieces of quartz of various colours are often added later. The main stones forming a god of the house should be heavy, and there is gender attached to the gneiss forming the centre of the shrine. The long pieces of gneiss are regarded as male, while oval ones are seen as female. ${ }^{84}$ The base stone for the shrine of the god of the house is integrated into the wall of the entrance room and accompanied by a beer libation celebrated by the family elder of the new father of the house.

A newly built house might comprise in addition to the ńngala only three core rooms plus a hucéd (kitchen) at the end. These rooms are usually a first dzadzaw (father's room), a hudokw ngwaz (granary for his first wife) and a huzhéb (main granary). A gwarbay for drying the harvest might be erected to mark the var ma gay (front court yard). A gurdede (store room) to germinate sorghum for beer making with an integrated goat house might also be built. The space between the free standing gurdede and the string of core rooms would develop later into the dalala (inner court) and so would the tobacco garden behind the kitchen. The inner fields (gad ma gay = head of my house) of the new compound would be regularly fertilised with manure and over time the new house would hopefully grow into a place which displays all the features of a well established traditional family home.

\section{Getting a "spirit of the house"}

Before a freshly married couple can move into a newly built house they have to organise the welcome to the "spirit of the house". After a vigil by a postmenopausal woman and some boys and girls who have been invited by the father of the house to attract a good house spirit, husband and wife are permitted to move in the following day.

However, there are varying rules about moving into a new house, depending on whether it is after a primary or a secondary marriage. In the case of a first marriage it is the wife who will spend a night in the new house together with her best female friend before her husband can move in. Her friend will install the future fireplace and prepare a first meal for her. In order to do so, she will arrive with a few cooking pots and various types of vegetables. The husband arrives the following day carrying his gad pats (personal spirit pot) and will install it underneath the top end of his bed. His wife will bring her personal spirit pot as well.

A few weeks after the freshly married couple has moved in, the father of the house will ask his wife to prepare her first sorghum beer to be used for a religious celebration called zom nngwece ma gay. The word nngwece means to make a "trace" or to set a "sign" and refers to the blessing of the new house. A libation is carried out by the tsava (elder) of the new father of the house. Neighbours, mostly relatives, are invited to attend and the elder comes and pours some of the beer

\footnotetext{
${ }^{84}$ Mafa like to attribute gender to rocks found in sacred sites according to their shape, although all stones or rocks can be referred to as ngwaz kwa (woman stone) if they are round or ńngura kwa (man stone) if they have a longish shape.
} 
on the floor of each room. It is significant in this context that it is the beer of the first day of preparation. This beer is called man manda besl or ziy wéshém meaning "beer without labour" which refers to the nature of this beer as being still unfermented and therefore tasting very sweet.

The family elder pours some of the sweet beer onto the roots of the tree next to the house, which is going to serve as new family shrine. He also pours beer over the zhigilé gay (god of the house) for which he has provided the base stone, and over all the sacred pots the father of the house has installed so far. It is unlikely that the newly married man already owns ancestor pots, but he will surely have a shokwétév (pot of the spirit of sorghum) and a zhigilé cived (god of the road). After the beer libations are carried out the tsava (family elder) sacrifices a cock to the room of the wife and to the front court, which involves blood being poured onto the ground. While the sacrifice inside the house only allows participation of close family members, the sacrifice in the front yard takes place under the eyes of all the neighbours. The cock slaughtered in the court yard will be prepared and consumed in public and in daylight, while the cock which has been slaughtered in the wife's room will be consumed later in the evening and in private. After the public meal in the front yard, fully fermented beer will be provided for public consumption to celebrate the founding of the new family home.

A few days after this celebration the tsəva will come again and sacrifice a goat. The sharing of the goat takes place in the wuram (large oval wooden bowl) and the tsava keeps almost all the meat for himself. During the slaughtering he does not separate the throat from the ma zhigile (stomach) of the goat but subsequently carries it placed together with the meat in the wooden bowl to his own house. Once the tsava has received the goat, the new father of the house is free and can now independently carry out all sacrifices which concern his family including his future children. There are some exceptions which will be discussed later.

\subsubsection{Inheritance of land}

The fields nearby the house are very important. We have already mentioned the galiy taba (tobacco garden) behind the kitchen. Tobacco is either consumed as snuff or smoked in iron pipes and is a very precious gift or item to share. Tobacco is also a very important element of ritual and is offered to family ancestors. Snuff is put together with intestinal contents, taken from a sacrificed goat, on ancestor pots as a base for a beer libation to a late father or grandfather. The tobacco garden is not really a field, but due to its social and ritual importance it is described as such in this context.

The fields near to the house (the inner fields) consist of three types. The most fertile field nearby the house is called gojeved, which is the field where the ashes of the house are disposed of. The other inner fields are referred to as gad ma gay, which can be translated as "fields near to the house" and vurziy-dak, which can be translated as "fields away from the house". The word vurziy means literally "testicle", while $d a k$ is the general word for an outer field. The fields in the plains are called dak vara $($ vara $=$ plains $)$.

The use of the word gad ma gay for the actual inner field refers to the father of the house as individual owner. It is near the house and a man takes pride in maintaining this field. Most manure is brought out to the inner field to keep it fertile. Mafa do not have a general word for fertility but use the expression hakeda ńruba'a (hakeda $=$ soil or earth, ńruba $=$ soft) if they want to refer to a good soil. The expression vursiy dak for the fields found in some distance of the house is nevertheless an indirect reference to soil fertility, although the word vursiy is only used to refer to the fertility of domestic animals (vursiy sukwiy mbela'a $=$ testicles of animal are very good). The reference to animal fertility as part of the name for a field could well be interpreted as an expression of hope for enough manure to keep this field fertile. 
The Mafa expression for inheritance is nndiy giy, meaning "eating the house". If a father dies his oldest son inherits those sections of his father's inner fields which contain a sacred site and all his father's goods. It is the youngest son of a group of full-brothers who inherits all the goods of his mother, which mainly consist of chickens and goats. He does not necessarily retain them but distributes them among his brothers. However, it is his right to decide who gets what from his mother. With regard to a father's goods, which also include the father's house, it is the oldest son who has the right to distribute these among his brothers. However, he will always give the first share to his most senior half-brother.

A father normally distributes land to his sons when they get married. If the father dies before all his sons are married, it is his oldest son who takes on this role. However, he will never give the land with a sacred site to his younger brothers. It is always the most senior brother after him who inherits that. This rule applies regardless of whether the next oldest son is a half or a full-brother.

The situation is different with ordinary land. If two pairs of half-brothers have received land to build their houses and have established their inner fields and then one of them dies, it is the remaining full-brother who will inherit the land. In the event of the middle brother of a group of three full-brothers dying, it is his next younger brother who inherits his inner fields. The reason for this is that it is always the youngest of a group of brothers who is considered to have the greatest need for land. This is also the reason why the oldest son of a deceased father might leave the father's house to one of his youngest brothers to live in. He might also leave his father's inner fields to one of his youngest brothers, although the oldest brother always remains responsible for any sacred site on them.

Getting married for the first time means that a man has to rely either on his father or on his eldest brother to get the land donated to him. If there is not enough land available in the family, the younger sons can be left behind without sufficient resources. This problem was often resolved in the past in such a way that those joint families which did not have sufficient land would ask other local kin for land. Such transactions would preferably take place within the social framework of the gad bulom (minimal lineage). Another solution might have been that a young man would settle at his mother's brother's place. A third solution consisted of getting a traditional lease on a piece of land in the context of a special relationship which existed between particular local clan groups. I discuss the concept of ńshibene as a representation of such a relationship at the end of this chapter.

\subsubsection{The birth of a first child}

The birth of the first child is a great event but there can be complications. One could be that the freshly married women is daray (sterile). Sterility is a serious issue for a woman and often leads to divorce and a repayment of the bridewealth by the father. For a man, the problem is quite serious as well, although an escape route exists for him. Once he finds out that he is sterile he has the chance to adopt a child or even to discreetly ask another man to sleep with his wife. However, the wish to have children is of course central and if a man can afford it he will soon marry a second wife so as to increase the size of his family.

We have seen above that it is important during the wedding ceremony to find out whether the first child of the father of a man is a girl or a boy. Mafa always wish that the first born child is a boy since this facilitates life in general. If the first born child is a girl the threshing of sorghum can only be done by night otherwise the corn might suddenly disappear from the granary. Whether the first child is a boy or a girl also plays a role during the harvesting of sorghum. In case the first born child is a girl two corn stalks are left uncut near the house and if it is a boy three corn stalks remain. Mafa call that ńzléb ray (ńzléb $=$ enclose or bind, ray $=$ hand) and want to prevent the 
sorghum from mysteriously disappearing. Another way of preventing the disappearance of the sorghum is to bind two (for a girl) and three (for a boy) strings of sorghum fibre around the tree which functions as the house shrine. These can only be removed after the sorghum has safely entered the father's main granary. Since the number "one" remains invisible in Mafa ritual counting the end result comes always out to be odd for female and even for male.

\section{Conception and pregnancy}

Mafa do not believe that sexual intercourse is the only cause of conception. If the personal gods of husband and spouse do not have children the couple will not have children. The personal god of a human (zhigile ndo) is as a male or female deity and as such a "child" of God and his wife. If the personal god is sterile how could the person this god is there for have children? This means that it is God who decides beforehand whether a baby is going to be conceived through sexual intercourse or not. Mafa express this procreational belief by saying that God himself slept with the woman. The religious thinking of Mafa extends such a possibility to other spiritual agents. It is the water spirit, in particular, to whom they like to attribute such a capacity. For example, when a women who walks by a river and afterwards becomes pregnant, it is believed that the water spirit slept with her. If a woman gives birth to twins it is a certain belief for traditional Mafa that the water spirit has made love to this mother.

Mafa believe that a woman is most fertile during menstruation ${ }^{85}$ because it is the blood which forms the child. A woman who does not not menstruate cannot conceive. This is most obvious in the case of a prepubertal girl or a postmenopausal woman which is seen as proof that menstruation is a sign of fertility. However, if a Mafa woman gets pregnant without menstruating her husband is at risk of death. ${ }^{86}$ Although female menstruation is seen as a sign of fertility a man is not permitted to have sexual intercourse during this time since a menstruating woman is seen as being impure. However, pregnancy is thought to be most likely to come about if intercourse takes place immediately after menstruation. Mafa say that due to the fact that there is always menstrual blood remaining in the body of a woman conception is also possible at other times between the periods. It appears to be a contradiction in terms that Mafa see women as being most fertile during menstruation but also consider them to be impure at this time and therefore, at the same time, avoid them. ${ }^{87}$

A menstruating woman is somehow taboo. During menstruation a woman is not allowed to hand her husband his food. In the past to do so would have meant he would run a great risk of being killed during tribal warfare. ${ }^{88}$ During menstruation, she stays at home most of the time, her husband avoids direct contact with her and she is not allowed to have contact with male visitors who have traditional priestly functions. A menstruating woman is neither allowed to brew ceremonial beer nor beer for ordinary consumption or for sale at the market. Mafa men comply with this prohibition from contact with a menstruating woman.

Avoidance rules exist not only for menstruating women but regarding sexual intercourse itself. These are mostly in relation to cultural goods of high religious significance. After a man has had intercourse with his wife he is not allowed to take sorghum out of his granary for the day after

\footnotetext{
${ }^{85}$ Kosack (1997:380) points out that, according to Mafa, a child is conceived in menstrual blood and concludes that this is why Mafa believe that a woman is most fertile while she has her period.

${ }^{86}$ Kosack (1997:381) points out that such a new born child gets its earlobe pierced in order to extract some blood. The blood is dribbled over a broken calabash piece and the father throws it away by moving his left hand anti-clockwise around his head.

${ }^{87}$ The question can be asked whether a Mafa man indirectly expects that a woman could conceive inappropriately if she was allowed to be in contact with sacred sites or religious objects while she has her period.

${ }^{88}$ Kosack (1997:380).
} 
because he is temporarily impure. He is also not allowed to have intercourse during the period he is threshing his sorghum or during times of important ritual tasks, like carrying out ancestor ceremonies. The risk of falling ill or even dying as a result of breaking the prohibition is one of the reasons why Mafa often say that they would not want to be a biy $d z a$ (mountain priest). They say, for example, that mountain priests take a great health risk. The word for impurity is sak, which means foot. Mafa are of the opinion that impurity arises from crossing the path of someone who is impure. Menstruating women and inappropriate sexual intercourse are the most common causes for impurity. Men who have been knowingly or unknowingly in touch or confronted with these should not carry out priestly tasks.

Kosack (1997:381) informs us that Mafa women consider a child to be a being in itself as soon as they discover that they are pregnant, which is usually about a month after the last period. When a woman discovers that only a little bit of blood is clotted in a delayed period she already counts this as a child. If a woman dies during her pregnancy the foetus or embryo will be buried separately from her. In case of a miscarriage the embryo is buried like a newborn baby which has died (op.cit.). A pregnancy is a very risk-laden time for a Mafa woman. She is obliged to always inform her husband where she goes and she is not allowed to leave the house during the night. After about seven months of pregnancy she cannot be involved in harvesting, grinding or cooking sorghum. A pregnant women is not permitted to visit her parents since she would risk losing her child, since the in-laws of a man are seen as potential enemies. ${ }^{89} \mathrm{~A}$ husband of a pregnant women often consults the stones (pebble divination) to establish whether a risk is involved if his wife visits her affines. Kosack (1997:382) quotes a case where the "stones" advised a Mafa woman to produce a pregnant clay copy of her personal god to prevent frequent miscarriages. This example indicates that the "stones" had identified that her personal god had miscarriages, which was the hidden cause for her having miscarriages as well.

\section{Birth and naming}

Kosack (1997:430) writes that birth is the moment of truth for a woman. If she had betrayed her husband or shown disrespect for her husband's kin in any other way, the child would not be born unless the misdeed had been brought into the open and dealt with. If the baby kicks the mother on her 'right' side it will be a boy, but if this happens on the left it will be a girl' (op.cit.). If a woman gives birth during full moon it will be a girl. For Mafa it is particularly important whether the first born child is a girl or a boy and it affects many ritual tasks, especially in relation to the ritual handling of sorghum. Sorghum can disappear or "walk away" over night if such rules are not respected. It is always more complicated for a man to handle sorghum if the first born child is going to be a girl.

It is the ngwaz ngwazla (blacksmith's wife) who functions as midwife. She is born differently (nya'a) from the majority of vavay (non-blacksmiths) and therefore adept at handling a risk-laden situation like giving birth. She not only has the technical but also the mental capacity to support a woman when she goes into labour. As soon as the child is born the placenta is taken out of the house and only then can the ambilical cord be cut with a knife made from a millet stalk. Next the placenta is buried by the midwife behind the house and so marks mposokw, the place of birth.

The new born baby is not breast fed straight away but some warm water is given to it to drink first. If the child is a boy, one of father's meat pots is used to bury the placenta in the ground. If it is a girl, the mother's cooking pot is used. If available, fresh corn or millet leaves are put on top of the placenta pot which is buried upside-down into the ground. Every newborn child is

\footnotetext{
${ }^{89}$ Lack of arable land and population pressure is one explanation why neighbouring villages were potential enemies. The history of tribal warfare in the area of Gouzda (see Chapter 4) proves this point.
} 
supposed to have its own placenta pot. The umbilical cord is kept in the house till the naming day, which takes place about a week later. Between birth and naming day the baby is not allowed to leave the house. During this time no family member is allowed to give anything away or to offer any food to neighbours since everything is considered to be "new" in the house. To do otherwise would seriously risk the baby's life and the fertility of the mother who is not allowed to cook for about two months.Also fire cannot be given out of the house to neighbours during this period (op.cit.:435).

On the naming day the baby is taken out of the house. If it is a girl the family has to wait till sunset. A meal is shared between the visitors (neighbours, friends and relatives) with sesame, if it is a girl, and with okra, if it is a boy. The umbilical cord is placed with some of the food and ochre on a piece of calabash. The midwife pierces the placenta pot with an iron sickle and places the cord in the resultened hole. ${ }^{90}$ No-one other than the mother has been allowed to touch the umbilical cord. Next the mother comes out of the house together with the baby. Then the father gives the first name followed by the mother of the mother and father's mother, who give the second and third names respectively. After that, neighbours and friends can also join in and give names. The father often consults the stones (pebble divination) before he decides which name he wants to give (op.cit.:438).

Hinderling (1984,III:311) informs us that the naming day is also the day when a newborn child receives its first gad pats (personal spirit pot). It is the ngwaz ngwazla who manifactures it in her function as potter and brings it on the day she buries the umbilical cord. It is from this day on that the child is perceived as a person in the full social sense. The personal spirit pot is only a few centimetres in diameter and has primary or secondary sex characteristics to identify it as male or female. Receiving a name and a personal spirit pot marks the social transition of a newborn baby into a recognisable member of a family and is a precondition to eventually getting married and becoming a mother or father. Only if the new member of the family ultimately has children, boys in particular, will there eventually be a chance to become a male or female ancestor. The personal spirit pot will then be replaced by an ancestor pot. If the new member dies in childhood, which is often the case, it will have to rely on the family members in the world beyond who had the chance to become ancestors.

If twins are born, special precautions apply and the "stones" have to speak in order to establish which ritual actions are necessary. Possible precautions are taken so that the time the newborn twins are kept inside is extended, or special measures applied in relation to the burial of the placenta and the ritual placing of the umbilical cord. In any case a halalay (a special twin pot) is ordered from the ngwaz ngwazla and kept by the father under his granary. The twin ceremony takes place during the month malama which is when vavay neither marry nor perform ancestral ceremonies, while ngwazla find this their most favourable month.

About a month after birth the heads of the mother and baby are shaved. It is only after this that her husband is allowed to take food from her or to have sexual intercourse with her. The hair of the child is kept under the granary. Twins are only shaved when their first twin ceremony takes place, which can be years later.

\footnotetext{
${ }^{90}$ Godula Kosack (1997:439) explains that the hole is made to allow the wind to enter the pot so that ' $n$ shefè' which she translates as 'soul' could enter the head of the child, but to my knowledge the word ńshefe means breath while the word for soul is mezheb meaning "shadow".
} 


\subsubsection{Transforming through death}

A newborn child receives a personal spirit pot not on the day of birth but about a week later, on the day of naming. The Mafa distinguish between three personal spirit pots: gad pats nngura (spirit pot of a man), gad pats ngwaz (spirit pot of a woman), and gad pats wudahay (spirit pots of children). The role of paternity and the handling of religious matters are socially linked. It is married men who primarily take care of the spiritual aspects of a person, a responsibility which begins with his own children and if he is or remains the eldest living son, he will one day be responsible for his father's ancestor pot. Apart from seniority, it is his place of residence which has importance for him in becoming responsible for the ancestor pot of his late father. He needs to live in his father's neighbourhood, otherwise he cannot carry out the ceremony. It is part of the funeral rites of a deceased father to become an ancestor. The following section describes the process of how a father's mezheb is transformed after his death into an ancestor spirit.

\section{Establishing the cause of death}

Traditional Mafa believe that the ancestors of a man appear intermittently in his dreams some time before death and that they arrive again immediately before death to lead the way into the world beyond. As soon as the death of the father of a family has occurred, the family members leave the house and begin the period of grief marked by public ululating and lamentation so that everybody knows what has happened. Next we hear an iron trumpet being blown and the beginning of drumming. Neighbours come to condole with the family and join them in expressions of public grief, performing funeral dances and beating the large drum of the bull festival. The eating bowl of the deceased is smashed on the path in front of the house and his mat is taken outside and thrown on the road.

The family members are not allowed to drink or eat until the ngwazla (blacksmith-undertaker) arrives. As soon as the ngwazla arrives, the eldest daughter of the deceased takes him inside the house where water mixed with some sorghum flour is given to him and he eats a small portion of porridge and sauce. He then examines the foodstuffs in the house and after he has established that nothing is poisoned, the family is allowed to eat as well.

Next the public grief is silenced and the blacksmith performs a sequence of pebble divinations inside the house to establish the cause of death and whether any further deaths can be expected in the village. Mafa refer to this particular divination as kwa mérézh. The word kwa means pebble while mérézh refers to the tree behind which the deceased is believed to hide after the occurrence of death. Each family member is examined three times and in the case of two positive answers it then becomes clear who is responsible for the death. Quite often it is one of the spouses of the deceased but it can also be somebody else from outside the family home. As soon as the responsible one is identified the blacksmith begins to establish which sacrifice is needed to appease the deceased. This can be a chicken or a goat. As soon as the sacrifice has been carried out public grief starts again outside the house.

The skin of the sacrificed goat is used to cover the face of the deceased who lies in his dzadzaw (father's room) while the ngwazla receives the meat. Throughout the funeral it is the ngwazla who will receive all the meat from sacrifices, the majority of which the vavay believe to be sak (impure). If a vavay were to eat funeral meat (even unknowingly) he would be considered as ngwazla which would render him endogamous straight away. Eating funeral meat is considered by non-blacksmiths as anthropophagism but blacksmiths have no problem with this at all. Funeral meat is their payment and since they are nya'a, eating funeral meat does not hold any risk for them. After the blacksmith has received a calabash of sorghum beer in addition to his payment he goes home. 


\section{Vengeance of the deceased}

Friends and neighbours of the deceased will come the next morning to take revenge for the deceased. They carry grass helmets, large shields, lances and bows and arrows. In the past this could lead to combat with a neighbouring settlement, often one with which marriage relationships also existed. Among the Mafa the exchange of women between neighbouring kinship groups and the rule of exogamy often coincided, in the past, with traditions of warfare between such groups. Apart from the physical reasons for competing over resources like land and women, metaphysical reasons are also at stake here. Women are exchanged under the rule of neighbouring patrilineal groups controlling not only the fertility of the land but also that of women. However, the women are not completely under the physical and ritual control of the patrilineal group although the land is. They still have ties with their patrilineal relations and often benefit from ritual occasions there and Mafa often remark that they marry the daughters of their enemies.

On their return each "warrior" puts a piece of bark from the wuma tree (Bauhinia reticulata) on the roof of the ńngala (foyer) of the deceased to signify that revenge has been successfully taken. The wuma tree often grows in boundary areas between settlements and the warriors would break off its bark and attach it to their arrows. The wuma tree represents the good luck to survive in a war and its fibre was once solely used to produce a man's gwadama (quiver). If someone killed another in tribal war some wuma fibre was bound around both his wrists and his forehead. The slain person could have been a potential in-law. When vengeance is complete the elder brother of the deceased opens the roof of the dzadzaw (sleeping room) of the father to signify that the proprietor has died. One of the younger daughters now opens the roof of the hudokw ngwaz (room of his first wife).

Vengeance has the dual purpose of avenging the death of the deceased which might have been caused by sorcery connected with the patrilineage of his wife and also of preventing further death or disease to enter the neighbourhood. The pebble divination performed the day before by the blacksmith might have indicated that one sacrifice was needed in the house of the deceased and another at the sacred site of one of the neighbourhoods of a village association. This means that death is something which affects a local community as a whole not only in terms of public grief, but also in terms of public defence. The hidden causes of disease are considered to be the most difficult to handle.

\section{The actual burial}

During the day of vengeance, the blacksmith's helpers dig the grave (dzavay). Depending on the social position of the deceased, this might be in a cemetery for an important man of his kinship group or a place in the inner fields of his joint family where his father has already been buried. At the same time the ngwazla begins to prepare the deceased for the shroud of a bull hide he is going to be wrapped and sewn into. If the deceased was not wealthy enough then goat's skin or even leaves can be used. Again, the meat of the bull belongs to the blacksmiths who share it among themselves after the funeral.

During the procedure of covering the deceased, he is laid out in the passage way connecting his dzadzaw and his hudokw (sacrifice room). This is a passage way which is less dark than the inner room and here a traditional man often counts the number of shadows he throws when establishing whether a component of his spirit is missing. This would mean that he is at risk of dying (see Chapter 2.3). Sewing a dead body in a fresh bull's skin is hard work for the ngwazla and might take a few hours. While this is being done, the public grief (singing of laments, drumming and dancing) continues outside the house but stops as soon as the blacksmiths have completed their task. 
The deceased is now carried out of the house and sited on the ground of his var ma gay (front court yard). The smell of the deceased body is less intense now and it no longer looks like a human being but rather like an ape. The body is entirely sewn into the bull skin with only the hands and feet still visible. The blacksmith then binds a piece of white cotton around the forehead and the children of the dead man are asked to sit between the legs of the deceased while the blacksmith supports his back in an upright position. This gesture means that the family is saying farewell to their father.

Now sorghum beer is distributed for public consumption. Some of the non-chiefly Mafa clans have a pseudo-clan relationship to each other which they refer to as ńshibene. This signifies that they do not marry each other's daughters which demands the exchange of funeral beer. It is often at this moment in time when such beer is consumed as well.

Next the ngwazla get ready to carry the deceased to the tomb. The deceased is lifted onto the shoulders of one of them and holding firmly onto the ankles he runs away from the house towards the grave. The maslay (best friend) follows with the personal objects (tobacco pipe, bonnet and goat hide) packed in a calabash. The deceased is placed inside the tomb and arranged in a sitting position. His personal belongings are placed around him. These include the pot hordodo he used for the fermented fat and ground bones of the last maray (bull) he sacrificed. There is a corn stalk to represent his weapons, a piece of string he used for oaths, the handle of a hoe and a besom for cleaning his house in the world beyond is also added. Then his eldest daughter throws a piece of earth into the grave and the blacksmith closes it.

\section{Chasing the deceased}

Public grief continues for several days when the ngwazla comes back to conduct a final pebble divination establishing whether the deceased is satisfied with his burial. If the stones say "no", more sacrifices (chicken or goat) have to be carried out until the father is satisfied and the stones say "yes". Mafa refer to this ritual as mmbel ndo (chasing the deceased). A fire has been burning next to the manhogany bed of the father since his death. As soon as it is established that the late father will leave his family in peace, the blacksmith places a piece of wood into the fire.

Preparations are then made by the blacksmith to shave the heads of the family members and the maslay of the deceased. The actual shaving takes place on the way to the grave. The blacksmith places his divination stones next to the spot where it is done. After the heads are shaved, porridge and sauce brought by visitors is served. The blacksmith is obliged to eat separately from the rest of the family. Next, sorghum, brought by neighbours, is put in water to germinate ready for funeral beer. It will take several days before the beer is ready.

Now the blacksmith takes the burning piece of wood he has placed in the fire earlier and puts it on the path where the shaving took place. The blacksmith's helper follows him with a basket filled with sorghum and groundnuts. As they pass by neighbours and other visitors outside the house a last outbreak of public grief takes place. The daughters of the house, carrying their father's sacred pots, follow the blacksmiths to the place where the heads have been shaved and all items are deposited halfway to the grave. This marks the end of public grief.

Several days later, when the sorghum beer is ready, the blacksmith returns to taste the beer. The personal spirit pot which has not yet been deposited will serve as a provisional spirit pot for the deceased father and the blacksmith will guide the hand of the oldest son as he carries out a beer

libation. During the libation, the late father is asked to allow his family to live in peace. Next the oldest daughter takes her father's bed (a mahogany plank) under her right arm and follows the blacksmith, who carries the sorghum beer, to the place halfway to the grave. The blacksmith orders the daughter to wash the bed with water, beer, ochre and mahogany oil. 
The mahogany bed is then brought back into the house and placed, supported by a new pair of stones, in the late father's dzadzaw. If the deceased has sacrificed a maray, a piece of fibre string from his dzadzaw and his wives hudokw are fixed together and used to repair the open roof of his room. On this day the drum used during the funeral party is brought back into the house. From this day on, the wife (or wives) of the deceased are free to remarry. If he had a young spouse who had her first marriage with him and has not yet borne a child, she can return to the house of her father. Her father can now also ask the oldest son of the deceased to return the bridewealth.

\section{Becoming an ancestor}

A couple of months after the burial the ncék daf sagam (meal for the ancestor to be) is prepared and the pot kéléhed (a small sauce pot) containing some of the meal is placed alongside a calabash of water, near the bed of the deceased. After a while, a mouse appears and eats from the meal offered to him. Mafa refer to this mouse as kwam sagam (mouse of the ancestor to be). Some sorghum beer is placed on the way to the grave and the same mouse is believed to go and drink from this beer.

Apart from the wives and sons of the late father the other participants in this ceremony include the blacksmith-undertakers, the married daughters, the best friend and the person who received the sirloin piece (zayi deba) of the sacrificed bull. If the deceased does not eat and drink, the blacksmith asks the "stones" again to find out which additional needs the deceased might have. A repetition of a meal for the ancestor is also referred to as mmbel ndo, meaning chasing the deceased. It might be a chicken or a goat which is offered to finally chase the deceased. After the sacrifice has taken place the participants wait again for kwam sagam to eat and drink. As soon as the deceased father has consumed, the blacksmith collects the pot kéléhed and takes it home. If the deceased is a woman the meal would be offered in a calabash.

A few days later a new beer is prepared. In the meantime, the new ancestor pot for the late father has been produced by the blacksmith's wife and delivered to the house of the oldest son of the deceased. The same people who participated at the initial "meal for the ancestor to be" arrive again. The oldest married daughter brings a goat and a cock to be sacrificed for the baba. The elder (tsava) of the son comes as well to introduce him into his duty as ancestor priest. First the cock is killed and the blood is poured over the new baba pot. Then the goat is killed in the hudokw of the son and some of the contents of the goat's intestines is handed by the oldest daughter to her brother who smears it onto the back of the ancestor pot. Next the son takes some tobacco and scatters some on top of the intestinal contents. His tsava now pours some beer from the new baba pot into a calabash and then balances the calabash on top of the intestinal contents and tobacco, leaving the calabash to balance freely. When the calabash stands freely without support on the back of the pot he takes the calabash and pours some beer on the ground of the dzadzaw of the oldest son. In doing so, he prays on behalf of the son: "My father, give us your blessing and make that freshness is with us and heat and illness disappear." is filled by the elder and handed over to the oldest son who repeats the same ritual.

When the oldest son has successfully completed his first baba ceremony, he is free to make an offering to his deceased father whenever necessary. Mafa believe that whenever a son performs this ritual his late father appears in spirit and stays next to him. Other relatives and friends from the world beyond accompany the deceased father but they are believed to stand behind him in order to assist. The deceased father stands in front because the offering is for him.

\footnotetext{
91 The Mafa words for this prayer are: aya halaw a baba ga, ka kalngaya ava ndohiy ngidehiy which means "Okay my father, you too have left now to live with the people of the other world," followed by the words aya guc ka nga yam a ga nga lang-lannga'a ma keluwd kwa, meaning: "Okay, let's sprinkle water, this will refresh you."
} 
This final phase of a traditional funeral is called mpiy baba a ray, meaning "introduction into the ritual handling of father's pot." During this introduction or ritual handover all members of the family, including the married daughters, are allowed to be present. In future ceremonies the married daughters of the new family ancestor have to wait outside the house, while the rites are carried out. This shows that married daughters represent a very important link between consanguineal and affine relationships. Such social bonds represent potential alliances between exogamous kinship groups and it seems that the daughter plays a crucial role in repairing these potential links which have possibly been put in jeopardy by the role of her mother as the wife of her deceased father.

The role of affinity in the social construction of political alliances cannot be underestimated in Mafa society. We will see in the next section, about understanding ritual activities in the wider community, how the exchange of women between chiefly and non-chiefly clans of a village mirrors this fact. It could be argued that the Mafa are keen to stress the ritual independence of the father of a house as the representative of the nuclear family (as the patrilineal cell and epitome of Mafa religious understanding of procreation) because they have been so successful in forming alliances. This view is reinforced by the fact that the oldest married daughter brings the goat from her husband's house to provide the intestinal contents for the son to demand fertility for his land and family.

The independence of the patrilineal group in the face of political alliances, controlled by chiefly clans, is rooted in the ritual handling of ancestor pots. The family model of ritual dependencies also serves as a model for political roles important in the wider community. We will see in the next sub-section how the patrilineal family metaphorically distributes political roles in the form of chiefly representations in the context of family rituals.

\subsubsection{Ritual handling of ancestor pots}

The Mafa word for a religious sacrifice involving sacred pots is varay while the word for sacred pots itself is mbut. For the re-enactment of history male ancestor pots are of greater relevance than female ones, although affinity is a crucial relationship in terms of marriage and the formation of political alliances. It seems that even though women are major pieces on the chessboard of Mafa political culture the end game is all about male control over the reproductive capacity of women. Women are socially "owned" by their fathers and husbands, who also own the land and domestic animals. The only ritual powers women exercise as mothers is over the personal spirit pots of their daughters while they are young and then later as married daughters when their deceased father becomes an ancestor. As soon as the father is established as family ancestor, the mother is excluded from the actual ceremony. In her role as wife she has become a member of her husband's family and participates there inside the house when her husband's late father receives an offering.

\section{Intestinal contents and blood}

After zom (sorghum beer), shuwed (intestinal contents) from sacrificed goats and pambaz (blood) are possibly the most important religious items to feature in the ritual handling of ancestor pots. The ritual significance of animal faeces is derived from the importance of manure to the intensive agricultural system of the Mafa. However, the manure Mafa use on their inner fields is mainly from cows rather than goats. This question is intrinsically linked to the fact that only bulls are sacrificed but never cows, although bulls are less important for the fertility of land. 
Unlike the bull, the cow gives calves and the transaction of calves has a long tradition ${ }^{92}$ in Mafa society. This is changing now with the introduction of chemical fertiliser and a market-orientated economy. A similar change is developing in the context of marriage payments, where goats are being increasingly replaced by money. The following account on the transaction of a calf is therefore more or less a reconstruction of how it was done in the past.

A man would hardly ever sell or slaughter a fertile cow. To exchange a calf he would have to find a third person who would function as an intermediary and who would be referred to as maslay, who is a kind of ritual friend in the context of such a transaction. At first eight goats would be given to the owner of the cow in exchange for a calf. The maslay would perform the transaction and receive a chicken, natron and tobacco as payment. The new owner would give the maslay a bundle of herbs and ask him to bless the calf so it will be fertile. The maslay would now spit over the herbs and say: "God, make the calf bear twin calves or give a calf every year." A few months later the maslay would come again with the owner of the cow, but this time to drink sorghum beer (zom) and receive gifts in the hopes that the calf would soon give birth. About two years later, the owner of the cow would return and if the transaction has been successful he would receive one additional goat ${ }^{93}$ as well as the first born calf, but the next calf would belong to the new owner.

We see from this example that the payment for a successful exchange of a calf is nine goats, the same number as in a marriage payment. Although it seems that a calf and a daughter are equal to nine goats, it is fertility which is at stake here. Men need to acquire the reproductive capacity of both cows and women. Neither their land and domestic animals nor their families would prosper without fertility. Transactions of fertility as a good can lead to wealth, but only if all conditions are fulfilled. One of these conditions is that women, being the "good" most sought after in terms of human fertility, are not allowed to perform sacrifices and, in the same respect, cows cannot be sacrificed for the sake of animal or land fertility. The only female animals used for sacrifices are goats and chickens. Goats are the most general means of exchange used by men to acquire fertility, which then in turn can lead to wealth.

We can conclude from this that although goats would not be sufficient to keep the terrace fields fertile, their intestinal contents nonetheless have a very high symbolic value as a representation of something which is most wanted - fertility! This is why I believe it is applied to the ancestor pots after a goat has been sacrificed. The other item of course is blood.

Blood also represents fertility - not so much the fertility of animals and land but human fertility. As we have seen from the section on birth, Mafa believe that a women is most fertile while she is menstruating. During the time of menstruation she is avoided by her husband especially for religious reasons and is perceived to be impure. If he wants to perform a sacrifice to his late father, he has to abstain from sexual contact during those times. Sexual intercourse and religious activities exclude each other. The same applies to certain agricultural activities in particular that of the handling of sorghum and bulls.

This means that sexual activity cannot be indulged in while a man makes spiritual contact with his ancestors and prays to God to provide him with wives so that children can be born to him. For Mafa men procreation is in substance perceived as male, which involves praying for fertility by excluding women. In terms of cosmology and gender, women are represented by a religious image of God's wife as a metaphysical entity, being rather form than substance. They can be the receivers and carriers of fertility but not the creators. The same applies to men, although they are in terms of gender perceived to be much closer to God. It is God the father, not individual men,

\footnotetext{
92 Van Santen \& Schaafsma (1999:427-446) argue that cows only recently gained symbolic and economic importance in Mafa society, a view I cannot agree with.

${ }^{93}$ When the first calf is a bullock the new owner would have to give a he-goat plus two additional goats.
} 
who is responsible for the creation of new life, which renders fertility a metaphysical issue. Transforming the blood of sacrificed animals into a plea for fertility from God is a purely male affair and any interference from women would pollute this ritual.

If traditional Mafa believe that children are born in blood and that blood is a symbol of human fertility, women being perceived to be most fecund during menstruation, why is it then that women are made so exclusive (or untouchable) during that time? This question brings us straight back to sexual intercourse and the fact that it is not allowed during menstruation. Its avoidance might have more to do with the relationship between a human father and God the father. It could be argued that a man is not allowed to make love to his wife during the time when only God has the right to "sleep" with her. All that is left for him to do is to sacrifice blood and to pray to his ancestors and God in the hopes that he will receive fertility in exchange. The blood of a sacrificed chicken or goat, therefore, seems to become a religious justification for a social organisation based on patrilineal descent. ${ }^{94}$

During a sacrifice, blood is poured, by the father of the house or by his family elder, on the ground and all the religious objects in the house. This would be especially the blood of a chicken, which is used to pour directly onto ancestor pots while the actual sacrifice takes place. After the chicken has been killed its liver is offered up because Mafa believe that God likes the liver most. The liver is roasted and shared among the participants. All this is performed by the father and his sons in the father's $d z a d z a w$ while the wives and unmarried daughters have to be separated in a granary further inside the house, but they too receive their share.

The purity of a man who sacrifices to God and his ancestors is also displayed in his mental attitude. His mind is rendered pure by abstaining from sexual intercourse or performing a sacrifice while one of his wives who is menstruating is still in the house. The dangers involved in handling the metaphysical elements of fertility are great, which is the reason why Mafa say that somebody who becomes a mountain priest should be pure in mind. This ideal cannot be achieved by everyone who is responsible for an ancestor pot of a late father. However, there are exclusions for oldest sons, for example, if they have committed incest (sleeping with a brother's wife would be considered as such) or if they do not live in the neighbourhood where the late father's placenta has been buried.

\section{Tobacco and natron}

After the goat or chicken is sacrificed and the blood and intestinal matter are applied, the father of house takes a piece of natron and offers it to his late father by putting it over the blood and the intestinal contents on the pot. At the same time he speaks to his late father and tells him that he is making these offerings to him. He then takes his tobacco horn and fills his hand with some of the tobacco. More tobacco is then added by his younger brothers as well as by their sons. When his left hand is full he puts it with his right hand on top of the contents of the intestines and the natron and tells his late father that this is for him.

Tobacco is a good of great emotional value. Sharing tobacco is not only a male but also a female activity although in religious context a woman is not permitted to offer tobacco. The tobacco is given by the son to please the late father in order to make him content to intervene from the world beyond and confer with God and his children on his behalf to receive the freshness of new life and to keep the heat of disease away. This request includes all male descendants and their families of a particular deceased father.

\footnotetext{
${ }^{94}$ I here paraphrase Fredrik Barth (1987:13), who makes this point when exploring ideas of descent and conception.
} 


\section{Libation and balancing the calabash}

The zom (sorghum beer) for the baba ceremony brewed by the first wife is poured into the $b a b a$ pot the night before by her husband, the father of the house. During the night the zom unfolds the mysterious qualities of nya' $a$ sorghum is "born" with so that it is ready on the day to be offered to God and the late father. To make zom takes four to five days. First the grain is put into water to germinate. The water is changed a couple of times so that later on the beer does have a strong odour. The next day the germinated corn is spread out in the upper part of the gurdede for drying. The following day the cooking and fermenting process begins and after another two or three days the beer is ready.

Zom has great religious significance. Handling sorghum as an agricultural plant is a very delicate process and, as we will see in the next section, the process of its production is accompanied by many rituals as is its storage and consumption. The consumption of sorghum is controlled by the father of the house who stores it in his huzhéb (main granary). He needs to be pure whenever he wants to enter his sorghum granary and is therefore not allowed to have sex the day before. Underneath the granary is the area where he keeps the shrkwétév (pot of the spirit of the sorghum), his halalay (twin pots), if he has any, as well as the gad pats wudahay (personal spirit pots of his children). During the month malama he keeps his male ancestor pots on top of the granary because this is the month of greatest spiritual danger (see next section on the seasonal calendar). His sorghum can easily disappear in a mysterious way if a mide (sorcerer) finds access to the spirit of sorghum. Sorghum is like a person and is considered to have a mezheb (soul). Sorghum beer is at the very centre of Mafa religious life and without it a man would have no social status at all. Even the bull, sacrificed every three years, because of the manure it produces, can be included as part of a religous theme incorporating the production and consumption of sorghum. Sorghum is the metaphysical epitome of fertility and zom, its religious substance, can be seen as the "Eucharist" of Mafa religion.

For the libation of zom the son of the deceased, acting as family priest, takes a small calabash and fills it with zom from the baba pot. He drinks a little and then makes a libation to the baba while he is saying a prayer to God and his deceased father (see plate 3a). Next he takes the calabash in both hands and tries to balance it freely on the back of the pot (see plate $3 b$ ). If the calabash will not stand freely he cannot really take his hands off. He tries several times, but if he cannot achieve the balancing it is decided to offer more natron and tobacco and to say another prayer. It often happens then that the calabash balances freely on the back of the ancestor pot. The family priest keeps both his hands off for about five to ten seconds and after this everybody is pleased that God has accepted the offering to the late father. During the whole process the present members of the family clap their hands in praise of God.

In case the balancing is not achieved, additional tobacco, natron, a chicken or even a goat might be needed. This might also involve a further pebble divination to determine why God does not accept the offer. There may be various reasons and once they are identified they need to be dealt with before a new attempt can be made.

\section{Ritual sharing of sorghum beer}

As soon as the libation and the confirmational balancing of the calabash has been achieved, the pouring and sharing of sorghum beer can begin. The different brothers and their respective sons receive metaphorical roles, according to their age and family positions, which reflect the political organisation of the Mafa in general. These metaphorical socio-political positions are named in accordance with the beer which is now ritually distributed as zom bay (beer of the great one) and zom biy gwala (beer of the great follower). To allocate the left hand to the bay and the right to the 
biy gwala is crucial in the context of this ritual. Other ritual beers are zom Goyé (beer of Goyé), zom matsam (beer of the jester) and zom ngwazla (beer of the blacksmith), but the use of the left or right hand is not so important here.

The father of the house does not necessarily pour and hand out the beer himself, but two other members of the family are chosen to share this work. The one who pours the beer from the pot is called the "child of the beer pot" while the one who hands out the calabashes is referred to as the "child of the calabash". Mafa operate a system of two calabashes which are held by the "child of the calabash", one in his left and one in his right hand. He first receives beer poured from the "child of the beer pot" into his right hand which he offers to the person who represents Goyé. Zom Goyé is the beer for Goyé who once "stole" sorghum from God's wife. Next the "child of the calabash" hands the calabash in his left hand to the first bay (see plate 3c). After the bay have emptied the calabash, it comes back and then the calabash in the right hand goes to the biy gwala (great follower). The pouring of beer continues and after beer has been offered to the matsam (jester) and the ngwazla (blacksmith) the process starts again with the beer of the bay. Towards the end beer is poured for the blacksmith's wife who is the only woman present with the men (see plate 3a). Finally zom ngwaz is poured for the first wife of the father of the house who receives it in her room (hudokw ngwaz) where she is waiting with her co-wives and the unmarried daughters (see plate $3 \mathrm{e}$ and $\mathrm{f}$ ).

Sacrifice beer is always consumed by people in pairs (see plate $3 \mathrm{~d}$ ) and it is now that the beer of the bay is drunk simultaneously from one calabash by two older brothers, the beer of the biy gwala by a pair of younger brothers and so on. Shortly before the baba pot is empty the family priest pours the rest of the pot into the small calabash and goes around pouring sorghum beer over other sacred objects in the house. He then says a final prayer and drinks the remains of the calabash. A typical prayer begins with offering beer to God in exchange for lang-lannga'a (freshness and health), daw (sorghum and millet), bokw (goats), zlé (cattle) and ngwaz (women). Depending on the religious context of the sacrifice, meaning whether it concerns only a part of the family due to an illness which has occurred, or whether it is part of the seasonal calendar of the wider community, the libation is over or continues outside the house. We assume in the context of this description that it was an ordinary baba sacrifice and that all that is left to do is the communal consumption of the sacrificed goat or chicken. Before I come to the essentials of a communal meal I will explain a little more about bay, biy gwala and matsam.

The word bay is derived from the adjective biya'a to refer to greatness which means that a bay is a great man in the political sense. The general role of a bay is to represent a local clan or lineage group of a community in the context of the maray (bull festival). The political function of a bay is linked to the tradition of a chiefly clan, kar bay, which we find in every Mafa village community. ${ }^{95}$ The name for a traditional chief is bay as well. ${ }^{96}$ On the level of agnatic descent a bay is ideally the tsava (elder) of the most senior lineage of a local clan group. On the family level the bay is the most senior brother of a group of collateral brothers. On the level of halfsiblingship the bay is the oldest son of a woman. Only the bay who is genealogically the most senior representative of a local clan group is a real bay whereas the bay on the sub-lineage and

\footnotetext{
${ }^{95}$ We find the word bay as a common reference to political power mainly among the western and southwestern neighbours of the Mafa. Pontié (1973:162ff), for example, speaks of 'buï’ or 'bi Gaolay' (p50) among the Giziga and Juillerat (1971:65) mentions 'bigwala' among the Muktele, while R. Lukas (1972:184) reports a 'bay' among the Muyang, who announces their bull festival. Vincent (1995:344) translates the term ' $b i$ ' as 'prince' in the context of the word 'Bi Erlam' = "'prince du ciel"', which is the word Mofu proper use for God. She also uses the translation 'prince' when she refers to the traditional chief as 'bi ndwhana', meaning "“chef grand", "chef suprême"” (Vincent 1991:249).

96 Synonyms are biy wudam, biy maray or biy Mafa.
} 
family levels are only metaphorical bay. However, in the context of ancestor rituals it is obligatory that somebody occupies the position of bay as a metaphor for prosperity and wealth.

The biy gwala are the followers or "disciples" of the bay. As in bay there are real and metaphorical biy gwala. The real biy gwala is ideally the tsava of the second oldest lineage of a local clan group. Their official role is the ritual release of the sacred bull during the bull festival. On the family level they are sons of a secondary marriage or half-brothers. The word gwala literally means younger married man. Like the bay, the biy gwala, in the case of the baba ceremonies, are metaphorical representatives of real biy gwala. It is the younter brother in his role as biy gwala who has the potential to become metaphorical bay as an older brother and custodian of the ancestor pot of a late father when the older brother has died or left home.

The matsam is another function we find during the bull festival, but which has much less ritiual inportance than bay and biy gwala. He is a jester and always arrives along with a fellow matsam disguised as "husband" and "wife". The comedy of the matsam is about inappropriate sexual intercourse and also about daily conflicts in Mafa family life. We will hear about these in the next section on community. During a baba ceremony the matsam, too, needs to be metaphorically represented. With regard to the ngwazla (blacksmith), a similar metaphorical presence is required during the sacrifice to a family ancestor. The blacksmith and his wife have a particular talent for removing evil and therefore must be represented by a member of the family.

We have seen from the ritual distribution of sorghum beer described above that the beer of the zom bay is always handled with the left hand, while the zom biy gwala requires the right hand. Mafa explain the allocation of the left hand to chieftaincy by saying that in the past women were bay as well. However, they say that men then took full control of agriculture because women were considered no longer capable of fulfilling that role. They therefore claim that they took the role of bay from them and this is why they use the left hand in ritual to symbolise their power. Mafa explain further that males did not do much cultivating in the past occupying themselves with their livestock but that this changed when agriculture became the most important activity. Whether or not there is any historical truth in this statement, it certainly indicates that, in the past, agriculture was considered as falling predominantly into the female and livestock into the male domain. We will hear more about the role of bay and biy gwala in the context of the bull festival in the next section of this chapter.

The other symbolic pattern occurring during a baba ceremony is that bay and biy gwala always drink in pairs. The same applies not only to matsam and ngwazla but also to friends (men and women) drinking together socially. Mafa consider even numbers as auspicious and odd numbers as inauspicious which I tend to understand as pairs representing maleness in a sense of control over their reproductive capacities and social order.

\section{The communal meal}

After the libation and ritual sharing of sorghum beer is over, the family gathers together for a communal meal (plate $3 \mathrm{~g}$ ). If a baba ceremony is for a sick member of the family then just a small chicken might be sacrified and the communal meal would only consist of a few people. Whatever the reason for a sacrifice to a late father is, the elder of the person who conducts the ritual would receive the left hind leg of a goat or the left leg and chest of a chicken. This is the share of the bay. During a baba ceremony which is part of the obligatory annual sacrifice to a late father a communal meal would already be prepared before the libation and sharing of sorghum beer. Such a meal takes place in the ńngala (foyer) of a house. Man and women eat separately but in-laws can be invited to such a meal. 
An obligatory $b a b a$ ceremony in the context of the seasonal calendar would only be part of one of many $b a b a$, as well as $b a b$ 'baba, ceremonies within a local neighbourhood. Such a sequence of rituals to God and the family ancestors is called zom baba and takes place in the context of the gad Gulom (minimal lineage) and the "way of the beer" begins there. The main part of the next section of this chapter will deal with the community dimension of Mafa ritual activities. Our guide will be the seasonal calendar and in the context of the feasts and festivals representing its peaks we will see how the "way of the beer" ritually unfolds.

\subsection{Community}

\subsubsection{The calendar of the Mafa}

The Mafa calendar consists of three geographically linked levels where each higher level is one lunar month advanced in comparison with the next lower one. If we imagine a connecting line being drawn between Ziver, Zlama and Gouzda, the highest level corresponds with Ziver at about $1,200 \mathrm{~m}$, the next lower level is identical with Zlama at about $900 \mathrm{~m}$, while the whole of our local research area, at about $600 \mathrm{~m}$, belongs to the lowest level. In accordance with the annual rotation of millet and sorghum, the Mafa calendar stretches over two solar years and the second month of the year, hedek, is regularly doubled in the year sorghum is harvested. However, Mafa always consider mafad $(f a d=4)$ as the fourth month, regardless of whether hedek was doubled or not.

The first month of a traditional Mafa year is masola, which those Mafa who follow the lower calendar like to begin at the end of the rainy season, around October. This means that sowing and hoeing are in one year with the harvest falling in the next. If masala is in Gouzda at the end of the rainy season, Zlama are already in hedek, and Ziver would be either in the second hedek (if sorghum was planted) or already in mafad. ${ }^{97}$ I have no data on the names of months in the Kwokwarhay (montagnards of high altitude, as in Ziver) dominated areas but I do have data on the Mafahay dominated region which corresponds with parts of the middle and lower altitude. I consider the Mafahay calendar to be the leading Mafa calendar.

On purely mathematical grounds, the regular alteration of 12 or 13 lunar months would lead the Mafa calendar to advance about one lunar month every eight years. ${ }^{98}$ Theoretically, it would take about 96 years to travel through a solar year adding one more year if traditional Mafa were to rely on the Gregorian calendar. Until recently, it was the biy vardeke of Moskota who had the authority to indicate the beginning of the new year in Mafa land. Moskota belongs to the same topographical level as Gouzda, which is the reason why masala always falls in Gouzda towards the end of the rainy season. Until about 40 years ago, the biy vardeke travelled regularly to Gudur to renew the mysterious transformational forces he controls by being nya' $a$ (born differently). However, the biy vardeké is still mentioned today in Gouzda when traditional Mafa explain the ritual intricacies of the beginning of their new year.

\footnotetext{
${ }^{97}$ Martin (1970:19) refers, in the case of Magoumaz, to mafad , in October, as the first month of the year, which corresponds with what I call the high level or Ziver calendar. Lavergne (1944:41f) provides us with a Mafahay ('Vouzi et Djele'), as well as a Bulahay, calendar. While his Mafahay calendar is in tune with my low level or Gouzda calendar where masala is in October followed by two hedek in November and December, his Bulahay calendar has hedek in September. This also confirms that the high level calendar is about three months in advance of the low level calendar. However, in comparison with the Mafahay calendar, Martin's Magoumaz as well as Lavergne's Bulahay calendar provide us with different names for most months.

98 The annual average of days per lunar month is 29.53 days. This would mean 29.53 days multiplied by $(12+13) 25$ results in 739.25 days divided by 2 results in 369.125 days per average Mafa year. This is about 5 days more than in a solar year. This is only a rough estimate and does not consider leap years and other adjustments.
} 
The sowing, hoeing and harvesting of sorghum is an intricate activity in religious terms and needs to take place in a ritually unified regional context. Sowing and harvesting still begins today at the highest level, which is Ziver, but we can only speculate whether this has to do with the fact that rainfall often starts earlier and ends later on the top of the mountains. Mafa would possibly express this by saying that "freshness" enters Mafa land in Ziver, because this is where the rain should begin to fall. Rain itself is nya' $a$ and, as such, possesses the mysterious force to germinate sorghum so that it can grow. The mysterious forces of rain are regionally controlled by the biy Mudukwa (biy yam of Moudoukwa) who is seen by Mafa of Gouzda as responsible for the timing of the rain.

Mafa also observe the stars to determine the time of the year. They observe, in particular, the sequence of the disappearance and reappearance of the Pleiades (ngwic ngwic = blinking), Orion (ngéshlé) and Cassiopeia (zhengezhe). According to astronomy Cassiopeia and the Pleiades disappear in the Northern Mandaras around the same time in March and Orion in April. Cassiopeia then reappears in July, the Pleiades in September and Orion in October. Mafa only seem to link the disappearance of the Pleiades with the time shortly before the first rain falls which also indicates the coming of the sowing time. Orion would then disappear in July and Cassiopeia in August, indicating the first and second hoeing period. Orion would then reappear in September, marking the last hoeing period. It is quite possible that I misinterpreted my Mafa informants since I only established the astronomical facts after my return from the field. ${ }^{99}$ However, what seems to be certain is that Cassiopeia, Orion and the Pleiades are known to the Mafa and they observe their annual disappearance and reappearance and link them to their agricultural cycle.

Of all the stars observed by the Mafa, the Pleiades are considered to be the most important since their disappearance indicates the beginning of the rainy season and a possible readjustment of the lunar calendar in the new year. The Mafa also observe the movement of the Milky Way when adjusting their calendar. Before the beginning of the rainy season the empty space to the north of the Milky Way expands and Mafa see this as a sign to repair the roofs of their houses. After the rainy season, towards the beginning of the dry season, the Milky Way moves back to the northern sky and the empty space to the south expands. Mafa begin to repair their terraces. The Pleiades reappear again towards the end of the rainy season during malama, the last month of the traditional year, around September.

Mafa often contradict each other when they are asked whether it is still hedek or already mafad, which indicates that the harvesting period is the time when the calendar is adjusted. However, most people do find agreement after a while when comparing the time of the year with the month they should be in. They are also aware in which lunar month Zlama (geographically their next highest neighbour) is in and if Zlama is still in hedek, Mafa of Gouzda know that it is a year of two hedek. When Zlama has mafad, and Gouzda is in its first hedek, the conclusion would then be that there is only one hedek in a year. The word hedek means abundance which is a reference to the harvest period. The next seven months following hedek are references to numbers: mafad ( $\mathrm{fad}$ $=$ four) mazlam (five), momokwa $($ mokwa $=$ six), matserad $($ tserad $=$ seven), matsamakad $\left(\right.$ tsamakad $^{\prime}=$ eight $)$, matsud $\left(t_{\text {sud }}=\right.$ nine $)$, makula $\left(k_{\text {sula }}=\right.$ ten $)$. The remaining three month are kiyi sulav (sulav = planting tool), məvah (vah= leaves) and malama (herbs used for sauces).

The Mafa word for year is nviy, which is a reference to the rainy season. The big divide in a traditional Mafa year is viya (rainy season) and ńgwar (dry season). The rainy season is the active time of the year, during which sowing and hoeing takes place. Without a rainy season there is no "freshness", but only "heat". However, as we will see below, most religious festivals take place

${ }^{99}$ I used Chris Marriott's SkyMap Pro 7 (Demo v.7.08). Copyright 1992-2000, C.A. Marriott, www.skymap.com. 
during the dry season, which indicates that the absence of freshness demands its request for the year to come. Mafa divide the year into three sub-seasons, which begin with zovad (ripening period) towards the end of the rainy season and ends with hudokw (moonlight dance period) during the extreme end of the dry season. There is another sub-season between these two which is often referred to as matasl, meaning the period of extreme cold. The word zovad contains the word $v a d$, meaning night and it is during this time when the traditional flutes, made out of various sizes of antelope horns, are played in concert during the night. The period of zovad belongs traditionally only to the ripening period of sorghum between masala and first hedek (October/November). The word hudokw is the name for a long cylindrical drum, which is played during moonlight when the harvest festival is over. In the area of Gouzda this is usually after the $6^{\text {th }}$ traditional month (momokwa), which falls in March or April. The period of cold (matasl) has no particular ritual allocated to it. However, there is an ordinary beer consumed during this period of the year (around January) which Mafa in the area of Gouzda refer to as zom mazlam (beer of the $5^{\text {th }}$ month), meaning "beer of the cold period".

The above shows that Mafa determine the seasons by observing constellations and the movement of the Milky Way but that the traditional festivals are launched according to their lunar months. The days of the week ${ }^{100}$ Mafa use are references to market days ${ }^{101}$ and, as such, have no significance for the calendar of their religious life. ${ }^{102}$ Ritual events and agricultural activities are monitored by the sequence of lunar months. Ritual activities are particularly intense during a sorghum year. A lunar month begins with the new moon, kiya til zlè (moon in cattle), meaning that the "moon is obscured by cattle". The second day or first visible moon is yam tama kiya, meaning "water in the mouth of the moon". The first visible moon is seen as a female moon due to the very fine line which indicates the shape of the full moon. The third day or second visible moon is called kiya nngura'a, meaning "moon of a man". This moon is seen as particularly male due to its shape, which Mafa interpret as a penis which is also a day when traditional Mafa men like to perform religious rituals. Apart from the first visible moon and the full moon (dam kiya $=$ female moon), all other figurations of the moon are male and it is therefore suitable to perform a religious ceremony on such days. In terms of even and odd numbers of lunar months, religious rituals are preferably performed in even months. This applies particularly to the sixth month (momokwa) which is the month when the Mafa of Gouzda like to perform their harvest festival.

The following description of the traditional months will begin with malama, which is the last month of the seasonal year followed by məsəla, the first month. The reason is that the changeover to the new year displays Mafa ritual activities in all their complexity and demonstrates the religious character of the opening of the year. I am going to describe the main religious and agricultural activities for each month with an emphasis on the sorghum year. In the course of my description, I will also refer to those ceremonies and festivals which have a particularly strong impact on the construction of local history. These are the zom baba (beer father ceremony), the ngwalala (harvest festival) and the maray (bull festival). I will lay them out in three separate sections and describe them in greater detail.

Although Mafa lunar months overlap the solar months of the Gregorian calendar, below I relate them one to one in order to indicate in which solar month the lunar month would ideally fall in the Gouzda area.

\footnotetext{
${ }^{100}$ Mafa use the Fulbe word luma to refer to the day of a week by adding the name of the market day, like e.g. Wednesday = luma Mokolo or Sunday = luma Koza. The word luma can mean market or week in general.

${ }^{101}$ Martin (1970:135f) provides a list and map (fig 21) of the main market days and the communities relating to them.

102 This applies only to Traditionalists, but not to Moslems and Christians. Moslems have their weekly 'assembly' on Friday at noon. The Seventh Day Adventists have their day of worship on Saturday, while Protestants and Catholics have theirs on Sunday.
} 


\section{Malama (September)}

Malama is the month when the ngwazla (blacksmiths) sacrifice to their family ancestors but the vavay (non-blacksmiths) keep their ancestor pots locked away under the roof of the main granary. During malama the biy vardeké of Moskota is held in the seclusion of his house. Mafa link the seclusion of the biy vardeké and their male ancestral pots and say biy a de gay, meaning "the great one enters the house". The only ceremony vavay carry out during malama is the twin ceremony. Vavay do not marry during malama while ngwazla consider malama as the preferred month to get married.

In terms of the agricultural year, malama is the month when the sorghum is almost ripe. Gouzda and Moskota belong, in calendar terms, to the same region, which means that malama falls in August/September. The male ancestor pots and the biy vadeké need to be in seclusion before malama begins, which means towards the end of the $12^{\text {th }}$ traditional month, meveh, and they can only emerge at the beginning of the first month of the new traditional year, mosala. In the past the biy vardeké was enclosed together with a new wife and performed ńngerma (sexual intercourse of the wedding night) during his seclusion.

\section{Mosala (October)}

Masala is the first month of the traditional Mafa year. At the beginning of masala the biy vardeké comes out of his seclusion in Moskota and Mafa take their ancestral pottery down from the main granary and, for the rest of the year, keep it in the hudokw ńngura (sacrifice room of a man). If a man has no hudokw nngura, it is placed on the floor of his huzhéb (main granary). The coming out of seclusion of the biy vardeké is referred to as biy a shkè auda te gay (the great one comes out of his house). After the biy vardeké leaves his seclusion the people of Gouzda begin their zom $b a b a$, which is the official sacrifice to the family ancestors in the context of the gad bulom (minimal lineage). The zom baba can also be referred to as zom masala and will be described below.

\section{Hedek (November)}

The word hedek means abundance and refers to the beginning of the harvest period. If sorghum is harvested there are going to be two hedek (including December). It is the biy yam of Moudoukwa who announces the beginning of the sorghum harvesting for the area of Gouzda, but before the actual harvest can start the zom zhigilé (beer for God) needs to be prepared.

\section{Mafad (December)}

If sorghum has been planted most of December still falls into the double month hedek. December is the main harvest month for millet and sorghum. If sorghum is harvested, a local community has to wait for their biy dza (mountain priest) to start the cutting. He has already waited for the preceding village community to cut theirs. One year before the next bull festival the melebay ceremony is performed by those whose fathers have already passed away. They are obliged to have a he-goat available, castrated shortly after the last bull festival. The zom melebay is prepared and the castrated he-goat (bazl dived) is sacrificed.

\section{Mazlam (January)}

The harvest period can continue into January. Mazlam is considered to be the coldest month of the year and the zom mazlam, beer of the $5^{\text {th }}$ month, is prepared then. This is not a ceremonial beer, but has some social significance. Relatives, neighbours and friends who helped with the harvest are invited to consume this beer. Mazlam is also the month when the threshing period 
begins. Threshing can continue into February and cross over into momokwa, the next $6^{\text {th }}$ traditional month. The threshing of sorghum is particularly complicated and rituals are performed to avoid the sorghum mysteriously disappearing.

\section{Momokwa (February)}

In Gouzda, momokwa (6 $6^{\text {th }}$ month) is the preferred month for performing the ńgwalala (harvest festival). The threshing must be completed and, in the case of sorghum being harvested, the preceding communities have to complete their harvest festival first. If it is the year of a bull festival, the harvest festival has to be completed before the bull festival takes place. This can lead to delays, but it is a minimum requirement that the harvest festival is still announced during momokwa although the actual rituals can then take place during the following month. Most of the time, due to the nature of lunar months overlapping with the Gregorian calendar, momokwa extends into March.

\section{Matserad (March)}

Matserad is the $7^{\text {th }}$ traditional month and in the area of Gouzda the harvest festival might still be going on as it begins. If it is the year of a bull festival it will follow suit and depending whether it falls into a year when sorghum has been harvested the bull festival might continue throughout matserad. During a year millet has been harvested the ritual release of the bulls is quicker in Gouzda since the village community is divided into sub-units liberating their bulls at the same time. In a year of melebay (see mafad), meaning one year before the next bull festival, the daf zhigilé (meal for God) is prepared by post-menopausal women and celebrated just after the harvest festival. As soon as all major purification ceremonies are over, the drum hudokw is released and the season of moonlight dances can begin.

\section{Matsamakad (April)}

The hudokw season of drumming and dancing during moonlight unfolds throughout the $8^{\text {th }}$ traditional month and continues during the $9^{\text {th }}$ month until the end of the dry season. During matsamakad those Mafa who hold a baba pot and can afford it, prepare the zom ńgwar (beer of the dry season). Sacrifices take place and libations to family ancestors are carried out. Those who cannot afford to celebrate zom ńgwar participate at the houses of relatives.

\section{Matsud (May)}

The first heavy rain might fall during the $9^{\text {th }}$ month and the sowing season begins.

\section{Makula (June)}

This is the main month of sowing.

\section{Kiyi sulav (July)}

The reason why kiyi sulov (moon of the planting tool) is so late in Gouzda might have to do with the fact that Ziver already had its kiyi sulov at the beginning of the rainy season, and it is presumably in this context that the name of the month makes sense. However, sowing might continue during this month, but normally this is the time when the first hoeing period begins. This is also the month when Mafa men compete in traditional wrestling to gain physical strength for the hoeing period. During this time the beer of the month madama, zom madama (madama = mucus), is consumed by the wrestlers. 


\section{Movah (August)}

This is the second hoeing period. At the end of this month the biy vardeké of Moskota goes into seclusion and traditional Mafa lock their ancestor pots away.

\subsubsection{The beer father ceremony}

A zom baba (beer father), is the agnate of a minimal lineage with a span of four to five generations while the genealogical eldest of his living descendants is considered to be the gad bulom (head of yams). Since Mafa imagine the next world (veved) as a mirror image of this world (wuda), it is not only the "head of yams" but also his late father and his late grandfather who are seen as custodians of ancestor pots. Mafa only cater for two consecutive generations of family ancestors, so the deceased grandfather of the deceased father becomes zom baba as soon as the last co-lineal "head of yams" dies. In this way the internal structure of a gad bulom changes every generation depending on the number of males being born to their future descendants and splits into two and then three new gad bulom accordingly.

The lack of an ancestor pot for a zom baba has an effect on the symbolic environment in which a libation to him is performed. It is no longer the back of the spirit pot which serves as ritual object but the var ma gay (front courtyard) of the house of the "head of yams" (see plate $3 \mathrm{~h}$ ). We can say that the var ma gay not only replaces but also contains the baba and bab'baba. Mafa express this by saying that the front courtyard of the eldest of a minimal lineage is like a family ancestor pot. Such an interpretation also reflects the sequential order in which libations to the spirit pots of family ancestors and to the front courtyard of a lineage elder are carried out. It is always the custodians of $b a b a$ pots who open the cycle, followed by those of $b a b$ 'baba pots, according to their seniority. It is the head of yams (gad bulom) who closes the cycle with a libation to a common beer father (zom baba).

Although the official time for performing a beer father ceremony is the first month of a new year, which is also the reason why Mafa refer to this sacred beer as zom mosala, the reality is different. In practice, Mafa can perform their zom baba right up till just before the harvest festival takes place, which in Gouzda, is around the $6^{\text {th }}$ month of the traditional year. It is always the eldest of the minimal lineage who begins it and there are additional local historical facors to be considered. These factors consist of the social and political position of a minimal lineage within the village community. However, before I describe them in greater detail we need to take a closer look at the "way of the beer" inside the gad' bulom as a model.

\section{The model of a gad bulom}

Not all Mafa communities refer to their minimal lineages as gad bulom. The Mafa of the northern Moskota Hills, for example, call the minimal lineage ńngala (lit. thrown to the ground). The word ńngala is used to refer to two wrestlers falling to the ground as they fight but it is also used to refer to the genealogical eldest of a minimal lineage who is seen as the one who symbolically won the fight. In Moskota, the beer libation to a deceased father is called zom baba (beer of the late father) while those married men whose fathers are still alive perform zom gay (beer of the house). There might be other regional differences regarding the existence of ritual relationships unfolding in the context of the minimal lineage, but it seems that the concept of the gad bulom is quite widely used.

The metaphorical meaning of "head of yams" is taken from the image of the mountain yams, where the old root on top decomposes as a bunch of new ones develops underneath. It is the next new one below the rotting head which becomes the new head. The following model of the gad 
bulom Fibay from the lineage ward Gura of Gouzda-Korbay shows its internal structure and the levels of unity it displays as a result of the ritual activities of its living representatives.

Table 3: The gad bulom Fibay of Gouzda-Gura

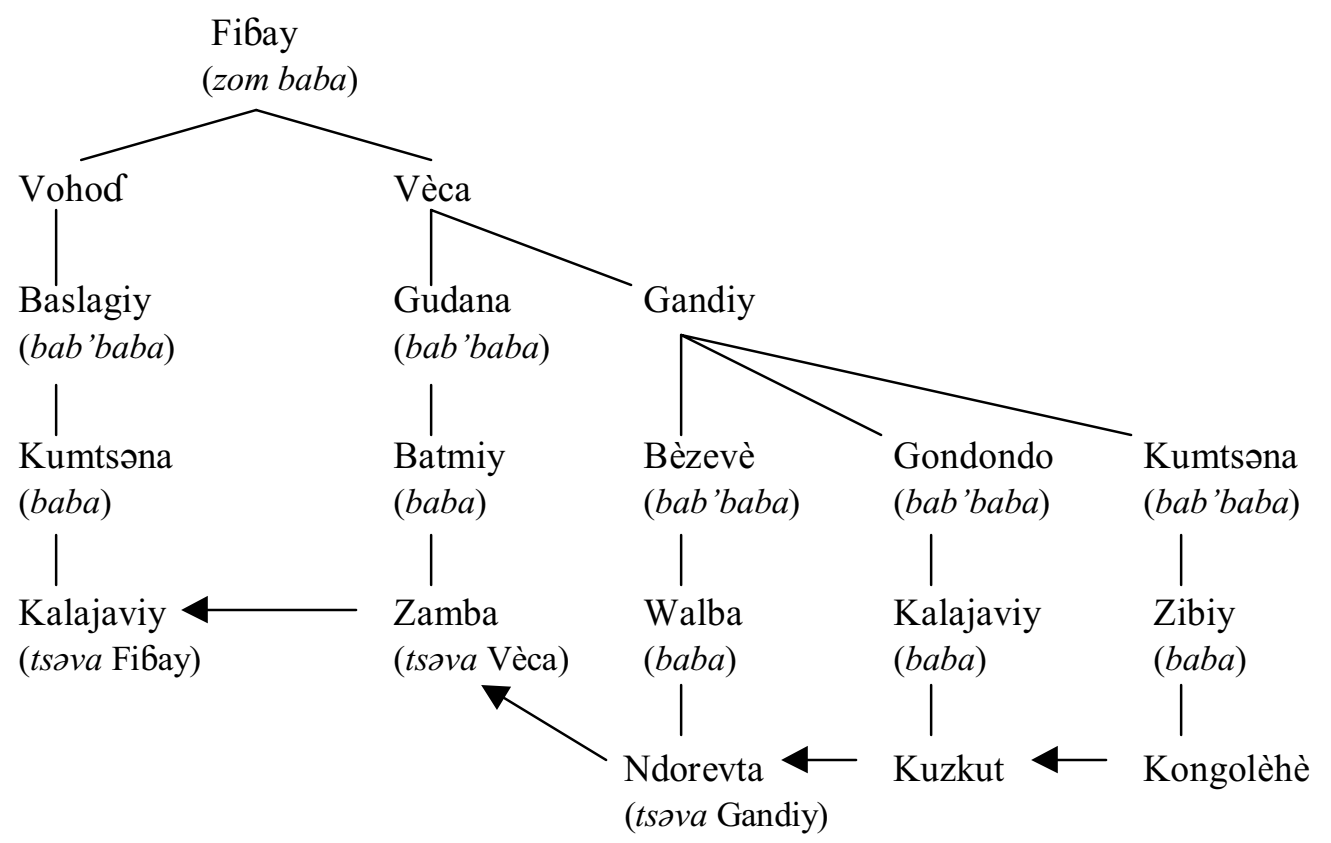

The example shows that Kalajaviy (tsəva Fibay) is the "head of yams". The whole "yam" consists of three branches. Assuming that Kalajaviy might die being the last of a group of brothers, the lineage would split between Vohod and Véca who would both become "beer fathers" while Fibay would lose his ritual significance. The next potential split would be between Véca and Gandiy. The potential of this gad bulom to divide itself into three new ones within the next two or three generations coincides with the ritual responsibilities of their three elders and the "way of beer" attached to them in the context of the beer father ceremony.

It is the front courtyard of Kalajaviy, as head of yams, which is considered to symbolise the ancestor pot of Fibay as beer father. To carry this out, Kongolèhè and Kuzkut would first bring beer to Ndorevta since he is their tsava in relation to Gandiy. Ndorevta in turn would bring sorghum beer to Zamba as he is his tsava in relation to Vèce. Finally Zamba would bring beer to Kalajaviy because he is his tsava in relation to Fibay. However, Kalajaviy would use his own sorghum beer and not the one brought to him by Zamba to carry out the libation to his front yard. It is not the beer itself but the renewed community links which are of importance here. What counts is that Kuzkut and Kongolèhè cannot ignore Gandiy represented by Ndorevta (as tsava Gandiy) as Ndorevta cannot ignore Vèca whose representative is Zamba.

The "way of the beer" of the minimal lineage Fibay might not be completed at one attempt or even in the chronological order mentioned above. The gad bulom Fibay is a rather large one and numbers altogether about 65 gay (houses), which means that the five tsava, who are custodians, not only of a $b a b a$ but also of a $b a b$ 'baba, altogether have about 20 younger brothers who only hold baba pots. They in turn have about 40 younger brothers who have no male ancestor pots but only their gad pats (personal spirit pots). All these spirit pots, including the female ones (mama and mam 'baba) need to be filled with sorghum beer between masala $\left(1^{\text {st }}\right.$ month) and the ngwalala (harvest festival) during momokwa ( $6^{\text {th }}$ month) so as to perform the beer father ceremony. 
However, Kalajaviy will open the cycle during masəla and make sacrifices to his $b a b a$ (Kumtsena) and bab'baba (Baslagiy). All bab gay (family heads) who are descendants of Kumtsena and Baslagiy will accordingly be part of the ceremony. At the end of the bab'baba ceremony for Baslagiy, Kalajaviy will perform his zom baba to Fibay at his var ma gay (front courtyard). Zamba (tsava Vèca) and Ndorevta (tsava Gandiy) who were excluded from Kalajaviy's $b a b a$ and $b a b$ 'baba will now be present as representatives of their sub-lineages. The day Zamba celebrates his own beer father ceremony he will bring zom to Kalajavi while Ndorevta will bring zom to Zamba on the day of his.

We can see from this example that the beer father ceremony begins inside the house of the eldest representative of a gad bulom and then moves out of the house into his front courtyard. The ancestor pots never leave the house but are carried to the foyer for their ceremonial use. After the ceremony they are stored in the sacrifice room, but are kept in the loft area of the main granary during the last month of the year, which is malama.

No man can perform the harvest festival unless he and his family have performed their beer father ceremony. He would be seen as impure because he has not completed the "way of the beer". As a result the whole community would be put at risk if the conditions for good fortune have not been fulfilled. Exchanging sorghum beer along the lines of patrilineal descent connects not only all living, but also all dead descendants of a "beer father". This means that the exchange of sacred beer transcends the celestial as well as the world beyond and acts as a symbolic currency or a religious stake in fertility and community growth. The individual person or traditional self is a genuine part of this transaction represented by his personal spirit pot, the personal god he is born with and the spirit pot of his dead father. Not to be part of a network of patrilineal descent would mean the absence of any spiritual protection and therefore exposure to impurity, disorder, disease and death, in short - misfortune.

\subsubsection{The harvest festival}

The harvest festival includes a sacrifice to the ancestor shrine of a local kin group normally consisting of one or more major lineages. The name for the harvest festival differs but is called ńgwalala in most areas dominated by Mafahay. In the Moskota region the harvest festival is called matamay. The ńgwalala festival begins at the highest topographical level in Ziver and travels around to the south and north of Ziver before it eventually arrives in the area of Gouzda in the middle of the dry season. The harvest festival marks the beginning of the new year, although it is performed in Gouzda during momokwa, which is already the $6^{\text {th }}$ lunar month of the traditional Mafa year.

It is after the biy vardeké of Moskota comes out of seclusion at the beginning of masala $\left(1^{\text {st }}\right.$ month) around October, that he announces matamay. This means that the translation harvest festival for matamay and ńgwalala does not only apply to the time after, but also the time during and, especially, before the harvest. However, not only ńgwalala but also matamay includes the wider village community and sacrifices at their major and minor community shrines which make the harvest festival much more inclusive than the beer father ceremony. At this point we can see a pattern emerging in which the place of sacrifice moves from inside the house via the front courtyard of the eldest of a minimal lineage to the mountain shrine of a local community. Such a mountain shrine represents the founding ancestor of a larger lineage or clan group within a village community and is regularly found on a rocky mountain top, generally referred to as $d z a$ (sacred mountain). The person who is in charge of a sacred mountain top is the biy $d z a$ (mountain priest or the great one of the sacred mountain). 
At the eve of the matamay festival of Moskota a blade of grass called wuzad (similar to the grass (sekko) matting) is ritually thrown towards Moudoukwa where the biy yam of Moudoukwa finds it the next morning in his tarokw (disused grindstone). The next day the biy vardeké is publicly liberated from seclusion, indicating the beginning of the new year and matamay (harvest celebrations) can begin in Moskota. The same day the biy yam takes the blade of grass he found in his tarokw and throws it towards Gudur. Today the biy vardeké is no longer kept in seclusion, but matamay is still considered, in the area of Gouzda, as the moment to begin the new year.

In the past it was straight after matamay that the biy vardeké went on his sacred pilgrimage to Gudur to exchange the kule (sacred medicine of "freshness") with the biy Gudur. On his way back he distributed his new kule among the chiefs (biy wudam) of each village community he passed through. During the dry season he continued to undertake sacred journeys through Mafa land in order to let everybody profit from his kulé. On these excursions the biy vardeké not only went to the foothills and slopes of the lower areas but also up to Ziver and Oupay. In Ziver, a special house was built for him where he spent the night during his time there. The name of the last biy vardeké who went to Gudur and undertook sacred journeys into Mafa land was Gatama Ngoya, who died about fifty years ago.

After matamay had taken place in Moskota at the beginning of mosala, all other Mafa communities could perform their harvest festival. Gouzda interpreted matamay and the liberation of the biy vardeké as the moment to take the ancestor pots out of seclusion and to begin their beer father celebrations, while their harvest festival would take place five lunar months later. Gouzda, nevertheless, sees masala as the first month of the new year and the people of Gouzda say that it is the official month of the ngwalala festival. This indicates a conceptual link between the harvesting period and the beginning of the new year. The ńgwalala does indeed mark a new start and represents a period of community purification, a view Mafa express by saying that they remove evil in the form of misfortune, death and disease by chasing it from one community to the next. In order to get rid of evil, it is necessary to follow a ritual procedure, the first of which is the "way of the beer" as it unfolds during the beer father ceremony. The harvest festival can be seen as a continuation of a purifying process becoming increasingly more inclusive as it moves from the family and minimal lineage to the various clan and lineage wards of a village community.

\section{The eve of the harvest festival}

Before the harvest festival can begin, a pebble divination has to take place the function of which is to uncover hidden causes for impurity or evil, so that the community is ready and prepared for the harvest festival. In the area of Gouzda, it is the biy ngwazla (chief of the blacksmith) of each village community who carries it out. The day the community divination takes place at the common ground of the chiefly clan of the village is called the day of the biy bay (great chiefs). The bay who attend are not the metaphorical but the real bay of the village community. They are the lineage elders of each local clan group a village is composed of. The community as a whole is represented by the village chief (biy wudam) who I also refer to as traditional chief.

When I speak of a village I mean a community and not a physical village. Mafa do not form villages in the physical sense but have their houses scattered in groups of hamlets over a hillside separated from each other by inner fields of varying size. In this sense I use the words village and community in a synonymous way. The word wudam for village community is derived from wa (breast/milk) and dam (daughter/girl). A wudam is either a single village community of exogamous kinship groups of various patrilineal descent headed by a biy wudam or a group of allied village communities unified by the authority of one of their traditional chiefs. Even in a federation of village communities each has its own biy wudam, but they are at the same time 
under the religious authority of the traditional chief of the village community heading the alliance.

Early in the morning of the day of mpiy kwa wudam (manipulation of the communal stones) the biy ngwazla visits the biy wudam and performs a first purifying ritual in the chief's house to prepare him to appear in public. He then guides him to the community's common ground where he ritually cleans a space with the amputated foreleg of a zhwé (wild cat) in order to remove danger. As a religious representation of the fertility and prosperity of the village, the chief is considered to be very vulnerable to the attacks of sorcerers. The biy wudam arrives at the common village ground where the all other bay and biy gwala, as well as the matsam, are already assembled.

Most villages have their communal divination stones which are usually kept near the common ground. Before the biy ngwazla begins to "play the stones" he sacrifices a cockerel and pours its blood over the stones. The sessions of question and answer can go on all day long. Discussions take place and the great ones of a village interpret the "stones" together with the blacksmith so they can identify potential evil, like the possibility of death or other unfortunate events which could unfold during the actual festival as well as taking possible preventative measures. Towards the end of the day sorghum beer is consumed communally which includes a libation to the common ground.

When the assembly is over every ngwaz gay (spouse) of those functionaries who were entitled to participate can put the germinated and ground sorghum on the fire to prepare the beer of the bay for the harvest festival. The next day after biy bay is called wud'wuda (day of the children), and here the word children is used in a metaphorical sense, referring to all those family heads who have no official function during the festival. This means that the second day of preparations is the day ordinary fathers tell their first wife to put the beer of the "children" on the fire.

The day mokwal is the actual eve of the harvest festival. It is the day libations to family ancestors are carried out. Mokwal is also the day the eldest of the various gad bulom bring their ceremonial beer to the biy dza (mountain priest) of their kinship group. On the evening of mokwal each biy $d z a$ of a wudam carries sorghum beer to the diy mbulom (community shrine) of his $d z a .{ }^{103}$ The beer is left there overnight and will be libated the following day. Most of the elders who brought beer to their biy dza are bay or biy gwala, which means that their beer is already brewed. This allows them to start off the cycle of libations to the family ancestors. Mokwal is the day when it is obligatory to cherish the female as well as the male ancestor pots. Married daughters visit their father's or brother's house to participate and a communal meal is prepared specially for them.

\section{The religious peak of the harvest festival}

The religious peak of the harvest festival is the sacrifice at the community shrine. Each clan or lineage section has its own diy mbulom (diy = eye, mbulom $=$ a mysterious wild cat), which means that a village has a range of community shrines representing the ancestor who is regarded as the founder or first comer of a local kin group. A wudam consists of various clan groups of different social and political status according to the time of their arrival and in terms of the social division they belong to by birth. The most striking difference in terms of social standing is presented by a vavay majority of up to $97 \%$ on the one hand, and a ngwazla minority of up to $3 \%$, on the other. This social differentiation between vavay and ngwazla is maintained by a prescriptive marriage system, which prevents them not only from exchanging women but also excludes the minority of blacksmiths from holding territorial rights over land.

\footnotetext{
103 The word $d z a$ refers to the shrine as well as to the ward a biy $d z a$ represents.
} 
A structural similarity between blacksmiths and women becomes apparent here since women are also excluded from exercising such rights. This includes the denial of priestly functions like the general opportunity of becoming mountain priest. In the case of the blacksmith minority, this exclusion from important community functions is socially compensated for by the unique position of acting as diviner for the community and as spiritual attendant for the traditional chief during its run-up. Women are excluded from any priestly functions but blacksmiths still carry out their own religious family services (such as the beer father ceremony). A woman is also not allowed to come near a sacred community site while she is of childbearing age. We will see below in the context of the bull festival that there is one exception which is the daf zhigile (meal for God), but again only postmenopausal women are allowed to come near the sacred community site during this ceremony.

We have already seen in our description of libations to family ancestors that not only the role of the ngwazla but also those of bay and biy gwala are given to male members of a family. These community functions, metaphorically allocated in the context of the family and the minimal lineage along the lines of family position and age, no longer exist in relation to the sacrifice at a community shrine. In the context of the wider community such distinguishing criteria for the allocation of the roles of bay and biy gwala are now replaced by the population size of local lineages or clan groups as well as the chronological order in which they arrived in a particular community. In the context of the application of these different criteria some community shrines enjoy a higher ritual significance than others. However, it is the vavay who struggle over such positions and never the ngwazla lineages.

The vavay are divided locally into chiefly and non-chiefly kinship groups and it is always the chiefly group (kar bay) who has the right to announce the most important annual sacrifice to their diy mbulom ḿbiya'a (main community shrine). Community shrines in general are dedicated to a founding ancestor believed to have settled there on his arrival. Such founding ancestors are often seen as the first who cultivated the land and therefore made it fertile for human use. ${ }^{104}$ However, the ritual authority of the chiefly clan group is limited and we find in many villages that a nonchiefly group possesses a certain ritual primacy in the context of the sequential order in which sacrifices to community shrines are carried out. These rights can exist due to the fact that they had settled longer in the area and once held chiefly powers. Older ritual rights can be represented by a shrine belonging to the village as a whole or only to sections of a village community. Their significance depends on the local historical context of individual communities. Such community shrines are often referred to as diy mbulom mutsor (mutsor $=$ hidden) representing the unofficial parts of local histories.

The sequential order for carrying out a series of sacrifices to community shrines has brought about categories of shrines which are either classified as great shrines, diy mbulom ḿbiya'a, or as ordinary shrines, diy mbulom, by dropping the adjective mbiya'a (great). A great shrine is always the main shrine of a local clan group whereas ordinary ones represent their territorial sub-sections or territories of associated lineages. The larger a local clan group the more segmented it usually is and the more sub-shrines their are. This means that the community shrines are signifiers of patrilineal rights over territorial land, which is, in the context of the worldview of the Mafa, the custodianship over its fertility. To put the stress on fertility rather than on territory is essential since it emphasises the view that it is fertility which renders the land valuable for Mafa rather than purely territorial rights. Claiming control over terrestrial feritility is generally derived from those who first worked the land and is not just an agricultural but also a religious matter.

\footnotetext{
104 The view that a first comer cultivated the land must be interpreted in the context of the agricultural system of the Mafa. Reclaiming land does not necessarily mean clearing the land for first use but can also be seen as a reference to the production and application of manure to intensify its agricultural potential.
} 
As we have seen the endogamous blacksmith group is normally excluded from any religious custodianship over community land by the means of a prescriptive marriage rule. However, some blacksmith lineages own community shrines, but they are rare and their cases can always be explained in the context of local history. In general, blacksmith only worship their family ancestors without referring to the most valuable common thing, which is territorial land, but benefit indirectly from the sacrifices of the non-blacksmith majority. In order to acknowledge the custodial primacy of the non-blacksmith, the blacksmith go around on the day of the sacrifice to the sacred sites of their local community distributing iron sickles to non-blacksmith dignitaries.

Only the religious representatives of vavay can perform the ritual on behalf of a local community. In the context of priestly community functions the biy $d z a$ needs to be distinguished from the biy wudam since the official role of the latter does normally not entail such responsibilities. However, it could happen that a biy $d z a$ is also biy wudam and it is in such cases that a traditional chief also performs the community sacrifice to a public shrine. Such a situation can only come about in a chiefly clan group, since non-chiefly groups can have a biy $d z a$ but never a biy wudam.

Mafa also distinguish between male and female community shrines. As a rule, a female shrine could never be regarded as the great shrine of a village. This means that female shrines always have secondary significance, although in some cases this could mean the second highest of a local community. Female shrines are not hidden markers for the existence of matrilineages in Mafa society but representations of an explicitly patrilineal descent system. We will see in the section on aspects of ritual and social structure how the word gwadar (major lineage), as a synonym for the reproductive capacity of women, is used to designate half-brothers and full-brothers as representations for the fission of lineages. Such fission is always secondary and always contained by the primacy of patrilineal descent, which is reflected in the concept of $d z a$. The word $d z a$ has a physical but also a religious meaning. In physical terms it means mountain and in metaphysical terms it is a sacred concept. It implies that a $d z a$ is nya' $a$ and has a spirit personality which can do good as well as bad and therefore requires regular ritual attendance.

The obligatory sacrifice to a $d z a$, represented by the diy mbulom as its mysterious "eye" takes place on the first day of the harvest festival. Since a wudam normally consists of a multitude of hamlets ${ }^{105}$ all clan or lineage segments who are represented by a diy mbulom carry out the sacrifice to purify their $d z a$ (sacred mountain). Although Mafa say that the sacrificed blood and the libation of sorghum beer is devoted to God and the land rather than to its founding ancestor, it is the latter who represents the moral link between God and the land. Sacred community sites often contain a sacred pot representing the founding ancestor, although these pots carry no sexual characteristics unlike the spirit pots for family ancestors. The founding ancestor is too far removed from the living memory of his descendants to be remembered as an individual person, as is the case with family ancestors. The fact that the pot carries no anthropomorphic characteristics is symbolically complemented by the fact that the place of worship has now moved away from the front courtyard of the elder of a minimal lineage to a more communal space (see plates $4 \mathrm{a}$ $4 h)$.

The following example demonstrates the typical way a sacrifice of a diy mbulom might be carried out. On the day of the sacrifice at the community shrine the mountain priest of a local clan group might first sacrifice a goat devoted to his deceased father's father. This sacrifice takes place in his sacrifice room together with the members of his family. Next he moves to his sleeping room where he carries out a second sacrifice and this time those lineage elders who are going to accompany him to the community shrine will participate. In genealogical terms it is the youngest of them who pours the sorghum beer while the mountain priest carries out a libation. When the

105 The general term for a hamlet is hwad ngwiy (stomach of a settlement) 
mountain priest is also the lineage senior he is also going to say the prayer. We assume, in our example, that the local group consists of three gad bulom and that the mountain priest belongs to the second eldest.

After the two offerings in the house of the biy $d z a$ are completed, he and his genealogical senior make their way to the diy mbulom. They are followed at a respectful distant by all those elders and family heads who consider their houses to be in order. This means they should all have conducted their zom baba and not committed any traditional offence, like, for example having sexual contact with one of their brothers' wives. The mountain priest and the lineage senior should not have had sex the night before the sacrifice is to take place. In our assumed example the reason why the mountain priest is not the genealogical senior of the local clan group lies in the fact that one ancestor from the oldest lineage branch committed a traditional offence rendering all subsequent elders of this branch sak (impure).

As soon as the biy dza and his genealogical senior arrive at the community shrine, they take out the pot diy waf (eye of the tree) from beneath a tree and wash it. The sorghum beer, which has already been brought to the shrine the evening before by the senior, is now poured into the "eye of the tree". The mountain priest offers tobacco and natron, beer is poured over the pot and the calebash is balanced on the back of the pot to see whether God will accept the offering. Next he carries out a beer libation to the ground of the sacred site accompanied by a prayer in which he thanks God and his founding ancestor for past community prosperity and requests "freshness" for land, animals and humans for the season ahead. Now the mountain priest and his lineage senior drink simultaneously from the same calabash and some beer is also given to the third lineage elder nearby as well as to the family heads who came close enough to the scene. A chicken is sacrificed and the blood is poured over the pot as well as onto the sacred ground. During the sacrifice all those men who attend nearby clap their hands in devotion to God. Finally the sacred pot is stored back in its usual place underneath the sacred tree and the mountain priest and his elder go back home. Women and children as well as men avoid crossing their path. The mountain priest goes straight to his house where he disposes of his walking stick and his shoulder bag, both powerful symbols of his religious dignity.

The Mafa word for impurity, sak, means foot, which explains why people have no wish to cross the mountain priest's path. Impurity could be picked up by the mountain priest on the way home or, a much more popular fear is that someone who is impure could die from the religious energy the mountain priest incorporates immediately after the sacrifice on the community shrine. Impurity seems to be seen as contagious in Mafa land and someone could unintentionally pick it up from another, who himself had become infected without having committed a traditional offence. However, there is also the belief that mide (sorcerers) can be killed by the religious energy the mountain priest is charged with when he comes from the great communal shrine. The concept of sak is central and plays a great role in Mafa religious behaviour. Hosting impurity invites illness and death and therefore lays the community open to grave misfortune. Purifying a community from evil through a sequence of sacrifices to the diy mbulom of the various $d z a$ of a wudam is one of the main religious functions of the harvest festival.

The first day of the harvest festival is not only the day for the most important ancestral sacrifice Mafa perform but also the day if the sons of daughters ( $k \partial r$ dam), who represent, in political terms, the potential enemies or competitors over land and the fertility it contains. At this point the reader should remember that the fertility of land is a result of the intensive farming techniques Mafa apply, not just farming alone but also of successful rearing of cattle and the application of the manure produced. There is not much space between neighbouring settlements and the densely populated hillsides have been the scene of much warfare over land. The visit of the sons of married daughters on the day of the sacrifice to the great ancestor is a sign of peace and 
reconciliation between neighbouring patrilines. On this day, the sons of married daughters go to the houses of their mother's brothers to participate at a communal meal at which it is their right to receive the head of a prepared chicken.

During the religious peak of the harvest festival, other affines also arrive for a visit and participate in drinking and eating. This marks the first days of the harvest festival as the main part of the festival. Towards the end of this part, the chasing of evil from the village takes place. Every owner of a $b a b$ 'baba pot assembles all the descendants of a deceased father's father at his house to conduct the offering over his spirit pot. After the occasion the father of the house lights a fire and takes some of the burning stalks in one hand and with a stick in the other hand he goes through all rooms of his house. He then leaves his house and goes towards the pathway leading westwards to chase impurity away. Mafa refer to the west as cived zhigilé, which is also the direction where they place the deity pot zhigile cived, meaning "the way of God".

Purifying the territory and making the community a fortunate one is the ultimate goal of the harvest festival. The genealogical order of patrilineal descent and the way it is locally carried out by passing on beer from the junior to senior level of co-lineals reflects the settlement history of the community performing it. However, chasing evil or getting rid of impurity in the direction of the sunset is, in the first instance, of symbolic and not geographical significance. Although the harvest festival always begins in Ziver, it travels in an alternating way backwards and forwards between the higher and lower positions of the area. This seems to be a movement which is guided by the topographical calendar since even numbering of lunar months in the context of where the festival is performed can so be maintained. The serpentine pattern the harvest festival makes on its way through central Mafa land appears to be similar to the route taken by the biy gwala through a local community when they liberate the sacred bulls. The sharp alternating turnings of the regional pattern is also similar to the semi-circular movements Mafa make around their necks when disposing of impurity as they ritually throw an object away from them. During that purifying action it is not only the hand but the whole body which performs a semi-circular movement before the object is disposed of. The ritual ntéwéla gad (a turn around the head) is carried out in many religious contexts, such as funerals (when chasing the deceased) or the Mafa bull festival (see below). ${ }^{106}$

With regard to the harvest festival the "turn around the head" is performed when chasing evil towards the west at the end of each bab'baba ceremony. Since Gouzda is at the topographically lower as well as the chronological tail end of the regional calendar, as the harvest festival travels through central Mafa land, they not only chase evil symbolically westwards but also geographically upwards towards a place called Motsagoy. Motsagoy is a village and already belongs to the Bulahay region of Gadala at the extreme southeast of Mafa land. Removing the evil from the local community by chasing it towards Motsagoy implies that this is the last place after Gouzda where misfortune can take refuge.

\section{The end of the harvest festival}

The last day of the harvest festival is called ngdal-gay, meaning "ending the festival". This is the day to drink the zom shidef (beer of the cooking pot), which is an ordinary beer prepared for enjoyment without any ceremony or sacrifice connected to it. Everybody can join in the drinking of this beer.

Compared with the beginning, the end of the harvest festival is not a centralised event. It might well be that one local group has its last zom shidef quicker than another one. It depends mainly on

\footnotetext{
${ }^{106}$ David, Sterner \& Gavua (1988:372) symbolically link the ritual ńtéwélə gad to the spirally twisted strip roulette and the impressions it leaves aound the necks of so many Mafa pots.
} 
the size and the complexity of the community shrines involved in the ritual order of ancestral sacrifices. This emphasises again that the beginning is politically more important than the ending. The communal divination and the day biy bay (when the dignitaries begin to brew their ceremonial beer) are events which involve the village community as a whole. The traditional chief is purified and protected that day by the chief of blacksmith so that he can drink and eat and appear in public during the harvest festival.

The beginning of the harvest festival is also relevant for neighbouring villages, waiting until their leading community has started the process. As soon as the festival is announced and its ritual preparations have started, then the associated villages can follow. This often leads to an overlapping of festivals in a neighbourhood of village confederations, since the village that follows might be smaller in size and therefore might already complete their zom shidef before the one which initiated its beginning has completed its course. The same rule of a centralised beginning applies to the bull festival, but due to issues of purity all sacred bulls of a village are ritually slaughtered on one specific day at the end of the bull festival.

\subsubsection{Bull festival}

The Mafa word for sacred bull ${ }^{107}$ and for the festival of its consecration is maray. The bull festival does not take place every year, but either every second, third, or fourth year, where a triennial cycle seems to be the way the majority of Mafa celebrate it, although no listing exists so far which would attribute the cycle of years to single communities. It therefore remains unclear whether there is actually any Mafa community with a biennial cycle, although we know that this is what most Bulahay groups seem to adhere to. With respect to a quadrennial cycle, I know only of Oupay but there might be other Mafa communities where some might not celebrate in any repetition of years at all. In the area of Gouzda, Mtskar is one such a case in that it has no regular pattern of performing the bull festival. A reason for this exception might lie in the origin of their chiefly clan, the Wula-Sakon, from Wula or Sukur. ${ }^{108}$ I will come back to the exception of Mtskar in Chapter Four where I reconstruct the settlement history of the locality.

In this chapter I will concentrate not so much on the cyclical pattern but more on the ritual activities and their symbolic meaning in the context of rituals typical for the triennial cycle of the Mafa bull festival. There are variations in terms of some of the roles and ritual objects used during the bull festival of which one is the teba (sacred rope). The teba represents a mysterious being resembling a snake found by forefathers of the community between the stones of terraces. A similar sacred rope is also found in many Mafahay as well as Kwokwarhay communities, but it does not exist everywhere. In Moskota, for example, the teba is replaced by a millet and okra stalk fitted into each other and filled with the intestinal contents of a sacrificed goat. Names and roles attributed to certain ritual actors can vary as well as the way the festival itself is performed.

However, what most village communities have in common is the fact that they consist of chiefly and non-chiefly clans, jointly represented by a traditional chief. Without exception, they all display the social dichotomy of ngwazla and vavay. The fact that a traditional chief signifies the political independence of a village has already been referred to in the context of the community's right to announce the harvest festival. The same applies to the bull festival, which follows suit

\footnotetext{
107 The general term for cattle is zlé. Traditionally it is the West African Shorthorn (Bos brachyceros) Mafa prefer as livestock. See Blench (1998) for its geographical distribution and Dineur \& Thys (1998) for the breed found in the northern Mandara Mountains (with an emphasis on the Kapsiki).

${ }^{108}$ Sterner (1998:121f) informs us that both the Wula and Sukur complete a biennial cycle (see also Sterner's table 12) but mentions the possibility of a previous three year cycle for Sukur. She also informs us of the absence of ritual release and recapture of the bull in Sukur.
} 
every three years, but unlike the harvest festival the bull festival does not need to be announced during a month of even number. However, the local sovereignity of a village to announce the bull festival is embedded in a regional pattern of the way it travels. As with the harvest festival, Gouzda is at the tail end following on from Zlama to Woulad, Mazay and Mouzoua (Mtskar does not celebrate it regularly). The photographic images (plates 5a to 10h) illustrate the bull festival of Zlama, where I had, in February 2000, the chance to witness it as it occurs under a new traditional chief.

It is during the bull festival that the whole range of dignitaries and ritual actors, like bay (great one), biy gwala (great follwer), gad bay (staff of the great one), matsam (jester) and biy ngwazla (chief of blacksmiths) unfold their real functions. The difference from the harvest festival is that the primary concern of the bull festival is the political unity of the village community and not so much the various degrees of local exclusiveness of clan and lineage wards. While the biy dza represents the unity and sovereignity of a local clan group during the harvest festival, it is the biy wudam who fulfils this function for a whole set of clan groups forming a local community during the bull festival. ${ }^{109}$

A biy wudam remains in office for life, although this is often not very well received by the rest of the community, especially if he lives for too long. ${ }^{110}$ The right of succession to this office circulates among lineages of the chiefly clan of a village and after a biy wudam has died, the bull festival temporarily ceases to be performed with all its ritual functionaries until a new chief has been installed. The replacement of a traditional village chief mostly entails changes in terms of ritual responsibilities held by particular lineages during the "reign" of a biy wudam. Such changes mainly affect the lineage groups of the local kar bay (chiefly clan) and not so much the nonchiefly groups. There is fierce competition in redistributing ritual functions during the bull festival and it seems to be a genuine part of a wider process of renewing these responsibilities, which involves a political and also a religious dimension. The wudam renews itself by exchanging its dignitaries and ritual functionaries related to the bull festival. The circulation and renewal of ritual responsiblities can be interpreted as part of an ongoing process of rendering a local community fortunate.

Before describing the process of renewal of the chief and his functionaries I want to briefly speak about the celebrations taking place between bull festivals and which lead to the next one to come. The announcement and opening of the bull festival will also form a separate section below as will the ritual release, the slaughtering of the bull and the sharing of the meat.

\section{The feasts between the bull festivals}

The triennial cycle of bull festivals is the most common one in Mafa land. This cycle has two interim years, with the second one calling for a special ceremony which is related to the next bull festival to come and known as the year of melebay. The fact that the year of melebay is always one year before the next bull festival determines a recurring calendar pattern in the context of crop rotation. Because the bull festival alternates between a sorghum and a millet year, the year of melebay alternates respectively. This means that when the bull festival is during a sorghum year, melebay is always in a millet year and vice versa. Melebay consists of the sacrifice of a castrated he-goat by those men whose fathers ares already dead, which means all married sons of a late father and not only the eldest one with the baba pot. The sacrifice of the he-goat, already

\footnotetext{
${ }^{109}$ Van Santen (1993) also describes the bull festival but hardly gives a mention to the role of the biy wudam and instead speaks of the biy $d z a$ as the main dignitary of the bull festival (op.cit.:210).

${ }^{110} \mathrm{~A}$ biy $d z a$ is also in office for life, but unlike the biy wudam, his community does not necessarily relish the fact that he will live to a ripe old age.
} 
castrated soon after the preceding bull festival, takes place somewhere between the harvesting and threshing period around the $4^{\text {th }}$ lunar month, mafad (December/January). A melebay ceremony brings about another ceremony called daf zhigilé (meal for God), a couple of months later. ${ }^{111}$ The "meal for God" consists of a meal prepared by postmenopausal women, which is then ritually consumed by their grandchildren nearby the community shrine of a local kinship group.

One of the purposes of the year of melebay is to remind a man that the bull festival is close and to consider the enclosure of his maray (sacred bull). The castrated he-goat used for the sacrifice during the melebay year has been fattened by then for almost two years. The sacrifice takes place in the context of the patrilineal kinship groups of a village and the zom melebay is prepared. There is no fixed day set for the sacrifice of the castrated he-goat, the occasion being referred to as bazl dived (slaughtering of a castrated he-goat), and could take place at any time between December and February (in Gouzda, before the harvest festival).

In addition to bazl dived, an assembly takes place during a melebay year and this concerns the village community as a whole. More beer is prepared to be taken to the common ground by the bay and biy gwala, representing their patrilineal kin, to participate in a libation there and to discuss the next bull festival to come. On this occasion the last bull festival is reviewed and some changes might be made in terms of the ritual personnel. These might result in someone new being appointed biy ngwazla or a different person being chosen to replace an old bay or biy gwala who has died. At the end of the melebay assembly a small procession goes around the common village ground and some of the biy gwala and other ritual actors will stage an imitation of the coming bull festival.

Next comes the harvest festival during momokwa ( $6^{\text {th }}$ month) followed by the daf zhigilé, which then leads over to zom ńgwar or "beer of the dry season". Zom ńgwar is a kind of repetition of zom baba (the beer father ceremony), but is not obligatory and only performed by those who can afford it. The "beer of the dry season" takes place every year and closes the circle of harvest celebrations before the sowing begins, whereas the meal for God is obligatory and only performed the year before the next bull festival. If sorghum is planted that year the following bull festival will be during a millet year, but if millet is planted during the year of melebay the bull festival will be in a sorghum year. ${ }^{112}$

The meal for God consists of meat, porridge and sauce and is prepared during the night by postmenopausal women who then carry it to the sacred site of their kinship group, which can be the patriline of their husbands or their sons. All old women of a ward gather nearby the community shrine and offer the meal for God by guarding it for a while at the sacred community site. Next they invite the children of the ward to eat and afterwards carry the rest of the meal to the road for passers-by and visitors to eat as well. The postmenopausal women are not supposed to leave until everything they have prepared has been consumed. At the same time families also eat some of their meal for God at home. To prepare it for ritual consumption the meal is transferred to an gandaf (eating bowl) which the father leaves over night in his sacred tree next to his house where he also keeps the skulls of the bulls he has previously sacrificed.

\section{The renewal of the chief and his functionaries}

\footnotetext{
111 The daf zhigilé (meal for God) is not the same as the zom zhigilé (beer for God). The latter takes place every year shortly before the sorghum is harvested (around November) and consists of sorghum beer being libated to some of the roots of sorghum plants to request God's good will to guard his sorghum. Some of the zom zhigilé is also poured into the shokwetev (sacred pot under the main granary).

${ }^{112} \mathrm{I}$ am uncertain as to whether the daf zhigile only takes place when melebay falls into a sorghum year or whether it takes place every melebay year.
} 
After a biy wudam has died, his gwarbay (sorghum platform and sunroof) is destroyed and, after an interim period following the completion of his funeral, the search for his replacement begins. Since Mafa practice lineage rotation for the office of the village chief there is a great likelihood that the new chief will be from a different lineage of a local chiefly clan. Chiefs have certain restrictions in their personal lives, which include being confined inside the village. Apart from the religious authority a chief represents by his function as a communal figurehead for fertility and prosperity, he has no political power at all. Unlike the biy vardeké of Moskota or the biy yam of Moudoukwa, he has no regional authority in terms of representational ownership over any natural or cultural phenomenon other than the maray. This is the reason why the biy wudam is also often referred to as biy maray, meaning "great one of the sacred bull". We need to look at the religious meaning of the bull festival to understand what he represents.

What is certainly of great importance is that only bulls are considered to have a sacred component. They represent the religious management of fertility and prosperity exclusive to the male members of a local community. The sacred bull is fattened during a period of seclusion inside the house. Its ritual release is of great symbolic significance for the purification of a local community and the traditional chief is a representation of all the bulls being liberated in a village after evil has been removed from them. The bull festival dramatises the renewal of the reproductive capacities of a village as a community of exogamous patriclans in which the biy wudam stands for its unity. A major purpose of the bull festival is to guarantee the continuity of that renewal in order to allow the alliance of local groups to prosper. However, if the traditional chief and the body of dignitaries and ritual functionaries attached to him are in charge for too long, people become discontented. The renewal of religious authority over the reproductive capacities of a village community can only happen after the death of the former biy wudam, and his replacement symbolises exactly this during the following bull festival. Change in terms of the redistribution of ritual responsiblities is welcomed and seen in itself as a sign of wanting the process of purification and community renewal to be successful.

Conflicts over issues of power sharing occur during the process of selecting a new chief, and there can be very serious allegations of exclusion of some of the chiefly lineages due to taboos they might have overstepped in the past. The selection process in itself tests out the political standing of a possible new chief by constructing all sorts of objections against a new chief-to-be. In this context it is particularly the lineage of the old chief who wants to hold on to religious authority in managing the local issues regarding the next bull festival. In this temporary struggle over religious authority the new candidate is not supposed to show a strong interest in becoming chief. Ideally, a new chief would expect to be persuaded by those who are involved in the selection process. It needs to be added here that being a traditional chief does not bring about any particular increase in personal wealth and being village chief is nowadays a position hardly anybody aspires to.

Once the chief is selected he is installed during a ritual in which a representative of the first settler of a village community might play the role of transferring responsibilities for the purification of the bulls before their ritual release. The ownership over the most powerful religious symbol, the sacred rope of a village (teba mbiya 'a = great rope), might be linked to someone whose family or lineage was formerly included into the rotation of local chieftaincy. As a result of such a local historical connection only a duplicate might be ritually handed over to the new chief. Other items are two iron lances, an indigo cotton gown and a red felt hat, all of which are symbols of chieftaincy and which therefore need to be in the possession of the new chief. The handing over of these symbolic valuables are often refused or denied by the lineage of the former chief, but are eventually passed on or remade by the dignitaries attached to the new chief. However, during the process of being selected and eventually invested as new chief, a candidate might have to face 
numerous humiliations, in particular, various matters held against him by representatives of other chiefly lineages of a village community.

If a village cannot find unity in its selection process it might even fall apart or, as in the past, war might broken out. This might have led to new alliances being formed. Today, it becomes increasingly difficult to replace a chief since the personal disadvantages are too great. A village chief is not allowed to leave his village and is therefore not in a position to go for any seasonal work. The reason why some villages do not celebrate the bull festival with all its ritual components is because they cannot replace their deceased chief. The communal processions consisting of the group of bay and biy gwala cannot take place, except for some private dramatic mimicry of the ritual release of sacred bulls.

As soon as the new chief is selected and instated, he replaces some of the old bay and biy gwala. These changes initially concern all his gad bay or personal representatives. The word gad means staff but is in reality an iron lance (see plates $5 \mathrm{~h}$ and $6 \mathrm{~g}$ ). Since even numbers, and, in particular, a pair of two, are important for Mafa symbolic classification, two lances and two gad bay (staff of the great one) exist. However, there is only one biy wudam, but he does not appear in public and keeps a low profile during the course of a bull festival. The chief is not supposed to go out but is represented by his first gad bay who is sent out by the chief himself, after being dressed with the chiefly clothes (indigo gown and a red felt hat), which are kept in the chief's house. The first gad bay has a double who is the second gad bay and both head the groups of other bay who are representatives of other chiefly and non-chiefly lineages. The first staff of the chief, who is the public representation of the chief, will be certainly replaced when a new chief is reinstated. A chiefly lineage whose turn it is to hold the chieftaincy would always want the public image of the chief to be representative of the lineage the chief himself belongs to.

The fact that there is only one real chief who, at the same time, is supposed to remain incognito, sending out, instead, his bay and biy gwala, highlights the metaphysical dimension of his function. The chief remains inactive and withdrawn rather like the role the women take (see plate $5 \mathrm{j})$. He keeps himself separate from the feasting public due to the high risk he runs of attracting pollution from those whose paths he might cross. The renewal of fertility and prosperity of the community and its ritual management by alliances of patrilines is mirrored by the periodicity of the bull festival and the rota of chiefly responsibilities. The replacement of a deceased village chief and some of his key representatives and disciples is obligatory, not only in political but also in religious terms, since the contrary could render a village community unfortunate.

\section{Announcement and opening of the bull festival}

The renewal of a village's chieftaincy after the death of an old chief can affect both the announcement and the opening period of a coming bull festival. During this period, social and political tensions might increase and in such a case a new chief needs to be quite determined in his desire to be chief, which seems rather difficult in the context of a tradition where such a desire is not very well perceived. The announcement of the next bull festival might be delayed due to the lack of agreement between the different kinship groups. These might be reluctant to fulfill certain ritual obligations in the time allocated to them. The representatives of lineages holding power over the confirmation of a new chief might then be seen to be wanting to exercise this power by delaying the announcement in an attempt to discourage the new chief. However, since the announcement and opening of the bull festival is embedded in the regional calendar of passing on the festival, agreement is almost always arrived at eventually.

There are various ways of celebrating the bull festival, which might differ between neighbouring or even associated villages. One difference might be whether the musicians of a village always 
play the flutes of antelope horn or whether they only do so when the bull festival falls into a sorghum year. Other differences occur in the context of ritual functions, for example, with regard to different types of biy gwala (great followers). It also depends on the size of a village community and it appears that the larger a village is the more complex the ritual differentiation of the bull festival might be. Most of the time such differences can be explained in the context of the local history of a village community, which is the subject of the next chapter. At this point I generalise and present a typical way of announcing and opening a bull festival. However, it is important to bear in mind that, within a group of villages forming a political alliance, there is always a connection between the order of announcement and the hierarchy of chiefly clans representing single village communities.

As for the harvest festival, a village divination takes place at which all bull festival officials are present. Possible causes for disturbances are discussed and put before the assembly by the chief of blacksmiths. The chief of blacksmiths was also the one who guided the village chief to the common ground of the chiefly clan after he had performed a set of rituals in the chief's house so he could eat and drink during the bull festival to come. The sorghum beer is put on a fire straight after the assembly so it will be ready for the opening ceremony called ńbade (pouring of the beer) which takes place at a community's common ground. As for the harvest festival, the two days between the "pouring of the beer" and the communal divination are referred to as the day of the biy bay (day of the great ones) and the day of the wud'wuda (day of the "children"). The purpose is to give the great ones the lead over the ordinary family heads in advising their wives to put the ceremonial beer on the fire, a time which I refer to as the eve of a festival.

One particular task on the eve of the bull festival is for the male youth of the village to clean the public pathways the biy gwala will use as they go from ward to ward to liberate the sacred bulls. The cleaning of the public pathways of the biy gwala is a task which takes place at the day ńbade, the last day of the eve of the bull festival. The way of the biy gwala winds itself through a village like a snake while the way of the bay is always straight from one public ground to another. The biy gwala's task is not only to ritually release but also to purify the sacred bull and the route they take is of significance. To cross or follow the biy gwala, while they do their dangerous work, is risky and can lead to misfortune and death of those who are impure. Since impurity is very contagious a person might have picked it up unknowingly from someone else by having crossed his path. It is the old men of the village who advise the male youth as to the direction the biy gwala will take and tell the youngsters to pick up particular stepping stones and put them back into place. Some of these stepping stones have fallen out of position between two bull festivals and the old men are supposed to know exactly which ones it is important for the biy gwala to step on.

The actual opening of the bull festival might take place in the late afternoon at one of the important common grounds of the village. A crowd begins to gather at the place towards the evening and eventually the bay and biy gwala arrive. It is possible that disagreements between old and new ritual functionaries have been clarified in the course of the day. However, once the crew of the new traditional chief arrives at the public ground to pour the beer of ńbade we can assume that a new era of bull festivals has begun. The flutes are played and drums are beaten. The bay and biy gwala take their respective places and a beer libation is carried out. The location where the libation is usually done has significance as a sacred place for the whole village. It might be the place of the kinship group who first settled there, or, some other local historical reason which gave it an exceptional ritual purpose for the community.

After the libation to a shrine at the village's common ground, a fire might be lit. Beer is shared out to the public and dancing and feasting begins. Later that night the bay and biy gwala prepare themselves to go home and ordinary community members often use millet or corn stalks as 
torches to show them their way home. Lights are lit everywhere in the village to ensure that the ritual functionaries arrive home safely. At this point, I recommend that the reader view all the 42 images relating to the bull festival in the order they appear on the CD-ROM before continuing to read further.

\section{The ritual release and recapture of the sacred bull}

The following day is the first day for releasing the sacred bulls of the chief and possibly those of his first gad bay or another ritually highly ranking person in the village. The first thing to occur on the first day of the bull festival is the arrival of the biy gwala mutsor, meaning the "hidden" great follower. Every owner of a bull has an anonymous biy gwala who normally belongs to his own lineage and whom he has identified by pebble divination. ${ }^{113}$ The biy gwala mutsor appears in front of the cattle shed to prepare the bull for its ritual release by performing a beer libation over the herbs the bull is fed with. He eventually takes some of the herbs in his right hand and carries them out of the house, throwing them ritually on the pathway leading away from the house. As he does this, he performs the semi-circle around his head, a movement signifying the removal of impurity. Mafa refer to this movement as ntéwéla gad (a turn around the head). With gifts of menda (tiger nut paste) and balbala (mixture of grilled sesame and beans) in his shoulder bag he eventually leaves the house. However, in some communities the biy ngwazla also arrives beforehand to prepare the house of the village chief for the arrival of the biy gwala mutsor.

When the biy ngwazla and the biy gwala mutsor have left, the group of biy gwala teba of the chiefly clan arrive at the chief's house to dedicate their sacred ropes in front of the chief's maray on behalf of the whole community. Part of this ceremony might be the cutting of pieces of madzaf ziy (euphorbia) into the beer libated at this occasion. The biy gwala drink the beer with the euphorbia pieces (see plate $5 \mathrm{~g}$ ), which function as madzaf (medicine) to enhance their personal protection throughout the bull festival. In some villages the biy gwala te6a are split into two ritual functions accordingly, which are biy gwala teba and biy gwala madzaf. The fact that these roles are sometimes separated shows the importance of madzaf for the biy gwala teba. Purifying the sacred bull is a risky ritual task which could not be achieved without medicinal protection. The mysterious transformational forces involved can lead to illness or sterility.

A similar scenario of the biy gwala teba preparing themselves for their ritual work might develop at the houses of representatives of non-chiefly clans of the village so long as they have a significant position, which might include the possession of a powerful sacred rope. The sacred ropes are made out of two strings of dark and light coloured fibre and those who are supposed to contain a "snake" inside are considered as the original ropes of a village while all the others are duplicates. There are always two biy gwala teba (or/and biy gwala madzaf) for one rope. Sometimes sacred ropes are considered to be male or female, but this is not always the case. However, if gender is allocated to the ropes the female ones are rolled up into an oval and the male ones into a longish shape.

Mafa consider the spiral form in which the sacred ropes are curled as representing a mysterious snake once found by some ancestors between the stones forming the terraces of the fields. To begin the liberation of the sacred bulls the biy gwala first pile their snakelike ropes one on top of the other, those nearest to the ground representing the earlier roots of the community history. The ropes higher up on the pile refer, in their relative positioning, to the more recent local history with the one on top representing the "youngest" group. After the beer libation and the euphorbia

\footnotetext{
${ }^{113}$ It is interesting that there is only one and not two biy gwala mutsor, a fact which seems to indirectly refer to the invisible "one" in the ritual counting of the Mafa also suggesting that the anonymous appearance of the biy gwala mutsor is analogous to this in ritual terms. Unfortunately, I have not enquired any further into this.
} 
consumption is completed, a chicken is sacrificed over the ropes which are eventually gathered up again by the biy gwala who now leave the house one after the other and take position in front of the chief's house. After a while the biy gwala of other important clans and lineages join the chief's biy gwala and wait together with them for the bay to get ready.

In the meantime the first gad bay, who is the deputy of the chief, is dressed up inside the chief's house. A red undershirt is covered with an indigo gown and the red felt hat is put on his head and then covered with a red and a white ribbon. The lance of the chief is handed over to him and his shoulder bag is adjusted. The drummers begin to beat the drum and then start to sing " $A$ biy $g a$, $a$ biy ga, a biy ga", meaning "oh my great one, oh my great, oh my great one." People now make way for the chief's deputy and his two drummers to come out of the chief's house (see plate $5 \mathrm{~h}$ ) where he will be joined by the other bay, who are representatives of all the other kinship groups who hold an entitlement to be bay. This includes the second gad bay, who is also dressed in an indigo gown, but unlike the chief's deputy he wears a black or indigo felt hat rather than a red one.

A procession begins to form where the biy gwala go ahead of the bay but eventually separate to release the first bull while the bay make themselves comfortable at a designated common ground nearby (see plates 6h and 8d). Unlike the bay, the biy gwala wear a goat hide over their buttocks and amulets of animal horn or iron around their necks and bear chests (see plates 6a and 7f). The difference in dress code between bay and biy gwala is of great historical significance, although this is now undergoing increasing change. In the past cotton clothes were not common among Mafa. During that time the bay were the only ones who wore full cotton clothes during the bull festival. It is important to note that at the same time the traditional chief himself only wore the traditional costume consisting of a particularly impressive goat hide over his buttocks and lots of iron armlets and bracelets. The only difference between him and ordinary men was that he wore an indigo strip of cotton around his left wrist and an iron amulet covered with the skin of a black mamba.

The symbolism of the indigo cotton gown and the red felt hat for the chief's deputy, although cultural items of Islam, can be interpreted as a sign of successful indigenous appropriation without conversion. The regional power represented by the Bornu and Wandala was intrinsically linked, for the montagnards, with being "Kirdi" or "Matakam" and therefore prime subjects for enslavement. The fact that only the representatives of the chief, but not the chief himself, were allowed to wear cotton clothes during the bull festival demonstrates that they were considered to be very powerful symbols but at the same time remained of external significance. Cotton clothes impressed the onlookers, as the fattened bull would presumably do when released, but the issue of community purification continued to be the actual religious target closest to the heart of traditional Mafa.

Today cotton clothes (western and oriental types) are worn by almost everybody in Mafa land, whereas traditional costumes are only worn by very old people or in ritual contexts. The fact that in some villages biy gwala still wear their traditional costumes when they release the sacred bull and that the chief still remains separated from the rest of the community during that time emphasises the religious character of the bull festival. When the biy gwala and bay leave the chief's house to do their ritual work, the biy gwala have a particular way of walking. They do not go straight to reach the next compound but perform sharp bends imitating the way a snake moves (see plate 7f). The snakelike walk of the group of biy gwala can be symbolically linked with the sacred rope, which also represents a snake. The symbol of the snake can be linked with the intestines and it needs to be pointed out here that the snake represents a mysterious force rather than a real snake. The "being" or "thing", sukwiy, once found by ancestors between the terrace stones was rather small and only looked like a snake, and is described as having no head or tail 
and rather like a worm. That sukwiy is considered to be inside the teba which is the most important religious item biy gwala use when they purify the sacred bull for its ritual release.

The metaphor of a snake for the sacred rope is also mirrored in the way the biy gwala meander through the village (see plate 6a). The first day, the only bulls to be released are those of the chief and of his political counterpart, which can be his deputy or an important representative of the non-chiefly clans. The following days, the processions of bay and biy gwala move through the various wards purifying and liberating the bulls. While the biy gwala move through the village the sacred rope is perceived to be very dangerous, especially for sorcerers. It also has the potential to enter into the stomach of a sorcerer where it mysteriously transforms itself into a snake and kills him. The biy gwala often divide into pairs and place their rope in front of the cattle shed of each person who has a sacred bull to be released. The teba has the religious function of removing evil and impurity from a sacred bull before its release. During the night the biy gwala place their ropes in the tarokw (old grindstone) of a family head whose maray is going to be the first to be liberated the following day. The metaphorical link of the intertwined fibres of the rope to the digestive tract is of importance. The carefully curled up sacred ropes and the snakelike walk of the biy gwala can be interpreted as images of social order. This is also mirrored in the order of the intestines curled up in the digestive tract and the way the ropes are arranged in the local order of kinship groups to each other.

The identification of the intestines with a snakelike being can also be interpreted as metaphors linking human and terrestrial fertility. The release of the first bull of each ward is often connected with the sacrifice of a ram. The biy gwala use the shuwed (intestinal contents) from this ram to smear over their bodies, teba and madzaf. They then carry out the rituals in front of the bull in his room inside the house where a libation with sorghum beer is made over the sacred rope and some of the herbs used to feed the bull. The biy gwala re-enter the house three times ${ }^{114}$ and come out again in a snakelike way, one after the other, disposing of the herbs with the ritual turn around the head. They subsequently collect their gifts of tiger nut paste, grilled sesame and beans as compensation for their work and then march away some distance from the house. There they line up in a row awaiting the liberation of the bull, which is carried out by one pair of biy gwala.

While the pair of biy gwala release the bull, the musicians play the antelope flutes (see plate 8c) accompanied by a group of singers and female dancers moving in a wavelike manner away from the house and back again (see plate 6c). First two females (often mother and daughter) of the household run out of the house in their traditional costumes (plate $6 \mathrm{~d}$ ). A relative of the owner of the bull takes up position next to the entrance holding a calabash filled with bean flour (plate 6e). Next the biy gwala appear followed by the sacred bull. The man waiting behind the entrance throws the bean flour over the back of the bull (plate 6f). This is the moment everybody has been waiting for and the crowd cheers, while the musicians and dancers build up to a climax. While young men recapture the bull, the two biy gwala who released the bull receive some bean flour, and as they did to the bull earlier, they now apply the flour to their bodies which are already covered with intestinal contents (plates $7 \mathrm{c}$ and $7 \mathrm{~h}$ ). The biy gwala also receive a meal and their share of sorghum beer. As soon as the bull is recaptured he is brought back into the house followed by the two females of the house. He is locked in his shed where he waits to be ritually slaughtered on the last day of the festival.

While the biy gwala do their job of purifying and then releasing the bull, the matsam entertain the crowd. The matsam also have their biy matsam (great jester) who has a "wife", ngwaz matsam, attached to him (see plate 8a). The matsam often wear wooden masks over the backs of their

\footnotetext{
${ }^{114}$ I didn't ask whether the invisible "one" needs to be added here in order to make it four. Considering that this is a regular phenomenon in Mafa ritual counting, I nevertheless assume that it applies here as well.
} 
heads and are dressed in a mixture of cotton and traditional clothing. Although they are considered as comedians they are feared by the crowd and supernatural powers are often attributed to them. A biy matsam is frequently a successful hunter and he often wears the hides of the wild cats he has killed as a sign of his mysterious powers. In the past matsam were often known as successful warriors during times of tribal warfare. Their reputation as hunters and killers has given them a leading role in a ceremony at the end of a bull festival where all those who have killed a person have to perform a ritual over a sacred pot called madzagay ( $\operatorname{mad} z=$ to blacken, to make black).

During the bull festival the matsam cover their faces with the charcoal from the bottom of cooking pots and deliberately eat and drink out of dirty bowls and calabashes. The biy matsam and his ngwaz matsam are very good at imitating and making fun of potential conflicts between husband and wife by dramatising emotions like jealousy, separation and reunion. Their play always contains scenes wherein the biy matsam pretends to penetrate his "wife" with a ridiculously long wooden penis. Matsam always possess imitations of weapons and regularly aim them at people, who react with a mixture of fear and amusement. They collect gifts of food and money during the bull festival. After the biy gwala have completed their work at a particular house the matsam line up in front of them to receive further "orders". In the context of a ritual hierarchy the matsam are seen as the subordinates of the biy gwala.

The blacksmiths, too, have a particular ritual function in the context of the release of the sacred bulls of a village community. The biy gwala as well as the group of the bay have their own ngwazla. The place a ngwazla is allocated by the biy gwala is always at the head of their group to provide them with ritual protection. They are specialists in removing impurities although ngwazla are not considered to be pure themselves. However, due to their exclusive social status they are perceived as being in a position to ritually transgress social boundaries by performing potentially impure actions, something a non-blacksmith would not be allowed to do. The ngwazla attached to the bay is the biy ngwazla (chief of blacksmiths). When the group of bay change place during the bull festival the biy ngwazla always goes ahead of the first and second gad bay. Before the chief's deputy can sit down again, the chief of blacksmiths ritually cleans the place where he is supposed to sit. He uses the amputated foreleg of a wild cat and sweeps the potential seat and after the deputy has taken his place he sweeps over his head in a symbolic gesture of purification.

The bay, dressed in their festive cotton gowns, await the gifts brought to them by the owners of the liberated bulls (see plate 8d). During the day the bay might change their locations a couple of times. If they are a new group, forming after the investment of a new chief, the actual pattern formed by these locations might change. The places where they rest to enjoy the fruits of the ritual labour of the biy gwala, who successfully liberate one bull after the other, mostly consist of groups of rocks and flat stones with some trees to give the necessary shade. While the two musicians beat the drums of the chiefs and praise the greatness of the absent biy wudam, the gad bay and bay spend the day drinking and eating what is provided for them. It is after the biy gwala have completed a day's work that the bay can make their way back to the chief's house, where his deputy is ritually undressed. Before it comes to this point the biy gwala arrive and report to them how the day went and any difficulties they encountered. If there have been problems they are discussed and later on the gad bay will report to the biy wudam chief as well.

The purification and ritual release of the sacred bulls of a village might take from between one week and several weeks, depending on the size of the village community. The order of the processions follows local historical criteria of first comers and late comers, chiefly and nonchiefly clans, social or political position and the way in which a kinship group of lower status is associated to one of higher status. The procedures applied depend on events and political 
arrangements a village community interprets as its local history, which also affects the way the bull festival begins, passes and ends.

The end of the bull festival is reached as soon as the last bull of a village has been successfully released. To celebrate the closure of this most important and time-consuming phase of the bull festival bay and biy gwala usually reunite at a particular common ground. The ending normally takes a certain ritual form in which the sacred ropes of the biy gwala need to be put ritually to rest in the context of a sacrifice. For a last time all sacred ropes of the village are piled up together in the order of the local historical positions of the kinship groups and the ward they represent and the blood of a chicken is poured over them. Another aim to be achieved is the ritual separation of the bay and biy gwala. Such a performance might involve the request of the chiefly drum (see plates $9 \mathrm{a}$ and $9 \mathrm{~b}$ ) by the biy gwala to open a dance in which the drum becomes the centre of a snakelike spiral which all bay and biy gwala join (plates 9c and 9d). After the spiral has narrowed down to the centre of the drums the musicians join them playing their flutes, and groups of young men of the village folow suit. While the public joins the dance the bay and biy gwala begin to separate out again in order to line up and to leave the common ground.

As at the beginning of the bull festival it is night and a big fire has been lit. Eventually the biy gwala return the chiefly drums and with these drums and the biy gwala in front the bay begin their final walk to the chief's house. They are accompanied by groups of young men carrying torches of corn stalks to light the path. Just before the whole procession reaches the house the bay and biy gwala who do not belong to the chiefly lineage drop out in order to make their way home to their own wards and houses. The gad bay and the bay of his lineage enter the chief's house where the his deputy is ritually undressed and the indigo gown, the red felt hat and the two iron lances are stored away for the next bull festival. The same night the leading biy gwala teba enters the house of the biy wudam and ritually disposes the sacred rope of the chiefly lineage. After all this is achieved the purification and liberation of the sacred bulls of the village is officially over.

\section{The ritual slaughtering of the sacred bull}

One or two days after the purification and release of the bulls, the slaughtering begins. The village chief looks at the weather and if it is very misty he will be pleased since this is interpreted as a sign from God confirming the success of the bull festival. Such misty weather following the release of the bulls is particularly welcomed by a new chief and his kinsmen, since it means that he is from now on accepted and fully respected. The day after the release is reserved for the biy gwala and matsam to bathe since they were not permitted to so during the period of purifying the bulls. This is the day when the biy gwala wash off the intestinal contents now crusted over their bodies and when the matsam get rid of all the charcoal and other dirt they have smeared on themselves during that phase.

All purified bulls are slaughtered within a very short period during the early hours of the morning. Mafa like to slaughter their bulls this early in the morning because they fear that impurity could be brought about again if too many spectators came along. The owner of the bull has to be pure too, which means that he is not supposed to make love to his wife the night before the ritual slaughtering. The rules of purity also apply to those who assist in the slaughtering of the bull. The house owner himself is not present when the actual killing takes place. This is carried out by a friend or neighbour.

First a long rope is slung around the bull's neck while he is still in his shed. The other end is put through a small hole in the wall above the door of the hudokw nngura (sacrifice room) and taken back out again through the door. The hudokw nngura is not far from the kudam zlè (cattle shed) and after the shed has been opened up the bull is pulled by the rope (using the hole above the 
doorway as a fulcrum) so that his head comes close to the entrance of the sacrifice room (see plate 10a). While the body of the bull remains in the lobby area between cattle shed and sacrifice room, his head is now forced through the door of the sacrifice room. When this position is achieved a clay bowl is held under his throat inside the sacrifice room so that the blood can enter into it (plate 10c). As soon as the throat has been cut and the blood completely drained out of the slaughtered bull, the owner returns into the lobby area where the bull has been turned on his back by the slaughterers. The owner of the bull holds the wooden handle of a hoe in his hand and while tapping the bull's head, chest and back legs with it he repeatedly calls out: "Who has killed my bull?" (plate $10 \mathrm{~d}$ ). He is supposed to appear surprised and moved that his beloved bull has been killed.

Next, water is handed in a gandaf (eating bowl) to the slaughterers who each dip their fingers in it and taking some in their mouths, they spit it over the bull. The owner of the bull sprinkles the rest of the water over everybody who helped and witnessed the slaughtering (plate 10e). Then the owner takes some green leaves from a tree and places them in the mouth of the bull (plate 10f). Sorghum flour is sprinkled from a small calabash on to the bull's chest and the eating bowl is put upside down over it (plate 10g). Finally the owner takes the slaughtering knife with some of the blood on it and positions it between the sorghum flour and the eating bowl on the dead bull's chest (plate 10h). It is an impressive sight seeing the fattened, then purified and now slaughtered bull being decorated in such a way. Finally, the owner takes a potsherd with some of the blood of the bull on it and places it on the public pathway outside the house.

The men of the slaughtering party now gather in the foyer to drink sorghum beer. The head of bull with the green leaves in its mouth is bent towards the room so that the arrangement of the white bean flour and the red blood on the blade under the gandaf on his chest remains visible. The beer is shared and consumed in the usual way by being poured from a clay pot into a calabash which is then shared out to the slaughterers and family members. When the beer has been consumed the bull is carved up in the following way.

First, the bull is separated from his skin and as soon as the fat underneath is accessible the women and children of the family come with knives and cut off small pieces which they eat immediately away. Next, the bull is rolled around and the process of carving up the skin continues. Dung from the cattle shed is used to soften the ground when he is turned over on his side. Eventually, his thorax is opened up with an axe but during the whole process the huge stomach remains untouched. The ribs with fleshy parts are carved up and rolled in cornflour before they are packed away to be distributed later. The entire stomach area is carved away from the front legs and hindlegs which remain connected over the spine and back. The front legs and hindlegs are now separated and the fleshy parts carved off the back are put aside. Then, the head is separated from the neck and placed together with the hindlegs in the cattle shed. The head is going to be part of a ceremony, while the hindlegs are going to be cut apart and distributed.

Now, the stomach section of the bull, which lies there on its own like a huge balloon, is cut open. The intestines, the various stomachs, the heart, the liver, the lung, the kidneys and so on are all being carved out and put aside. The large intestines are rolled up like a skein of wool and cut in two. In their physical form they resemble the sacred rope and it is indeed the biy gwala who will receive this part of the digestive system of the bull. After the intestines for the biy gwala have been cut the intestinal contents are squeezed out and poured into a large bowl. A soup will be cooked from this and consumed by the family later on, a highly regarded meal among Mafa.

After the slaughtering of the bull is completed and before the sharing of the meat can take place, a neighbour, his nephew (son of his daughter) and his married sister enter the cattle shed to pick up some of the dung produced by the bull. They carry the dung in their hands out of the house and 
put it out on the roadside. This is done three times ${ }^{115}$ and called ngwazla hutsad auda, meaning "blacksmith takes fertilizer outside" (hutsad = ashes, fertiliser). The ritual distribution of manure on the road leading away from the house reinforces the view that the bull festival is also a religious quest for land fertility.

\section{Sharing the meat of the sacred bull}

The meat from the purified and slaughtered bull is shared in a particular way. The right hindleg is for the oldest married son of the owner of the bull. If there is no married son then his brother will receive it. In case there is no married son or brother, a male lineage member close to his family will receive the right hindleg instead. The left one is for his oldest married daughter. The rib cage is for his wife or wives. The front part between the ribs down to the testicles is for the sons of his married sister or daughter. The neck is for the person who fed the bull, which can be a male or female member of the family or even the owner of the bull. The part behind the neck on the back is for those who held the bull for slaughtering. The back with the spine is divided in three parts, the highest part for his first daughter, the middle part for his first sister and the lowest part together with the tail is for his mother. The upper right front leg is for his matrilateral uncle. The upper stomach is for his tsava (family elder). The long intestines are for the biy gwala so are the intestines in the form of a small spiral ${ }^{116}$ connected to the lower stomach. The latter is placed inside the lower stomach where it is conserved for several weeks. Later it is taken out and distributed to the most important biy gwala. The feet are given to the blacksmith while the village chief receives the throat.

It is the first maslay (best friend) who separates the meaty parts between the back legs, which are given to the second maslay while the first mazlay receives the meaty parts of the head. ${ }^{117}$ The first maslay normally arrives after the bull has been carved up and the sharing of the meat is completed and he scrapes the meaty parts off the bull's head. The head is then taken outside to a place nearby the house where the children who helped fatten the bull cook the head and consume the meat left on it by the best friend of the owner. The skull is later carried back into the cattle shed for a sacrifice and beer libation called zom gad zlé, meaning "beer for the head of the bull". A few months later, during an even month in the early rainy season, a neighbour attaches a rope around the skull and pulls it out of the cattle shed on to the front courtyard of the house, from whence it is hung in the sacred tree of the house.

\section{Getting a new bull}

In the past it was the ideal of a man to fatten a bull for at least a year or even longer. This is now changing and there is far less ritual slaughtering of bulls which have been fattened in the traditional way. Bulls as well as cows are nowadays sold on the market to make a monetary profit. The meat of a fattened bull slaughtered at the end of the bull festival cannot be sold but must be shared among relatives and friends. The redistribution of the meat of all the fattened bulls symbolises the prosperity of the village community as a whole, but it is exactly this part of the bull festival which changes first. The period of fattening a bull is getting shorter and shorter and the bulls released at a bull festival are often only bought a matter of weeks or even days before the beginning of the festival. What seems to have survived is the ritual release of the bull, but there are also changes occuring here. First of all the traditional costumes worn by the biy gwala

\footnotetext{
${ }^{115}$ Here again, I assume that the invisible "one" needs to be added in order to make it even.

${ }^{116}$ The name of this part is ńdadawak, which is also the word for the rolled fibre head ring worn when carrying heavy loads.

${ }^{117}$ Every Mafa man should have not only one, but two maslay. This reinforces the importance of the number two in their ritual counting and worldview.
} 
are disappearing. Secondly the application of intestinal contents to the body of the biy gwala has diminished to just a small amount being put on the face. The number of bulls being released is declining and it seems it will only be a matter of time before the bull festival of the Mafa disappears completely.

The lack of sacred bulls might go hand in hand with a development in which the replacement of a traditional village chief can no longer be achieved, because few men nowadays would agree to take on this role. Too many personal disadvantages are attached to the office and it is not a job to get rich by. Most of the gifts received by the traditional chief at ritual occasions, like shares of sacrificed meat or sorghum beer, are redistributed and cannot be sold at the market. The interim periods after the death of a village chief and his replacement are getting longer. This leads to a situation where the traditional value and status attached to fattening, slaughtering and sharing the meat of a sacred bull gradually becomes lost along the way. The market forces for buying and selling cattle replace the traditional forces of a communal quest for fertility and prosperity, and the religious aspects of purification attached to that.

\subsubsection{Aspects of ritual and social structure}

The ritual activities described above, in the context of the beer father ceremony, the harvest festival and the bull festival, display different levels of community integration. They are not only a spatial but also a chronological component of the traditional calendar. The smaller the spatial range of a ritual, the earlier in the seasonal year it is performed. The succession of rituals begins with the beer father ceremony, followed by the harvest festival and ends every three years with the bull festival. The beer father ceremony is concerned with the continuity of the minimal lineage as the smallest local group of patrilineal descent, while the harvest festival aims for the territorial unity of local clan groups. The bull festival stands for the political unity of the village community as a whole with the purification of its territory at centre stage.

\section{Linking status and alliance}

Traditional Mafa communities generally consist of three types of local status groups: chiefly clans, non-chiefly clans and blacksmiths, where a certain dualism cannot be denied. There is first of all the general social division between vavay (non-blacksmiths) and ngwazla (blacksmiths) with the non-blacksmiths being $97 \%$ and the blacksmiths only about 3 per cent. Within a village community the non-blacksmiths can be sub-divided into kar bay (chiefly clan) and non-chiefly clans. ${ }^{118}$ The non-chiefly clans are preferred marriage partners for the daughters of chiefly clans. In this function they can be referred to as sasak. Certain non-chiefly clans are also often referred to as kada. While there is no literal meaning for sasak, the word kada can be translated as "dog", a pejorative expression referring to the fact that kada are generally considered as strangers. ${ }^{119}$ However, the distinction between sasak and kada is not as straightforward as it sounds, which means that kada daughters can indeed be marriage partners for kar bay. My experience is that the word $k \partial d a$ is mainly used by so-called sasak clans to state that sasak have a higher social status since they are not obliged to exchange ritual beer outside their local clan group. This is different for the so-called kada who are often obliged to bring religous beer to their chiefly or non-chiefly host clans demonstrating that they have received their land from them.

\footnotetext{
118 There is no general Mafa word for non-chiefly clan.

119 Martin's (1970:77f) interpretation of the word 'kéda' $(k \partial d a)$ as the general word for stranger is far too simplistic. There are strangers in villages who are not at all considered as kada but simply as people who are not born there. Martin makes no mention of the word sasak as a reference to a particular social status but only as a clan name (op.cit.:35,87).
} 
Everything depends on the history of the relationships between the chiefly and the various nonchiefly clans of a local community and we will see in Chapter Four which forms such relationships can take. At the moment I only want to mention the general social divisions which exist in a traditional village and to point out the importance of local marriage preferences between chiefly and non-chiefly groups, which they have developed over time. The fact that the nonchiefly clans function as wife givers for chiefly ones has influenced the way Mafa communities are socially divided. Every village consists of a majority of lineages belonging to one chiefly clan and a minority of lineages who belong to a group of non-chiefly clans. Therefore, the men of the chiefly clans marry most of the women from the non-chiefly clans. ${ }^{120}$

This might also be one of the reasons behind the fact that some non-chiefly clans have developed pseudo-clan relationships between each other. These relationships can exist beyond village boundaries and are generally referred to as ńshibene. ${ }^{121}$ Pseudo-clan relationships do not exist between chiefly clans. Clans which are ńshibene to each other do not intermarry but do exchange funeral beer. The obligation to exchange funeral beer normally only exists between groups of the same patrilineal descent. The fact that non-chiefly clans have developed pseudo-clan relationships can be interpreted as a political reaction to their role as wife givers to the chiefly clans. Since non-chiefly clans are generally not as numerous as chiefly ones, the latter have a stronger interest in finding women outside the village. However, the local development of chiefly clans, and the marriage preferences coming into existence alongside it, have brought about territorial communities of chiefly and non-chiefly clans.

\section{Ritual control and social structure}

Clan exogamy seems to be at the root of a mode of exchange which concerns itself with the maintenance of a moral system where men exercise ritual control over the reproductive capacity of women. Because Mafa men are not allowed to marry their clan sisters, fathers are obliged to give their daughters into marriage outside their own clan group. The children of a married woman are born into her husband's group and if they get divorced she must leave her children behind, or give them back when they reach a certain age. A woman belongs to her husband's clan only so long as she is married to him, which also gives her the right to benefit from her husband's ancestor worship. As long as she is married she is excluded from direct participation in the worship of her father's ancestors.

The social appropriation of children by fathers and the induction of married daughters into the religious service of their husband's families is supported by the idea that God the father controls his wife when new life is born. For traditional Mafa, conception is not just a matter of coition but has a metaphysical dimension. It is a generally held belief that a man will not become a father if his personal god is sterile. Personal gods of men are considered to be the "children" of God and his wife. This means that not only the concept of paternity but also that of power over any reproductive capacities is taken from the religious image of God "standing behind" his supreme

\footnotetext{
${ }^{120}$ This has also been recognised by Martin (1970:163).

121 The meaning of shiben is to lease or to rent, but ńshibene means a great deal more than that. The exclusion of intermarriage in favour of a chiefly clan might have brought about a situation in which land is leased out between nonchiefly clans. Also Zuiderwijk (1998:100ff) discusses ńshibene (he spells it 'inshushume' or 'ushushume'), but seems to have missed the rather complex meaning of this concept, especially when it is used to refer to existing pseudo-clan relationships and in its significance in the context of bride service. In its latter function Mafa tend to speak only of $s h i b$ (to work on the land of a future father in-law). However, the meaning of the expression ńshibene in the context of leasing or renting out land (especially between pseudo-exogamous clan groups) could be interpreted as a replacement for the institution of intermarriage (alliances are formed via the fertility of land rather than that of daughters).
} 
wife when she "makes" children. The guiding power of men in this world can therefore be seen as a social reproduction of the ontological principle of God the father as first mover. ${ }^{122}$

The Mafa idea of creation and paternity not only influences their social thinking but also their political thought, and their principle of agnatic descent can be interpreted in this context. I have already discussed the ritual function of the gad bulom (in the context of the beer father ceremony) and explained the concept of gwaliy, as the word for clan and kinship in general, but have not yet explored any intermediate concept of patrilineal descent linking both, which is that of gwadar. The word gwadar also means pelvis, as such containing an indirect reference to human fertility, which would be expressed among Mafa, if at all, by saying gwadar ndo mbela'a (the human pelvis is good). This means there is no Mafa word for fertility but they refer to the pelvic region as a metaphor for the reproductive capacity of women.

The word gwadar (or 'godar' as it is spelt by Martin) ${ }^{123}$ is an expression used to refer to a specific lineage connection on an intermediate level of descent between the gwaliy and the gad Gulom but Mafa seldom use it. Unlike the gwadar, the gwaliy is a segmented kin group with a local ancestor of between five to seven or more generations removed. There is not necessarily a lineage elder of a gwadar as is the case with the gad bulom although there might be several gwadar identifiable in a clan or lineage ward of a village. Such gwadar are quite often distinguished on the basis of two local ancestors being half-brothers which is a lineage fission Mafa refer to as ngwaz ngide, meaning "other woman". The expression ngwaz ngide brings us back to the fact that women serve as patrilineal indicators in constructing and maintaining a genealogical split. However, it is far from clear whether these particular ancestors actually had the same father, which confirms the metaphorical meaning of the concept.

The concept of gwadar (major lineage) is particularly important for the large chiefly clans of a village who have split into groups and sub-groups of lineage wards. We often find the notion of ngwaz ngide being used to explain the genealogical intricacies of how new lineage wards came about. In the context of such local background histories a gwadar can also develop because a local ancestor "inherited" (levirate) the wife of his deceased brother. If the late brother was older, the children his younger brother inherited might even be considered to be senior to his own. So inherited sons often become founders of new lineage wards, but, at the same time, retain the right to carry out sacrifices on sacred sites of their ward of origin.

\section{Ritual and territoriality}

The Mafa system of patrilineal descent is of major significance for the way they construct locality and community, although alliances (created and maintained by the institution of marriage) represent a most important bond between chiefly and non-chiefly clans. This is of great relevance for the territorial integrity of a village and counteracts the parallel scenario where Mafa men marry the daughters of their enemies. Both situations occur, but the existence of large chiefly clans which function as wife takers points to the development of such a system as a tool for political integration. However, it is unlikely that this preferred way of intermarrying was intended to reduce the potential for physical conflict since one of the main causes for warfare was the chronic shortage of land. It was important for multi-clan communities to expand in order to strengthen their political potential and to gain control over local resources. Another argument is the control over human resources and tributes which had to be paid to the Wandala and Fulbe.

\footnotetext{
122 See Carol Delaney (1986) for the theoretical debate on "primitive" procreative beliefs and the notion of paternity.

${ }^{123}$ Martin (1970:74) speaks of 'godar' and not of gwadar and does not refer the metaphorical meaning of the word although he, too, identifies 'godar' as major lineage and writes 'On peut appeler ces godar lignages majeurs parce qu'ils sont l'unité maximum de segmentation des groupes de parenté chez les Matakam.'
} 
The vertical stratification of enlarged Mafa communities allowed the internal exploitation of weaker sections and the maintenance of tributes provided protection for all (both the weak and the strong) against sudden slave raids.

Warfare was an indispensable tool for gaining ritual control over the territories of neighbouring communities, and here we need to avoid using purely secular images of territoriality. As soon as a larger village conquered a smaller neighbour, the ritual right of that neighbour to announce their religous festivals independently was restricted. However, the internal integrity of the conquered village stayed intact, meaning that the inner composition of ritual sequencing remained untouched. In cases where this right was not respected, any misfortune was interpreted as being a result of inappropriate changes in the ritual design of a community.

Mafa rituals can be seen as significant sites of political dispute over local resources of fertility and land, a process which incorporates not only continuity but also change. This brings us to the concept of custodianship, especially with regard to land fertility and the ritual removal of impurity, resulting in a religious quest for community prosperity rather than the pure maintenance of territorial rights. We also need to ask whether access to terrestrial fertility is just about land or about fertility in general. Although Mafa have no general word for fertility, it appears to be the primary concern in most of their religious practices. So, what else could fertility mean for traditional Mafa other than prosperity, wealth or even power? In this sense, land, animals and women are fertile, and in relation to these, the word fertility can also be replaced by the word productivity. Other possible symbols for fertility could be resources which are most needed or desired, like manure, children, land, sorghum, cows, wives, rain, and, not forgetting, in the past, the power over fellow humans in the context of the regional slave economy. Power is also perceived to be invested in things which are not wanted at all, like plagues, slave raids, droughts, poverty and sterility.

To reproduce good things impurity needs to be removed or chased away in exchange for wealth and prosperity. Exchanging misfortune for good fortune has a metaphysical component and does not only include things of this world but also those of the parallel worlds. This could mean a sacrifice to God and the ancestors wherein divination would be the most important tool for identifying the item to represent the transaction and the method for carrying it out. We can see from this that the metaphysical worldview provides a conceptual framework in which terms like fertility, productivity, misfortune, disease and exchange can be understood. Entities like rain, sorghum, ancestors, land, rocks, rivers, twins, blacksmiths, bulls, can have the invisible quality nya'a, which allows them to mysteriously transform themselves, to multiply or to completely disappear. To keep control over such processes, regular ritual activities need to be carried out.

\section{Ritual and symbolic classification}

I have described above the most relevant ceremonies and festivals for the social and political construction of a village. All community rituals seem to have in common a strong component for removing impurity. We have also seen the importance of even numbers and pairs or couples, as ritual representations which Mafa seem to believe invite good fortune. Their ritual use can also be interpreted as an attempt to influence the mysterious forces certain things are endowed with and which make them different from other things. The mysterious force nya'a is relatively inaccessible to ordinary people and therefore needs ritual attention by specialists who are also nya'a (born differently).

The ngwazla are the epitome of such a specialist group, where symbolic dualism is also perfectly achieved in terms of social structure. However, it is only the vavay who stand for general prosperity, whereas the ngwazla are considered as impure and socially infertile. It seems to be a 
contradiction in terms that those who are seen as the most impure should have so much ritual responsibility for the vavay. Apart from marriage, the ngwazla play a role in most vavay rituals. There seem to be similarities between the mysterious forces of blacksmith and the power of twins. They too are seen as being nya'a and can be understood as the "empirical" proof of the mysterious forces which, under normal circumstances, remain physically invisible. This is a very dangerous situation and special ritual attention needs to be paid to managing their potential for destruction. The symbolic similarity of twins and blacksmiths is also reflected in the Mafa calendar. The twin ceremony (halalay) is carried out during the month malama, which is the same month when blacksmiths serve their family ancestor, while the non-blacksmiths deliberately lock away their ancestor pots. Blacksmiths like to get married during malama, but nonblacksmiths do not. It seems to be the month Mafa have devoted to the forces of nya'a and apart from the twin ceremony, non-blacksmiths do not perform any other rituals during malama.

I have referred to the existence of symbolic dualism in Mafa society quite frequently in the course of this chapter to emphasise its relevance to the religious life of traditional Mafa. Another reason why I stress its structural importance is to link the concept of nya' $a$ with that of the person. The dualism between body and mind seems to be inherent in Mafa philosophical thought which becomes apparent in the model of the spirit or soul, mezheb (shadow), as an invisible mirror image of the visible (physical) person. The concept of a visible and an invisible part of the human might also have served as a model for the belief in a visible and invisible world which are perceived as being parallel but not inseparable from each other. The fear that the spirit of an individual could be "eaten" or "kidnapped" by mide (sorcerers) shows how concerned Mafa are with the mental components of their world. Material, as well as immaterial things, like sorghum or a human soul, can suddenly disappear when the transformational forces of nya' $a$ are being used negatively. Divination to identify the source of the problem, followed by the appropriate ritual action, will be required to bring about a positive transformation.

Other structural elements of Mafa symbolic thinking are found in the ritual distinction of male and female and right and left. We have seen in Chapter One that the principles of male and female are metaphysical entities and that the male principle enjoys ontological superiority over the female one. I have interpreted this as a gender-driven model of procreation which allows Mafa men to maintain the moral right to control all reproductive capacities. This becomes particularly apparent in the context of their ritual counting during the wedding night in order to establish whether the first-born child of the father of a man was a male or a female. Mafa in the area of Gouzda count "two" plus an invisible "one" which makes it "three" and, therefore, odd for a girl. If it was a boy they count "three" and add an invisible "one" in order to make it even. They argue that they cannot accept a higher number being allocated to a female than to a male. Since the first possible even number is "two" and the second possible one is "four", they cannot use the "two" for male. Therefore an invisible "one" is added to "three" in order to count for male superiority in the process of symbolic procreation.

However, their ritual counting also displays the underlying idea of the metaphysical unity of male and female in their concept of the invisible "one" which they tend to add in order to make odd numbers even. I therefore tend to believe that the invisible "one" Mafa add has a unifying rather than a separating function. They know that they cannot reproduce without women, but it would be morally inconceivable for them to see men and women as socially and politically equal. To embrace the female aspects of the forces of nya'a therefore requires taking control not only over terrestrial but also over human fertility. However, dealing with the female qualities of the universe is perceived as a potentially very dangerous undertaking and so requires the utmost ritual care. That the ultimate purpose of Mafa ritual is to strive for unification rather than the separation of the sexes (in terms of cosmological principles as well as in sexual relations) is also 
demonstrated in the fact that the calabash is balanced on the back of the ancestral pot. The ritual actor has to take both hands off the calabash and only when this is achieved has God accepted the offering.

That the Mafa of Gouzda reverse left and right as well as odd and even presumably represents a rare ethnographic case. As Hertz (1909) and Needham (1973) pointed out, most societies consider the left side and even numbers as female and the right side and odd numbers as being symbolically male. The fact that Mafa reverse the two could be explained in the context of the high population density and scarcity of arable land and the social issue of males wanting to control all reproductive capacities. This might explain why the metaphorical "beer of the bay" is always handed out with the left and not the right hand. If a custodian has the real position of a bay he will use the left hand himself to carry out the sacrifice, while a real biy gwala would always use the right hand. The reason is not that Mafa perceive the left hand as always being male, it is in fact the contrary. The left hand is in most situations perceived as female and only in particular contexts is the order reversed. Such a situation occurs when a bay uses his left hand because he represents "greatness" rather than "following". He stands for the prosperity and the good fortune of his group and by doing so he embraces the female and the male elements by using his left hand. We will see in Chapter Four how the notions of bay and biy gwala are used as structural devices for the historical integration and ritual maintenance of the Mafa as an ethnic group.

\subsubsection{The "way of the beer"}

The "way of the beer" begins with the moral bond between a late father and his oldest living son and ends with the relationship between the ritual representatives of at least two local communities. The passing of sacred beer can take many forms, all of which are derived from the image constituted of the ritual dependency between a dead father and his oldest living son. Such ritual relationships can be expressed in terms of relative age or genealogical positions, and the differing social statuses of co-locating groups or the consecutive time of their arrival. Another indicator is the population size of local groups. The larger a group the more important it becomes. What is essential is that the "way of the beer" re-enacts the correct historical sequences of how these relationships are believed to have come about so that the rituals attached to them can have the moral capacity to maintain the social and political order they are intended to represent.

Earlier, I referred to sorghum beer as the "Eucharist" of Mafa religion. This is not truly correct, since the sacrament or elements of the Lord's Supper consist of the mysterious transformation of wine into the blood and bread into the flesh or body of Jesus Christ as the "son" of God, through his self-sacrifice. The lowest common denominator is found in the literal meaning of Eucharist, the Greek word for thanksgiving. However, there are similarities in the importance of the symbolic meaning sorghum beer has as the ritual substance and epitome of the mysterious transformational forces. Not only sorghum, but also sorghum beer is nya' $a$, the latter having not only a metaphysical quality but also an obvious physical effect. Mafa like to become rather uplifted by the alcohol during their religious services, especially after the balancing of the calabash on the back of a spirit pot has been achieved and the party is finally convinced that God is favourable to the ritual action taking place. However, they rarely become drunk from religious beer, since the amount is usually limited and cannot be bought in the marketplace.

In the following chapter we will reconstruct local history as it unfolds in the context of the "way of the beer". The aim is not only to demonstrate that the ritual design of Mafa communities I have presented above is coherent, but also to show how history is ritually re-enacted by not only 
evoking old histories but also by embracing the emerging new ones. ${ }^{124}$ This means that the "way of the beer" is not simply the re-enactment of existing local power relations but also represents social and political change taking place over time. How the political integration of multi-clan communities came about is what is ritually re-enacted in the purification ceremonies and festivals described above.

One of the main themes of local historical change centres around accounts of who was first and who subsequently became the chiefly clan of a village community. New chiefly power evolved in the context of the growing numbers of members of one local kinship group over another, a principle which could potentially lead to fundamental change in existing power relations. The formation of multi-clan communities through the creation of new chiefly alliances of warfare and political co-operation represents only one side of the story. The other main theme is the striving for territorial independence and ritual autonomy of the smaller (non-chiefly) clan groups. This is manifested in the fact that traditional Mafa always prefer to receive rather than to give ritual beer to representatives of other groups. Despite the intense process of population growth, political integration and territorial contestation, safeguarding local and ritual autonomy remains the most important political issue for the Mafa.

${ }^{124}$ As Kelly \& Kaplan put it, 'rituals in ongoing practice are a principal site of new history being made' (1990:141). 


\section{$4 \quad$ Reconstructing local history}

\section{Introduction}

The local study area (figure 3) consists of six traditional village communities (wudam) each of them represented by a traditional village chief (biy wudam). The names of the villages are Gouzda, Mafmay, Woulad, Mazay, Mouzoua and Mtskar. There are also administrative villages which overlap the distribution of traditional communities. For example, in administrative terms, Mouzoua is no longer considered as a village and has become a part of Mazay instead. However, in traditional terms, Mouzoua must be considered as an independent community, attached to Mtskar rather than to Mazay. The same applies to Mafmay, which is administratively a part of Gouzda. In traditional terms, Mafmay is a village in its own right but, as such, is associated with Gouzda. Overlapping or crosscutting boundaries between administrative and traditional communities also exists inside villages where small traditional wards have been administratively merged with larger wards, regardless of their traditional belonging.

This has brought about two systems of community running alongside each other without too much problem; the traditional villages represented by a traditional chief (biy wudam), and the administrative villages by a village head (lawan). At the organisational level of the village ward we find the lineage representative (bay) and the administrative ward head (bulama). Mafa try to avoid traditional and administrative functions being held by one and the same person although this is not always the case. During my time in the mid and late 1980s a man called Faisam was not only the village head of Mtskar, but also the traditional chief and the mountain priest. However, Faisam was an outstanding personality and, after his death in the early 1990s, the succession was split. In this work I will not comment much further on the subject of overlapping community structures, but concentrate mainly on the reconstruction of the local history of the traditional villages.

Lavergne (1944:17) sees 'Goussda' to be part of the Wandala zone of influence with 'Mozogo' as their outpost, officially confirmed under the Germans in 1912. Lavergne (1944:22) mentions Gouzda a second time in the context of the "Mafa" autour de Roua et surtout Soulédé' from where the 'Vuzei ou Vuzi' and the 'Djélé ou Zélé' also migrated to Gouzda and 'Djinglia'. ${ }^{125}$ Martin (1970:42n) mentions the killing of the Wandala chief Tigréa Haissa of Mozogo, in $1928,{ }^{126}$ by the inhabitants of Gouzda. It is interesting to note how his grandson, in the year 2000 , is now fighting for his political survival as the last representative of the Wandala zone of influence in Mafa land. ${ }^{127}$ It seems that Koza, the capital of the canton of Koza, of which the area of Gouzda is part, only developed into a Wandala outpost after 1912. In the mid 1990s a Mafa replaced a Wandala as Koza's chef de canton. The main reason for this recent power shift from Wandala to Mafa is that the Wandala only represent a small minority of the population in the

\footnotetext{
${ }^{125}$ For geographical reference to places mentioned in relation to the regional origin of clans found in the research area, please refer to figures 1, 2 and 3. Depending on the distance from the research area, these places are found on different maps. Some of the older maps of other authors are not correct and I have chosen not to refer to them. However, to give one important example, Martin (1970, fig. 2) places 'Mtseukar' (Mtskar) north of 'Moudougoa' (Moudoukwa), but this Mtskar (there are several Mtskar in Mafa land) clearly neighbours Gouzda immediately to its north.

${ }^{126}$ Capitaine Lenoir (1929) reports violent events in the area of 'Gousda' (Gouzda) which took place in July 1929.

${ }^{127}$ In March 2000, the chef de canton of Mozogo, a Wandala, came to see the regional MP, a Mafa, complaining about rumors to reduce the canton of Mozogo in size by giving a large section of it the status of a canton. The chef de canton expressed worries about the loss of incoming taxes. The MP later explained to me that the Wandala were only a very small minority in the canton of Mozogo while the majority were Mafa. Compared with the importance of Mozogo as a centre for the collection of tributes during the time of slavery during the $19^{\text {th }}$ century, as indicated by Denham's report (see chapter 1.2.1), it seems that the Wandala, although only a minority, were able to hold on to Mozogo until now.
} 
plain of Koza and Mozogo. However, Koza, as base for Wandala administrative powers, was only founded during colonial times. Mozogo, however, was presumably already in existence in precolonial times, as our reinterpretation of Denham's reference to 'Musgow' (see Chapter 1.2.1) strongly suggests.

We do not know when Gouzda came into existence as a traditional village community and the same applies to the other five villages of the local research area. However, the area of Gouzda, situated along the lower eastern slopes and foothills of the Ziver-Oupay massif shows that currently, the Vuzay and the Zhéle are the dominating groups in terms of population size and territory occupied (figure 7). Lavergne (op.cit.), too, named the Vuzay and the Zhélé as the largest of the Mafa clans and identified them correctly as originating from the area of Soulédé. The stream of migration of these two very large Mafahay clans took a northwesterly direction and was parallel to the Vuzay in the south and to the Zhélé in the north. The parallel pattern of geographical distribution of the Vuzay and Zhélé is also found in the area of Gouzda with the Vuzay as the chiefly clan of Gouzda and the Zhélé as the chiefly clan of Woulad and Mazay. However, Woulad, as well as Mazay, are under the traditional authority of the biy wudam of Mtskar, who is Wula-Sakon. The traditional authority of the chief of Mtskar is expressed by the fact that Woulad and Mazay cannot announce their harvest festival unless Mtskar has received ritual beer from the Ruwa of Mazay (figure 7) who are their representatives.

Oral tradition indicates that the Wula-Sakon, coming from Wula in Gouzda, founded Woulad, Mazay and Mouzoua before they settled in Mtskar. The Zhélé followed, coming later from Djinglia, and settled first in Woulad and then in Mazay. Mafa would express this relationship by saying that the Wula-Sakon are the bay of the Zhélé who, in turn, are their biy gwala. To provide continuity for their authority, the Wula-Sakon trusted the Ruwa of Mazay to ritually represent them. The Ruwa are a very small clan group (figure 6 and 7) but it is their responsibility to bring sorghum zom to the Wula-Sakon the day before their biy $d z a$ carries out the great annual sacrifice of the harvest festival. This frees the way for the Zhélé of Mazay and Woulad, but only after they themselves have carried sorghum beer to the Ruwa of Mazay. Only after the mountain priest of Mazay-Ruwa has carried out a great annual sacrifice on his sacred site can the Zhélé then perform theirs. This example proves that local history is ritually re-enacted and shows that sequences of the local arrival of groups are reflected in the way sacred beer is exchanged between them. The following chapter is going to explore the ritual relationships of the various kinship groups in our research area, according to their sequences of local arrival, the oral traditions attached to them and the "way of the beer" as representation of its historical re-enactment.

\section{Introduction to the digital map (CD-ROM)}

The digital map ${ }^{128}$ (figure 8) with the title Traditional Mafa Settlements allows the reader to zoom into each of the neighbourhoods of the research area and to study the local distribution of families (gay) and sacred sites in relation to lineage descent and ritual functions. In the following section, I

\footnotetext{
128 The underlying data have been collected and mapped on the ground by myself and my field assistant Paul Jikdayé between June and December 1985. The mapping base was a large sheet of graph paper on which I had transferred the topography (only marking the contour lines (every 100 metres) and the river system ) to a scale of 1:50,000 from a IGN (Paris 1965: feuille NC-33-XIV-4c-4d) topographical map to the scale of 1:10,000 on my graph paper. Orientation in the field was achieved with the help of an altimeter and visual estimation of distances within the perimeter (of not more than $500 \mathrm{~m}$ ) of each local ward. We, therefore, first mapped all villages and wards which was fairly easy since almost all ward boundaries can be delineated in accordance to rivers and mountain tops. We next inquired into the "way of the beer" by registering all elders of minimal lineages of their line of descent and the distribution of ritual responsibilities within their wards and then mapped all houses and sacred sites in relation to this information. The points on the map were numbered and linked to a register in order to re-identify the data from our inquiry. The cartographic result of this work is this digital map which must be read with Acrobat Reader (simply double click the map icon on the CD-ROM).
} 
often refer to the relationship between elders (as ritual actors) and the group they represent by the religious sacrifices they perform on one or several of the sacred sites. The map represents a settlement pattern which has been generated by the forefathers of the inhabitants of the study area over a long period of time on the basis of their indigenous worldviews. Continuous ritual activity was, and still is, the main tool constituting and maintaining indigenous territorial space, which enabled me to study the way locality is historically reproduced in Mafa land. As such, the digital map is also a document of an historical situation as it was during the time when the actual mapping took place in 1985. Many of the ritual actors have died since and a new generation of traditional Mafa has taken over their tasks. They in turn might re-interpret some of the ritual sequences either because they represent a different social context or due to a general trend of secularisation and globalisation of indigenous worldviews. The spatial evidence provided by the digital map is an essential part of the methodology of this study since it allows us to empirically link the oral accounts of the practitioners of the "way of the beer" with the settlement pattern they physically reproduce. This, in turn, proves that the historical ideas guiding their ritual activities are culturally conditioned and therefore determines the physical process of spatial reproduction.

I now want to explain how the digital map can be read. ${ }^{129}$ I have separated the key from the actual map and the reader needs to arrange the key (figure 9) next to the map (figure 8) on the same screen. The digital map is very big (in printed form at least A0 format) and to read the individual symbols the map needs to be enlarged so that the available screen is almost filled by perhaps only one village ward. This can be done by simply clicking the desired ward name in the bookmark section of the map as well as the correct genealogical key bookmarked below. Figures 6 and 7 show the traditional wards (figure 6) and clan sections (figure 7) which one might want to access on the large map on the screen. Figure 7 also shows the main pattern of local beer exchange within the research area. The large digital map displays the lineage connections of each family home (gay) according to the various levels of segmentation, beginning with the maximal lineage (gwaliy) and ending with the minimal lineage (gad bulom). Some clan sections consist only of one maximal lineage while others are occupied by several maximal lineages, a situation which, especially in large clan sections, has led to greater segmentation.

This is why, in some cases, individual houses (gay) show only two, and in other cases, three instances of segmentation nested into each other, whereby the innermost symbol (see figure 8) always refers to the minimal and the outermost symbol to the maximal lineage the father of the house (bab gay) belongs to. The symbols allocated to the genealogical key of the map (figure 9) display this fact accordingly and correspond with the lineage trees (tables 3 to 9) given further down in the context of the settlement history of the local kinship groups. Due to the density and complexity of lineage segmentation the territorial dominates the genealogical principle. This means that the political descent of lineage groups is derived in the first instance from the local context of the villages or wards they occupy. If we randomly scan the map we always find that the full colours at the centre of the symbols are grouped next to each other inside individual wards, which means that they belong to the same gad bulom. We also see that most wards contain one or more sacred sites, an indication of the supremacy of the territorial principle.

The colour scheme used to designate local descent is consistent on all levels of segmentation with blue representing old or earlier and red representing young or later, with green always referring to a chronological middle position. Within the regularity of blue, green and red I distinguish between dark and light, which brings us up to a maximum of 6 colours, enough to cover all possibilities of local segmentation. Due to the virilocal rule of post-marital residence a son traditionally resides in the same village ward as his father (see Chapter 3.2.1 on shinek and

${ }^{129}$ Due to software limitations no linguistic fonts or diacritics appear in the digital map (including the key). 
mposokw), a fact which regularly brings about between one to four minimal lineages occupying one and the same ward. The spatial reality of such a settlement pattern becomes apparent in the regularity in which individual colours appear on the map next to each other inside most of the over eighty traditional wards. ${ }^{130}$

As we can see from the key of the electronic map (figure 9), other symbols appearing together with those for individual family homes (gay) refer to whether the father of the house (bab gay) is a tsava (lineage elder) or a biy dza (mountain priest). Like the functions of village chief (biy wudam), chief's staff (gad bay), chief's representative (bay), chief's follower (biy gwala) and chief's jester (matsam), they are designed as black symbols framing the nested colour symbols of local descent. We can see that almost each village ward owns such functions which reconfirms the decentralised political structure of Mafa society. However, there is a vertical process of political organisation at work which shows up in the map as well. The houses of chiefly and nonchiefly clan wards of a local community appear as hexagons while non-chiefly clans appear as circles. These circles or hexagons of houses form the outer part of the coloured symbols and refer not only to the social status of the father of the house but also to the maximal or major lineage to which he belongs.

The non-blacksmiths (vavay) and blacksmiths (ngwazla) are allocated different geometrical symbols. All blacksmith houses are displayed with a triangle in which a colour refers to its clan of origin which are mostly non-blacksmith. This means that although the blacksmith lineages have been endogamous for a long time they still claim to have descended from non-blacksmith clans. Chief blacksmiths (biy ngwazla) can be recognised by an outer large black triangle.

Another social division made visible on the map is that between Traditionalists and Christians. I also indicate the position of so-called strangers living in a ward, meaning all those who have their placenta buried in a different clan ward or village. If we explore the electronic map in the modern settlement area in the valley of Gouzda, we recognise that most Christians live within this. We can also see that the symbol for Christians often carries the symbol of being a stranger as well which means that Christians separate themselves from the traditional settlement areas higher up in the mountains. As already mentioned, all the different sacred sites Traditionalists ritually connect with in the context of the "way of the beer" are displayed in the digital map. For the reconstruction of the local history the most important religious sites are the major and minor mountain shrines (diy mbulom), the killer shrines (madzagay) and the ancient shrines (with no function). I am going to explain their individual significance in the chapter to come and a fuller understanding of the analytical content of the digital map should therefore develop in due course.

\subsection{The local history of kinship groups}

The Wula-Sakon of Mtskar are not only considered to be the first settlers of Woulad, Mazay and Mouzoua, but also of the ward Wula in Gouzda-Korbay. Gouzda is a very large village and can be divided into upper and lower sectors. The upper one is also referred to as Gouzda-Makanday and lower as Gouzda-Kərbay. This study is only concerned with Gouzda-Korbay, where we find a large village ward by the name Wula, consisting of the four smaller wards Gəd-Wula, Magiva, Var-Hudokw and Giy-Zluwed (figure 6). The ward name Wula is a reference to the Wula-Sakon of Mtskar, who settled in Gouzda-Wula before they moved on to Mouzoua and then Mtskar, but

\footnotetext{
${ }^{130}$ There are instances where no lineage segmentation is displayed. Such instances always refer to family heads who moved in from neighbouring villages or clan wards only recently. If they are not Christians they tend to attend the ancestor rituals in their home villages or clan wards. Before they do so, they take sacred beer to their host's elders but are not permitted to carry sacred beer across boundaries to their own lineage elders.
} 
there is no living ritual link between Gouzda and Mtskar. Therefore, we see no evidence of a representative being left behind by the Wula-Sakon as is the case with the Ruwa of Mazay. However, there are ancient sacred sites in Gouzda-Wula which are reported to be former shrines of the Wula-Sakon. These shrines (see ward Giy-Zluved on figure 8) are not in use anymore and have no ritual significance for the Vuzay and Magiva who now occupy the four wards of Wula. Oral tradition does not inform us as to why the Wula-Sakon left Gouzda, but it is claimed that they moved on before the arrival of the Vuzay.

The Wula-Sakon, Vuzay and Zhélé are the largest clan groups in our research area and the local historical evidence clearly proves that the Vuzay and Zhélé arrived in the area of Gouzda after the Wula-Sakon had moved on. The Vuzay and Zhélé represent the so-called Soulédé tradition of the Mafahay faction while the Wula-Sakon can be identified as representatives of a proto-Mafa tradition which originates from Wula proper (Wula-Hanko and Wula-Mango) and Sakon (Sukur). Before I go into the ways these three large clans have segmented over time into local wards and lineage groups, I want to present an overview of the other clan groups found in the research area.

The total number of gay in our local area is 1763 which brings us to about 200 inhabitants per square kilometre. ${ }^{131}$ The family heads of 1626 of them are Traditionalists while only 137 are nonTraditionalists (mainly Christians). ${ }^{132}$ Among the 1626 Traditionalists are 43 blacksmiths, ${ }^{133}$ which brings us altogether to 1583 non-blacksmiths household heads. Of the total of 1583 traditional non-blacksmiths, 1436 settle in their own clan wards while only 147 do not. Among the 1436 households of non-blacksmiths, 1018 households belong to 5 chiefly clans and 418 households to 15 non-chiefly clans. ${ }^{134}$

The 20 clan groups (found in the 17 clan sections shown on figure 7) of the research area occupy a total of 29 clan wards (some clans are found in more than one village). Among the chiefly clans it is the Zhélé, Vuzay and the Zlagam and among the non-chiefly clans the Zhwé and Goyé who overlap village (wudam) boundaries. Boundaries between wards and villages are physically represented by characteristics like hillsides and watercourses, but they have a religious significance as well. Sacred beer is not carried across village boundaries unless they separate allied villages, as we have seen in the case of the Ruwa of Mazay. However, the bay of Ruwa cannot carry out a sacrifice in Mtskar, which is the religious destination of his beer. It is a generally accepted rule that the place of residence of the custodian must coincide with the place the sacred site (diy mbulom) is found. The political nature of this location is not only determined by the patrilineal connection of the custodian but also by the wudam which accommodates this link. I have already referred to the idea of a local patrilineal descent as the concept of shinek (Chapter 3.2.1) which is here subsumed under that of wudam. However, the concept of wudam only governs the external boundaries of village communities, whereas the internal ones fall into a different category as soon as a village exists of more than two clan wards. Since this is usually the case, the concept of shinek (patrilocal descent) continues to apply between the various clan wards inside a village community which qualifies them as $d z a$ (independent sacred mountain). In order for a clan ward to be recognized as $d z a$ it must have a biy $d z a$ (mountain priest) and a diy mbulom ḿbiya'a (major mountain shrine).

We have seen in the previous chapter that the "way of the beer" unfolds annually during the harvest festival telling us for each clan ward how the local history of existing social and political

\footnotetext{
${ }^{131}$ If we assume an average of six individuals per family household, we come to a total of almost 11,000 inhabitants which brings us to an average of about 200 inhabitants per square kilometre, assuming that the research area consists of about $55 \mathrm{sq} . / \mathrm{km}(8 \mathrm{~km}$ long and $7 \mathrm{~km}$ wide at its most extreme points and a maximum of $300 \mathrm{~m}$ difference in height).

132 This brings us to $8.43 \%$ non-Traditionalists and Christians.

133 This brings us to $2.72 \%$ blacksmiths (not counting those who converted to Christianity).

134 This brings us to $60.14 \%$ traditional family heads belonging to chiefly and $39.86 \%$ to non-chiefly clans.
} 
relations is ritually re-enacted. Not all of the 29 clan wards have the ritual importance of a $d z a$; some are only associated to the $d z a$ of their local host clan. In such cases the ritual relationship of the guest clan is analogous to the relationship between members of the same lineage of a ward. However, an associated clan ward also has its internal "way of the beer" and here, too, the concept of shinek applies, which means that a custodian of a shrine subordinate to the $d z a$ of the host clan must live in the clan ward he is descended from. This is the case, for example, with the Gozla of Gouzda-Kərbay, who are ritually accommodated by the major lineage Vagsa of the Vuzay-Kerbay. The elder (tsava) of the Vagsa comes and carries out a beer libation at the front courtyard (var ma gay) of the elder of the local Gozla before the latter can perform the annual sacrifice at their sacred site (diy mbulom).

The following sections are organised according the sequences of the local arrival of kinship groups, from where they originally came and how they have moved around inside the research unit. Below, I will describe how the representatives of the most historically significant clan groups are connected with the ritual network of beer exchange. We will also examine the social status of groups and the ritual relationships as well as the social positions they hold in the context of the harvest and bull festival. This will lead us to a reconstuction of the history of the social and political relationships in the research area, which emerges like the image of a jigsaw puzzle. ${ }^{135} \mathrm{I}$ begin with the Goyé as the autochthonous representatives of the inhabitants of the research area. Although the Goyé number altogether no more than 17 families, I will describe their "way of the beer" in greater detail since the general pattern of ritual beer exchange emerging in this context will serve as an introduction to similar patterns in the other kinship groups.

\subsubsection{The Goyé}

The name Goyé refers to scabies on the scalp and the Goyé are known as the specialists in healing this. The Goyé are considered as the autochthonous people in the area and it is believed that they lived in a cave before they became "civilised" by the Zhwé. The Zhwé saw a fire ${ }^{136}$ in the night and when they eventually got hold of Goyé and his family they taught him how to build a house out of stone and dung. Fires are usually lit in the early morning hours in the colder period of the year following the rainy season. The Gura also claim to have met Goyé by first seeing his fire and eventually meeting him. While the Gura tend to describe their "historical" meeting with the Goyé as a meeting of equals, the account of the Zhwé portrays them as "non-civilised" ${ }^{137}$ However, most inhabitants of Gouzda refer in a rather amused manner to the claim that the Goyé once lived in a cave, but nevertheless see them as the representatives of the first inhabitants.

Gura and Goyé eventually became ńshibene, meaning that they stopped marrying each other's daughters by entering a pseudo-clan relationship. The Goyé and Gura say that they "share one stone" (nta kwa sotad) which means that they consider each other as "brothers". The marriage restriction not only made them "brothers", but also stopped the practice of bride-service, that is to say working in the fields of a future father-in-law. This meant there was no longer any need for the option that a son-in-law would lease some of the land after marriage. However, we could also say that ńshibene means leasing or borrowing due to the fact that the bride-service link is disabled. As we have seen in Chapter Three, one underlying meaning of the word ńshibene is to

\footnotetext{
135 A jigsaw puzzle only in relation to local variations of the "way of the beer".

${ }^{136}$ Schönmeier (see Hinderling 1984, III:23) mentions a similar legend in Moudoukwa, where a fire was seen as far as Muktele land.

${ }^{137}$ The Zhwé might have ulterior political motives in stressing this aspect of their early relationship with the Goyé since they are not only considered as the former chiefly clan of Gouzda (between the Wula-Sakon and the Vuzay), but also as former blacksmiths. Although the Zhwé have an important ritual position, their social status is much more controversial than the social status of the Gura.
} 
lease or to borrow land from a "brother" of the same clan. This is why I refer to ńshibene as a pseudo-clan relationship, and it seems that the Goyé and the Gura entered such a relationship, while the Zhwé did not, but taught them how to build houses of stone and dung. The Zhwé claim to have later learnt from the Vuzay how to build houses of sand and clay. Oral tradition likes to claim that the Zhwé were already kar bay (chiefly clan) at the time, as were the Hizhé of Mazay (after the Wula-Sakon but before the Zhélé) with whom the Zhwé share a pseudo-clan relationship.

Although the "way of the beer" ritually re-enacts the local historical positions of groups we must abstain from attempting to construct a chronological sequence of this very early time of settlement history of the area and focus rather on its metaphorical meaning. The distinctiveness of the individual fire stands for a sign of mutual recognition and marks Goyé as a free agent in ritual matters on his mountain top in Gouzda. The Goyé of Gouzda are not obliged to bring ritual beer to anybody if they want to bring a sacrifice to their mountain shrine, which is not the case for the Goyé of Mouzoua and Mazay.

The Goyé themselves deny that they once lived in a cave, and claim that their ancestors came from the Moskota area. ${ }^{138}$ They pride themselves on having introduced sorghum ${ }^{139}$ and, in fact, most religious beer parties dedicate the first calabash to Goyé, referring to it as daw zom Goyé (sorghum beer of Goyé). In any religious context it is only after the ritual consumption of the zom Goyé that the beer of the bay is poured, a custom which exists not only in the area of Gouzda but was also reported to me in Moskota. The local historical position of Goyé, as the mythological bringer of sorghum, must be understood in the context of the religious worldview of the Mafa. Goyé is also often named as the one who can verify that God has only one wife, who he is believed to have seen when he went to "steal" the first sorghum grain from her and hid it inside his foreskin. The mysterious transformational qualities (nya'a) Goyé was allegedly born with allowed him to travel up to the celestial world and subsequently to reduce the sorghum grain to the size it is today.

Why Mafa have allocated this mythological act of cultural invention to Goyé and not to somebody else must remain unanswered, but we find similar notions in other parts of the Northern Mandaras. ${ }^{140}$ However, it would be difficult to understand the way traditional Mafa appropriate their land without considering the underlying cultural (and often only local) truth conditions. The divine invention of sorghum by the Goyé and their historical image as representatives of the autochthonous kinship group also includes attributing the development of terrace farming to them. Modern Mafa often comment that this is what the divine invention of sorghum actually meant. They say that Goyé did not really travel up to heaven but consider him as the originator of terrace farming. The fact that the first calabash of any religious beer is shared in honour of Goyé (daw zom Goyé) shows that this is a commonly held belief.

\footnotetext{
${ }^{138}$ Martin (1970:35) connects the 'Goya' (Goyé) with the group of families (including the 'Sassak, Vouzi' (Vuzay), and 'Ldagam' (Zlagam) who had come from 'Goudour' (Gudur) in order to found Soulédé. Hinderling (1984, III:43) mentions 'Goya' (from his 1953 field material) as an ancestor of a Soulédé clan who still lived in 'Marwa (Maroua).

${ }^{139}$ Martin (1970:33) mentions the legend of the first settler of Douvar (situated at the southern end of the Ziver-Oupay massif) who descended from heaven on a rope and who had only one arm and one leg (which is a common Mafa metaphor for the singularity of God) and who brought 'du mil' (Martin leaves it open whether this means millet or sorghum). This first inhabitants lived like Goyé between the rocks and did not build a house. Hinderling (1984, III:10) refers to the people of Douvar as autochthonous people since they see themselves as 'dzikile-(Gottes-)Leute', meaning people who descended from God (zhigilé).

140 Vincent (1991, vol 1:150-160) informs us about similar images of autochthony among the Mofu-Diamaré, especially with regard to their alleged primitiveness (e.g. living in caves) and she also mentions their fires being seen by newly arriving kinship groups. However, Vincent does not mention the invention of cultural goods, as in the case with the Goyé, by such allegedly "primitive" or "animal-like" autochthonous or "pre-historical" groups.
} 


\section{The "way of the beer" of the Goyé}

Local history does not clearly indicate whether the Goyé of our research area moved from Mouzoua to Gouzda or vice versa. There are very few Goyé. In Gouzda-Kərbay they consist of 8 households and in Mouzoua and Mazay of not more than 4. The two maximal lineages (gwaliy) listed below consist of three minimal lineages ( $g a d$ bulom) in the case of the Goyé of Gouzda and the two minimal lineages in the case of the Goyé of Mouzoua and Mazay. Their lineage elders (tsəva) are mentioned with their personal names in brackets behind each minimal lineage including their respective ritual duty in the context of the "way of the beer".

The gwaliy Galaza-Goyé of Gouzda-Krbay consists of: gad Gulom Gaslagasl (tsava Dzaviy is the biy dza) gad bulom Gudukoyé (tsava Koma brings beer to Dzaviy) gad bulom Ndelmé (tsava Ganday brings beer to Dzaviy)

The gwaliy Ngokwa-Goyé of Mouzoua and Mazay consists of: gad bulom Ngweléo of Mouzoua (tsəva Tsiydemé brings beer to the Gozla) gad bulom Gonondo of Mazay (tsəva Bundiy brings beer to the Hizhé)

Apart from the daw zom Goyé, "sorghum beer of Goyé", the offices the Goyé hold in the context of the "way of the beer" carry no specific ritual weight. The biy dza of the Goyé of Gouzda belongs to the senior lineage which not only holds the custodianship over a diy mbulom mbiya' $a$ (major mountain shrine), but also over a madzagay (killer shrine) as well as a diy mbulom woyam (river shrine). The madzagay is not for all Goyé of Gouzda, but only for the senior lineage since somebody from this branch once killed an in-law during tribal conflict. To protect the mental health, not only of the person who carried out the killing, but also of his descendants, an annual sacrifice is carried out. The river shrine consists of a large stone found in the river nearby and is mainly sacrificed to in the context of annual fishing.

The Goyé of Mouzoua and Mazay also have a mountain shrine but it does not have the religious significance of a $d z a$, since their tsava cannot carry out the sacrifice without the ritual permission of the Gozla-Vindiye of Mouzoua-Ndav-Gay (see figure 8). The responsible elder of the Goyé of Mazay is junior to the lineage elder of the Goyé-Mouzoua, but is obliged to bring sacred beer to the Hizhé of Mazay before he can ritually relate to his senior in Mouzoua. The reason is that some Goyé of Mouzoua had moved to Mazay due to good relations with a maternal uncle (kükwa) of Hizhé descent. Although the clan wards of Goyé-Mouzoua and Goyé-Mazay are next to each other the tsava of Goyé-Mazay cannot cross the village boundary with ritual beer.

There is a third group of Goyé who live as strangers in the clan ward of the Zhélé-Kərbay in Mazay-Tingweting. They consist of 5 households and are classified in the digital map key (figure 9) as Goyé-Moskota. They are recognized as strangers from Moskota and it is therefore anomalous that they have a sacred site at which they carry out an annual ritual for the harvest festival. However, they have to bring beer to the Zhélé lineage elder of Mazay-Tingweting, who, in turn, first carries out a sacrifice on the front courtyard of the lineage elder of the GoyéMoskota. The Goyé of Mazay (from the ward Goyé) also own a rain shrine in Gəd-Dza of Mazay-Zhélé. The Hizhé, the host clan for these Goyé, settled in Mazay before the Zhélé and Zhélé-Gəd-Dza formerly belonged to them. This is the reason why the the Goyé of Mazay-Goyé have free access to their rain shrine in Zhélé-God-Dza of today.

We can see on the digital map (figure 8) that the clan wards of the Goyé of Gouzda and Mouzoua also accommodate strangers. They are either descendants of the chiefly clan of the Vuzay-Korbay of Gouzda or the Gozla-Kərbay of Mouzoua. Since the clan ward of the Goyé of Gouzda has the status of a ritually independent clan ward $(d z a)$, they bring beer to the biy $d z a$ of the Goyé- 
Gouzda before they attend the annual sacrifice where their shinek is. It is different for the strangers of Goyé-Mouzoua because they are local Gozla and live still on their fathers' land which had once been given to the Goyé. They are not obliged to bring ritual beer to the elder of the Goyé, but only to their own lineage elders in Mouzoua-Gozla.

The Goyé of Gouzda also have an attached ward which is referred to as Wuyak. Wuyak means sand but is also a general reference to newly cleared land. Goyé-Wuyak now belongs to the modern settlement area of Gouzda, found in the bottom of the valley not higher than 500 metres. Such non-mountainous areas have only been settled in and farmed since the early 1980s and have no ritual significance. The digital map (figure 8) shows that the modern settlement area has no regular sacred sites. Wuyak and Mbala are the most common names for newly occupied land. The word mbala means literally "hard ground" and refers to vertisol, soil which is known for its high clay content.

\section{The meaning of ward names occupied by the Goyé}

The meaning of other settlement names found in the research area can be obtained from table 4 . The Mafa like to use metaphors of the human body to refer to parts of their local landscapes. The Goyé of Gouzda live in Gad-Woyam, which means literally "head of the river" (gad = head; woyam = river). There are two Ged-Woyam in our research area, one is in Mouzoua, where it is part of the clan wards Gozla and Zhwé and the other one is in Gouzda-Kərbay, where it is part of the clan wards Goyé and Vuzay-Kərbay. The example of Gouzda-Gəd-Woyam best shows how the word gad is used to refer to a particular landscape as the head of a river. The main river in our research area is the river Gouzda and its head is there where the main arm of the river turns eastwards because it hits the mountain foot. ${ }^{141}$ This mountain foot is called head of the river, because it controls the flow of the river like the head is a metaphor for decision-making powers. The Goyé of Gouzda live where the "head" (meaning the mountain foot) reaches the river.

The other ward names mentioned in the context of the Goyé are Ndav-Gay and Gəd-Dza. NdavGay means literally "heart of the house" and refers to the position of a ward or a group of wards in the centre of a traditional village. Wards of the name Ndav-Gay are often densely populated because of the fertility of the land, which has been intensely manured for generations. Grd-Dza means literally "head of the mountain" and as we can see on the digital map (figure 8) such wards are always found on the top of a local massif. Living on top or higher up generally signifies seniority or greater power. I have referred in more detail to the metaphorical meaning of place names in previous works (Müller-Kosack 1987a, 1991, 1997b).

\subsubsection{The Wula-Sakon}

The name Wula-Sakon is a reference to the Wula as well as to the Sukur (Sakon). The WulaSakon today live in Mtskar where they are the kar bay (chiefly clan). They claim to have arrived via Bao on the Ziver plateau into the area of Gouzda, after they had crossed the plateau of Mokolo, coming originally from Wula proper or Sukur. It remains unclear whether my informants confused Bao on the Ziver plateau with Hosséré Bao situated between Ouanday (Wanday) and Magoumaz, or whether both places played a role in their migratory history but only the last one is remembered. Whichever is the case, we find the so-called Sukur tradition not only in the area of Gouzda, but also in $\mathrm{Ziver}^{142}$ as well as in Magoumaz ${ }^{143}$ and in Moudoukwa. ${ }^{144}$

\footnotetext{
${ }^{141}$ Note to be confused with the English word headwaters or upper reaches which means the source.

${ }^{142}$ My field material shows that the former chiefly clan of Ziver is called Sakon. The Sakon claim to have originated from Sukur. They also claim links with Magoumaz, but say that they accessed the Ziver mountain via Vouzod.
} 
However, we do not know how the clan name Wula-Sakon came about since it refers simultaneously to two ethnic groups, the Wula proper (Wula Hanko and Wula Mango) and the Sukur. But the situation is even more complex, since the name Wula is also an old synonym for the most remote montagnard groups living in the mountains to the west and southwest of the Koza Plain. ${ }^{145}$ This indicates that the word Wula is presumably of Wandala origin and, as such, has a derogatory connotation similar to Matakam, although we can assume with good reason that the word Wula has been in use longer than the word Matakam.

This would imply that the word "Wula", as a synonym for Mafa or Matakam, refers to an old strata of proto-Mafa kinship groups which lived in the area already before the coming of the Vuzay and Zhélé as the representatives of the Mafahay (Soulédé tradition). Such an interpretation is congruent with the local historical position of the Wula-Sakon of Mtskar within the research area, but does not resolve the problem of the twofold meaning of the ethnonym Wula - one, an ethnic name for the Wula proper and second, a synonym for Matakam. The clan name WulaSakon rather suggests that the ethnonym Wula is derived here from the Wula proper who see themselves as being closely attached to the Sukur (Sakon). This view is also in line with the idea that the tradition of origin of the Wula-Sakon points to the Wula proper and Sukur area of today. The Wula proper see themselves closely linked with the Sukur, an ethnographic view which has already been expressed by J.H. Shaw (1935, Appendix A:8-11) who groups the Wula with the Sukur on the grounds of a shared Gudur tradition. The field material I collected among the Wula proper confirms this. The Wula proper still today recognise the ritual seniority of the Sukur in the context of the Gudur tradition,. This is different with the Wula-Sakon of Mtskar who do not derive their chiefly tradition from Gudur but see themselves as Mafa and refer to the biy vardeké of Moskota as the only Gudur representative relevant for them. The Wula-Sakon are fully aware that they are not "true" Mafa but claim to have forgotten their original customs, although, in comparison with villages dominated by "true" Mafa clans, some differences nevertheless do exist.

The Wula-Sakon of Mtskar do not celebrate the bull festival every three years as the other villages do, but only every four (like e.g. Oupay), a pattern which coincides with the Mafahay cycle of twelve. The Wula-Sakon explain that they prefer to fatten their sacred bulls for longer since this increases the size of the bull and is generally considered to be very desirable. However, the 4 years cycle of the bull festival is not often found in the Northern Mandaras but a two year cycle exists fairly widely. We know, for example, that the biennial cycle of the bull festival is not only followed by the so-called Bulahay groups, but also among the Wula proper, as well as among the Sukur and most groups of the Gwoza Hills (including the Lamang but not the Zelidva and Glavda). The biennial, as well as the quadrennial cycle, always coincides with a sorghum year. It is possible that the Wula-Sakon of Mtskar have not adopted the triennial cycle (as it is celebrated in most Mafa villages) and have dropped their original biennial cycle, preferring a quadrennial one. Such an interpretation is confirmed by the fact that the Wula-Sakon often leave out a couple of bull festivals and choose to perform it at intervals of 12 years instead. Apart from this ceremonial oddity, the Wula-Sakon maintain the same political functionaries as the other

\footnotetext{
${ }^{143}$ Martin (1970:33f) refers to the 'Chiler' and 'Wola' as groups of 'Sokone (Soukour)' origin, but says that the two clans are not directly related. My field materials show that the Wula-Sakon of Mtskar are in occasional contact with other 'Wula-Sakon' found in Magoumaz. Martin (op.cit.) does not mention Wula-Sakon in Magoumaz but only two groups who came originally from Sukur. However, the clan name 'Wola' could well be a reference to the Wula proper. ${ }^{144}$ Martin (1970:34) mentions a kinship group in Moudoukwa which came from 'Soukour' before the arrival of the 'Mouktélé' (Gozla).

${ }^{145}$ Moisel (1912-1913) refers on his map to the area east and northeast of the Ziver-Oupay Massif as 'Ula-Maskate' and Mouchet (1948:107) mentions, in the context of the ruling clan of the Mada, a 'Ula-Matakam' tradition of origin from the southwest of Mada land. Richard (1977:35) confirms this tradition talking of 'Oula' and 'Matakam' in the west from where the founding ancestor Mada originally came from.
} 
kinship groups of the research area, which means that they have a biy wudam and the gad bay, the bay as well as the biy gwala.

The Wula-Sakon of Mtskar consist of two maximal lineages, Wéslém and Dakowal, the Wéslém settling first in Mtskar, followed by Dakowal. This makes Wéslém the oldest maximal lineage of Mtskar. The following lineage tree shows the connections between the minimal lineages who derive their ancestry from Wéslém. The figures in brackets behind each minimal lineage refer to the number of families they consist of. I estimated an average of 6 individuals per family which means, for example, that all the descendants of Wéslém add up to a total of 407 individuals.

Table 5: Local lineage tree of the Wéslém of Wula-Sakon

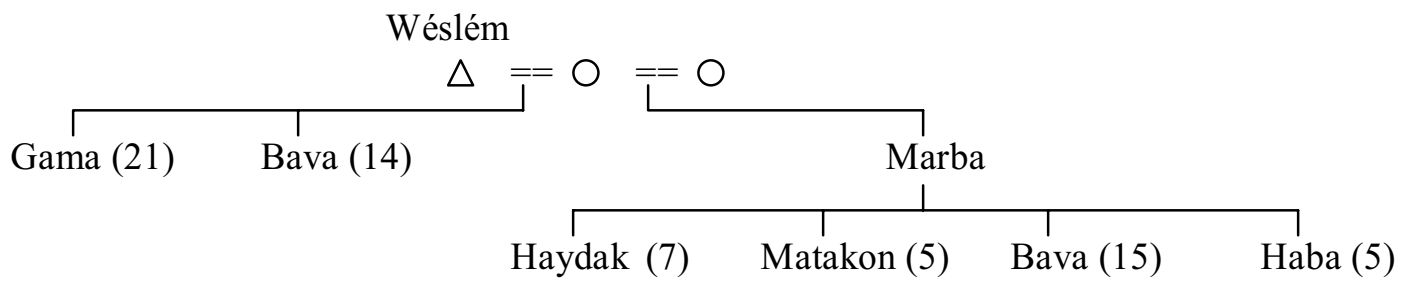

Wéslém had two wifes. Gama and Bava are the ancestors who descended from his marriage to his first wife while Marba had a different mother. Marba had four descendants, who today form the ancestors of four gad bulom which are Haydak, Matakon, Bava and Haba. If we consult the key of the digital map (figure 9), we see that the sequence of their genealogical seniority is displayed in a vertical order which is a principle maintained throughout the map. The names given in brackets behind each agnate are the references to the villages or village wards in which their descendants live today. The numbers behind the minimal lineages in the diagram above as well as in all the following genealogical diagrams refer to the number of gay (families or housholds) of each gad' bulom.

We can see from the digital map (figure 8) that the descendants of Wéslém live today in two village wards of Mtskar, which are Wéslém and Marba. The Wéslém settled first in Gəd-Wula in Gouzda from where they moved (before the arrival of the Vuzay of Gouzda) to Hizhé in Mazay. Three ancient shrines are still found in Giy-Zluwed of Gouzda-Wula and these are allocated to the Wula-Sakon, but no sacrifices are celebrated there. When the Wéslém departed from Hizhé they left the Ruwa behind as their local representatives and moved on to settle first in GadMejéké in Mtskar, where they still have their most important sacred site in the south of the ward. From Gəd-Mejéké they moved on to Wéslém from where the Marba eventually fanned out in order to settle in their own ward (first in Mtskar-Zlagam and then in Marba). The Wéslém have a second major mountain shrine in Wéslém itself. It is the elder of the Wéslém-Bava who is the priest for both sacred sites, but he is accompanied by the elder of the Wéslém-Gama. The reason why the younger lineage, Bava-Wéslém, is responsible for the two major shrines is due to an historical impurity (sak) attached to the lineage of Gama.

Due to their specific local historical position, the elder of the Ruwa of Mazay brings annual beer to the elder of the Bava-Wéslém. The elder of the Marba also brings sorghum beer to the elder of the Wéslém. The annual sacrifice of the Wéslém at their major shrine in Gəd-Mejéké is the first to take place in the whole of Mtskar in the context of the harvest festival. For this occasion they are accompanied by the biy-dza of all Wula-Sakon of Mtskar who is a descendant from the second but much larger maximal lineage Dakowal (more about this further below). Gəd-Mejéké is today occupied by descendants of the gad bulom Warama-Gojélé of the Dakowal and their elder also accompanies the Wéslém at their most important sacrifice. The Bava-Wéslém, as well 
as the Gama-Wéslém, also have a minor shrine in Wéslém itself to which they make discrete offerings after the sacrifices at their two major shrines have taken place.

Marba was the son of Wéslém's second wife who was a woman he had abducted during tribal warfare. Wéslém later discovered that the woman was already pregnant but he nevertheless decided to adopt the child as his son who was Marba. The descendants of Marba settled in Mtskar-Zlagam before they moved on to Marba. At the time a group of Vuzay from Mazay (early descendants of Vuzay Ftélé) lived in Marba and later left for Mondouza. The Vuzay still have an ancient sacred site in Marba, but this site is no longer in use. Marba is considered as Wéslém territory and the elder of the Haydak-Marba brings beer to Wéslém before he is allowed to carry out the annual sacrifice at their main shrine, ${ }^{146}$ which is found in the west of Mtskar-Zlagam. This is the reason why the Zlagam of Mtskar bring beer to Haydak-Marba before they can carry out their own sacrifice. The Marba have a second minor shrine in Marba which belongs to HabaMarba and a killer shrine (madzagay) which belongs to Bava-Marba.

The ancestor of the second maximal lineage of the Wula-Sakon is Dakowal who also had two wives. The descendants of Dakowal arrived in Mtskar after the Wéslém but are much more numerous, numbering 888 individuals.

The diagram (table 6) shows that Ndura and Jèkuwè belong to one gwadar (see Chapter 3.3.5 for detailed meaning) which is derived from the fact that they have the same mother. However, although Bliwa has a different mother (ngwaz ngide), he is older than Jèkuwè, a fact which gives him a specific ritual position in the context of the "way of the beer".

Table 6: Local lineage tree of the Dakowal of Wula-Sakon

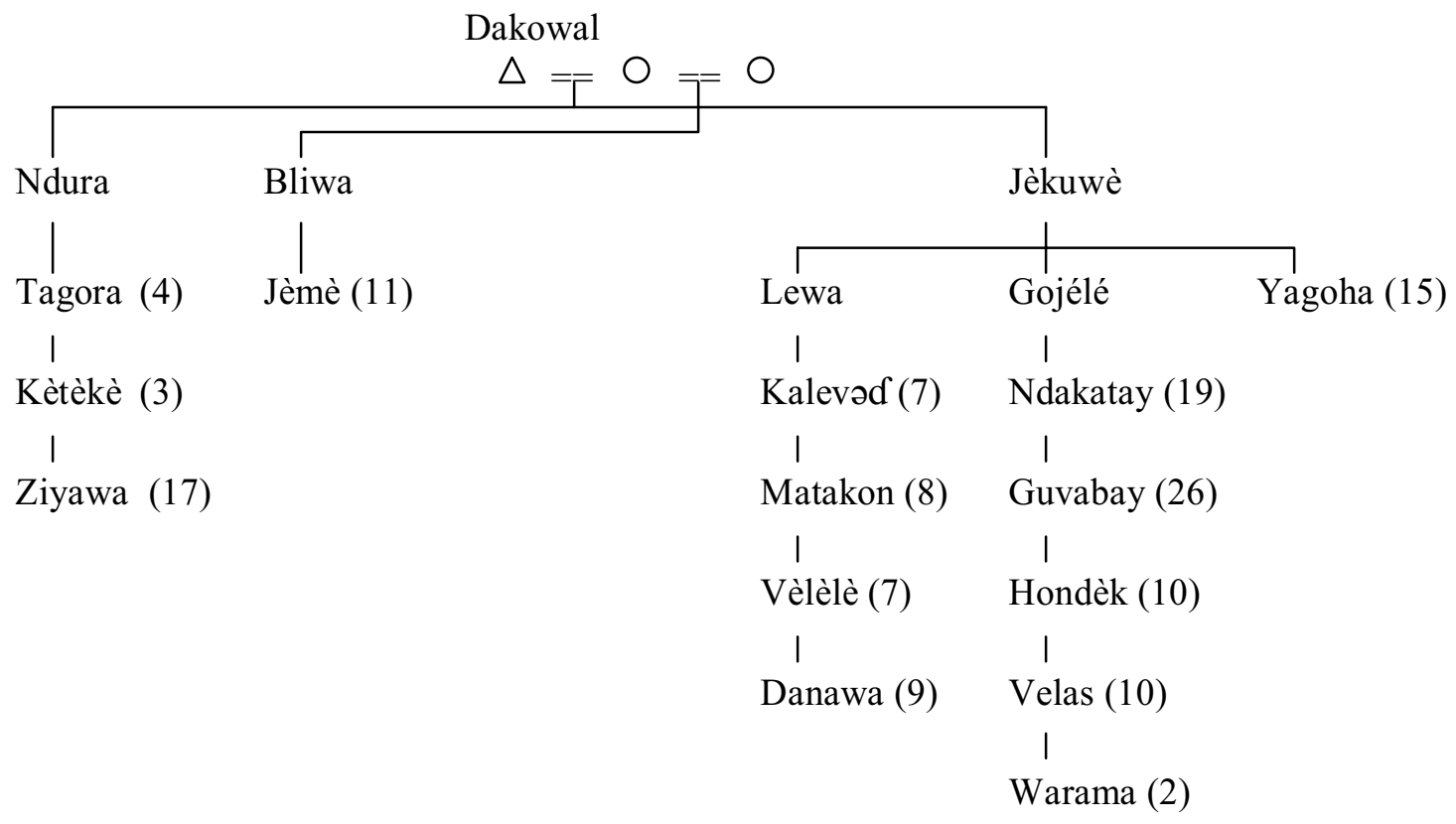

With 113 families, Jèkuwè is the largest major lineage of the maximal lineage Dakowal. With 67 families, the Gojélé is the largest main branch of the Jèkuwè and the Guvabay, with a total of 26 families, form its largest minimal lineage. The key of the digital map (figure 9) shows that the Guvabay-Gojélé live in Diy-Gəd-Bay. They provide the biy wudam of Mtskar whereas the Ndura and Ndzakatay provide the gad bay. As we have seen in Chapter 3.3.4, it is the first gad bay who

\footnotetext{
${ }^{146}$ Only a main shrine to the Marba but a minor shrine in relation to the Wéslém (see figure 8).
} 
represents the biy wudam during the bull festival, while the chief himself remains in the background. In the case of the Wula-Sakon it is the gad bay from the Ndzakatay-Gojélé who is the chief's deputy.

Although the Ndura are senior to the Jèkuwè in both local and genealogical terms, they are much fewer in number, which is the reason why they are generally considered today as the main biy gwala and not as the first bay. The fact that they are still considered as second gad bay is a right they could hold on to, but this example again shows that it is number which dominates seniority among the kar bay of Mtskar and not the other way around. If we consider that the main purpose of their purification rituals is the enhancement of human and terrestrial fertility it is not surprising that the Gojélé-Jèkuwè are the bay. This becomes particularly obvious in the context of the bull festival, while the annual sacrifice of the harvest festival is slightly more inclined to consider seniority instead of size. However, due to the fact that the Gojélé have developed into the largest lineage group of the Jèkuwè, the name Gojélé has become a synomym for all Jèkuwè and includes, as such, not only the Gojélé, but also the branches Lewa and and Yagoha.

The success of the Gojélé (being a synonym for all descendants of Jèkuwè) in terms of their reproduction has not only brought about their position as bay of Mtskar, but they also have the mountain priesthood for all Wula-Sakon. The diy mbulom mbiya'a (major mountain shrine) of the Wula-Sakon is found in the east of Derngasla. Although the Wéslém have retained the right to open the annual ritual cycle of Mtskar with a sacrifice to their major mountain shrine in Ged Mejéké, the elder responsible for this offering is not the biy $d z a$. The biy $d z a$ of all Wula-Sakon is the biy wudam (from the large lineage Gojélé/Jèkuwé) although the diy mbulom mbiya'a he is responsible for was originally the shrine of the major lineage Ndura.

The Ndura settled first in Gouzda-Wula from where they moved on to Mouzoua God-Prad. According to oral tradition, all of this happened before the arrival of large numbers of Vuzay and Zhélé. From Mouzoua they moved on to Mtskar, first to Derngasla and from there to Mtskar DiyTsəndad and eventually to Ndura. Altogether the Ndura have three shrines. The first is found in Mouzoua God-Prad, the second is the shrine in Derngasla, already mentioned, and the third is an ancient shrine in Diy-Tsəndad. The shrine in Mouzoua is a diy mbulom mutsor. The word mutsor refers to something which is hidden and means in this case that the Ndura control the chronological sequence in which the Gozla of Mouzoua carry out their annual sacrifices. The biy $d z a$ of Gozla-Mouzoua is obliged to send sorghum beer to the elder of Ndura (figure 7) before he is morally entitled to carry out a sacrifice at this diy mbulom mutsor of the Ndura followed by a sacrifice to the diy mbulom ḿbiya'a of all Gozla-Mouzoua. I will return later within the section on the Gozla to a local historical narrative attached to this specific ritual sequence.

So far, we have established that after the descendants of Wéslém, those of Ndura arrived in Mtskar. They were followed by the descendants of Bliwa and Jèkuwè all coming from GouzdaWula before the migratory wave of the Mafahay, represented by the Vuzay and Zhélé, arrived. Bliwa is in genealogical terms considered to be senior to Jèkuwè, but the Jémé (who are the descendants of Bliwa) are not of great ritual importance. This might have to do with their lack of numbers. Nowadays they total no more than 11 families and are more or less absorbed by the Jèkuwè/Gojélé. In the context of the bull festival the Jémé-Bliwa are like the Ndura, only biy gwala and not bay. However for the annual sacrifice of the biy dza the tsava (elder) of the Jémé brings beer to the major mountain shrine in Derngasla. After an opening ritual in the house of the biy $d z a$ in Diy-Gəd-Bay, the tsəva of the three main branches make their way to the shrine, where it is the tsava of the Ndura who leads the procession, followed by the biy dza. For the sacrifice itself it is the tsava of the Ndura who drinks first since his ancestor founded the shrine. However, it remains the task of the biy $d z a$ to libate the beer to the ground and to balance the calabash on the back of the pot as well as to say the prayer asking for the prosperity of the community as a 
whole. The tsava of the first settler, Wéslém, does not participate at this great mountain sacrifice of the Wula-Sakon. However, he has taken sorghum beer to the house of the biy dza at Diy-GədBay, a gesture which entitles his branch to benefit from the blessings stemming from this sacrifice.

These examples show that the "way of the beer" of the Wula-Sakon represents not only the history of their arrival but also of their local development, especially in terms of population size. As the oldest local maximal lineage, the Wéslém open the annual cycle of ritual activities of the harvest festival. However, it is the second oldest maximal lineage locally, the Dakowal, whose annual sacrifice represents the more religiously powerful event for the Wula-Sakon of Mtskar. The ritual significance of the Gojélé/Jèkuwè, as the most numerous branch, shows that chiefly power is firstly a matter of locality and population size and only secondly, one of genealogy and seniority. However, both sets of criteria play a role and are embedded in the ritual re-enactment of the local history of kinship groups. The "way of the beer" of the Wula-Sakon is very complex and reaches beyond the village boundaries of Mtskar. One of the most important ritual agents representing the historical importance of the Wula-Sakon are the Ruwa of Mazay.

\subsubsection{The Ruwa}

The Ruwa live in the clan ward Ruwa in Mazay and, with only three families, are the smallest clan group in the research area. The outstanding ritual importance of the Ruwa has already been mentioned several times. Their biy $d z a$ is not only mountain priest for the Ruwa but also for the whole of Mazay which makes it the only village in the research area in which a diy mbulom ḿbiya'a (great ancestor shrine) not only serves a $d z a$ (independent clan ward) but also a wudam (traditional village). The Ruwa have gained this very strong ritual position thanks to their relationship to the Wéslém of Wula-Sakon who consider them as their "children" they left behind when they moved on from Mazay to settle in Mtskar (first in Gəd Méjéke and eventually in Wéslém). In order to historically re-enact this relationship of political paternity, the biy $d z a$ of Ruwa as the "son" brings sorghum beer to the tsava (elder) of the Wéslém as his "father" which, in turn, frees Mazay to follow its internal "way of the beer". All of this takes place during the harvest festival as I have described it in the previous chapter.

The geographical origin of the Ruwa is thought to be the village Roua, east of Soulédé, which is surprising since the Wula-Sakon claim to have originated from Wula proper (next to Sukur), in the southwestern corner of Mafa land. A local narrative informs us that the current Ruwa of Mazay only resettled in Mazay a couple of generations ago. The story goes that the old Ruwa line had died out and that Mazay intended to use this as an opportunity to gain political independence from Mtskar. At the time, the Zhélé had already become chiefly clan of Mazay after replacing the Hizhé, who had similarly replaced the original Wula-Sakon. The abolishment of the Ruwa as the ritual link with Mtskar turned out to be inauspicious for the prosperity of Mazay and divination recommended they should be brought back. The people of Mazay went to the village Roua (on the boundary to the Mofu-Diamaré), and brought back new Ruwa, whose descendants today are the biy dza of Mazay. This example reminds us that the "way of the beer" is not just a mechanical re-enactment of settlement history but a re-interpretation of the course of local historical events of ritual actors, adhering to a shared religious worldview.

The Mafa word ruwa refers to the tree Parkia biglobosa. It is difficult to explain why the Ruwa are traditionally linked with the village, Roua, which is geographically situated to the southeast while their political fathers, the Wula-Sakon, originally came from the southwestern corner of Mafa land. One explanation is that the Wula-Sakon, coming from the direction of Bao on the Ziver plateau when they immigrated into the area of Gouzda, claim to have had links with Roua 
near Soulédé. Bao on the Ziver plateau and Roua east of Soulédé are not far away from each other and are situated on the main east to west migration route leading into the research area. However, place names often repeat themselves in Mafa land and I have already referred to another Bao on the Wanday plateau (near Wula proper). There is also a second Roua, this time in the northwestern corner (towards the Gwoza Hills) of Mafa land. It is also possible that only the Ruwa who replaced the original Ruwa of Mazay came from Roua near Soulédé. This could have helped to politically reconcile the new chiefly clan of Mazay, the Zhélé (who are proper Mafahay of the Souléde tradition), with the fact that the Wula-Sakon had re-gained ritual supremacy over Mazay. There are other reasons to assume that the original Ruwa of Mazay were not from Roua near Soulédé but a manifestation of an older link between the Wula proper and Sukur. This possible assumption is based on the fact (verbal information from Judy Sterner and Nic David) that the Sukur traditionally refer to the Wula proper as Ruwa. Whoever the original Ruwa of Mazay were, they still function as historical representatives of the Wula-Sakon of Mtskar. Mazay cannot perform its purification rituals without paying tribute to this relationship of paternity in the context of the "way of the beer".

The two sacred sites of which the Ruwa are ritual masters are considered to have gender which means that their male and female sacred sites are representations of the concept of male and female that Mafa hold good. They are divine representations of God and his wife who both represent the natural condition for any reproductive capacity. Mafa like to say that they are like man and woman. Such ontological metaphors are quite common among Mafa who also refer to their universal God as having only one and not several wives. Male and female sacred sites are therefore representations of the male and female principles anthropology likes to refer to as symbolic dualism meaning that the principles of male and female can be understood as an indigenous mode of classification. ${ }^{147}$ Male and female sacred sites also exist in other wards of the research area but the great shrines of Mazay are certainly the most prominent ones among them.

It is the male shrine which is more important and therefore seen as the real diy mbulom mbiya' $a$ (great shrine) of Mazay. The male shrine is found in Ruwa itself, while the female shrine is situated in Merkanjé, a couple of hundred metres away. The tsava of the Merkanje accompanies the biy $d z a$ of Ruwa in carrying out his religious duty but in Ruwa itself he goes on his own. Before the biy dza of Ruwa says his prayer and makes the sacrifice to the main shrine he visits the other biy $d z a$ of Mazay and carries out a beer libation at their var ma gay (front courtyard). These biy $d z a$ are from the local clan ward Zhélé (who are the actual chiefly clan), the Hizhé (who are the former chiefly clan) and the Vuzay of Mazay. The Merkanjé do not have their own biy $d z a$ since they only have a kind of sacred lease on their land, which in reality belongs to the $d z a$ of the Vuzay and Hizhé. This is why their elders bring beer to the biy dza of Vuzay and Hizhé who, in turn, carries out a libation at their var ma gay. All other biy dza of Mazay bring sorghum beer directly to the mountain priest of the Ruwa who in turn takes sorghum beer and a living cockerel to the Wéslém of Mtskar.

\subsubsection{The Zhwé}

The Zhwé are the most powerful clan of biy gwala in the area of Gouzda. Oral tradition informs us that the Zhwé were the kar bay (chiefly clan) of Gouzda before the Vuzay took this position away from them. The story goes that the Vuzay borrowed their red bonnet and then conveniently forgot to give it back. This means that they were once kar bay, but now they have become the

\footnotetext{
${ }^{147}$ I have already referred, in the two previous chapters, to the extensive use of symbolic dualism among Mafa. One of the reasons for this might be the high population density encouraging its application as a conceptual tool for monitoring complex ritual relationships.
} 
first biy gwala of Gouzda. A similar situation occurs in Mazay, where the Hizhé, as former kər bay, have become the first biy gwala of Mazay. The Hizhé and Zhwé have a pseudo-clan relationship (ńshibene) which involves them behaving endogamously to each other. They have both become wife givers to the Vuzay and Zhélé as their local kar bay, who outnumbered them. The Zhwé and Hizhé are also referred to as having been ngwazla before they became vavay, although the Zhwé admit to this much more freely than the Hizhé and it might well be that the Hizhé are only included because they are ńshibene to the Zhwé.

The Zhwé have a very important ritual position in Gouzda-Korbay. They play a decisive role in investing the new chief of Gouzda after the old one has died and they have a diy mbulom mutsor (hidden or anonymous shrine) on the territory of the Vuzay Korbay. This anonymous sacred site is found in Gouzda-Bédégwé, where the biy $d z a$ of the Vuzay lives. Before the biy $d z a$ of the chiefly clan of Gouzda can carry out his annual sacrifice on behalf of all Vuzay of Gouzda, the biy dza of the Gouzda-Zhwé visits him at home. After he has carried out a beer libation at the front courtyard of the biy $d z a$ of the Vuzay (figure 7), he goes on to perform a sacrifice at the diy mbulom mutsor in Bédégué since this sacred site represents their former custodianship over this land. It is only after this that the biy $d z a$ of the Vuzay-Korbay can carry out his duty of sacrificing on the shrine of his local clan group.

The Zhwé claim to have originated from Mouhour (Muhur), which is one of the so-called Bulahay groups to the west of the Mofu-Gudur (see Chapter 1.1.2), where they were southeastern neighbours of the Mafa. The alleged reason for them leaving Mouhour was that the chief of Mouhour, at that time, had died and his chief blacksmith was supposed to be buried alive with him. Fortunately they escaped and fled from Mouhour. From Vouzod ${ }^{148}$ they eventually arrived in the area of Gouzda, where they allegedly met the Goyé and the Gura. They claim to have brought with them the most powerful taba (sacred rope) ${ }^{149}$ as well as some blacksmith's tools. The Zhwé claim to possess the original sacred cord which they found in a gap between the terrace stones. Original ropes in general have the potency to multiply, and it is the Zhwé who own the most powerful one in the area of Gouzda. This is why a common ground in the ward GouzdaZhwé functions as the place where the bull festival ends its traditional cycle for the whole region.

The Zhwé did not always occupy the triangle where the villages Gouzda, Mouzoua and Mtskar share a common boundary. They originally lived in Gouzda-Hwad-Woyam, which is a sub-ward of Kudon, and Gouzda-Madzov, which is a sub-ward of Ged-Woyam. Gouzda-Kudon is the name for the largest ward to be found in the research area, and is separated from Gouzda-God-Woyam by coming down through the rift valley which divides Gouzda-Gura and Gouzda-Zlodongoy. We do not know whether Kudon was an separate village in the past, but we do know that it is the place from where the Vuzay (particularly from Gouzda-Varzlay) began to spread and to develop their chiefly power into the rest of Gouzda. The ownership by the Zhwé of a diy mbulom mutsor in Kudon-Bédégwé marks their local historical importance.

The local history of the Zhwé is also closely attached to Gouzda-Modzov. The Goyé and Zhwé are considered to be the first settlers of Modzov, today occupied by a branch of the Vuzay lineage Laguwa-Vagsa. The Laguwa, like most other Vuzay lineages of Gouzda, originate from Varzlay in Kudon. The main historical evidence for the former presence of the Zhwé of Modzov is a sacred site which is today owned by a Zhwé blacksmith who lives in Gouzda-Gura. Oral tradition says that although Goyé had originally given shelter to Laguwa, he refused to allow him access to his farmland. It was the Zhwé of Modzov who subsequently gave land to the Laguwa, who, in

\footnotetext{
148 Martin (1970:55) also mentions 'Joué' (Zhwé) living in 'Vouzad' (Vouzod).

149 The ritual function of the sacred tə6a as a religous symbol of social order and fertility has been described in the context of the bull festival (see chapter 3.3.4).
} 
turn, managed to remain ritually independent from the Zhwé. It is orally reported that all Zhwé were still ngwazla at the time and that it was only later that many of them become vavay.

Another oral tradition tells us about a war between the Vuzay-Vagora and the Zhwé of Madzov, in which the Vagora not only killed Zhwé but also their own clan brothers, including, for example, the Laguwa. As a consequence of these killings, the Vagora were deprived by the other local Vuzay of the right to continue as a chiefly lineage. We do not really know whether the Zhwé of Modzov gave land to the Laguwa before or after this war and there are several other uncertainties which cannot be easily resolved. One of them is the question of the former blacksmith status of all Zhwé and whether they could have been a chiefly clan while they were still endogamous blacksmiths. There are no oral traditions which hint that the Zhwé had already been living in the area of Gouzda at the time the Wula-Sakon were still based in Gouzda-Wula. The question arises whether the Zhwé were a chiefly clan in the same mould as the Vuzay, Zhélé or Wula-Sakon of today. With regard to the size of the land and lineage populations of the chiefly clans of today, in particular the Vuzay of Gouzda, the answer must be almost certainly no. The section on the local history of the Vuzay Korbay of Gouzda will demonstrate that the large size of chiefly clans today is closely linked with the arrival of the Mafahay. The "hidden" sacred site of the Zhwé in Bédégwé and the Zhwé blacksmith shrine in Modzov are historical manifestations of such a development. Other historical manifestations of the relationship between the Zhwé and the Vuzay Kərbay is their role in investing the new traditional village chief of Gouzda. It is said that the Zhwé bring a goat into the house of every newly invested chief in order to make the goat open its bowels. They subsequently collect the goat pellets and take them home. They are said to be the only ones who know when the chief is going to die since they always know the number of pellets of goat excrement which they equate with the remaining years of his life. Every year the elder of the Zhwé is said to throw one pellet away. The elder of the Zhwé also supervises how the chief of blacksmith (today no longer a Zhwé) hands the sacred rope of the village (a copy of the original one held by the Zhwé) over to the new chief. Every year after the harvest festival the traditional chief of Gouzda is obliged to invite the elder of the Zhwé to drink sorghum beer at his house.

The literal meaning of the name Zhwé refers to a particular variety of wild cat called $z h w e ́$, which also carries some religious significance. Its paw is used, throughout the whole region, to ritually clean the sitting place of the gad bay (chief's deputy) during the bull festival. The Zhwé eventually left Gouzda and settled temporarily in Mouzoua but soon moved back across the border and settled in Gouzda-Zhwé where we find the great shrine of the Zhwé, who are today all vavay (non-blacksmiths). All Zhwé are descended from a common ancestor called Menda. ${ }^{150}$

The descendants of Menda's oldest son, Mbeutélé, are most segmented due to the fact that Ziyahad and Javiy moved from Gouzda to Mtskar where they developed into two new gad bulom. The gad bulom Godaliy is the oldest minimal lineage of the Zhwé, in genealogical as well as in settlement terms. However, we can see from the digital map (figure 8) that the biy dza of GouzdaZhwé is from the gad bulom Bava, although the Godaliy still own the most important sacred rope of Gouzda-Korbay. The biy dza is responsible for the major shrine, as well as the killer shrine, found there and also for the sacrifice to the hidden shrine of Vuzay-Bédégwé mentioned earlier (which I have also classified as major shrine). The major shrine in Gouzda-Zhwé is for all Zhwé, but the Zhwé of Mtskar and Mouzoua are not allowed to carry sacred beer across the village boundaries. In the past, such an act could have caused a war since the other clans of Mouzoua or Mtskar would have assumed that Gouzda was trying to lay claim to their territory.

\footnotetext{
${ }^{150}$ Menda is also the ancestor of the Zhwé of Vouzod as well as a group of Zhwé living in Bigidé (see figure 3). My Gouzda informants are of the opinion that the spreading of the Zhwé along the eastern Ziver-Oupay Massif took place over a fairly short period of time. This assessment of theirs sounds feasible to me since the various Zhwé lineages in the region would be much more fragmented into local maximal lineages.
} 
Table 7: Local lineage tree of the Zhwé

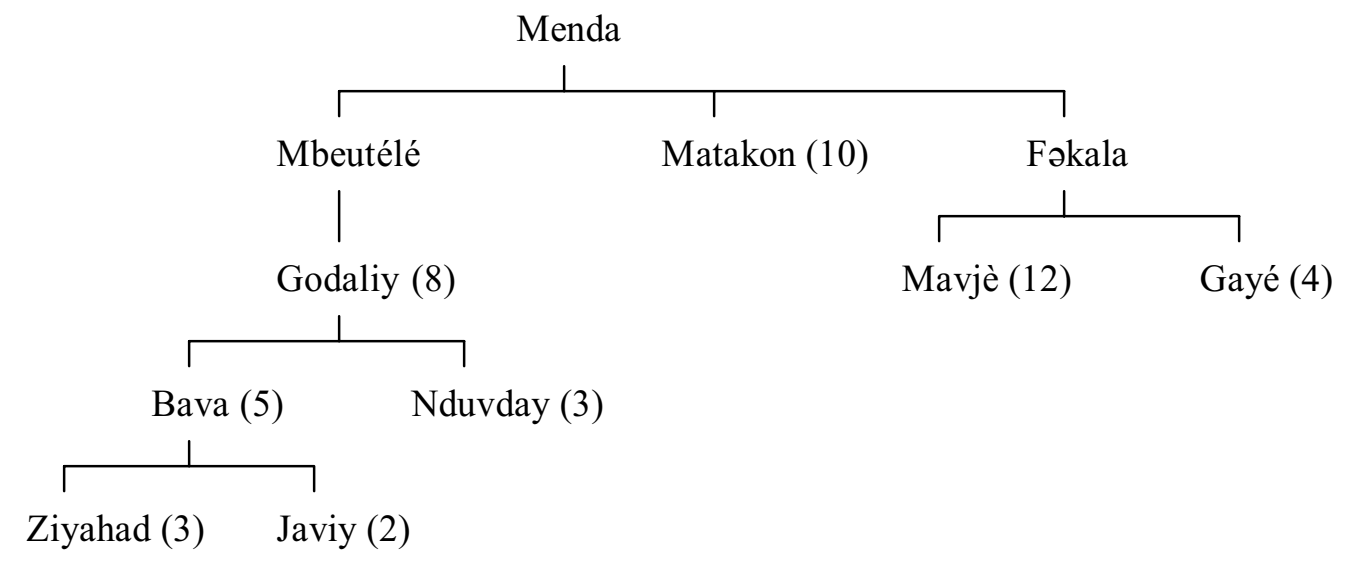

The Zhwé of Mouzoua have their own major shrine and mountain priest who is from the lineage Matakon, which marks them as independent clan ward of Mouzoua. The Zhwé of Mouzoua have a quality of healing, for people suffering sensory impairment, and also a river shrine. The Zhwé of Mtskar live on the land of the Wula-Sakon and have no sacred site. For the harvest festival their local elder brings beer to the elder of the ward Gəd-Mejéké, who, in turn, carries out a beer libation to the front courtyard of this elder's house. To celebrate their own lineage ancestors, the Zhwé of Mtskar join their relatives in Gouzda-Zhwé. The Zhwé of Gouzda still have a small ward by the name Dak-Zlama in Gouzda-Gəd-Woyam. This piece of land only recently came into the possession of Gouzda as a result of a war with Zlama. This is why we still find a minor shrine there which is marked as the shrine of strangers, but, in reality, it is an old shrine of Zlama. The few Zhwé who live in Dak-Zlama also go to Gouzda-Zhwé in order to celebrate their territorial cult.

\subsubsection{The Hizhé}

After Ruwa, the Hizhé claim to be the second oldest clan residing in Mazay. The Hizhé claim to have come from Douvar, a massif to the north of Mokolo, at the southern end of the Ziver-Oupay Massif (figure 3). They also say that they once lived together with the Zhwé in Douvar ${ }^{151}$ and that they share an eponymous ancestor of the name Malay Daw, a claim which needs to be understood in the context of their pseudo-clan relationship. Malay Daw was a blacksmith and he had two sons, Hizhé and Zhwé, which is why they exchange funeral beer and do not marry each other's daughters. This particular funeral beer is exchanged on the day when the spirit of a deceased person is chased away (see Chapter 3.2.9). Like the Zhwé, the Hizhé refer to Mouhour (in the area of the Bulahay groups) as their real place of origin. They frequently visit their clan brothers in Douvar, and say that Hizhé are also found in Zlengzleng (also spelt Ldinglding) which is a Kwokwarhay settlement south of Tourou (figure 3). When they visit them, they are invited to participate in their ancestor cult.

The Hizhé say that a mountain priest of the name Gozhé once lived in Hizhé and that he was their authentic great ancestor. A legend informs us that Gozhé once wanted to sacrifice a goat at the sacred site dza malay, but had forgotten to bring his knife. A boy of the Malakwa lineage guarded the goat while he went home to fetch his knife but when he came back the goat had died. Gozhé interpreted this as a sign that the ancestors did not want to wait for him to kill the goat and had therefore decided to "eat" in his absence. Since the boy (who had fallen asleep) had remained

${ }^{151}$ The question whether the Zhwé of Vouzod came from Douvar must remain unanswered due to lack of information. 
present at the sacred site throughout the time of his absence, he decided to make him his assistant. Gozhé later left to live in Godaliy (presumably Dughwede) in the Gwoza Hills and Hizhé had gained the custodianship of their land. The Hizhé today consist of four minimal lineages, Nduvay, Dalma, Bengwémé and Wala which are descended from Ehémevéd and Malakwa.

Table 8: Local lineage tree of the Hizhé

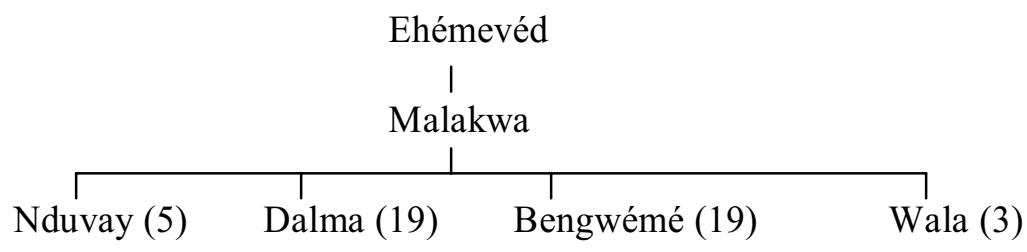

The biy dza of the Hizhé is from the oldest lineage Nduvay. He is responsible for the major shrine (called $d z a$ malay) situated on the highest mountain top of Hizhé which represents Gozhé and Malakwa. There is also a minor shrine which belongs to the lineage Dalma, as well as a killer shrine related to the killing of leopards which goes back to Malakwa. The biy $d z a$ is also responsible for the killer shrine while the elder of the second oldest lineage, Dalma, is the custodian of the minor one.

The Hizhé bring ritual beer to the Ruwa (figure 7), but not to anybody else. As a former chiefly clan, they hold particular responsibilities as biy gwala. The two most important biy gwala taba, not only of Hizhé but of the whole of Mazay, is from the youngest lineage Wala. We can see from the digital map (figure 8) that the lineage elders of Nduvay, Dalma and Bengwémé are the bay of Hizhé, but the Dalma also have a less important biy gwala madzaf. Oral tradition reports that the Hizhé lost their red bonnet to the Zhélé due to the fact that the Zhélé of Mazay and Woulad joined forces. However, the real reason is that the Zhélé eventually outnumbered the Hizhé and therefore became kar bay of Mazay while the Hizhé remained the most important biy gwala. The position of the Hizhé as former kar bay is also displayed in the custom that the Hizhé get hold of the traditional chief in his house in Zhélé Mazay. They fix a goat hide over his back like they do for a female who is given into marriage. The ritual is called ńkilbe gojévad which is a reference to the first part of a traditional marriage (see Chapter 3.2.5). In this ceremony the traditional chief ritually becomes a "wife to be" and, as such, symbolises the reproductive capacities of the village as a whole. The Hizhé do not like this ceremony since it is very dangerous, can lead to the early death of the village chief and they fear that they could be blamed.

The common ground of Mazay is found in the south of Hizhé, the place where the bull festival begins and ends. The sacred pebble divination carried out to explore the hidden risks and dangers of the impending bull festival takes place there. The stones for the pebble divination are safeguarded there under a particular succulent creeper, madzaf ziy (Cissus quadrangularis), and it is the biy gwala of Hizhé who take religious care of this place while the biy ngwazla of Mazay carries out the divination. It is the main biy gwala (in his role as first disciple) of Hizhé who determines the day the bull festival should be publicly announced. The first bulls released are those of the biy dza of Ruwa followed by the bull of the biy wudam of Mazay and his gad bay, all found in Zhélé. From Zhélé, the bull festival takes its course through Hizhé and ends in Vuzay (which includes Merkanjé) and Ruwa. It is the biy dza and bay of Ruwa who now carries out a sacrifice at a common ground next to the male sacred site of Ruwa which then opens the hudokw period (see Chapter 3.3.1) at the end of the dry season. 


\subsubsection{The Gozla}

The Gozla consist of 186 families (1116 individuals) and, next to the Vuzay, Zhélé and WulaSakon, are the most numerous clan group in the research area. The Gozla of Mafmay refer to themselves as Tsékore and claim to be the first settlers of Mafmay, saying that they arrived as a consequence of famine in their home region. All Gozla claim to be Mahtal ${ }^{152}$ from Muktele land (see Chapter 1.1.2) and say that they are closely related to the biy yam of Moudoukwa who is also Gozla and the most powerful regional traditional authority after the biy vardeké of Moskota. Other Gozla groups in our research are the Gozla of Mouzoua, who are the only Gozla in the area of Gouzda regarded as chiefly clan and the Gozla of Woulad, who refer to themselves as Dawta and finally those of Gouzda. The Gozla of Woulad say that they came with the Zhélé-Panbao from Djinglia to settle in Woulad and the Gozla of Mouzoua settled in Mouzou-God-Prad together with the Ndura of Wula-Sakon, but also say that the Ndura already lived there when they arrived. The Gozla of Mouzoua lived in Woulad before they moved on to Mouzoua and the Dawta-Gozla took their place when they arrived with the Zhélé-Panbao, one of the first Zhélé groups to settle in Woulad.

The above accounts leave questions with regard to places of origin outside the research area but show a clear sequence of arrivals between the Gozla of Mouzoua and Woulad, although all Gozla claim to originate from Muktele land. If we try to chronologically tabulate their arrival, we find the Gozla of Gouzda and the Gozla-Dawta (Woulad) at the tail end and the Tsékore Gozla (Mafmay) followed by those of Mouzoua at the early beginning of a common settlement history. The Gozla of Mouzoua say that they had been left behind by the Ndura when they moved on to Derngasla in Mtskar. In terms of clanship the Gozla of Mouzoua are closer to those of Woulad, while those of Mafmay are seen to be closer to a Gozla group from Ziver. The difference in closeness is expressed in the context of funeral beer being exchanged among them. The funeral beer the Gozla of Mouzoua and Woulad exchange is called zom kar mama (beer of my mother's son) while the one the Gozla of Mouzoua exchange with those of Mafmay is referred to as zom kar baba (beer of my father's son). Every year during harvest festival the tsava of the Gozla of Mouzoua goes to the house of the tsava of Dawta in Woulad to libate beer at his front courtyard (figure 7). The reason why he goes there instead of the Dawta bringing beer to Mouzoua is that he is not permitted to cross the village boundaries with sacred beer. The only local exception to this rule is the biy dza of Ruwa since he represents the Wula-Sakon as the only chiefly tradition which can represent the confederation of Mtskar, Mouzoua, Mazay and Woulad as a whole.

The Gozla of Mouzoua are also referred to as Mouzoua and local history reports that they once bought themselves free from the dependency of the Ndura by paying an annual tribute of sesame for the right to sun dry their harvest on the large rock of Mouzoua. This large rock has given GədPrad its name since it means literally "flat on top" which is a reference to the shape and geographical position of Ged-Prad within Mouzoua. The Ndura owned the flat part of the rock but eventually accepted an offer of the Gozla of Mouzoua to purchase the rock from them. In order to secure payment, the inhabitants filled a very large natural hole found in the flat rock of Gəd-Prad with tiger nuts and put a calf on top. The Ndura accepted, including the right of access to a diy mbulom mutsor (hidden mountain shrine) situated at the margin of the flat rock (which is marked as minor shrine on the digital map). In the past, they made offerings at this site before the Mouzoua could celebrate at their diy mbulom mbiya'a (great ancestor shrine). What has remained of the old "way of the beer" is that the tsava of the Ndrua comes every year to drink beer in Mouzoua and to make a beer libation to the front courtyard of the biy wudam of Mouzoua. Before

${ }^{152}$ The language of the Muktele is called matal. 
the tsava of the Ndrua visits the traditional chief of Mouzoua beer is sent to his house in Mtskar. ${ }^{153}$

The "way of the beer" of the Gozla can therefore be reconstructed as a re-enactment of the local history of the Gozla and the Ndura of Wula-Sakon with the Gozla of Woulad connecting with the Gozla of Mouzoua similarly to the way the Mouzoua connect with the Ndura. Both moved on and left someone behind as their representatives who then took on the ritual obligation to produce and provide sorghum beer while the ones who had moved would receive and consume it. In general terms it is the biy gwala who represents the one who is the provider of ritual beer while the bay represents the ritual receiver. However, the one who is biy gwala at the one end of the "way of the beer" can be bay at the other end or the other way around. The Ndura for example are the kar bay of the Gozla of Mouzoua but the biy gwala of the Gojélé who are the great bay (or biy bay) of Mtskar (see section on the Wula-Sakon). The ritual dependency of the Gozla of Mouzoua on the Ndura of Wula-Sakon endows the Gozla with the right to be kar bay of the traditional village Mouzoua. However, this ritual dependency gives the chieftaincy of Mouzoua a flavour of political weakness which is one of the reasons why the Zhwé, being the only other clan of Mouzoua do not fully acknowledge the Gozla-Mouzoua as chiefly clan.

Apart from their link with the the rainmaker of Moudoukwa, the Gozla are not very highly regarded locally. They are often referred to as kada which is a general assumption that they are strangers from Mahtal (Muktele). Some Gozla of the research area have retained a custom of reusing the skin of a $\operatorname{dog}(k a d a)$ in the context of their marriage rituals. The non-Gozla, and especially the ruling Mafahay clans (in particular the Zhélé and Vuzay) say that the Muktele consume dogs (which is true for Muktele land) but the Gozla of our research area have stopped eating dogs.

The clanship ties of the Gozla with the rainmaker of Moudoukwa were much stronger in the past than they are today. Then, the Gozla were regarded much more as local representatives of the biy yam of Moudoukwa. This representational function occurred in Woulad in such a way that the Dawta were entitled to choose girls from the Zhélé of Woulad to pass them on for marriage to the biy yam (rainmaker). In return for this exchange, the Zhélé were entitled to consume sorghum beer in every Dawta house after each bull and harvest festival. Although the function of the Dawta as "wife collectors" for the regional biy yam has now ceased, the elder of the Dawta still invites the council of Zhélé elders to drink beer in his house at the end of each bull and harvest festival of Woulad. The original reciprocity in the context of the ritual exchange of daughters and sorghum beer between the regional rainmaker and the local chiefly clan has now been shifted. The chiefly clan has retained its right to receive sorghum beer, but the rainmaker has lost the right to receive women in exchange. The general loss of regional traditional power over natural resources like rain has weakened the political weight of the rainmaker's local representative to the advantage of the local chiefly clan. This gain of ritual influence of the local chiefly clan is a result of modern change which can no longer justify the reproductive capacity of women being linked to the production of rain (mediated by sorghum beer).

\subsubsection{The Zhélé}

The Zhélé of Mazay and Woulad, with 1668 individuals (143 households in Mazay and 135 in Woulad), are the second largest clan group in the research area. At the same time, together with

\footnotetext{
${ }^{153}$ I assume that the reason why this beer can cross the village boundary is that Mouzoua and Mtskar are situated next to each other and the beer does not have to traverse a third village. The other reason is that Mouzoua was in the past a satellite village of Mtskar. The chiefly status of the Gozla of Mouzoua is very much a result of this old dependency to Mtskar.
} 
the Vuzay (the largest clan group), they are representatives of the most recent wave of local immigration. There is a general indication that Woulad was once inhabited by sections of the Wula-Sakon of Mtskar, but because we do not know who the Wula-Sakon left behind as their representatives there is no proof to support this idea. Therefore, we can only speculate that the Gozla of Mouzoua once had this role since they followed the Ndura from Woulad to Mouzoua. The Gozla of Woulad of today are only indirectly linked to the Wula-Sakon which becomes obvious by the fact that they provide sacred beer for the Mouzoua who then, in turn, deliver a share of theirs to the Ndrua. I pointed out above that the Gozla-Dawta came from Djinglia together with the Zhélé-Panbao in order to replace the Gozla, now in Mouzoua, and so no Zhélé of Woulad brings beer to the Dawta.

The situation is different in Mazay, where the Ruwa represent the Wéslém of Mtskar and the biy $d z a$ of the Zhélé recognises this link by providing him with a share of sacred beer (figure 7). Also the Zhélé of Mazay once lived in Djinglia. Both the Zhélé of Mazay and those of Woulad are the kar bay in these two villages but only the Zhélé of Woulad have a biy wudam since the one of Mazay died. The Zhélé of Mazay and Woulad altogether consist of five local maximal lineages. Four of them are found in Woulad but I begin with the lineage tree of the Zhélé of Mazay, whose great ancestor was Verdéké.

Verdéké allegedly had two sons, Oeté and Zangwiy, but all descendants of Oeté are today referred to by the lineage name Jéwélé (also referred to as Méwélé). With 88 households (528 individuals) the Jéwélé are the largest lineage, as opposed to the Zangwiy and Gadayé with only 55 households (330 individuals). Gadayé was a nephew of Jéwélé but is today linked with Zangwiy because they are considered to be as equally remote as Jéwélé. Among the Jéwélé, the Haydak (which includes the Mongocé Luhda and Méjéwé) is the largest branch with 69 households (414 individuals), Luhda being orginally adopted by Haydak (Luhda came from Kerawa). ${ }^{154}$ Although the Jéwélé (or Méwélé) are the larger and genealogically older group, the Zangwiy are considered to be the first Zhélé who settled in Mazay. This is why the bay of the Zangwiy brings ritual beer to the elder of the Ruwa (who in turn brings beer to the Wéslém of Mtskar). The biy $d z a$ of the Zhélé of Mazay, who is from the lineage Haydak-Jéwélé, brings beer for this purpose to the bay of Zangwiy. Although the bay of the Zangwiy is considered to have a very important role, the Zangwiy as a whole (due to their smaller size) are considered by the Jéwélé as their biy gwala. The Zangwiy, in turn, consider the Gadayé as their biy gwala and it is an elder of the Gadayé who is the most important biy gwala of all Zhélé.

Table 9: Local lineage tree of the Zhélé of Mazay

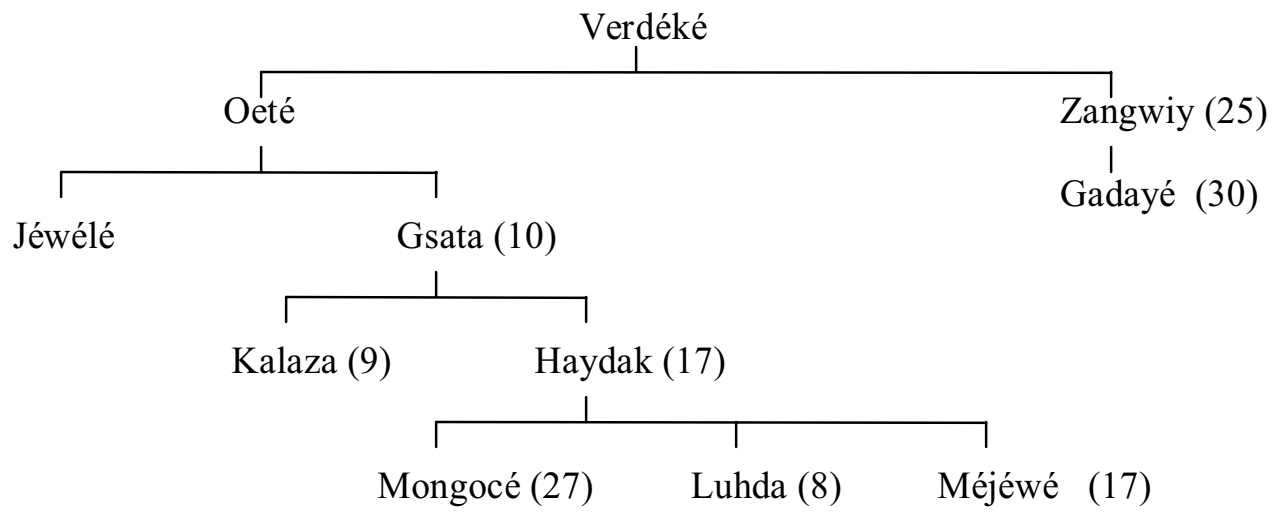

\footnotetext{
${ }^{154}$ Not the Wandala town but a village of the name Kerawa which is situated in the northeastern corner of Mafa land, not far from Roua (near the Nigerian border and the Gwoza Hills).
} 
The most important bay of the Jéwélé is from the lineage Gsata while the biy dza of all Zhélé of Mazay is from the lineage Haydak-Jéwélé, the largest. The most important sacred shrine of the Zhélé-Mazay is found in Guvdad and is considered by the mountain priest to be a male shrine whereas he considers the minor shrine of Gad-Dza to be a female one. This minor shrine belongs to Gsata which is the oldest Jéwélé lineage. The Mongocé, which is the largest lineage of the Jéwélé, have a minor shrine in Guvdad while the Zangwiy and Gadayé each have a minor one in Ndav-Gay. We see from this that the important lineages have their own shrines, but the major sacred site of Guvdad, although allocated to Jéwélé, is shared by all lineages. The respective lineage elders are responsible for the minor shrines but bring beer to the biy dza of the Zhélé who sacrifices to the major site in Guvdad.

We can see from the above, that the "way of the beer" of the Zhélé of Mazay runs in two directions. The first is represented by the beer the biy $d z a$ and other lineage elders bring to the bay of Zangwiy, who, in turn, takes it to Ruwa to serve the rule of first comers in the context of the wider village community. The second is represented by the beer all other lineage elders (including the bay of Zangwiy) bring to the biy $d z a$ of Zhélé, who, in turn, carries out the sacrifice to the sacred mountain in his function as the representative of the genealogically older lineage section. A third point is that, although the bay of Zangwiy represents the role of the first comer among the Zhélé of Mazay, the larger lineage branch, Jéwélé, still consider them as their biy gwala. We can assume that the Jéwélé lineages would also be considered as bay if the Zangwiy were genealogically older, ${ }^{155}$ a view which re-enforces the importance of population growth for the allocation of status. However, the traditional chieftaincy circulates between the Zangwiy and Jéwélé. The last biy wudam was from the lineage Haydak and the next one is supposed to be from the lineage Zangwiy. As soon as the election process is completed the new chief of Mazay will appoint his first gad bay to function as his deputy and he is presumably also going to be a Zangwiy.

\section{The Zhélé of Woulad}

The only ritual link the Zhélé of Mazay and Woulad share is that both have to wait for WulaSakon of Mtskar to announce the harvest festival, since they are considered as the first settlers of the confederation of Mtskar. It is said that the Wula-Sakon also once settled in Woulad, but we do not know which lineage and there is no representative of the Wula-Sakon found in Woulad. This implies that there is no "way of the beer" directly or indirectly linking the Zhélé of Woulad with the Wula-Sakon of Mtskar. However, the Gozla-Dawta and Zhélé-Panbao inform us that the first settlers of Woulad were the Malkeza who originated from Vouzod, but apart from one family there are no others left, and in addition, there is no ritual role for them. After the Malkeza, the Zhélé-Panbao arrived followed by the Gozla-Dawta who replaced the Gozla of Mouzoua living at the time in Woulad. ${ }^{156}$ The Zhélé-Panbao originally arrived in Woulad-Dzamba which is situated immediately to the south of Djinglia, from where the Zhélé had moved onto at the time and where the Zhélé are also the chiefly clan. The Zhélé of Woulad-Panbao consist of the lineages Zagwiy and Vasla which belong to the two maximal lineages Méndé and Mazawal.

The major lineage Kétiwé consists of the Jéwéday, Velas and Gwézéow and numbers altogether 38 households (228 individuals) while the Zagwiy number only 15 families (90 individuals). We

\footnotetext{
${ }^{155}$ The Ndura of Wula-Sakon, who are not only first comers but also genealogically older in relation to the numerous Jèkuwè, are still considered as biy gwala of the Jèkuwè.

${ }^{156}$ I have already referred to the "way of the beer" linking the Dawta-Gozla via the Gozla-Mouzoua with the Ndrua of the Wula-Sakon in Mtskar. I also mentioned the custom of the Zhélé elders to be provided with sorghum beer by the elders of the Dawta due to their old connections with the rainmaker of Moudoukwa.
} 
can see from the lineage tree that the Jéwéday (which also includes the Gwézéow) are by far largest branch of the maximal lineage Méndé with a total of 35 houses (210 individuals).

Table 10: Local lineage tree of the Zhélé of Woulad

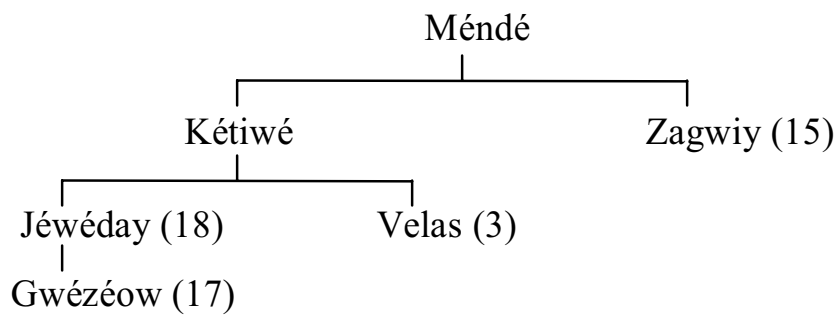

The maximal lineage Mazawal consists of 60 households (360 individuals), which means that the descendants of Mazawal, with 7 houses (48 individuals), are only slightly more numerous than those of Méndé. Some Zhélé also seem to believe that Zagwiy of Méndé and Vasla of Mazawal are closely linked, an opinion which might be based on the fact that they both share the village ward Panbao. Among the Zhélé-Panbao, it is the elder of the Zagwiy who receives beer from the elder of the Vasla, which indicates that the Zagwiy are the first Zhélé who settled in Panbao. If we follow the oral tradition that the Zhélé-Panbao are the first Zhélé who settled in Woulad (at the time in Woulad-Dzamba) we must conclude that this is a reference not only to the Zagwiy but also to the Vasla.

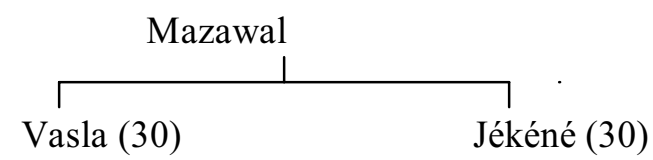

The Kétiwé and Jékéné settle in Dzamba where the major shrine of all Zhélé is found towards the boundary with Panbao and allocated to the Ketiwé. The Jékéné settle in the southwestern part of Dzamba and own three sacred sites in Dzamba, a minor ancestor shrine, a killer shrine and a healing shrine (see figure 8). The ritual relationships of Dzamba are quite complex. The elders of the Kétiwé and Velas no longer live in Dzamba but in the modern settlement area of Woulad which is the reason why they do not receive ritual beer from their younger lineage brothers. The biy $d z a$ of the Zhéle is a Catholic by the name Jacques-Mari. ${ }^{157} \mathrm{He}$ is from the lineage Gwézéow and the only Christian in the research area who acts as mountain priest. The biy wudam of Woulad is from the lineage Jéwéday of Dzamba, as is his first gad bay while his second gad bay is from the lineage Velas. With regard to the "way of the beer" the Jékéné (who own the minor shrine) and the Jéwéday (who own the major shrine) do not exchange beer for each other's sacrifice on their respective ancestor shrines in Dzamba. However, in the context of the bull festival the Jékéné are considered as biy gwala and the Kétiwé as bay. With respect to the circulation of the village chieftaincy, it is the Jéwéday of Dzamba and the Zagwiy of Panbao who hold the right to provide the biy wudam.

We can summarise from this that the two maximal lineages, Méndé and Mazawal, share between them most ritual responsibilities and it seems that the Méndé are biy dza as well as biy wudam. In the context of the "way of the beer", especially in relation to ancestor shrines, there seem to be some significant internal differences. The Vasla of Mazawal bring beer to the Zagwiy of Méndé

${ }^{157}$ When I went for a visit in February 2000, I was told that Jacques-Mari had been forced by the Catholic mission to make his mind up. Jacques-Mari decided to remain as mountain priest and was therefore excommunicated by the church. 
since the latter hold the most important shrine in Panbao, while the Jékéné of Mazawal and the Kétiwé of Méndé do not exchange beer for their respective shrines in Dzamba. The reason for this might be that the "way of the beer" is already interrupted inside the Kétiwé of Méndé since two of their lineage elders no longer live in Dzamba but in the modern settlement area.

The third maximal lineage of the Zhélé of Woulad is Vicé and the fourth is Wandala. The Vicé and Wandala live in Bémbéré with the Vicé consisting of 17 houses (102 individuals) and the Wandala of only 5 households (30 individuals). They arrived in Woulad only recently and possess no particular ritual responsibilities.

\section{The Mafahay tradition of the Zhélé}

The Zhélé say they originally came from Soulédé which ties in with the classic Mafahay tradition. The Zhélé and the Vuzay are the largest clans who claim to represent the Mafahay or "true Mafa" in our research area where they number around 534 households (3204 individuals) which is about one third of the local population. The proportion of chiefly clans to non-chiefly clans in this situation appears to be reversed since all the chiefly clans represent two thirds of the local population and the non-chiefly clans represent only one third. The example of the Zhélé is a good opportunity to discuss the meaning of the ethnographic term Mafahay. Lavergne (1944:23) speaks first of the 'mafahai' and includes the Zhélé (with 28,000 individuals) and the Vuzay (with 8,000 individuals) as the most significant among them. ${ }^{158}$ Although Lavergne's population figures are only rough estimates, the Zhélé appear to be by far the larger group. To my knowledge there are no statistics which say the exact number of Zhélé living among the Mafa of today. However, most of those to whom I spoke seem to be convinced that the Zhélé outnumber the Vuzay. We find this demographic relation to be the other way around in our research area where the Vuzay number 399 houses (2394 individuals) and the Zhélé only 135 houses (810 individuals). This brings us back to Lavergne (op.cit.:22) who already pointed to Gouzda as an area dominated by Vouzay and not by Zhélé.

Martin (1970:35) reports the Soulédé tradition of origin of the Zhélé as stemming from a legend in which a sparrowhawk, coming from Mozogoy, ${ }^{159}$ carried a baby boy in his beak and laid him down in Soulédé. The 'Goya [Goyé], ${ }^{160}$ Sassak, ${ }^{161}$ Vouzi [Vouzay]' and 'Ldagam [Zlagam]' who had arrived from Gudur some time before, saw the baby being brought to the ground and called out in astonishment: "My son! my son!" and subsequently gave him the name 'Jélé' (Zhélé). The topic of an ancestor being brought by a bird and his subsequent adoption is quite common in Mafa oral tradition. ${ }^{162}$ Martin (op.cit.) does not connect the word for lion, mariy zhélé (sacred bull of the Zhélé), with the clan name Zhélé, although it is a common belief among Mafa that the Zhélé of Soulédé once secretly fattened a lion for their bull festival (maray). The story goes that nobody was aware of this until the "bull of the Zhélé" was ritually released, but by then it was already too late. The lion killed many non-Zhélé while the Zhélé themselves stayed in hiding. Traditional Mafa often tell this story when they want to explain why the Zhélé are so numerous today.

\footnotetext{
${ }^{158}$ Lembezat (1961:7f) refers to the 'Vouzi' and 'Zele (ou Djele)' as the 'Mafahai (ou Mafa)' and states that the Vouzay mainly live around Soulédé while the Zhélé live more around Roua.

159 According to Martin (1970:88) Mozogoy is a massif not far from Maroua.

${ }^{160}$ I have already pointed out that the Goyé are seen in the area of Gouzda as the autochthonous people whereas they claim themselves to stem from Moskoto. However, Martin (op.cit.) mentions the Goyé in the context of the Soulédé tradition.

${ }^{161}$ Martin (op.cit.) refers to the 'Sassak' as a clan while I refer to sasak as a general word for non-chiefly clan groups which are preferred marriage partners for chiefly clans (see chapter 3.3.5).

${ }^{162}$ Within the research area it is the ancestor of the clan Magiva who was brought by a bird and subsequently adopted by the clan Vuzay of Gouzda-Kərbay.
} 
Boulet (1975:25ff) is of the opinion that the 'Vouzi' and the 'Djélé' left Gudur for Soulédé as the result of severe plagues of locusts and considers them as the first and most important inhabitants of Mafa land. In his opinion the 'plus important ...Vouzi' (op.cit.) settled first in the south and centre of Mafa land of today and then moved towards the west and northwest while the Zhélé did the same by settling first in the east and northeast (op.cit.). The parallel movement of Vuzay and Zhélé in west and northwesterly direction through Mafa land had already been stated by Lavergne (op.cit.), and I have referred to that above in connection with our research area.

Although the Zhélé are generally considered to be the most numerous clan of the Mafa, their status as chiefly clan is not as high as it seems to be for the Vuzay. This assumption first mentioned by Boulet (op.cit.) is authenticated by the information I gathered in the area of Gouzda as well as in Moskota. It is difficult to explain why the Zhélé are seen to rate slightly lower in public opinion than the Vuzay, especially since number appears to be such an important condition for a chiefly clan. It seems that the enormous success of the Zhélé in increasing their number contributed at the same time to the diminishing of their social status because they used an unethical ploy to physically reduce the number of their competitors for regional domination.

\subsubsection{TheVuzay}

Not only Vuzay men but also Vuzay women (the latter after marriage) often refer proudly to themselves as being Duzay or Nduzay, which means "born" into the clan Vuzay (being a member of the Vuzay clan by birth). The Vuzay in the research area consist of only one maximal lineage which goes back to Fətélé who settled first (coming from Soulédé) in upper Gouzda or GouzdaMakanday. The chiefly clan of Zlama is also of Vouzay descent which shows that the Vuzay settle closer to the higher regions of the Ziver Platau.and the Ziver-Oupay Massif. It remains unclear whether Fətélé really came to Makanday or whether it was his son Waslimbay who first settled there. For Gouzda-Korbay, the place of arrival of most Vuzay lineages is Gouzda-Varzlay (see figure 8). The lineage tree below shows the various major lineages (in bold) of the Vuzay within Gouzda-Kərbay and their line of descent to Fətélé via Waslimbay Dakoza, Haraha and Tewjuwé. Dakoza's older brother Danawa is considered as the first Vuzay settler among the kər bay of lower Gouzda who was then followed by Dakoza himself and who eventually become the ancestor of all other major lineages of the Vuzay of Gouzda-Kərbay. Among the descendants of Dakoza, the Vagora are considered as the oldest and the Glémé the youngest major lineages.

The descendants of Haraha total 314 families (1884 individuals) and form the largest major lineages of the Vuzay of Gouzda, consisting of the Vagsa, Lafay, Laguwa and Glémé, while the rest (Danawa and Vagora) number only 67 houses (402 individuals). The population growth of the lineage groups which derive their descent from Haraha are responsible for the development of Gouzda-Korbay to the size and importance it displays today. The largest among these successful lineages are the Vagsa with 133 families (798 individuals), followed by Laguwa with 96 houses (576 individuals) and the Glémé with 65 households (390 individuals), while the Lafay consist only of 20 families (120 individuals).

The oldest major lineage, Danawa, totals 50 families (300 individuals) and the Vagora only 17 houses (102 individuals). These figures show that the descendants of Vagora are the smallest major lineage of the Vuzay-Kərbay while those of Vagsa, with 798 individuals, form the largest.

The key for the digital map (figure 9) shows which wards of Gouzda-Kərbay the various lineages of the Vuzay occupy today. Varzlay in Gouzda-Kudon is the ward where most lineages of the Vuzay arrived, coming from Gouzda-Makanday. The Glémé today inhabit Varzlay, but the major shrine and the common ground found there indicate that Varzlay is one of the earliest inhabited wards of the Vuzay of Gouzda. The elder of the major lineage, Vagora, is the biy dza of all 
Vuzay-Korbay. I have already mentioned him in the context of the "hidden" ancestor shrine (diy mbulom mutsor) of the Zhwé in Bédégwé. After the biy dza of the Zhwé has carried out his sacrifice in Bédégwé, the biy dza of the Vuzay is free to perform the great sacrifice on their major ancestor shrine in Varzlay. This is done during the harvest festival and it is tsava of the Glémé who accompanies the biy dza. The Glémé, too, have a minor shrine in Varzlay as have the Vagsa, being the oldest major lineage in genealogical terms to have descended from Haraha (figure 7).

Table 11: Local lineage tree of the Vuzay

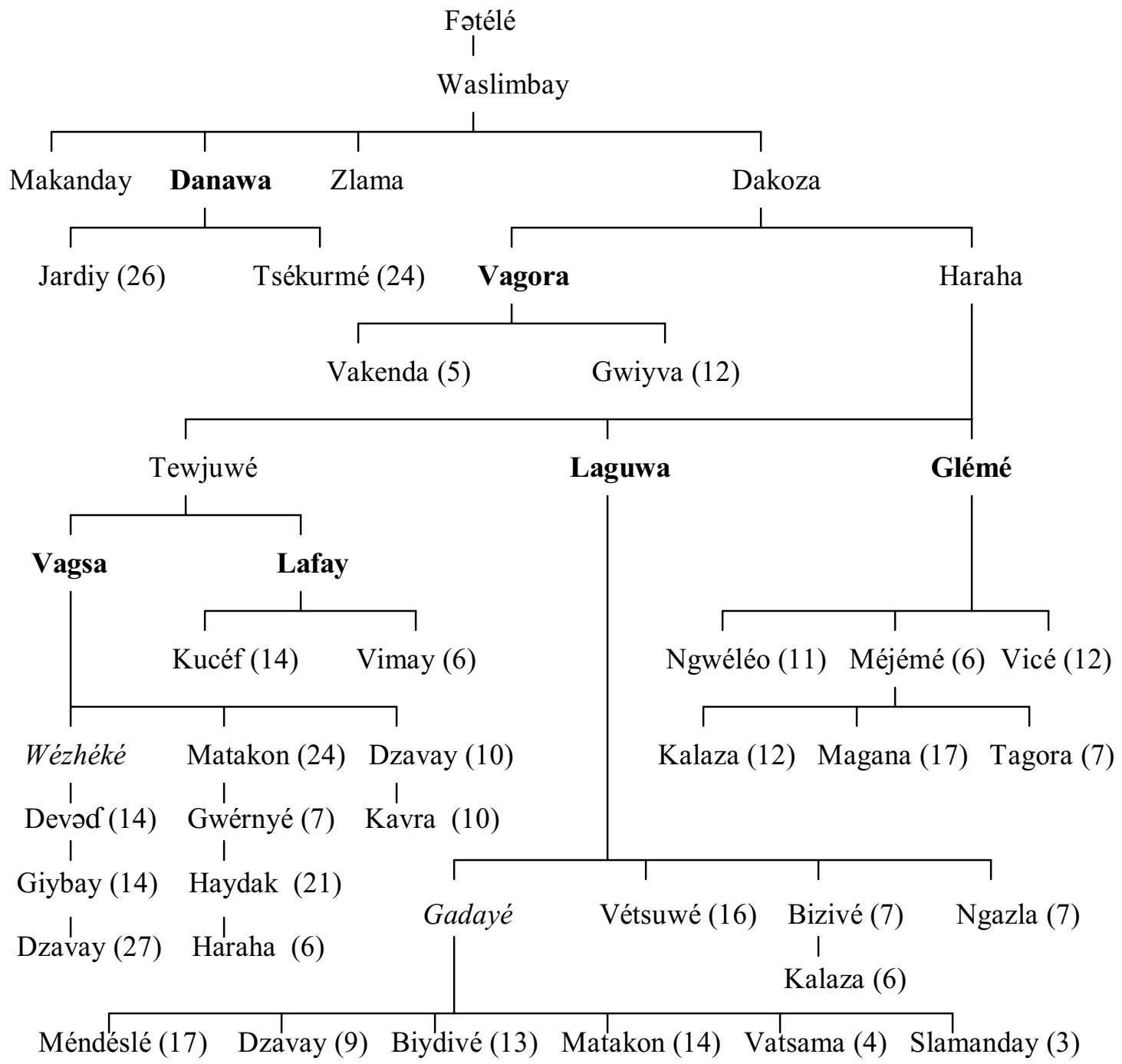

All lineages of the Glémé and the Vagora live in Gouzda-Kudon. Apart from Varzlay, the Gléme are also found in Mbokom (and Mbala north of it), while the Vagora are not only found in Bédégwé (and Wuyak east of it) but also in Dabla. However, Dabla as well as the ward, Danawa, are no longer regarded as part of Kudon, although these two wards also belong to the oldest wards of the Vuzay of Gouzda-Korbay. Although Dabla belongs traditionally to the Vagora, as we can see from their minor shrine there (which belongs to the lineage Gwiywa), other Vuzay lineages have moved there, especially Glémé and Vagsa. Danawa is not a mixed ward and almost solely occupied by Danawa lineages along with their minor and other shrines. There are also some Danawa living in Gouzda-Gəd-Woyam, but they go to Danawa for their lineage sacrifice during the harvest festival. The Vagsa of Deb-Dza are the other Vuzay lineage living in Kudon. They 
own a minor shrine and a killer shrine there which indicates that they are the owners of the land. However, we can see from the digital map (figure 8) that many Christians and other strangers (mostly from other clan wards of Gouzda) have settled in Deb-Dza.

West of Varzlay lie the lineage wards Lafay, Madzov and Méndézé which are part of GouzdaGəd-Woyam. Lafay is occupied by the major lineage, Lafay, with a killer shrine indicating that they are in charge of the land. Madzov is occupied by Laguwa and Méndézé by Vagsa. While Méndézé has a killer shrine which is owned by the local Vagsa, the Laguwa of Madzov have no local shrine. I mentioned earlier, in the context of the Zhwé, that they offered land to the Vuzay while they were still considered as blacksmiths, and the major shrine of Madzov is a legacy of this time. The Zhwé blacksmith of Gouzda-Gura is responsible nowadays for this shrine and it has no significance for the Vuzay. However, it is interesting that, apart from this major blacksmith shrine, we find only killer shrines among the Vuzay of Gouzda-God-Woyam. This indicates that the Vuzay were not capable of achieving ritual custodianship of Madzov, Méndézé and Lafay but, at the same time, there is no "way of the beer" linking them with the original owners of the land. All Vuzay of Gəd-Woyam bring their ritual beer to their lineage elders who in turn bring beer to the mountain priest from the oldest lineage Vagora.

Wula is occupied by Gadayé-Laguwa who are also found in Gəd-Kezla, while the rest of Kezla (Wazl, Debon and Diy-Gagad) belongs to the descendants of Wézhéké-Vagsa. The Gadayé and Wézhéké are both sons from so-called levirate marriages in which Vagsa and Laguwa married the wives of their deceased brothers and adopted their children as a result. Due to their somewhat ambiguous social status the Gadayé and Wézhéké moved on from Varzlay to settle in Wula and Kezla. However, Magiva, who had been brought by the mythical bird and subsequently adopted by Glémé of Varzlay, settled first in Wula and the Gadayé followed later. Apart from oral tradition and the three ancient local shrines of the Wula-Sakon in Giy-Zluved, signifying that they were the former settlers of Gouzda-Wula, there is no evidence of any other earlier occupation. However, according to oral tradition, the Wula-Sakon had already moved on from Gouzda-Wula before the Gadayé-Laguwa arrived. The Gadayé have a killer shrine and a healer shrine in VarHudokw, served by local lineages, while the Gadayé of Gəd-Wula own a minor shrine which is served by their lineage elder who lives in Gəd-Kezla. This shows that the Gadayé of Gəd-Kezla came from Gəd-Wula. The Wézhéké of Kezla own a minor shrine in Diy-Gagad and another, more important one, in Varzlay. The lineage elder of the Wézhéké goes to the one in Varzlay to perform a sacrifice on behalf of all Vagsa. The Vuzay of Gouzda-Kərbay like to say that the major shrine of Varzlay (served by the mountain priest) is a male while the shrine of the Vagsa is a female shrine. The fact that the Vagsa own a separate shrine in Varzlay is presumably a result of their genealogical position (being the oldest son of Tewjuwé) and their large number.

\subsubsection{The Zlagam}

The Zlagam, too, claim a Mafahay tradition of Soulédé origin. They occupy two clan wards in the research area which is Zlagam of Mtskar and the lineage wards Zernday, Zagay and Ngaruwa of Mafmay, where they are the kar bay. The first wards the Zlagam inhabited in Mafmay were Zernday, followed by Zagay and then Ngaruwa. The main shrine of the Zlagam is therefore found in Zernday, but the biy dza responsible for the shrine has moved to Mafmay-Tsekoré which is in the clan ward Gozla. This is the reason why he sends a "son" to carry out the sacrifice on the major shrine of the Zlagam of Mafmay. Next to the main shrine is a killer shrine and a second one is found in Zagay. There is no shrine in Ngaruwa.

The Zlagam of Mafmay consist of three local maximal lineages numbering, in all, 141 households (846 individuals). In comparison to the non-chiefly clans of Mafmay, the Ziver Gozla and Kor- 
Zhigilé, which total 61 families (366 individuals), the Zlagam provide about $60 \%$ of the population of Mafmay. However, at the moment the Zlagam of Mafmay have not replaced their biy wudam who circulates between the lineages of Zernday and Zagay.

For the beginning of the harvest and bull festival, Mafmay depends on Gouzda-Korbay since they were conquered by Gouzda only about 60 or 70 years ago. As a consequence of this defeat Mafmay lost its status as an independent village and became part of the federation of Gouzda. The kar bay of Gouzda are the bay of the Zlagam of Mafmay as the Wula-Sakon are the bay of Mouzoua, Mazay and Woulad. However, nobody from Mafmay brings beer to Gouzda since nobody has moved or left a bay (representative) behind. Oral tradition reports that Gouzda had tried to expand its sphere of influence for many years. Due to the strong alliance of the villages of the confederation of Mtskar attempts by Gouzda to conquer Mazay or Mouzoua failed. This was not the case with Mafmay, which was not part of any alliance before. Nevertheless, the successful integration of Mafmay into a federation with Gouzda was the last of its kind happening in the research area. With the end of local warfare, which had lasted as a means of aggressive village expansion into the $1930 \mathrm{~s}$ or $1940 \mathrm{~s}$, the traditional village boundaries of our research area have remained more or less stable.

\subsection{The historical relevance of the "way of the beer"}

The above section has shown that the kinship groups occupying the research area today personify various types and categories of local historical events. The first to be mentioned is the ritual reenactment of the mythological past in the form of the "beer of Goyé" which is categorically served at the beginning of religious ceremonies. The section on the Goyé has shown that this beer is not of great historical relevance except that Goyé represents the divine origin of sorghum as the most powerful substance Mafa use in their religious rituals. The Goyé are therefore more of metaphorical than historical importance. However, without their mythical ancestor no "way of the beer" would exist in the first place, and presumably the reason why it is celebrated at the beginning of religious ceremonies.

The historical relevance of the "way of the beer" stems from the fact that Mafa believe in the moral right to exploit the fertility of their land because it has been passed on to them by their forefathers. However, as we have seen in the section above, the situation is not as straightforward as we might want to believe and there are other criteria which need to be taken into consideration. A very important one is that the reproductive capacity of some groups turned out to be greater than others. As a result, "the way of the beer" became increasingly governed by the criterion of group size but the moral right of the first comer to carry out the initial sacrifice remained. This can be seen in ritual relationship between the Zhwé and the Vuzay of Gouzda-Kərbay or the Gozla of Mouzoua and the Ndura (Wula-Sakon) of Mtskar.

If we examine the "way of the beer" in our research area we find that the moral principle behind the exchange of ceremonial beer is that local groups ritually re-enact a shared history. Here, it is the territorial principle which dominates descent, a structural situation which is reflected in the fact that ritual beer can only be carried across village boundaries in exceptional circumstances. The Ruwa of Mazay who carry religious beer as far as Mtskar, are the only example of such an exception. The reason is that all other clan groups of Mazay and Mouzoua consider the WulaSakon of Mtskar to be their ritual overlords and the village boundaries inside their "territory" can therefore be ignored. This example shows how the "way of the beer" is a tool for managing ritual as well as historical relationships. 
The study of the "way of the beer" enables us to reconstruct the local history of kinship groups within the territorial constraints of neighbouring settlements. The Wula-Sakon were dominant in the research area before the Zhéle and Vuzay groups grew to the size they are today. In the case of Gouzda, no ritual relationship exists between the Vuzay and the Wula-Sakon whereas, in the case of Mazay, the Zhélé ritually depend on the Wula-Sakon as their local historical first comers. However, the absence of a ritual relationship between the Vuzay of Gouzda and the Wula-Sakon of Mtskar only emphasises the political domination the Vuzay have achieved within the local research area. They are the most convincing historical proof of the Mafahay domination over a former non-Mafa population within the area. Being situated in the most populated centre of Mafa land of today gives the research area high regional significance. The local study of the "way of the beer" gives us an historical insight into the process of Mafaisation. Considering Lavergne's (op.cit.) references to a high Mafahay population in existence in the 1930s, we can be almost certain that the Mafa had already begun to emerge as the dominant ethnic group during precolonial times. 


\section{Summary and conclusion}

The previous chapter has provided us with empirical evidence that the "way of the beer" is a ritual re-enactment of local history. We have studied the operational mode of the various ways beer is exchanged in order to reconstruct the local history of kinship groups and the territorial relationships they represent. I was able to show that the Mafahay groups of the local research area, in particular the Zhélé and Vuzay, belong to the most recent wave of immigrants who brought about the settlement structure of chiefly and non-chiefly clans we find there today. I have also shown that previous groups of immigrants consist of an earlier non-Mafa tradition of which the Wula-Sakon of Mtskar are the most significant representatives. There are other groups of nonMafa origin found in the research area but all consider themselves today as Mafa. On average, only about half the population of the research area are Mafahay groups. This proves the point I make in the first chapter that the Mafa, as the largest group of the Northern Mandaras, have come about through a process of ethnic merging. We do not now how long this process took but we can assume, with good reason, that it was linked with the regional history of slavery and that the development of the Mafa was not the result of colonial influence.

However, we should nevertheless distinguish between the physical history of the large ethnic group we refer to today as Mafa, and the history of the name Mafa. Although it is obvious that the process of Mafaisation of the centre of the Northern Mandaras must have already been completed in pre-colonial times, we still do not know when the autonym Mafa came into use. Colonial powers relied mainly on ethnic references used by the Wandala and Fulbe, particularly, the derogative name Matakam for the Mafa and so-called Bulahay, or Kirdi for all montagnards. These names were sometimes combined as in Kirdi-Matakam, for example. Although Lavergne recognised, as early as the $1930 \mathrm{~s}$, the existence of a large ethnic group called Mafa, it was not until the 1970s that ethnography recognised this as the correct autonym for the Mafa people. However, it was the late 1980s before the Mafa could be disentangled from the former Matakam by recognising that the so-called Bulahay groups do not refer to themselves as Mafa.

This ethnographically unsatisfactory situation regarding the Mafa can also be extended to the ethnography of the neighbours of the Mafa. It is only since the 1990s that the groups on the Nigerian side of the northern Mandara Mountains have become an integrative part of regional ethnographic comparison, mainly through the work of David \& Sterner, among the Sukur, and my own work in the Gwoza Hills. It is significant that the international divide of the Northern Mandaras not only existed between Cameroon and Nigeria, but also between ethnographers representing different traditions of origin and language affiliation. To overcome this divide was one of the main reasons why I launched the Northern Mandaras Homepage and presented the regional context in such a detailed manner in Chapter One of this study. The CD-ROM accompanying this publication contains a copy of version 1.03 of the Northern Mandaras Homepage for further reference and to stimulate regional comparison based on both the Nigerian and the Cameroonian sides of the mountains.

We saw in the previous chapters that the ritual complex of the Mafa is highly structured, involving a sophisticated system of social and political dignitaries managing traditional communities of chiefly and non-chiefly clans. The reconstruction of the "way of the beer" has shown that the concepts of "greatness" and "following" must be understood in the context of population growth and the economic importance of the terrace farming system. It is characteristic for the system of bay and biy gwala that a junior lineage has the general potential to dominate a senior lineage simply on the grounds of a higher rate of reproduction. Almost any kinship group which grew large enough therefore had the potential to become chiefly clan, kar bay (lit. Son of a 
great one). This indicates that the Mafa concept of chieftaincy is not an aristocratic but a common or egalitarian system.

The system of bay and biy gwala has its conceptual starting point in the patrilineal and virilocal family home, the gay. This brings about an entitlement of the first born son to be considered as potential bay and for the second born son to be a potential biy gwala. This entitlement for an older brother to be bay and a younger brother to be biy gwala is analogous to groups and remains in place as long as a senior lineage or first comer can be successful in terms of its reproduction. As soon as a junior or late comer lineage increases dramatically in number this principle can be challenged and the roles become reversed if the challenge (by peaceful means or through war) renders success. Such reversals of status not only happen within one and the same group but also between different kinship groups if they compete over one territory. Without competition over arable land, "greatness" (bay) and "following" would be empty concepts.

The principle of number dominates that of seniority as soon as a local lineage reaches a certain size and is embedded in the religious worldview of the Mafa. They interpret it as a sign of good fortune when this happens, which is why we see human, animal and terrestrial fertility being always at the centre stage of their ritual concerns. For a man to have many wives provides the best chance for him to multiply his influence and to become bay. To have many animals, goats and cattle, not only allows him to produce a plethora of sorghum, but also to form good relationships with his neighbours. To sacrifice a bull every three years epitomises the egalitarian concept of greatness Mafa strive for and demonstrates for everyone to see that good fortune is on his side.

A large kinship group attracts a large "following" which leads to multiclan settlements under the auspices of a chiefly clan. Smaller local clan groups form exogamous or pseudo-clan relationships (ńshibene) because they have become wife givers to the larger chiefly clans of their area. Alliances were formed, based not only on competition over the successful control of resources of land and women, but also for the purpose of the defence of this very control. A large kinship group which manages to settle in a local area for a very long time is considered as particularly powerful and auspicious since their success is not only based on greatness, but also on seniority. The influence of such a group can comprise the territories of several other chiefly communities and it is almost impossible to overcome its ritual control while it maintains its large number.

The Wula-Sakon of Mtskar are an example of seniority and greatness coming together and we have seen how they moved around in the research area, leaving ritual representatives of their greatness behind. Non-chiefly kinship groups which function as chiefly representatives are very common in Mafa land and although they are often small in size, they still manage to retain certain ritual rights in the context of the purification ceremonies of their local communities. If such rights are based on past greatness, it is seniority which remains the main principle of ritual importance. These older but not numerous local clans are important for the success and prosperity of the whole community and a dominating clan would not easily dare to ignore them. It is thus the principle of seniority which remains in place in ritual terms and this is the main reason why we were able to reconstruct the local history of kinship groups and the communities they have formed.

The exchange of ceremonial beer is not specific to the Mafa but also found among the other ethnic groups of the Mandara Mountains. However, I have never seen such ritual complexity nor so many variations as exist in Mafa land. It seems therefore that the "way of the beer" I have described and analysed in this study is typical of the Mafa. Even within the Mafa there are regions of less ritual density. The Mafa-Kwokwarhay (those who live in the high massif areas) 
seem to have less complex sequences of ritual beer exchange. The elders of Ziver (a typical Kwokwarhay village) pointed out to me that the main difference between the Mafahay and the Kwokwarhay were that the former had such complicated rituals. I conclude from this the Mafahay created this sophisticated system in the course of their westward migration. They made it morally feasible to value number over age without having to discount ritual seniority. The enormous size of their two major clans, Zhélé and Vuzay, proves this hypothesis to be correct. 


\section{Mafa glossary}

Baba:

Bab'baba:

Bab babhiy nga:

Bab gay:

Balak zhigilé:

Bay:

Biy bay:

Béré-béré:

Biy dza:

Biy gwala:

Biy gwala madzaf:

Biy gwala mutsor:

Biy gwala teba:

Biy gwalahiy zhigilé:

Biy vardeké:

Biy wudam:

Bukway:

Biy yam:

Cived:

Cived zhigilé:

Daf [daf]:

Daf [daf] zhigilé:

Dak:

Dak vara:

Dalala:

Dasay yam:

Daw-daw-a-gad:

Daw Goyé:

Dəma'a:

Doray:

Diy mbulom:

Diy mbulom madzagay:

Diy mbulom ḿbiya'a:

Diy mbulom mutsor:

Diy waf:

Dza:

Dzadzaw:

Gad bay:
Deceased father or his ancestor pot.

Deceased father's father or his ancestor pot.

Family ancestors.

Father of a house; family head.

"Shelf of God", metaphorical reference to the "first floor" of a celestial world.

Great one; chief; lineage representative.

First chief; eve of a festival; the day when the great ones start to brew beer.

Large ceremonial knife used during a wedding ceremony.

Mountain priest.

Great follower; disciple.

Great follower with medicine.

Secret or anonymous great follower.

Great follower with sacred rope.

Great followers (or disciples) of God; a metaphor for personal gods who are God's envoys.

Most influential traditional Mafa chief with seat in the northern Moskota hills. He is also known as biy Moskota.

Great one of a village; traditional village chief.

Goat hide.

Great one of the rain; rainmaker.

Road; direction; authorisation.

West; direction of sun-set.

Porridge of ground sorghum, millet or beans.

"Meal for God" prepared by post-menopausal women.

General term for a terrace field away from the house.

Field in the plains.

Inner courtyard.

Iron bracelet used in rituals relating to the water spirit (nihed).

General term for sorghum.

First sorghum "stolen" from God's wife by a man called Goyé.

Young girl.

Sterility.

General term for a sacred community site.

A sacred site for a lineage whose members killed affines in tribal warfare.

Major community shrine.

Anonymous or "hidden" community shrine.

Sacred pot of a community shrine.

Ritually independent local clan ward. Dza is also a synonym for a major community site (diy mbulom ḿbiya'a) which signifies that the people of a $d z a$ own their land and therefore are not obliged to bring religious beer to anyone.

Father's living and sleeping room.

Chief's staff; deputy of the biy wudam. There are always two gad bay in a traditional village community. 


\author{
Gandaf: \\ Gad bulom: \\ God ma gay: \\ Gad pats: \\ Gezhem zhigilé: \\ Gojeved: \\ Gurdede: \\ Gwada: \\ Gwadama: \\ Gwadar: \\ Gwaliy: \\ Gwarbay: \\ Hakeda: \\ Halalay: \\ Hedek: \\ Hesheked: \\ Hutsad: \\ Huzhéb: \\ Hucéd: \\ Hudokw: \\ Hudokw ńngura: \\ Hudokw ngwaz: \\ Hwad ngwiy: \\ Jéjé:
}

Kalak:

Kəda:

Kar bay:

Kar dam:

Kezlid:

Kiyi sulav:
Eating bowl made of clay.

Minimal lineage (lit.: head of yams), referring to the lineage elder as the "head" and to the lineage ancestor as the "beer father" (see zom baba).

Terrace fields near to the house.

Personal spirit pot.

"Divine bag" of a personal god, a metaphorical bag in which a personal god contains a human being throughout life.

The most fertile field nearby the house. These are the fields where the ashes of the house are disposed of.

Free-standing store room and goat house (kudam bokw).

Female best friend.

Quiver.

Pelvis; term for major lineage used to designate half-brothers

and full-brothers as representations for the fission of clans and maximal lineages (see also ngwaz ngide).

Patri-clan; kinship group; patrilateral kin.

Platform to dry sorghum which is also used as a sunroof.

General term for earth. It comprises the physical earth but also includes the world beyond (veved) inside it.

Twin ceremony; sacred grove; remote patrilineal ancestor.

November/December, second and/or third traditional months referring to the beginning of the harvest period. This month is regularly doubled to adjust the lunar calendar to the solar year. General term for bushland; metaphor for a cosmological wilderness.

Ashes; fertiliser.

Father's main granary (male ancestor pots are kept on top

during the month of malama).

Kitchen.

Female granary and male sacrifice room. The word hudokw also refers to the seasonal period of the moonlight dance during the second half of the dry season. It is also the name for a long cylindrical drum played during that season.

Father's sacrifice room.

First wife's granary and sleeping room.

Hamlet.

General term for father's or mother's mother. Mafa use the term jéjéga (my grandmother) to address both and someone can also refer to his father's older brother's son as kar'jéjéga (son of my grandmother).

Shed.

Dog; also derogatory term for a local stranger, particularly those who have no land and are therefore obliged to bring ceremonial beer to their local host.

General term for a local chiefly clan group.

Daughter's son.

Clay bowl used in crab divination.

July; eleventh traditional month. 


\author{
Kudam bokw: \\ Kudam zlé: \\ Kulé:
}

Kükwa:

Kwa kuray:

Kwa mérézh:

Kwam sagam:

Lak:

Lang-lannga'a:

Madzagay:

Mafad:

Makula:

Malama:

Mama:

Mam'baba:

Maray:

Maslay:

Matamay:

Matsamakad:

Matserad:

Matsam:

Matsud:

Ma zhigilé:

Mazlam:
Mbut [ḿbut]:
Medemay:
Masala:
Méslégéd:
Motasl:
Metemas:
Movah:
Mezheb:
Mide:
Mishél ndo:
Mmbel [mómbel] ndo:
Momokwa:
Goat house (is part of gurdede).

Cattle shed (sacred bull is kept there).

Mysterious remedy the Mafa chief of Moskota received from the

chief of Gudur. The remedy was sprinkled on to people in order to evoke "freshness" (see lang-lannga'a). It was also given to local village chiefs for further distribution.

General term for matrilateral uncle (mother's brother). Mafa distinguish between kükga (my maternal uncle) and kük'babga (my father's maternal uncle).

Mysterious stones the rainmaker uses to produce or to withhold rain.

Pebble divination carried out as part of a funeral.

A mouse ( $k$ wam) representing an ancestor to be (sagam).

Traditional sauce.

Freshness or coolness; good health; being without pain. The concept of "freshness" is often applied in prayers as a quest for a healthy and prosperous life.

Sacred pot for someone who killed another human, a leopard or sacrificed ten bulls (maray).

December, fourth traditional month.

June, tenth traditional month; beginning of sowing.

September, last month of the traditional year.

Deceased mother or her ancestor pot.

Deceased father's mother or her ancestor pot.

Bull festival; sacred bull.

Male best friend; a man is supposed to have two maslay.

Equivalent to n'gwalala (harvest festival) in the northern

Moskota hills.

April, eighth traditional month.

March, seventh traditional month.

Jester, comedian. Christians often translate matsam as "devil".

May, ninth traditional month.

The part of the stomach of a sacrificed goat or bull which contains partly digested herbs. It means literally "mouth of God" which refers to the ritual significance of the digestive tract.

January, fifth month of the traditional year.

General term for a religious pot.

A young girl promised for marriage.

October, first month of the traditional Mafa year.

Diviner.

Cold period of the year (around January).

General term for millet.

August, penultimate traditional month; second hoeing period.

Soul; spirit; shadow; mirror image.

Sorcerer; misfortune caused by sorcery.

A well established man.

"Chasing the deceased", a ceremony which is part of a funeral.

February, sixth traditional month. The harvest festival is announced in the area of Gouzda. 


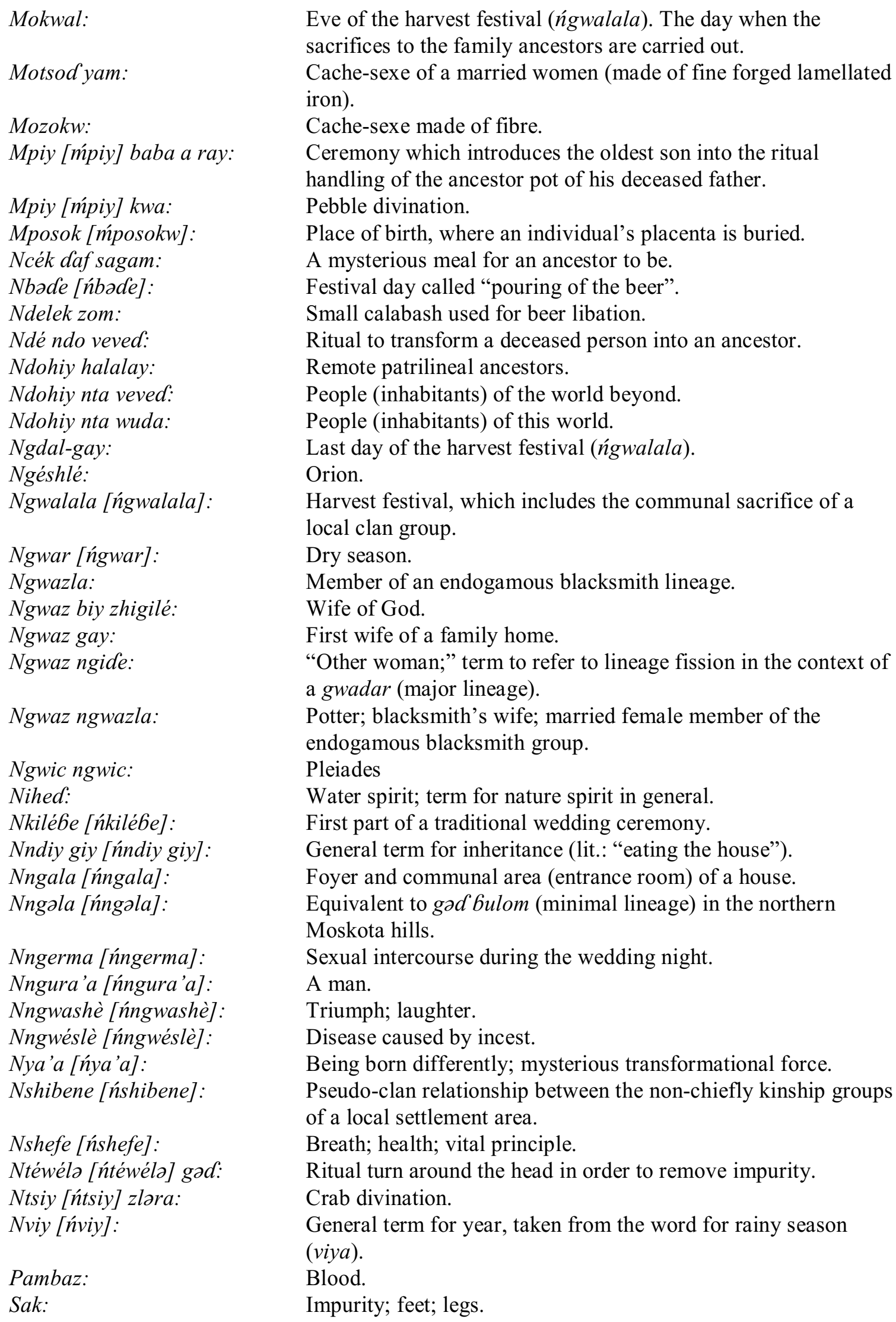

Mokwal:

Motsod yam:

Mozokw:

Mpiy [mípiy] baba a ray:

Mpiy [mípiy] kwa:

Mposok [ḿposokw]:

Ncék daf sagam:

Nbade [ńbade]:

Ndelek zom:

Ndé ndo veved:

Ndohiy halalay:

Ndohiy nta veved:

Ndohiy nta wuda:

Ngdal-gay:

Ngéshlé:

Ngwalala [ńgwalala]:

Ngwar [ńgwar]:

Ngwazla:

Ngwaz biy zhigilé:

Ngwaz gay:

Ngwaz ngide:

Ngwaz ngwazla:

Ngwic ngwic:

Nihed:

Nkilébe [ńkilébe]:

Nndiy giy [ńndiy giy]:

Nngala [ńngala]:

Nngəla [ńngəla]:

Nngerma [ńngerma]:

Nngura'a [ńngura'a]:

Nngwashè [ńngwashè]:

Nngwéslè [ńngwéslè]:

Nya'a [nya'a]:

Nshibene [ńshibene]:

Nshefe [ńshefe]:

Ntéwéla [ńtéwéla] gad:

Ntsiy [ńtsiy] zlara:

Nviy [ńviy]:

Pambaz:

Sak:

Eve of the harvest festival (ńgwalala). The day when the sacrifices to the family ancestors are carried out.

Cache-sexe of a married women (made of fine forged lamellated iron).

Cache-sexe made of fibre.

Ceremony which introduces the oldest son into the ritual handling of the ancestor pot of his deceased father.

Pebble divination.

Place of birth, where an individual's placenta is buried.

A mysterious meal for an ancestor to be.

Festival day called "pouring of the beer".

Small calabash used for beer libation.

Ritual to transform a deceased person into an ancestor.

Remote patrilineal ancestors.

People (inhabitants) of the world beyond.

People (inhabitants) of this world.

Last day of the harvest festival (ńgwalala).

Orion.

Harvest festival, which includes the communal sacrifice of a local clan group.

Dry season.

Member of an endogamous blacksmith lineage.

Wife of God.

First wife of a family home.

"Other woman;" term to refer to lineage fission in the context of a gwadar (major lineage).

Potter; blacksmith's wife; married female member of the endogamous blacksmith group.

Pleiades

Water spirit; term for nature spirit in general.

First part of a traditional wedding ceremony.

General term for inheritance (lit.: "eating the house").

Foyer and communal area (entrance room) of a house.

Equivalent to gad 6ulom (minimal lineage) in the northern

Moskota hills.

Sexual intercourse during the wedding night.

A man.

Triumph; laughter.

Disease caused by incest.

Being born differently; mysterious transformational force.

Pseudo-clan relationship between the non-chiefly kinship groups of a local settlement area.

Breath; health; vital principle.

Ritual turn around the head in order to remove impurity.

Crab divination.

General term for year, taken from the word for rainy season

(viya).

Blood.

Impurity; feet; legs. 


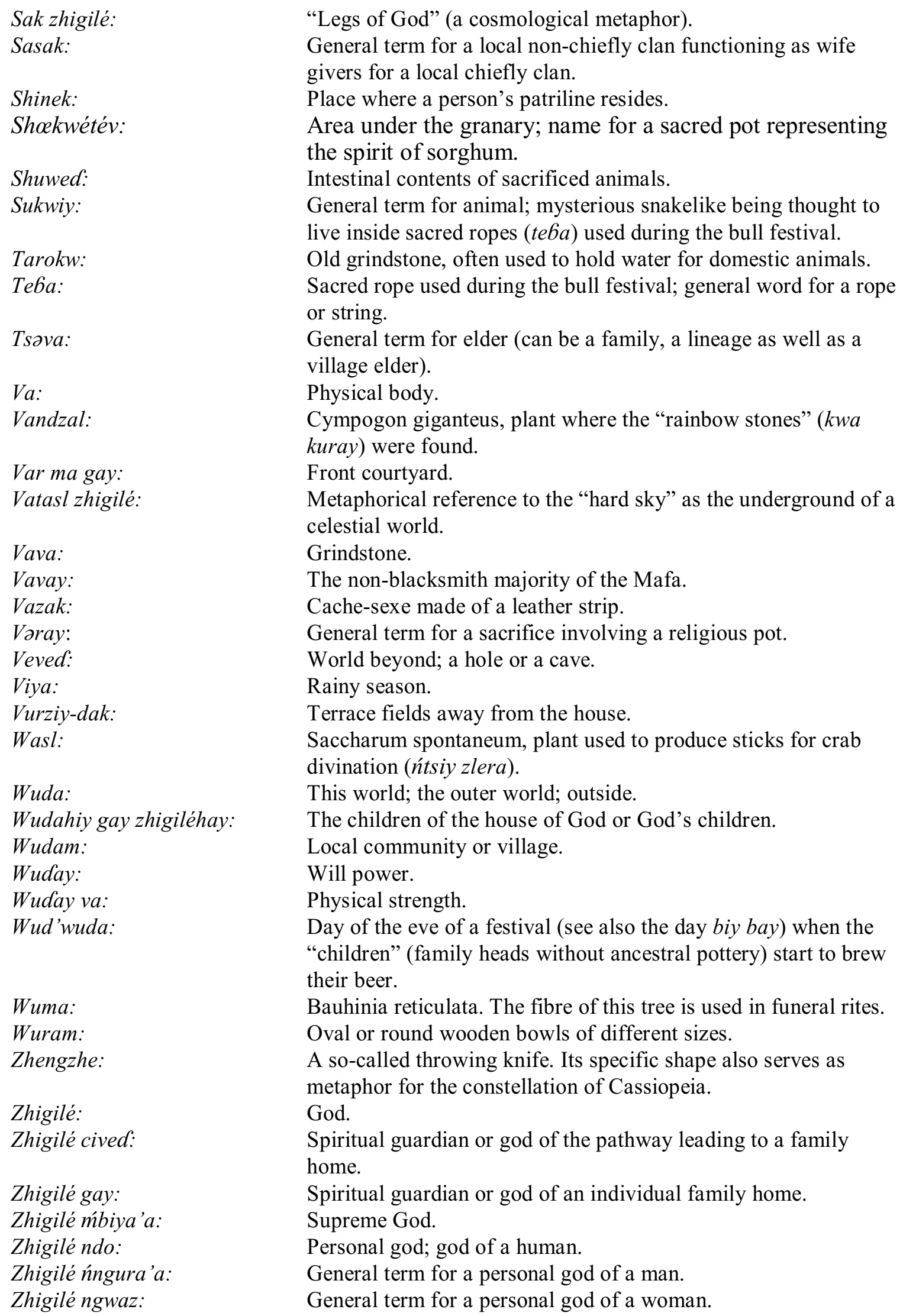


Zhigilé riy vava:

Zhigilé wuda:

Zhigilé wudahay:

Zlanggoy:

Zlanglokw:

Zlé:

Zom:

Zom baba:

Zom bay:

Zom biy gwala:

Zom gay:

Zom gad zlé:

Zom Goyé:

Zom kar baba:

Zom kar mama:

Zom madama:

Zom matsam:

Zom mazlam:

Zom melebay:

Zom ńgwar:

Zom ngwaz:

Zom ngwazla:

Zom shidef:

Zom zhigilé:

Zovad:
Personal god of a woman. Riy means hand and vava means grindstone, referring to the grindstone found in the kitchen next to which this sacred pot is often kept.

Spiritual guardian or god of the outdoor space surrounding a family home.

Personal god of children.

Unattached granary and female sleeping area.

Attached granary and female sleeping area.

General term for cattle.

Sorghum beer.

Ancestor of a gad bulom (minimal lineage) and the annual cult of family ancestors I refer to as the beer father ceremony.

Ritual beer being scooped for the metaphorical great ones (shared out with the left hand) during a family ceremony. In the context of the bull festival it is the beer the real great ones receive from the owner of a released bull.

Ritual beer being scooped for the metaphorical great followers (disciples of the great one) during a family ceremony. In the context of the bull festival it is the beer the real great followers receive from the owner of a released bull.

Equivalent to zom baba (beer father ceremony) in the northern Moskota hills (see also ńngala).

Ritual beer for the head of a sacrificed bull. First ritual beer being scooped during religious ceremonies. Funeral beer; metaphor for beer exchanged between kinship groups only distantly related (lit.: beer of my father's son). Funeral beer; metaphor for beer exchanged between kinship groups more closely related (lit.: beer of my mother's son). Ordinary beer prepared for the traditional wrestlers gaining physical strength for the hoeing period to come.

Ritual beer being scooped for the metaphorical jester in the context of a family ceremony. In the context of the bull festival it is the beer the real jesters receive from the owner of a released bull.

Ordinary beer prepared during the cold period of the year. Beer of melebay, a ceremony which includes the sacrifice of a castrated he-goat (bazl dived).

Ritual beer of the dry season, similar to the beer father ceremony (zom baba) but not compulsory.

Ritual beer being scooped for the women of a house.

Ritual beer being scooped for the blacksmith and his wife.

Beer of the cooking pot, an ordinary beer consumed on the last day of harvest festival (ńgwalala).

Beer for God.

Ripening period. 
Sorrel. The "thing" (sukwiy) found between the terrace stones, which later become the "snakelike being" of the first sacred rope $(t \partial 6 a)$, was ritually wrapped in sorrel leaves when taken home. 


\section{Bibliography}

\section{General references}

van Andel, A. 1998. Changing Security: Livelihood in the Mandara Mountains region in North Cameroon. Academisch Proefschrift (Doctoral dissertation). Universiteit van Amsterdam.

Barth, F. 1987. Cosmologies in the Making: A Generative Approach to Cultural Variation in Inner New Guinea. Cambridge: Cambridge University Press.

Barth, H. 1857. Travels and discoveries in North and Central Africa: being a journal of an expedition undertaken under the auspice of H.B.M. 's Government in the years 1849 -1855. 5 vols. London: Longman, Brown, Green, Longmans, \& Roberts.

van Beek, W. 1978. Bierbrouwers in de bergen: de Kapsiki en Higi van Noord-Kameroen noordoost Nigeria, Proefschrift (Doctoral dissertation). Rijksuniversiteit te Utrecht.

van Beek, W. 1987. The Kapsiki of the Mandara Hills. Propect Heights, Illinois: Waveland Press Inc.

Blench, R. 1998. Le West African Shorthorn au Nigeria. In Des taurins et des Hommes, Cameroun, Nigeria, pp249-93. C. Seignobos \& E. Thys (eds). Paris: Editions de l'Orstom.

Beauvilain, A. 1989. Nord-Cameroun: Crises et Peuplement, 2 vols. Publication of doctoral dissertation at the University of Rouen (France). Copyright: Alan Beauvilain.

Biersack, A. 1989. Local Knowledge, Local History: Geertz and Beyond. In The New Cultural History, pp. 72-96, Lynn Hunt (ed). Studies on the History of Society and Culture. Berkley.

Boutrais, J. 1984. Les unités naturelles. In Le nord du Cameroun, des hommes, une région, pp. 23-62. Collection Mémoires, 102. Paris: Editions de l'ORSTOM.

Bovill, E.W. 1965. The Bornu Mission, 1822-25, Part 2. Missions to the Niger, 4 vols. The Hakluyt Society, Second Series CXXIII-CXXX. Cambridge University Press.

Cyffer, N. 1994. English - Kanuri Dictionary. Westafrikanische Studien, 3. Frankfurter Beiträge zur Sprach- und Kulturgeschichte. Köln: Rüdiger Köppe Verlag.

David, N. 1976. History of crops and people in North Cameroun to AD 1900. In Origins of African plant domestication, pp. 223-67. J. de Wet, A. Stemler \& J.R. Harlan (eds). The Hague: Mouton Publishers.

Delaney, C. 1986. The meaning of paternity and the virgin birth debate. Man (n.s.) 21(3):494513.

Dineur, B. \& E. Thys. 1998. Caractéristique phanéroptiques et barymétriques de la race kapsiki. In Des taurins et des Hommes, Cameroun, Nigeria, pp39-45. C. Seignobos \& E. Thys (eds). Paris: Editions de l'Orstom.

Dominik, H. 1903. Bericht des Oberleutnants Dominik über die Gebiete zwischen dem oberen Benue und dem Tschadsee. Deutsches Kolonialblatt 16:105-52. Berlin.

Douglas, M. 1966. Purity and Danger: An analysis of concepts of pollution and taboo. London: Routledge \& Kegan.

Dumas-Champion, F. 1995. Régicide et initation: limitation des règes et le cycle initiatique dans les monts Mandara (Cameroun et Nigeria). Journal des Africanistes 65 (1):5-34.

Ela, J.-M. 1994. Le kirdi et la kirditude. Le Kirdi 1:8-14.

Ferrandi, J. 1928. Conquête du Cameroun-Nord (1914-1915): Préface du Général de division J. Aymerich des Troupes Coloniales. Paris: Charles-Lavauzelle \& Cie.

Fontaine, M. 1995. Santé \& Culture en Afrique Noire: Une expérience au Nord-Cameroun. Paris: L'Harmattan. 
Forkl, H. 1983. Die Beziehungen der zentralsudanischen Reiche Bornu, Mandara und Bagirmi sowie der Kotoko-Staaten zu ihren südlichen Nachbarn unter besonderer Berücksichtigung des Sao-Problems. Münchner Ethnologische Abhandlungen, 3.

Forkl, H. 1995. Politik zwischen den Zeilen, Arabische Handschriften der Wandala in Nordkamerun, Deutch-arabische Texte, übersetzt und herausgegeben, Kommentar und Chronologie von Hermann Forkl unter Mitarbeit von Reinhard Weipert. Islamkundliche Untersuchungen, 194. Berlin: Klaus Schwarz Verlag.

von Graffenried, C. 1984. Das Jahr des Stieres: Ein Opferritual der Zulgo und Gemjek in Nordkamerun, Studia Ethnographica Friburgensia, 11. Freiburg: Universitätsverlag.

von Graffenried, C. 1987. Vers une approche pluridisciplinaire des "fêtes du taureau" dans les Monts Mandara (Cameroun du Nord),' In Langues et cultures dans le bassin du lac Tchad (Journées d'études les 4 et 5 septembre 1984), pp. 113-22. Collection Colloques et Séminaires. Paris: Editions de l'ORSTOM.

Gula, E. 1996. 'Glavda Material Culture and the Utiva/Tsufga ritual complex'(BA final year essay) 56 p. Department of Creative Arts. University of Maiduguri.

Hallaire, A. 1965. 'Les monts du Mandara au nord de Mokolo et la plaine de Mora,' (unpublished) 162 p.. Paris: ORSTOM.

Hallaire, A. 1971. Hodogway (Cameroun nord): Un village de montagne en bordure de plaine. Atlas des structures agraires au sud du Sahara, 6 (ORSTOM). Paris: Mouton \& Co.

Hallaire, A. 1984. Les principales production. In Le Nord du Cameroun: des hommes, une région, pp. 402-27. Collection Mémoires, 102. Paris: Editions de l'ORSTOM.

Hallaire, A. 1991. Paysans montagnards du Nord-Cameroun: Les monts Mandara. Collection à travers champs. Paris: Editions de l'ORSTOM.

Hertz, R. 1909. La prééminence de la main droite; étude sur la polarité religiouse. Revue philosophique 63:553-580.

Jaouen, R. 1995. L'Eucharistie du mil: Langage d'un peuple expressions de la foi. Paris: Editions Karthala.

Jouaux, C. 1989. Gudur: chefferie ou royaume? Cahiers d'Etudes Africaines 114, 29 (2):259-88.

Juillerat, B. 1971. Les bases de l'organisation sociale chez les Mouktélé (Nord-Cameroun): structure lignagères et marriage. Mémoires de l'Institut de l'Ethnologie, 8. Paris: Musée de l'Homme.

Juillerat, B. 1981. Elements d'ethno-histoire des Muktele et du Mandara septentrional. In Contribution de la recherche ethnologique a l'histoire des civilisation du Cameroun, (ed) C. Tardit, vol 1, pp. 205-208. Colloques Internationaux du Centre Nationale de la Recherche Scientifique (24-28 Septembre 1973), 551. Paris: CNRS.

Kelly, J.D. \& M. Kaplan. 1990. History, Structure and Ritual. Annual Review of Anthropoloy 19:119 -50 .

Lange, D. 1987. A Sudanic Chronicle: The Borno Expeditions of Idris Alauma (1564-1576) according to the account of Ahmad b. Furtu: Arabic text, English translation, commentary and gazetteer. Studien zur Kulturkunde, 86. Wiesbaden: Franz Steiner Verlag.

Lange, D. \& S. Berthoud. 1972. L'interiéur de l'Afrique occidentale d'après G. L. Anania (XVIe siècle). Cahiers d'histoire mondiale 14 (2):299-351.

Lembezat, B. 1952. Mukulehe, un clan montagnard du Nord-Cameroun: coutumes, rite, croyances. Paris: Editions Berger-Levrault.

Lovejoy, P.E. 1983 (1995). Transformations in slavery: A history of slavery in Africa. African Studies Series, 36. Cambridge University Press.

Lukas, R. 1973. Nicht-Islamische Ethnien im südlichen Tschadraum. Arbeiten aus dem Seminar für Völkerkunde der J.W.Goethe-Universität Franfurt/M. Wiesbaden: Franz Steiner Verlag.

Lukas, R. 1972. Das Muyang-Massiv (Nordkamerun). Afrika und Übersee 55:157-187. 
MacEachern, A.S. 1990. Du Kunde: Ethnogenesis in north Cameroon. Doctoral dissertation, University of Calgary.

MacEachern, A.S. 1993. Selling the iron for their shackles: Wandala-montagnard interactions in northern Cameroon. Journal of African History 34:247-270.

Marchesseau, G. 1945. Quelque éléments d'ethnologie sur les Mofou du massif de Durum. Bulletin d'Etudes Camerounaises 10:7-53.

Mathews, A.B. 1934. 'Reorganisation of the Madagali District in Conjunction with Bornu Province. Mandated Hill Area.' National Archives, Yolaprof 2301. Kaduna: Nigeria.

Meek, C.K. 1931. The northern Tribes of Nigeria. 2 vols. Oxford University Press.

Mohammadou, E. 1981. L'Implantation des Peuls dans l'Adamawa: Approche chronologique. Contribution de la recherche ethnologique à l'histoire des civilisation du Cameroun, vol. 1. Colloques internationaux du CNRS 551, pp. 229-47. Paris.

Mohammadou, E. 1982. Le royaume du Wandala ou Mandara au XIXe siècle, African Languages and Ethnograhy, 14. Tokyo.

Mouchet, J. 1938. Vocabulaires comparatives de 15 (5) parlers du Nord-Cameroun. Journal de la Société des Africanistes 8:123-44.

Mouchet, J. 1944. Duvangar, Rites agraires et classes d'âge,' Bulletin de la Société d'Etudes Camerounaises 6(Juin):51-61.

Mouchet, J. 1946a. Quatre recettes de poisons à flèches utilisés par des animistes de la région du Nord-Cameroun. Notes africaines 29(12):10.

Mouchet, J. 1946b. Note sur la Conversion à l'Islamisme en 1715 de la Tribu Wandala.' Bulletin de la Société d'Etude Camerounaises 15-16:105-07.

Mouchet, J. 1947a. Prospection ethnologiques sommaire de quelques massifs du Mandara. Bulletin de la Société d'Etudes Camerounaises 17-18(Mars/Juin):99-139.

Mouchet, J. 1947b. Prospection ethnologiques sommaire dans les montagnes du Mandara. Bulletin de la Société d'Etudes Camerounaises 19-20(Sept/Dec):93-104.

Mouchet. J. 1948. Prospection ethnologiques sommaire de quelques massifs du Mandara. Etudes Camerounaises 21-22:39-54.

Mouchet, J. 1949. Prospection ethnologiques sommaire de quelques massifs du Mandara. Etudes Camerounaises 25(Juin):105-19.

Mouchet, J. 1950. Vocabulaires comparatifs de dix parlers du Nord-Cameroun. Etudes Camerounaises 29-30.

Mouchet, J. 1953. Vocabulaires comparatifs de 7 parlers du Nord-Cameroun. Etudes Camerounaises 41-42:137-206.

Mouchet, J. 1957. Prospection ethnologique sommaire des massifs du Mandara: Massiv de Gemjek. Etudes Camerounaises 55:3-15.

Müller-Kosack, G. 1992. Book Review. Princes montagnards du Nord-Cameroon: Les MofuDiamaré et le pouvoir politique, 2 vols, J.-F. Vincent, Paris: Editions l'Harmattan, 1991. Anthropos 87:636:38.

Müller-Kosack, G. 1994. 'Field notes from the Gwoza Hills (NE Nigeria),' in collaboration with the Sonderforschungsbereich 268 (Westafrikanische Savanne), J.W.-Goethe-Universität, Frankfurt, (on file with the author), $145 \mathrm{p}$.

Müller-Kosack, G. 1996a. 'Lokalität, Ethnizität und Sprachzugehörigkeit in den Gwoza Hills (NE Nigeria),' paper delivered at the Frobenius-Institut (Frankfurt), in collaboration with the Sonderforschungsbereich 268 (Westafrikanische Savanne), J.W.-Goethe-Universität, Frankfurt 1995, (on file with the author).

Müller-Kosack, G. 1996b. The Dughwede in NE-Nigeria: montagnards interacting with the seasons. In Berichte des Sonderforschungsbereiches 268 (Frankfurt), 8, pp. 137-70. 
Müller-Kosack, G. 1996c. 'Unpublished fieldnotes on the Gwoza Hills (including a detailed reconstruction of male initiation (dzum zugune) among the Dughwede).' London.

Müller-Kosack, G. 1999a. Northern Mandaras Homepage (www.gmk.clara.net): An ethnographic encyclopædia on the northern Mandara Mountains of Cameroon and Nigeria. CD-ROM version 1.03. London: Mandaras Publishing.

Müller-Kosack, G. 1999c. No cry for death. Mandaras Publishing (www.gmk.clara.net) London.

Müller-Kosack, G. 1999d. Book Review: Malte-Brun, Victor Adolphe. 1999. Au lac Tchad entre 1851 et 1856. In Bulletin de liaison de Méga-Tchad, réseau international de recherches pluridisciplinaires dans le bassin du lac Tchad (CNRS/LLAO \& LLACAN, Universität Frankfurt), No 99 (1\&2). www.uni-bayreuth.de/africanistik/mega-tchad/index.html.

Müller-Kosack, G. 2000a. No cry for death. In Actas del Simposio Electrónico International, Africa ante el tercer milenio, (ed) M.J. de los Reyes, pp. 45-50. Bs. Aires: Centro de Estudios Internacionales para el Desarrollo (CEID).

Müller-Kosack, G. 2000b. 'Ethnicity and the slave mode of production in the Northern Mandaras.' Paper delivered at the Cambridge conference of the Society of Africanist Archaeologists (SAfA), 12-15 July 2000.

Needham, R., (ed). 1973. Right and Left: Essays on Dual Symbolic Classification. Chicago: Chicago University Press Press.

Nyssens, O. 1990. Tradition orale et povoir rituel chez les Vamé du Nord-Cameroun. In Relation interethniques et culture materielle dans le bassin cu lac Tchad, Colloques et Séminaires, pp. 213-34. Paris: Editions de l'ORSTOM.

Peletz, M.G. 1995. Kinship Studies in Late Twentieth-Century Anthropology. Annual Review of Anthropology 24:343-72.

Podlewski, A.-M. 1966. Les Forgerons mafa: Description et évolution d'un groupe endogame. Cahiers Sciences Humaines, 3(1). Paris: Editions de l'ORSTOM.

Pontié, G. 1973. Les guiziga du cameroun septentrional: L'organisation traditionelle et sa mise en contestation. Mémoires ORSTOM, 65. Paris: Editions de l'ORSTOM.

Pory, J. 1896. Leo Africanus: The history and description of Africa and of the notable things therein contained, (1526) translated by John Pory. New York: The Hakluyt Society.

von Puttkamer, J. 1904. Bericht des Kaiserlichen Gouverneurs von Puttkamer über seine Reise in das Tschadsee-Gebiet. Deutsches Kolonialblatt 15:80-82;121-23;186-88;321-23. Berlin.

Rapport Annuel du Gouvernement Français a l'assemblé générale des Nations Unies sur l'administration du Cameroun, placé sous la tutelle de la France, année 1950, 484 p.

Report by His/Her Britannic Majesty's Government to the Council of the League of Nations and theUnited Nations on the Administration of the years:

1927-30. British Cameroon. London: Colonial Office.

1961-37. Cameroons under British Mandate. London: Colonial Office.

1947-53. Cameroons under United Kingdom Trusteeship. London: Colonial Office.

1954-61. Cameroons under United Kingdom Administration. London: Colonial Office.

Richard, M. 1977. Traditions et coutumes matrimoniales chez les Mada et les Mouyeng (NordCameroun). Collectanea Instituti Anthropos, 10. St Augustin: Anthropos-Institut (Haus der Völker und Kulturen).

Rihll, T. 1996. The origin and establishment of Ancient Greek slavery. In Serfdom \& Slavery: Studies in Legal Bondage, (ed) M.L. Bush, pp. 89-112. London: Longman.

Rudin, H.R. 1938. Germans in the Cameroons, 1884-1914: A Case Study in Modern Imperialism. London: Jonathan Cape Ltd.

Schoffeleers, M. 1991. Twins and unilateral figures in Central and Southern Africa: Symmetry and Asymmetry in the symbolization of the sacred. Journal of Religion in Africa 21(4):345-372. 
Seignobos, C. \& O. Iyébi-Mandjek. 2000. Atlas de la province Extrême-Nord Cameroun. Paris: Editions de l'IRD.

Seignobos, C. \& H. Tourneux. (in print). Le Nord-Cameroun à travers ses mots: Glossaire de termes anciens et modernes relatifs à la région. Paris: Karthala.

Shipton, P. 1994. Land and Culture in Tropical Africa: Soils, Symbols, and the Metaphysics of the Mundane. Annual Review of Anthropology 23:347-77.

Simons, P. 1995. Substance. In A companion to metaphysics, (eds) K. Jaegwon \& E. Sosa, pp. 480-484. Oxford: Blackwell Publishers Inc.

Smith, A. \& N. David. 1995. The production of space and the house of Xidi Sukur. Current Anthropology 36(3)441-71.

Shaw, J.H. 1935. 'Madagali District.' National Archives, SPN 17/3 25073 (3947). Kaduna: Nigeria.

Sterner, J. 1998. The Ways of the Mandara Mountains: A comparative regional approach. Doctoral dissertation. London: School of Oriental and African Studies.

Strümpell, K.F. 1912. Die Geschichte Adamauas nach mündlichen Überlieferungen. Mitteilungen der Geographischen Gesellschaft Hamburg, 26.

Tomlinson, G.J.F. 1916. 'Report on Dikoa District of the Northern Cameroons,' Colonial Office report CO 879/118 (Correspondence relating to the territories of the Cameroons under British administration and their bounderies), No 14, Public Records Office, Kew. London.

Vaughan, J.H. \& A.H.M. Kirk-Greene, (eds). 1995. The Diary of Hamman Yaji: Chronicle of a West African Muslim Ruler. Indiana University Press.

Vincent, J.-F. 1971. Divination et possession chez les Mofu: montagnards du Nord-Cameroun. Journal de la Société des Africanistes 61(2):71-132.

Vincent, J.-F. 1978a. Sur les traces du major Denham: le Nord-cameroun il y a cent cinquante ans. Mandara “Kirdi” et Peul. Cahiers d'Etudes Africaines 72(18,4):575-606.

Vincent, J.-F. 1978b. Main gauche, main de l'homme: essai sur le symbolisme de la gauche et de la droite chez les Mofu, Cameroun du Nord. Systèmes de signes: textes réunis en hommage à Germaine Dieterlen, pp. 485-509. Paris: Hermann.

Vincent, J.-F. 1982. 'Le chef maître du temps, calendrier rituel et religieux chez les Mofu,' exposé L.A. 221, dec. 1982, doc. manus. Clermont-Fd, (13 p., 4 tabl).

Vincent, J.-F. 1991. Princes montagnards du Nord-Cameroun: Les Mofu-Diamaré et le pouvoir politique. 2 vols. Premiere partie: Presentation des chefferies montagnardes MofuDiamaré. Deuxieme partie: Les porteurs du pouvoir. Troiseme partie: La theorie Mofu du pouvoir politique. Paris: Editions l'Harmattan.

Vincent, J.-F. 1995. "Renouveler le territoire": Parcours des frontières et purification de la principauté (Mofu-Diamaré, Cameroun). In La Construction religieuse du territoire, pp. 324-37. J.-F. Vincent, D. Dory \& R. Verdier (eds). Paris: L'Harmattan.

Wente-Lukas, R. 1970. Eisen und Schmied im südlichen Tschadraum. Paideuma 17:112-143.

Wolff, Dr. 1914. Eine Bereisung der Tschadseeländer: Bericht des landwirtschaftlichen Sachverstaendigen Dr Wolff. Deutsches Kolonialblatt 25:392-405 (mit Kartenskizze).

Wolff, E. 1971. Die sprachliche Situation im Gwoza District (Nordostnigeria). Journal of African Languages 10(1):61-74

Wolff, E. 1974. Neue linguistische Forschungen in Nordostnigeria. Afrika und Übersee 58(1):7-27.

Zimmermann, E. 1906. Bericht über eine Bereisung des Mandara-Gebirges vom 16. bis 20. November 1905. Deutsches Kolonialblatt 17:457-64. 


\section{References exclusively on the Mafa}

Abega, S.C. 1994. Le refus de l'acte de mariage chez les femmes Mafa. African Anthropology 1(1/2):94-102.

Avontuur, S., \& M. de Wit. 1994. 'Time allocation of Mafa Farmers, a household study on labour investments in soil and water conservation.' Leiden: University of Leiden.

Barreteau, D. 1980. Comparaison dans le groupe mafa des langues tchadiques (NordCameroun). In Problèmes des comparatisme et de dialectologie dans les langues africaines, SELAF (Bibliotheque 79), pp. 41-42. Paris.

Barreteau, D.1994. Mafa-mofu: Comparaison des lexèmes verbaux dans deux langues tchadiques du Cameroun. In Etudes comparatives, Dialectométrie, traits communs, pronoms, (eds) H. Jungraithmayr \& H. Tourneux Geuthner, Etude tchadiques, 23 p. Paris.

Barreteau, D., Le Bléis, Y. 1987. Lexèmes et thèmes verbaux en mafa. In Cahiers du LACITO (CNRS-LACITO, 2), pp. 31-52. Paris.

Barreteau, D. \& Y. Le Bléis. 1990. Lexique Mafa: langue de la famille tchadique parlée au Cameroun, Etudes Tchadiques Monographies. Paris: Editions de l'ORSTOM.

Barreteau, D., R. Breton \& M. Dieu. 1984. Les langues. In Le Nord du Cameroun: des hommes, une région, pp. 159-80. Collection Mémoires 102. Paris: Editions de l'ORSTOM.

Boisseau, J. \& M. Soula. 1974. La femme dans sa communauté territoriale clef du cosmos mafa (Cameroun septentrional): approche, rencontres, échanges. 3 vols. Centre de Recherches Cooperatives, No 46. Ecole Pratique des Hautes Etudes, VIe Section (Sorbonne). Paris: Bureau d'Etudes Coopératives et Communautaires.

Boisseau, J. 1975. 'N'kudi maray: fête du taureau ou la célébration et la convivialité mafa,' 108 p. (unpublished). Paris.

Boisseau, J. \& J.-M. Laurendeau. 1965. 'Lexique mafa-français,' 230 p. (unpublished). Mission catholique de Djinglia.

Boulet, J. 1970. Un terroir de montagne en pays mafa: Magoumaz (Cameroun du Nord). Etudes rurales 37-39:198-211. Paris.

Boulet, J. 1975. Magoumaz: pay Mafa (Nord Cameroun). Etude d'un terroir de montagne (Cartes, Annexes). Atlas des structures agraires au sud du Sahara, 11. Paris: Editions de l'ORSTOM.

Boutrais, J. (avec collaboration de M. Seati). 1972. Dictionnaire des villages du MarguiWandala, 89 p. (1 carte h.t.) Répertoire géographique du Cameroun, 25. Sciences Humaines, 95. Yaoundé: ORSTOM.

Boutrais, J. 1973. La colonisation des plaines par les montagnards au nord du Cameroun (Monts Mandara). Travaux et Documents de l'ORSTOM, 24 (Cartes, Annexes), Paris.

Bregeot, G. 1991.'Etude économique du système foncier chez les Mafa du Nord-Cameroun.' Montpellier: Université de Montpellier.

David, N. 1992. The archaeology of ideology: mortuary practices in the central Mandara highlands, northern Cameroon. In An African commitment: papers in honour of Peter Lewis Shinnie, (eds) J. Sterner \& N. David, pp. 181-210. Calgary: Calgary University Press.

David, N., J. Sterner \& K.B. Gavua. 1988. Why pots are decorated. Current Anthropology 29 (3):365-89.

Eichenberger, H. \& G. Eichenberger. 1978. 'Slebau da'ai mofa: Grammaire-méthode mofa,' 110 p. (unpublished). Mokolo: Librairie évangélique.

Gardi, R. 1955. 'Eisengewinnung bei den Matakam (Mandara-Bergland),' with sections by G. Spannaus \& H. Thede. Göttingen: Institut für den Wissenschaftlichen Film. 
Gavua, K.B. 1990. Style in Mafa material culture. Doctoral dissertation. University of Calgary.

Genest, S. 1974. Savoir traditionnel chez les forgerons Mafa. Revue Canadienne des Etudes Africaines 8(3):495-516.

Genest, S. 1976. La transmission des connaissances chez les forgerons Mafa (Nord-Cameroun). Doctoral dissertation. Laboratoire d'anthropologie. Quebec: Université Laval.

Gnowe, R. 1982. 'Le Marai ou boeufs de case de Mokolo: au service du credit embouche,' 21 p. (rapport de stage). FONADER/FSAR, Maroua: CNFZV.

Grall, R.F. 1936. Etude anthropologique, ethnique et démographique des Kirdi Matakam et des Kirdi Kapsiki de la circonscription de Mokolo (Nord-Cameroun). Anthropologie 46:625631.

Gubry, P. 1991. Rétention de la population et développement en milieu rural: A l'écoute des paysans mafa des monts Mandara (Cameroun). In Du politique a l'économique: Etudes historiques dans la bassin du lac Tchad. Actes du Colloques Méga-Tchad, (ed) J. Boutrais, vol 3, pp. 119-163.

Gubry, P. \& others. 1996. Le retour au village: une solution a la crise économique au Cameroun?. Paris: Editions l'Harmattan.

Hinderling. P. 1954a. Negerschmiede, Metalltechnik exotischer Voelker: Führer durch die Sonderausstellung (31. Januar bis 28. März). Museum für Völkerkunde. Basel.

Hinderling, P. 1954b. Die ethnographische Sammlung von Nordkamerun der Expedition GardiHinderling 1953. Verhandlungen der Naturforschenden Gesellschaft 65:106-22. Basel.

Hinderling, P. 1954c. Siedlung und Hausbau bei den Matakam. Korrespondenzblatt der Geographish-Ethnologischen Gesellschaft 4. Basel

Hinderling, P. 1955a. Versuch einer Analyse der sozialen Struktur der Matakam. Africa 25:405 -26. London.

Hinderling, P. 1955b. Schmelzöfen und Eisenverarbeitung in Nordkamerun. Stahl und Eisen 75:1233-66.

Hinderling, P. 1959. Stoffbildendes Schnurverschlingen. Baessler Archiv, Neue Folge 7(1):1-79.

Hinderling, P. 1960. Schnüre und Seile: Methode zur technischen Bestimmung von Fäden für den völkerkundlichen Gebrauch. Bulletin der Schweizerischen Gesellschaft für Anthropologie und Ethnologie 1959/60:1-13.

Hinderling, P. 1965. Über die Herstellung von Schnur- und Ledertaschen in Nordkamerun. In Basler Beiträge zur Geographie und Ethnologie (Ethnologische Reihe, 2). Festschrift Alfred Bühler, (eds) C.A. Schmitz \& R. Wildhaber, pp. 183-86.

Hinderling, P. 1969 'Die Mafa, Ethnographie eines Kirdi Stammes in Nordkamerun,' 234 p. (unpublished, with annexes). Saarbrücken: Sozialpsychologische Forschungsstelle für Entwicklungsplanung and der Universität des Saarlandes.

Hinderling, P. 1974. Entwicklungsprobleme Nordkameruns. In Kamerun, Strukturen und Probleme der sozioökonomischen Entwicklung, (eds) H. Illy, von Hase \& Koehler, pp. 297-15. Mainz.

Hinderling, P. 1984a. Soziale und religiöse Strukturen. Die Mafa: Ethnographie eines KirdiStammes in Nordkamerun, vol 1. Hannover: Verlag für Ethnologie.

Hinderling, P. 1984b. Materialien. Die Mafa: Ethnographie eines Kirdi-Stammes in Nordkamerun, vol 3. Hannover: Verlag für Ethnologie.

Hinderling, P. \& E. Kawalde. 1972. 'Die Mafa: Vom Leben eines Stammes im Mandaragebirge Nordkamerun (Les Mafa: De la vie d'une tribu dans les monts mandara du NordCameroun),' 14 p. (unpublished). Evilard (Suisse).

Hinderling, P. \& Schönmeier, H. 1968. 'Entwicklungsprobleme Nordkameruns.' Studie im Auftrag des Bundesministeriums für wirtschaftliche Zusammenarbeit. Saarbrücken: Sozialpsychologische Forschungsstelle für Entwicklungsplanung. 
Hurault, J. 1956. 'Exemples pris chez les Kirdi de la région de Mokolo.' Mission d'études au Cameroun (rapport). Paris: Institut géographique national.

Hurault, J. 1958. Quelques aspects de la structure sociale des montagnards Kirdi du nord Cameroon. Bulletin de l'Institut Française d'Afrique Noire (séries B) 20:111:22.

Iyebi-Mandjek, O. 1993. Les migration saisonaires chez les Mafas, montagnards du NordCameroun, une solution au surpeuplement et un frein a l'émigration definitive. In Mobilites spatiales et urbanisation, Asie, Afrique, Amerique, (eds), V. Dupont, C.Z. Guilmoto, Cahiers des Sciences Humaines, 29 (2-3), pp. 419-41.

Iyebi-Mandjek, O. \& C. Seignobos. 1997. Le suivi des migrants mafa a travers quatre terroirs. In Agricultures des savanes du Nord-Cameroun: vers un un développement solidaire des savanes d'Afrique centrale, (eds) L. Seiny-Boukar, J.-F. Poulain \& G. Faure, pp. 159-88. Paris: CIRAD.

Kosack, G. 1991. Gibua - Du wirst nicht sterben: ethnosoziologische Deutung einer MafaGeschichte (Nord-Kamerun). Paideuma 37:73-91.

Kosack, G. 1992. Aus der Zeit der Sklaverei (Nordkamerun): Alte Mafa erzählen.’ Paideuma 38:177-94.

Kosack, G. 1995a. Frauenforschung in einer anderen Kultur, Grenzen des Erfassens am Beispiel der Hexerei. In Frauenforscherinnen stellen sich vor, (ed) I. Nagelschmidt, pp. 152-64. Leipzig: Universitätsverlag.

Kosack, G., 1995b. Christianisierung, eine Chance zur Emanzipation? Die Bedeutung der Religion für die Mafa-Frauen (Nordkamerun). Anthropos 90:206-17.

Kosack, G. 1997a. Das Wasser in den Geschichten, im Leben der Mafa. In L'Homme et l'eau dans le bassin du Lac Tchad, Actes du Colloque Méga-Tchad, (eds) H. Jungraithmayr, D. Barreteau \& U. Seibert, pp. 297-304. Paris: Editions de l'ORSTOM.

Kosack, G. 1997b. 'Die Mafa im Spiegel ihrer oralen Literatur: Eine Monographie aus Sicht von Frauen.' Habilitationsschrift (988 p.). Universität Marburg.

Kosack, G. 1999. Wird die Polygynie in der modernen Gesellschaft überleben? Überlegungen zur Mehrfrauenehe am Beispiel der Mafa in Nordkamerun. Anthropos 2.

Kosack, G. (in print) L'idee des femmes Mafa d'elles-mêmes illustrée sur l'éxemple de la sorcellerie dans leurs contes. In La réprésentation des femmes, discours, normes et conduites, (eds) R. Carre, M. Dupré \& D. Jonckers. Clermont Ferrand: MSH.

Kosack, G. \& H. Tourneux. 1997a. Contes animaux du pays mafa. Paris: Karthala.

Kosack, G. \& H. Tourneux. 1997b. Contes mysterieux du pays mafa. Paris: Karthala.

Lavergne, G. 1944. Le pays et la population Matakam. Bulletin de la Société d'Etudes Camerounaises 7 (sept):7-22.

Lavergne, G. 1949a. Une peuplade du Haut-Cameroun, les Matakam. Bulletin Information France Outre-Mer 137:11-14.

Lavergne, G. 1949b. Folklore africain, une peuplade du Haut-Cameroun: les Matakam. Paris: Imprimerie Servant-Crouzet.

Lavergne, G. 1991. Folklore africain, une peuplade du Haut-Cameroun: les Matakam. Paris: Ministère de la cooperation et développement (reprint of 1949 edition).

Le Bléis, Y. 1987. Les extensions verbales en mafa. In Etudes tchadiques, Classes et extensions verbales, (eds) H. Jungraithmayr \& H. Tourneux, pp. 99-114. Paris: Geuthner.

Lembezat, B. 1961. Les populations païennes du Nord-Cameroun et de l'Adamaoua. Monographies Ethnologiques Africaines (Institut International Africain). Paris: Presses Universitaires de France.

Lenoir, (Capitain). 1929. 'Rapport sur les événéments, juillet 1929, a Gousda,' Archives du Gouvernement Générale de l’A.E.F., série géographique, Togo-Cameroun, 1883-1953, carton 30, dossier 260, Aix-en-Provence: Archives d'Outre-Mer. 
Martin, J.-Y. 1967a. 'Etudes de zones d'accueil dans 4 cantons au Nord de Mokolo,' (unpublished). Yaoundé: ORSTOM.

Martin, J.-Y. 1967b. 'Magoumaz, une communité rurale en pays matakam: Etude sociologique,' (unpublished) $116 \mathrm{p}$. Yaoundé: ORSTOM.

Martin, J.-Y. 1968. 'Les Matakam du Nord-Cameroun: Dynamismes sociaux et problémes de modernisation,' (unpublished). Yaoundé: ORSTOM.

Martin, J.-Y. 1970. Les Matakam du Cameroun: Essai sur la dynamique d'une société prèindustrielle. Mémoires ORSTOM, 41. Paris.

Martin, J.-Y. 1981. Essai sur l'histoire prè-coloniale de la société matakam. In Contribution de la recherche ethnologique à l'histoire des civilisations du Cameroon, vol 1, (ed) C. Tardi, pp. 219-27. Colloques Internationaux du CNRS, 551. Paris: Editions du CNRS.

Martin-Sauveur, M. 1967. Les résistances à la scolarisation d'une ethnie africaine: les Matakam $d u$ Nord-Cameroun. Paris: D.E.S.F.L.S.H.

Moisel, M. \& others. 1912-13. Mubi (C3.C-171); Dikoa (B3.C-179); Kusseri (B4.C-170); Marua (C4.C-172). In Karte von Kamerun in 31 Blatt und 3 Ansatzstücken im Massstabe von 1:300000 (Berlin).

Mohammadou, E. 1988. Les lamidats du Diamaré et du Mayo-Louti au XIXe siècle (NordCameroun). African Languages and Ethnography XXII, Institute for the Study of Languages and Cultures of Asia and Africa, (ed) Shun'ya Hino, Tokyo University of Foreign Studies (Tokyo, Nishigahara 4, Kitu-ku).

Müller-Kosack, G. 1981a. 'Mafa-Schiede arbeiten mit dem Steinhammer: technische Feldnotizen aus Soulédé (Nordkamerun),' (on file with the author). Frankfurt.

Müller-Kosack, G. 1981b. 'Schmiede und Töpferinnen der Mafa von Sulédé (Nordkamerun),' (with author). Super 8 Film (15 Minuten). Frankfurt.

Müller-Kosack, G. 1985. 'The Mafa smiths of Guzda (North Cameroon),' Quaterly report to Ministère de l'Education, de la Science et de la Recherche Scientifique (22 July 1985). Yaoundé.

Müller-Kosack, G., 1986. 'Social and settlement structure among the Mafa of Guzda, Mafmay, Mckar, Muzua, Mazay and Wulad (North Cameroon).' Final report to Ministére de l'Education, de la Science et da la Recherche Scientifique (3 Oct.1986). Yaoundé.

Müller-Kosack, G. 1987a. 'Der Weg des Bieres, Siedlungs- und Sozialstruktur in fünf MafaDörfern (Nordkamerun). MA dissertation, J.W.-Goethe-Universität Frankfurt am Main.

Müller-Kosack, G. 1987b. 'Sammlung sakraler Töpfe der Mafa (Reproduktionen) für das Frobenius-Institut an der Universität Frankfurt/Main, avec collaboration de Ministère de Culture et l'Information du République du Cameroon in Yaoundé (the collection is with the Frobenius-Institut in Frankfurt).

Müller-Kosack, G. 1988a. Sakrale Töpfe der Mafa (Nordkamerun) und ihre kulträumliche Dimension. Paideuma 34:91-118.

Müller-Kosack, G. 1988b. Comment: Why Pots Are Decorated, N. David, J. Sterner \& K. Gavua. Current Anthropology 29(3):365:390.

Müller-Kosack, G. 1989 'Problèmes de l'interpretation des donnes ethnographiques sur l'origine de quelques éléments de la civilisation mafa.' Paper delivered at Séminaires MégaTchad, Datation et Chronologie, ORSTOM, Bondy 11-12 septembre 1989.

Müller-Kosack, G. 1991. Zur Siedlungsstruktur der Mafa (Nord-Kamerun). Paideuma 27:105-40. Müller-Kosack, G. 1997a. Water and the Mafa. In L'homme et l'eau dans le bassin du lac Tchad, Actes du Colloque Mega-Tchad, Colloques et Seminaires, (eds) H. Jungraithmayr, D. Barreteau \& U. Seibert, pp. 229-304. Paris: Editions de l'ORSTOM. 
Müller-Kosack, G. 1997b. 'Cived Zom, Studie zur Historizität der Mafa Nordkameruns,' (2 vols), vol 1: Fiktionaler und analytischer Teil (Interpretation von Literatur und Feldnotizen), vol 2: Dokumentarischer Teil (Feldnotizen von 1985 bis 1989 mit Index), 15 analytische Karten (Siedlungs- und Sozialstruktur der Dörfer Guzda, Mafmay, Wulad, Mazay, Muzua, Mckar), Mafa-Wörterverzeichnis (Transskription nach Barreteau \& Le Bléis, 1990). Doctoral dissertation (unpublished), 780 p. Frankfurt: J.W.-Goethe-Universität.

Müller-Kosack, G. 1999b. Metaphysics of Mafa and Dughwede bull-festivals. Mandaras Publishing (www.gmk.clara.net). London.

Nassourou, T. (n.d.) 'Les forgerons et leur fonctions (dans la société Mafa),' Ms.

Oumate, O. 1984. Le "Maray" ou l'embouche bovine intensive de case des monts Mandara. In Autosuffisance alimentaire au Cameroun (Commission nationale agro-pastorale de Maroua), pp. 75-82.

Podlewski, A.-M. 1961a. Etude démographique de trois ethnies païennes du Nord-Cameroun: Matakam, Kapsiki, Goude. Recherches et Etudes Camerounaises 4:1-70. Yaoundé.

Podlewski, A.-M. 1961b. Enquete sur l'émigration des Mafa hors du pays Matakam. Recherches et Etudes Camerounaises 5 (2):74-93. Yaoundé.

Podlewski, A.-M.1966a. Les forgerons mafa, description et évolution d'un groupe endogame. Cahiers Sciences Humaines, 3, Paris: Editions de 1'ORSTOM.

Podlewski, A.-M. 1966b. La dynamique des principales populations du Nord-Cameroun (entre Benoué et lac Tchad). Cahiers ORSTOM, série sciences humaines, 3 (4), pp. 7-194, (cart, tabl, bibliogr). Paris.

Podlewski, A.-M. 1981. Influence de l'islamisation des populations traditionnelles du NordCameroun sur leurs comportement démographiques. In African Historical Demography, vol 2 (8 p.). Proceedings of a Seminar held in the Centre of African Studies, University of Edinburgh (April 1981).

Podlewski, A.-M. 1983. Evolution d'une population intégralement endogame: les "forgerons mafa" (Nord Cameroun). In Démographie et destin des sous-populations, Colloque de Liège (21-23 septembre 1981), AIDELF, no 1, pp. 367-371.

Ridell, J.C. \& D.J. Campbell. 1986. Agricultural intensification and rural development: the Mandara Mountains of North Cameroon. African Studies Review 29(3):89-106.

Rossing, M.O. 1978. Mafa-Mada: A comparative study of Chadic languages in North Cameroon, (394 p.). Madison: University of Wisconsin.

Roymans, A. 1997. 'The customary land tenure system among the Mafa \& social dynamics (North Cameroon),' M.A. disseration (151 pages), Centre for Envrionmental Studies, Leiden University.

van Santen, J. 1991. Twins and the meaning of the number two in Mafa society. In World and I. Washington Times Corporation.

van Santen, J. 1992. Der Autonomieansatz in der Niederländischen Entwicklungsdiskussion: Veränderungen der Frauenökonomie bei den Mafa (Nord Kamerun) im Zuge der Islamisierung. Peripherie 47/48:171-190.

van Santen, J. 1993a. Dot, commerce et contreband: strategie d'accumulation chez les femmes islamisées de Mokolo. In Itineraire d'accumulation au Cameroun, (eds) P. Geschiere \& P. Konings, pp. 301-335. Paris: Karthala.

van Santen, J. 1993b. They leave their jars behind: the conversion of Mafa women to Islam. (Doctoral dissertation), Leiden: VENA publications.

van Santen, J. 1995. We attend but no longer dance: changes in Mafa funeral practices due to Islamization. In Mort et rites funeraires dans le bassin du lac Tchad, Colloques et Séminaires, pp. 161-87. Paris: Editions de l'ORSTOM. 
van Santen, J. 1997. Regional balance and national integration in Cameroon: A historical overview of Mafa integration in national politics. In Regional balance and national integration in Cameroon, Lessons learned and the uncertain future, (eds) P. Nkwi \& F. Nyamjoh, ICASSRT, Monograph, 1, pp. 242-60. Yaoundé.

van Santen, J. 1998a. "If you pray the Muslim community takes care of you": Changes in social arrangements within Mafa society after Islamization. In Changing gender and kinship in Sub-Saharan Africa \& South Asia, (eds) C. Risseeuw \& P. Palriwala. Sage Publications.

van Santen, J. 1998b. Islam Gender and Urbanisation among the Mafa of north Cameroon: the differing Commitment to "home" among Muslims and non-Muslims. Africa 68(3).

van Santen, J. \& J. Schaafsma. 1999. "Se faire pleurer comme une femme": la signification symbolique du taureau et l'introduction récente de la vache chez les Mafa (NordCameroun). In L'homme et l'animal dans le bassin du lac Tchad, Colloque et séminaires, (eds) C. Baroin \& J. Boutrais, pp. 427-46. Paris: Editions IRD.

Schaafsma, J. 1998. "Partir chez les Foulbe": Les migrations masculines saisonaires dans la société Mafa (Cameroun du Nord) et leurs consequences sur les femmes demeurant a la campagne ainsi que sur leurs taches agricoles.' M.A. dissertation (106 pages), Centre for Environmental Studies, Leiden University.

Schaafsma, J. \& A.B. Zuiderwijk. 1997. Male out-migration: changing women's roles and consequences for environmental management. The case of the Mafa in northern Cameroon. In Gender and Land Use, Diversity in Environmental Practices, (eds) M. de Bruyn, I. van Halsema \& H. van d. Hombergh, pp. 125-146. Amsterdam: Thela Publishers.

Schilling, C. 1989. Geomorphologische Beobachtungen im Mandara-Bergland: Nord-Kamerun. Frankfurter Geowissenschaftliche Arbeiten 10 (Serie D, Physische Geographie), pp.131-40.

Schilling, C. \& D. Köhlhoff. 1989. Wasser für Guzda: Ein Projekt zur Verbesserung der Wasserversorgung in Nord-Kamerun. Wasserwirtschaft 79(10):510-13.

Schmitz-Cliever, G. 1979. Mafa (Nord-Kamerun). In Schmiede in Westafrika: Ihre soziale Stellung in traditionellen Gesellschaften, pp. 3-40. Kulturanthropologische Studien, 4. München: Kommissionsverlag Karl Renner (Hohenschäftlarn).

Schönmeier, H. 1979. Animismus, Krankheit und sozialer Wandel bei den Bergkirdi. Curare 3:163-173.

Schönmeier, I. 1966. 'Das Erziehungsverhalten der Mafa,' (unpublished). Diplomarbeit am Psychologischen Institut der Universtität des Saarlandes, Saarbrücken.

Seignobos, C. (avec collaboration de F. Lafarge). 1982a. Nord Cameroun, Montagnes et hautes terres: Collection Architecture traditionelles. Paris: Editions Parenthèses (Roquevaire).

Seignobos, C. 1982b. Note sur "les ruines du Mudkwa" en pay Mafa. Révue Géographique du Cameroun 3:41-45.

Seignobos, C. 1988. Le sommet du mont Ziver, un agrosystéme montagnard relique. In L'homme et la montagne tropicale, pp. 123-34. Bordeaux: Separit.

Steck, B. 1972. Mokolo dans ses relations avec le milieu rural environant. In Cahier ORSTOM, série Sciences humaines, 9 (3), pp. 309-323.

Sterner, J. 1992. Sacred pots and "symbolic reservoir" in the Mandara highlands of northern Cameroon. In An African commitment, papers in honour of Peter Lewis Shinnie, (eds) J. Sterner \& N. David, pp. 171-80. Calgary: University Calgary Press.

Sterner, J. \& N. David. 1991. Gender and caste in the Mandara Highlands, northeastern Nigeria and northern Cameroon. Ethnologie 30(4):355-69.

Strümpell, K.F. 1923. Wörterverzeichnis der Heidensprachen des Mandara-Gebirges (Adamaua). Zeitschrift für Eingeborenen-Sprachen 13:47-74;109-49 (Berlin, 1922-23). 
Vallerie, M. 1964. 'Etude pédologique du Margui-Wandala (périmètre Matakam),' Yaoundé: ORSTOM.

Vallin, (Capitain). (n.d.) 'Rapport sur les coutumes Matakam.'

Zigla, W. 1981. 'Les boeufs "Marai” de Mokolo,' (rapport de stage), 19 p. Maroua: CNFZV.

Zuiderwijk, A.B. 1998. Farming gently, farming fast: Migration, incorporation and agricultural change in the Mandara mountains of Northern Cameroon. (Doctoral dissertation) Proefschrift. Centre of Envrionmental Science. Leiden: State University. 
Figure 1: The northern Mandara Mountains of NE Nigeria and N Cameroon

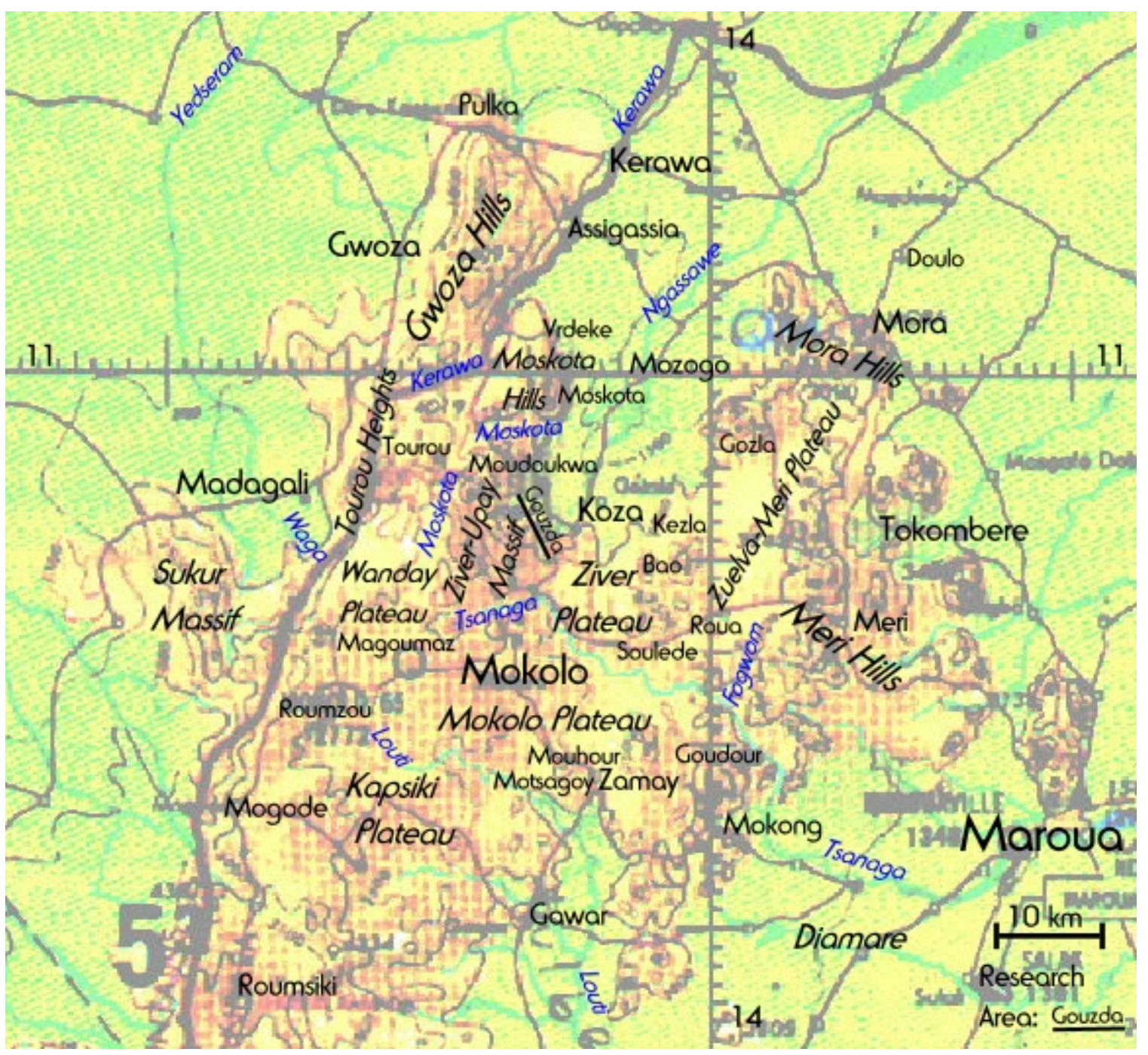


Figure 2: Distribution of ethnic groups in the northern Mandara Mountains

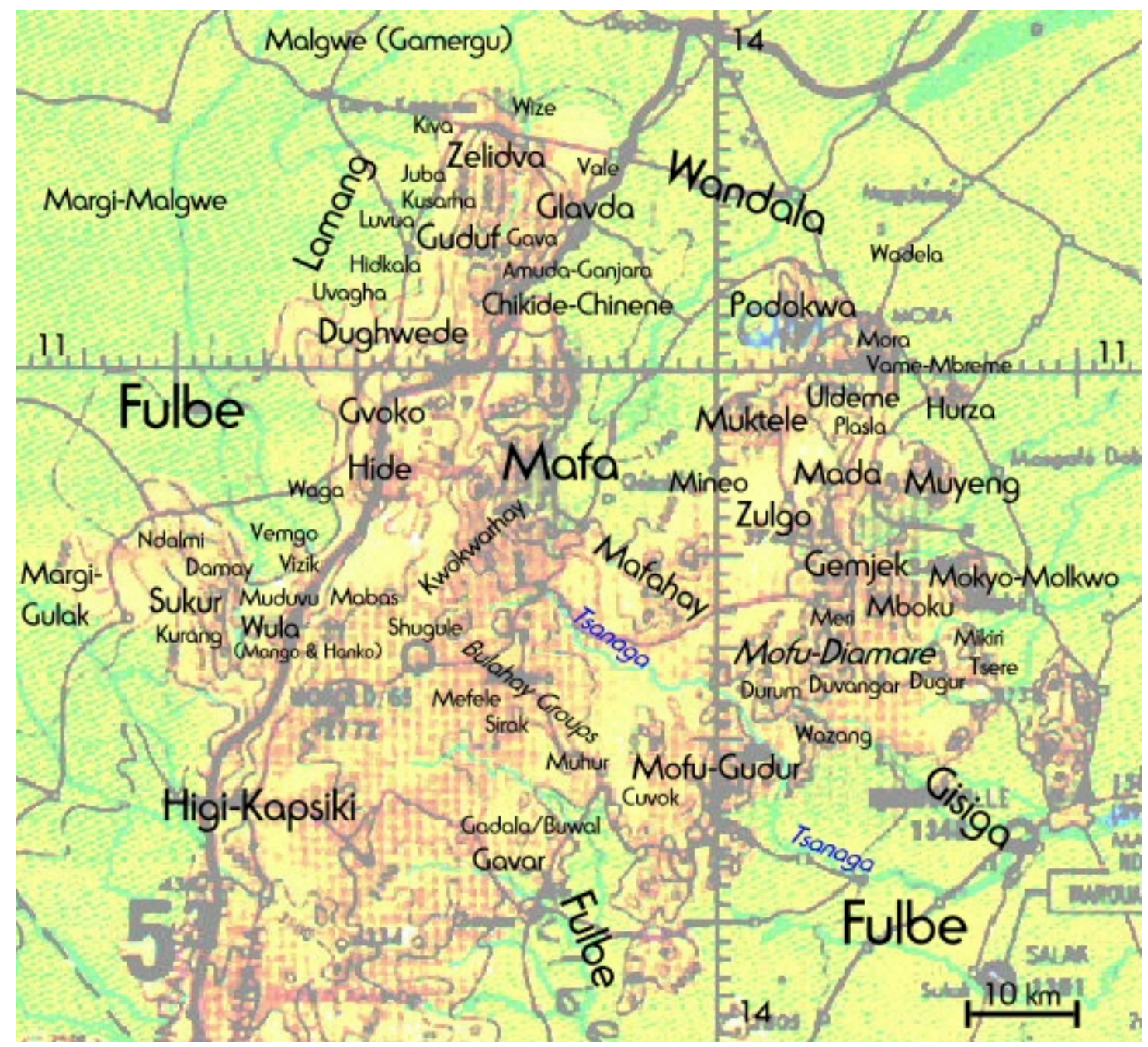


Figure 3: Geographical location of the study area

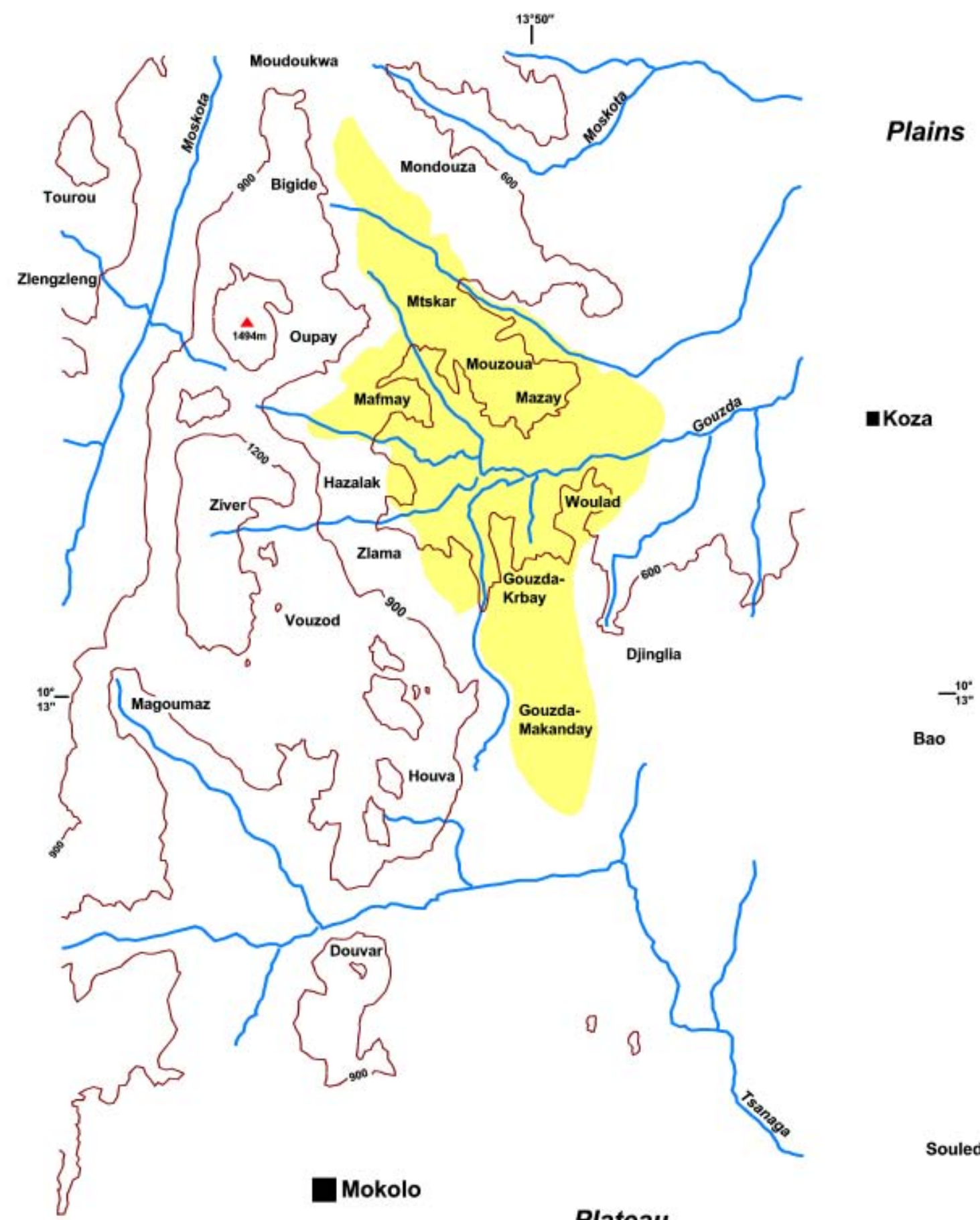

\section{Plateau}

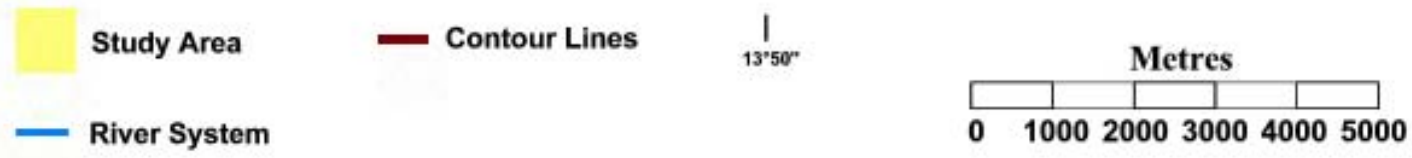


Figure 4: Pairs of calabash pieces used in Mafa crab divination
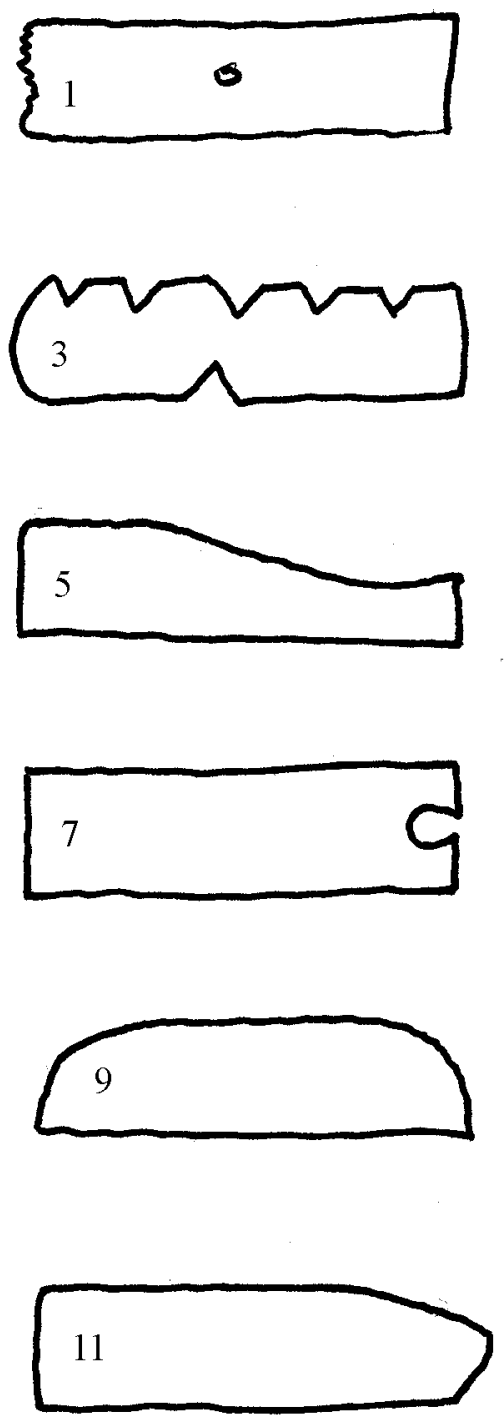

1 Quiver (gwadama)

3 Well-established man (mishél ndo)

5 Young man (yngura'a)

7 Blacksmith (ngwazla)

9 Small calabash used for beer libation (ndelek zom)

11 Misfortune caused by sorcery (mide)
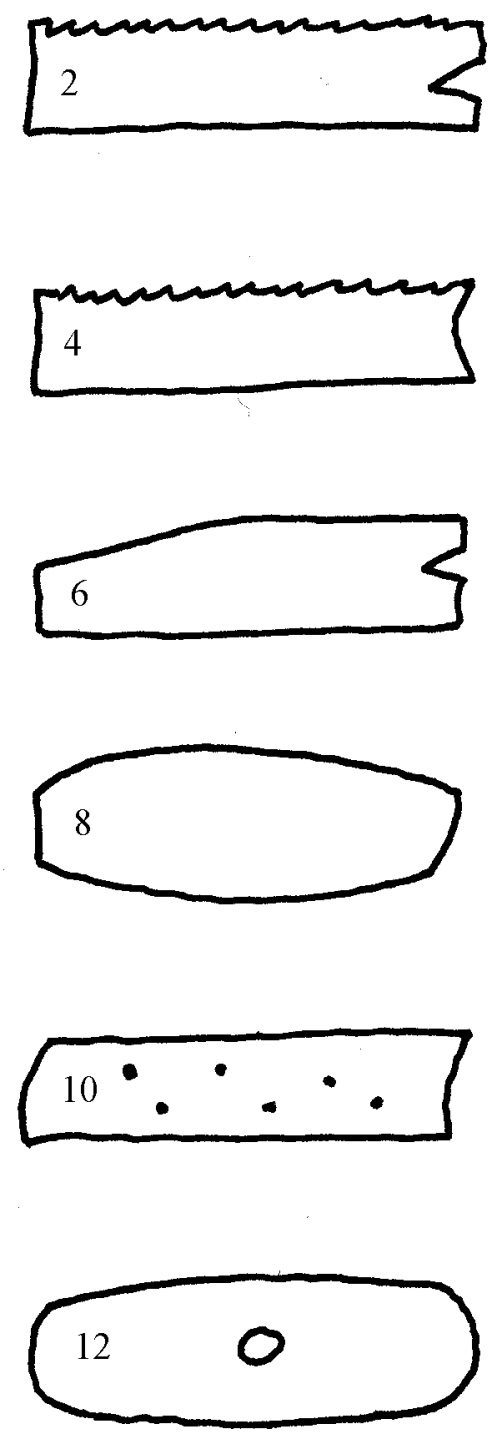

2 Triumph or laughter (yngwashè)

4 Woman (ngwaz)

6 Young girl (dama'a)

8 Road or direction (cived)

10 Sorghum (daw)

12 Disease caused by incest (yngwéslè) 
Figure 5: Plan of a Mafa house

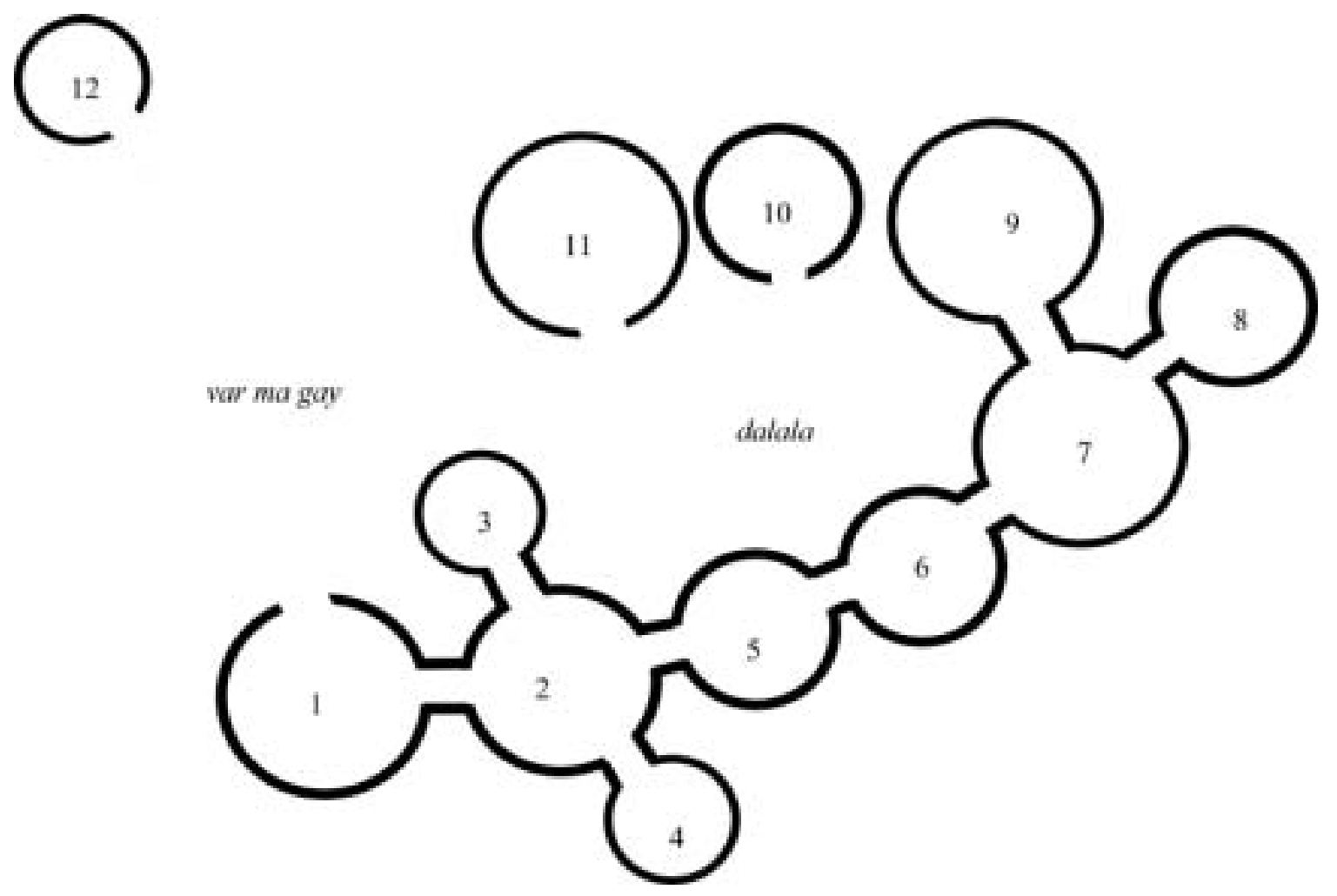

1 yngala = foyer and communal area (entrance room)

2 dzadzaw = father's living and sleeping room

3 kalak $=$ son's room

4 kudam zlé = cattle shed (maray is kept here)

5 hudokw nngura = father's sacrifice and granary room

6 hudokw ngwaz = first wife's sleeping and granary room

7 huzhéb = father's main granary room

8 hucéd $=$ kitchen

9 zlanglokw $=$ granary room and female sleeping area

10 gurdede \& kudam bokw = store room with goat house

11 zlanggoy $=$ granary room and female sleeping area

$12 \mathrm{kalak}=$ shed 
Figure 6: Traditional villages and wards of the local study area

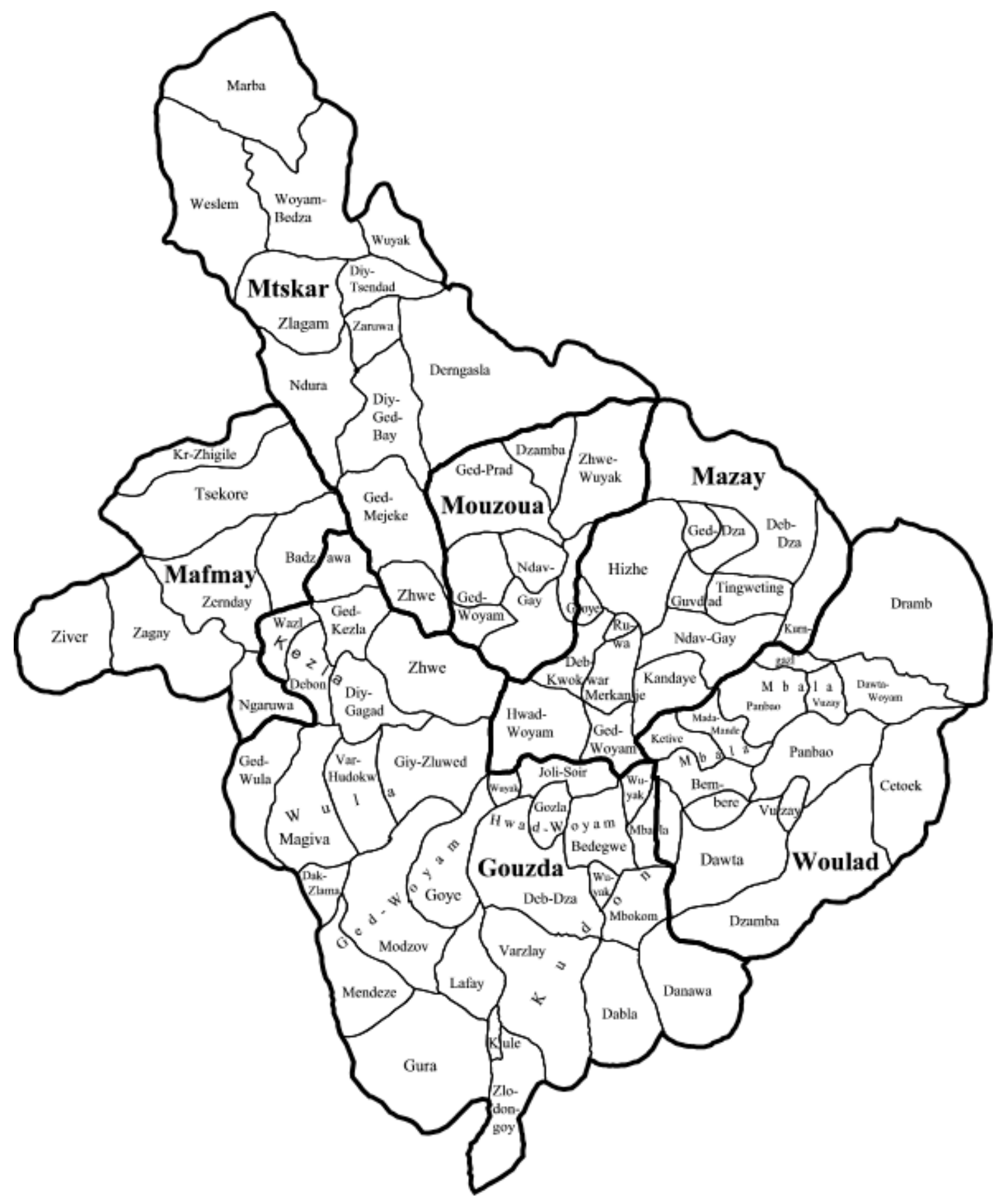


Figure 7: Clan sections and main pattern of local beer exchange

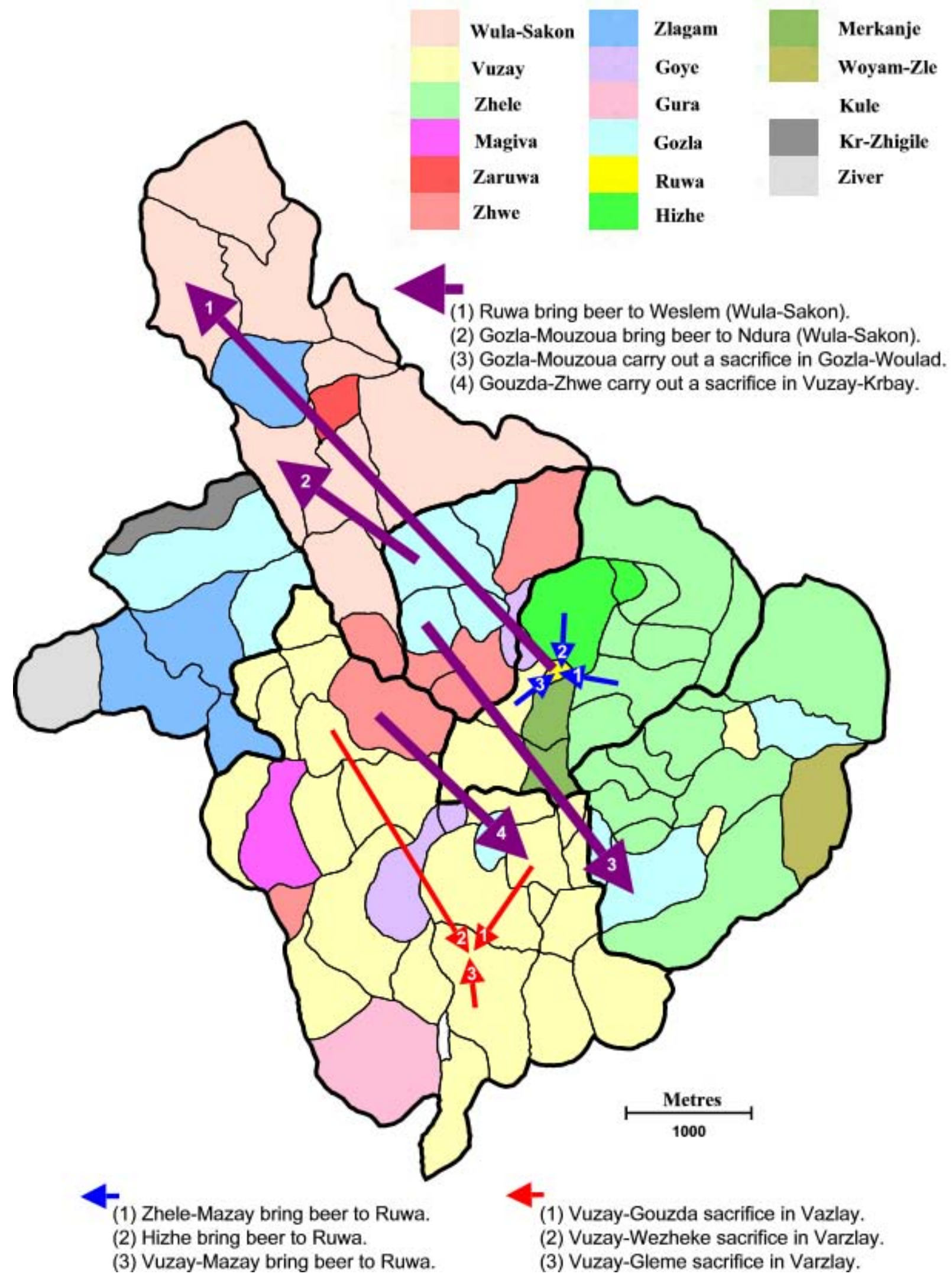




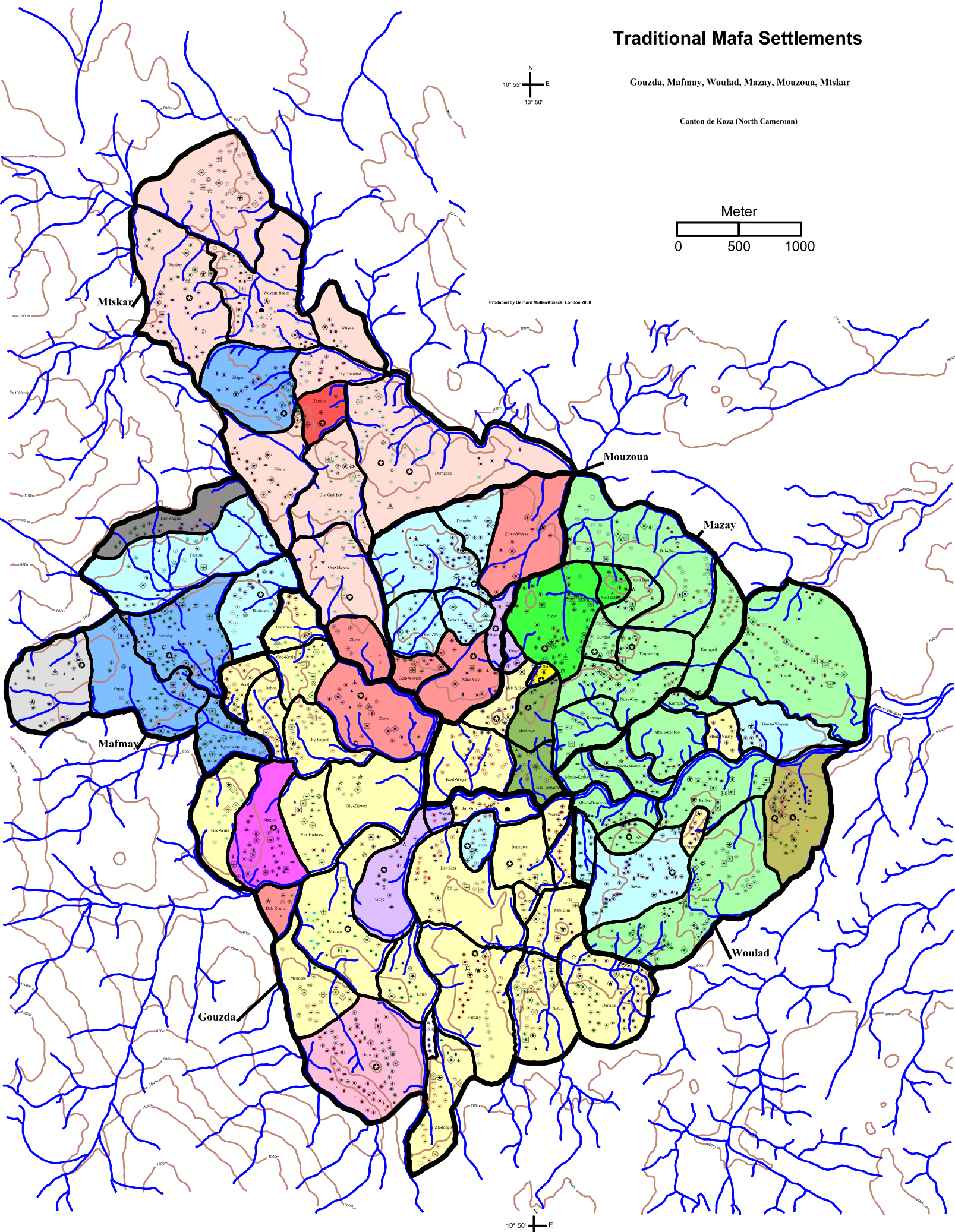


Figure 9 (CD-ROM): Key of Traditional Mafa Settlements

Clan Sections

Goye (Gouzda, Mouzoua, Mazay)

Gozla (Mafmay, Mouzoua, Woulad, Gouzda)

Gura (Gouzda)

Hizhe (Mazay)

Kr-Zhigile (Mafmay)

Kule (Gouzda)

Magiva (Gouzda)

Merkanje (Mazay)

Ruwa (Mazay)

Vuzay (Gouzda, Mazay, Woulad)

Woyam-Zle (Woulad)

Wula-Sakon (Mtskar)

Zaruwa (Mtskar)

Zhele (Mazay, Woulad)

Zhwe (Gouzda, Mouzoua, Mtskar)

Ziver (Mafmay)

Zlagam (Mafmay, Mtskar) 
Topography, Traditional Boundaries and Modern Functions

- Contour line

- River system

$\square$ Ward boundary

D Village boundary

Q Christian

I Christian church

Primary school

Traditional Elders, Strangers and Blacksmiths

+ Lineage elder (tseva)

- Stranger

$\triangle$ Chief blacksmith (biy ngwazla)

- Vuzay-Cembe blacksmith (ngwazla)

$\Delta$ Zhwe blacksmith (ngwazla)

A Zhele blacksmith (ngwalza)

$\triangle$ Gura blacksmith (ngwazla)

Common Grounds and Traditional Cemeteries 㨁 Common ground

-ф- Traditional cemetery 


\section{Traditional Functionaries}

X Mountain priest (biy dza)

$\because$ Village chief (biy wudam)

$\square$ Chief's staff (gad bay)

$\square$ Chief's representative (bay)

$\diamond$ Follower of the chief (biy gwala)

$\bigcirc$ Chief's jester (matsam)

\section{Sacred Sites}

2 Major mountain shrine

(7) Minor mountain shrine

(2) Killer shrine (madzagay)

f. Rain or river shrine

荬 Healing shrine

* Ancient shrine

Family heads of chiefly clans and their lineages

The Gozla of Mouzoua

$\square$ GOZLA-VINDIYE (Mouzoua)

- Godariy-Vindiye (Ged-Prad, Dzamba, Ndav-Gay)

- Haydak-Vindiye (Ged-Woyam \& Ndav-Gay)

- Galiy-Vindiye (Dzamba Mouzoua)

- Danawa-Vindiye (Dzamba Mouzoua) 
The Vuzay of Gouzda-Krbay

$\square$ WASLIMBAY-DANAWA (Vuzay Gouzda)

- Jardiy-Danawa (Danawa, Madzov, Bedegwe-Wuyak)

- Tsekurme-Danawa (Danawa \& Bedegwe Wuyak)

$\square$ DAKOZA-VAGORA (Vuzay-Kudon Gouzda)

- Vakenda-Vagora (Bedegwe Gouzda)

- Gwiyva-Vagora (Dabla Gouzda)

$\square$ TEWJWE-VAGSA (Vuzay Gouzda)

Wezheke-Vagsa (Kezla Gouzda, Dabla, Mazay Hwad-Woyam

- Deved-Wezheke (Diy-Gagad Gouzda)

- Giybay-Wezheke (Diy-Gagad Gouzda)

- Dzavay-Wezheke (Debon, Wasl, Dabla Gouzda)

Matakon-Vagsa (Kudon Gouzda)

- Matakon (Deb-Dza \& Varzlay Gouzda)

- Gwernye-Matakon (Deb-Dza \& Bedegwe Gouzda)

- Haydak-Matakon (Deb-Dza, Dabla, Bedegwe, Mbokom)

- Haraha-Matakon (Varzlay Gouzda)

Vagsa-Dzavay (Mendeze Gouzda)

- Dzavay (Mendeze Gouzda)

- Dzavay-Kavra (Mendeze Gouzda) 
The Vuzay of Gouzda-Krbay (continued...)

TEWJWE-LAFAY (Vuzay Gouzda)

- Kucef-Lafay (Lafay Gouzda)

- Viymay-Lafay (Lafay Gouzda)

HARAHA-LAGUWA (Vuzay Gouzda)

$\bigcirc$ Gadaye-Laguwa (Wula \& Kezla Gouzda)

- Mendesle-Gadaye (Wula Var-Hudokw)

- Dzavay-Gadaye (Ged-Kezla Gouzda)

- Biydive-Gadaye (Ged-Kezla Gouzda)

- Matakon-Gadaye (Ged-Wula Gouzda)

- Vatsama-Gadaye (Ged-Wula Gouzda)

- Slamanday-Gadaye (Ged-Wula Gouzda)

- Vetsuwe-Laguwa (Madzov)

Laguwa-Biyziwe (Mazov Vuzay Gouzda)

- Biyzive (Madzov Gouzda)

- Kalaza-Biyzive (Madzov Gouzda)

- Ngasla-Laguwa (Madzov Gouzda)

$\square$ HARAHA-GLEME (Vuzay Gouzda)

- Ngweleo-Gleme (Mbokom \& Mbala Mbokom)

$\bigcirc$ Mejeme-Gleme (Zlodongoy, Dabla, Mbokom)

- Mejeme (Dabla)

- Kalaza-Mejeme (Mbokom, Bedegwe, Mbala)

- Magana-Mejeme (Zlodongoy Gouzda)

- Tagora-Mejeme (Dabla Gouzda)

- Vice-Gleme (Varzlay Gouzda) 


\section{The Wula-Sakon of Mtskar}

$\square$ WESLEM (Wula-Sakon)

- Gama-Weslem (Weslem Mtskar)

- Bava-Weslem (Weslem Mtskar)

Marba-Weslem (Marba Mtskar)

- Haydak-Marba (Marba)

- Matakon-Marba (Marba)

- Bava-Marba (Marba)

- Haba-Marba (Marba)

$\square$ NDURA (Wula-Sakon)

- Tagora-Ndura (Ndura Mtskar)

- Keteke-Ndura (Ndura Mtskar)

- Ziyawa-Ndura (Ndura Mtskar)

$\square$ BLIWA (Wula-Sakon)

- Jeme-Bliwa (Woyam-Bedza \& Wuyak Mtskar)

$\square$ JEKUWE (Wula-Sakon)

$\bigcirc$ Lewa-Jekuwe (Woyam-Bedza, Diy-Tsendad)

- Kaleved-Lewa (Diy-Tsendad)

- Matakon-Lewa (Woyam-Bedza)

- Velele-Lewa (Woyam-Bedza)

- Danawa-Lewa (Woyam-Bedza)

Gojele-Jekuwe (Derngasla, Diy-Ged-Bay, Ged-Mejeke)

- Ndzakatay-Gojele (Derngasla)

- Guvabay-Gojele (Diy-Ged-Bay)

- Hondek-Gojele (Diy-Ged-Bay)

- Velas-Gojele (Derngasla)

- Warama-Gojele (Ged-Mejeke)

- Yagoha-Jekuwe (Woyam-Bedza Mtskar) 


\section{The Zhele of Mazay and Woulad}

\section{$\square$ ZHELE-JEWELE (Mazay)}

- Gsata-Jewele (Ged-Dza \& Deb-Dza Mazay)

- Kalaza-Jewele (Kandaye \& Ndav-Gay Mazay)

Haydak-Jewele (Zhele Mazay)

- Haydak (Kandaye, Kurngazl, Deb-Dza)

- Mongoce-Haydak (Deb-Dza, Guvdad, Kurngazl)

- Luhda-Haydak (Guvdad)

- Mejewe-Haydak (Deb-Dza Mazay)

$\square$ ZHELE-ZANGWIY (Mazay)

- Zangwiy-Zangwiy (Ndav-Gay \& Tingweting)

- Gadaye-Zangwiy (Ndav-Gay, Tingweting, Deb-Dza)

$\square$ ZHELE-MENDE (Woulad)

Ketiwe-Mende (Dzamba Woulad \& Mbala Ketiwe)

- Jeweday-Ketiwe (Dzamba Woulad \& Mbala Ketiwe)

- Gwezeow-Ketiwe (Dzamba Woulad)

- Velas-Ketiwe (Mbala-Ketiwe \& Dzamba Woulad)

- Zagwiy-Mende (Panbao Woulad \& Mada-Mande)

$\square$ ZHELE-MAZAWAL (Woulad)

- Vasla-Mazawal (Panbao, Mbala Panbao, Dramb)

- Jekene-Mazaval (Dzamba Woulad \& Dramb)

$\square$ ZHELE-VICE (Woulad)

- Teode-Vice (Bembere Woulad \& Mbala Bembere)

- Hataha-Vice (Bembere Woulad \& Mbala Bembere) ZHELE-WANDALA (Woulad Bembere)

- Wandala Zhele (Bembere \& Mbala Bembere) 
The Zlagam of Mafmay

$\square$ ZLAGAM-ZAGAY (Mafmay)

- Manay-Zagay (Zagay)

- Tewawa-Zagay (Zagay)

- Mecewele-Zagay (Zagay)

$\square$ ZLAGAM-ZERNDAY (Mafmay)

- Takenda-Zernday (Zernday)

- Vatsama-Zernday (Zernday)

- Makola-Zernday (Zernday \& Wasl)

$\square$ ZLAGAM-MBONDOM (Mafmay)

- Ganday-Mbodom (Wasl Gouzda)

- Ndihem-Mbodom (Ngaruwa Mafmay)

- Kalay-Mbodom (Ngaruwa Mafmay)

- Ndelem-Mbodom (Ngaruwa Mafmay)

Family heads of non-chiefly clans and their lineages

The Goye of Mouzoua, Mazay and Gouzda

GOYE-NGOKWA (Mouzoua \& Mazay)

- Ngweleo-Ngokwa (Goye Mouzoua \& Mazay)

- Gonondo-Ngokwa (Goye Mouzoua \& Mazay)

GOYE-GALAZA (Gouzda)

- Gaslagasl-Galaza (Goye Gouzda)

- Gudukoye-Galaza (Goye \& Goye-Wuyak)

- Ndelme-Galaza (Goye \& Goye-Wuyak) 
The Gozla of Mafmay, Woulad and Gouzda

$\bigcirc$ GOZLA-KOTONG (Mafmay)

- Vice-Kotong (Badzawa Mafmay \& Tsekore)

- Giydime-Kotong (Tsekore)

- Bava-Kotong (Badzawa, Mafmay \& Gouzda)

Sakon-Kotong (Tsekore \& Badzawa Mafmay)

GOZLA-JEME (Woulad)

- Jeme (Dawta Woulad)

- Zakaha-Jeme (Dawta \& Dawta Mbala)

- Ngasla-Jeme (Dawta \& Dawta-Woyam)

GOZLA-SLEMTAKON (Gouzda)

- Ndifde-Slemtakon (Gozla Gouzda)

- Ngaruwa-Slemtakon (Gozla Gouzda)

\section{The Gura of Gouzda}

\section{$\bigcirc$ GURA-KOTEVA (Gouzda)}

- Bhomda-Koteva (Gura)

- Ngaruwa-Koteva (Gura)

- Fibay-Koteva (Gura)

The Hizhe of Mazay

$\bigcirc$ HIZHE-MALAKWA (Mazay)

- Nduvay-Malakwa (Hizhe Mazay)

- Dalma-Malakwa (Hizhe \& Ged-Dza)

- Bengueme-Malakwa (Ged-Dza Hizhe)

- Wala-Malakwa (Hizhe Mazay) 
The Kr-Zhigile of Mafmay

KR-ZHIGILE-JIMEGED (Mafmay)

- Felew-Jimeged (Kr-Zhigile)

- Kakam-Jimeged (Kr-Zhigile)

The Kule (Vrdeke) of Gouzda

$\bigcirc$ VRDEKE-KULE (Gouzda)

- Ndukombay-Kule (Kule Gouzda)

The Magiva of Gouzda

MAGIVA (Gouzda)

- Ndasla-Magiva (Magiva Gouzda \& Var-Hukokw)

- Manay-Magiva (Magiva Gouzda)

- Kotsem-Magiva (Magiva Gouzda)

The Merkanje of Mazay

MERKANJE-GODALIY (Mazay)

- Slanawa-Godaliy (Merkanje \& Ged-Woyam)

- Baslagiy-Godaliy (Merkanje \& Ged-Woyam)

The Ruwa of Mazay

$\bigcirc$ RUWA (Mazay)

- Danguwa-Ruwa (Ruwa Mazay)

The Vuzay of Mazay and Woulad

FTELE-MBENDE (Vuzay Mazay)

- Warday-Mbende (Deb-Kokwar Mazay)

- Bava-Mbende (Deb-Kokwar \& Hwad-Woyam Mazay)

VUZAY-ZLAMA (Woulad)

- Zlama-Vuzay (Vuzay Woulad \& Vuzay Mbala) 
The Woyam-Zle of Woulad

WOYAM-SLE TRAST (Woulad)

- Kucef-Trast (Cetoek)

- Bidive-Trast (Cetoek)

- Matakon-Trast (Cetoek)

The Zaruwa of Mtskar

ZARUWA-TEONDE (Mtskar)

- Wetende-Teonde (Diy-Tsendad)

- Weneme-Teonde (Zaruwa)

- Wucived-Teonde (Diy-Tsendad \& Zaruwa)

The Zhwe of Gouzda, Mtskar and Mouzoua

ZHWE-GODALIY (Gouzda \& Mtskar)

- Godaliy-Mbeutele (Zhwe Gouzda)

Bava-Godaliy (Zhwe Gouzda \& Mtskar)

- Bava (Dak-Zlama \& Zhwe Gouzda)

- Ziyahad-Bava (Zhwe Mtskar)

- Javiy-Bava (Zhwe Mtskar)

Nduvday-Godaliy (Zhwe Gouzda)

ZHWE-MATAKON (Mouzoua)

- Matakon-Menda (Zhwe Ndav-Gay Mouzoua)

ZHWE-FKALA (Mouzoua)

- Mavje-Fkala (Wuyak Mouzoua)

- Gaye-Fkala (Ged-Woyam Mouzoua)

The Ziver of Mafmay

ZIVER-BAGA (Mafmay)

- Diy-Mafa-Baga (Ziver)

- Hanawa-Baga (Ziver) 


\section{The Zlagam of Mtskar}

ZLAGAM-NZIYAMA (Mtskar)

- Mavina-Nziyama (Zlagam Mtskar)

Kolem-Nziyama (Zlagam Mtskar)

Family heads of associated non-chiefly clans and their lineages

The Goye of Zhele Mazay

- Goye-Moskota (Deb-Dza Mazay)

The Malguce of Zhele Woulad

- MALGUCE (Woulad Dzamba)

The Sadao of Zhele Mazay

- SADAO (Mazay Deb-Dza)

The Teme of Woyam-Zle Woulad

- TEME (Woulad Cetoek)

The Zhele of Wula-Sakon Mtskar

$\bigcirc$ Zhele (Woyam-Bedza Mtskar) 
Table 1: Ethnic groups, their language affiliations and estimated numbers

Although the population figures below are only rough estimates they allow us to realistically imagine a total of about half a million montagnards living in the northern Mandara Mountains of Cameroon and Nigeria. See Chapter 1.1.2 for more details and also compare with figure 1 and 2.

\begin{tabular}{|c|c|c|c|c|}
\hline Ethnic Unit & Ethnic Group & Language/Dialect & Linguistic Group & Population \\
\hline Mafahay & \multirow{2}{*}{ Mafa } & $\begin{array}{l}\text { mafa-centre \& mafa- } \\
\text { east }\end{array}$ & \multirow{6}{*}{ mafa-south } & \multirow{2}{*}{150,000} \\
\hline Kwokwarhay & & $\begin{array}{l}\text { mafa-centre \& mafa- } \\
\text { west }\end{array}$ & & \\
\hline Duvangar & \multirow{9}{*}{ Mofu-Diamare } & \multirow{3}{*}{ mofu-north } & & \multirow{3}{*}{20,000} \\
\hline Wazan & & & & \\
\hline Durum & & & & \\
\hline Meri & & merey & & 5,000 \\
\hline Mboku & & mboku & mafa-northeast & 4,000 \\
\hline Mokyo-Molkwo & & melokwo & \multirow{10}{*}{ mafa-south } & 8,000 \\
\hline Tsere & & \multirow{3}{*}{ dugwor } & & \\
\hline Mikiri & & & & 300 \\
\hline Dugur & & & & \\
\hline Mofu-Gudur & Mofu-Gudur & mofu-south & & 26,000 \\
\hline Shugule & \multirow{5}{*}{ Bulahay } & shugule & & \multirow{5}{*}{10,000} \\
\hline Mefele & & & & \\
\hline Sirak & & mefele & & \\
\hline Muhur & & & & \\
\hline Cuvok & & cuvok & & \\
\hline Gadala & Gadala & buwal & \multirow{2}{*}{ daba-north } & 3,000 \\
\hline Gavar & Gavar & gavar & & 5,000 \\
\hline Kapsiki & Kapsiki & psikye & kamwe & 30,000 \\
\hline Sukur & Sukur & \multirow{2}{*}{ sakun } & \multirow{2}{*}{ sakun or kamwe } & 5,000 \\
\hline Damay & Damay & & & \multirow{4}{*}{300} \\
\hline Kurang & Kurang & psikye & kamwe & \\
\hline Ndalmi & Ndalmi & $?$ & margi & \\
\hline Muduvu & Muduvu & sakun & sakun or kamwe & \\
\hline Wula Mango & \multirow{2}{*}{ Wula proper } & $?$ & \multirow{2}{*}{ kamwe } & \multirow{2}{*}{200} \\
\hline Wula Hanko & & ? & & \\
\hline Mabas & \multirow{2}{*}{ Mabas } & \multirow{2}{*}{ mabas } & \multirow{4}{*}{$\begin{array}{l}\text { wandala-west or } \\
\text { lamang }\end{array}$} & \multirow{2}{*}{1,250} \\
\hline Vizik & & & & \\
\hline Vemgo & Vemgo & $?$ & & 500 \\
\hline Hide & Hide & xedi & & 10,000 \\
\hline Gvoko & Gvoko & gvoko & wandala-west & 15,000 \\
\hline Dughwede & Dughwede & dughwede & \multirow{5}{*}{$\begin{array}{l}\text { wandala-west or } \\
\text { wandala-east }\end{array}$} & 20,000 \\
\hline Guduf & \multirow{3}{*}{ Guduf } & \multirow{4}{*}{ afakbiya } & & \\
\hline Gava & & & & 30,000 \\
\hline Kusarha & & & & \\
\hline Chikide & \multirow{2}{*}{ Chikide-Chinene } & & & 3,000 \\
\hline Chinene & & nakacha or cena & & 300 \\
\hline Amuda & \multirow{2}{*}{ Amuda-Ganjara } & & ala-east & 100 \\
\hline Ganjara & & glavda & wantara-east & 100 \\
\hline Glavda & Glavda & & & 30,000 \\
\hline
\end{tabular}


Table 1: (continuing...)

\begin{tabular}{|c|c|c|c|c|}
\hline Ethnic Unit & Ethnic Group & Language/Dialect & Linguistic Group & Population \\
\hline Waga & \multirow{4}{*}{ Lamang } & \multirow{6}{*}{ lamang } & \multirow{6}{*}{$\begin{array}{l}\text { lamang or } \\
\text { wandala-west }\end{array}$} & 500 \\
\hline Uvagha & & & & \multirow{3}{*}{15,000} \\
\hline Hidkala & & & & \\
\hline Luvua & & & & \\
\hline Western Zelidva & \multirow{6}{*}{ Zelidva } & & & \\
\hline Juba & & & & \\
\hline Northern Zelidva & & & \multirow{9}{*}{ wandala-east } & \\
\hline Kiva & & wandala & & 30,000 \\
\hline Wize & & & & \\
\hline Eastern Zelidva & & glavda & & \\
\hline Vale & Vale & wandala or glavda & & 50 \\
\hline Wandala & \multirow{2}{*}{ Wandala } & \multirow{2}{*}{ wandala } & & 40,000 \\
\hline Wadele & & & & 50 \\
\hline Podokwa & Podokwa & parekwa & & 15,000 \\
\hline Mora & Mora & mura & & 2,500 \\
\hline Vame & \multirow{2}{*}{ Vame-Mbreme } & \multirow{3}{*}{ ndreme } & \multirow{3}{*}{ mafa-northeast } & \\
\hline Mbreme & & & & 3,500 \\
\hline Hurza & Hurza & & & 3,000 \\
\hline Muktele & Muktele & matal & mafa-northwest & 15,000 \\
\hline \begin{tabular}{|l} 
Uldeme \\
\end{tabular} & \multirow{2}{*}{ Uldeme } & wuzlam & mafa-south & \multirow{2}{*}{7,000} \\
\hline Pelasla & & pelasla (ndreme) & mafa-northeast & \\
\hline Mada & Mada & mada & \multirow{5}{*}{ mafa-south } & 10,000 \\
\hline Muyeng & Muyeng & muyang & & 8,000 \\
\hline Mineo & Mineo & minew & & 6,000 \\
\hline Zulgo & Zulgo & zulgwa & & 8,000 \\
\hline Gemjek & Gemjek & gemzek & & 4,000 \\
\hline Northern Giziga & \multirow{2}{*}{ Giziga } & \multirow{2}{*}{ giziga } & giziga-north & \multirow{2}{*}{80,000} \\
\hline Southern Giziga & & & giziga-south & \\
\hline
\end{tabular}


Table 2a: Mafa bibliography (sorted by year)

\begin{tabular}{|c|c|c|}
\hline UTHOR/S & YEAR & TOPIC \\
\hline Moisel, M. \& others. & 1913 & Map (first topogr. by German colonial powers) \\
\hline Strümpell, K.F. & 1923 & Ethnography (and word list including Matakam) \\
\hline Lenoir, (Capitain) & 1929 & Pacification (by the French in the N. Mandaras) \\
\hline Grall, R.F. & 1936 & Ethnography (Kirdi Matakam and Kirdi Kapsiki) \\
\hline Lavergne, G. & 1944 & Monograph (first monograph on the Matakam) \\
\hline Lavergne, G. & 1949 & Monograph (reprint of monograph from 1944) \\
\hline Lavergne, G. & 1949 & Monograph (reprint of monograph from 1944) \\
\hline Hinderling, $P$. & 1954 & Architecture (house and settlement) \\
\hline linderling, $P$. & 1954 & Material culture (collection) \\
\hline tinderling, $P$. & 1954 & Blacksmiths (exihition) \\
\hline Gardi, R. & 1955 & Blacksmiths (film on iron smelting) \\
\hline Hinderling, $\mathrm{P}$. & 1955 & Blacksmiths (iron smelting) \\
\hline Hinderling, $P$. & 1955 & Social structure (of the Matakam) \\
\hline Hurault, J. & 1956 & Ethnography (examples from Kirdi of Mokolo) \\
\hline Hurault, J. & 1958 & Social structure (of the Matakam) \\
\hline Hinderling, $P$. & 1959 & Textile (string making and weaving) \\
\hline Hinderling, $P$. & 1960 & Textile (making strings and ropes) \\
\hline Podlewski, A.-M. & 1961 & Demography (Matakam, Kapsiki, Goude) \\
\hline Podlewski, A.-M. & 1961 & Migration (Mafa, rural-urban migration) \\
\hline Lembezat, B. & 1961 & Monograph (regional, includes the Matakam) \\
\hline Vallerie, M. & 1964 & ogy (perimeter Matakam) \\
\hline au, J. \& J.-M. Laurendeau & 1965 & Dictionar \\
\hline Hinderling, $P$. & 1965 & Textile (making bags from string an \\
\hline Podlewski, A.-M. & 1966 & Blacksmiths (functions \& principle of endogamy) \\
\hline Podlewski, A.-M. & 1966 & Demography (general, includes the Mafa) \\
\hline Schönmeier, I. & 1966 & Socialisation (gen. behaviour towards children) \\
\hline Martin, J.-Y. & 1967 & Community (sociological study of Magoumaz) \\
\hline Martin, J.-Y. & 1967 & Refuge Zones (zones d'accueille in 4 cantons) \\
\hline Martin-Sauveur, M. & 1967 & Scolarisation (Mafa resistance against it) \\
\hline Hinderling, P. \& Schönmeier. & 1968 & Development (North Cameroon, Mafa) \\
\hline Martin, J.-Y. & 1968 & Sociology (social dynamics and modernisation) \\
\hline Hinderling, $P$. & 1969 & Monograph (the Mafa, unpublished) \\
\hline Boul & 1970 & e (the case of $M$ \\
\hline J.-Y. & 1970 & lamics) \\
\hline Steck & 1972 & Mol \\
\hline Boutrais, J. (avec coll. de M. Seati) & 1972 & hical index of Mafa villages) \\
\hline Boutrais, J. & 1973 & I migration into adjact. plains) \\
\hline Genest, S. & 1974 & sm. of traditional knowledge) \\
\hline Boisseau, J. \& M. Soula & 1974 & Cosmology (gender ontology, role of women) \\
\hline Hinderling, $\mathrm{P}$. & 1974 & Development (North Cameroon, Mafa) \\
\hline Boisseau, J. & 1975 & Bull festival (celebrating conviviality, Djinglia) \\
\hline Boulet, J. & 1975 & Land Tenure (the case of Magoumaz) \\
\hline Genest, S. & 1976 & Blacksmiths (transm. of traditional knowledge) \\
\hline Rossing, M.O. & 1978 & Dictionary (Mafa-Mada, comparison) \\
\hline Eichenberger \& G. Eichenberger. & 1978 & Linguistics (Mafa language course) \\
\hline Schmitz-Cliever, G. & 1979 & Blacksmiths (social position, W.African context) \\
\hline Schönmeier, $\mathrm{H}$. & 1979 & IIness (traditional belief and social change) \\
\hline Barreteau, D. & 1980 & Linguistics (dicussion of mafa language group) \\
\hline Zigla, W. & 1981 & Bull Festival (in Mokolo, unpublished) \\
\hline
\end{tabular}


Martin, J.-Y.

Podlewski, A.-M.

Seignobos, C.

Seignobos, C. (avec F. Lafarge).

Gnowe, R.

Podlewski, A.-M.

Oumate, $\mathrm{O}$.

Hinderling, $P$.

Barreteau, D., R. Breton \& M. Dieu

Hinderling, $P$.

Ridell, J.C. \& D.J. Campbell.

Müller-Kosack, G.

Barreteau, D. \& Y. Le Bléis

Le Bléis, $Y$.

Müller-Kosack, G.

Seignobos, C.

Mohammadou, E.

Müller-Kosack, G.

Müller-Kosack, G.

David, N., J. Sterner \& K.B. Gavua.

Schilling, C. \& D. Köhlhoff.

Schilling, C.

Barreteau, D. \& Y. Le Bléis

Gavua, K.B.

Sterner, J. \& N. David.

Gubry, P.

Bregeot, G.

Lavergne, G.

Kosack, G.

Müller-Kosack, G.

van Santen, J.

David, N.

Sterner, J.

Kosack, G.

van Santen, J.

lyebi-Mandjek, $O$.

van Santen, J.

van Santen, J.

Avontuur, S. \& M. de Wit.

Barreteau, D.

Abega, S.C.

van Santen, J.

Kosack, G.

Kosack, G.

Gubry, P. \& others.

Kosack, G. \& H. Tourneux.

Kosack, G \& Tourneux.

Roymans, A.

Iyebi-Mandjek, O. \& C. Seignobos.

Müller-Kosack, G.

van Santen, J.

Kosack, G.
1981

1981

1982

1982

1982

1983

1984

1984

1984

1984

1986

1987

1987

1987

1987

1988

1988

1988

1988

1988

1989

1989

1990

1990

1991

1991

1991

1991

1991

1991

1991

1992

1992

1992

1992

1993

1993

1993

1994

1994

1994

1995

1995

1995

1996

1997

1997

1997

1997

1997

1997

1997
History (oral traditions and precolonial history)

Islamisation (demographic issues)

Archaeology (the Mondouza strongholds)

Architecture (a study of the Mandara Mountains)

Bull Fattening (in Mokolo, unpublished)

Blacksmiths (a demographic study, endogamy)

Bull Fattening (in Mokolo, unpublished)

Field Notes (general materials on the Mafa)

Linguistics (system of regional classification)

Monograph (social structure \& religious practice)

Agriculture (intensification \& reg. development)

Collection (reproductions of sacred pottery)

Linguistics (Mafa verb themes \& lexemes)

Linguistics (Mafa verb extensions)

Social Structure (ritual and local history)

Agriculture (agro-system on top of mount Ziver)

History (Fulbe lamidats of Zamay and Gawar)

Pottery (sacred pots, spatial dimension)

Pottery (sacred pots, functional differentiation)

Pottery (symbolic reservoir, style, decoration)

Dam Building (small dams, local development)

Geography (Gouzda, geomorphological study)

Linguistics (Mafa-French dictionary)

Material Culture (Mafa style)

Blacksmiths (gender \& caste)

Demography (population, retention)

Land Tenure (economic study, PhD)

Monograph (reprint of 1949 edition)

Oral Literature (sociological interpretation)

Settlement (Mafa, settlement structure)

Twins (meaning of number two)

Funeral (ethno-archaeological study)

Pottery (sacred, symbolic reservoir)

Slavery (oral traditions, local history)

Women (Islamisation, economic change)

Migration (Mafa, seasonal migration)

Women (economomics, coping strategies)

Women (Mafa, conversion to Islam)

Development (water, socio-economic study)

Linguistics (Mafa-Mofu, comparison, verbs, lex.)

Marriage (refusal of marriage by Mafa women)

Funeral (Islamisation, changes in practice)

Sorcery (epistemolog. limits of understanding)

Women (Christianisation \& emancipation)

Migration (return to the village)

Folk Tales (animal tales)

Folk Tales (mystery tales)

Land Tenure (Mafa, social dynamics)

Migration (Mafa, interregional migrantion)

Monograph (social structure \& ritual)

Politics (Mafa, national integration)

Water (in Mafa folk tales) 
Müller-Kosack, G.

Schaafsma, J. \& A.B. Zuiderwijk. Kosack, G.

Zuiderwijk, A.B.

van Santen, J.

van Santen, J.

Schaafsma, J.

Müller-Kosack, G.

van Santen, J. \& J. Schaafsma.

Kosack, G.

Kosack, G.

Nassourou, T.

Vallin, (Capitaine).
1997 Water (cultural siginficance of water)

1997 Women (male out-migration, roles)

1997 Monograph (oral literat. \& perspective of women)

1998 Agriculture (development, agricultural change)

1998 Gender (Islamisation and urbanisation)

1998 Islamisation (women, community change)

1998 Women (male-outmigrat. \& women)

1999 Bull Festival (Mafa \& Dughwede)

1999 Bulls \& Cows (symbolic classification)

1999 Polygyny (women's perspective)

in print Sorcery (women's perspective)

no date Blacksmiths (functional roles, unpublished)

no date Ethnography (Matakam, customs of) 
Table 2b: Mafa bibliography (sorted by topic)

\begin{tabular}{|c|c|c|}
\hline AUTHOR/S & YEAR & TOPIC \\
\hline Seignobos, C. & 1988 & Agriculture (agro-system on top of mount Ziver) \\
\hline Zuiderwijk, A.B. & 1998 & Agriculture (development, agricultural change) \\
\hline Ridell, J.C. \& D.J. Campbell. & 1986 & Agriculture (intensification \& reg. development) \\
\hline Seignobos, C. & 1982 & Archaeology (the Mondouza strongholds) \\
\hline Seignobos, C. (avec F. Lafarge). & 1982 & Architecture (a study of the Mandara Mountains) \\
\hline Hinderling, $\mathrm{P}$. & 1954 & Architecture (house and settlement) \\
\hline Podlewski, A.-M. & 1983 & Blacksmiths (a demographic study, endogamy) \\
\hline Hinderling, $\mathrm{P}$. & 1954 & Blacksmiths (exihition) \\
\hline Gardi, R. & 1955 & Blacksmiths (film on iron smelting) \\
\hline Nassourou, T. & no date & Blacksmiths (functional roles, unpublished) \\
\hline Podlewski, A.-M. & 1966 & Blacksmiths (functions \& principle of endogamy) \\
\hline Sterner, J. \& N. David. & 1991 & Blacksmiths (gender \& caste) \\
\hline Hinderling, P. & 1955 & Blacksmiths (iron smelting) \\
\hline Schmitz-Cliever, G. & 1979 & Blacksmiths (social position, W.African context) \\
\hline Genest, S. & 1974 & Blacksmiths (transm. of traditional knowledge) \\
\hline Genest, S. & 1976 & Blacksmiths (transm. of traditional knowledge) \\
\hline Gnowe, R. & 1982 & Bull Fattening (in Mokolo, unpublished) \\
\hline Oumate, $\mathrm{O}$. & 1984 & Bull Fattening (in Mokolo, unpublished) \\
\hline Boisseau, J. & 1975 & Bull Festival (celebrating conviviality, unpublished) \\
\hline Zigla, W. & 1981 & Bull Festival (in Mokolo, unpublished) \\
\hline Müller-Kosack, G. & 1999 & Bull Festival (Mafa \& Dughwede) \\
\hline van Santen, J. \& J. Schaafsma. & 1999 & Bulls \& Cows (symbolic classification) \\
\hline Müller-Kosack, G. & 1987 & Collection (reproductions of sacred pottery) \\
\hline Martin, J.-Y. & 1967 & Community (sociological study of Magoumaz) \\
\hline Boisseau, J. \& M. Soula & 1974 & Cosmology (gender ontology, role of women) \\
\hline Schilling, C. \& D. Köhlhoff. & 1989 & Dam Building (small dams, local development) \\
\hline Podlewski, A.-M. & 1966 & Demography (general, includes the Mafa) \\
\hline Podlewski, A.-M. & 1961 & Demography (Matakam, Kapsiki, Goude) \\
\hline Gubry, P. & 1991 & Demography (population, retention) \\
\hline Hinderling, P. \& Schönmeier. & 1968 & Development (North Cameroon, Mafa) \\
\hline Hinderling, $\mathrm{P}$. & 1974 & Development (North Cameroon, Mafa) \\
\hline Avontuur, S. \& M. de Wit. & 1994 & Development (water, socio-economic study) \\
\hline Boisseau, J. \& J.-M. Laurendeau & 1965 & Dictionary (Mafa-French, unpublished) \\
\hline Rossing, M.O. & 1978 & Dictionary (Mafa-Mada, comparison) \\
\hline Strümpell, K.F. & 1923 & Ethnography (and word list including Matakam) \\
\hline Hurault, J. & 1956 & Ethnography (examples from Kirdi of Mokolo) \\
\hline Grall, R.F. & 1936 & Ethnography (Kirdi Matakam and Kirdi Kapsiki) \\
\hline Vallin, (Capitaine). & no date & Ethnography (Matakam, customs of) \\
\hline Hinderling, $\mathrm{P}$. & 1984 & Field Notes (general materials on the Mafa) \\
\hline Kosack, G. \& H. Tourneux. & 1997 & Folk Tales (animal tales) \\
\hline Kosack, G \& Tourneux. & 1997 & Folk Tales (mystery tales) \\
\hline David, N. & 1992 & Funeral (ethno-archaeological study) \\
\hline van Santen, J. & 1995 & Funeral (Islamisation, changes in practice) \\
\hline van Santen, J. & 1998 & Gender (Islamisation and urbanisation) \\
\hline Schilling, C. & 1989 & Geography (Gouzda, geomorphological study) \\
\hline Mohammadou, E. & 1988 & History (Fulbe lamidats of Zamay and Gawar) \\
\hline Martin, J.-Y. & 1981 & History (oral traditions and precolonial history) \\
\hline Schönmeier, $\mathrm{H}$. & 1979 & IIness (traditional belief and social change) \\
\hline
\end{tabular}


Podlewski, A.-M.

van Santen, J.

Bregeot, G.

Roymans, A.

Boulet, J.

Boulet, J.

Barreteau, D.

Eichenberger \& G. Eichenberger.

Le Bléis, $Y$.

Barreteau, D. \& Y. Le Bléis

Barreteau, D. \& Y. Le Bléis

Barreteau, D.

Barreteau, D., R. Breton \& M. Dieu

Moisel, M. \& others.

Abega, S.C.

Hinderling, P.

Gavua, K.B.

Boutrais, J.

Iyebi-Mandjek, O. \& C. Seignobos.

Podlewski, A.-M.

lyebi-Mandjek, O.

Gubry, P. \& others.

Steck, B.

Lavergne, G.

Kosack, G.

Lembezat, B.

Lavergne, $\mathrm{G}$.

Lavergne, $\mathrm{G}$.

Lavergne, G.

Hinderling, $P$.

Müller-Kosack, G.

Hinderling, $P$.

Martin, J.-Y.

Kosack, G.

Lenoir, (Capitain)

Vallerie, $\mathrm{M}$.

van Santen, J.

Kosack, G.

Müller-Kosack, G.

Müller-Kosack, G.

Sterner, J.

David, N., J. Sterner \& K.B. Gavua.

Martin, J.-Y.

Martin-Sauveur, M.

Boutrais, J. (avec coll. de M. Seati)

Müller-Kosack, G.

Kosack, G.

Hinderling, $P$.

Hurault, J.

Müller-Kosack, G.

Schönmeier, I.

Martin, J.-Y.
1981

1998

1991

1997

1970

1975

1980

1978

1987

1987

1990

1994

1984

1913

1994

1954

1990

1973

1997

1961

1993

1996

1972

1944

1997

1961

1991

1949

1949

1984

1997

1969

1970

1991

1929

1964

1997

1999

1988

1988

1992

1988

1967

1967

1972

1991

1992

1955

1958

1987

1966

1968
Islamisation (demographic issues)

Islamisation (women, community change)

Land Tenure (economic study, PhD)

Land Tenure (Mafa, social dynamics)

Land Tenure (the case of Magoumaz)

Land Tenure (the case of Magoumaz)

Linguistics (dicussion of mafa language group)

Linguistics (Mafa language course)

Linguistics (Mafa verb extensions)

Linguistics (Mafa verb themes \& lexemes)

Linguistics (Mafa-French dictionary)

Linguistics (Mafa-Mofu, comparison, verbs, lex.)

Linguistics (system of regional classification)

Map (first topogr. by German colonial powers)

Marriage (refusal of marriage by Mafa women)

Material culture (collection)

Material Culture (Mafa style)

Migration (downhill migration into adjact. plains)

Migration (Mafa, interregional migrantion)

Migration (Mafa, rural-urban migration)

Migration (Mafa, seasonal migration)

Migration (return to the village)

Mokolo Town (urban-rural relationship)

Monograph (first monograph on the Matakam)

Monograph (oral literat. \& perspective of women)

Monograph (regional, includes the Matakam)

Monograph (reprint of 1949 edition)

Monograph (reprint of monograph from 1944)

Monograph (reprint of monograph from 1944)

Monograph (social structure \& religious practice)

Monograph (social structure \& ritual)

Monograph (the Mafa, unpublished)

Monograph (the Matakam, social dynamics)

Oral Literature (sociological interpretation)

Pacification (by the French in the N. Mandaras)

Pedology (perimeter Matakam)

Politics (Mafa, national integration)

Polygyny (women's perspective)

Pottery (sacred pots, functional differentiation)

Pottery (sacred pots, spatial dimension)

Pottery (sacred, symbolic reservoir)

Pottery (symbolic reservoir, style, decoration)

Refuge Zones (zones d'accueille in 4 cantons)

Scolarisation (Mafa resistance against it)

Settlement (geographical index of Mafa villages)

Settlement (Mafa, settlement structure)

Slavery (oral traditions, local history)

Social structure (of the Matakam)

Social structure (of the Matakam)

Social Structure (ritual and local history)

Socialisation (gen. behaviour towards children)

Sociology (social dynamics and modernisation) 
Kosack, G.

Kosack, G.

Hinderling, $P$.

Hinderling, $P$.

Hinderling, $P$.

van Santen, J.

Müller-Kosack, G.

Kosack, G.

Kosack, G.

van Santen, J.

van Santen, J.

van Santen, J.

Schaafsma, J. \& A.B. Zuiderwijk.

Schaafsma, J.
1995 Sorcery (epistemolog. limits of understanding)

in print Sorcery (women's perspective)

1965 Textile (making bags from string and leather)

1960 Textile (making strings and ropes)

1959 Textile (string making and weaving)

1991 Twins (meaning of number two)

1997 Water (cultural siginficance of water)

1997 Water (in Mafa folk tales)

1995 Women (Christianisation \& emancipation)

1993 Women (economomics, coping strategies)

1992 Women (Islamisation, economic change)

1993 Women (Mafa, conversion to Islam)

1997 Women (male out-migration, roles)

1998 Women (male-outmigrat. \& women) 


\section{Table 4: Settlement names and their meaning}

Cetœk:

De6-Dza:

De6-Kwokwar:

Diy-Gagad:

Diy-Gəd-Bay:

Diy-Tsəndad:

Dramb:

Dzamba:

Gəd-Kezla:

Gəd-Méjéké:

Gəd-Prad:

Gəd-Wula:

Gəd-Woyam:

Giy-Zluwed:

Goyé:

Gura:

Guvdad:

Hwad-Woyam:

Kandayé:

Kezla:

Kər-Zhigilé:

Kurngozl:

Mazay:

Mbala:

Mbokom:

Ndav-Gay:

Ruwa:

Var-Hudokw:

Varzlay:

Wasl:

Woyam:

Woyam-Bedza:

Wulad(Woulad):

Wuyak:

Zagay:

Zernday:

Zhwé:

Zlagam:

Zlodongoy:
Gone forever.

Back of the mountain.

Back of the settlement.

Eye of the Acacia albida.

Eye of the chief great one.

Eye of the Khaya senegalensis.

Fertile ground.

Swampy ground.

Divided at the summit.

Came from the summit.

Flat rock on top.

Wula on top.

Head of the river.

House of bush meat.

Scabies on the scalp.

Bronze.

Ficus platyphylla.

Stomach of the river.

You are with me.

Divided.

Son of God.

Small hill in the plains.

Widow.

Hard ground.

Bombax costatum.

Heart of the settlement.

Parkia biglobosa.

Common ground for moonlight dance.

Battlefield.

Saccarum spontaneum.

On the river.

On the mountain river.

Smashed to pieces.

Sandy ground.

Listen.

Locust.

Wild cat.

Forked branch.

Rift valley 
Table 12: Mafa informants interviewed from 1985 to 1989

\begin{tabular}{|c|c|c|c|c|c|}
\hline No & Name: & Age: & Date: & Place/Location: & Main theme: \\
\hline 1 & Jikdaye & 20 & $24 / 05 / 1985$ & Gouzda-Gura & bull festival \\
\hline 2 & Gonondo & 30 & $24 / 05 / 1985$ & Gouzda-Gura & lineage terminology \\
\hline 3 & Gonondo & 30 & $02 / 06 / 1985$ & Gouzda-Gura & use of ochre \\
\hline 4 & Zlakena & 70 & $26 / 06 / 1985$ & Gouzda-Gura & rain making \\
\hline 5 & Gonondo & 30 & $27 / 06 / 1985$ & Gouzda-Gura & bull festival \\
\hline 6 & Tongay & 50 & 28/06/1985 & Gouzda-Zhwé & iron technology \\
\hline 7 & Jekene & 70 & $30 / 06 / 1985$ & Gouzda-Zhwé & legend of origin \\
\hline 8 & Ngibay & 65 & $01 / 07 / 1985$ & Gouzda-Wula & village chief \\
\hline 9 & matsam & 50 & $02 / 07 / 1985$ & Gouzda-Kule & role of matsam \\
\hline 10 & Gonondo & 30 & 02/07/1985 & Gouzda-Gura & bull festival \\
\hline 11 & Komanda & 60 & 03/07/1985 & Gouzda-Gura & ancestor cult \\
\hline 12 & Ndegwe & 58 & $04 / 07 / 1985$ & Gouzda-Zlodongoy & role of matsam \\
\hline 13 & matsam & 50 & $05 / 07 / 1985$ & Gouzda-Kule & role of matsam \\
\hline 14 & Zlakena & 70 & 05/07/1985 & Gouzda-Gura & ancestor cult \\
\hline 15 & Bogoma & 65 & $13 / 07 / 1985$ & Gouzda-Varzlay & cult of mbulom \\
\hline 16 & Zlakena & 70 & 21/07/1985 & Gouzda-Gura & harvest festival \\
\hline 17 & Zhege & 65 & $17 / 08 / 1985$ & Gouzda-Bedegwe & rituals \\
\hline 18 & Tongay & 50 & $22 / 08 / 1985$ & Gouzda-Zhwé & blacksmiths \\
\hline 19 & Ndukoye & 65 & $20 / 08 / 1985$ & Gouzda-Gura & blacksmiths \\
\hline 20 & Warda & 25 & $27 / 08 / 1985$ & Gouzda-Gura & blacksmiths \\
\hline 21 & Budam & 52 & $28 / 08 / 1985$ & Gouzda-Danawa & Mafahay \& Bulahay \\
\hline 22 & Gudaygəd & 70 & $17 / 09 / 1985$ & Gouzda-Deb-Dza & Gozla of Gouzda \\
\hline 23 & Bazlima & 70 & 07/10/1985 & Gouzda-Zlodongoy & Gleme-Magana \\
\hline 24 & Ngweleow & 70 & $29 / 10 / 1985$ & Gouzda-Madzov & role of bay \\
\hline 25 & from Magiva & $(?)$ & $30 / 10 / 1985$ & Gouzda-Magiva & legend of origin \\
\hline 26 & Ngibay & 65 & $02 / 11 / 1985$ & Gouzda-Wula & ritual relationships \\
\hline 27 & from Soulede & $(?)$ & 08/11/1985 & Gouzda-Kudon & threshing rituals \\
\hline 28 & Zlakena & 70 & $23 / 11 / 1985$ & Gouzda-Gura & taboos \\
\hline 29 & Tongay's wife & 45 & 22/01/1986 & Gouzda-Zhwé & traditional pottery \\
\hline 30 & Hahad & 65 & $23 / 01 / 1986$ & Gouzda-Kudon & traditional pottery \\
\hline 31 & Hahad & 65 & 24/01/1986 & Gouzda-Kudon & traditional pottery \\
\hline 32 & Sawazla & 60 & 02/02/1986 & Gouzda-Bedegwe & role of biy gwala \\
\hline 33 & Gonondo & 30 & $07 / 02 / 1986$ & Gouzda-Gura & sorcery \\
\hline 34 & Zlakena & 70 & $14 / 04 / 1986$ & Gouzda-Gura & sacrifice \\
\hline 35 & Zlakena & 70 & 09/06/1986 & Gouzda-Gura & harvest festival \\
\hline 36 & Zlakena & 70 & $20 / 10 / 1986$ & Gouzda-Gura & biy gwala mutsor \\
\hline 37 & Zhege & 65 & $21 / 10 / 1986$ & Gouzda-Bedegwe & biy gwala mutsor \\
\hline 38 & Ngibay & 65 & $22 / 10 / 1986$ & Gouzda-Wula & village chief \\
\hline 39 & Marenje & 55 & $22 / 10 / 1986$ & Gouzda-Gura & biy gwala mutsor \\
\hline 40 & Zlakena & 70 & $01 / 12 / 1986$ & Gouzda-Gura & minimal lineage \\
\hline 41 & Marenje & 55 & 01/12/1986 & Gouzda-Gura & minimal lineage \\
\hline 42 & Zlakena & 70 & $01 / 12 / 1986$ & Gouzda-Gura & minimal lineage \\
\hline 43 & Kalajavi & 70 & $05 / 12 / 1986$ & Gouzda-Gura & minimal lineage \\
\hline 44 & Zlakena & 70 & $06 / 12 / 1986$ & Gouzda-Gura & inheritance \\
\hline 45 & Zlakena & 70 & 13/09/1986 & Gouzda-Gura & twin ceremony \\
\hline 46 & Marenje & 55 & 13/09/1986 & Gouzda-Gura & twin ceremony \\
\hline
\end{tabular}




\begin{tabular}{|c|c|c|c|c|c|}
\hline 47 & Fudahngwa & 90 & 06/10/1988 & Gouzda-Wula & worldview \\
\hline 48 & Ndegwe & 61 & 13/10/1988 & Gouzda-Zlodongoy & traditional calendar \\
\hline 49 & Pardapa & 27 & $17 / 10 / 1988$ & Gouzda-Goye & role of Goye \\
\hline 50 & Zlakena & 73 & 18/10/1988 & Gouzda-Gura & cosmology \\
\hline 51 & Zhege & 68 & 19/10/1988 & Gouzda-Bedegwe & cosmology \\
\hline 52 & Ngweleow & 73 & $24 / 10 / 1988$ & Gouzda-Kule & kule ceremony \\
\hline 53 & Zlakena & 73 & 04/11/1988 & Gouzda-Gura & cosmology \\
\hline 54 & Wala & 75 & $22 / 11 / 1988$ & Gouzda-Deb-Dza & wedding ceremony \\
\hline 55 & Zlakena & 73 & $24 / 11 / 1988$ & Gouzda-Gura & wedding ceremony \\
\hline 56 & Hahad & 68 & 24/11/1988 & Gouzda-Kudon & wedding ceremony \\
\hline 57 & Bogoma & 68 & $24 / 11 / 1988$ & Gouzda-Varzlay & wedding ceremony \\
\hline 58 & Zlakena & 73 & 28/11/1988 & Gouzda-Gura & religion \\
\hline 59 & Bazlina & 55 & $28 / 11 / 1988$ & Gouzda-Zlodongoy & nature spirits \\
\hline 60 & Gazawa & 50 & 28/11/1988 & Gouzda-Zlodongoy & house spirit \\
\hline 61 & Bogoma & 68 & $28 / 11 / 1988$ & Gouzda-Varzlay & spirit of sorghum \\
\hline 62 & Ndegwe & 61 & $03 / 12 / 1988$ & Gouzda-Zlodongoy & role of matsam \\
\hline 63 & Zlakena & 73 & $05 / 12 / 1988$ & Gouzda-Gura & religion \\
\hline 64 & Gazawa & 68 & 08/12/1988 & Gouzda-Mendeze & history of slavery \\
\hline 65 & Zhege & 68 & $09 / 12 / 1988$ & Gouzda-Bedegwe & ritual drinking \\
\hline 66 & Ndegwe & 61 & 19/12/1988 & Gouzda-Zlodongoy & cutting sorghum \\
\hline 67 & Ndegwe & 61 & $20 / 12 / 1988$ & Gouzda-Zlodongoy & star constellations \\
\hline 68 & Bicime (fem.) & 80 & 02/01/1989 & Gouzda-Mbokom & history of slavery \\
\hline 69 & Wandala & 80 & 13/01/1989 & Gouzda-Dabla & harvest festival \\
\hline 70 & Wandala & 80 & $14 / 01 / 1989$ & Gouzda-Dabla & role of biy gwala \\
\hline 71 & Budam & 55 & 16/01/1989 & Gouzda-Danawa & crab divination \\
\hline 72 & local man & $(?)$ & $21 / 01 / 1989$ & Gouzda-Dabla & architecture \\
\hline 73 & Danagay (fem.) & 45 & 22/01/1989 & Gouzda-Madzov & ethnogr. objects \\
\hline 74 & local woman & 60 & $22 / 01 / 1989$ & Gouzda-Madzov & ethnogr. objects \\
\hline 75 & Tsamaye & 70 & 22/01/1989 & Gouzda-Zhwé & ethnogr. objects \\
\hline 76 & Tsamaye & 70 & 23/01/1989 & Gouzda-Zhwé & sacred rope \\
\hline 77 & Zlakena & 73 & 03/02/1989 & Gouzda-Gura & religion \\
\hline 78 & Zlakena & 73 & 14/02/1989 & Gouzda-Gura & mythology \\
\hline 79 & Budam & 55 & 17/02/1989 & Gouzda-Danawa & crab divination \\
\hline 80 & Gazawa & 68 & $22 / 02 / 1989$ & Gouzda-Mendeze & chiefly lineages \\
\hline 81 & Gadaye & 65 & $04 / 11 / 1985$ & Woulad-Dawta & role of the Gozla \\
\hline 82 & Mblata & 70 & $04 / 11 / 1985$ & Woulad-Mbala & role of the Gozla \\
\hline 83 & Jikdaye & 26 & 01/02/1986 & Gouzda-Gura & place names \\
\hline 84 & Jaques-Marie & 65 & 06/06/1986 & Woulad-Dzamba & mountain priest \\
\hline 85 & Gwiyeke & 55 & $27 / 10 / 1986$ & Woulad & bull festival \\
\hline 86 & Mblata & 60 & $28 / 10 / 1986$ & Woulad-Mbala & biy gwala mutsor \\
\hline 87 & Gsata & 70 & 21/11/1988 & Woulad-Panbao & links to biy vardeké \\
\hline 88 & Ngarua & 65 & 04/07/1985 & Mazay-Merkanjé & local history \\
\hline 89 & Gwejeme & 70 & 04/07/1985 & Mazay-Vuzay & ritual seniority \\
\hline 90 & Vice & 40 & $10 / 07 / 1985$ & Mazay-Ruwa & role of the Ruwa \\
\hline 91 & local man & 60 & $05 / 09 / 1985$ & Mazay-Hizhé & ritual relationships \\
\hline 92 & Tekulemiy & 70 & $10 / 09 / 1985$ & Mazay-Merkanjé & local history \\
\hline 93 & Vadzaye (fem.) & 70 & $11 / 09 / 1985$ & Mazay-Gəd-Woyam & blacksmiths women \\
\hline 94 & Jikdaye & 25 & $13 / 11 / 1985$ & Mazay & place names \\
\hline 95 & Sawazla & 55 & 06/02/1986 & Mazay-Hizhé & bull festival \\
\hline
\end{tabular}




\begin{tabular}{|c|c|c|c|c|c|}
\hline 96 & Bazlagwiy & 80 & $23 / 10 / 1988$ & Mazay-Hizhé & biy gwala mutsor \\
\hline 97 & Tekulemiy & 70 & $24 / 10 / 1988$ & Mazay-Merkanjé & role of Merkanjé \\
\hline 98 & Jekuve's son & 30 & 08/11/1988 & Mazay-Hizhé & Hizhé and Zhwé \\
\hline 99 & Jekuwe & 75 & $11 / 11 / 1988$ & Mazay-Hizhé & ritual relationships \\
\hline 100 & Wandala & 70 & $28 / 11 / 1988$ & Mazay-Hizhé & spirit of sorghum \\
\hline 101 & man from Goye & 45 & $10 / 06 / 1985$ & Mouzoua-Goye & blacksmiths \\
\hline 102 & Yadak & 70 & 09/09/1985 & Mouzoua & village boundaries \\
\hline 103 & Wala & 75 & 09/09/1985 & Mouzoua-Ndav-Gay & Gozla and Ndura \\
\hline 104 & Dazna Ndule & 75 & $11 / 09 / 1985$ & Mouzoua-Gəd-Prad & diy mbulom mutsor \\
\hline 105 & Vimay & 70 & $14 / 02 / 1986$ & Mouzoua-Zhwé & ngwazla and vavay \\
\hline 106 & biy dza & $(?)$ & 05/06/1986 & Mouzoua-Gozla & harvest festival \\
\hline 107 & Ngweleow & 70 & $01 / 11 / 1988$ & Mouzoua-Ndav-Gay & myths and legends \\
\hline 108 & Ngweleow & 75 & 01/11/1988 & Mouzoua-Zhwé & Zhwé and Hizhé \\
\hline 109 & Faisam & 70 & $06 / 02 / 1986$ & Mtskar-Diy-Gəd-Bay & ndoday \\
\hline 110 & Faisam & 70 & $16 / 09 / 1986$ & Mtskar-Diy-Gəd-Bay & Wula-Sakon \\
\hline 111 & Pereved & 70 & $18 / 09 / 1985$ & Mtskar-Woyam-Bedza & Wula-Sakon \\
\hline 112 & Gwedana & 70 & $20 / 09 / 1985$ & Mtskar-Ndura & Wula-Sakon \\
\hline 113 & Vetsuwe & 70 & $21 / 09 / 1985$ & Mtskar-Weslem & Wula-Sakon \\
\hline 114 & elder of Marba & $(?)$ & 29/01/1986 & Mtskar-Marba & Wula-Sakon \\
\hline 115 & Koradiy & 70 & $04 / 02 / 1986$ & Mtskar-Derngazla & bull festival \\
\hline 116 & Ndoye & 75 & 04/06/1986 & Mtskar-Ndura & harvest festival \\
\hline 117 & Faisam & 70 & $30 / 10 / 1986$ & Mtskar-Diy-Gəd-Bay & biy gwala \\
\hline 118 & Faisam & 70 & 04/10/1988 & Mtskar-Diy-Gəd-Bay & Wula-Sakon \\
\hline 119 & Faisam & 70 & $06 / 10 / 1988$ & Mtskar-Diy-Gəd-Bay & bull festival \\
\hline 120 & Jikdaye & 25 & $23 / 05 / 1985$ & Mafmay & magic stones \\
\hline 121 & Mbere & 60 & $27 / 05 / 1985$ & Mafmay-Ziver & Zhwé blacksmiths \\
\hline 122 & Meje & 55 & $28 / 05 / 1985$ & Mafmay-Ziver & iron technology \\
\hline 123 & Kofulengwiy & $(?)$ & $29 / 05 / 1985$ & Mafmay-Ziver & iron technology \\
\hline 124 & Jikdaye & 25 & $30 / 05 / 1985$ & Gouzda-Gura & cultural vocabulary \\
\hline 125 & Yagay & 70 & $02 / 10 / 1985$ & Mafmay-Zernday & Zlagam of Mafmay \\
\hline 126 & elder & $(?)$ & $24 / 10 / 1985$ & Mafmay-Ngaruwa & myths and legends \\
\hline 127 & Yagay & 70 & 03/06/1986 & Mafmay-Zernday & harvest festival \\
\hline 128 & Telkoslem & 60 & $01 / 11 / 1986$ & Mafmay-Zagay & biy gwala \\
\hline 129 & elder & $(?)$ & $28 / 11 / 1986$ & Mafmay-Ngaruwa & ritual relationships \\
\hline 130 & elder & $(?)$ & $30 / 11 / 1986$ & Mafmay-Ngaruwa & settlement terms \\
\hline 131 & older man & 60 & 29/12/1988 & Oupay & ritual relationships \\
\hline 132 & elder & $(?)$ & $10 / 01 / 1989$ & Ziver & ritual relationships \\
\hline 133 & Bava & $(?)$ & $02 / 06 / 1985$ & Zlama & ritual relationships \\
\hline 134 & Magaliy & 60 & $25 / 10 / 1988$ & Zlama & the Zlama caves \\
\hline 135 & Wandala & 70 & $19 / 02 / 1987$ & Tourou & the Hide \\
\hline 136 & biy Moskota & 55 & $15 / 11 / 1988$ & Moskota-Vərdeké & Gudur tradition \\
\hline 137 & biy Moskota & 55 & $06 / 12 / 1988$ & Moskota-Vərdeké & local terms \\
\hline 138 & biy Moskota & 55 & $06 / 12 / 1988$ & Moskota-Vərdeké & role of biy vardeké \\
\hline 139 & elder & 70 & $07 / 12 / 1988$ & Moskota-Vərdeké & Journey to Gudur \\
\hline 140 & elder & 65 & $15 / 02 / 1989$ & Mouhour & ritual relationships \\
\hline
\end{tabular}




\section{Plates}
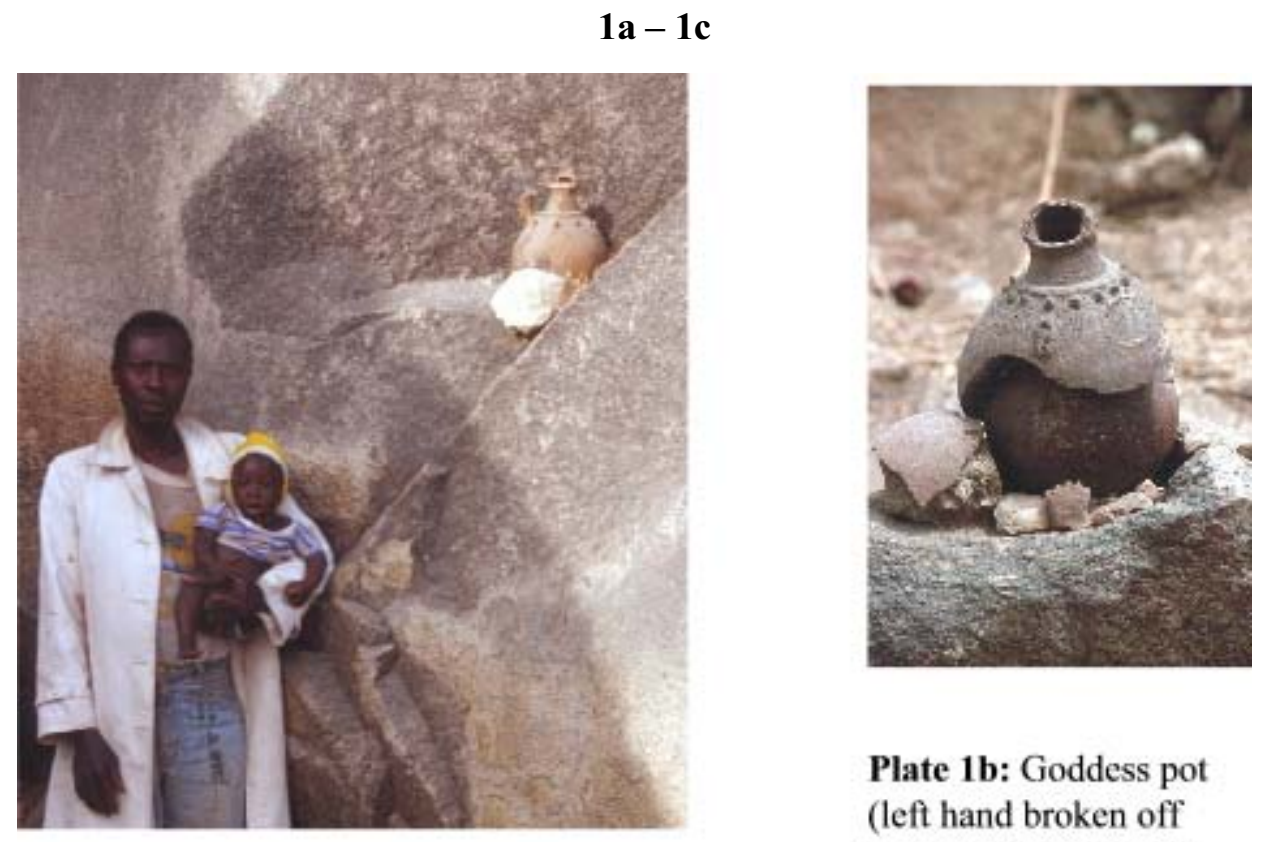

Plate 1b: Goddess pot (left hand broken off and placed separately at foot of pot).

Plate 1a: Father with pot of his god. The pot has male sex characteristics and a right arm stretching upwards.

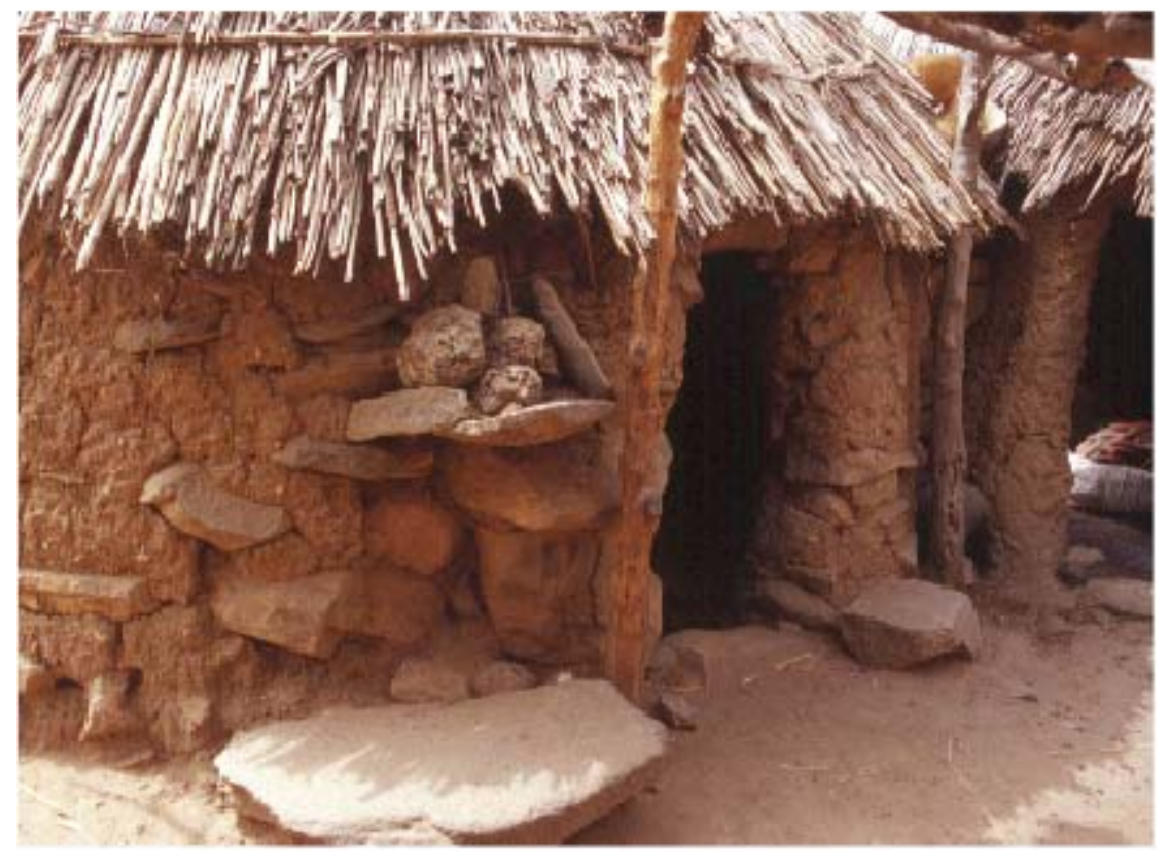

Plate 1c: House god consisting of round (female) and longish (male) stones. 
$\mathbf{2 a}-\mathbf{2 b}$

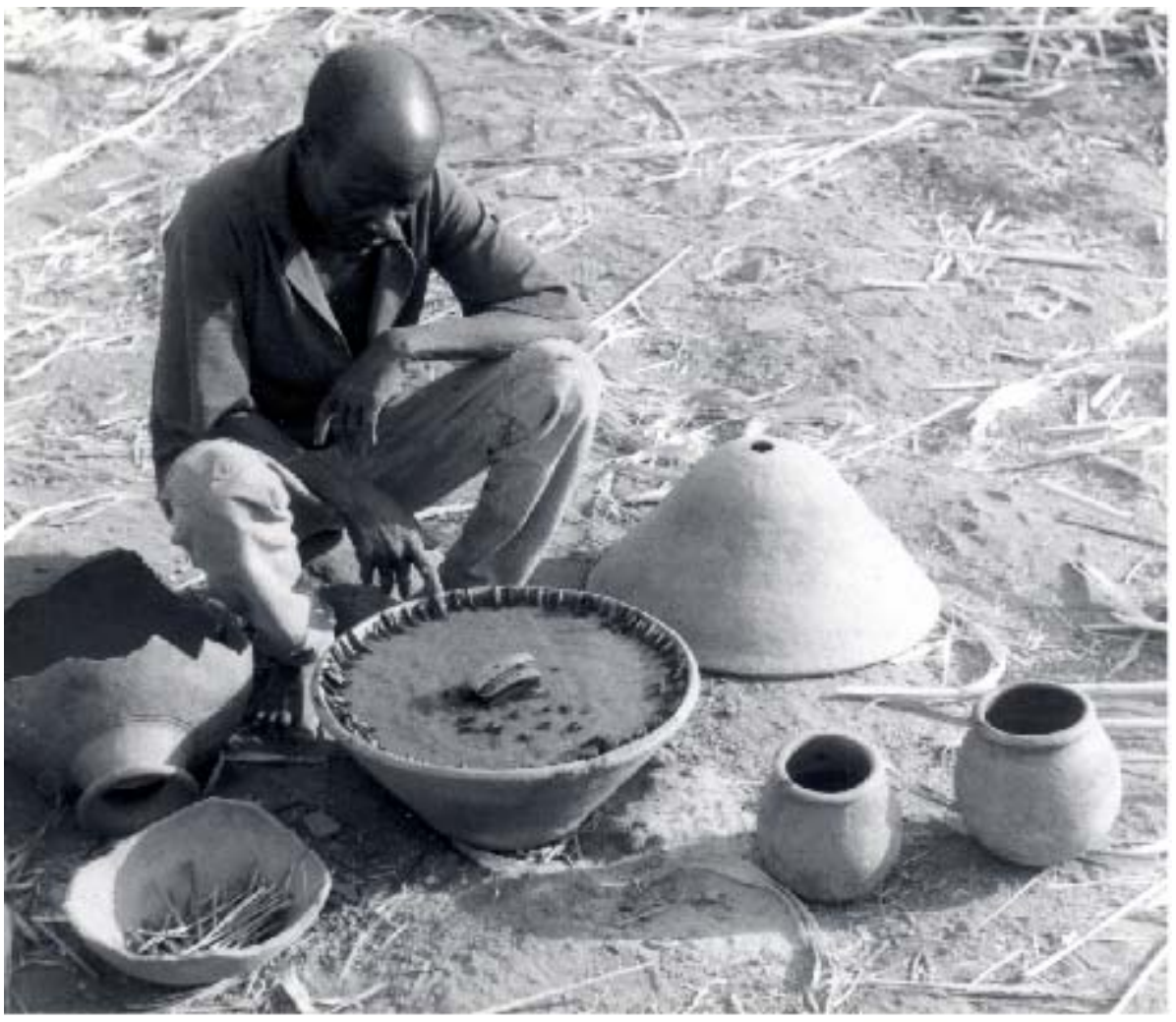

Plate 2a: Diviner in front of arranged divination bowl.

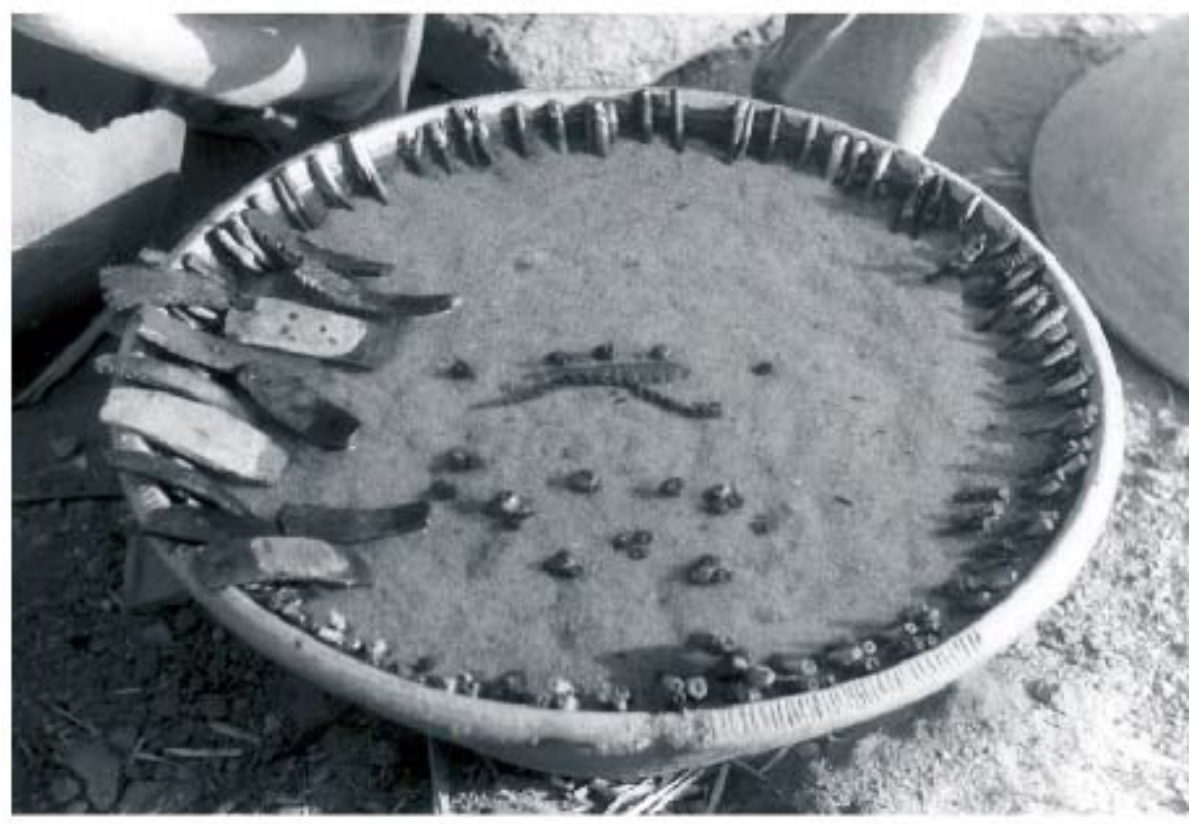

Plate 2b: Contents of divination bowl before it is arranged, before they are positioned. 
$\mathbf{3 a}-\mathbf{3 b}$

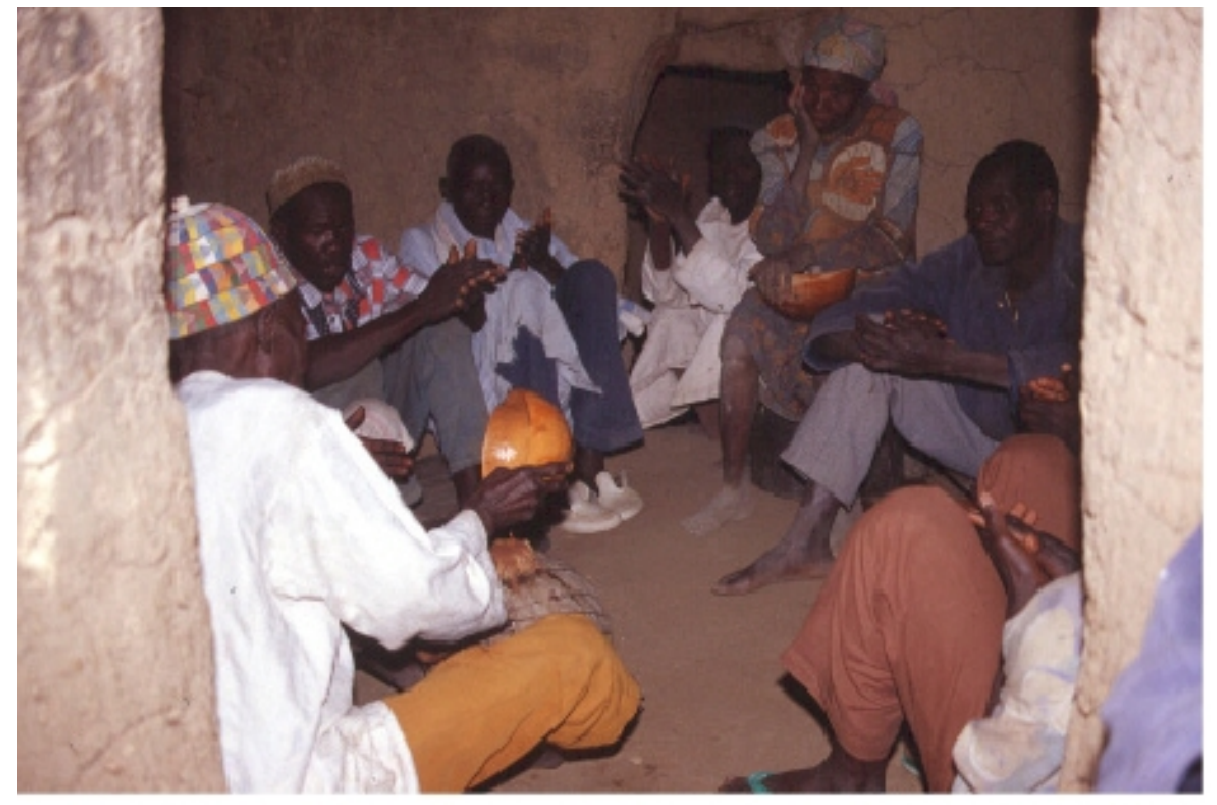

Plate 3a: Family head libates sorghum beer to the baba pot.

Plate 3b: Family head balances calabash on the baba pot.

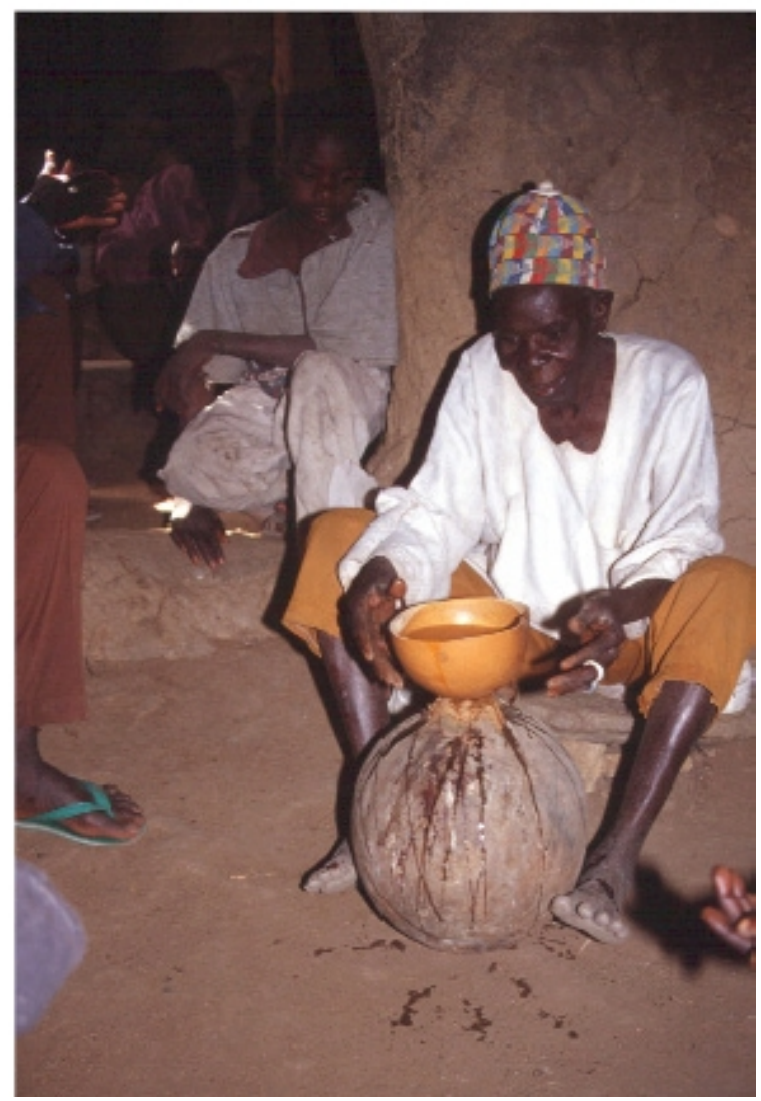




$$
3 c-3 d
$$

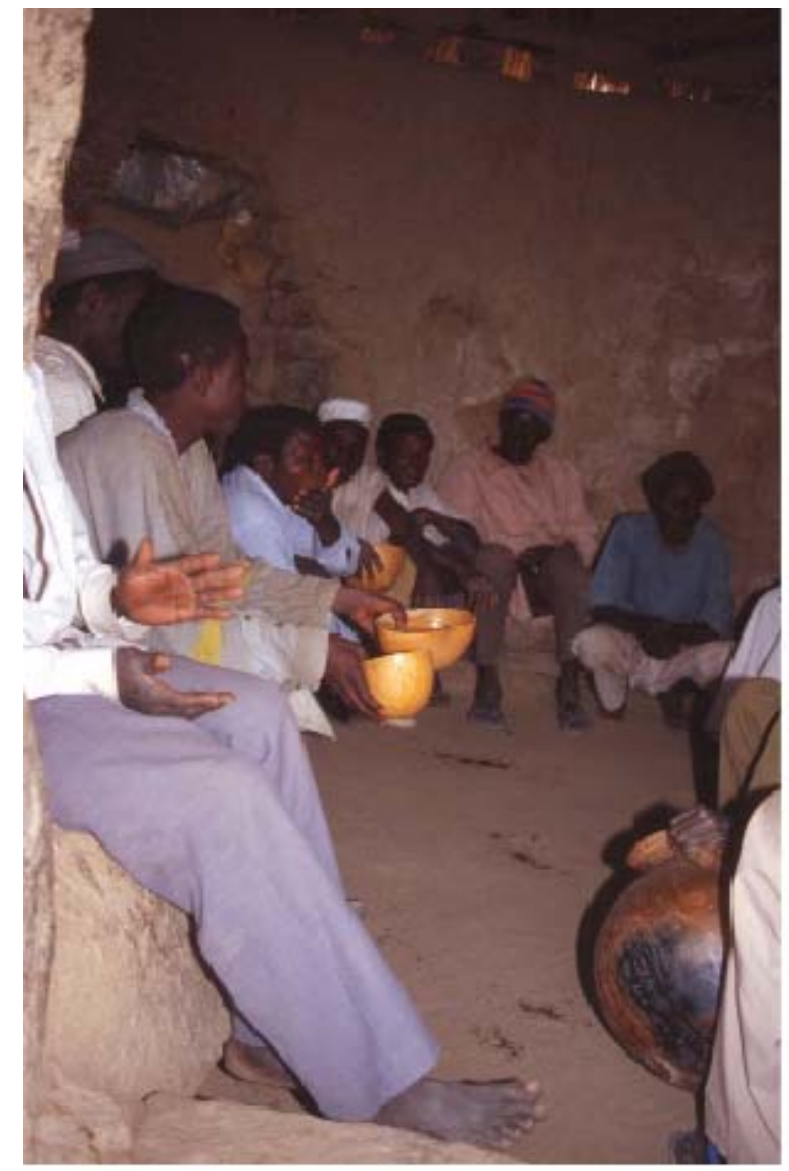

Plate 3c: Calabash with baba beer for bay given with the left hand.

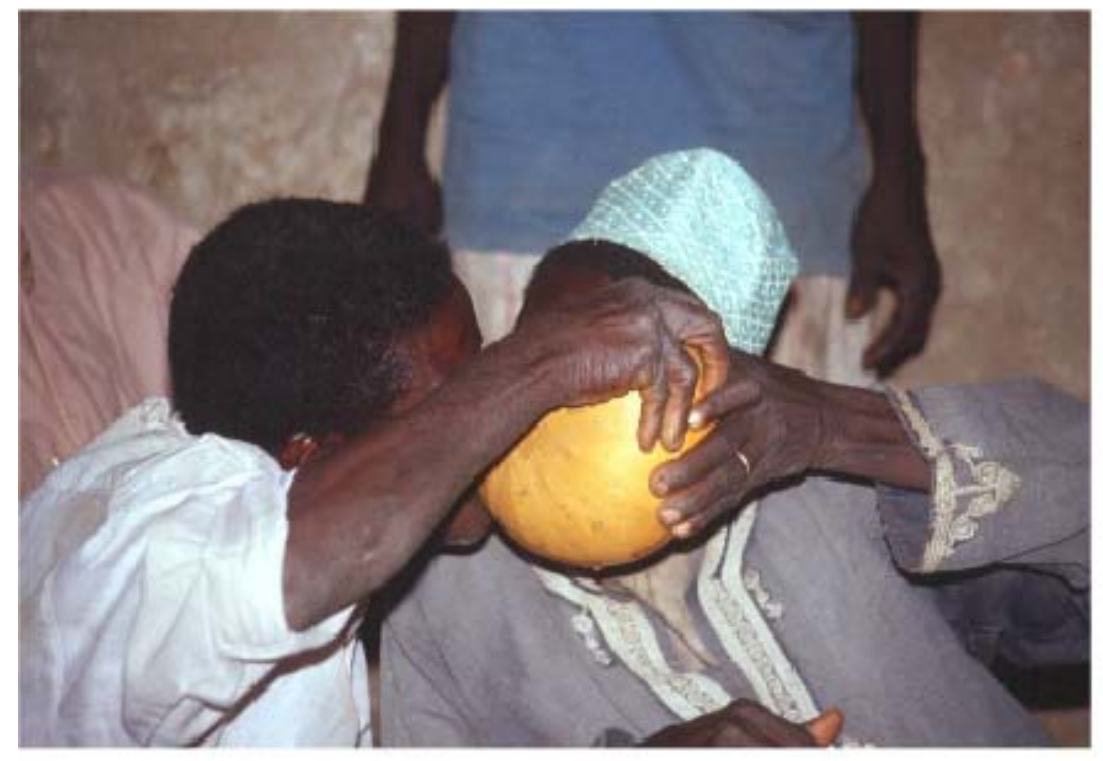

Plate 3d: $B a b a$ beer is consumed in pairs. 
$3 e-3 f$

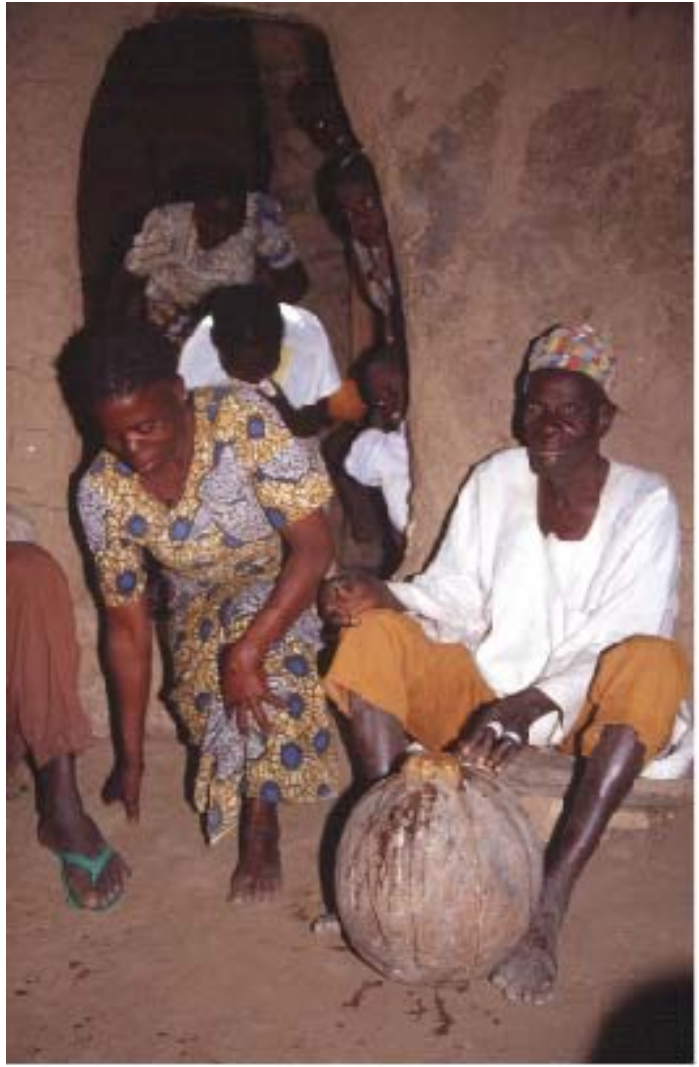

Plate 3e: Women entering the house to attend baba ceremony.

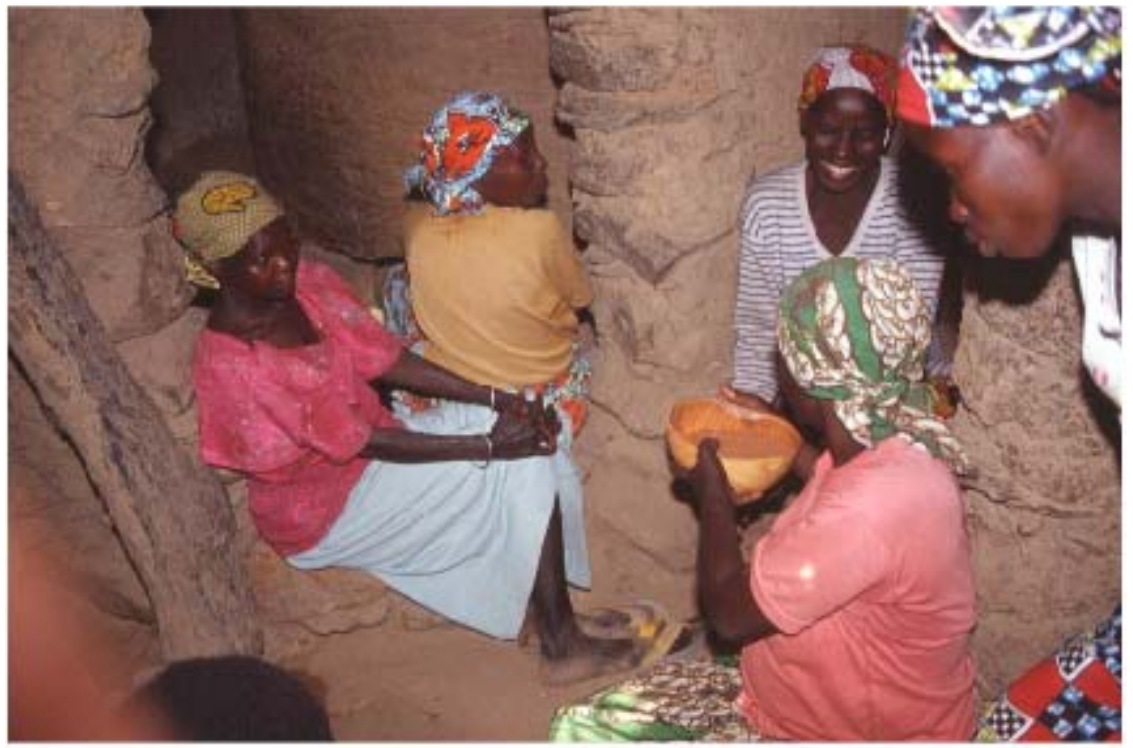

Plate 3f: Women sharing baba beer. 
$3 g-3 h$

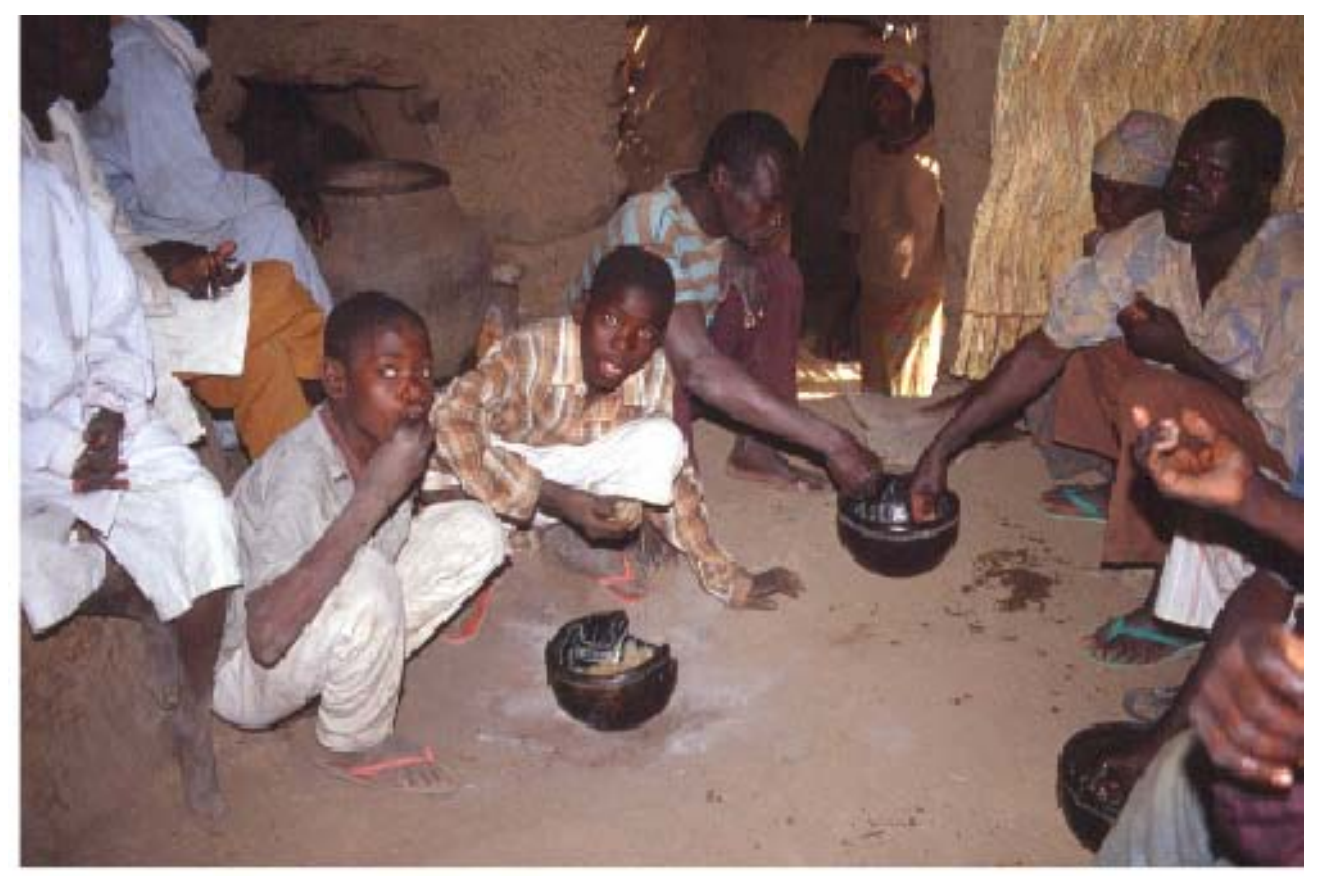

Plate 3g: Communal meal during baba ceremony.

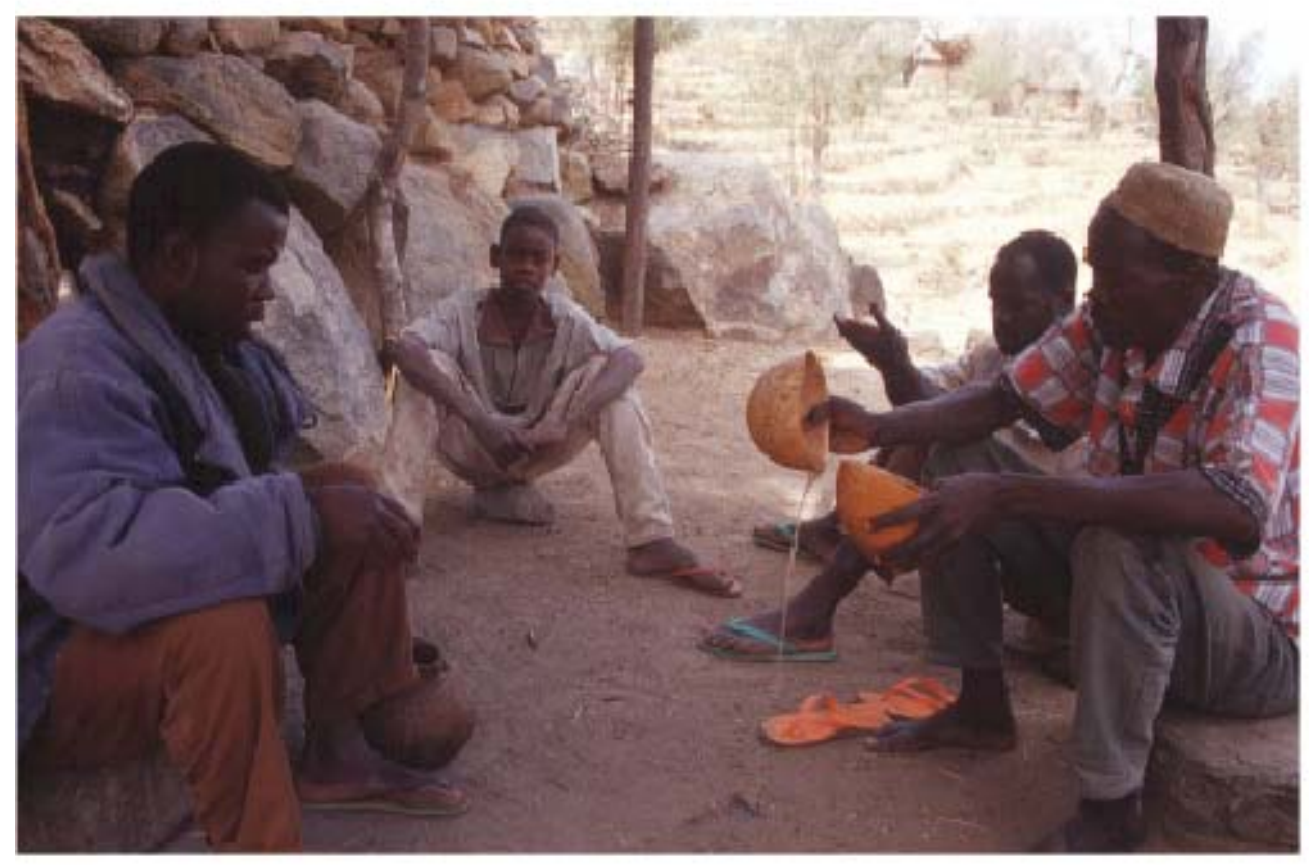

Plate 3h: Beer libation to var ma gay (front courtyard). 


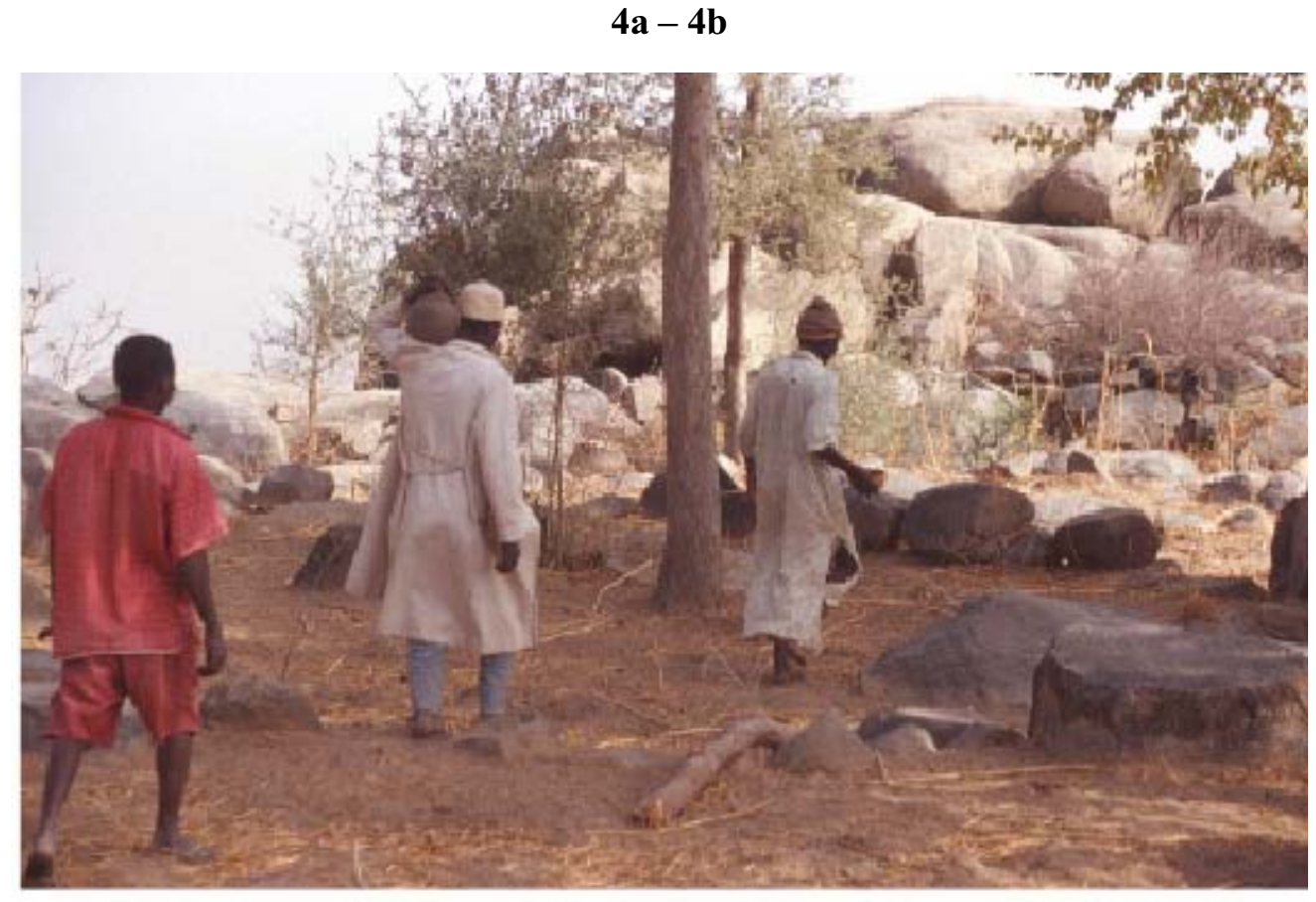

Plate 4a: Biy dza and his helpers on their way to perform a community sacrifice.

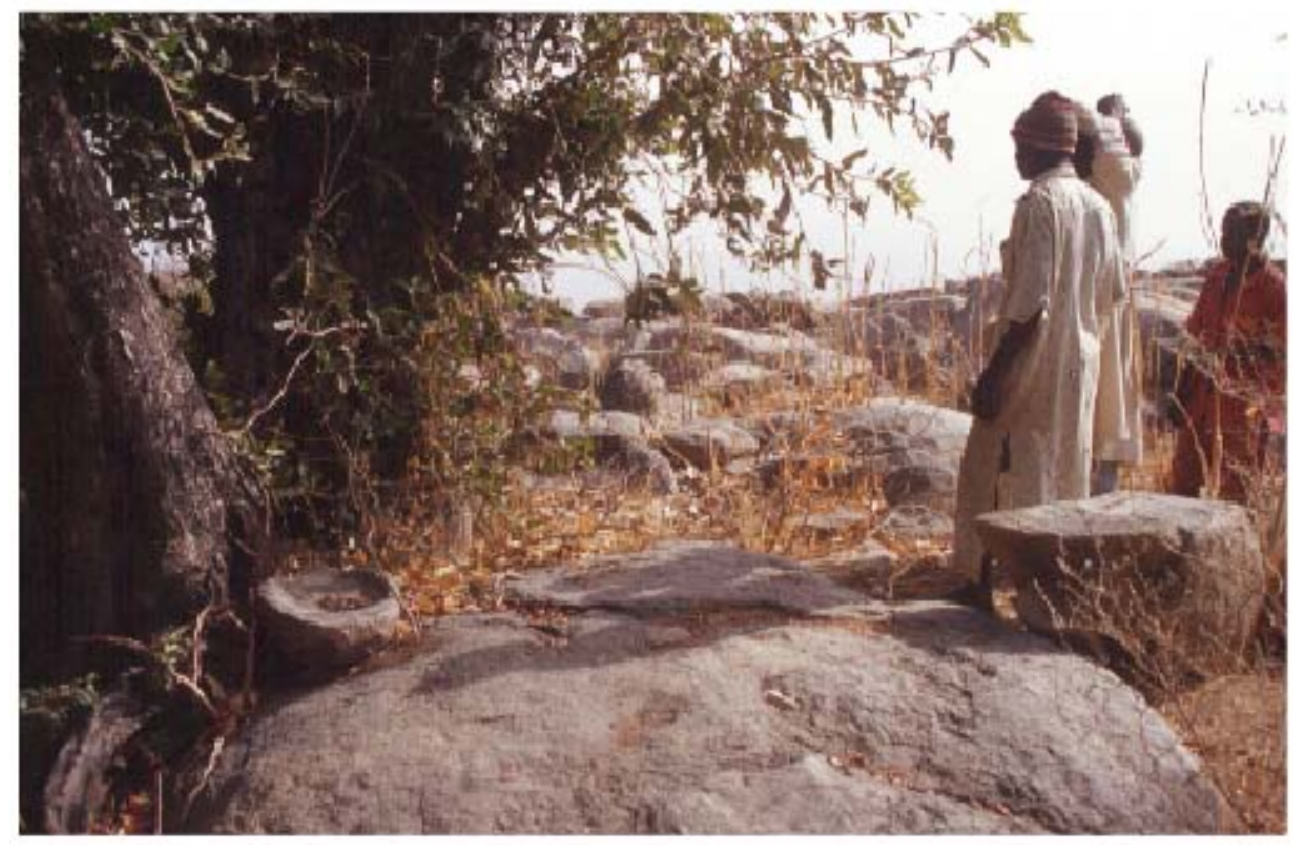

Plate 4b: Biy dza arrives with his helpers in front of diy mbulom. 
$4 c-4 d$

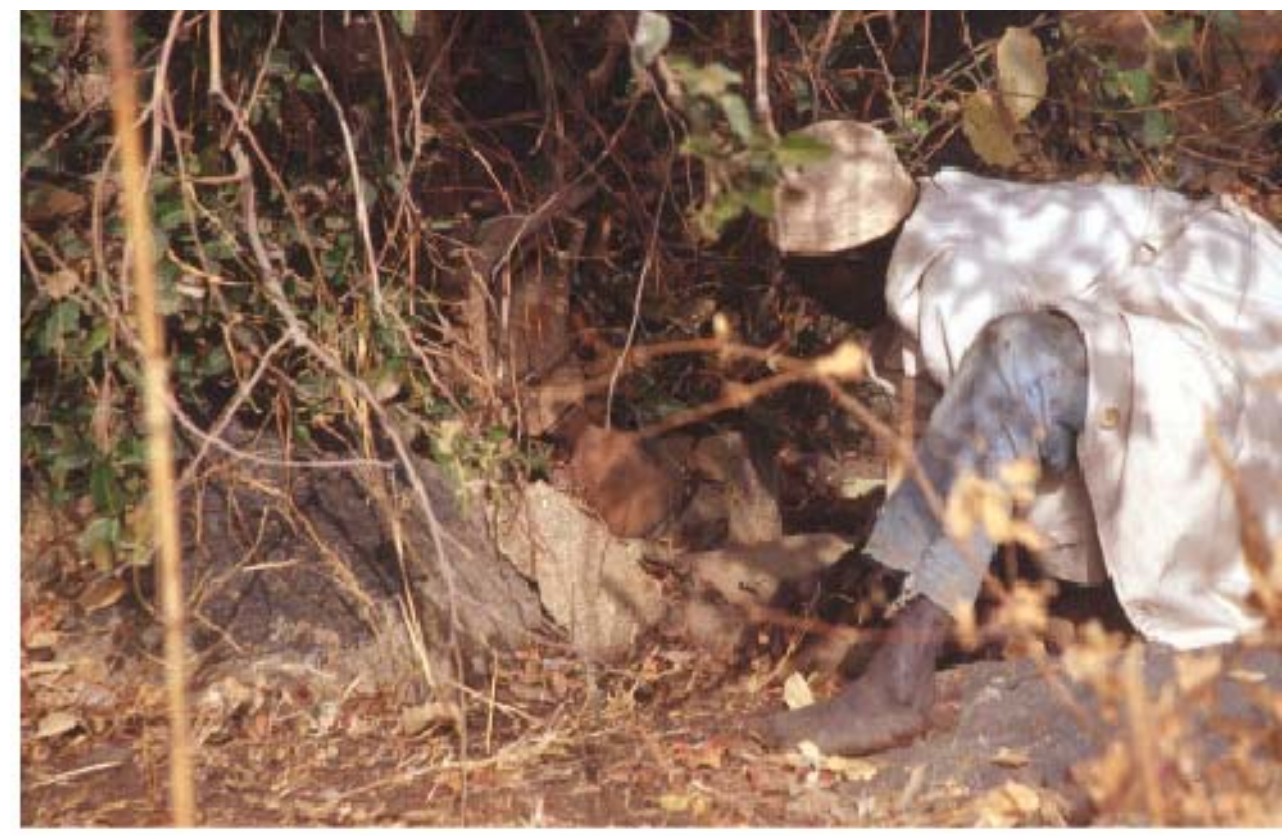

Plate 4e: Biy dza takes diy wof (lineage ancestor pot) out of diy mbulom.

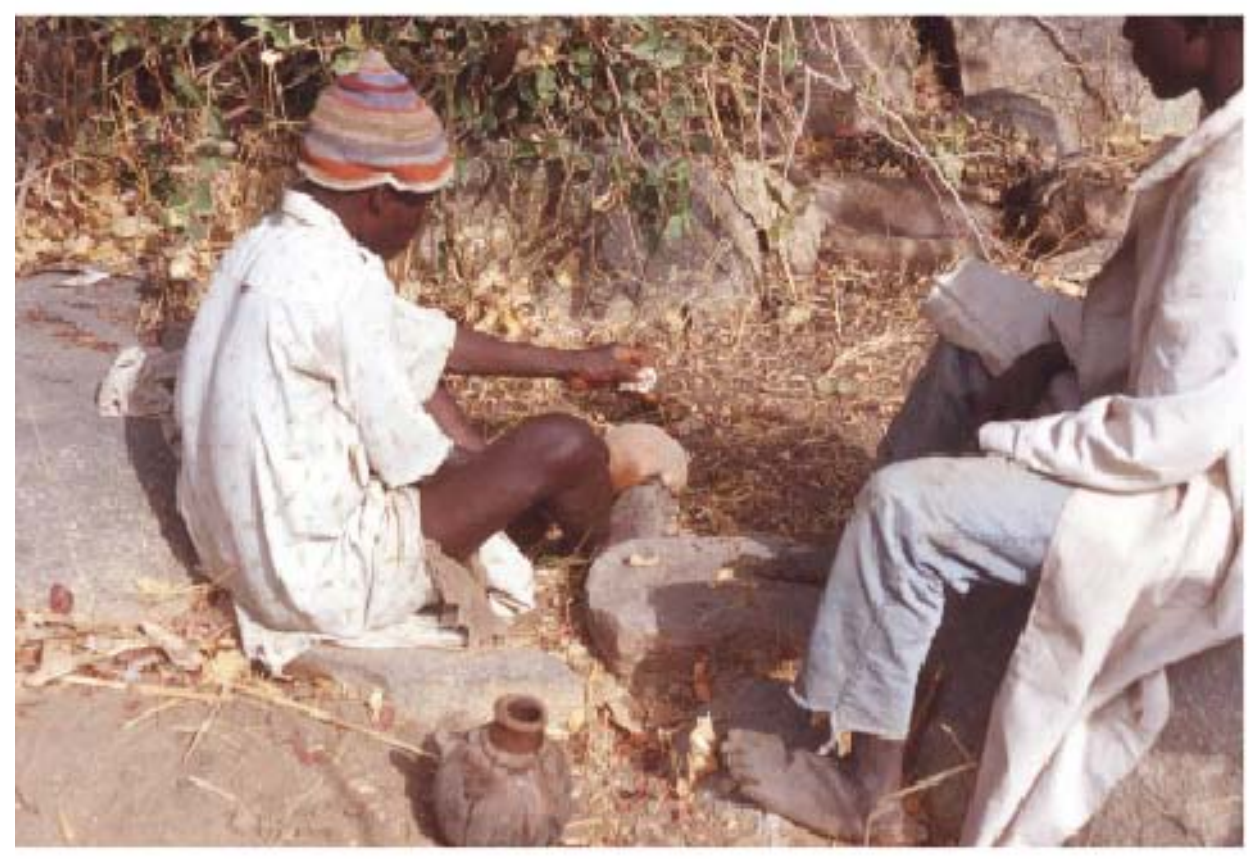

Plate 4d: The lineage of biy dza is in the position of bay, therefore he offers natron to his lineage ancestor (represented by diy wof) by using his left hand . 


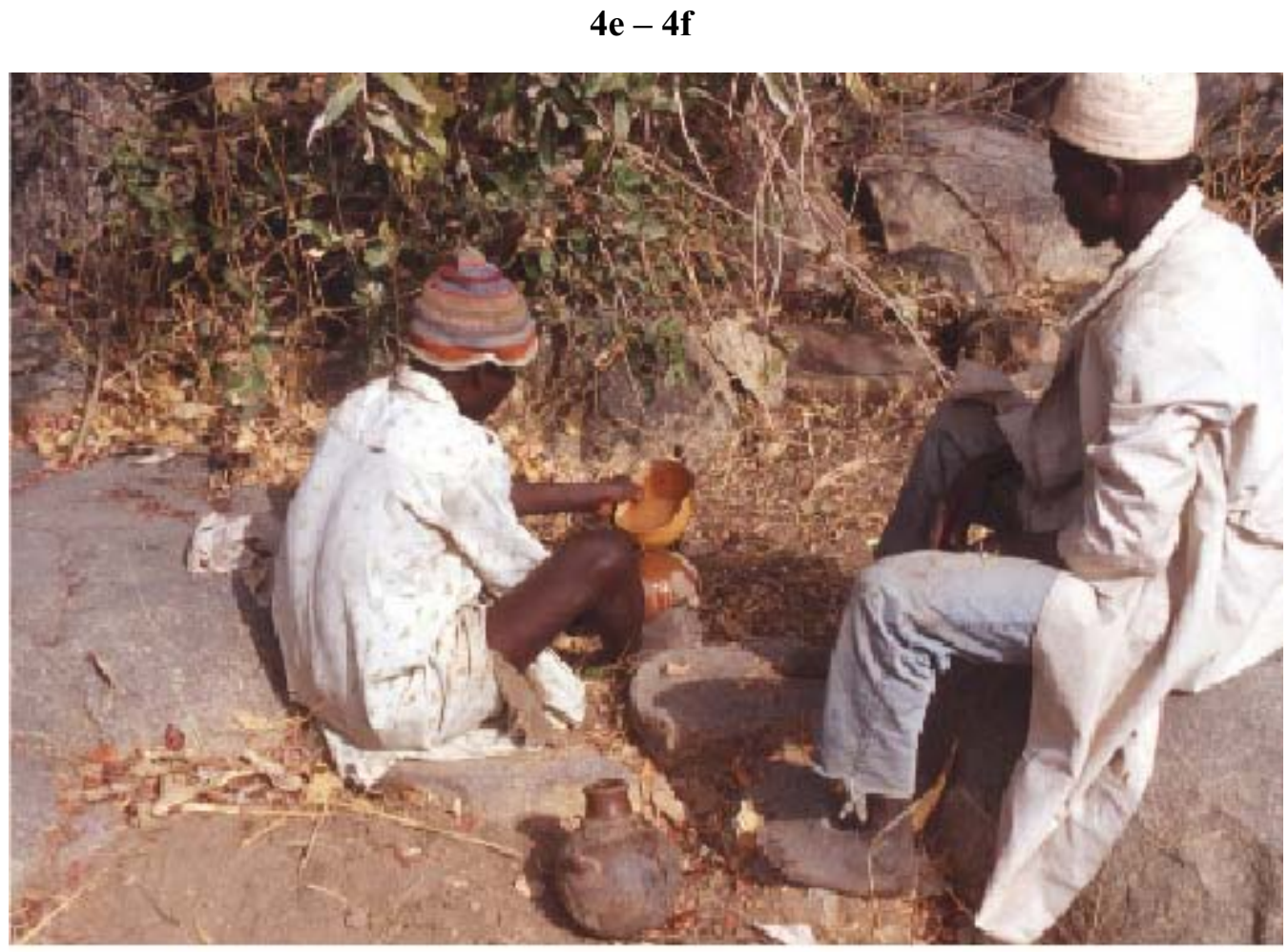

Plate 4e: The lineage of biy dza is in the position of bay, therefore he offers zom to his lineage ancestor (represented by diy wof) by using his left hand.

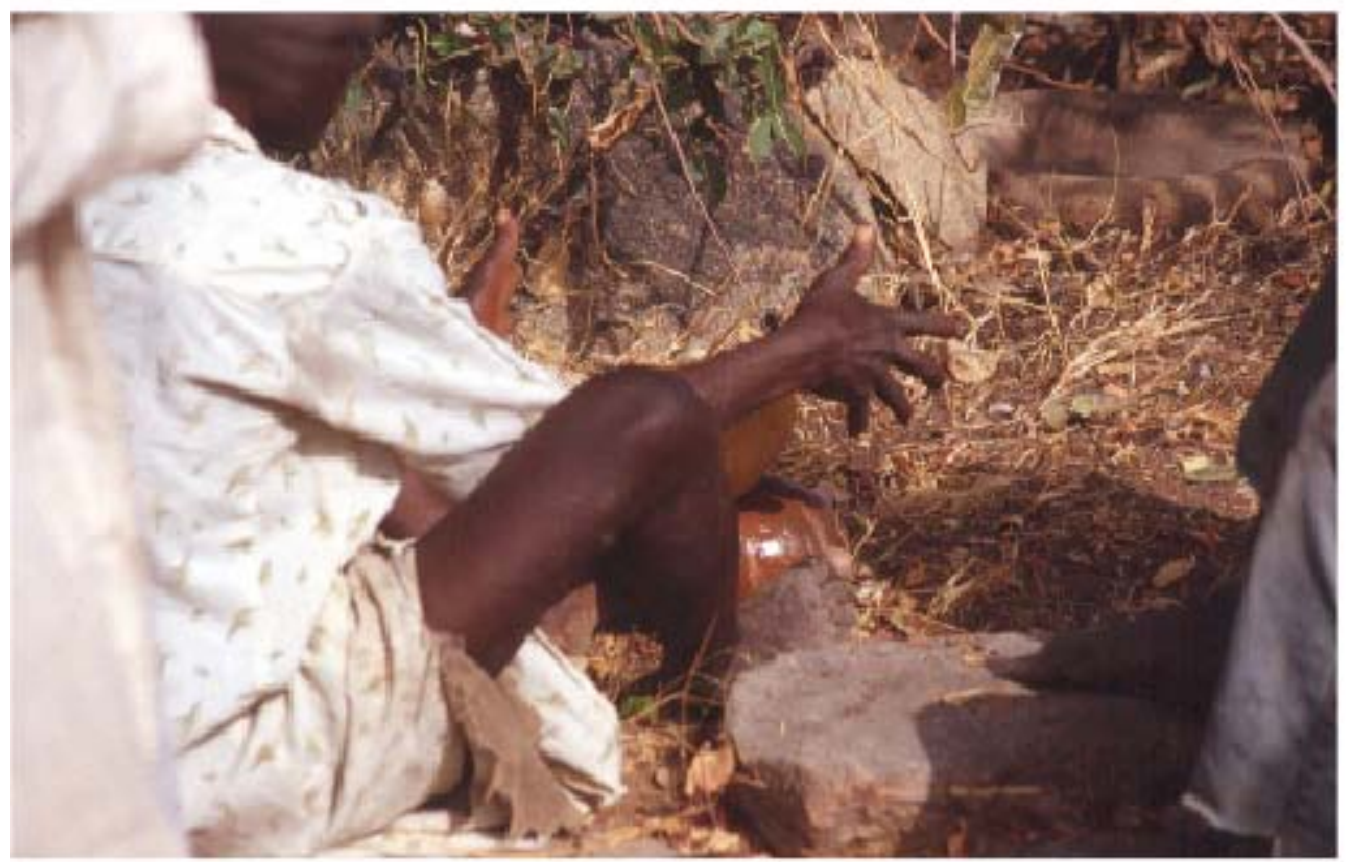

Plate 4f: Biy dza balances the calabash on back of lineage ancestor pot (diy wof). 


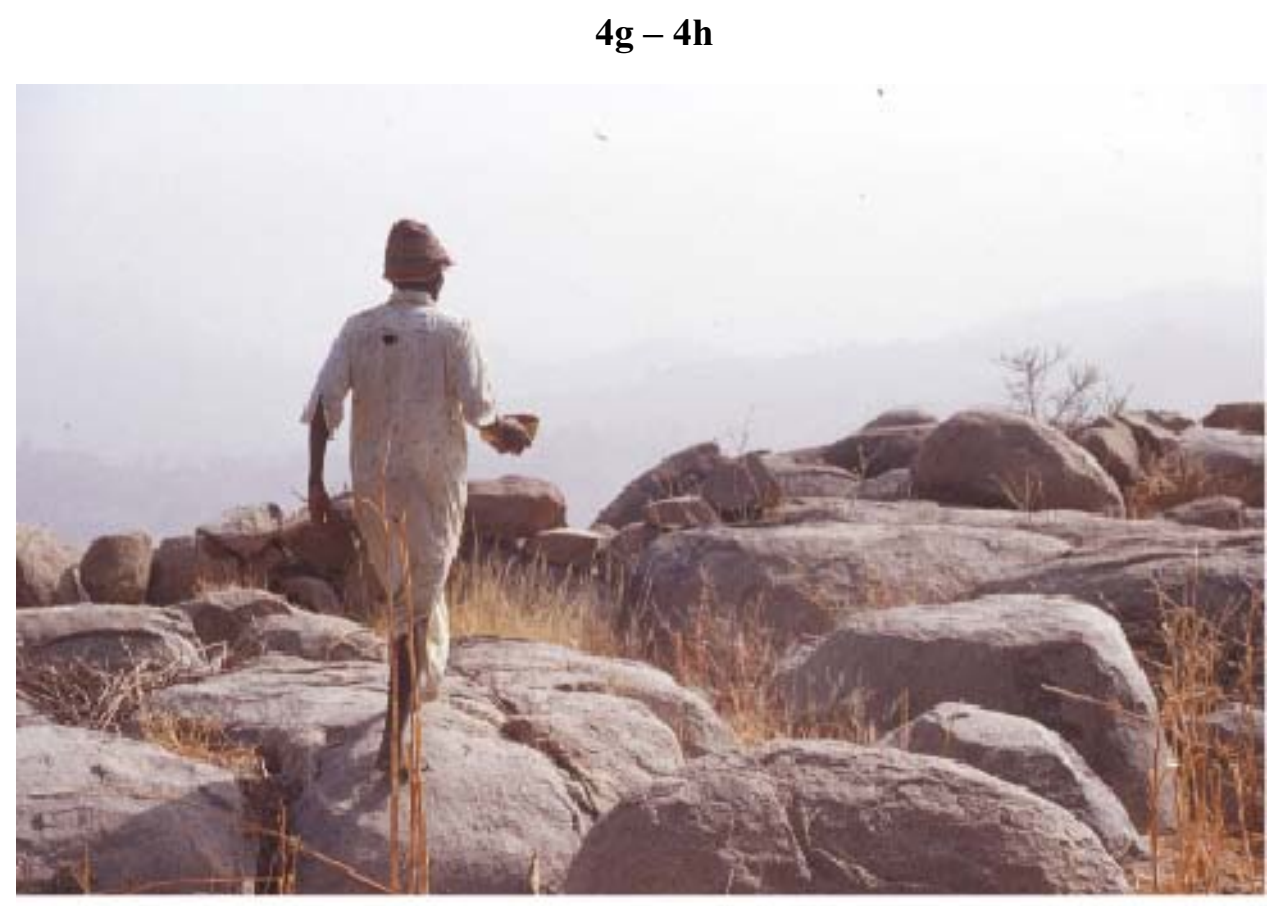

Plate 4g: Biy dza with calabash of zom on his way to sacred rock of Zlama.

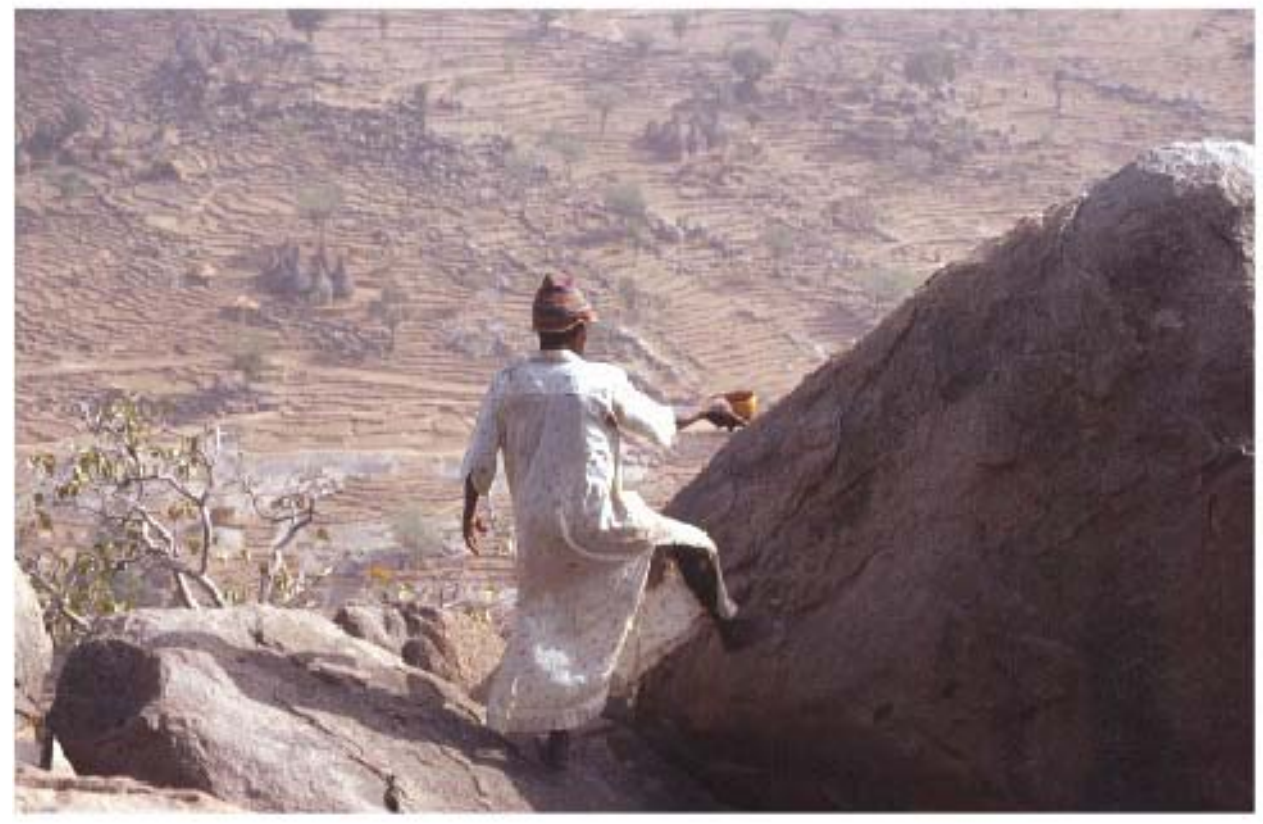

Plate 4h: Biy dza performs a beer libation at the main sacred rock of the community of Zlama (overlooking Gouzda). He now uses his right hand since his clan group, in this ritual context, only represents the former chiefly clan of Zlama. 
$\mathbf{5 a}-\mathbf{5 b}$

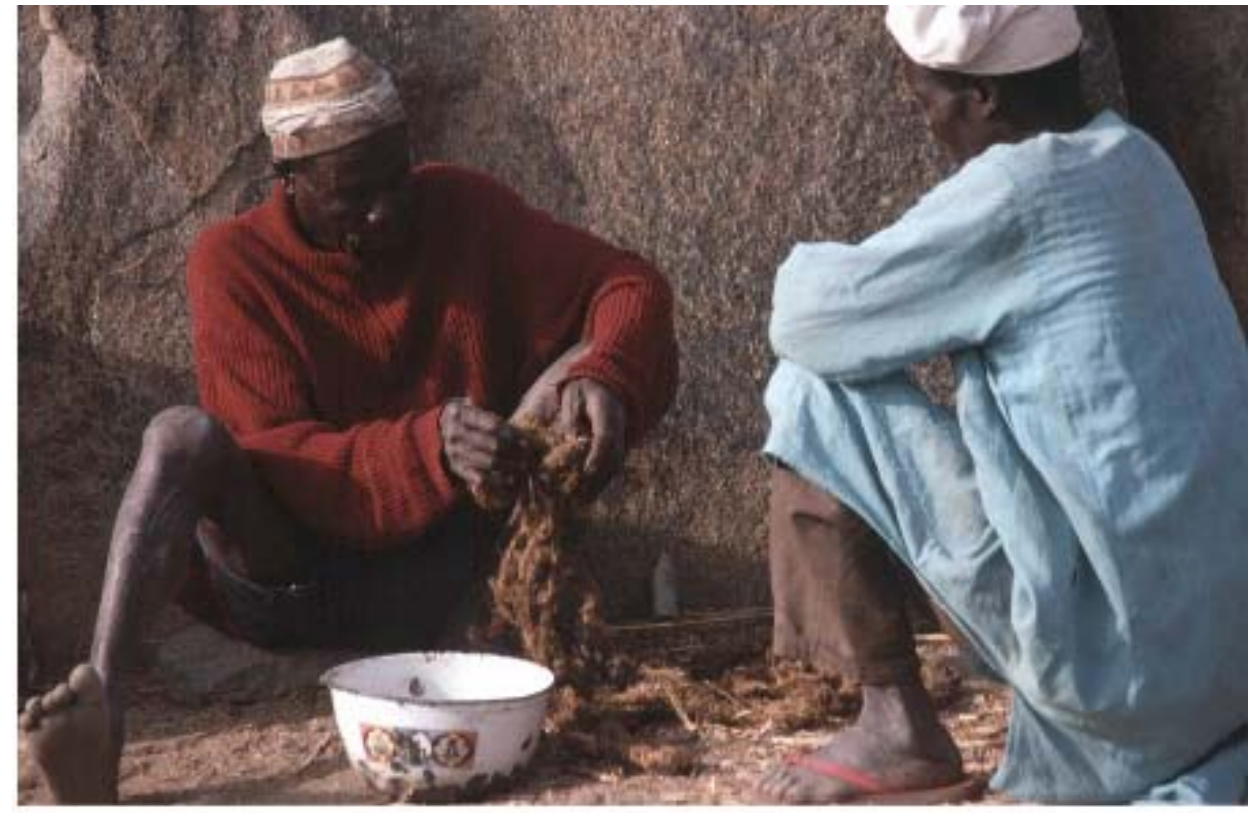

Plate 5a: New village chief (biy wudam) takes some fibre from a piece of sacred rope of the previous village chief.

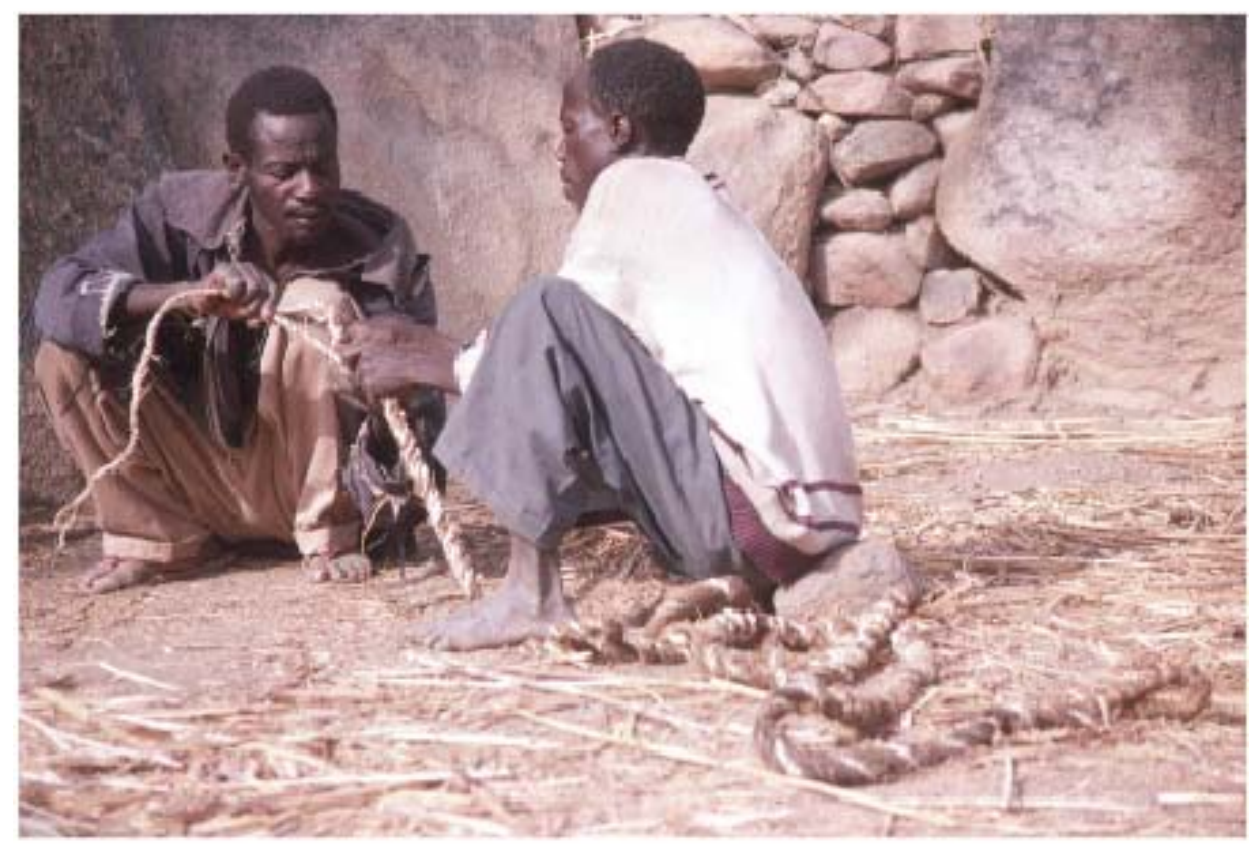

Plate 5b: Strings of fibre are being intertwined to make a new sacred rope. 


$$
5 c-5 d
$$

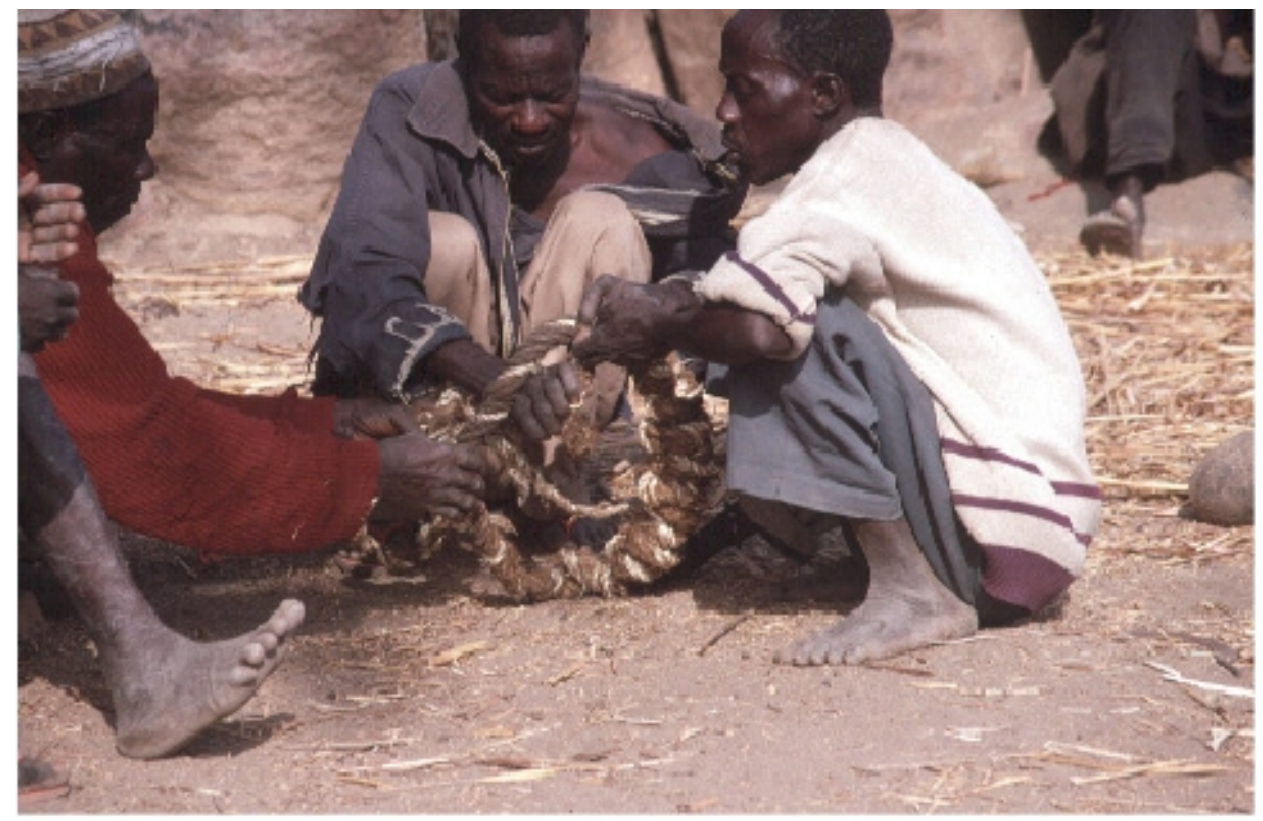

Plate 5c: New sacred rope being curled up for the first time.

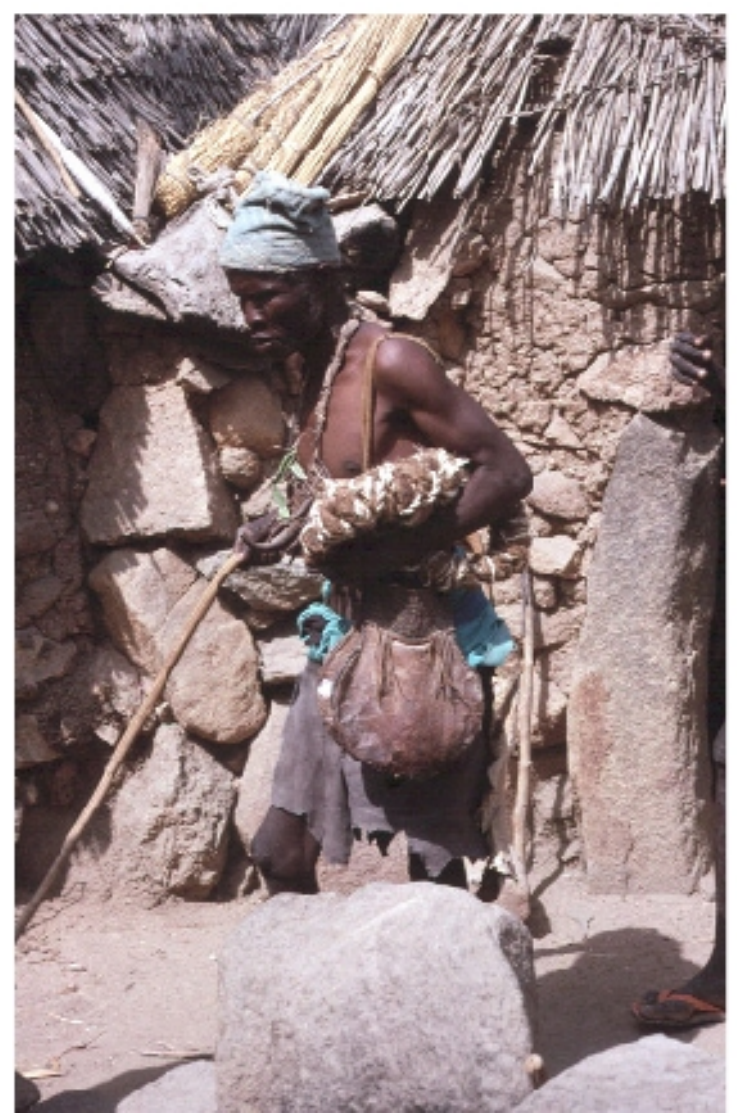

Plate 5d: New chiefly biy gwala carries new rope for the first time. 


\section{$5 e-5 f$}

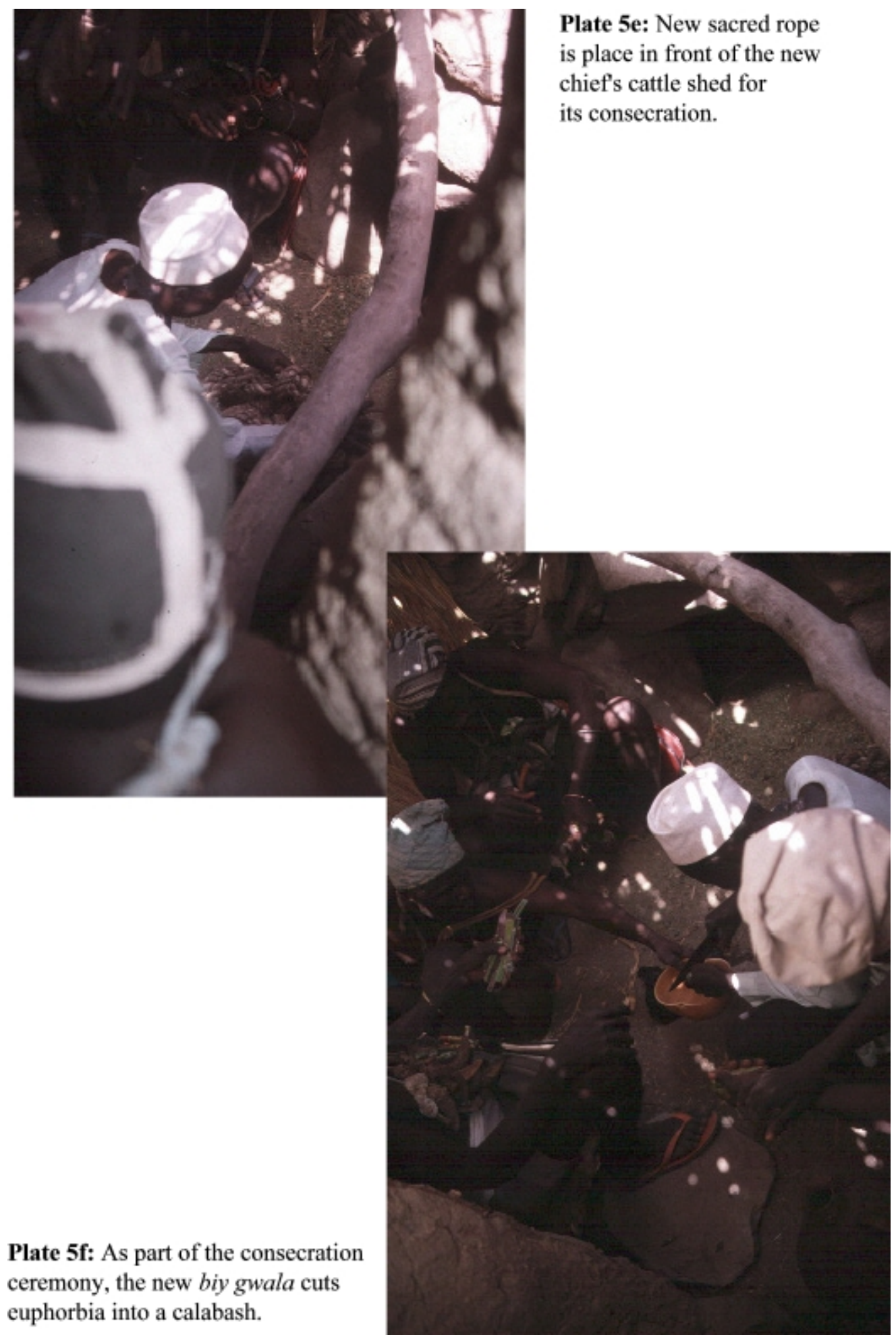


$5 g-5 h$

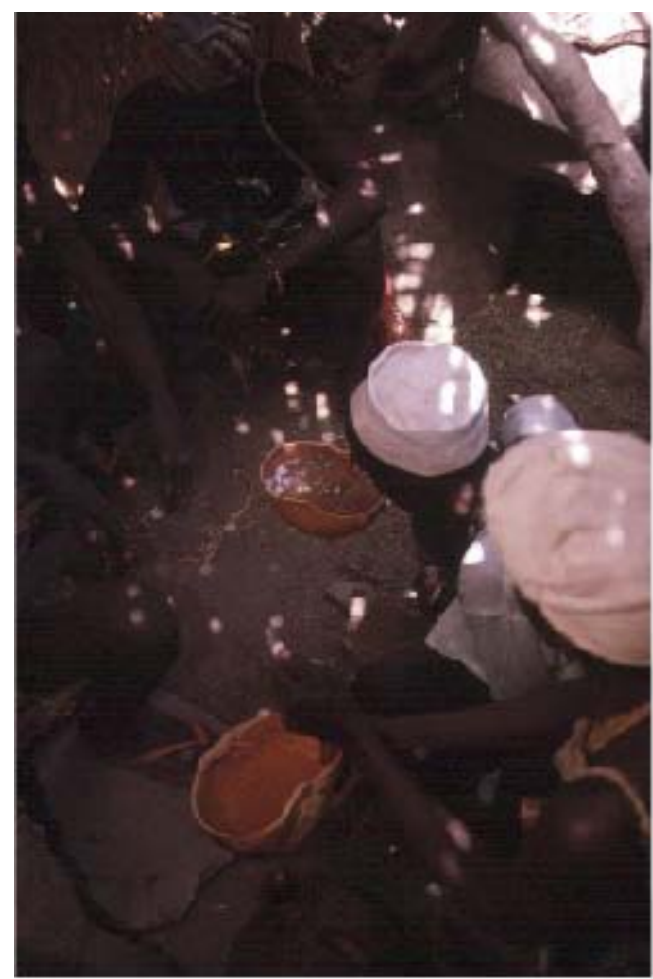

Plate 5g: New biy gwala consumes sorghum beer with euphorbia pieces inside.

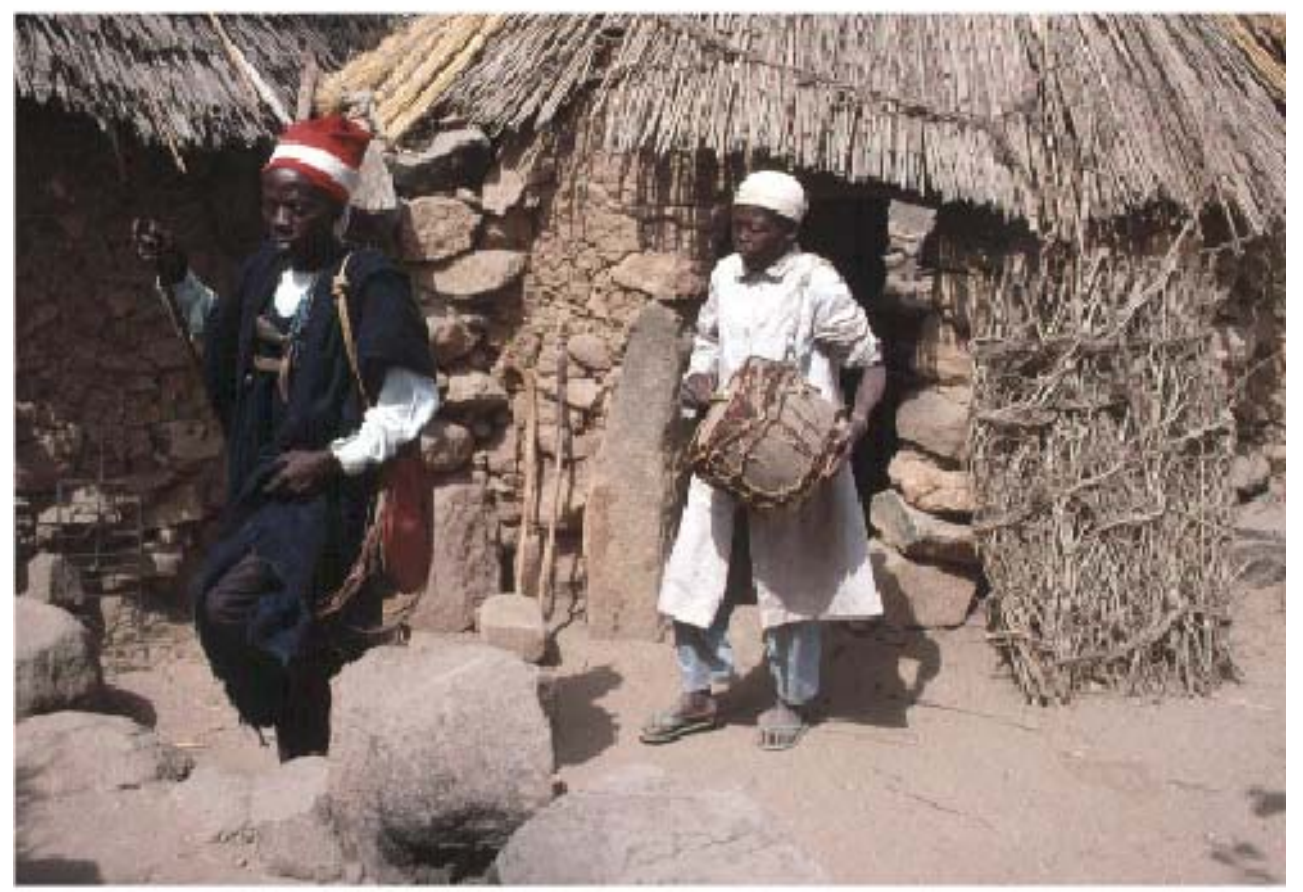

Plate 5h: First gad bay (deputy) of new village chief leaves the chief's house after he has been dressed inside for the first time. 


\section{$5 \mathbf{i}-\mathbf{5 j}$}

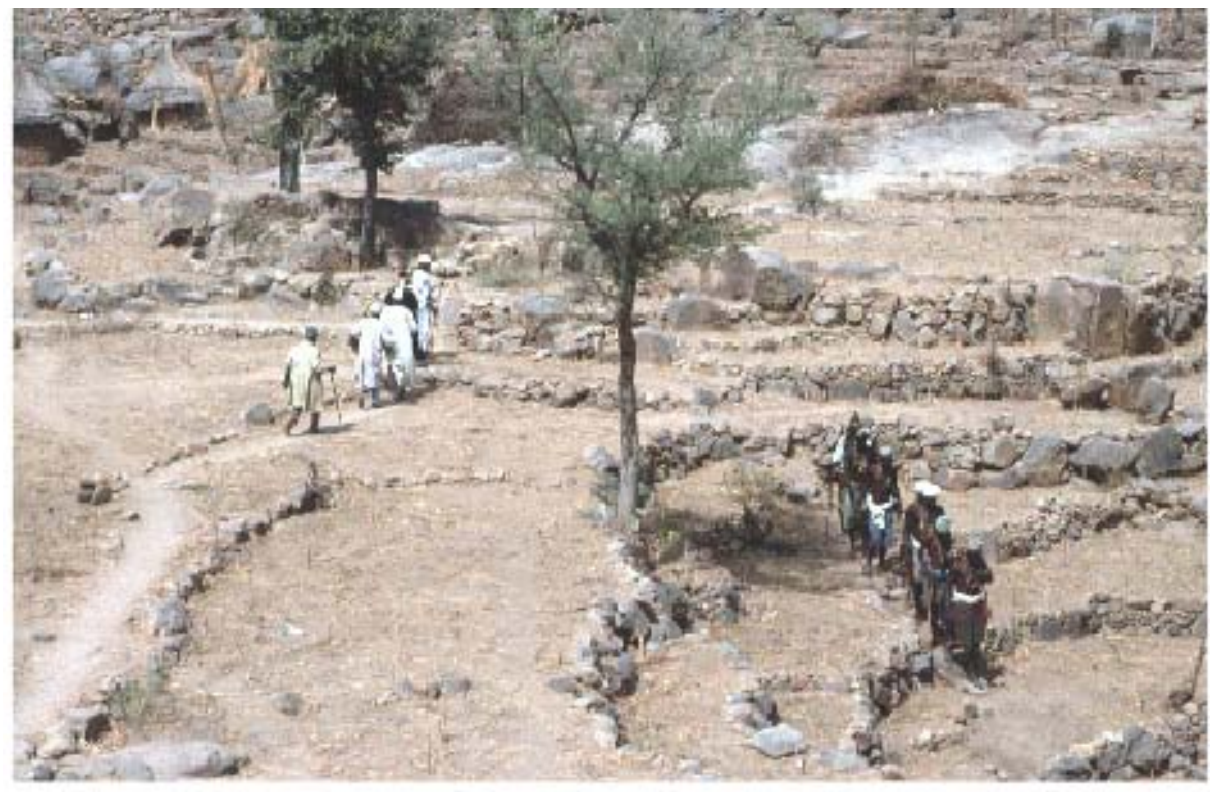

Plate 5i: Group of bay and biy gwala leave the chief's compound to attend the bull festival of Zlama.

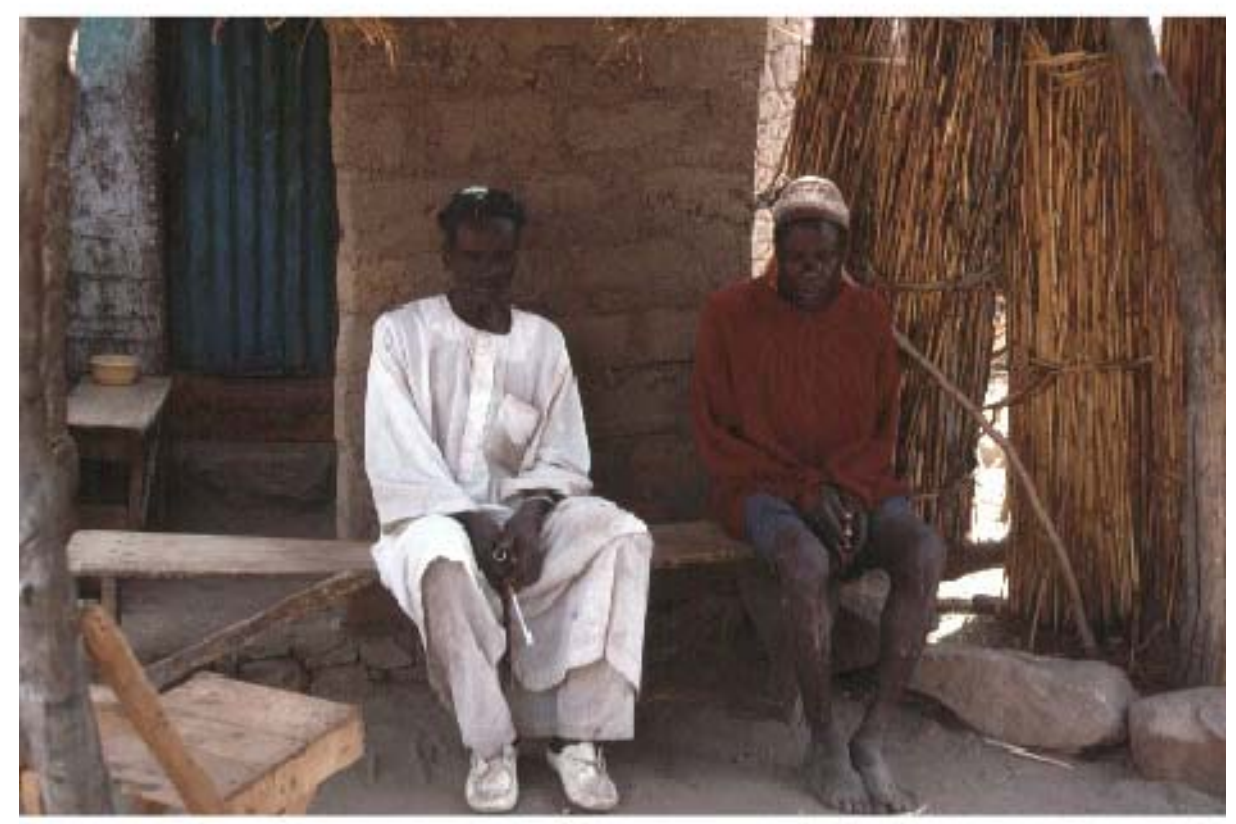

Plate 5j: The new village chief (biy wudam) of Zlama has to stay behind. His friend (in white dress) keeps him company. 


$$
6 a-6 b
$$

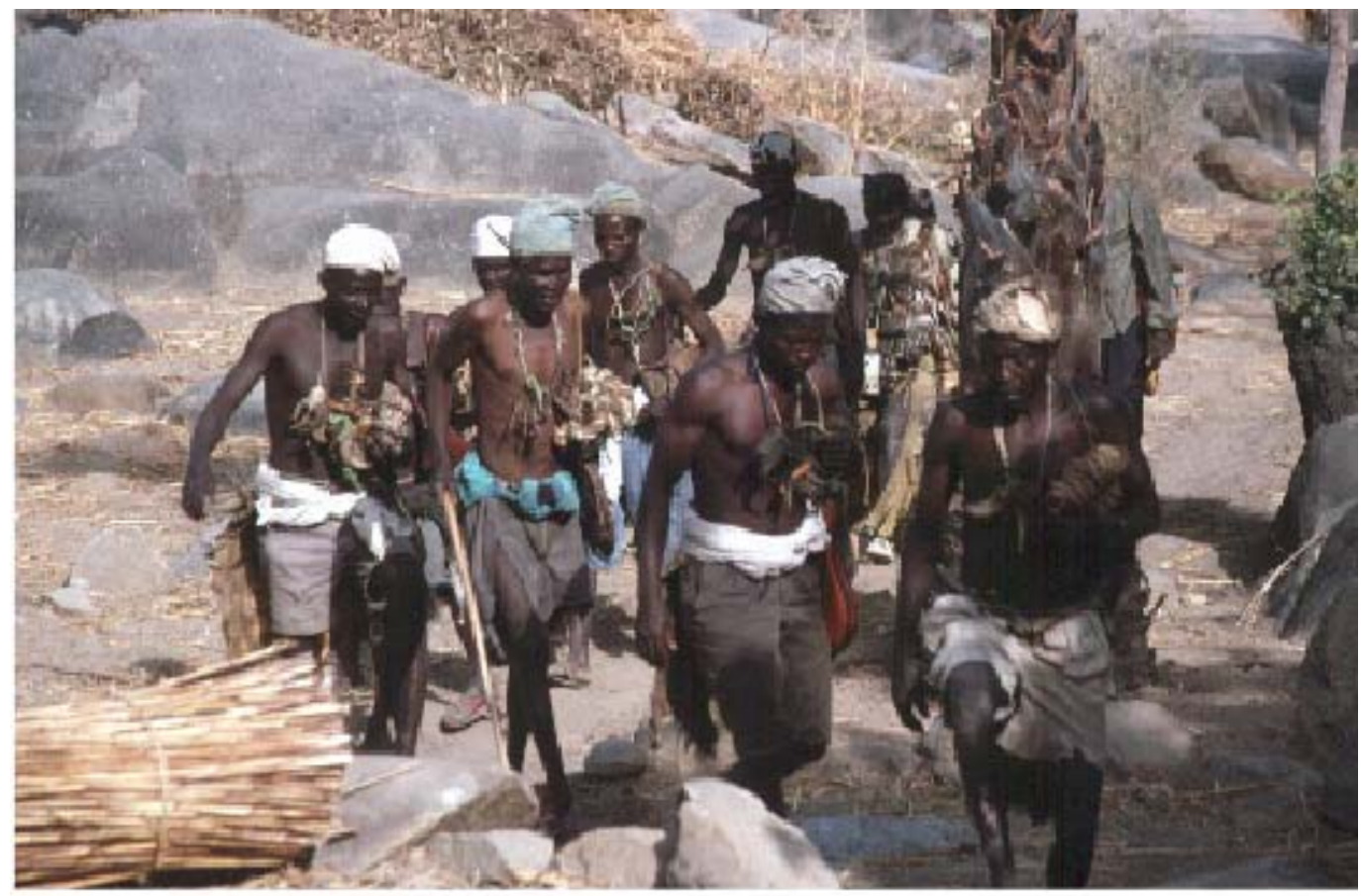

Plate 6a: Biy gwala arrive to liberate the first bull of the bull festival of Zlama.

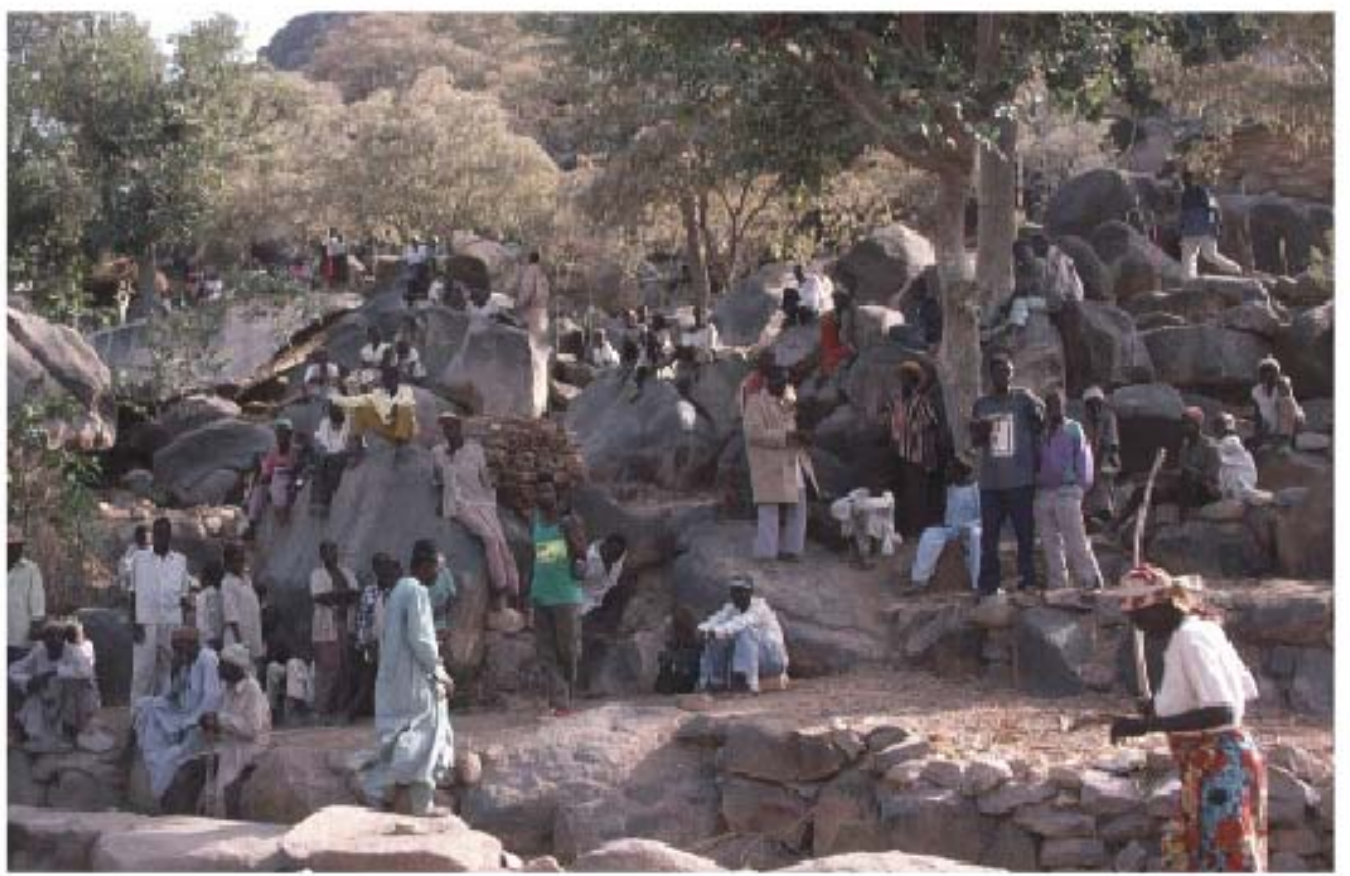

Plate 6b: Crowd awaiting the first bull to be released. 


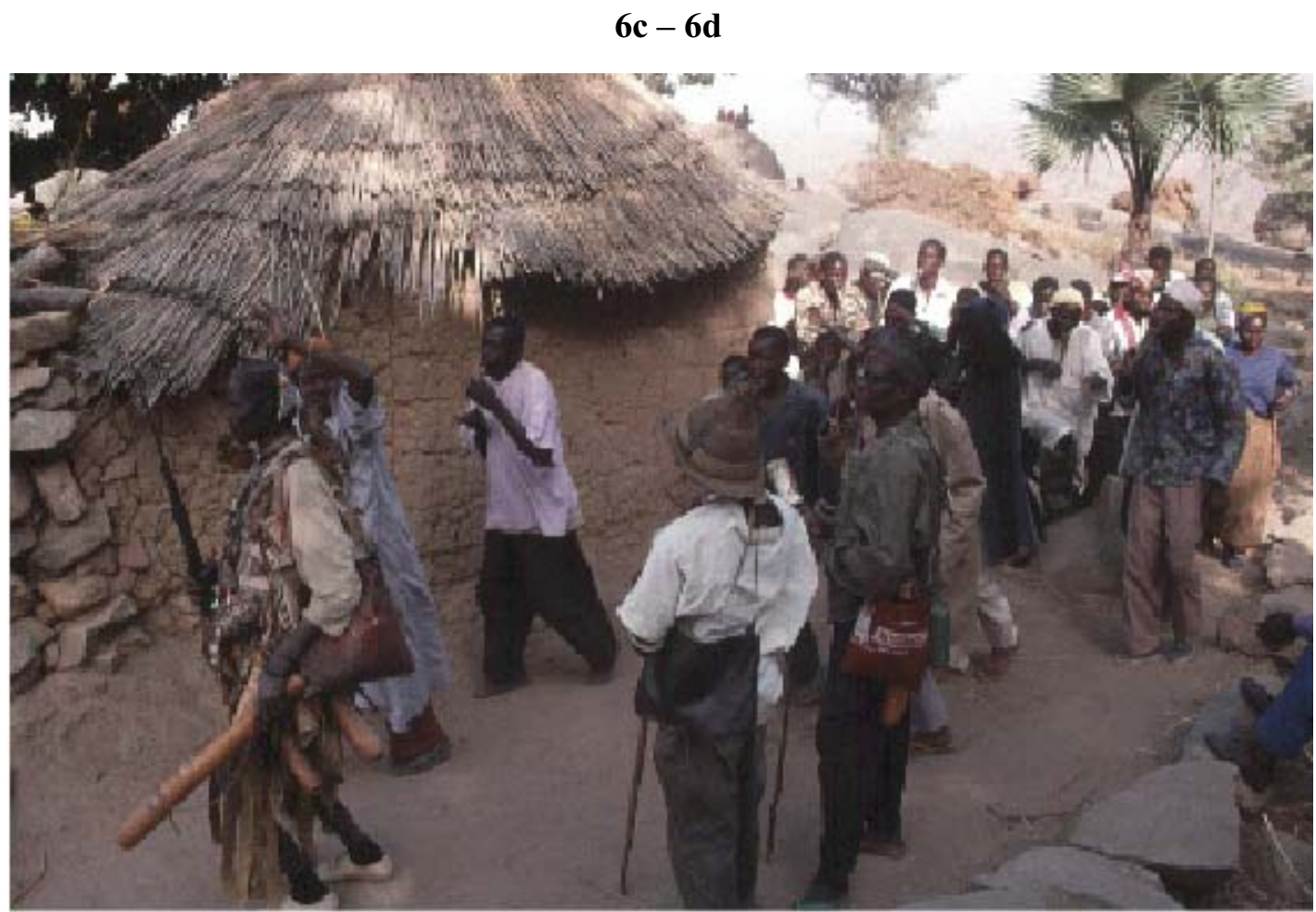

Plate 6e: Matsam, flute players and dancers await the release of the first bull.

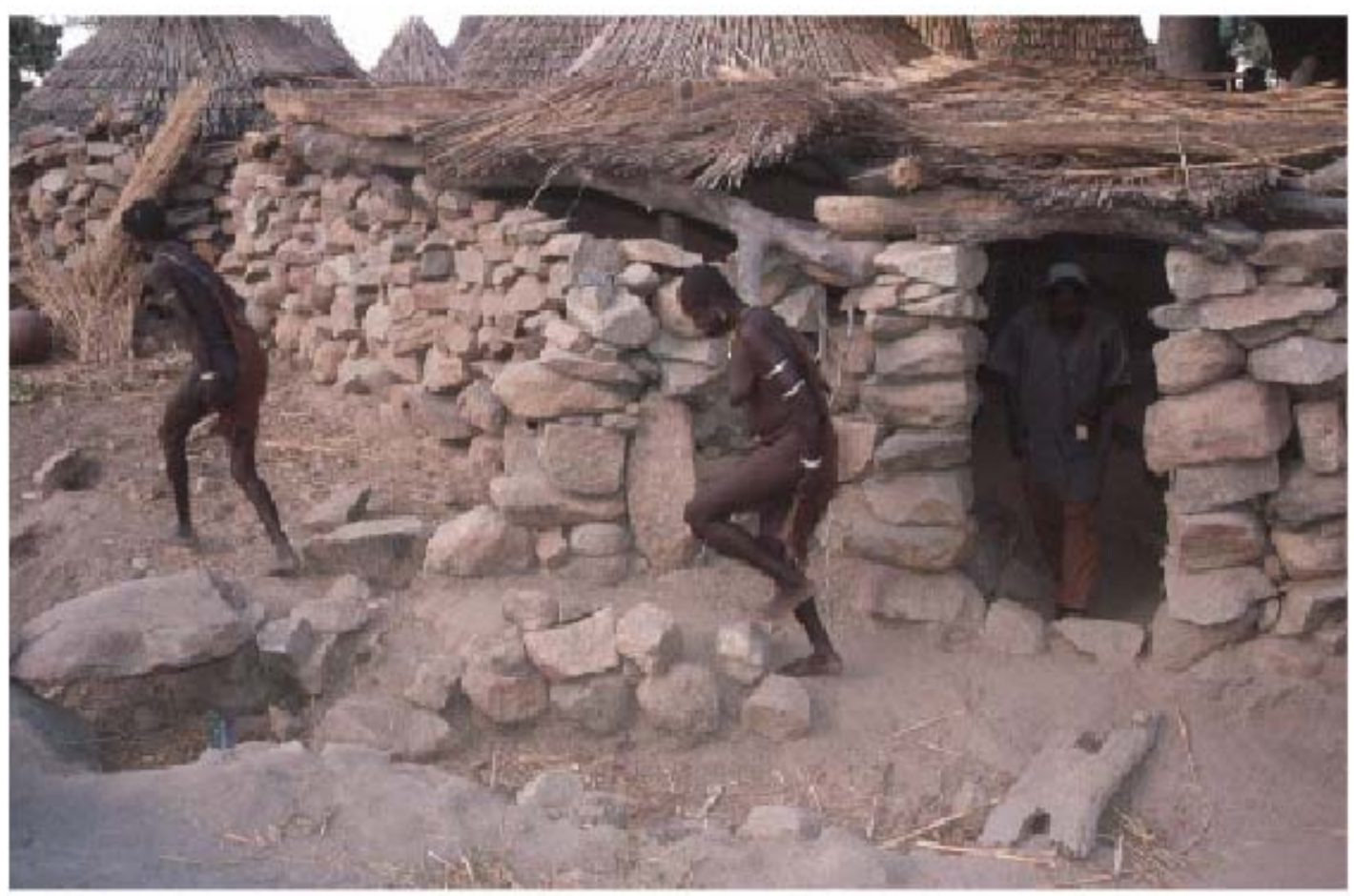

Plate 6d: Wives of the bull's owner leave the house shortly before the bull is released. 


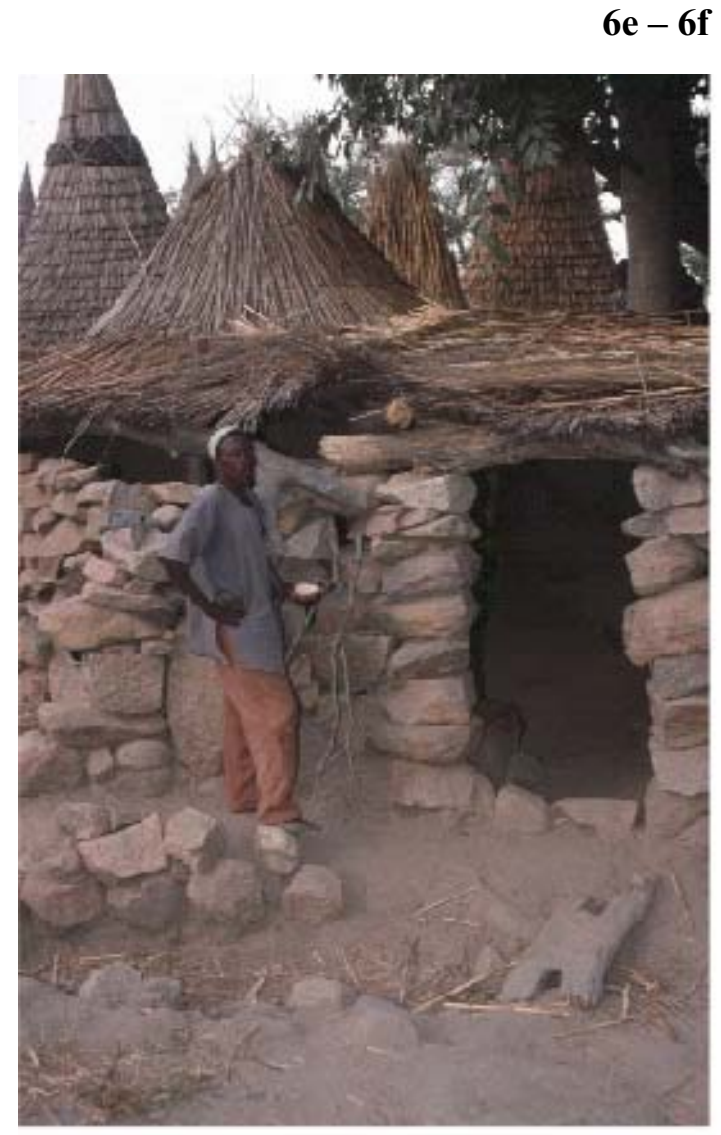

Plate 6e: Man with bean flower waits for bull to come out.

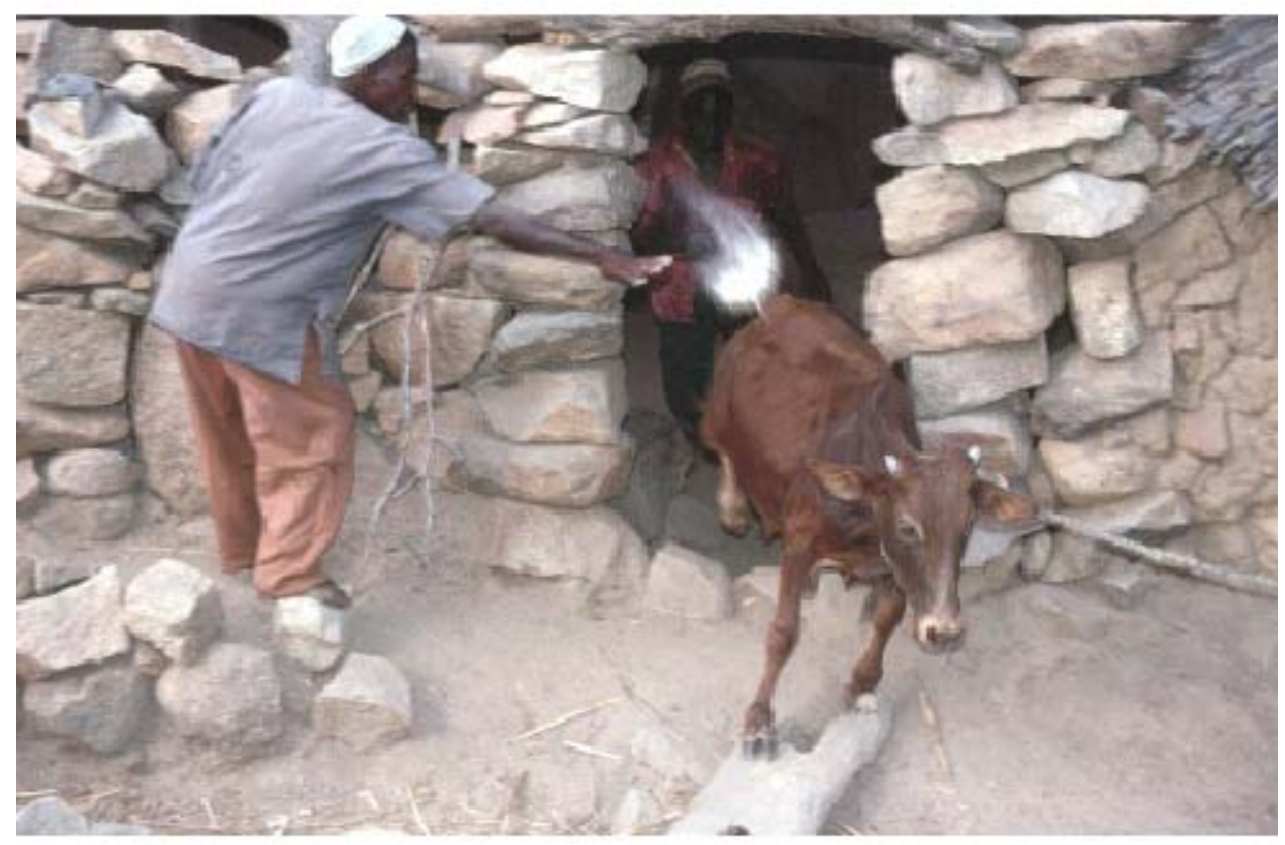

Plate 6f: Bean flower is thrown over the back of the purified bull. 


$$
6 g-6 h
$$

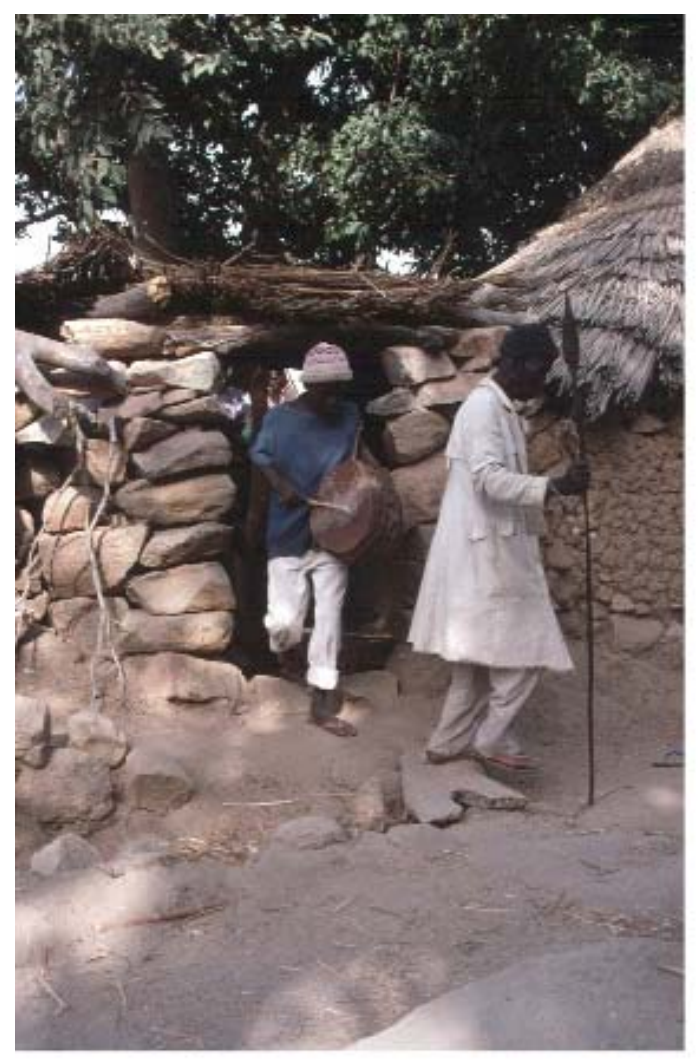

Plate 6g: Second gad bay leaves the house after his bull has been released. He is a representative of the ancient chiefly clan of Zlama. This is the reason why his bull is the first to be purified in Zlama.

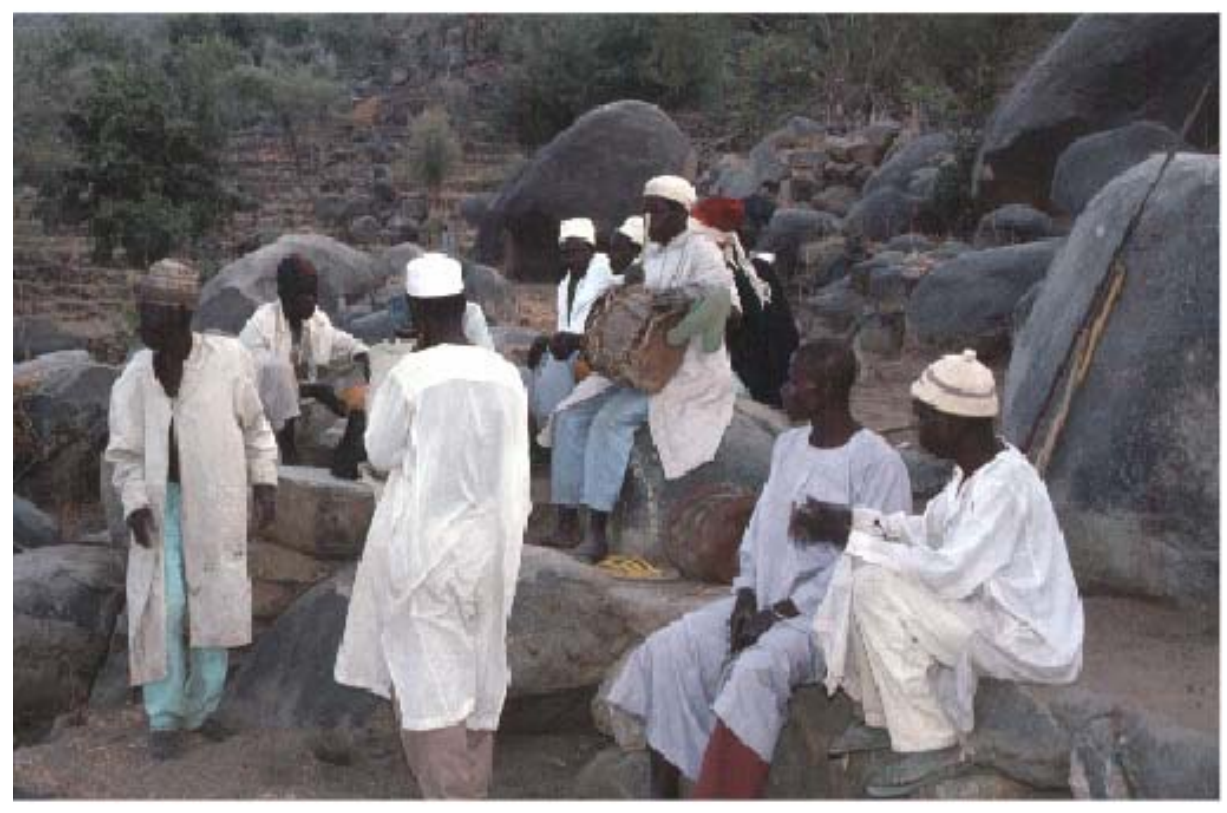

Plate 6h: Group of bay praise the release of the first bull. The drummer beats the chiefly drum and the bay sing: "A biy ga, a biy ga...", meaning "oh my great one...". 
$7 \mathbf{a}-7 \mathbf{b}$

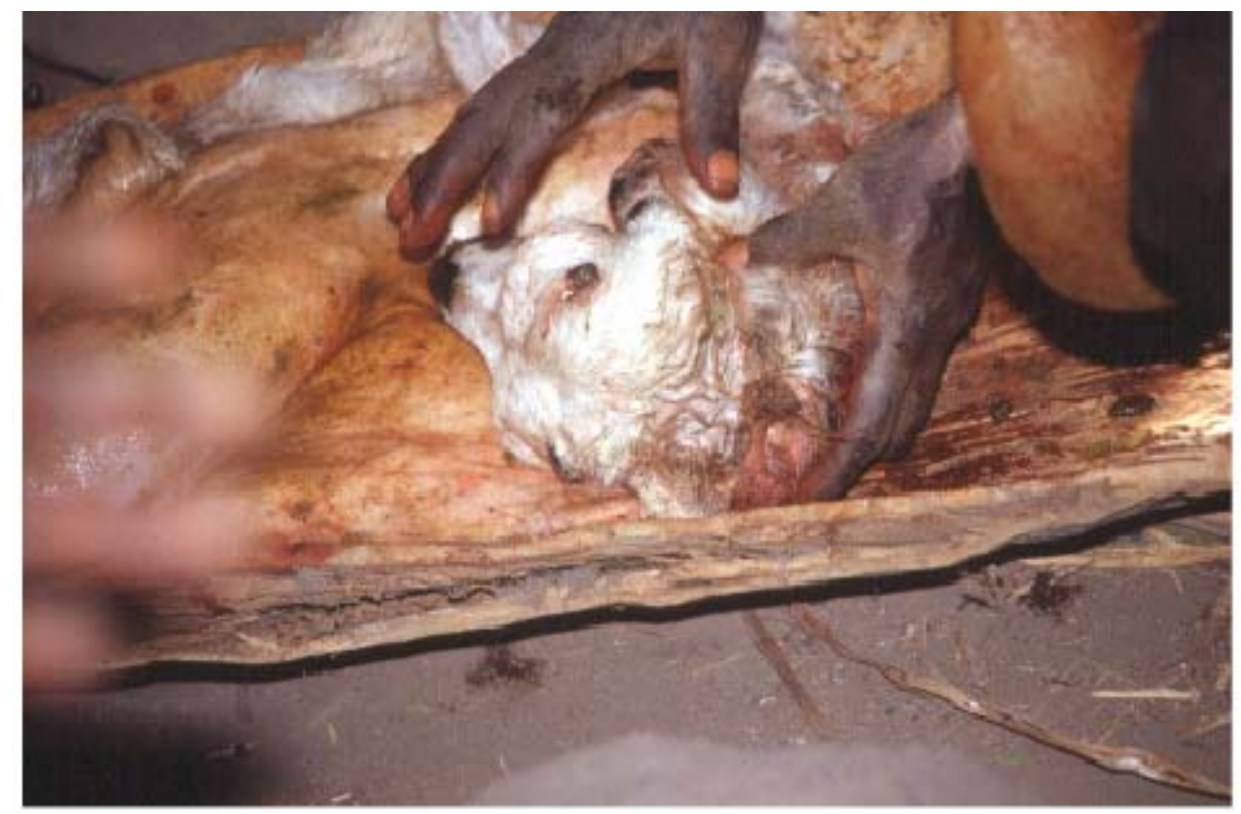

Plate 7a: A ram has been sacrificed and its intestinal contents will be used by the biy gwala to smear over their bodies before the purify the next village ward.

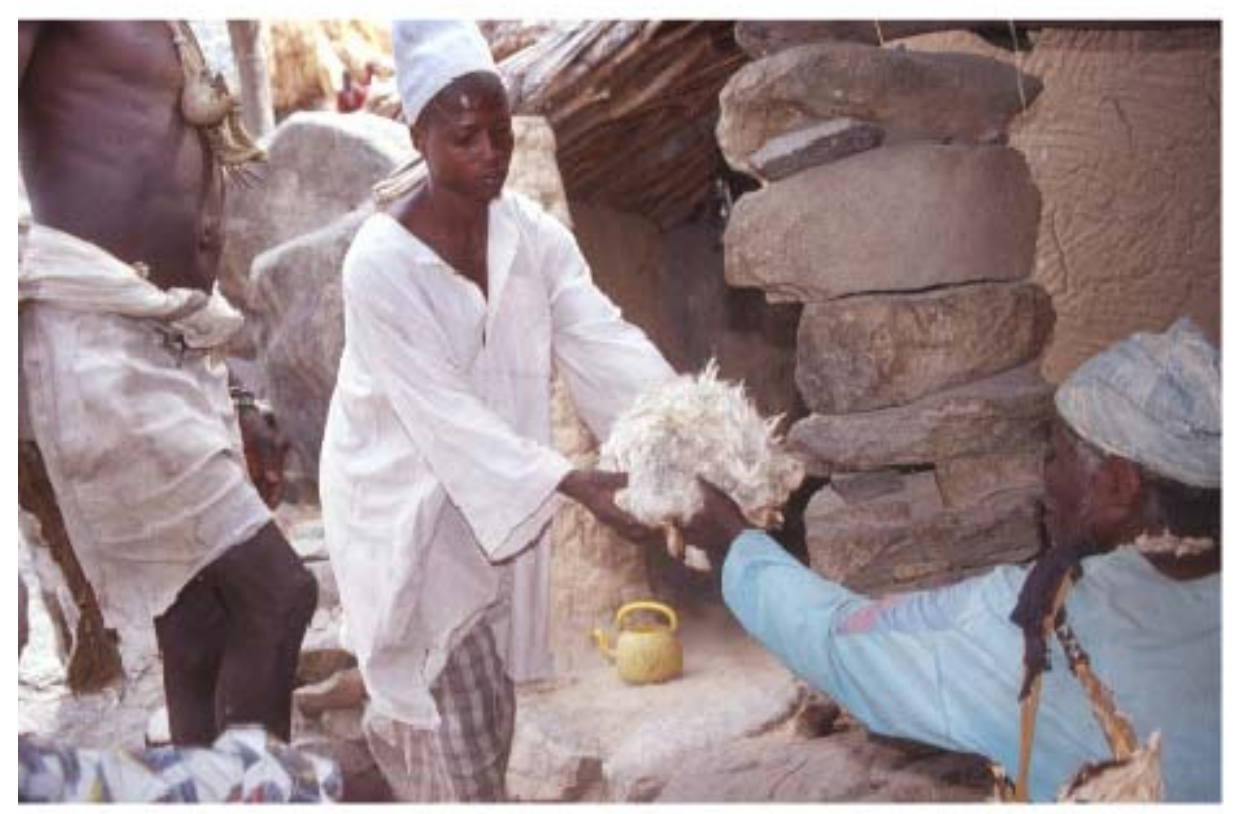

Plate 7b: Son of the second gad bay brings the head of the ram to the bay of the next village ward of Zlama, where bulls are going to be release. 
$7 c-7 d$

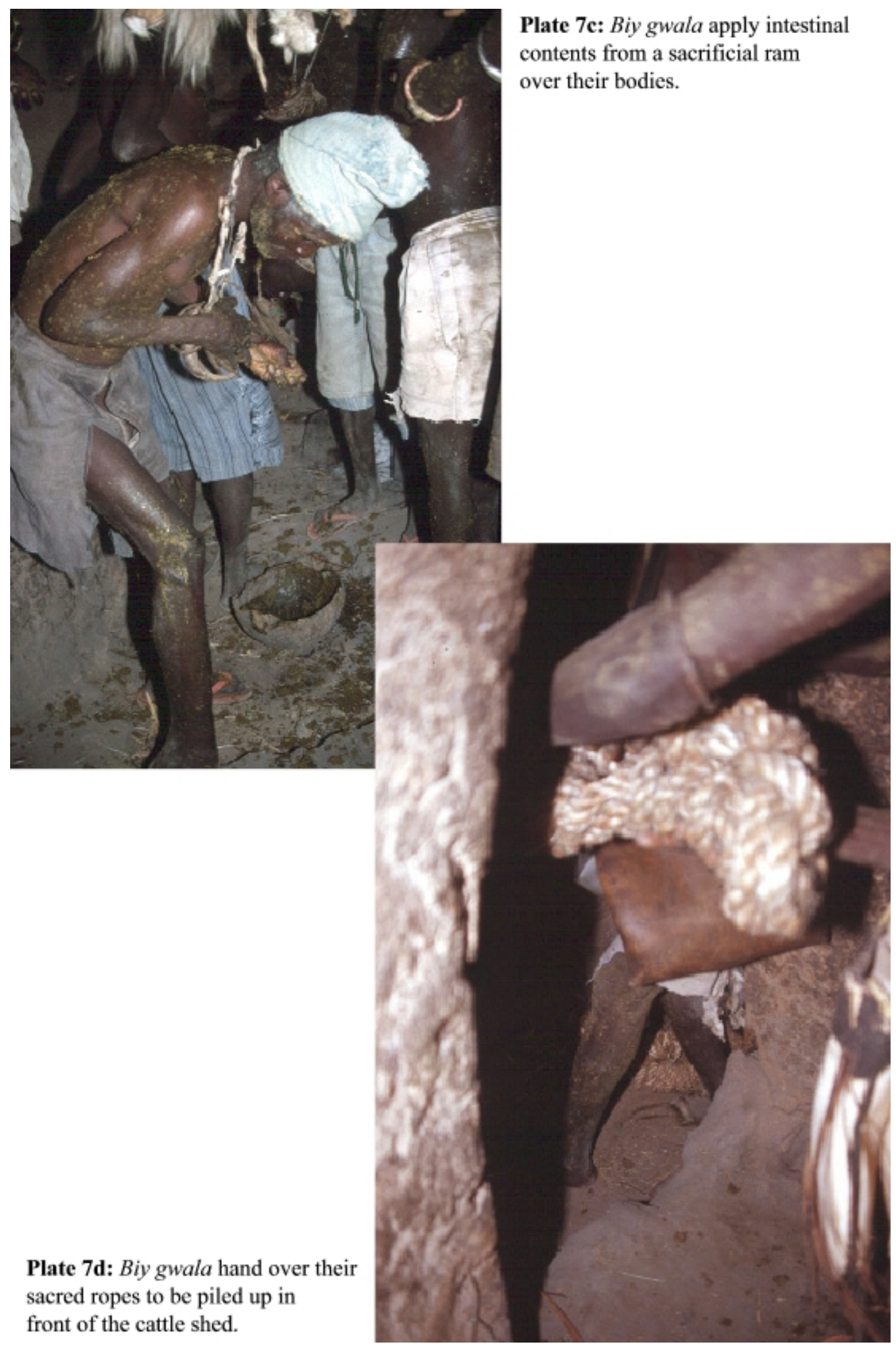




\section{$7 e-7 f$}

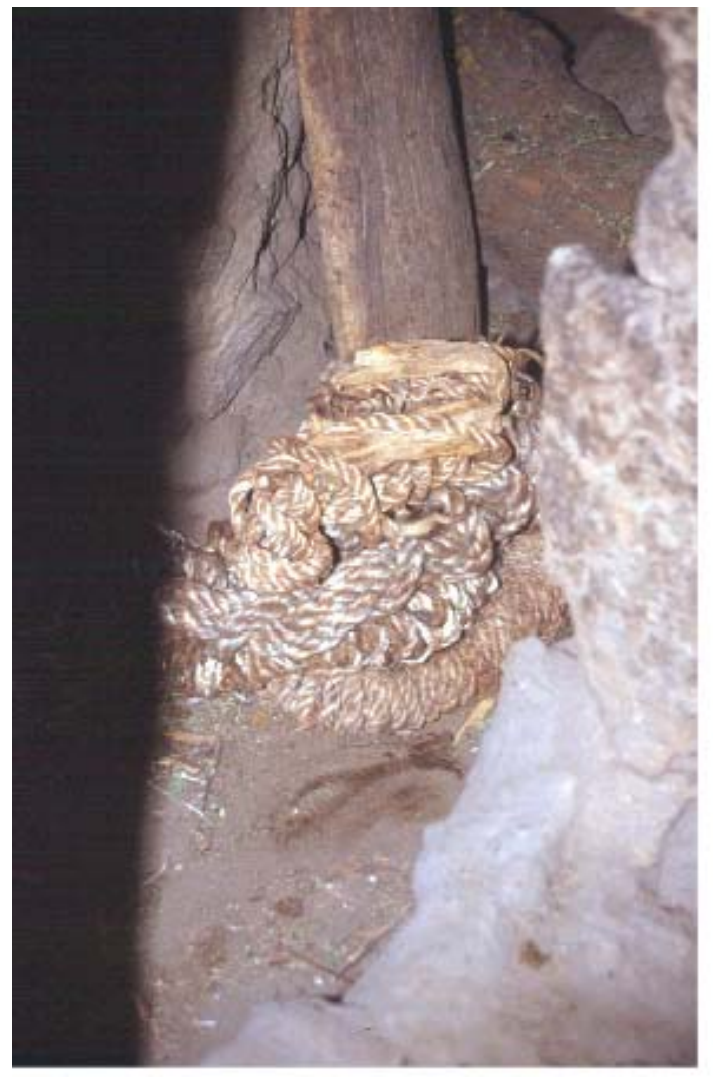

Plate 7e: Sacred ropes piled up in front of the cattle shed. The topmost represents the youngest and the bottom one the oldest village ward of Zlama.

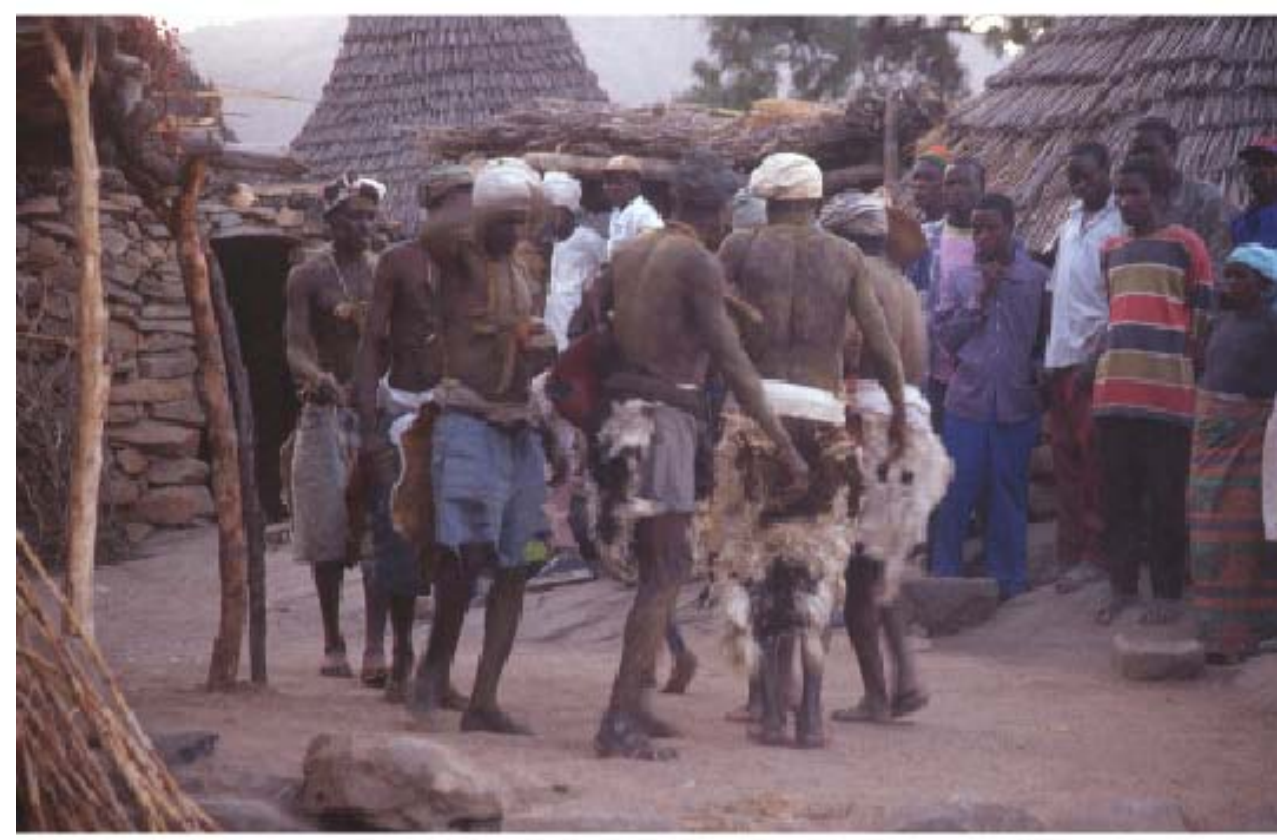

Plate 7f: Biy gwala perform "a turn around the head" away from the house followed by a sharp turn around towards the house (snakelike walk). 
$7 g-7 h$

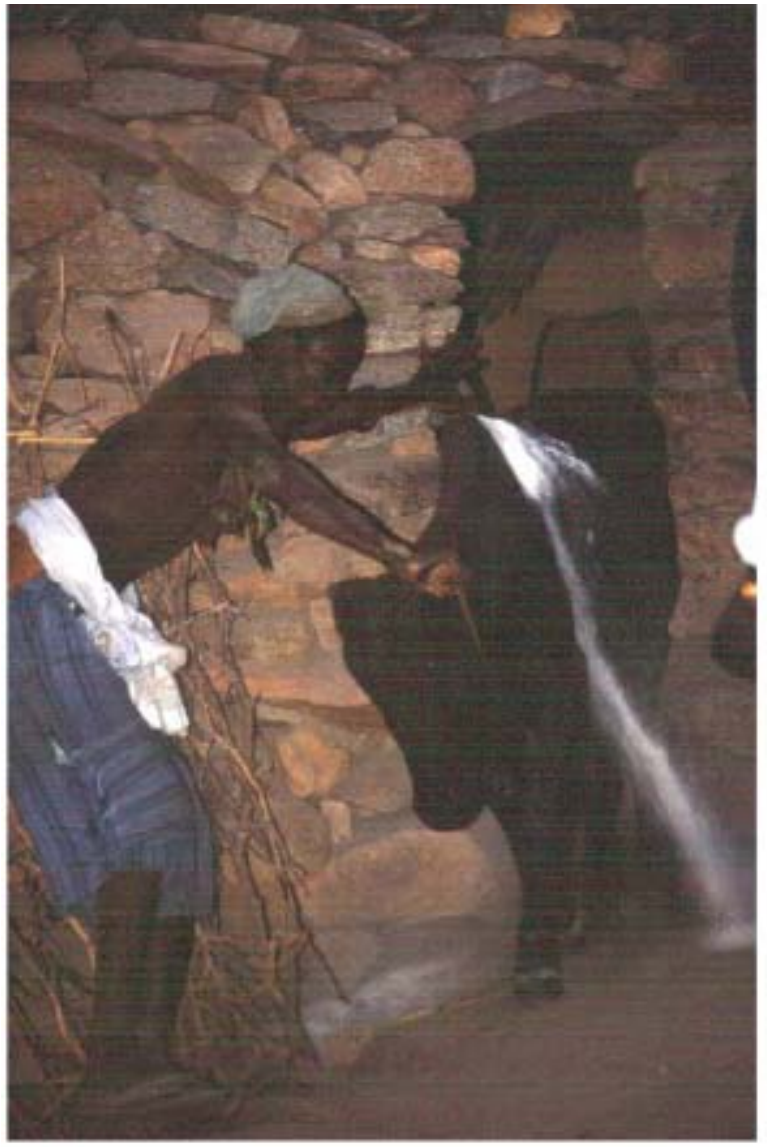

Plate 7g: Biy gwala

liberates the bull.

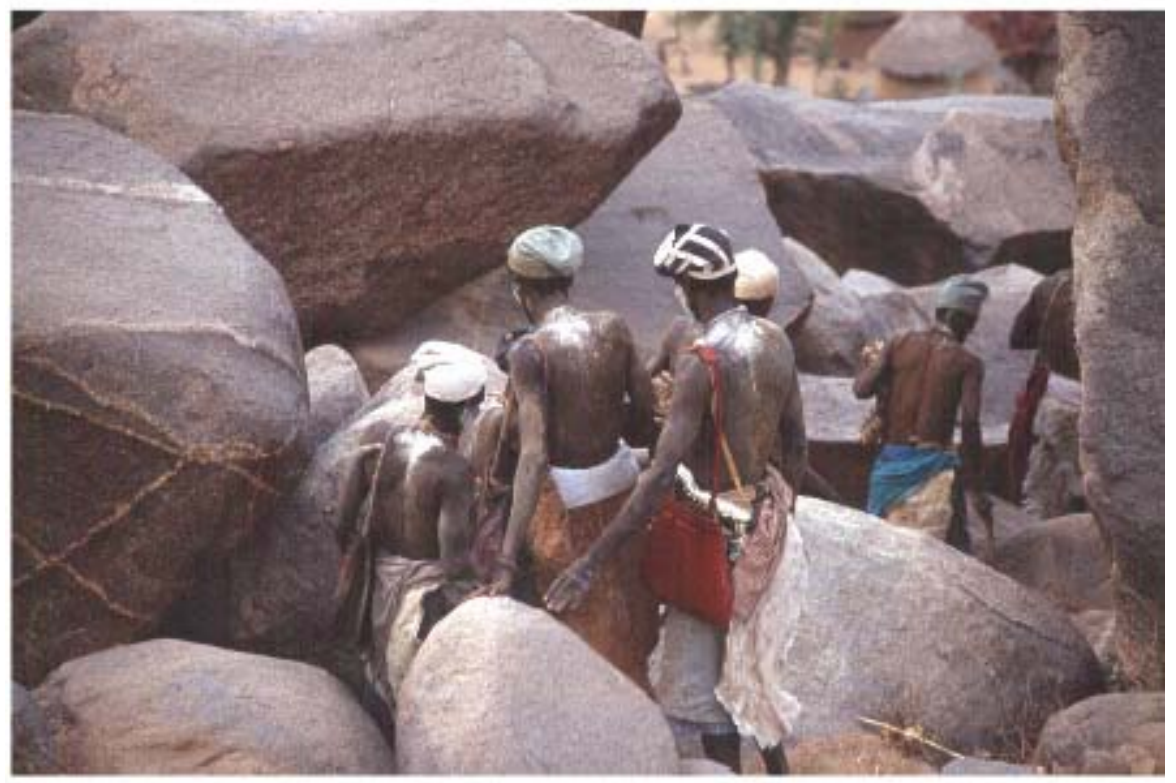

Plate 7h: Biy gwala too leave with bean flour over their backs. 
$\mathbf{8 a}-\mathbf{8 b}$

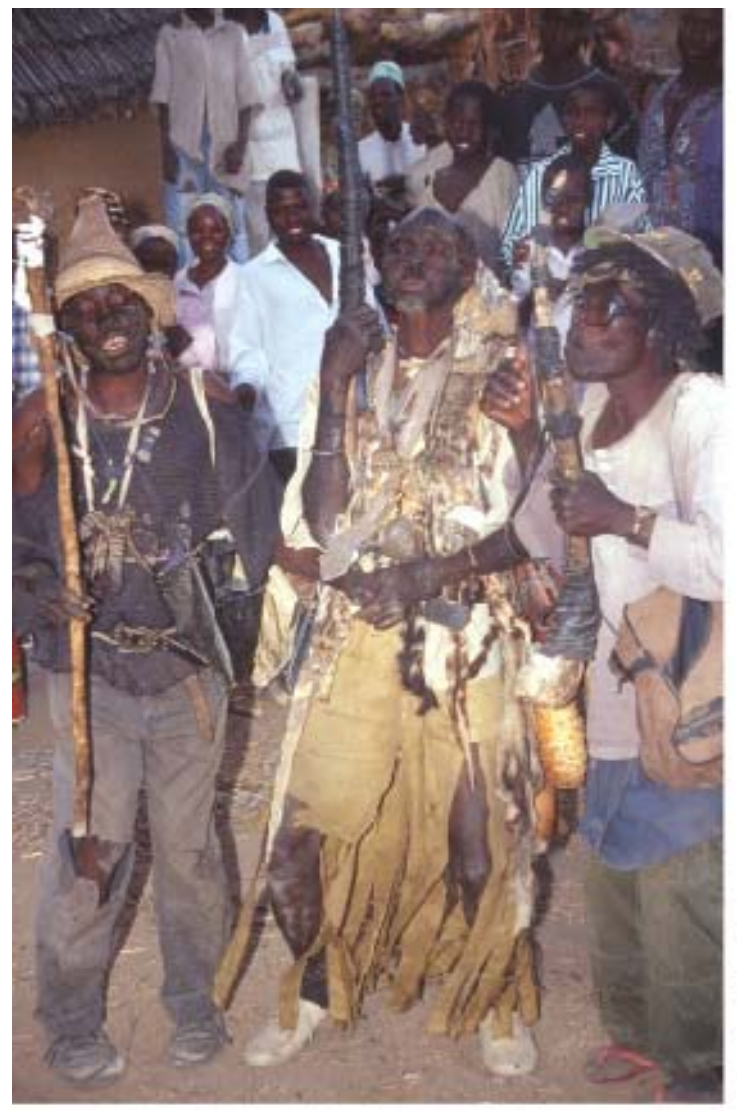

Plate 8a: Matsam entertain the crowd. "Matsam man" (in the middle) shows his wooden penis while "matsam wife" stands next to him (on his right).

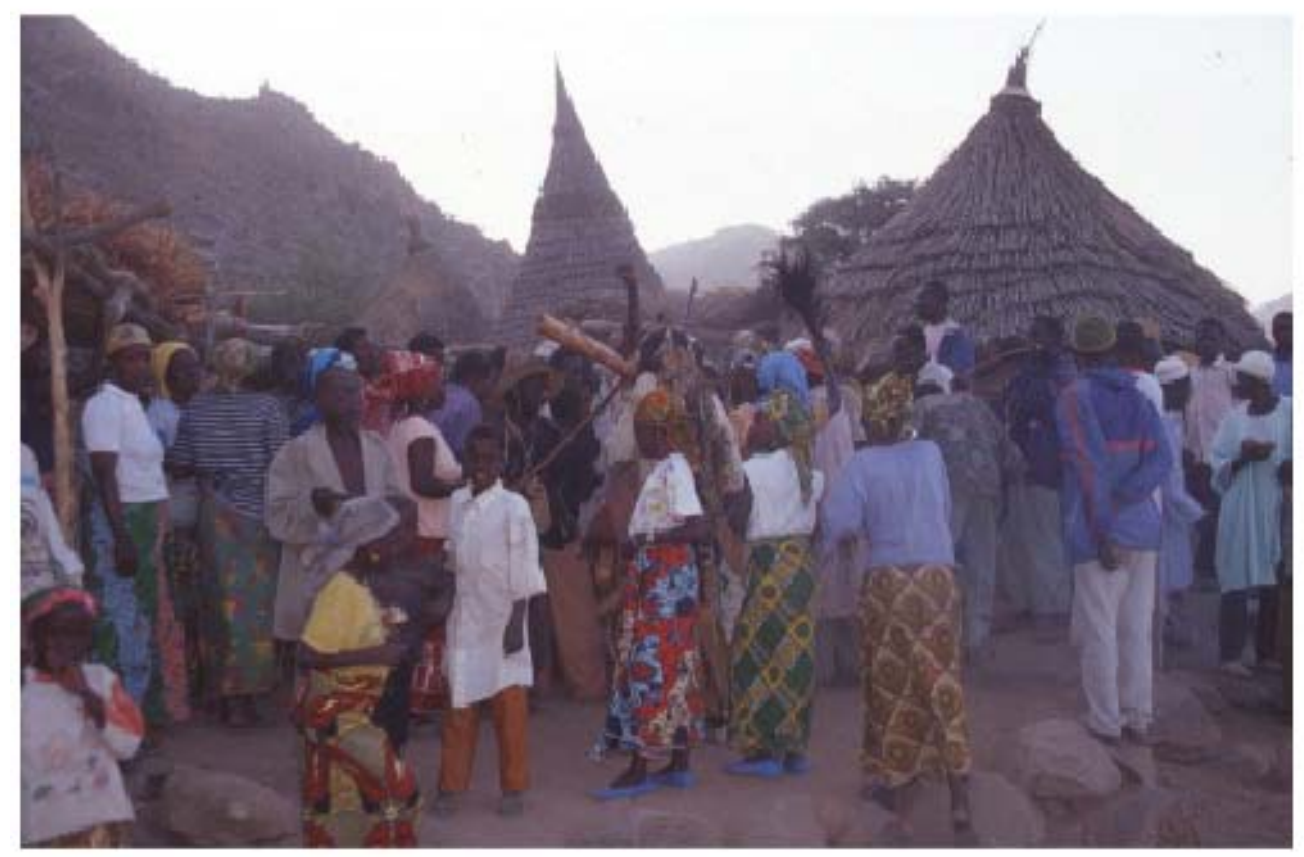

Plate 8b: Crowd awaits the release of the next bull. 


\section{$8 c-8 d$}

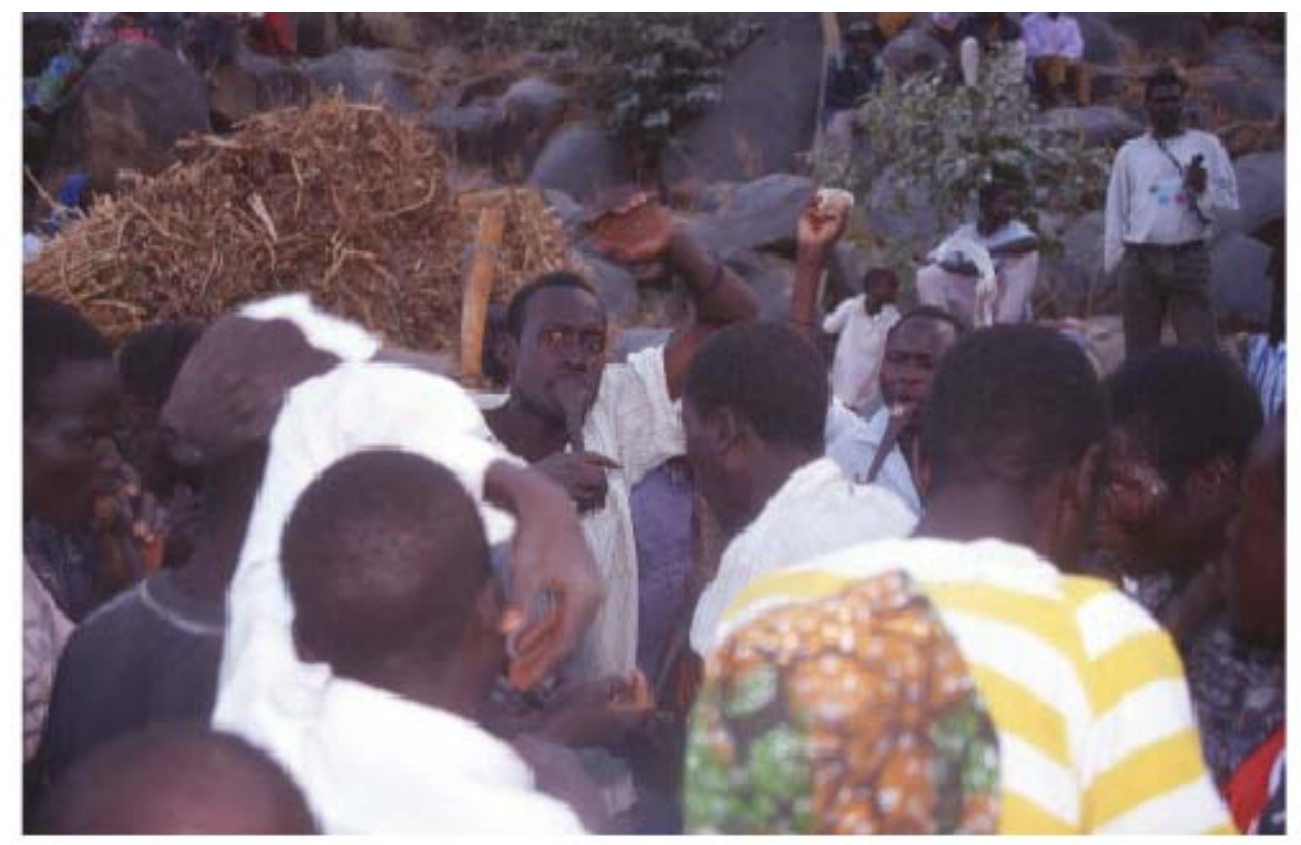

Plate 8c: Flute players.

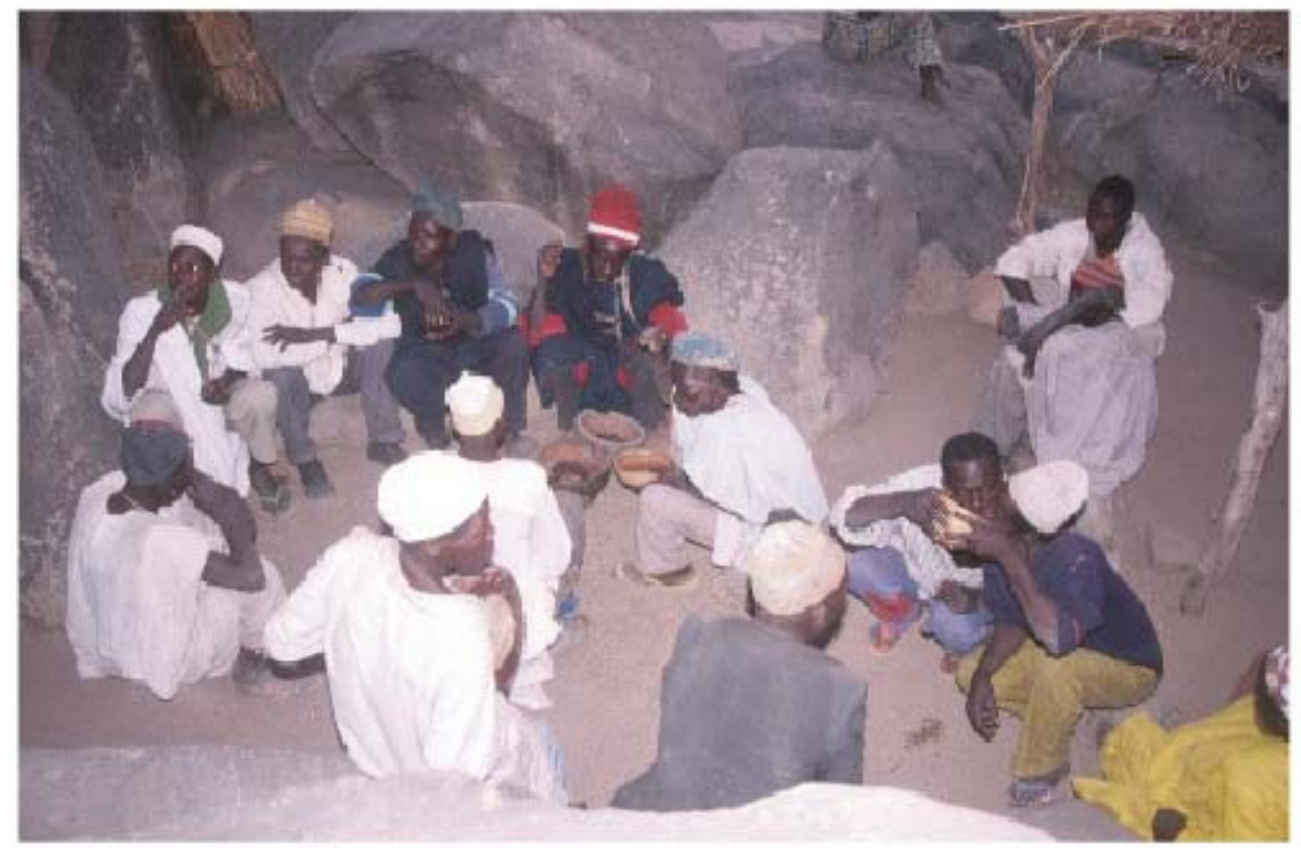

Plate 8d: Two gad bay enjoy with the other bay. Only the first gad bay (chief's deputy) carries a red felt hat. The second gad bay is a representative of the ancient chiefly clan. 


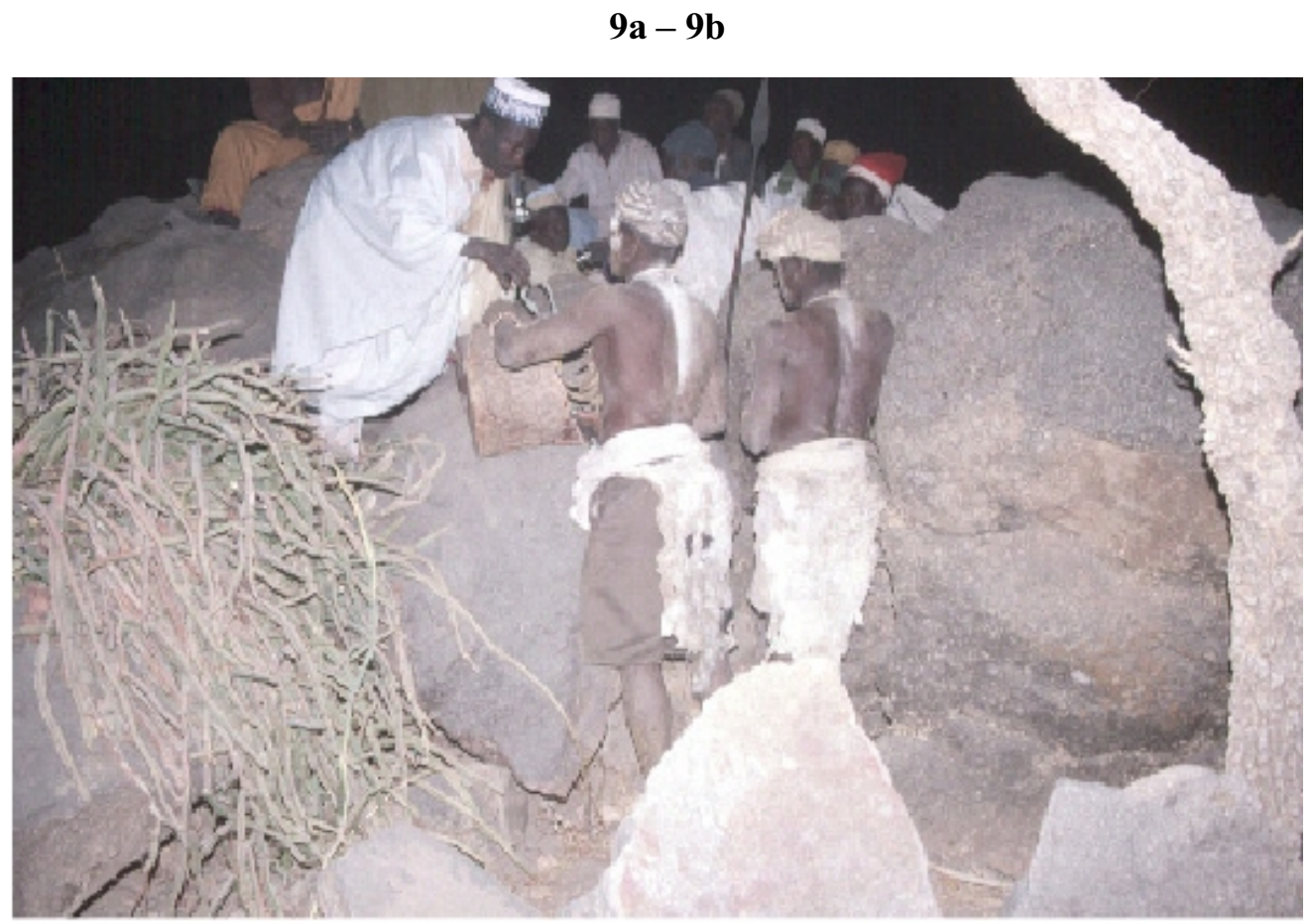

Plate 9a: Biy gwala demand the chief's drum at the end of the bull festival.

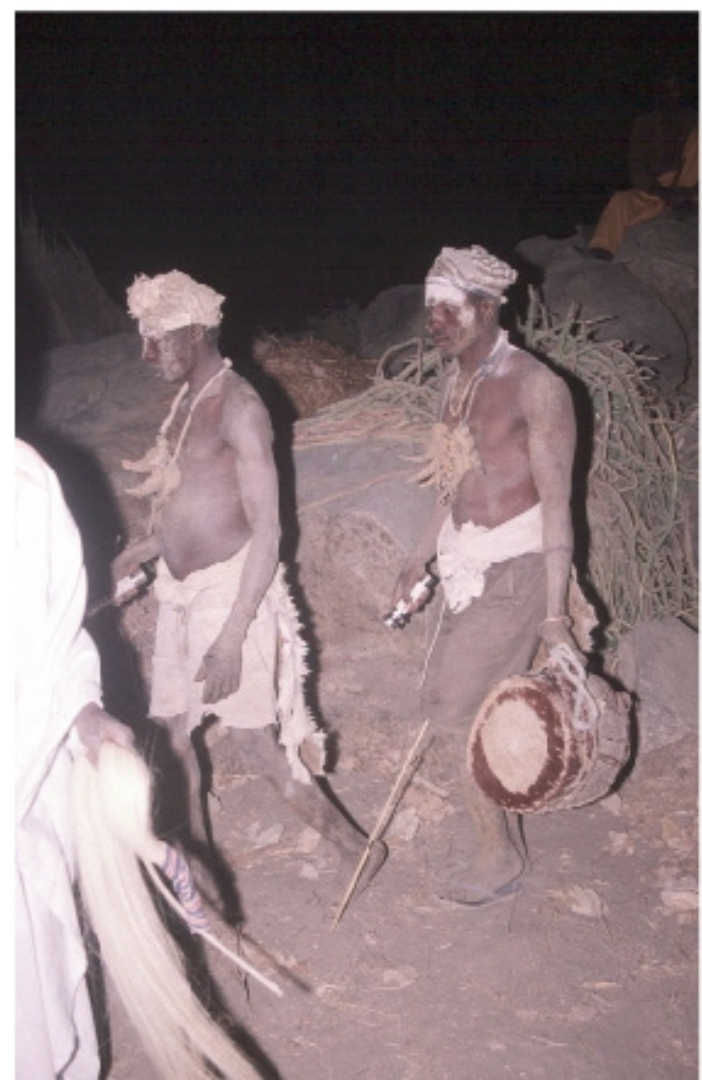

Plate 9b: Biy gwala leave with the chief's drum. 


$$
9 c-9 d
$$

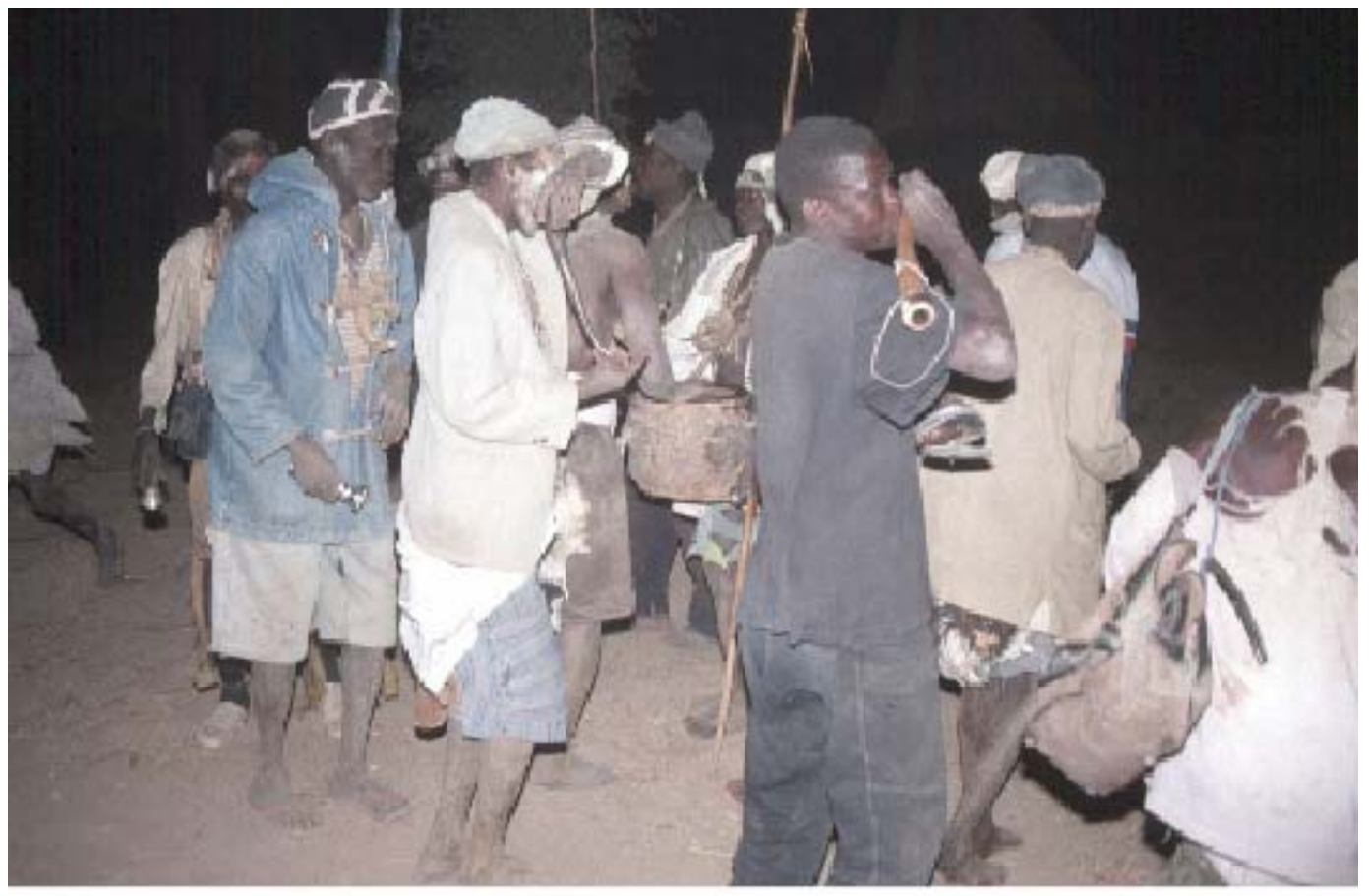

Plate 9e: Biy gwala and flute players dance with the chief's drum.

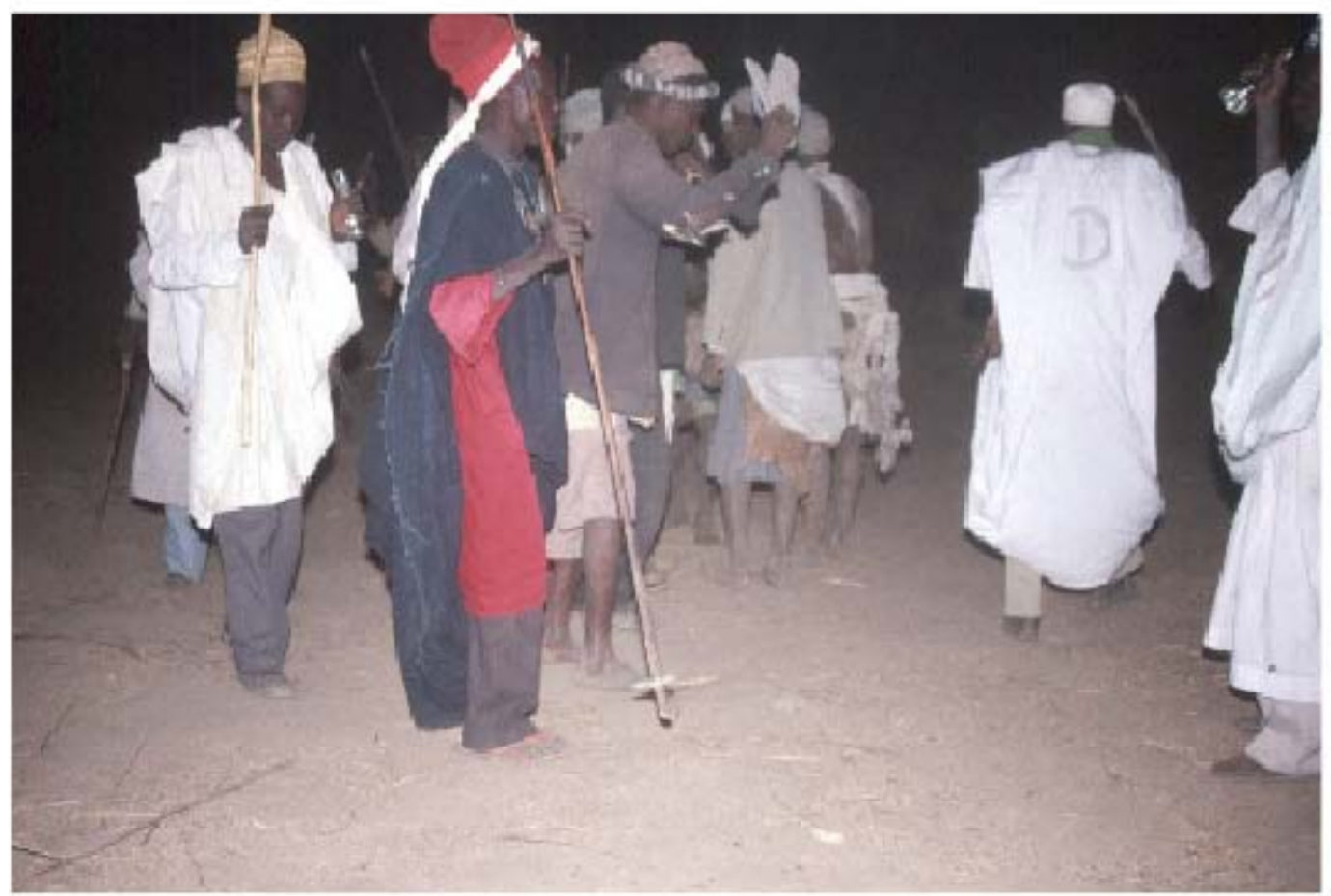

Plate 9d: Bay join the biy gwala dancing with the chief's drum. Later they receive back the drum, which marks the end of the bull festival of Zlama. 
$10 a-10 b$

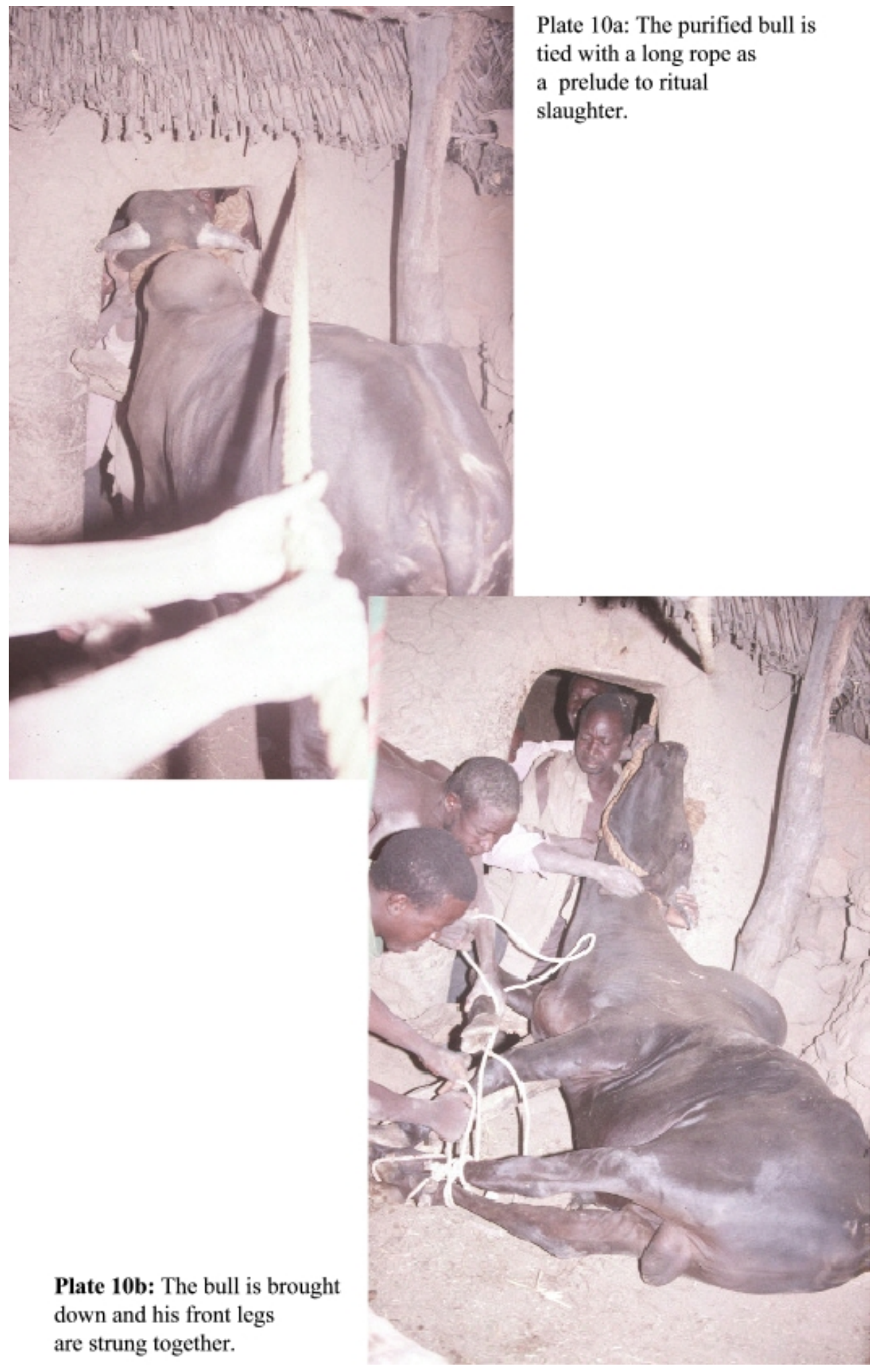




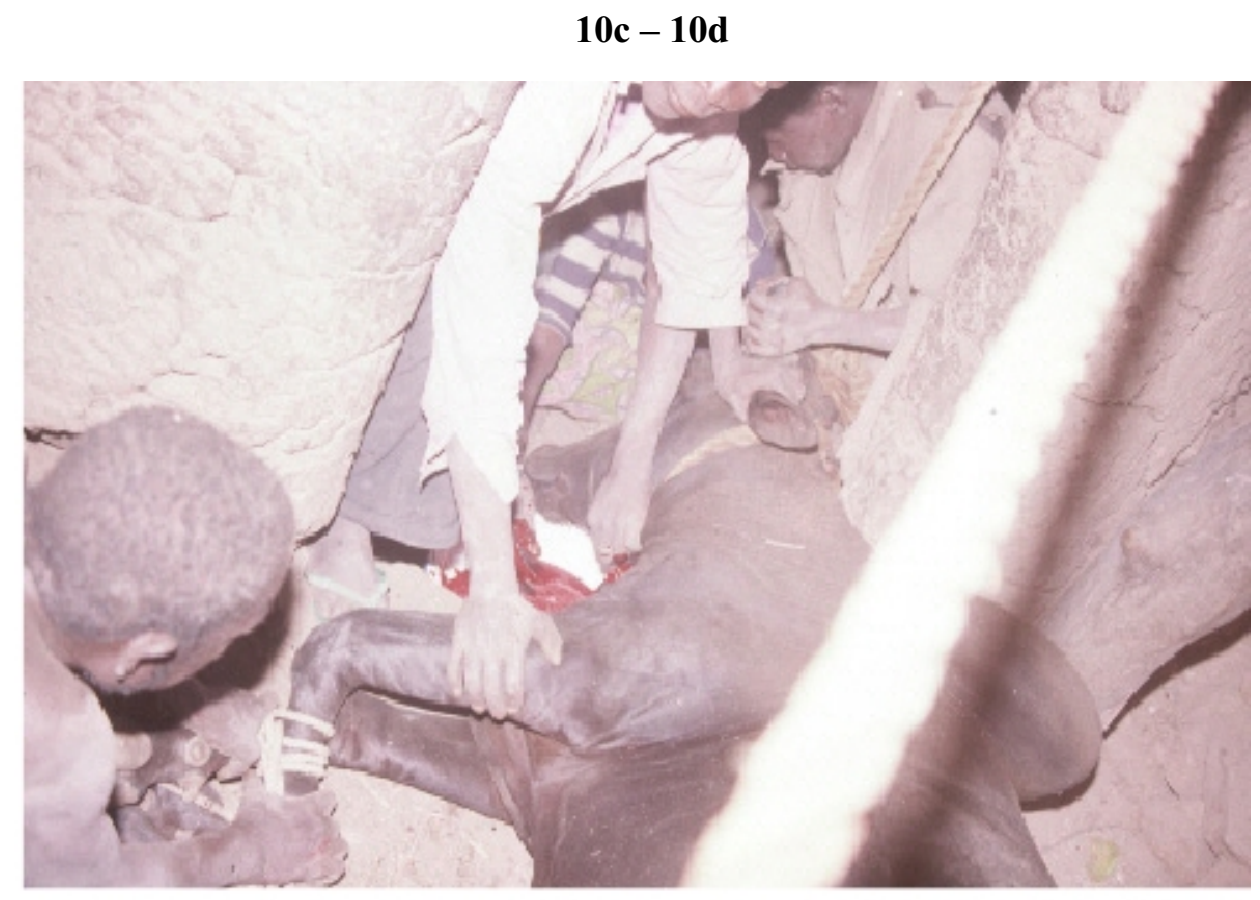

Plate 10c: The head of the bull is placed inside the sacrifice room where his throat is cut by the slaughterers.

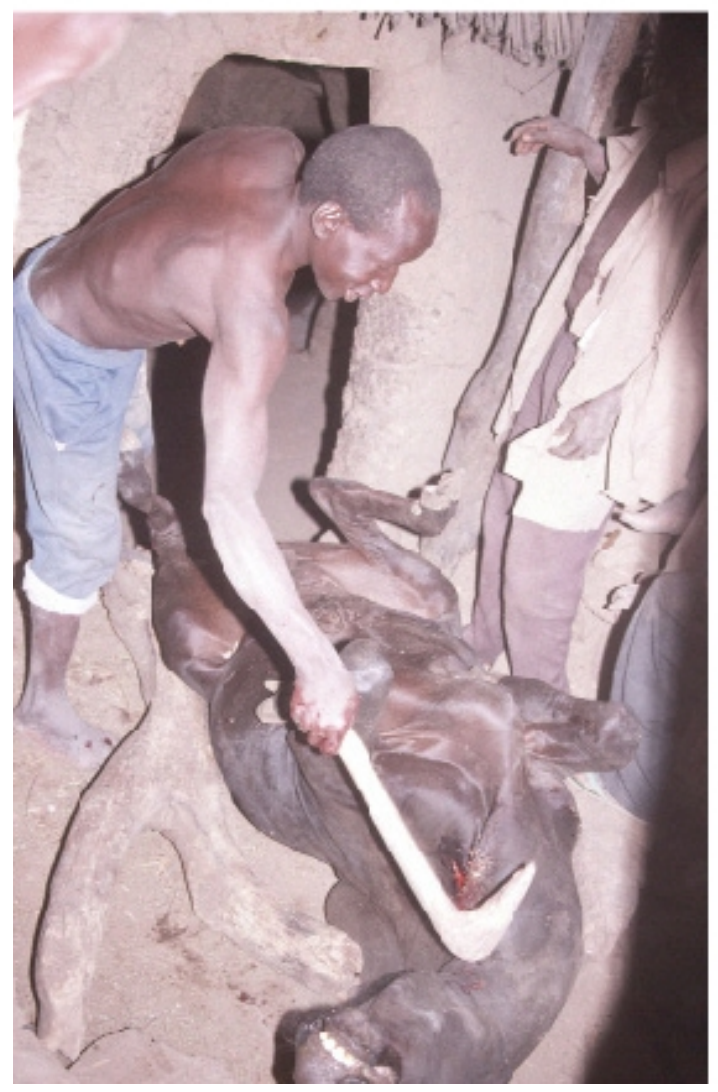

Plate 10d: Now the owner of the bull enters and taps the body of the bull with the handle of a traditional hoe and he repeatedly calls out: "Who killed my bull?...". 


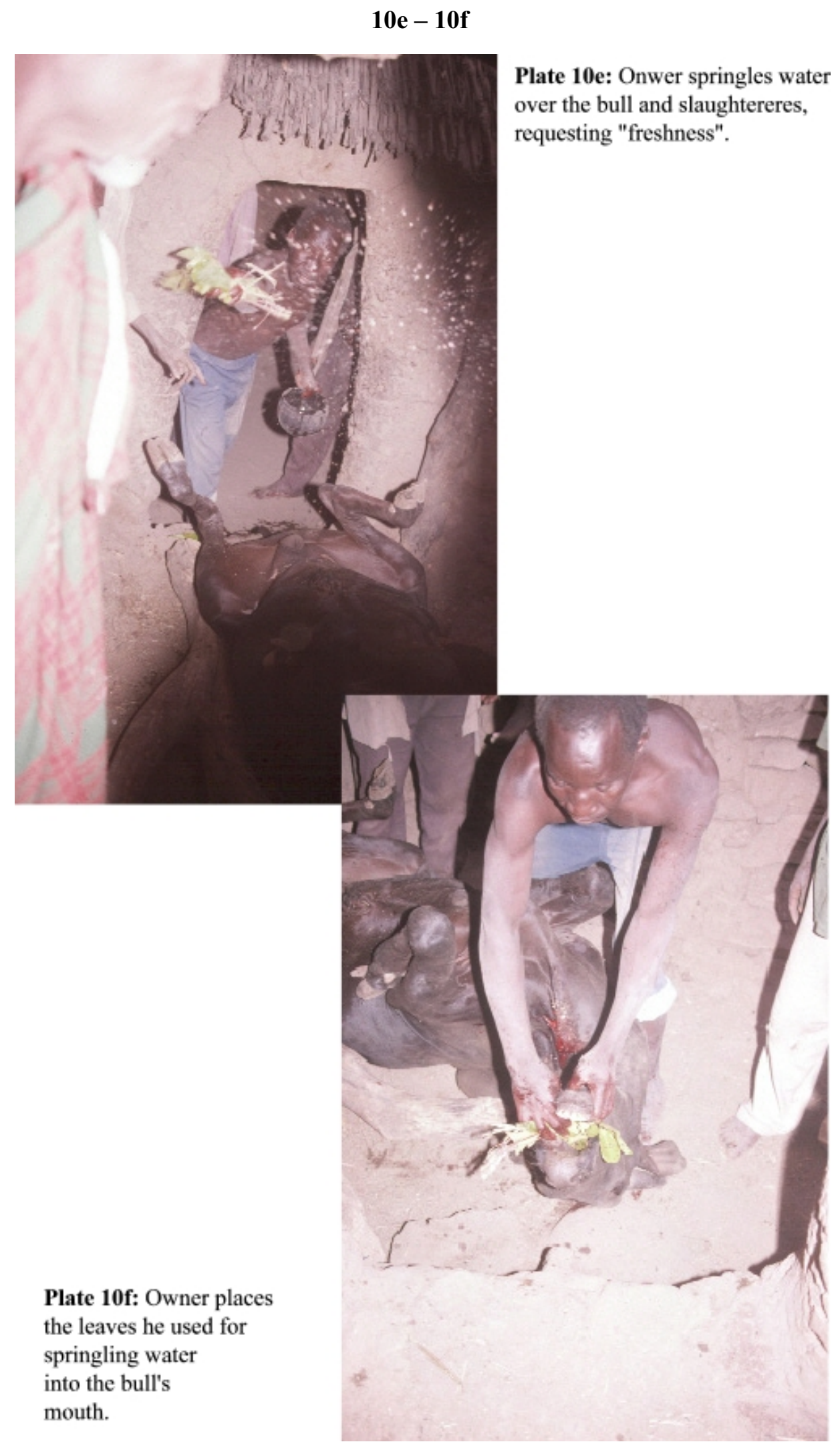


$10 g-10 h$

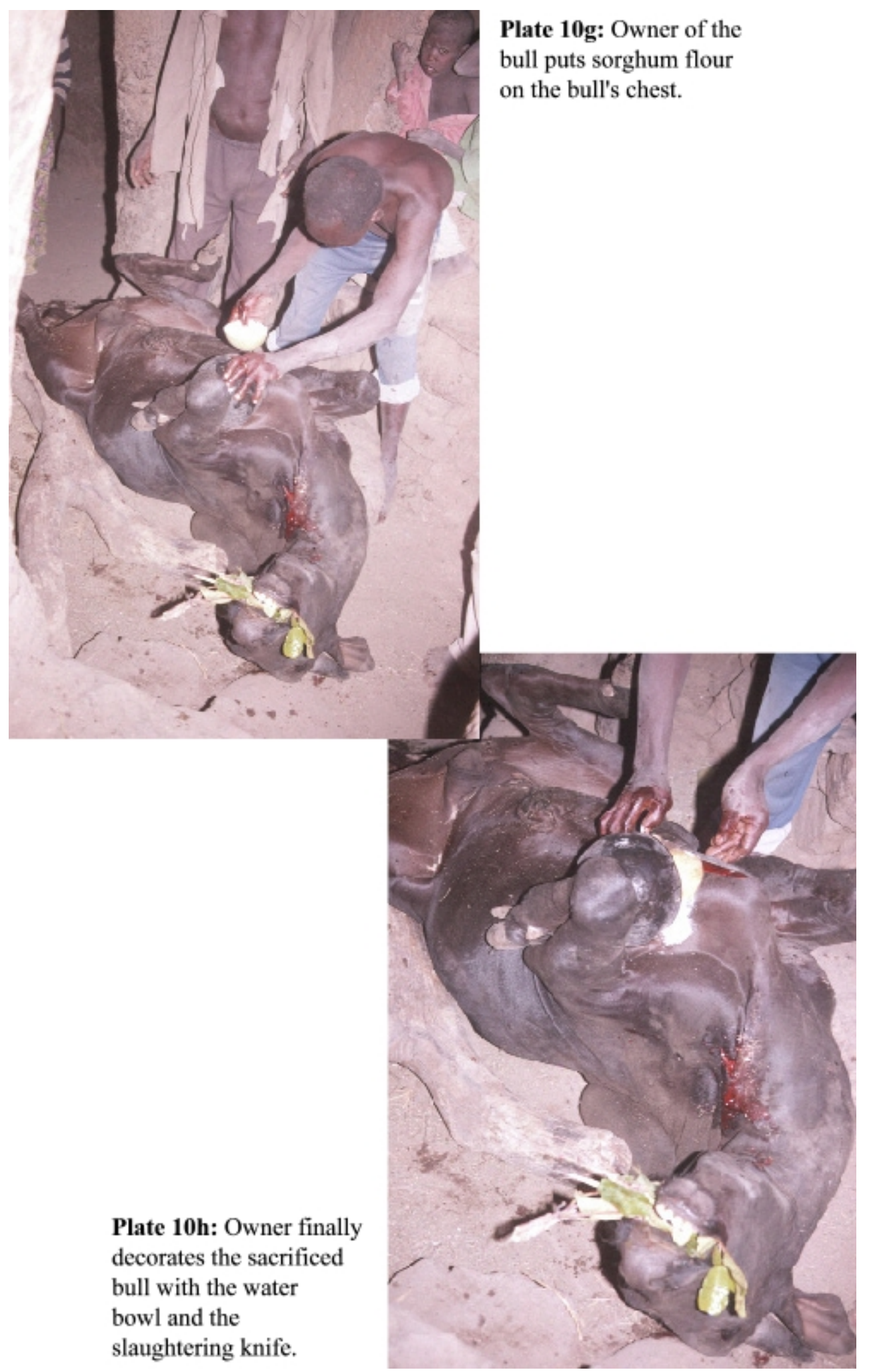

